





\section{GESAMVELTE ABHANDLLYGEN}

ZLR ALLGEMEINEN

\section{IIUSKEL- UYD IERVEIPHYSIK.}





\section{GESAIMELTE ABHANDLUYGEN}

ZUR ALLGEMELNEN

\section{MUSKEL- UND NERVEIPHYSIK}

VON

Ehil du Bois-Reyarond.

ERSTER BAND.

MIT XXIX IN DEN TEXT GEDRUCKTEN HOLZsCHNITTEN UND VIER TAFELN.

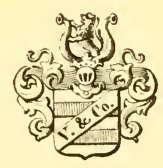

LEIPZIG、

VERLAG VON VEIT \& COMP. 1875 . 
UEBERSETZUNGSRECHT VORBEHALTEN. 
DEM

\section{ANDENKEN}

SEINES FREUNDES

\section{HENRY BENCE JONES}

GEWIDMET

VOM

VERFASSER. 



\section{Vorrede.}

Bei geistigen Neigungen, welche mich sehr rerschiedenen Richtungen des Naturerkennens mit fast gleicher Stärke zutrieben, ward mir das Loos, meine bisherige Forscherarbeit beinah ausschliesslich einem einzigen, scheinbar ganz beschränkten Gegenstande zu widmen. Ich war erst zweiundzwanzig Jahre alt, als Johannes MüLLen mich ror die Frage nach dem Quell ron NoBmi's Froschstrom stellte, und nach vierunddreissig Jahren bin ich noch damit beschäftigt, die Antwort auf diese Frage zu suchen. Diese Gestaltung meiner wissenschaftlichen Laufbahn hat mir manchen Schaden gebracht. Während ich oft meiner ganzen Willensstärke bedurfte, um trotz der Ermüdung, die aus der Einförmigkeit meiner Arbeit entsprang, bei der Stange zu bleiben, schalten mich Leute einseitig, welche von Höhe und Umfang, und den allerwärts sich rerzweigenden Beziehungen meiner Aufgabe keine Ahnung hatten. Mein ganzes wissenschaftliches Ansehen war wie auf Eine Karte gestellt, ja ein Knabe, der meine Thatsachen nicht achtete, weil er selber keine fand, und der sich eimbildete, den für ihn doch etwas zu festen Bau meiner Hypothesen umgeworfen zu haben, durfte fragen, was nach seinen Thaten denn ron mir noch übrig bleibe?

Bei heutiger Gelegenheit aber kommt meine scheimbare Einseitigkeit mir zu Gute. Streben fast alle meine Arbeiten Einem Ziele zu, so bilden sie anch ein zusammenhängendes, einheitliches Ganze. Einen ersten Abschnitt dieser Arbeiten fasste ich, in jugendlichem Selbstrertrauen. und mit einer noch durch keine Berufsgeschäfte und keine übermässige Bedenklichkeit gehemmten Productionskraft, in meinen 'Untersuchungen' 
zusammen. ${ }^{1}$ Dies allzu keck angelegte Unternehmen gerieth in's Stocken, indem der Gegenstand mir unter den Händen so mächtig wuchs, und neben mir durch Andere theils auf meinen Anstoss, theils ron mir unabhängig so rasch gefördert wurde, dass ich die bis dahin gen̈bte Art der Veröffentlichung meiner Ergebnisse aufgeben musste. Nene Methoden machten es nothwendig, fast das ganze, schon einmal durchmessene Gebiet noch eimmal abzusuchen, und die durch diese Methoden ermöglichte Art der Behandlung stimmte schlecht mit der ursprünglichen, nur auf qualitative Ermittelung berechneten Anlage des Ganzen. Bei mehr und mehr beschränkter Mnsse, und durch meine Stellung als Akademiker zu periodischen Bekamntmachungen gezwminen, musste ich fortan den allgemein gebränchlichen Weg einschlagen, das einigermaassen Sichergestellte und rorlänfig Abgeschlossene in einzelnen Abhandlungen herauszugeben. Wenu ich, was noch immer mein Torsatz ist, später eimmal zur Vollendung der 'Untersuchmngen' zurückkehre, werde ich sie doch gleichsam nur buchhändlerisch abschliessen kömen. Das in der Torrede zum ersten Bande der 'Untersuchmngen' rom März 1848 entworfene Schema auszufüllen, ward unthmulich. Allein das dort angekündigte neunte Capitel, welches einen Ueberblick über die allgemeine Mnskel- und Nerrenphysik geben sollte, wäre bei dem hentigen Zustande der Wissenschaft ein umfängliches Werk ron grösster Schwierigkeit.

Einen kleinen Theil meiner seit 1851 reröffentlichten Abhandlumgen über allgemeine Muskel- und Nerrenphysik, der sich auf Parelektronomie und auf Sichtbarmachung des Muskelstromes und seiner negativen Schwankung am lebenden menschlichen Körper bezog, habe ich in grösserer Ausführlichkeit schon der zweiten Abtheilung des zweiten Bandes der 'Untersuchungen' einverleibt. Der bei weitem grösste Theil, fast alle meine wissenschaftlichen Arbeiten seit dem Jahr 1855 umfassend, ist in verschiedenen Zeitschriften zerstrent. Die der dentschen Wissenschatt längst rühmlich bekannte Verlagshandlung, deren Tame anf diesem Buche steht, hat geglaubt, Physiologen und Physikern einen Dienst zu erweisen, indem sie diese Arbeiten in eine Sammlung rereinigte, zu deren

1 Untersuchungen über thierische Elektricität. Berlin bei G. Reimer. Bd. I. 1848; - Bd. II. 1. Abth. 1849; - 2. Abth. 1860. - In der Sammlung ist dies Werk kurz als 'Untersuchnngen' angeführt. 
Teranstaltung sie, als Besitzerin des 'Archirs für Anatomie, Physiologie und wissenschaftliche Medicin', ${ }^{1}$ in welchem riele meiner Aufsätze erschienen, ein besonderes Recht hatte. Des Ueberdrusses ungeachtet, den man beim Zurückgehen auf abgethane Dinge stets empfindet, habe ich mich dem Wunsche des Hrn. Verlegers gefügt.

Die Grundsätz, enach denen ich bei Auswahl, Anordnung und Abdruck der Arbeiten verfuhr, sind folgende. Dem Titel des Werkes entsprechend sind nur Arbeiten aufgenommen, welche auf allgemeine Muskelund Yervenphysik, wozu auch die Lehre von den elektromotorischen Fischen gehört, mehr oder minder unmittelbar sich beziehen. Doch rechnete ich dazu anch solche, welche auf Verrollkommnung und Begründung der Beobachtungsmethoden, oder auf Erforschung der physikalischen Bedingungen der ron mir studirten Erscheinungen gerichtet sind. Da diese neben jenem besonderen Interesse noch ein allgemeines beanspruchen, und die Besonderheit ihres Ursprunges sugar oft ganz in ihnen zurïcktritt, so habe ich diese Arbeiten, olne Rücksicht auf die Zeitfolge, ans der Reihe der übrigen ausgeschieden, und sie machen den ersten Band der aus zwei Bänden bestehenden Sammlung aus. Dieser erste Band enthält somit rorzugsweise Dinge, welche anch solche Physiker angehen, denen Untersuchungen über thierische Elektricität u. d. m. fern liegen, und es ward deshalb beschlossen, ihn auch einzeln abzugeben, daher jeder Band sein eigenes Register erhielt.

Auch sonst ist in beiden Bänden ron der Zeitfolge insofern abgesehen, als dem Inhalte nach rerwandte Aufsätze ohne Rücksicht darauf zu Gruppen rereinigt wurden, in welchen sie aber damn nach der Zeitfolge geordnet sind.

Es kamn natürlich nicht fehlen, dass in Abhandlungen, die sich über einen Zeitraum ron zwanzig Jahren erstrecken, Einzelnes veraltet, unrollkommen, ja geralezu umrichtig erscheint. Ebenso liegt es in der Natur der Dinge, dass in dieser Sammlung Hanches zweimal und öfter sich gesagt findet. Da aber die Sammlung den Zweck hat, die zerstrenten Original-Abhandlungen zu ersetzen, so habe ich mir, wie auch die literarische Wahrhaftigkeit gebot, ohne es anzuzeigen, keine Aende-

1 Es ist i: der Samml ing kurz als 'Archiv für Anatomie u. s. w.' angeführt. 
rungen erlaubt, als kleine stilistische Verbesserungen. Dagegen wird man zum Zweck der Milderung jener Uebelstände eine Anzahl Zusätze und Hinweise antreffen, welche durch eckige Kilammern ausgezeichnet sind.

Damit die Sammlung die Original-Abhandlungen um so vollständiger ersetze und $\mathrm{um}$ beider Vergleich zu erleichtern, ist die Pagination der Abhandlungen in den Text aufgenommen. Sind am Eingang einer Abhandlung mehrere Stellen angegeben, wo sie gedruckt steht, so ist in der Sammlung die Pagination der ersten (ursprünglichen) Stelle wiederholt. Die Abbildungen sind meist mit Hülfe derselben Stöcke und Platten hergestellt, welche für die Original-Abhandlungen gedient haben.

Ein grosser Uebelstand, der mit dem getreuen Wiederabdruck einiger meiner Aufsätze verbunden war, entsprang aus deren polemischem Charakter. Nichts kann mir ferner liegen, als das Andenken an literarische Fehden ernenern zu wollen, welche nach der allgemeinen Meinung längst gegenstandslos wurden, nichts mir widerwärtiger sein, als den Verdacht persönlichen und noch dazu nnversöhnbaren Grolls auf mich zu laden. Allein so sehr ich es wünschte, ich fand es ummöglich, jene Aufsätze fortzulassen, und meist auch, die tief in sie hineingewirkten polemischen Stellen daraus zu entfernen. Letzteres ist in einigen Fällen geschehen. Die übrigen Stellen der Art mögen als Denkmal der unvermeidlichen Kämpfe stehen bleiben, unter welchen hier, wie anderswo, die Wahrheit geboren wird, und aus denen sie schliesslich stets siegend hervorgeht.

Berlin, im Juni 1875.

\author{
Der Verfasser.
}




\section{Inhalt.}

U. Ueber Polarisation an der Grenze ungleichartiger Elektrolyte

(Monatsberichte der Akademie 1856. S. 395.)

II. Ueber innere Polarisation poröser, mit Elektrolyten getränkter Halbleiter

(Monatsberichte u. s. w. 1856. S. 450.)

III. Ueber den Einfluss, welchen die Dimensionen innerlich polarisirbarer Körper auf die Grösse der secundär-elektromotorischen Wirkung üben .

(Monatsberichte u. s. w. 1859. S. 68.)

IV. Ueber gleichartige und nicht polarisirbare Elektroden .

(Monatsberichte u. s. w. 1859 . S. 443.)

V. Ueber den secundären Widerstand, ein durch den Strom bewirktes Widerstandsphänomen an feuchten porösen Körpern . . . . . . . 80

(Monatsberichte u. s. w. 1860 . S. 816. .)

§. I. Einleitung . . . . . . . . . . . . . . . . . . 80

§. II. Von den fenchten porösen Körpern, welche secundären Widerstand zeigen . . . . . . . . . . . . . . . 84

§. III. Vom äusseren secundären Widerstande . . . . . . . . 87

§. IV. Vom inneren secundären Widerstande . . . . . . . . 90

§. V. Nähere Untersuchung des inneren secundären Widerstandes 96

§. VI. Abhängigkeit des äusseren secundären Widerstandes von Stromstärke und Querschnitt. . . . . . . . . . . 101

§. VII. Nähere Untersuchung des Eintrittsendes des feuchten porösen Körpers, welches der Sitz des äusseren secundären Widerstandes ist . . . . . . . . . . . . . . . 104

§. VIII. Vom äusseren secundären Widerstande bei Tränkung der Zuleitungsbänsche mit verschiedenen Flüssigkeiten . . . 105

§. IX. Vom äusseren secundären Widerstande bei Zuleitung des Stromes durch metallische Elektroden . . . . . . . 108

§. X. Zur Theorie des äusseren secundären Widerstandes. . . . 111

§. XI. Noch Einiges über den inneren secundären Widerstand . . 116

§. XII. Was sich zur Zeit über die Natur des inneren secundären Widerstandes sagen lasse ........... 120

§. XIII. Anwendung der Erfahrungen über den secundären Widerstand anf die elektrophysiologisehen Versuche . . . . 122

§. XIV. Ueber Elektrotransfusion am erregbaren Muskel . . . . : 126 
VI. Ueber ein Verfahren um feine galvanometrische Versuche einer grösseren Versammlung zu zeigen . . . . . . . . . . . . . . . . . (Poggendorff's Annalen der Physik und Chemie. 1855. Bd. XCV. S. 607.)

VII. Zur Theorie der astatischen Nadelpaare.

(Poggendorff's Annalen u. s. w. 1861. Bt. ('XII. s. 1.)

Hierzu Taf. IV. Fig. 1-3.

VIII. Beschreibung einiger Yorrichtungen und Versuchsweisen zu elektro-

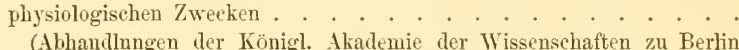

1862. Berlin 1863. 40. Physikalische Klasse. S. 75.)

Hierzu Taf. I-III.

§. I. Vom Multiplicator . . . . . . . . . . . . . . .

§. II. Vom Gebranch der Spiegelbussolen zu thierisch-elektrischen Versuchen . . . . . . . . . . . . . . 152

§. III. Von den Zuleitungsgefässen . . . . . . . . . . . . 157

§. IV. Von den Bäuschen . . . . . . . . . . . . . . . 160

§. V. Vom Modellirthon als Ersatzmittel der Eiweisshäutchen . . 161

§. VI. Von den Zuleitungsröhren mit Thonspitzen . . . . . . 163

§. VII. Vom feuchten Arbeitsraume . . . . . . . . . . . . 167

§. VIII. Von den Vorrichtnngen zum elektrischen Tetanisiren . . . 168

§. IX. Vom Schlüssel . . . . . . . . . . . . . ‘. . . . 171

§. X. Vom Gebrauch des Schlïssels beim Tetanisiren durch Inductionsströme . . . . . . . . . . . . . . . 174

§. XI. Vom Compensator, einer Vorrichtung zum Messen der elektromotorischen Krraft der Nerven und Muskeln . . . . . 176

§. XII. Vom Rheochord in seiner Anwendung zu elektrophysiologischen Versuchen . . . . . . . . . . . . . 187

§. XIII. Von einem beim Gebranch des Rheochords in Reizversuchen zu beachtenden Umstande . . . . . . . . . . . . 196

§. XIV. Vom Schwankungsrheochord, einer Vorrichtung zum Erweise des allgemeinen Gesetzes der Nervenerregung dureh den strom.

§. XV. Vom Zuckungstelegraphen . . . . . . . . . . . .

§. XVI. Von einer Vorrichtung zu Versuchen über chemische Reizung der Muskeln . . . . . . . . . . . . . . 211

§. XVII. Von der feuchten Reizungsröhre . . . . . . . . . . 211

§. XVIII. Vom Froschwecker, zum Gebranch bei Versuchen an elektromotorischen Fischen. . . . . . . . . . . . .

§. XIX. Vom Froschunterbrecher, zum Gebranch bei denselben Versuchen . . . . . . . . . . . . . . . . 215

IX. Ueber den zeitlichen Verlauf voltä̈lektrischer Inductionsströme . . . 22s

(Monatsberichte u. s. w. 1862 . S. 372.)

§. I. Abäntlerung des Nagnetelektromotors dureh Hrn. Hezmнoctz

§. II. Bezeichnung ter hier noch zn lösenden Aufgabe . . . .

§. III. Induction in der Nebenrolle durch Oeffnen des intucirenden Kreises . . . . . . . . . . . . . . . 237

§. IV. Induction dureh schlitssen des inducirenten líreises . . 238 
Seite

§. V. Induction durch Oeffnen einer Nebenleitung zur Hauptrolle. 244

§. VI. Induction durch Schliessen einer Nebenleitung zur Hauptrolle 245

§. VII. Bedingungen der Congruenz der Aufangs- und Eudinduction 247

§. VIII. Andere Ableitung der Congruenzbedingungen . . . . . . 249

§. IX. Versuche zur Bestätigung der Theorie . . . . . . . . 250

§. X. Schlussbemerkungen . . . . . . . . . . . . . . . 254

X. Anleitung zum Gebrauch des runden Compensators . . . . . . 257

(Arehiv für Anatomie u. s. w. 1871. S. 608.)

XI. Fortgesetzte Besehribung neuer Vorrichtungen für Zwecke der allgemeinen Nerven- und Muskelphysik

266

(PoggendorfF's Amualen u. s. w. 1673. Jubelband, S. 591.)

§. I. Der Quecksilberschlüssel . . . . . . . . . . . . . 266

§. II. Die Doppelwippe. . . . . . . . . . . . . . . . 267

§. Ill. Die Frosehpistole . . . . . . . . . . . . . . . 269

§. IV. Das Federmyographion . . . . . . . . . . . . . 271

XII. Ueber aperiodische Bewegung gedämpfter Magnete. . . . . . . . 284 Erste Abhandlung.

(1lonatsberichte u. s. w. 1s69. S. so7.)

§. I. Einleitung . . . . . . . . . . . . . . . 284

§. II. Allgemeine Gleichung der Bewegung gedämpfter Magnete, und periodische Bewegung soleher Magnete . . . . . . 286

§. III. Aperiodische Bewegung gedämpfter Maguete. . . . . 288

§. IV. Uebersicht der Bewegungsformen ungedämpfter und gedämpfter Magnete . . . . . . . . . . . . . 290

§. V. Aperiodische Bewegung nit Anfangsgesehwindigkeit . . . 292

§. VI. Herleitung der Bedingung fïr die zum Ueberschreiten des Nullpunktes nöthige Anfangsgesehwindigkeit . . . . . . 295

§. VII. Verhalten aperiodisch sich bewegender Magnete bei kurzer Einwirkung eines Stromes . . . . . . . . . . . 301

§. VIII. Verhalten aperionliseh sich bewegender Magnete bei Ablenkung dnreh einen beständigen Strom. . . . . . . . 303

§. IX. Sonstige Combinationen von Lage und Geschwindigkeit des Magnetes und von ihn treffenden Kräften . . . . . . . 304

§. X. Nähere Bestimmung der experimentellen Bedingungen, unter denen die Bewegung gedämpfter Magnete aperiodisch wird.

§. XI. Die Beruhigungszeit des gedämpften Magnetes in ihrer Abhängigkeit von dessen verschiedenen, im Vorigen betrachteten Zuständen

§. XII. Bestätigung der für den Fall einer. Anfangsgesehwindigkeit theoretisch gefundenen Bewegungsgesetze aperiodiseher Magnete . . . . . . . . . . . . . . . . 312

§. XIII. Vorzïge der Beobachtung an aperiodischen Magneten . . 321

XIII. Ueber aperiodische Bewegung gedämpfter Magnete . . . . . . . 324 Zweite Abhandlung.

(Monatsberichte u. s. w. 1×70. S. 537.)

Hierzu Taf. T. Fig. 4-s.

§. I. Einleitung . . . . . . . . . . . . . . . . . . 324

§. II. Die fundamentalen Eigensehaften unserer Differentialgleichung 326 
§. III. Erster Hauptfall: $a x+x^{\prime}$ und $b x+x^{\prime}$ sind einerlei Zeichens . . . . . . . . . . . . . 330

§. IV. Physikalische Anwendung der gewonnenen Ergebnisse, und Vergleichung dieser Ergebnisse mit denen der ersten Ab-

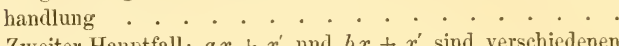

§. V. Zweiter Hauptfall: $a x+x^{\prime}$ und $b x+x^{\prime}$ sind verschiedenen Zeichens . . . . . . . . . . . . . . . 335

§. VI. Behandlung des Grenzfalles $\varepsilon=n$. . . . . . . . 339

§. VII. Die Curven der Geschwindigkeiten bezogen auf die Ablenkungen $\mathrm{im}$ allgenteinen Fall $\varepsilon>n$...... . . $3+1$

§. VIII. Die Curve der Geschwindigkeiten bezogen auf die Ablenkungen im Grenzfall $\varepsilon=n$. . . . . . . . . . . 349

Zusatz von Hrn. Kronecker zur vorigen Abhandlung . . . . . 351

XIV. Ueber aperiodische Bewegung gedämpfter Magnete . . . . . . . 353

Dritte Abhandlung.

(Monatsberichte u. s. w. 1873. S. $7+8$. )

§. I. W. Sienens' aperiodische Magnete ohne Astasirung . . . 353

§. II. Verschiedenes Verhalten aperiodischer Magnete bei teleskopischer und bei makroskopischer Ablenkung . . . . . . 355

§. III. Von der besten Art, den Haur'schen Stab anzubringen . . 363

§. IV. Sir Willian Thomson's aperiodische Magnete ohne Dämpfung . . . . . . . . . . . . . . 366

XV. Ueber aperiodische Bewegung gedämpfter Nagnete. . . . . . . . 368

Vierte Abhandlung.

(Monatsberichte u. s. w. 1874. S. 767.)

§. I. Warum es an gewissen Bussolen misslang, den Nagnet in branchbarer Weise aperiodisch zu machen. . . . . . 368

§. II. Fortgesetzte Bemerkungen iiber die beste Art, den Haur'schen Stab aufzustellen. . . . . . . . . . . . . 372

§. III. Von den Schwankungen der Gleichgewichtslage des Magnetes in Folge der täglichen Variation des Erdmagnetismus, oder den .Variationsschwankungen“" . . . . . . . . . . 376

§. IV. Von der fleichgewichtslage des Nagnetes bei höherer Astasie 379

Zusatz . . . . . . . . . . . . . . . . 389

\section{Nachweis zu den Kupfertafeln.}

\begin{tabular}{|c|c|c|c|c|c|c|c|c|c|c|c|c|c|c|}
\hline \multirow{2}{*}{\multicolumn{5}{|c|}{ Taf. I-III. }} & \multirow{2}{*}{\multicolumn{10}{|c|}{ Taf. IV. }} \\
\hline 1,1 & & & & & & & & & & & & & & \\
\hline $2,2 \mathrm{a}$ & , III & . & • & . , 164 &,$\quad 2$ & . & $\dot{.}$ & . & - & 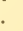 & • & . & , & 139 \\
\hline 6 & I & . & . & , 183 & .. & & . & . & . & & . & . & , & 140 \\
\hline $7,7 \mathrm{a}, 7 \mathrm{~b}$ & II & . & • & ., 191 & 4 & & . & . & • & $\cdot$ & • & • & 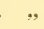 & 30 \\
\hline $8,8 \mathrm{a}$ & II & . & . & " 199 & 5 & . & . & - & - & & & & 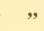 & 338 \\
\hline 9 & I & 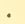 & . & , 207 & 6 & • & . & • & - & $\cdot$ & & • & . & $3+1$ \\
\hline 10 & III & . & • & , 211 & , & • & . & - & - & & & & . & 348 \\
\hline 11 & II & . & . & . 212 & , & . & . & - & . & & & & , & 349 \\
\hline $12,12 \mathrm{a}$ & 111 & & & 216 & & & & & & & & & & \\
\hline
\end{tabular}




\section{METHODEN}

UND

\section{PHYSIKALISCHE BEDINGUNGEN.}



I.

\section{Ueber Polarisation an der Grenze ungleichartiger Elektrolyte.}

(Gelesen in der Gesammtsitzung der Königl. Akadenie der Wissenschaften zu Berlin am 17. Juli 1856.) ${ }^{1}$

An der Grenze ron Metallen und Elektrolyten erzengt der elektrische Strom bekanntlich die zuerst ron J. W. RitTer beobachtete elektromotorische Gegenkraft, deren Ursprung Vouta sofort richtig in der elektromotorischen Rückwirkung der ausgeschiedenen Zersetzungsstoffe suchte. An der Grenze rerschiedener Metalle tritt nach PeLtien's Entdeckung gleichfalls, wemn auch auf sehr rerschiedenem Wege entsprungen, eine elektromotorische Gegenkraft auf. An der Grenze rerschiedener Elektrolyte dagegen fehlte es bisher an einer entsprechenden Wahrnehmung. Durch die folgenden Beobachtungen wirl diese Lücke ausgefüllt.

Um diese neue Art ron Polarisation nachzuweisen, bedarf es sehr kräftiger elektromotorischer und höchst empfindlicher stromprüfender Vorrichtungen. Ich bediente mich einer säule ans dreissig Grove'schen Gliedern der kleineren in meinen 'Untersuchungen'" beschriebenen Art, und meines Sultiplicators ron 24160 Windungen.

Das allgemeine Princip der Beobachtung ist das nämliche, welches für die Ritter'sche und die ohen bezeichnete Peltier'sche Polarisation gilt, und darin besteht, dass der die polarisirbare Reihenfolge von Leitern enthaltende Kettentheil $A$ erst eine gewisse Zeit hindurch einen Theil des Säulenkreises bildet, dann aber, nach einer Zwischenzeit, die man gewöhnlich möglichst abzukürzen strebt, zu einem Theile des Mnltiplicatorkreises gemacht wird. Hierzu reicht aus, dass, während der dem Süulen-

${ }^{1}$ Monatsberichte der Akademie. 1856. S. 395. - Auch abgedruckt in Molesснотт's Untersuchungen zur Naturlehre des Menschen und der Thiere. 1858. Bd. IV. S. 144 .

2 Bd. I. S. 446.

E. du Bois-Reymond, Ges. Abh. I. 
und dem Multiplicatorkreise gemeinsame Kettentheil $A$ mit der säule verbunden ist, der Multiplicatorkreis [396] an einer Stelle $\alpha$ geöffnet werde, wenn aber $A$ am Multiplicator auf secundär-elektromotorische Wirkung ${ }^{1}$ geprüft wird, die Lücke $\alpha$ geschlossen werde, unmittelbar nachdem der Säulenkreis an einer Stelle $\beta$ geöffnet wurde. Bei Anwendung so kräftiger Säulen indess und so empfindlicher Multiplicatoren, wie wir ihrer bedürfen, genügt diese Versuchsweise nicht. Es würden dabei am Multiplicator die von mir in meinen 'Untersuchungen' ${ }^{2}$ beschriebenen Wirkungen störend anftreten, welche man wahrnimmt, wemn man eines seiner Enden, oder nach Einschaltung eines hinlänglichen Widerstandes, den die Verknüpfungsstelle nicht symmetrisch hälftet, auch seine beiden Enden, mit dem einen Ende einer Säule verknüpft. Um diese und alle ähnlichen Störungen sicher abzuschneiden, wurde folgende Anordnung getroffen.

Fig. 1.

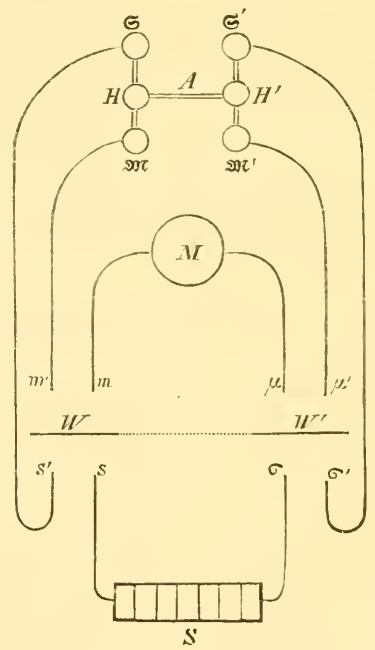

1 Unter secundär-elektromotorischer Wirkung verstehe ich in dieser und den folgenden Abhandlungen jede Art elektromotoriseher Wirkung, welche in eincr irgendwie beschaffenen Reihe von Leitern als Folge des Durchgangs eines Stromes, der der ursprüngliche genannt wird, auftritt.

2 Bd. II. Abth. I. S. 496. 
[397] Im nebenstehenden Schema bedentet $S$ die Säule, $\boldsymbol{M}$ den Multiplicator, $A$ den polarisirbaren Kettentheil. $s^{\prime} s, \sigma \sigma^{\prime}$ stellen demgemäss zwei Lücken im Säulenkreise, $m^{\prime} m, \mu \mu^{\prime}$ zwei Lücken im IIultiplicatorkreise ror. Die beiden Kreise sind mit Inbegriff der acht Enden ihrer beiden Unterbrechungsstellen, $m^{\prime} m, \mu \mu^{\prime}, s^{\prime} s, \sigma \sigma^{\prime}$, auf das vollkommenste ron eimander isolirt. $\boldsymbol{W} \boldsymbol{U}^{\prime \prime}$ ist eine Wippe, welche aus zwei Hälften, $\boldsymbol{H}^{\boldsymbol{r}}$ und $\boldsymbol{H}^{\boldsymbol{\prime}}$ besteht, die zwar in einem Stücke bewegbar, doch jede für sich gleichfalls höchst vollkommen isolirt sind. Je nachdem die Wippe sich an $s^{\prime} s, \sigma \sigma^{\prime}$, oder an $m^{\prime} m, \mu \mu^{\prime}$ lehnt, lässt sie den Strom der Säule durch $A$ hindurch, oder macht sie die in $A$ erzeugten secundär-elektromotorischen Wirkungen am Multiplicator sichtbar.

Da die Stärke der Polarisation wesentlich von der Dauer des Säulenschlusses und ron der Zeit abhängt, welche zwischen Oeffummg des Säulenund Schliessung des Multiplicatorkreises rerstreicht, ist es zweckmässig, um vergleichbare Wirkungen zu erhalten, die Wippe durch ein Uhrwerk bewegen zu lassen, welches die Uebertragung der Schliessung rom einen Kreis auf den anderen stets in hinlänglich gleicher, nach Belieben bald kürzerer, bald längerer Zeit vollführt, und ausserdem die Dauer des Säulenschlusses auch innerhalb so kurzer Zeiträume zu regeln erlaubt, dass es ohne beträchtliche Fehler nicht gelingen würde, die Wippe mit der Hand umzulegen.

In dem Schema bedeuten ferner die Kreise $9 \mathfrak{X}, \mathfrak{M} \mathfrak{X}^{\prime}$ meine gewöhnlichen Zuleitungsgefässe, mit Platinenden in gesättigter Kochsalzlösung. , ऽ' dagegen sind ähnliche Zuleitungsgefässe, in denen, um nicht die Beständigkeit der säule zu gefährden, das Platin durch Kupfer, und die Kochsalz- durch gesättigte schwefelsaure Kupferoxydlösung ersetzt ist.

$H$ und $H^{\prime}$ endlich sind Hülfsgefässe, die durch Heberröhren mit den beiderseitigen Zuleitungsgefässen verbunden sind. Auf Seiten des Multiplicators sind die Röhren mit Kochsalz-, auf der der Säule mit Kupferlösung gefüllt, und ihre in die Hülfsgefässe tauchende Mündung ist mit Blase verschlossen. Zwischen den Hülfsgefässen kamn man nunmehr, wie man sieht, heberförmige Röhren mit beliebigen Flüssigkeiten gefüllt anbringen, ja man kamn die Hülfsgefässe selber mit be- [398] liebigen Flüssigkeiten anfüllen, ohne dadurch die Reinheit und Gleichartigkeit der in den Zuleitungsgefässen befindlichen Lösungen, mit anderen Worten, ohne das Gleichgewicht im Multiplicator- und die Beständigkeit des Strumes im Säulenkreise zu gefährden.

Die mit Flüssigkeiten gefüllten Heberröhren zwischen den Hülfsgefässen durften, wie eine spätere Fulge lehren wird, nicht füglich mit Blase oder Fliesspapier verschlossen werden. Die darin befindlichen Flüssigkeiten mussten deshalb stets denen in den Hülfsgefässen an Dichte 
nachstehen. Um die Röhren im gefüllten Zustande in die Hülfsgefässe umstürzen zu können, waren ihre Enden capillar ausgezogen, ${ }^{1}$ wenn der Widerstand der Flüssigkeit es erlaubte, ihren Querschnitt stellenweise dergestalt zu verkleinern. Im anderen Falle wurden Papierscheiben auf die Mündnngen der Röhren gelegt, die der atmosphärische Druck so gegen deren abgeschliffene Ränder presste, dass man die Röhren umkehren und ihre Enden mit aller Ruhe in die Flüssigkeit der Hülfsgefässe eintanchen konnte, worauf die Papierscheihen wieder entfernt wrurden.

Man denke sich nun zunächst die Hülfsgefässe suwohl als die sie verbindende Heberröhre, gleich den Zuleitungsgefässen des Multiplicators und den Heberröhren zwischen diesen und den Hülfsgefässen. mit gesättigter Kochsalzlösung gefüllt. Die Wippe $\boldsymbol{W} \boldsymbol{W}^{\prime \prime}$ ist gegen die Enden $m^{\prime} m, \mu \mu^{\prime}$ gelehnt, und hält also den Multiplicatorkreis geschlussen. Die Nadel steht auf Null, und die Platinenden des Multiplicators sind so gleichartig, dass auch nach mehreren Minuten Offenstehen des Multiplicatorkreises bei dessen Schliessen keine in Betracht kommende Wirkmng erfolgt. Jetzt wird das Uhrwerk ausgelöst und überträgt durch Umlegen der Wippe die Schliessung von den Enden des Multiplicatorkreises $m^{\prime} m, \mu \mu^{\prime}$, auf die Enden des Säulenkreises $s^{\prime} s, \sigma \sigma^{\prime}$. Die Hülfsgefässe und die sie verbindende Heberö̈hre roll Kochsalzlösung werden ron dem Strom der dreissiggliederigen Grove'schen [399] Säule durchkreist, olne dass eine Spur daron ihren Weg in den Multiplicatorkreis fände. Wir lassen, durch Anhalten des Uhrwerks, die Kette beliebig lange Zeit geschlossen, voransgesetzt, wie gesagt, dass wir darauf rechnen können, dass das Offenstehen des Multiplicaturkreises die Gleichartigkeit der Platimplatten nicht zu sehr gefährde, damn lösen wir wieder das Lhrwerk aus. Nach gegebener Zeit überträgt es im Nu die Schliessung rom Säulen- auf den Multiplicatorkreis, die Nadel aber bleibt, wenn Alles in Ordnung ist, durchans unbewegt. Dies dient beiläufig noch zum Zeichen, dass, während des vorhergehenden Zeitraumes des Versuches, kein Theil des Stromes seinen Weg anch nur bis durch die Platinenden des Inltiplicators bindurch gefunden hat, was ja hätte der Fall sein kümnen, ohne dass der während jenes Zeitraumes daron abgeschnittene Multiplicator etwas verriethe. Aber nachträglich würden wir. wemn etwas der Art stattgefunden hätte, durch die auf den Platinenden entwickelten Ladungen am Multiplicator daron Kumle erhalten.

1 Vergl. Walker in Poggexdorfy's Ammalen u. s. w. 1825. Bd. IY. S. 319; - Fechner ebendas. 1839. Bd. Xlyili. S. 5 ; - Becquerel in den Comptes rendus cte. 29 MIars 1847. t. XXIV. p. 505. 
Nun wiederholen wir genan denselben Tersuch, mit der einzigen Abänderung, dass wir das mit Kóchsalzlösung gefüllte Heberrohr durch ein mit verdünnter S'chwefelsäure gefülltes ersetzen. ${ }^{1}$ Lässt man jetzt den Säulenstrom anch nur 5" lang durch die Reihe der Elektrolyte: Kochsalzlösung, verdümute Schwefelsäure, Kochsalzlösung hindurchgehen, so fliegt, beim Schliessen des Multiplicatorkreises, die Nadel mit Heftigkeit an die Hemmung, einen Strom in der Elektrolytenreihe ron umgekehrter Richtung ron der des Süulenstromes anzeigend. Der secundäre Strom ist imnerhalb gewisser Grenzen, die ich noch nicht näher bestimmt habe, um so stärker, je grösser stärke und Dauer des ursprünglichen Stromes. Er ist nur von sehr kurzer Daner. Lässt man zwischen Oeffnung des Säulen- mo Schliessen des Multiplicatorkreises einen Zeitraum von nur $10^{\prime \prime}$, so erfolgt bereits nur noch ein sehr schwacher Ausschlag. Bei einer noch längeren Zwischenzeit bleibt die Nadel röllig in Ruhe. Ob diese Ausgleichung bei geschlossenem Kreise [400] noch schneller vor sich gehe, was wohl möglich wäre, habe ich noch nicht zur Entscheidung gebracht.

Werden auch die Hülfsgefässe mit der verdümnten Schwefelsäure gefüllt, so ist der Erfolg der nämliche. als ob sie und das sie rerbindende Heberrohr Kochsalzlësung enthielten, d. h. es findet keine secmndärelektromotorische Wirkung statt. Füllt man aber jetzt das Heberrohr mit Kochsalzlösung, wobei, wie gesagt, die Sïnre dliesmal solche Dichte haben muss, dass die Lösung sicher darauf sehwimmt, ${ }^{2}$ so erfolgt ein Ausschlag von gleicher Richtung, als ob die Hülfsgefïsse die Lösung und das Rohr die Säure enthalten hätten.

Aehnlich der verdümnten Schwefelsänre verhielten sich hinsichtlich der Richtung der Wirkung noch folgende Flüssigkeiten: Chlorwasserstoffsäure; gewöhnliche Salpetersäure; dieselbe mit dem gleichen Volum destillirten Wassers verdünnt; Ammoniak; gesättigte Salpeterlösung. ${ }^{3}$ Die Wirkung war aber schon bei der Chlorwasserstoffsäure schwächer als bei der verdümnten Schwefelsäure, und nahm bei den übrigen Flüssigkeiten noch mehr an Stärke ab, in der Ordnung, wie sie genamnt sind.

Man sieht, das mit einer dieser Flüssigkeiten gefüllte Heberrohr zwischen den Hülfsgefässen voll Kiochsalzlösung verhält sich, abgesehen von der freilich unvergleichlich geringeren Stärke der Wirkmigen, nicht anders, als es ein an dessen Stelle über die Hülfsgefässe gebrückter Streif eines polarisirbaren Netalles. z. B. Platinblech. thun würde.

${ }^{1} \mathrm{HSO}_{4}: \mathrm{HO}:: 1: 8 \mathrm{dem}$ Volum nach. Dichte etwa 1.13.

2 Nämlich mindestens $\mathrm{HSO}_{4}: \mathrm{HO}:: 1$ : 4, Dichte etwa 1.22.

31.1377 Dichte bei $17^{\circ} \mathrm{C}$. 
Sehr verschieden gestaltet sich der Erfolg mit einigen anderen Flüssigkeiten, nämlich mit concentrirter Kalihydratlösung, Brunnenwasser, destillirtem Wasser, Hühnereiweiss und den hinsichtlich des Widerstandes und der elektrochemischen Beschaffenheit nahestehenden thierischen Säften.

Zwar was die Umstände, die die Stärke der secundär-elektromotorischen Wirkung bestimmen, und den zeitlichen Verlauf letzterer betrifft, so giebt sich kein Unterschied zu erkemmen. [401] Während aber bei den erstgenamnten Flüssigkeiten die secundär-elektromotorische der ursprünglichen Wirkung entgegengesetzt ist, ist sie ihr hier gleich gerichtet. Bezeichnet man jene Art der Polarisation als negatir, so hat man es hier nit positiver Polarisation zu thm, wozu im Gebiete der Ladungserscheinungen an der Grenze von Metallen und Elektrolyten höchstens die von Martexs und BeEtz an Eisen und von mir an rerquicktem Zink beobachtete positive Polarisation ein Seitenstück bietet. ${ }^{1}$ Mit der Kalihydratlösung zwisehen Kochsalz aber schien mir die positive Wirkung kaum weniger stark als die negative mit der verdünnten Schwefelsäure; mit dem Wasser und Hühnereiweiss, besonders dem letzteren, ist sie zwar beträchtlich schwächer, doch vollkommen regelmässig und ausgesprochen, und in Betracht des grossen Widerstandes dieser Flüssigkeiten ist es noch die Frage, ob wirklich die secundär-elektromotorische Kraft eine bedeutend kleinere war.

Auch mit den übrigen genannten Flüssigkeiten kamn man natürlich dieselbe Versuchsreihe durchmachen, wie mit der verdünnten Schwefelsäure, nämlich nachweisen, dass wenn die Hülfsgefässe dieselbe Flüssigkeit enthalten wie das sie rerbindende Heberrohr, keine seeundär-elektromotorische Wirkung erfolgt, aber sofort, und in der gleichen Richtung wiederkehrt, wenn jetzt das Heberrohr mit Kochsalzlösung gefüllt wird.

Ian kamn, mit Beobachtung gewisser Rücksichten, diesen Versuchen noch eine andere Gestalt geben, die zwar weniger rollkommen, dafür aber mehr geeignet ist, gewisse, zur Entscheidung einiger Punkte dienliche Abändermngen zuzulassen. Sie besteht darin, anstatt die Flüssigkeiten, deren Grenze der Sitz der Polarisation werden soll, in Röhren und Gefässen zu beherbergen, Fliesspapierbäusche damit zu tränken, und durch deren Berührungsstellen den Strom hindurchzusenden. Die Zuleitungsgefässe $\mathfrak{M}, \mathfrak{M}$ nehmen alsdann die gewöhnlichen, mit gesättigter Kochsalzlösung getränkten Zuleitungsbäusche auf. Die Zuleitungsgefässe $\mathfrak{S}$, $\mathfrak{S}^{\prime}$ erhalten dergleichen mit gesättigter schwefelsaurer Kunferoxydlüsung getränkt. An [402] Stelle der Hülfsgefässe treten Hülfsbäusche,

1 Untersuchungen u. s. w. Bd. I. S. 236. 610. 
welche für gewöhnlich mit Kochsalzlösung getränkt sind, und nach dit des Schliessungsbansches dauernd über die in $\mathfrak{M}$ und $\mathfrak{S}$ und die in $\mathfrak{M}^{\prime}$ und $\varsigma^{\prime}$ befindlichen Znleitungsbäusche gebrückt werden. Von den mit Kupferlösung getränkten Bäuschen $\subseteq$ und $\complement^{\prime}$ sind sie zur Verhütung dauernder gegenseitiger Verunreinigung durch Sicherheitsbäusche getrennt, d. h. durch einige Lagen Fliesspapier, die anf Seiten der Zuleitungsbäusche mit Kupfer-, auf Seiten der Hülfsbäusche mit Kochsalzlösung getränkt sind.

Auf den Hülfsbäuschen kömen nummehr, wie zwischen den Hülfsgefässen die Heberröhren, balkenförmige Bäusche, d. h. vierseitig prismatische Bäusche, aus eiuer grossen Anzahl Fliesspapierlagen bestehend, ron etwa $60^{\mathrm{mm}}$ Länge, $15^{\mathrm{mm}}$ Breite, $10^{\mathrm{mm}}$ Dicke, mit beliebigen Flüssigkeiten getıänkt, angebracht werden. Die Hülfshäusche schützt man abermals durch Sicherheitsbäusche gegen dauernde Verumreinigung mit den zu prüfenden Flüssigkeiten. Es versteht sich, dass man die Hülfsbäusche nach Bedürfniss anch mit anderen Flüssigkeiten als nit Kochsalzlösung tränken kann, gerade wie man die Hülfsgefässe mit dergleichen anfüllen kann; alsdamn müssen sie auch von den .Znleitungsbäuschen des Inultiplicators in $\mathfrak{M}$, $\mathfrak{M}^{\prime}$ durch Sicherheitsbäusche getremnt werden.

Mit Hülfe dieser Vorrichtmng lassen sich alle obigen Versuche bequem mnd sicher mit dem nämlichen Erfolg ausführen. Ein balkenförmiger Bausch mit verdünnter Schwefelsäure getränkt, zwischen den mit Kochsalzlösung getränkten Hülfsbäuschen durchströmt, giebt negative Polarisation. Ein ähnlicher Bausch mit Kalilauge getränkt, an Stelle jenes gesetzt, giebt positive Polarisation u. s. w.

Nur in dem Falle, dass man die Bäusche mit verhältnissmässig schlecht leitenden Flüssigkeiten, mit Wasser, Hühnereiweiss n. d. m. tränkt, giebt sich damit ein anderer Erfolg zu erkennen, als mit denselben Flüssigkeiten in Gefässen und Röhren. Alsdamn nämlich mischen sich secundär-elektromotorische Wirkungen einer ganz anderen Art ein, die den Gegenstand einer späteren Mittheilung ${ }^{1}$ ausmachen werden.

[403] Bei dieser Form des Versuches kam man nun anch so rerfahren, dass man, nach Entfernung der Hülfsbäusche, den balkenförmigen, z. B. mit Schwefelsäure getränkten Bausch ummittelbar über die Znleitungsbänsche der Säule in $\subseteq$, $\boldsymbol{S}^{\prime}$ brückt, auf denen in ihren oberen Schichten mit Kochsảzlösung getränkte Sicherheitsbäusche ruhen. Nachdem der Strom einige Zeit hindurchgegangen, überträgt man den Schwefelsäurebausch rasch anf die Zuleitungsbäusche des Multiplicators,

1 Es ist die folgende Abhandlung. 
oter vielmehr auf teren Sicherheitsbäusche, und beobachtet auch so die negative Polarisation des durchströmt gewesenen Bausches. Natürlich wird es hierbei nur selten gelingen, die Nadel nicht in der einen oder der anteren Richtung ausschlagen zu sehen, auch wem der Schwefelsäurebausch gar keinem Strom ausgesetzt gewesen ist. Indessen ist es stets leicht, die Wirkung der Durchströmung nachzuweisen, und dafür hat dies Verfahren, welches das der Uebertragung heissen mag, den Vortheil, dass es die Vorkehrungen zur Isolation des Säulen- und Multiplicaturkreises, die Wippe, und die übrigen etwas künstlichen Vorrichtungen der ersten Versuchsweise entbehrlich macht.

Da weder die Kochsalzlösung noch eine der in Berührung damit geprüften Flüssigkeiten an und für sich eine secundär-elektromotorische Wirkung zeigt, so kann es nicht zweifelhaft sein, dass es die Grenze der beiden ungleichartigen Flüssigkeiten ist, die in Folge des Stromes der Sitz einer negativen oder positiven elektromotorischen Kraft wird. Indessen gelingt es, bei ter eben beschriebenen Methode tes Uebertragens, dies auch noch ummittelbar durch den Versuch darzuthun, indem man nämlich den polarisirten Schwefelsäurebausch dergestalt auf die Multiplicaturbäusche bringt, dass er sie mit anderen Stellen seiner Oberfläche berührt, als die, mit denen er auf den Säulenbäuschen auflag. oder indem man die Schichten Fliesspapier dlavon ablöst, mit denen er diese Bäusche berïhrte.

Die durch den Säulenstrom bewirkte Ungleichartigkeit des Bausches ist also eine ebenso oberflächliche und örtliche wie die eines Platinstreifes sein würde, den man an Stelle des Bausches über die Säulenbäusche gebrückt hätte; und, wie hier, setzt sich ohne Zweifel auch dort die elektromotorische Wir- [404] kumg aus zweien zusammen, die an den beiden durchströmten Grenzen ungleichartiger Elektrolyte ihren Sitz haben.

Um dies durch den Tersuch zu erhärten, dient eine Anordnung, welche an Pestren's thermö̈lektrisches Krreuz erinnert. In dem Schemal oben S. 2 denke man sich tie Zuleitungsbänsthe in $\subseteq$ und $9 \mathfrak{X}^{\prime}$, also über's Kreuz, turch einen balkenförmigen Kochsalzbausth, hingegen tie in $\mathfrak{S}^{\prime}$ und $\mathfrak{M}$ durch einen eben solchen Schwefelsäurebausch verbunden. An der Kreuzungsstelle lässt man die beiden ungleichartigen Bäusche rinander berühren. Dabei läuft die Gleichartigkeit des Multiplicatorkreises keine Gefahr, weil darin verdüunte schwefelsäure beiderseits gesättigte Kochsalzlïsung herührt. Löst man aber das Uhrwerk aus und lässt die Wippe auch nur wenige Secunden lang die Säule durch die Berührungsstelle der beiden ungleichartigen Bäusche schliessen, so erhält man eine kräftige negative Wirkung, gleichriel ob der Strom rom Salz zur Säure, oler umgekehrt floss. Ich habe den Versuch auch mit 
Brumnenwasser anstatt nit der Säture angestellt, was in diesem Falle aus gewissen Gründen, die später einleuchten werden, erlaubt war. Gleichviel ob der Strom rom Wasser zur Salzlösung, oder umgekehrt floss, es erfolgte ein schwacher positirer Ausschlag. Nach diesen beiden allerdings nur unvollkommenen Erfahrungen zn urtheilen, würle die secundärelektromotorische Kiraft an der Grenze zweier ungleichartigen Elektrolyte, gleich der an der Grenze von Metallen und Elektrolyten, nicht nur ihrem Zeichen, sondern anch ihrer Grösse nach unabhängig sein ron der Richtung des ursprünglichen stromes.

Hier war ter Sitz der secundär-elektromotorischen liraft auf eine einzige Grenze zweier moleichartigen Elektrolyte beschränkt. Lmgekehrt vermag man ans ungleichartigen Elektrolyten eine Ladungssäule gleich der RitTeR'schen, nur freilich riel schwächer wirksam, aufzubanen.

Dies gelingt gut genug, um die Richtigkeit des Princips zu beweisen, mit Hülfe runder Pappscheiben, wie nan sie, mit Flüssigkeit getränkt, als Zwischenleiter bei den VoutA'schen Säulen alter Bauart anzuwenden pflegte. Ian weicht davon eine Anzahl in Kochsalzlösung, eine gleiche Anzahl [405] in rerdümnter Schwefelsäure auf, unt baut auf jedem der Hülfsbäusche eine Hälfte der Säule auf, indem man mit Salz beginnt, Säure folgen lässt, daun Salz, damn Säure, u. s. f. bis man mit Säure schliesst, und zuletzt beirle Sänlenhälften durch einen Salzbausch rerbindet. Es hat keine Schwierigkeit, bei Gegenwart eines hinreichenden ausserwesentlichen Widerstandes, das Wachsen der secundär-elektromotorischen Kraft mit wachsender Anzahl der Wechsel zwischen Salz und Säure nachzuweisen.

Eine Säule aus abwechselnd mit Kochsalz- und Kalihydratlösung getränkten Pappscheiben aufgebaut, gewährt das merkwürdige Schanspiel einer Ladungssäule, deren Strom dem ursprünglichen gleichgerichtet ist.

Es bleibt mir übrig, einen Begriff ron der absoluten Stärke der hier stattfindenden Wirkungen mitzutheilen. Folgendes ist Alles, was ich in dieser Beziehung rermag. Ein auf den Hülfsbäuschen befindlicher, mit der verdünnten Schwefelsäure von 1-13 Dichte getränkter balkenförmiger Bausch wurde eine Minute lang dem Strome der dreissigliederigen Grove'schen Sïule ausgesetzt, und dam durch den Multiplicator ron 4650 Windmngen entladen, dessen halbe Länge aber nur benutzt und dessen Empfindlichkeit ansserdem durch Vorlegen einer Nebenschliessung sehr rermindert wurde. Es erfolgten $6^{0}$ Ausschlag. Nachdem diese Wirkung unmerklich geworden war, wurde in den Multiplicatorkreis eine kleine Säure-Alkalikette mit Platinelektroden aufgenommen. Obschon sie den Widerstand des Kreises $n$ m ihren eigenen rermehrte, trieb sie doch 
die Nadel im ersten Ausschlage bis auf $40^{\circ}$. Ihre elektromotorische Kraft ist also sehr viel grösser, obschon bei der grossen Schwingungsdauer der Nadel allerdings in Anschlag kommt, dass die Kraft der Säure-Alkalikette annähernd beständig bleibt, während die der Polarisation im schnellen Sinken begriffen ist.

Vollends erscheint die secundär-elektromotorische Kraft an der Grenze der Elektrolyte klein in Vergleich zu der des ursprünglichen Stromes. Es würden Vorrichtungen ron, wie ich glaube, bisher unerreichter Vollkommenheit dazu gehören, um diese neue Art der Polarisation bereits während der Dauer des [406] ursprünglichen Stromes, durch Veränderung seiner Stärke bemerklich zu machen, wie dies mit der Polarisation an der Grenze von Metallen und Elektrolyten der Fall ist, und es ist deshalb leicht erklärlich, dass sie in den messenden Versuchen an Ketten mit mehreren flüssigen Leitern nicht in die Augen gefallen ist.

Was die Ursache der neuen secundär-elektromotorischen Erscheinung betrifft, so könnte man vielleicht daran denken, ob nicht für die Elektrolyte etwas Aehnliches stattfinde, wie für die Metalle nach Peltier. Aber abgesehen davon, dass thermoëlektrische Ströme bei Elektrulyten noch nicht nachgewiesen sind - in den Versuchen ron NoвпI und $\mathrm{mir}^{1}$ handelt es sich um poröse Halbleiter, die mit Elektrolyten getränkt sind - habe ich mich auch mittels eines Thermometers, an dem ich ${ }^{1} / 50^{0} \mathrm{C}$. ablesen konnte, ganz unmittelbar überzeugt, dass die Temperatur an der ron dem Strom der dreissiggliederigen GrovE'schen Säule durchflossenen Grenze von Kuchsalalissung und rerdünnter Schwefelsäure ron der Richtung des Stromes unabhängig ist.

Es liegt denn auch wohl unstreitig näher, die nene Art der Polarisation in Beziehung zu setzen zur elektrolytischen Wirkung des Stromes, auf der ja auch die Polarisation der metallischen Elektroden beruht. Indem der Strom die Grenze zweier ungleichartigen Elektrolyte überschreitet, muss er die elektropositiven Bestandtheile der Flüssigkeit, die er rerlässt, und die elektronegativen derjenigen, in die er eintritt, freimachen, und die freigewordenen zur Verbindung antreiben, wem dieselbe möglich ist. So kamn zwischen den beiden Flüssigkeiten eine schicht einer dritten entstehen, und die Möglichkeit einer mit Stärke und Dauer des ursprünglichen Stromes bis zu einer gewissen Grenze wachsenden secundär-elektromotorischen Wirkung liegt am Tage.

1 Monatsberichte u. s. w. 1852. S. 117; - MoLeschoтt's Untersuchungen u. s. w. Bd. IJ. S. 253 ; - U'ntersuchungen u. s. w. Bd. II. Abth. II. S. 201. [Hr. Wild hat seitdem reine Hydrothermoströme entdeckt. PoggendorfF's Annalen u. s. w. 1858 . Bd. (III. S. 353.] 
Dass wirklich etwas der Art stattfinde, lehrt folgender Versuch. Zwischen zwei Salzbäusche schaltete ich einen mit reilchenblanem Lackmuspapier bekleideten Wasserbansch. Nachdem der Strom der dreissiggliederigen Grove'schen Säule [407] eimige Zeit hindurchgegangen, fand ich das Lackmuspapier da, wo der Strom darin eingetreten war, entschieden gebläut, da, wo er es verlassen hatte, schwächer geröthet; HumpHry DAvy's Behauptung zuwider, wonach Färbung ron Reagenzpapieren durch Jonen nicht anders als an den Poldrähten stattfinden sollte.

In der That trifft an der ersten Stelle das mit dem positiven Strom wandernde Natrium den gegen den Strom wandernden Sauerstoff, der von der Zersetzung des Wassers herrührt, und kamn damit Natron bilden; während das elektronegative Chlor an der anderen Grenze mit dem Wasserstoff Chlorwasserstoffsäure bildet. Das Natron und die Chlorwasserstoffsäure aber finden keine elektronegativen und -positiven stoffe, mit denen sie sich rerbinden könnten, und treten deshalb ans dem elektrochemischen Spiel der Molekeln aus, indem sie ihre Ladung beziehlich dem Wasserstoff und Sanerstoff übergeben.

Es ist hiernach wohl sehr wahrscheinlich, dass die gegebene Erklärung der Polarisation an der Grenze ungleichartiger Elektrolyte im Allgemeinen die richtige sei. Neine Bemühungen aber, in der Ausführmng dieser Theorie noch einen Schritt weiter zu thun, sind erfolglos geblieben. Ich wünschte nämlich eine Anordnung herzustellen, die in Bezug auf diese neue Art der Polarisation dasselbe leistete, wie die Grove'sche Gaskette in Bezug auf die RitTER'sche Ladung. Als ich aber auf sehr mamigfaltige Art Ketten mit mehreren flüssigen Leitern nach dem Schema anordnete: Chlornatrium, Chlorwasserstoffsäure, Wasser, Natron, Chlornatrium, erhielt ich stets einen Strom in der Richtung von der Säure durch das Wasser zur Basis, oder, wie man leicht sieht, negativer Polarisation entsprechend, wenn man sich Säure und Basis durch den Strom ausgeschieden denkt, während Wasser zwischen Chlornatriumlösung, wie wir oben fanden, vielmehr positive Polarisation giebt.

Befremdend ist denn auch, rom Standpunkt der obigen Theorie aus, der Mangel an Uebereinstimmung zwischen der elektrochemisehen Beschaffenheit der Flüssigkeiten und der Richtung, in der sie, zwischen Kochsalz durchströnt, secundär-elektromotorisch wirken. Unter den Flüssigkeiten, die nega- [408] tive Polarisation gaben, befinden sich saure, neutrale und alkalische; unter den positiv wirksamen, gleichfalls neutrale und alkalische.

Unstreitig ist es jetzt noch nicht an der Zeit, eine in's Einzelne gehende Deutung dieser rerwickelten Erscheinungen zu geben, wo sie 
erst in so geringer Ausdehmung studirt sind und die Lehre ron der Elektrolyse überhaupt erst im Entstehen begriffen ist. Wemn ich aber diese Untersuchung schon jetzt veröffentliche, so geschieht es, weil ich vor der Hand keine Veranlassung habe, sie weiter fortzusetzen. Was ich selber dabei beahsichtigte, war nur, mich zum Zweck gewisser thierischelektrischen Versuche über die rerschiedenen secmdär-elektromotorischen Wirkungen zu unterrichten, die beim Durchströmen einer irgendwie beschaffenen Reihenfolge von fenchten Leitern stattfinden. Dies mag es entschuldigen, dass sich z. B. mter den obigen Zusammenstellungen ungleichartiger Elektrolyte keine einzige findet, ron der nicht Kochsalzlösung das eine Glied ansmachte. 
II.

\section{Ueber innere Polarisation poröser, mit Elektrolyten getränkter Halbleiter.}

(Gelesen in der Sitzung der physikalisch-mathematischen Klasse der Königl.

Akademie der Wissenschaften zu Berlin am 4. August 1856.)1

In der am 17. Juli der Akademie gemachten Mittheilung habe ich eine neue Art von Polarisation beschrieben, welche ihren Sitz an der Grenze ungleichartiger Elektrolyte hat, die rermöge ihrer verschiedenen Dichte auf einander gelagert sind. In Folgenden werde ich eine zweite Art von Polarisation beschreiben, die sich in solchen Theilen von Ḱreisen bemerklich macht, welche scheinbar nur aus Elektrolyten bestehen, und die sich mit jener ersten Art, wemn nicht zu ihrer Scheidung besondere Torkehrungen getroffen sind, algehraïsch zu summiren pflegt.

Die Vorrichtungen zu Beobachtung dieser Polarisation sind im Wesentlichen ganz dieselben, die in der vorigen Abhandlung vorkamen, eine vielgliederige Grove'sche Sïule, der Multiplicator von 24160 Windungen, die beiden Paare ron Zuleitungsgefässen, und die Wippe nebst dem in gegebenen Zeiträumen sie bewegenden Uhrwerk. Ebenso sind stets dieselben Vorsichtşmasssegeln wie dort, hinsichtlich der Isolation der beiden Kreise von einander, der Gleichartigkeit des Multiplicatorkreises u. d. m., als mit äusserster Sorgfalt getroffen zu denken.

Mim stelle sich num die Vorrichtung in der oben S. 6.7 beschriebenen Gestalt ror, wo die beiden Paare ron Zuleitungsgefässen mit Zuleitungsbäuschen versehen, unl über sie gebrückte Hülfsbäusche an Stelle der Hülfsgefässe getreten sind. Wir wollen dies die Hförmige Anordnung nemnen, da, wemn die Hülfsbäusche sowohl als der über sie gebrückte durchströmte Bausch ron der Art sind, die ich die balkenförmige nemne (s. oben S. 7) und die hier die bequemste ist, die drei balkenförmigen Bäusche zusammen die Gestalt eines $\mathrm{H}$ bilden, dessen Querstück der auf

1 Monatsberichte u. s. w. 1s56. S. 450. - Auch abgedruckt in MoLeschott's Untersuchungen u. s. w. 1858. Bil. IV. S. 158. 
Polarisation zu prüfende, abwechselnd dem Säulen- und dem Multiplieatorkreis angehörige Leiter $A$ der vorigen Abhandlung (s. oben S. 3) darstellt.

[451] Es wurde gesagt, dass man, bei dieser Form des Versuches, die Polarisation an der Grenze ungleichartiger Elektrolyte mit Sicherheit nur damn beobachten könne, wenn der die Hülfsbäusche und den darüber gebrückten balkenförmigen Bausch tränkende Elektrolyt ein verhältnissmässig gut leitender sei. Ist dies nicht der Fall, so treten Störungen auf, welche eben auf der neuen hier darzulegenden Art von Polarisation beruhen.

Wird z. B. der das Querstück des $\mathrm{H}$ bildende balkenförmige Bausch mit destillirtem oder Brunnen-Wasser getränkt über die mit Ḱochsalzlösung getränkten, die Schenkel des $\mathrm{H}$ vorstellenden Hülfsbäusche gebrückt, so sollte rein positive Wirkung erfolgen, nach dem zn urtheilen, was sich mit dem heberförmigen Wasserrohr zwischen den mit Kochsalzlösung gefüllten Hülfsgefässen zuträgt (s. oben S. 6). Man erhält aber einen negativen Ausschlag, dem ein stärkerer positiver Rückschwung folgt. Die grössere Stärke des Rüickschwunges beruht nicht etwa auf der Entladung der polarisirten Platinenden des Multiplicators, demn lässt man eine gewisse Zeit zwischen Oeffnung des Sänlen- mo Schliessung des Multiplicatorkreises, so erfolgt ein rein positiver Ausschlag. Dasselbe ist der Fall, wemn die Daner der Durchströmung eine gewisse Grenze überschreitet, endlich wenn man den balkenförmigen Bausch sehr kurz nimmt. Verlängert man ihm hingegen, so tritt die positive Wirkung mehr und mehr, zuletzt bis zur Unmerklichkeit, zurück.

Es ist also klar, dass man es mit zwei secundär-elektromotorischen Wirkungen zu thun hat, einer positiven, die wir schon kennen, an der Grenze des Wassers und der Kochsalzlösung, und einer negativen, welche, flüchtiger als jene, anfangs schneller, damn langsamer mit der Dauer der Durchströmung wächst, und deren Stärke merkwürdigerweise von der Länge des durchströmten Wasserbausches abzuhängen scheint. ${ }^{1}$

1 Dieser letztere Umstand erklärt, weshalb in dem oben S. 8. 9 beschriebenen Versuche nach dem Schema des Pextier'schen Kreuzes ein Wasserbausch ohne Gefahr vor Täuschung angewendet werden konnte. Da nur eine sehr kurze Strecke der vom Strom durchflossenen Hälfte des Bausches sich nachmals im Multiplicatorkreise befand, musste die secundär-elektromotorische Wirkung. die uns hier beschäftigt, versehwinden gegen die Polarisation an der Grenze des Wassers und der Kochsalzlösung. Die in diesem Aufsatz enthaltenen Erfahrungen sind es beiläufig, dic mich bestimmten, die Heberröhren zwischen den Hülfsgefässen (s. oben S. 3) nicht mit Blase, Fliesspapier oder sonst einem Stoff der Art zu versehliessen, obschon dies in vielen Fällen allerdings ohne Schaden hätte geschehen können. 
[452] Es gelingt leicht, diese neuhinzugetretene Wirkung von der ersteren getrennt darzustellen, indem man auch die Hülfsbäusche mit Wasser statt mit Kochsalzlösung tränkt. Alsdann hat der Säulenstrom innerhalb der Strecke, die nachher zu einem Theil des Multiplicatorkreises wird, keine Grenze ungleichartiger Elektrolyte zu überschreiten, die erstere Art der Polarisation ist ausgeschlossen und mit Kochsalzlösung oder sonst einer gutleitenden Flüssigkeit in den Hülfsbäuschen und dem balkenförmigen Bausch erhält man, wie aus der vorigen $\mathrm{Ab}$ handlung hervorgeht, keine Spur von secundär-elektromotorischer Wirkung. Mit Wasser dagegen erfolgt ein starker negativer Ausschlag.

Es giebt eine andere Art, die neue secundär-elektromotorische Wirkung zu beobachten, welche man die Methode der vier Bäusehe nennen kann, und welche geeignet ist, eine bessere Einsicht in deren Natur zu gestatten. Der durchströmte balkenförmige Wasserbausch ruht mit seinen beiden Enden auf den Zuleitungsbäuschen der säule auf. Die Zuleitungsbäusche des Multiplicators sind mit Fortsätzen versehen, die ich Keilbäusche nemne, und von denen es schwer ist, ohne Abbildung ein klares Bild zu geben. ${ }^{1}$ Es genüge zu sagen, dass sie, wagerecht frei in die Luft ragend, in senkrechte Schneiden ron etwa $15^{\mathrm{mm}}$ Länge auslaufen. Diese Schneiden werden, mit Sicherheitsbäuschen bekleidet, an zwei beliebige Punkte des durchströmten Wasserbausches angelegt. Die Sicherheitsbäusche bestehen aus einigen Lagen nach den Keilbäuschen zu mit Salzlösung, nach dem Wasserbausch zu mit Wasser getränkten Fliesspapieres. Sie erfüllen hier den wichtigen Zweck, zu verhindern, dass nicht Salzlösung von den Schneiden der Keilbäusche aus in den Wasserbausch eindringe. Ge- [453] schieht dies, so mischt sich die Polarisation an der Grenze des Wassers und der Kóohsalzlösung in das Ergebniss ein, die man ja eben daraus zu verbamnen sucht. Unter dem Schutz der Sicherheitsbäusche aber kann man nummehr mittels dieser Vorriehtung ein beliebiges Stück der Länge des Wasserbausches auf eine darin entwickelte secundär-elektromotorische Kraft prüfen, und gelangt dabei zu folgenden Ergebnissen.

Rückt man mit den in beständigem Abstande gehaltenen Schueiden dem balkenförmigen Wasserbausch entlang, so erhält man, unter sonst gleichen Umständen, stets einen gleich starken negativen Ausschlag.

Legt man die Schneiden zweien von der Mitte des Bausches gleich weit entfernten Punkten seiner Länge nach an, und wählt dabei ihren Abstand bald kleiner, bald grösser, so wächst die Stärke der secundär-

1 [Eine Abbildung der Keilbäusche findet sich in der hier als fünfte folgenden Abhandlung 'Ueber den secundären Widerstand u. s. w.'] 
elektromotorischen Wirkung mit jenem Abstande, roransgesetzt, dass ein hinlänglicher ausserwesentlicher Widerstand im Multiplicatorkreise zugegen ist.

Die Stärke der secundären Wirkung wächst bis zu einer Grenze, die ich noch nicht bestimmt habe, mit der Dauer des ursprünglichen Stromes und mit seiner Dichte im durchströmten Bausche, d. h. mit dem Quotienten aus dem Querschnitt des Bausches in die Stromstärke. Diese Wirkung ist, wie schon hemerkt, sehr flüchtiger Art; natürlich kann man sie [innerhalb gewisser Grenzen] um so länger nach Entfermung des Bansches aus dem Säulenkreise nachweisen, je grösser Dauer und Dichte des ursprünglichen Stromes waren.

Aus alledem folgt, dass hier jeder durchströmte Querschnitt der Sitz einer gleich grossen secundär-elektromotorischen Kraft in der dem ursprünglichen strom entgegengesetzten Richtung wirl. Der Bausch wird zeitweise in eine Art ron secundärer Säule aus gleichförmig in seinem Inneren vertheilten elektromotorischen Elementen rerwandelt, und die neue Polarisation wird daher passend den Namen der inneren Polarisation erhalten, im Gegensatz zur äusseren Polarisation der Elektrolyte, welche an deren Grenze ilıren Sitz hat.

Um die Natur jener secundär-elektromotorischen Elemente im Inneren des Bausches etwas näher kennen zu lernen, wird [45t] es nützlich sein, unsere Versuche auf einige andere Körper auszudehnen.

Beim Tränken des durchströmten Bausches mit Hühnereiweiss. Ammoniakflüssigkeit, Essigsäure, schwefelsaurer Küperoxydlösung nimmt man ebenfalls Zeichen immerer Polarisation wahr. Bei der letzteren Flüssigkeit sind sie fast unmerklich. Zusatz ron Alkohol zum Wasser, wodurch der eigenthümliche Widerstand des letzteren erhöht wird, vermindert die Stärke der inneren Polarisation. mod macht sie, bei wachsendem Alkoholgehalt, zuletzt ummerklich.

Keine ron diesen Flüssigkeiten, und ebensowenig destillirtes und Brumen-Wasser, zeigt an und für sich eine Spur ron innerer Polarisation. Ian kann dies mittels des heberfürmigen Rohres zwischen den Hülfsgefässen zeigen, inclem man alle drei nit derselhen Flüssigkeit füllt. Bequemer ist es, sich einer oben offenen Hförmigen Rime aus Guttapercha zu bedienen, welche wagerecht zwischen den Zuleitungsgefässen der Sïlule und des Multiplicators aufgestellt wird, gegen deren Zuleitungsbäusche man ihre vier, mit Blase oder Fliesspapier überbundenen Enden stassen lïsst.

Offenbar muss also die Substanz des Bansches selber, d. h. die Holz-

- faser des Papieres, hier eine Rolle spielen. Es muss daher untersucht werden, ob auch andere, in trockenen Zustand für Nichtleiter geltende 
poröse Körper, wemn sie in ihren Hohlräumen Wasser oder rerhältnissmässig schlecht leitende Flüssigkeiten enthalten, die Erscheinumg der inneren Polarisation darbieten.

Der Erfolg dieser Untersuchung ist, dass es fast schwerer hält, porüse Kürper aufzufinden, die mit Wasser vder mit einer Flüssigkeit ron entsprechenden Leitungsterhältnissen getränkt, keine innere Polarisirbarkeit zeigen, als das Gegentheil. Die innere Polarisirbarkeit stellt sich somit als eine sehr allgemein verbreitete Eigenschaft fenchter poröser Körper dar.

Zur Untersuchung dienten rorzüglich zwei Methoden, die der vier Bäusche, und die der Hförmigen Anordnung, die man begreiflich noch mit anderen Materialien herstellen kann als mit Bäuschen. Doch rersteht es sich ron selber. dass das erstere Verfahren bei weitem allgemeiner angewendet werden kann. [455] Wo es anging, ertheilte ich den feuchten porösen Körpern die Gestalt eines Prisma's ron $50 \mathrm{~mm}$ Länge und einem quadratischen Querschnitt ron etwa $15^{\mathrm{mm}}$ Seite. Halbflüssige Körper wurden in der Hförmigen Guttapercharimne mntersucht.

Die anf innere Polarisirbarkeit geprüften Körper lassen sich in folgende vier Gruppen bringen:

I. Unorganische Körper, als da sind Kreide, Kalkstein, Thonschiefer, Trachyt, Bimsstein, Hydrophan, erhärteter Gyps, gebrannter Thon, plastischer Thon. Alle diese Stoffe, und noch manche ihnen ähnliche, zeigen mit Wasser getränkt ein mehr oder weniger hohes Maass imnerer Polarisirbarkeit. Der plastische Thon ${ }^{1}$ im lufttrockenen Zustande giebt nur eine sehr schwache, und mit dem achtfachen Gewicht Wassers angerieben, keine merkliche Spur ron Polarisation. Dazwischen aber liegen alle Stufen der Wirksamkeit bis zur Erzengung eines Ausschlages ron beinahe $90^{\circ}$, den man mit dem Thon im guten plastischen Zustand erhält; so dass die Stärke des Polarisationsstromes, der durch ein gegebenes Prisma fenchten Thones in einem gegebenen Kreise erzengt wird, ein Maximum besitzt in Bezug auf den Wassergehalt des Thones. Aber noch ein ganz dümnflüssiger Thoubrei gab in der Hförmigen Guttapercharinne eine deutliche secundär-elektromotorische Wirkung, welche ansblieb, wenn ich während der Uebertragung der Schliessung rom Säulenauf den Multiplicatorkreis die Flüssigkeit in dem Querstück des H mit einem Glasstab umrührte.

Mit Kochsalz-, mit Kalihydratlösung oder, wenn ihre Natur es er-

1 Es war derselbe Modellirthon der hiesigen Königl. Porzellan-Manufaetur, dessen ich mich zur Wiederholung der thermoëlektrischen Versuche Noвılı's bedient hatte. Vergl. Untersuchungen u. s. w. Bd. II. Abth. II. S. 201.

E. du Bois-Reymond, Ges. Abh. I. 
laubte, mit Säuren getränkt, liessen die aufgezählten Körper meist keine Spur imerer Polarisirbarkeit erkemnen. Nur Bimsstein mit Schwefelsäure und Kreide mit Kalihydratlösung getränkt machen eine Ausnahme.

Dentliche Zeichen innerer Polarisirbarkeit rersagten hingegen auch mit destillirtem Wasser als Tränkungsflüssigkeit: Asbest (nach der Faserrichtung durchströmt), reiner Quarzsand in seinem ursprünglichen $\mathrm{Zu}$ stande, derselbe fein gemahlen und geschlemmt, wie er von der hiesigen Königl. [456] Porzellan-Manufactur gebraucht wird, ${ }^{1}$ gebrannte Magnesia, Schwefelblumen. Die vier letzteren Stoffe wurden in Gestalt eines dicken Breies in der Hförmigen Rinne untersucht.

Eis, Krystalle von schwefelsaurem Zink- und Küpferoxyd sind auch unwirksam; nicht zu verwundern, da man sie sich im Imneren als trocken zu denken hat, und wenn in den beiden letzteren Flüssigkeit enthalten wäre, diese doch zu den besserleitenden würde zu rechnen sein.

II. Organische, aber nicht organisirte Körper, als: Geromnenes Hühnereiweiss, geronnener Faserstoff, durch Schlagen des Blutes erhalten, Seife aller Art. Diese Körper zeigen imnere Polarisirbarkeit. Die der Seife befolgt, in Bezug auf den Wassergehalt, ein ähnliches Gesetz wie die des Thones.

Blutkuchen, erstarrter Leim, seidene Schnur, Schweizer Käse, krystallisirter Rohrzucker gaben keine innere Polarisation.

III. Organisirte Pflanzentheile aller Art, oder pflanzliche Gewebe, gleichriel ob frisch, mit ihren natürlichen Säften gefüllt, oder nach der Trockniss, nach mannigfacher Verarbeitung erst mit Wasser getränkt, zeigen sehr starke immere Polarisirbarkeit. Stücke von Stengeln oder Blattstielen, von holzigen Zweigen, Prismen aus saftreichen Früchten, aus Wurzeln und Knollen geschnitten, warfen nach wenigen Secunden Aufenthalt im Kreise der dreissiggliederigen Grove'schen Säule die Nadel des Multiplicators für den Nerrenstrom, ja oft die des MIultiplicators für den Muskelstrom (4650 Windungen) mit Heftigkeit an die negative Hemmung. Das sogenamnte Albumen der Pará-Nuss (des Samens ron Bertholletia excelsa) gab allerdings keine Spur ron Wirkung, schien aber auch fast vollständig zu isoliren.

Hölzerne Stäbe aus verschiedenen Holzarten in Brunnenwasser gesotten, von Querschnitt zu Querschnitt zwischen den Zuleitungsbäuschen der Säule durchströmt, und mittels der Kéilbäusche abgeleitet, gaben erstaunlich starke Wirkung. Wurden sie mit Salzlösung getränkt, so war zwar die innere Polarisation noch wahrnehmbar, jedoch unrergleichlich kleiner als vorher. Wurde die Hförmige Guttapercharime mit einem

1 Ich verdankte ihn der Güte des Hrn. Dr. Elsner. 
[457] Brei von Eichensägespänen und Brunnenwasser gefüllt, so gab sie lebhafte Polarisation. Wurde der Brei während der Uebertragung der Schliessung rom Säulen- auf den Multiplicatorkreis umgerührt, so blieb die Wirkung aus.

Hanfene Schnur, Baumwollendocht, geben kräftige Wirkung, so dass sich mit Hülfe dieses Verhaltens eben so sicher, aber freilich auch eben so umständlich, eine Verfälschung der Seide mit Baumwolle nachweisen liesse, wie nach Rousseau's Vorschlag eine Verfälschung des Olivenöls durch dessen verminderten Widerstand.

Endlich bedarf es kaum der Erwähnung, dass hieher die innere Polarisirbarkeit des Fliesspapieres gehört, welche uns zum Ausgangspunkt für unsere ferneren Beobachtungen gedient hat.

IV. Die vierte Gruppe von Körpern wird durch die thierischen Gewebe gebildet. Die secundär-elektromotorischen Erscheinungen dieser Gewebe, mit Einschluss der Nerven und Muskeln, werde ich zum Gegenstande besonderer Mittheilungen an die Akademie machen, und begnüge mich hier mit der vorlänfigen Bemerkung, dass man auch an diesen Körpern der inneren Polarisirbarkeit als einer weit verbreiteten Eigenschaft begegnet.

Wir kehren zurück zur näheren Erforschung der Erscheinung selber. Leider habe ich an unmittelbaren Ergebnissen der Beobachtung nicht viel mehr aufzuzählen.

Was die absolute Grösse der Wirkungen betrifft, so bin ich vor der Hand eben so wenig im Stande, eine allgemein vergleichbare Bestimmung dieser Grösse mitzutheilen, als mir dies für die äussere Polarisation der Elektrolyte möglich war. Doch muss ich es zweifelhaft lassen, ob nicht in günstigen Fällen die imnere Polarisation der feuchten porösen Körper im Kreise der Sänle selber, die sie hervorrief, bemerkt werden könne. Wenigstens liesse sich darauf der Umstand beziehen, der bei obiger Versuchsreihe sich an verschiedenen porösen Körpern ergab, dass nämlich diejenigen darunter im Allgemeinen die stärkste innere Polarisation gaben, die, mit demselben Elektrolyten getränkt, den ursprünglichen Strom am meisten schwächten. Der Unterschied in der Stärke des letzteren schien frei- [458] lich oft zu beträchtlich. um auf die secundär-elektromotorische Kraft der inneren Polarisation gedeutet zu werden; auf der anderen Seite aber fehlt es, wie sich zeigen wird, an einer nothwendigen Beziehung zwischen Widerstand und innerer Polarisirbarkeit der feuchten porösen Körper, wodurch jener Umstand erklärlich würde.

Die innere Polarisation der feuchten porösen Körper zeigt dieselbe Abhängigkeit ron der Temperatur, wie die gewöhnliche Polarisation an der Grenze der Elektrolyte und der Metalle. Ich stellte die ursprüngliche 
Vorrichtung mit den Hülfsgefïssen voll Wasser zwischen den Zuleitungsgefässen der Sänle und denen des Multiplicators her, aber an Stelle des über die Hülfsgefässe gebrückten heberförmigen Rohres, dessen wir ms zur Untersuchung der Polarisation an der Grenze ungleichartiger Elektrolyte bedienten, trat jetzt ein System von Röhren, dessen nach abwärts gebogenen mittleren weiteren Theil ich mit Wasser und mit imnerlich polarisirbaren Stoffen anfüllen und damn seine Temperatur bis zum Siedepunkt des Wassers erhöhen komite. Es wurde Sorge getragen, dass der Widerstand des erwärmten Theiles gegen den des übrigen Mfultiplicatorkreises ammähernd rerschwand, so dass die Verminderung dieses Widerstandes durch Erhöhung der Temperatur nicht in Betracht kam. Mit Baumwollendocht und Fliesspapier gelang der Versuch nicht, insofern die imnere Polarisation dieser beiden Körper sich als zu schwach erwies, um unter den Umständen des Versuches eine merkliche Wirkung am Multiplicator für den Nervenstrom zu erzeugen. Hingegen bei Gegenwart von Hanfschnur, von Thonschiefer oder ron Badeschwamm in dem Rohr ergab sich bei $100^{\circ} \mathrm{C}$. für die beiden ersteren Körper eine dentliche Verminderung, für den letzteren, der sehr starker innerer Polarisation fähig ist, ein gänzliches Verschwinden der secundär-elektromotorischen Wirkung.

Mit diesem, trotz deu danernden Bemühungen, die ich dem Gegenstande gewidmet habe, ziemlich kärglichen Material haben wir es num zu unternehmen, uns eine Neinung über die Ursache der immeren Polarisation zu bilden.

[459] Zuerst will ich hier, wie bei der äusseren Polarisation der Elektrolyte, einige Vermuthungen kurz zurückweisen, auf die man beim ersten Anblick verfallen könnte.

Hier, wie dort, kann zunächst nicht an Temperatur-Unterschiede als an die Ursache der Polarisation gedacht werden. Zwar würde diese Hypothese hier mehr als dort berechtigt sein, insofern es nicht an Spuren fehlt, dass an der Uebergangsstelle des Stromes aus einem besseren in einen schlechteren, und an der aus einem schlechteren in einen besseren Leiter, verschiedene Erwärmmng stattfinde, und insofern es sich hier um feuchte poröse Körper handelt, an denen Thermoströme wirklich nachgewiesen sind. Zu den Temperaturströmen am mensehlichen Körper und den Thonthermoströmen NoBILI's kamn ich jetzt beiläufig noch ganz ähnliche Ströme hinzufügen, die ich an Fliesspapierbäuschen beobachtet habe. Allein hier so wenig wie bei der äusseren Polarisation ist es mir gelungen, unter den Umstïnden meiner Versuche, mittels des oben S. 10 erwähnten Thermometers, einen Temperatur-Unterschied nachzuweisen, obschon nicht unmöglich wäre, dass bei einer anderen Anordnung ein 
solcher bemerklich würde; und ausserdem sprechen noch eine Menge Gründe gegen einen solchen Ursprung der neuen secundär-elektromotorischen Kraft.

Es handelt sich vielmehr sichtlich dabei, wie schon oben s. 16 bemerkt wurde, um Erzengung sehr kleiner negativ elektromotorischer Krïfte auf dichtgedrängten Punliten des feuchten porösen Körpers, und die zur Erklärung dieser Thatsache zuerst zu lösende Frage ist die nach den Eigenschaften, welche poröse Kürper, und nach denen, welche Elektrolyte besitzen müssen, damit erstere, mit letzteren getränkt, imnere Polarisirbarkeit darbieten.

Man könnte, mit Hinblick auf die pflanzlichen und thierischen Gewebe, daran denken, dass in einem imnerlich polarisirbaren Körper ein hänfiger Wechsel zweier Elektrolyte stattfinde, an deren Grenze negative äussere Polarisation entwickelt wird. Diese Meinung ist mlaltbar gegenüber der immeren Polarisirbarkeit gewisser anderen Körper, z. B. des mit destillirtem Wasser getränliten Hydrophans.

[460] Die für die innere Polarisirbarkeit 'wesentlichen Eigenschaften der feuchten porösen Körper kümnen weder chemische noch mechanische sein. Zwischen Holzfaser, Kieselsäure, kohlensaurem Kalk einerseits, und destillirtem Wasser andererseits, ist wohl an keine chemische Wechselwirkung, auch unter dem Einflusse des Stromes, zu denken. Was aber ihre physische Beschaffenheit betrifft, so bieten die immerlich polarisirbaren Körper alle erdenklichen Abändermugen des festen Aggregatzustandes dar, während imnerlich polarisirbare und nichtpolarisirbare Körper mitunter ganz gleiche Aggregatzustände zu besitzen scheinen. Ich erimere nur an Sandstein, Seife, geromnenen Faserstoff und Thonbrei, welche alle innere Polarisirbarkeit besitzen, während Asbest, Küse, Leim und Iagnesiateig die Erscheinmo nicht zeigen. Das Einzige, was sich aus einer Betrachtmng der mechanischen Eigenschaften der imnerlich polarisirbaren Körper entnehmen lässt, ist, dass die Stärke der inneren Polarisation einigermaassen gleichen Schritt zu halten scheint mit der Annäherung der festen Theilchen aneinander. Also z. B. ist die imere Polarisation des Kalksteins, des Holzes und des durch Schlagen gewonnenen Faserstoffes stärker als die der Kreide, des Fliesspapiers und des Blutkuchens. Auch gelang es mir durch einen während des Versuches passend ansgeübten Druck die innere Polarisirbarkeit des Fliesspapieres scheinbar zu erhöhen; aber ich rersuchte rergeblich, eimem lockeren Haufwerk fester Theilchen, das mit Wasser getränkt keine innere Polarisirbarkeit zeigte, wie dem Teig ron Schwefelblumen oder gebrannter Bittererde, solche durch Zusammendrücken zu ertheilen.

Von eben so geringer Bedentmg ist für die imnere Polarisirbarkeit 
offenbar die elektrochemische Beschaffenheit der tränkenden Elektrolyte. Wasser, insbesondere destillirtes, haben wir zur Tränkung der porösen Körper, welche imnere Polarisation zeigen sollen, am meisten geeignet gefunden; aber auch Essigsäure, schwefelsaure Kupferoxydlösung und Ammoniakflüssigkeit lassen die Erscheinung in geringem Grade zu. während Kochsalzlösung, die Mineralsäuren, Kalihydratlösung, nur ausnahmsweise eine Spur davon wahrzunehmen erlauben.

Dagegen drängt sich im Lauf der Versuche sofort die Be- [461] merkung auf, deren denn auch gleich Anfangs Erwähuung geschah, dass nämlich die Elektrolyte, mit denen getränht poröse Körper innerlich polarisirbar werden, sämmtlich ein gewisses, beträchtliches Maass eigenthümlichen Widerstandes besitzen. Dabei handelt es sich ganz bestimmt um den eigenthümlichen Widerstand, und nicht etwa darum, dass der Widerstand des imnerlich zu polarisirenden Körpers einen grossen Theil des Gesammtwiderstandes des Kreises ausmache. Dies geht daraus hervor, dass, trotz der grüsseren darin herrschenden Stromdichte, ein mit Salzlösung oder verdünnter Schwefelsäure getränkter Zwirnsfaden doch keine Spur von innerer Polarisation zeigt.

Da die wesentliche Bedingung für das Zustandekommen innerer Polarisation ron Seiten des Elektrolyten sich somit auf dessen elektrisches Leitvermögen bezieht, so erscheint es rathsam, auch einmal die innerlich polarisirbaren porösen Körper aus diesem Gesichtspmkte zu betrachten. Und wirklich bietet sich dabei alsbald eine einfache und in den meisten Fällen ansreichende Erklärung der nenen Thatsachen dar.

Zunächst ist es an der Zeit zu bemerken, dass die secundär-elektromotorischen Wirkungen der feuchten porösen Körper ihrem Gesetze nach genau dieselben sind, die man erwarten sollte rou einem Stück wohlausgeglühter, also metallähnlich leitender Kohle, die mit irgend einem Elektrolyten getränkt, dem Strom ausgesetzt würde. Jedes beiderseits vom Elektrolyten bespülte Kohlenplättchen, welches der Strom durchläuft, müsste wirken wie eine metallische Zwischenplatte, es müssten sich daran die Anionen und Kationen ausscheiden, und in Folge daron das Plättchen der Sitz einer Polarisation der gewöhnlichen Art werden.

Ich habe dies durch den Versuch bestätigt. Terkohlte Zweige rom Faulbaum (Prunus Padus) und ron Erlen (Alnus), wie sie zur Bereitung von Schiesspulver gebraucht werden, die ich aber nachträglich ausgeglülıt hatte, tränkte ich mit Wasser, Kochsalzlösung, verdümnter Schwefelsäure, schwefelsaurer Kupferoxydlüsung. Bereits nach kurzem Aufenthalt im Kíreise eines einzigen Grove'schen Bechers gaben sie die kräftigsten Wirkungen ganz nach demselben Gesetze, wie der frische [462] Zweig es gethan haben würde. So rerhielten sich beiläufig auch Cylinder 
erstarrten Leimes, in dem Messingfeilspäne vertheilt waren, und die ich mir dadurch rerschaffte, dass ich den mit Feilspänen gemengten Leim in geölten Reagenzgläsem erstarren liess und das Glas über dem entstandenen Cylinder zertrümmerte. Verschiedene Kíohlenstücke wirkten übrigens sehr verschieden kräftig, wie es ja seit langer Zeit bekannt ist, dass die Leitung der Kónle ausserordenthichen Schwankungen unterworfen ist.

Unter anderen Unregelmässigkeiten, die hier für uns ron keiner Bedeutung sind, bot sich aber eine dar, die wohl unserer Aufmerksamkeit werth ist. Tränkte ich nämlich nach einander ein und dasselbe Kohlenstück mit Wasser und mit Kochsalzlösung, so sollte, erwartete ich, die durch gleich lange Schliessung einer und derselben Kette bewirkte Polarisation im ersten Falle schwächer ausfallen als im letzteren. Keinesweges traf dies zu, sondern micht selten war die Polarisation in der mit Wasser getränkten Kohle trotz der sehr viel geringeren Stromstärke bedeutend stärker als in der mit Salzlösung.

Man kann diese Erscheinung so auffassen, dass man sich vorstellt, die in der Kóohle oder dem mit Messingspänen erfüllten Leimcylinder stattfindende Polarisation, und die ron uns sogenannte innere Polarisation der feuchten porösen Körper, hätten mit einander nichts gemein, als das Gesetz, wonach die secundär-elektromotorischen Kräfte im Inneren des Leiters rertheilt sind. Ihre physische Ursache sei übrigens ganz rerschieden; und man kann alsdann die Art der inneren Polarisation, die den Gegenstand dieser Abhandlung bildet, die ächte, und die der Kohle und des Leimcylinders voll Nessingspäne die unächte imnere Polarisation nennen. Jan kann sich vorstellen, die sich oft zeigende stärkere innere Polarisation der Wasserkohle im Gegensatz zu der der Salzkohle beruhe darauf, dass die Kohle in jenen Fällen noch zum Theil die ächte imnere Polarisation des Holzes behalten habe, und dass diese sich bei der Wasserkohle zur unächten inneren Polarisation hinzufüge, welche bei der Salzkohle allein hervortrete.

Viel einfacher und ohne Zweifel naturgemässer ist es wohl, folgendermaassen zu schliessen. Es giebt nur eine Art der in- [463] neren Polarisation; die rermeintlich ächte der feuchten porösen Körper und die unächte der Kiohle und des Leimeylinders beruhen auf derselben physischen Ursache.

Die Körper, welche nur mit schlechtleitenden Elektrolyten getränkt, innere Polarisirbarkeit zeigen, gelten allerdings im trockenen Zustande gemeinhin für Nichtleiter, wenigstens im Gebiete des Galvanismus. Im Gebiete der Reibungselektricität, wo in dieser Beziehung schärfer unterschieden wird, gelten aber bereits deren viele für Halbleiter. Berührt 
man damit den Knopf eines geladenen Elektroskopes, so fallen die Goldblätter langsam znsammen. Jene Körper leiten also, wenn auch noch so schwach; und in sehr dümnen Schichten kam sogar ihr Leitrermögen nicht ganz únbeträchtlich sein.

Dabei ist anzunehmen, dass sie nach Art der Metalle, physisch, nicht elektrolytisch leiten. Wemn sie folglich den Strom in einen Elektrolyten ein- oder aus ihm herausführen, so werden daran, wie an metallischen Elektroden, die Zersetzungsstoffe ausgeschieden werden; und es kömnen, ja es müssen sugar dergestalt secundär-elektromotorische Krräfte in umgekehrter Richtung des ursprünglichen Stromes zu Stande kommen. ganz wie dies bei Zersetzung des Wassers zwischen Platinelektroden der Fall ist.

Wollte man durch Elektroden aus irgend einem der obigen Halbleiter, die man in irgend einen Elektrolyten tanchen liesse, merkliche Ladungen zu Wege bringen, so würde dies aus leicht begreiflichen Gründen fehlschlagen. Keine Säule würde kräftig. kein Multiplicator empfindlich genug sein, damit eine Wirkung wahrgenommen würde. Leichter würde dies schon gelingen, wemn man, anstatt den schlechten Leiter in Gestalt ron Elektroden in den Kreis zu bringen, ihm die Form eimer ausnehmend dümnen Zwischenplatte zu ertheilen rermöchte. Am zweckmässigsten aber würde die Anordnung, wenn man nicht bloss eine einzige solche düme Zwischenplatte, sondern deren eine gewisse, nach den Umständen verschiedene Anzahl in den Kreis bringen könnte.

Diese Anordnung leistet indess noch nicht ganz was sie soll. Man sieht nämlich, dass dabei auch mit gutleitenden Elektrolyten Ladung eintreten müsste, ja sogar, wegen des [464] geringeren Widerstandes, noch stärker, wem man, wie wir dies in dieser Verhandlung bis auf Weiteres thun wollen, daron absieht. dass ein und derselbe Strom an der Grenze rerschiedener Elektrolyte und Halbleiter rermuthlich nicht stets einerlei secundär-elektromotorische Kraft erzeugt. Dies nun scheint mit unseren Versuchen im Widerspruch.

Allein jetzt stelle man sich die halbleitenden Zwischenplatten ron unzähligen kleinen Oeffinungen durchbohrt ror, so dass der Elektrolyt frei durch sie zusammenhängt. Fr wird nun eine Nebenschliessung für den übrigen Theil der Zwischenplatten abgeben, und die Folge wird sein. dass der Stromtheil, ter noch durch die Zwischemplatten selber geht und der allein die secuntär-elektromotorische Kraft erzengt, abhängig wird ron dem eigenthümlichen Widerstande des Elektrolyten. Er wird um so kleiner, je besser der Elektrolyt leitet; und um so kleiner wird folghich die seemdär-elektromotorisehe Kraft. Es kommt aber noch hinzu, dass die Wirkung, die diese Kraft nachher im Multiplieatorkreise herrorzu- 
bringen rermag, abermals geschwächt wird durch die Nebenschliessung, die cler durch die Oeffinmeen der Zwischenplatten zusammenhängende Elektrolyt darbietet, und folglich $\mathrm{nm}$ so kleiner wird, je geringer der eigenthümliche Willerstand des Elektrolyten, so dass sie, bei einem gewissen hohen Grade ron Leitungsfähigkeit des letzteren, gänzlich rerschwinden kamn. Freilich wird, mit abnehmendem Widerstande des Elektrolyten, auch die Stromstïlie zunehmen. Allein man sieht, dass die Verminderung der secundïr-elelitromotorischen Wirkung aus jenen Gründen ihre Vermehrung ans diesem Grunde leicht überwiegen könne.

Da num andererseits mit einem Elektrolyten ron unendlich grossem Widerstande die secundär-elektromotorische Wirkung offenbar gleichfalls verschwindet, so ist dentlich, dass ihre Stärke, bezogen auf den eigenthümlichen Widerstand des tränkenden Elektrolyten, ein Maximum haben, und dass dieses Maximum bei um so geringerem Widerstande des Elektrolyten stattfinten müsse, je geringer der Widerstand des porösen Halbleiters ist.

[465] Man sieht ferner, dass was hier rom eigenthümlichen Widerstande des Elektrolyten und des porösen Halbleiters gesagt wurde, anch Anwendung findet auf das Verhältniss der Grösse der Oeffnungen in den Zwischenplatten zu deren übriger Oberfläche. Verschwinden die Oeffnungen gegen die übrige Oberflïche, so muss dies für die secundärelektromotorische Wirkung im Wesentlichen dieselbe Folge nach sich ziehen, als ob der eigenthümliche Widerstand des Elektrolyten verhältnissmässig ein sehr grosser wäre. Verschwindet dagegen der stehengebliebene Theil der Zwischemplatten gegen die Oeffnungen, so wird dies für die secundär-elektromotorische Wirkung so sein, als ob der eigenthümliche Widerstand des Elektrolyten gegen den des porösen Halbleiters rerschwände.

Mit Hülfe dieser Vorstellung hat es keine Schwierigkeit mehr, sich ron den hauptsïchlichsten Erscheinungen der inneren Polarisation Rechenschaft zu geben. Dass diese dabei wirklich die Gesetze befolgen müsse, die wir oben S. 15.16 gefunden haben, und mit steigender Temperatur an Kraft abnehmen könne, braucht nicht erst bemerkt zu werden. Sodann ist deutlich, weshalb ein und derselbe poröse Körper, in welchem, wemn er vollständig getränlit ist, stets dieselbe räumliche Anordnumg des Elektrolyten und des halbleitenden Gerüstes stattfindet, folgweise mit Flüssigkeiten von immer kleinerem Widerstande getränkt, bei einem gewissen mittleren Grade dieses Widerstandes die stärkste secundär-elektromotorische Wirkung giebt. So gab Fliesspapier mit rerdümntem Alkohol getränkt nur schwache innere Polarisation; starke mit destillirtem und Brumnen-Wasser; schwächere mit Essigsäure, Ammoniak, schwefel- 
saurer Kupferoxydlösung, unmerkliche mit Kochsalzlösung, Salpetersäure u. d. m.

Hat man zwei poröse Körper, in denen man nahezu eine und dieselbe räumliche Anordnung des Elektrolyten und des halbleitenden Gerüstes annehmen kamn, deren eigenthümlicher Widerstand aber sehr verschieden ist, so findet sich's, in Uebereinstimmung mit unserer Theorie, dass der besserleitende Körper Zeichen innerer Polarisation noch mit Elektrolyten von so kleinem Widerstande giebt, dass der schlechtleitende Körper damit ganz umpolarisirbar erscheint. So geben Holz und [466] mangelhaft geglühte Kohle mit Wasser stärkere innere Polarisation als mit Kochsalzlösung, während wohlgeglühte Kóohle sich umgekehrt rerhält.

Natürlich giebt es einen Grad des Widerstandes des porösen Gerüstes, wo auch bei schlechtleitenden Elektrolyten kein merklicher Stromtheil hindurch kamn, und deshalb die secundär-elektromotorische Wirkung verschwindet. So erklärt sich's, dass Quarzsand, Schwefelblumen, Seide keine immere Polarisation wahrnehmen liessen. Dass die Kieselsäure im amorphen Zustande, wie im Hydrophan, besser leitet, als im krystallisirten, überrascht nicht nach dem ähnlichen Verhalten des Diamants und der Kohle, des Zimnobers und des schwarzen Schwefelquecksilbers. ${ }^{1}$

Erlaubt es die Beschaffenheit eines porösen Halbleiters, das Verhältniss der in einem gegebenen Raum enthaltenen Menge seiner eigenen Substanz und eines Elektrolyten nach Belieben abzustufen, so bestätigt sich was oben hinsichtlich des Einflusses einer solchen Veränderung anf die Grösse der secundär-elektromotorischen Wirkung gesagt wurde. So haben wir an Thon und Seife bei einem möglichst kleinen sowohl, als bei einem sehr grossen Wassergehalt die secundär-elektromotorische Wirkung rermisst, während sie bei einem gewissen mittleren Feuchtigkeitsgrad einen oberen Grenzwerth erreichte; und so fanden wir (s. oben S. 21), dass die imnere Polarisirbarkeit des kohlensauren Kalkes, der Holzfaser und des geromenen Faserstoffes mit der Verdichtung wuchs.

Auf das rerschiedene Verhältniss der mit dem Elektrolyten erfüllten Hohlräume zum halbleitenden Gerüst könnte man rersucht sein, auch den oben S. 19 erwähnten Umstand zurückzuführen, dass ron zwei nit demselben Elektrolyten getränkten Halbleitern, welche ungleich stark immerlich polarisirbar sind, derjenige sich in der Regel als der bessere Leiter im getränkten Zustand erweist, der die schwächere secundärelektromotorische Wirkung giebt. Der rerschiedene Widerstand der Halbleiter selber kamn der Grund nicht sein; demn alsilamn [467] käme gerade

1 Vgl. Rıess, die Lehre von der Reibungselektricität. Berlin 1853. Ba. I. s. 37 . 30 . 
umgekehrt dem besseren Leiter die stärkere Polarisation zu. Aber auch die eben angedentete Vermuthung scheint nicht zuzutreffen. Wenigstens fand ich, dass von zwei gleich grossen Stücken Kreide und Bimsstein, ron denen letzterer bei grösserem Widerstande die stärkere Polarisation zeigt, nach einstündigem Sieden das Stück Bimsstein die grössere Wassermenge aufgenommen hatte.

Wie dem auch sei, die gegebene Theorie schliesst sich den Thatsachen hinreichend an, um für die richtige gelten zn können. Immerhin bleiben schon aus dem Kreise meiner bisherigen Erfahrungen manche übrig, die sich ihr nicht zu fügen scheinen. Dahin gehört z. B. der Fall der Kreide, welche mit Kalihydrat getránkt beträchtlich stärkere innere Polarisation zeigt, als mit Wasser, während man das Gegentheil, ja ein völliges Verschwinden der Polarisation mit der Kalilange erwarten sollte. Jedoch ist micht zu rergessen, dass ansser den bereits angedenteten Hülfsmitteln der Theorie zur Erklärmg derartiger Abweichungen - verschiedener Widerstand des Elektrolyten und des porösen Halbleiters, und rerschiedene rămmliche Anordnung beider - noch ein Umstand in Betracht kommt, den wir bisher absichtlich ausser Spiel gelassen haben, der aber möglicherweise einen sehr bedentenden Einfluss übt. Dies ist die mit rerschiedenen Stoffen, vielleicht, ja muzweifelhaft, sehr verschiedene elektromotorische Krraft der secundären Kiette: Halbleiter, Anion, Elektrolyt, Kation, Halbleiter, auf deren Erzeugung durch den ursprünglichen Strom die innere Polarisation beruht. Es mögen zwischen den Halbleitern selber, in Bezug auf ihre Polarisationsfähigkeit, Unterschiede stattfinden, wie zwischen den Metallen, und anch die verschiedenen Elektrolyte mögen, in Verbindung mit dem nämlichen Halbleiter, mehr oder weniger günstig wirken.

Ich bemerke noch, dass die Art, wie in dieser Theorie die Leitmng des Stromes in den feuchten porüsen Halbleitern zum ersten Mal ron mir aufgefasst ist, überhaupt die richtigere sein dürfte, und geeignet scheint, einen Anhalt zu bieten zur besseren Beurtheilung der auffallenden elektromotorischen Erscheinungen, die uns die Hant des Menschen gezeigt hat, der ströme [468] wegen ungleichzeitiger Benetzung, ${ }^{1}$ der Temperaturstrüme, ${ }^{2}$ der Ströme beim Andrücken ron Bänschen, ${ }^{3}$ die alle

1 Monatsberichte u. s. w. 1852. S. 123; - MoLeschotт's Untersuchungen u. s. w. Bd. II. §. 259 ; - Untersuchungen u. s. w. Bd. II. Abth. II. S. 218.

2 Ionatsberichte u. s. w. 1852. S. 120; - Моцеsснотт's Untersuchungen u. s. w. Bd. II. S. 256 ; - Untersuchungen u. s. w. A. a. O. S. 206.

3 Monatsberichte u. s. w. 1852. S. 125 ; - 1854. S. 289; - MoLeschott's Untersuchungen u. s. w. Bd. II. S. 261 ; - Bd. IV. S. 6 ; - Untersuchungen u. s. w. A. a. O. S. 222 . 268.322 . 
ihr Entsprechendes bei den Metallen haben. Auch die Noвw'schen Thonthermoströme, und die oben S. 20 erwähnten Thermoströme an Fliesspapierbäuschen dürften ans demselben Gesichtspunkte zu betrachten sein, d. h. nicht als Thermoströme der Elektrolyten. sondern als solche der metallisch, nicht elektrolytisch leitenden Halbleiter, die mit den Elektrolyten getränkt sind. Dies ist deshalb wahrscheinlich, weil nach NoвпI ${ }^{1}$ nur mit Thon, nicht mit Kalk, Baryt und Gyps, diese scheinbaren Hydrothermoströme erhalten werden, während der Elektrolyt beliebig Wasser, Säure oder Salzlösung sein kann, ohne dass der Strom aufhört, in derselben Richtung zu erscheinen. ${ }^{2}$.

1 Memorie ed Osservazioni edite et inedite ec. Firenze 1834. Yol. I. 1. 81. 87.

2 Schon im ersten Bande meiner 'Untersuchungen', S. 377, hake ich unter dem Namen der 'Peltier'schen Ladungen' einige mittels der Methode der Uebertragung gemachte Erfahrungen beschrieben, welche zum Theil auf die jetzt erkannte innere Polarisation feuchter poröser Halbleiter zurïckzuführen sincl, und der Keim der jetzt entwickelten Theorie ist gleichfalls bereits dort zu finden. Doch sind jene Ergebnisse so unvollkommen, auf so wenige Körper beschränkt und dermaassen mit anderen Wirkungen vermengt, deren Scheidung mir erst seitdem gelungen ist, z. B. mit der äusseren Polarisation der Elektrolyte, dass ich bitten möchte, sie als nicht vorhanden anzusehen. bis ich Gelegenheit gefunden haben werde, sie von meinem jetzigen Standpunkt der Kenntniss aus zu erläutern. Dieselbe Bitte gilt in Bezug auf die in meinen 'Tntersuchungen' (Bd. I. S. 240; - Bd. II. Abth. I. S. 331) enthaltenen Andeutungen hinsichtlich der secundär-elektromotorischen Wirkungen der Muskeln, und auf eine Mittheilung. die ich darüber der British Association zu Belfast im September 1852 machte, und die sich im Rejrort etc. p. 78 abgedruckt findet. So werde ich auch später nicht ermangeln, das Verhältniss der in dieser Abhandlung dargelegten Erfahrungen zu den von Hrm. Musk af Rosenschöld in Poggendorff's Annalen u. s. w. 1838. Bd. XLIII. S. 207 beschriebenen Thatsachen zu crörtern. 
III.

\section{Ueber den Einfluss, welchen die Dimensionen innerlich polarisirbarer Körper anf die Grösse der secundär-elektro- motorischen Wirkung iiben.}

(Gelesen in der Sitzung der physikalisch-mathematischen Klasse der Königl. Akademie der Wissenschaften zu Berlin am 31. Januar 1859.)1

Die wichtige Rolle, welche die immere Polarisation bei gewissen thierischelektrischen Erscheinungen spielt, hat mich reranlasst, sie noch nach mehr Richtungen weiter zu verfolgen, als dies in meiner ersten Yittheilung darüber ${ }^{2}$ geschehen ist. Unter anderen ward es mir wünschenswerth, eine dentliche Vorstellung daron zu erlangen, wie die Dimensionen [69] des innerlich polarisirbaren Körpers auf die Stärke der secundärelektromotorischen Wirkung einwirken. Offenbar muss das Verhältniss ein sehr rerwickeltes sein, insofern nämlich der Widerstand der innerlich polarisirbaren Körper stets ein grosser im Vergleich zu dem der Sänle und des Multiplicators ist, die ursprüngliche und die secundäre Stromstärke fulglich schon in dieser Weise von den Maassen jenes Körpers abhängen; zweitens bei wachsendem Querschnitt des imnerlich polarisirbaren Körpers die Dichte des gleich stark gedachten ursprünglichen Stromes darin abnimmt, die secundär-elektromotorische Kraft aber unzweifelhaft nicht mit der ursprünglichen Stromstärke, sondern rielmehr mit dieser Dichte nach irgent einem Gesetze wächst.

Um einigermaassen die Folgen dieser verschiedenen Abhängigkeiten zu übersehen, wollen wir gewisse einfache Voranssetzungen machen, wodurch wir in Stand gesetzt werden, uns der Rechnung zu bedienen.

Es heisse nämlich

$E$ die elektromotorische Kraft der Säule, die den ursprünglichen Strom liefert;

1 Monatsberichte u. s. w. 1859 . S. 68 .

$2 \mathrm{~S}$. die vorhergehende Alhandlung (II). 
$S$ der Widerstand des Säulenkreises gemessen bis zum innerlich polarisirbaren Körper;

$\boldsymbol{M}$ der Widerstand des Multiplicatorkreises ebenso gemessen;

$q$ der Querschnitt jenes prismatisch gedachten Körpers;

$L$ dessen Länge gemessen zwischen den den Grundflächen des Prisma's angelegten Endbäuschen des Säulenkreises;

$m L$, worin $m$ eine Constante $<1$, seine Länge gemessen zwischen den Keilbäuschen des Multiplicatorkreises;

$\sigma$ dessen Widerstand für die Einheit der Länge und des Querschnittes; endlich $t$ die Daner der Schliessung des ursprünglichen Stromes.

Die Stärke des ursprünglichen Stromes wird sein

$$
I=\frac{E}{S+\frac{\sigma L}{q}}
$$

Wir wollen amnehmen, die im durchströmten Körper im Augenblick der Oeffnung des Säulen- und Schliessung des Multiplicator[70]kreises (die als gleichzeitig betrachtet werden) gegenwärtige und im letzteren Kreise wirksame Summe $E^{\prime}$ secundär-elektromotorischer Kräfte sei 1 . der Dauer des ursprünglichen Stromes, 2. seiner Dichte, beides zwischen gewissen Grenzen, 3. der Länge der in's Auge gefassten Strecke $m L$ einfach proportional. Da die Dichte $=$ dem Quotienten aus dem Querschnitt in die Stromstärke, so wird also $E^{\prime}$ dem Querschnitt, innerhalb gewisser Grenzen, umgekehrt proportional sein.

Dies scheint ganz unverfänglich, doch ist zweierlei dazu zu bemerken. Erstens muss man sich den innerlich polarisirbaren Körper von sehr gestreckter Gestalt denken, damit man ohne merklichen Fehler $E^{\prime}$ der Strecke $m L$ proportional setzen kömne, weil nämlich die Ableitung zum Multiplicatorkreise nicht von den Grundflächen des Prima's aus, sondern mittels der Keilbäusche geschieht, in welche sich die Stromcurven hineinbiegen müssen, so dass ein Theil der zunächst den Ableitungsstellen ihren Sitz habenden elektromotorischen Kräfte nicht zur Wirkung kommt. Für's 'Zweite sind Gründe rorhanden anzunehmen, dass die in einem Querschinttselement erzeugte secundär-elektromotorische Kraft im Multiplicatorkreise nur mit einem Theile wirkt, welcher nicht unabhängig ist von dem Querschnitt des innerlich polarisirten Körpers, von seiner Länge, und rom Widerstande des Multiplicatorkreises.

Sieht man von diesen Umständen ab, so hat man also

$$
E^{\prime}=-n \cdot t \cdot \frac{I}{q} \cdot m L
$$


Körper auf die Grösse der secundär-elektromotorischen Wirkung üben.

Setzt man hierin für $I$ dessen Werth aus (I), so erhält man

$$
E^{\prime}=-n \cdot t \cdot \frac{E}{S+\frac{\sigma L}{q}} \cdot \frac{m L}{q}
$$

Unter der schon erwähnten Voraussetzung einer sehr gestreckten Gestalt des imnerlich polarisirbaren Körpers ist dessen Widerstand zwischen den Keilbäuschen ohne merklichen Fehler zu setzen

$$
=\frac{m \sigma L}{q} \text {. }
$$

[71] Es ergiebt sich folglich für die in ersten Augenblick der Schliessung des Multiplicatorkreises stattfindende Stromstärke der Ausdruck

$$
I^{\prime}=-n \cdot t \cdot \frac{E}{\left(S+\frac{\sigma L}{q}\right)\left(\boldsymbol{M}+\frac{m \sigma L}{q}\right)} \cdot \frac{m L}{q} .
$$

Wie man sieht, kommen in diesem Ausdruck die Dimensionen des polarisirbaren Körpers $L$ und $q$ nur zusammen und zwar dergestalt verbunden vor, dass sie den Widerstand des Körpers angeben, insofern er von den Dimensionen abhängt. Liesse man daher $L$ und $q$ in gleichem Verhältniss sich verändern, so dass

$$
\frac{L}{q}=r=\text { const. }
$$

so würde die im ersten Augenblick stattfindende secundär-elektromotorische Wirkung dieselbe bleiben, welches auch der Werth von $L$ und $q$ wäre.

Ein Ergebniss, welches auch ohme Rechnung einleuchtet. Bleibt nämlich der Widerstand des innerlich polarisirbaren Körpers unverändert, so bleibt dies auch die Stärke des ursprünglichen Stromes, und ebenso der Widerstand des secundären Kreises, d. h. des Kŕreises, der aus jenem Körper und dem Multiplicatorkreise besteht. In dem Maasse, wie der Querschnitt wächst, nimmt freilich, bei sich gleich bleibender Stärke des ursprünglichen Stromes, die Dichte dieses Stromes im Querschnitt und folglich die secundär-elektromotorische Kraft im Längenelemente ab. Allein da in demselben Maasse die Länge wachsen soll, so bleibt schliesslich $E^{\prime}$, die Summe der secundär-elektronıtorischen Kräfte, constant, und bei sich gleichbleibendem Widerstande des secundären Kreises also auch die Stärke der secundär-elektromotorischen Wirkumg im ersten Augenblick.

Denken wir uns nummehr $r$ veränderlich und untersuchen die Function $I^{\prime}=f(r)$, so zeigt sich, dass diese für $r=0$ und $r=\infty$ verschwindet und dazwischen ein Maximum hat für

$$
\left.r=\frac{1}{\sigma}\right\rceil / \frac{S M}{m},
$$


wenm also $S=M$ und $m=1$, für

$$
\sigma r=\frac{\sigma L}{q}=S=M,
$$

oder für den Fall, dass der Widerstand des imnerlich polarisirbaren Körpers gleich ist dem des Säulen- und dem des Multiplicatorkreises. Geben wir $S$ und $\boldsymbol{M}$ ihre allgemeine Bedeutung wieder, denken uns $q$ beständig, und nur $L$ veränderlich, so findet ein Maximum statt für

$$
L=\frac{q}{\sigma} \sqrt{\frac{S M}{m}} .
$$

Umgekehrt bei beständigem $L$ und veränderlichem $q$ für

$$
q=\sigma l] \frac{m}{S \cdot I}
$$

Bemerkenswerth ist noch, was sich ereignet, wemn man sich denkt, dass der Widerstand des Säulen- sowohl als des Inltiplicatorkreises rerschwindet gegen den des innerlich polarisirbaren Leiters, und umgekehrt. In beiden Fällen hört die Function $I^{\prime}=f^{\prime}(r)$ auf, ein Naximum zu besitzen. Im ersten Fall nämlich wird sie

$$
I^{\prime}=\frac{n t E}{\sigma^{2} \cdot r}
$$

im zweiten

$$
I^{\prime}=\frac{m n t E \cdot r}{S M} .
$$

Die Stärke (ler secundär-elektromotorischen Wirkung wird also im ersten Falle dem Widerstand des polarisirbaren Leiters, insofern er ron dessen Dimensionen abhängt, umgekehrt, im zweiten gerade proportional sein.

Es wäre mun ron hohem Interesse gewesen, die wichtigsten unter diesen Schtüssen durch den Tersuch zu prüfen, theils um die Gestaltung des Phänomens unter den fraglichen Umständen wirklich zı erkemmen, theils um sich ron dem Maass von Wahrheit und Irrthum in den gemachten Voranssetzungen zu überzengen. Dies würde indessen für's Ersteerfordert hahen, dass diese Versuche in messende umgewandelt würden, wozu die Beseitigung der Polarisation der Platinenden des Multiplicator[73]kreises und die Anwendung eines wirklichen galvanometrischen Messwerkzenges, statt des MLultiplicators für den Nervenstrom, oder Gradnirung: des letzteren, ror Allem nöthig geworden wären. Für's Zweite ist aber noch zu beachten, dass der Ausdruck (II) die Stärke der secundär-elektromotorischen Wirkung unter den gemachten Voranssetzungen genan nur im ersten Augenblick nach der als gleichzeitig betrachteten Oeffinung des Säulen- und Schliessung des Multiplicatorkreises darstellt. Zur Bewährung dieser Formel und der daraus abgeleiteten Schlüsse kömte folglich nur 
geschritten werden mit Hülfe der von Hrn. Poggendonfe für das Studium der secundär-elektromotorischen Erscheinumgen empfohlenen und zwar äusserst schnell bewegten Wippe, etwa in der Gestalt, die Hr. SIEMEss derselben ertheilt hat. ${ }^{1}$

Obschon ich num dies Alles für nicht unausführbar hielt, so würde es doch auf alle Fälle ein so weit aussehendes Unternehmen geworden sein, dass ich vor der Hand daron abstehen zu müssen glaubte. Ich habe mich damit begnügt, ron jenen Schlüssen solche durch den Versuch zu bestätigen, welche dazu keine eigentlichen Maassbestimmungen erfordern, wobei ich also ausser Acht lassen durfte erstens, dass die bei Schliessung des Multiplicator- nach Oeffnung des Säulenkreises erfolgende Summe secundär-elektromotorischer Wirkungen anf die Nadel der Grösse der im ersten Augenblick stattfindenden secundär-elektromotorischen Kraft möglicherweise nicht einfach proportional ist; und zweitens, dass wenn anch diese Proportionalität stattfünde, der Ausschlag der Nadel doch nicht entfernterweise ein getreues Maass jener Summe liefert. Sogar von solchen Prüfungen habe ich übrigens nur den allerkleinsten, wemn auch wichtigsten Theil bisher anzustellen rermocht.

$$
\text { I. } \frac{L}{q}=\text { const. }
$$

Ein Punkt, der zunächst zur experimentellen Bestätigung einlud, war das oben der Formel (II) entnommene Ergebniss, dass die Grösse der secundär-elektromotorischen Wirkung von [74] der Länge und dem Querschnitt ganz umabhängig sei, wenn nur das Verhältniss beider beständig bleibe.

Ich liess von einem geschickten Tischler aus demselben Stück Weissbuchenholz fünf Paar Stäbe von verschiedener Grösse schneiden, an denen diese Bedingung möglichst genau erfüllt war. Sie besassen nämlich (in rheinischen Zollen) folgende Maasse:

\begin{tabular}{|c|c|c|c|c|c|}
\hline & I. & II. & III. & IV. & V. \\
\hline Länge & $1^{\prime \prime}$ & $2^{\prime \prime}$ & $3^{\prime \prime}$ & $4^{\prime \prime}$ & $6^{\prime \prime}$ \\
\hline Querschnitt & $\begin{array}{l}1 / 8{ }^{\prime \prime} \times 1 / 8^{\prime \prime} \\
=1 / 64 \square\end{array}$ & $\begin{array}{l}2 / 8 \times 1 / 8 " \\
=2 / 64 \square^{\prime \prime}\end{array}$ & $\mid \begin{array}{c}3 / 8 " \times 1 / 8 \\
=3 / 64 \square^{\prime \prime}\end{array}$ & $\begin{array}{l}2 / 8 " \times 2 / 8 " \\
=4 / 64 \square^{\prime \prime}\end{array}$ & $\begin{array}{l}3 / 8 \times 2 / 8 " \\
=6 / 64 \square^{\prime \prime}\end{array}$ \\
\hline
\end{tabular}

Diese Stäbe wurden in destillirtem Wasser gesutten, bis sie untersanken umd anzunehmen war, dass sie alle auf allen Punkten gleichmässig damit durchtränkt seien. Die Stäbe wurden, bei den folgenden Versuchen, nm ihnen den ursprünglichen strom zuzuleiten, mit ihren beiden Enden zwischen die Zuleitungsbänsche der Säule eingeklemmt. Die Enden waren,

1 Tgl. Poggendorff's Annalen der Physik und Chemie. 1844. Bd. LXI. S. 586;

- 1857. Bd. CII. S. 70. - Vergl, unten, S. 48.

E. du Bois-Reymond, Ces. Abh. I. 
wie ich es häufig bei diesen Tersuchen thue, um das Eindringen des Kupfersalzes zu rerhindern, mit Schildern aus Modellirthon bekleidet. Der Modellirthon ist zwar selber innerlich polarisirbar, ${ }^{1}$ indessen rerschwinden die secundär-elektromotorischen Wirkungen, deren er fähing ist, gegen die des Holzes sogar bei gleichen Dimensionen; vollends musste dies hier der Fall sein, wo die Dicke der Thonschilder gegen die Länge der Stähe, mit Ausnahme vielleicht des kürzesten, kaum in Betracht kam.

Die grösstmögliche Dünne der Schilder war übrigens noch durch eine andere Betrachtung geboten. Durch ihre Einführung in den Siulenkreis geht der erste Factor des Nenners in (II) über in

$$
S+\frac{2 \tau \lambda}{q}+\frac{\sigma}{q}
$$

wo $\tau$ den eigenthümlichen Widerstand des Thons, $\lambda$ die Dicke des Thonschildes bezeichnen. Da in dem hinzugetretenen Gliede [75] der Querschnitt des innerlich polarisirbaren Körpers nicht mehr mit der Länge zusammen in der Art vorkommit, dass dadurch der Widerstand jenes Körpers ausgedrückt wird, insofern er von den Dimensionen abhängt, so würde, wenn dieses Glied einen grossen Einfluss ausïbte, die Schlussfolge, auf deren Bestätigung im Versuch es hier abgesehen ist, in ihren Vordersätzen untergraben werlen. Es muss also darauf geachtet werden, dass $2 \tau \lambda: q$ möglichst klein sei, was, da $\tau$ durch die Natur der Dinge und $q$ durch den angewandten Stab gegeben sind, nur dadurch geschehen kann, dass man $\lambda$ möglichst klein, $d$. h. die Thonschilder möglichst dümn nimmt.

Um die secundär-elektromotorische Wirkung ron den Stäben abzuleiten, wurden ihnen die mit doppelten Eiweisshäutchen bekleideten Schneiden der Keilbäusche angelegt; wem die Stäbe nicht quadratisch waren, der einen breiten Seite, allen aber an zwei im Toraus bezeichneten, von ihren beiden Enden gleich weit entfernten und zwar so gewählten Stellen, das $m={ }^{11} / 12$.

Einige Vorversuche lehrten, dass, um am Multiplicator für den Nervenstrom einen Ansschlag ron passender Grösse durch die secundärelektromotorisehe Wirkung dieser Stäbe zu erhalten, der Durchgang des Stromes von zehn Groveschen Elementen während eines gewissen durch das Uhrwerk ${ }^{2}$ abgemessenen Bruchtheils einer Secunde genügte, dessen absoluten Werth ich noch nicht kenne und daher vorläufig mit $1 / n$ " bezeichne. Diese Anordnung wurde beibehalten, da anzmehmen war, dass der Widerstand der mit destillirtem Wasser getränkten stäbe noch immer

1 s. oben Abh. II. S. 17.

2 S. oben Abh. I. S. 3. 
gross genug war im Vergleich zu dem der zehngliederigen Grove'schen Säule, damit nicht eine Annäherung an den durch (IV) ausgedrückten Zustand stattfinde, während es aus Gründen, die ich hier noch nicht erörtern mag, zweckmässig schien, die Schlıessung des Säulenkreises möglichst kurz dauern zu lassen.

Die Stärke des ursprünglichen Stromes, die begreiflich mit allen Stäben dieselbe sein musste, wurde durch den Ausschlag [76] bestimmt, den er an einer Tangentenbussole mit Spiegelablesung hervorbrachte. Der Spiegel schwang so viel schneller als das Nadelpaar des Multiplicators für den Nervenstrom, dass es keine Schwierigkeit hatte, zuerst den Ausschlag durch den ursprünglichen Strom, dann den durch die secundärelektromotorische Wirkung zu beobachten.

Es wurden nun nach eimander, jedoch ohne in Bezug anf die absolute Grösse der Stäbe irgend eine Ordnung zu beobachten, mit jedem der beiden zu einem Paare gehöriger Stäbe vier Versuche angestellt. Bei zweien ging der Strom in der eimen, bei den beiden anderen in der anderen Richtung durch die Stäbe. Die Zahlen in der folgenden Tabelle sind demnach Mittel aus acht Ablesungen. Die Zahlen in der mit $U$ bezeichneten wagerechten Reihe sind die Ausschläge durch den ursprünglichen Strom, die in der mit $S$ bezeichneten die durch die secundärelektromotorische Wirkung.

\begin{tabular}{c|c|c|c|c|c} 
& I & II & III & IV & V \\
\hline$U$ & $38 \cdot 2$ & $49 \cdot 9$ & $34 \cdot 9$ & $45 \cdot 4$ & $46 \cdot 0$ \\
\hline$S$ & $55 \cdot 8$ & $59 \cdot 5$ & $45 \cdot 7$ & $53 \cdot 6$ & $50 \cdot 6$
\end{tabular}

Die Zahlen der zweiten Reihe stimmen zwar nicht besonders, indem die unter II und III eine etwas grosse Abweichung vom Mittel zeigen. Da aber die Zahlen der ersten Reihe in demselben Simne abweichen, so ist klar, dass in diesen Fällen, aus irgend einem Grunde, das Product aus Stärke in Dauer des ursprünglichen Stromes beziehlich grösser oder kleiner war als sonst. Erwägt man, dass während die absoluten Dimensionen der Stäbe so ausserordentlich wachsen, die Zahlen, welche die ungefähre Grösse der secundären Wirkung bemessen, sich beinahe gleich bleiben, und höchstens spurweise eine Abnahme nach der Richtung der wachsenden absoluten Dimensionen erkennen lassen; nimmt man hiezu die zahlreichen Fehlerquellen, als da sind verschiedene Leitungsfähigkeit und Polarisirbarkeit des Holzes, rascheres Austrocknen der Stäbe von kleinerem Querschnitt, rerschiedene Leitungsfähigkeit und Dicke der Thonschilder, rer- [77] schiedene Dauer der Schliessung des Säulenkreises (da das Uhrwerk bei so kurzen Zeiträumen etwas weniger verlässlich arbeitet), verschiedenes Anlegen der Keilbäusche, Austrocknen der Eiweisshäutchen 
und Eindringen des Salzes in die Häutchen, и. d. m.: so gelangt man zu dem Schlusse, dass das theoretisch vorhergesehene Gesetz sich im Versuch hinreichend bewährt habe, un annehmen zu können, dass es nicht allzuweit von der Wahrheit abweiche. In diesem Schlusse wird man noch bestärkt durch die Wahrnehmung, zu der uns alsbald Gelegenheit werden wird, wie rasch und gesetzmässig die secundär-elektromotorischen Wirkungen sich verändern, sobald nicht bloss die absoluten, sondern anch die relativen Dimensionen des imerlich polarisirbaren Körpers sich verändern.

\section{Maximum in Bezug auf $L$.}

Demnächst rersuchte ich nämlich jetzt, das durch die Rechnung rerkündigte Maximum der secundär-elektromotorischen Wirkung in Bezug auf den Leitungswiderstand des innerlich polarisirbaren Körpers, sofern er durch die Dimensionen bestimmt wird, nachzuweisen, und zwar zuerst indem ich, bei beständigem Querschnitt, allein die Länge wachsen liess. $\mathrm{Zu}$ diesem Zweck brachte ich auf der eimen schmalen Seite der in der rorigen Versuchsreihe mit $\mathrm{V}$ bezeichneten, $6^{\prime \prime}=156 \cdot 9^{\mathrm{mm}}$ langen, mit destillirtem Wasser getränkten weissbuchenen Stäbe, eine willkürliche Theilung an, deren Grade beiläufig sehr nahe $=2^{\mathrm{mm}}$ waren. Der Stab wurde mit dem einen Ende eingeklemmt, so dass er wagerecht frei schwebte. An die eine seiner dabei senkrecht gestellten breiten Seitenflächen wurden die mit doppelten Eiweisshäntchen bekleideten Keilbäusche des Sänlenkreises, an die andere, jenen genan gegenüber, die des Multiplicatorkreises gelegt, so dass also $m$ hier $=1$ war. Der ursprüngliche Strom wurde von nur fünf GrovE'schen Elementen geliefert. Die Dauer der Durchströmung war auch hier nur $1 / n^{\prime \prime}$. Ich gebe die Zahlen einer Versuchsreihe, in Mitteln ans zwei Beobachtungen mit rerschiedener Richtung des ursprünglichen Stromes.

[78] In folgender Tabelle zeigt die erste Columne $(L)$ die zwischen den heiden Paaren ron Querbänschen begriffenen Längen des feuchten Holzstabes in Graden jener willkürlichen Theilung an; die zweite und fünfte (No.) enthalten die Nummern der Versuche; die mit $S$ und $U$ bezeichneten haben dieselbe Bedeutung wie in der vorigen Tabelle. Beim Verfolgen der Versuchsnummern bemerkt man, dass ich zuerst $I$, von 5 bis auf $80^{\circ}$ wachsen und dann wieder bis auf $5^{0}$ sinken liess. Dies hatte zum Zweck die Veränderungen der verschiedenen Theile der Vorrichtung, die während der mehrere Stunden langen Daner des Versuches nicht wohl zu vermeiden waren, unschädlich zu machen. Man sieht, dass muserer Vorhersicht gemäss, ein Maximum der secundär-elektromotorischen Wirkung 


\begin{tabular}{r||r|r|r|r|r|r}
\multicolumn{1}{l|}{$L$} & No. & $U$ & $S$ & No. & $U$ & $S$ \\
\hline 5 & 1 & $75 \cdot 5$ & $3 \cdot 7$ & 26 & $53 \cdot 7$ & $3 \cdot 0$ \\
\hline 10 & 2 & $54 \cdot 5$ & $17 \cdot 5$ & 25 & $39 \cdot 0$ & $7 \cdot 0$ \\
\hline 15 & 3 & $39 \cdot 2$ & $26 \cdot 2$ & 24 & $35 \cdot 0$ & $22 \cdot 0$ \\
\hline 20 & 4 & $34 \cdot 2$ & $34 \cdot 0$ & 23 & $31 \cdot 7$ & $30 \cdot 5$ \\
\hline 25 & 5 & $25 \cdot 5$ & $30 \cdot 5$ & 22 & $27 \cdot 5$ & $31 \cdot 7$ \\
\hline 30 & 6 & $23 \cdot 7$ & $30 \cdot 0$ & 21 & $24 \cdot 0$ & $30 \cdot 2$ \\
\hline 35 & 7 & $23 \cdot 2$ & $32 \cdot 5$ & 20 & $22 \cdot 7$ & $31 \cdot 5$ \\
\hline 40 & 8 & $19 \cdot 7$ & $29 \cdot 2$ & 19 & $19 \cdot 2$ & $26 \cdot 5$ \\
\hline 45 & 9 & $16 \cdot 7$ & $26 \cdot 0$ & 18 & $20 \cdot 0$ & $30 \cdot 0$ \\
\hline 50 & 10 & $16 \cdot 0$ & $25 \cdot 5$ & 17 & $15 \cdot 5$ & $24 \cdot 2$ \\
\hline 60 & 11 & $12 \cdot 0$ & $22 \cdot 0$ & 16 & $15 \cdot 2$ & $26 \cdot 2$ \\
\hline 70 & 12 & $9 \cdot 7$ & $19 \cdot 0$ & 15 & $11 \cdot 5$ & $20 \cdot 0$ \\
\hline 80 & 13 & $9 \cdot 4$ & $17 \cdot 0$ & 14 & $9 \cdot 2$ & $16 \cdot 5$
\end{tabular}

in Bezug auf die Länge des imnerlich polarisirbaren fenchten Leiters wirklich stattfindet. Dasselbe liegt zwischen den Längen $20^{\circ}$ und $35^{\circ}$. Die Ausschläge schwanken hier so wenig, dass ihre Untersehiede innerhalb der Grenzen bleiben, zwischen denen sie sich anch auch ohne Veränderung der Länge zeigen würden, wenn die Keilbäusche [79] mehrmals entfernt und wieder hinangeschoben worden wären. Jenseit des Maximums nimmt die secundär-elektromotorische Wirkung weit langsamer ab, als sie diesseit desselben anstieg.

Aehnliche Versuche mit gleichem Erfolg, wenn auch nicht so wohl ausgesprochener Gesetzmässigkeit der Zahlen, habe ich auch noch mit dem oben S. 35 mit III bezeichneten Stäbepaar angestellt.

\section{Maximum in Bezug auf q.}

Nummehr handelte es sich darum, das Dasein eines Maximums auch in Bezug auf $q$, bei beständig gehaltenem $I$, nachzuweisen. Dies hatte sehr viel grössere Schwierigkeiten. Erstens giebt es keine Art den Querschnitt des innerlich polarisirbaren feuchten Leiters mit solcher Leichtigkeit zu verändern, wie seine beim Versuch in Betracht kommende Länge, und zweitens wird der Vergrösserung des Querschnittes durch die Maasse der Bäusche sehr bald eine nicht zu überschreitende Grenze gesetzt, wemm nicht ganz andere Einrichtungen nöthig werden sollen. 
Zuerst schnitt ich aus grossen Kartoffeh Prismen ron ungefähr $40^{\mathrm{mm}}$ Länge und möglichst grossem Querschnitt, klemmte sie, an ihren Grundflächen mit möglichst dümen Thonschildern rersehen, zwischen die Zuleitungsbäusche der Säule ein, und legte ihnen die mit doppelten Eiweisshäutchen bekleideten Keilbäusche des Multiplicatorkreises an. Es zeigte sich, dass bei 1" langer Daner des ursprünglichen Stromes dreissig Grove'sche Glieder nothwendig waren, um am Multiplicator für den Nervenstrom eine secundär-elektromotorische Wirkung ron passender Stärke zu erzengen. Ich spaltete num das Prisma der Länge nach, beobachtete abermals die secundär-elektromotorische Wirkung, und so fort, bis ich das Prisma auf einen ganz dünnen Streifen des Kartoffelgewebes zurückgeführt hatte. Allein nur in seltenen Fällen gab sich, und auch nicht ganz überzeugend, anfangs eine Verstärkung, und erst später eine Schwächung der Wirkung in Folge der Verdünnung des Prisma's kund. Nur das zeigte sich allerdings, dass von einer gewissen Grenze an die Wirkungen mit weiter wachsender Dicke nicht mehr merklich zunehmen. Unter der Voraussetzung, dass ein Maximum wirklich vorhanden und die Formel (III) richtig sei, war es deutlich, dass dies Maximum [80] in diesen Versuchen nicht erreicht werden konnte, weil die Bäusche sowohl, als die Kartoffeln, rermöge ihrer absoluten Dimensionen, nicht die Anwendung eines Prisma's ron sulchem Querschnitt erlaubten, dass die in (III) ansgesprochene Bedingung erfüllt würde. Es konnte aber, von den im Zähler stehenden Factoren dieses Ausdrucks, $\sigma$ naturgemïss nicht rerkleinert werden. $L$ konnte es deshalb nicht, weil damn die Gesetze der linearen Stromvertheilung auch nicht mehr annähernd anwendbar gewesen wären, und weil dadurch die secundär-elektromotorische Wirkung selber zu sehr geschwächt worden wäre. Aus demselben Grunde kann die Verkleinerung ron $m$ nicht riel helfen, die ich übrigens fruchtlos bis zu $m=1 / 2$ trieb.

Eben so unglücklich war ich mit aus Thon gekneteten stäben von rerschiedenem Querschnitt, und mit balkenförmigen Fliesspapierbäuschen, die mit destillirtem Wasser getränkt waren, und ron denen ich Schicht um Schicht ablöste um ihren Querschnitt allmählich zn verklemern. Indessen führte mich dieser letztere Versuch auf den Gedanken der Methode, mit deren Hülfe es mir zuletzt doch gelang, das Maximum der secundärelektromotorischen Wirkung auch in Bezug auf den Querschnitt darzuthum.

Es war nämlich klar, dass es sich darum handelte, einen imnerlich polarisirbaren Körper von geringerem eigenthümlichen Widerstande zu haben, als Kartoffelgewebe, Thon, Fliesspapier mit Wasser getränkt. Ein solcher ist das mit einer Salzlösung getränkte Holz, welches sich damit noch immer, obschon bei weitem nicht so stark wie mit Wasser, kräftiger 
secundär-elektromotorischer Wirkungen fähig zeigt. ${ }^{1}$ Die Anwendung des Holzes bot aber eine doppelte Schwierigkeit. Erstens die, es vollkommen gleichmässig mit der so schwer darin eindringenden Salzlösung zu tränken, zweitens die, dass man nicht weiss, wie man den Querschnitt nach Belieben reränderlich machen kömne. Denn daran, ein fenchtes Holzprisma etwa zu spalten oder mit der Säge allmählich zn verkleinern, war ans vielerlei Gründen nicht zu denken.

[81] Ich half mir folgendermaassen. Aus Birkenfournier liess ich eine hinlängliche Anzahl Streife ron 6" Länge, $1 / 2$ " Breite und 1/16" Dicke schneiden. Einen Theil davon sott ich in gesättigter Kochsalzlösung, bis sie darin untersanken. Auf die in passenden Abstand gerückten Zuleitungsbänsche der Säule legte ich num zuerst einen Streif mit seinen beiden Enden flach auf, gegen Verumreinigung mit dem Kunfersalz durch ein Thonschild geschützt. An die eine Kante des Streifes schob ich, in geringer Entfernung ron dessen Enden, die Keilbänsche des Inultiplicatorkreises, hier natürlich ohne Eiweisshäntchen, da ja der Streif gleichfalls mit Kochsalzlösung getränkt war. Nachdem die secundär-elektromotorische Wirkung unter diesen Umständen bestimmt war, legte ich auf den ersten Streif eimen zweiten, auf diesen einen dritten, und so fort nach Bedürfniss, indem ich Sorge trug, dass die Kante der Streife stets in genaue Berührung mit den Schneiden der Keilbäusche kam. Die Säule musste, bei ${ }^{1} / n$ " danerudem Durehgang des Stromes, dreissiggliederig genommen werden. Die secundäre Wirkmg wurde wie bisher am Mnltiplicator für den Nervenstrom, die ursprüngliche an der spiegelbussole beobachtet. In der folgenden Tabelle, deren Zahlen das Mittel aus vier Ablesungen bei verschiedener Richtung des ursprünglichen Stromes, und bei wachsender und abnehmender Anzahl der Streife sind, bedeuten die obersten Zahlen die Anzahl der angewandten Fournierstreife.

\begin{tabular}{c|c|c|c|c|c|c|c} 
& 1 & 2 & 3 & 4 & 5 & 6 & $S$ \\
\hline$U$ & $27 \cdot 7$ & $33 \cdot 1$ & $42 \cdot 0$ & $44 \cdot 1$ & $44 \cdot 5$ & $45 \cdot 0$ & $46 \cdot 5$ \\
\hline$S$ & $5 \cdot 0$ & $6 \cdot 7$ & $4 \cdot 0$ & $4 \cdot 1$ & $2 \cdot 8$ & $?$ & $?$
\end{tabular}

Bei 6 , vollends bei 8 Streifen fand nur noch eine ungewisse Spur secundärelektromotorischer Wirkung statt.

Da, bei verschwindendem Querschnitt des imnerlich polarisirbaren Körpers, die secundär-elektromotorische Wirkung nothwendig gleichfalls verschwinden muss, so ist durch diese Versnchsreihe nummehr ein Maximum jener Wirkung auch in Bezug auf den Querschnitt erwiesen, wenn

1 S. oben Abh. II. S. 18. 
gleich die ihr entsprechenden Zahlen von 1 bis 2 Streifen nur unbedentend wachsen.

[82] Besser spricht sich das Gesetz in folgender Versuchsreihe ans, welche mit ähnlichen Streifen angestellt wurde, die ich aber, statt in Kochsalzlösung, in schwefelsaurer Kupferoxydlösung gesotten hatte. Hier fielen die Thonschilder zwischen den Streifen und den Säulenbäuschen fort, hingegen ward es nöthig, die Keilbäusche mit mehreren Lagen Fliesspapier zu bekkeiden, ron denen die innersten mit Kochsalzlösung, die äussersten mit schwefelsaurer Kúupferoxydlösung getränkt waren. Die secundär-elektromotorische Wirkung war so sehr viel grösser, ${ }^{1}$ dass es genügte, fünf Grove'sche Glieder $1 / n$ " lang einwirken zu lassen, dass aber ausserdem die Empfindlichkeit des Multiplicators für den Nerrenstrom noch bedentend gemässigt werden musste. Die Zahlen in der mit $1 / 2$ bezeichneten senkrechten Spalte sind mit einem der Länge nach in zwei gleich breite Hälften zerschlitzten Fournierstreife gewonnen.

\begin{tabular}{c|c|c|c|c|c|c|c|c|c} 
& $1 / 2$ & 1 & 2 & 3 & 4 & 5 & 6 & 8 & 10 \\
\hline$U$ & $13 \cdot 2$ & $19 \cdot 6$ & $47 \cdot 3$ & $60 \cdot 6$ & $67 \cdot 2$ & $65 \cdot 7$ & $68 \cdot 2$ & $67 \cdot 0$ & $56 \cdot 3$ \\
\hline$S$ & $10 \cdot 7$ & $19 \cdot 6$ & $22 \cdot 6$ & $19 \cdot 0$ & $11 \cdot 7$ & $11 \cdot 0$ & $7 \cdot 7$ & $5 \cdot 5$ & $3 \cdot 0$
\end{tabular}

Das Dasein eines Maximums in Bezug auf den Querschnitt ist hienach nicht zu bezweifeh. Befremdend ist jedoch, dass mit der Kupferlösung das Maximum wie mit der Salzlösung bereits bei zwei Dicken erreicht wurde. Nach Formel (III) hätte man erwarten sollen, dass, wegen des grösseren $\sigma$ und des kleineren $S \boldsymbol{M}$, das dem Maximum entsprechende $q$ mit der Kúpferlösung grösser hätte sein müssen. Dagegen ist es aber doch eingetroffen, dass mit den mit Salzlösungen getränlten Holzstreifen das Maximum bei einem viel geringeren Querschnitt erreicht wurde, als mit den mit destillirtem Wasser getränkten Fliesspapierbäusehen, dem Thon und den aus Kartoffeln geschnittenen Prismen.

Diese Versuche heweisen somit hinlänglich streng Folgendes: Die Stärke der secundär-elektromotorischen Wirkung imnerlich polarisirbarer Körper ist eine Function des Widerstandes dieser Körper, in sofem er durch die Dimensionen bestimmt wird. Diese Function besitzt ein Maximum, welches bei beständiger [83] Länge und wachsendem eigenthümlichen Widerstande der imnerlich polarisirbaren Körper in Bezug auf $q$ weiter hinausrückt. Bei weiter wachsendem Querschnitt rerschwindet die secundär-elektromotorische Wirkung.

Diese Ergebnisse stimmen mit obiger Theorie überein, und sind

1 S. oben Abh. II. S. 22. 25. 26. 
zum Theil eigenthümlich genug, um es wahrscheinlich zu machen, dass diese Uebereinstimmung nicht auf einem blossen Zufall beruhe.

Weiter bin ich in dieser Richtung nicht fortgeschritten. Das Bisherige genügte für meine Zwecke, und diese Prüfungen stellten sich doch auch bei dieser lockeren Art der Behandlung als viel zu schwierig heraus, als dass es sich für mich der Mühe verlohnt hätte, damit weiter fortzufahren. Es däucht mir aber hier ein schönes Feld für weitere Bestrebungen in scharf messendem sinne offen zu stehen. 
IV.

\section{Ueber gleichartige und nicht polarisirbare Elektroden.}

(Gelesen in der Gesammtsitzung der Königl. Akademie der Wissensehaften zu Berlin am 30. Juni 1559.) ${ }^{1}$

Jedem, der der Entwickelung der Elektrophysiologie während der letzten Jahrzehende gefolgt ist, sind die Schwierigkeiten bekamnt, welche die sogenannte Polarisation der Elektroden den elektrophysiologischen Untersuchungen in den Weg legt: sei's dass es sich darum handele, elektrische Ströme von thierischen Theilen dergestalt in den Multiplicatorkreis abzuleiten, dass ihre Stärke bestimmt werden kann, sei's dass umgekehrt Ströme von beständiger und gemessener Stärke thierischen Theilen zugeführt werden sollen.

Um so grösseres Interesse musste daher im Jahr 1854 Hrn. JuLEs Regnauld's Angabe erwecken, dass es ihm gelungen sei, unpolarisirbare Elektroden dadurch herzustellen, dass er Platten aus reinem, mehrmals destillirtem Zink in reine, nentrale schwefelsaure Zinkoxydlösung ron der Concentration tauchte, bei der sie das Maximum ihres Leitrermögens besitzt. $^{2}$ Die Unpolarisirbarkeit die- [444] ser Combination erklärte Hr. Regraulid aus dem Umstande, „dass, da die elektrolytischen Wir-

1 Monatsberichte u. s. w. 1859. S. 443. - Auch abgedruckt in Moleschoтт's Untersuchungen u. s. w. 1860. Bd. VII. S. 119.

2 Nach Hrn. E. Becquerel theilen salpetersaures Kupfer und schwefelsaures Zinkoxyd, und vermuthlich die sehr löslichen oder gar zerfliesslichen Salze überhaupt, die Eigensehaft der Sehwefelsäure und einiger anderen Säuren, dass das Leitvermögen ihrer wässerigen Lösungen bezogeu auf den Procentgehalt ein Maximum zeigt. Das Leitvermögen einer gesättigten schwefelsauren Zinklösung von $1 \cdot 4410$ Dichte bei $14 \cdot 40^{\circ} \mathrm{C}$. verhielt sich in Hru. Becqueneq's Versuchen zu dem derselben Lösung, wenn sie bis zum doppelten und vierfachen Volum verdünnt wurde : : $5 \cdot 77: 7 \cdot 13: 5 \cdot 43$. (Für Silber $=100000000$. S. Annales de Chimie et de Physique ete. 1846. 3 me Sér. t. XVII. 1 r. 280 et suiv.; - p. 289). Hr. Becquerel und Hr. Regnauld sagen nicht, bei welchem Grade der Verdümung das Maximum stattfinde. Hr. de la Rive aber, indem er Hrn. Becquerel's Beobachtungen anführt, giebt an, lass dies bei Verdoppelung des Volums der gesättigten Lösung der Fall sei (Traité d’Électricité etc. t. II. Paris 1\$56. p. 56). 
„kungen darin die chemische Natur der Elektrodenplatten unverändert „lassen, die von fremdartigen Ablagerungen herrührenden entgegengesetzten „Spannungen sich nicht entwickeln kömen.“ Er fügte hinzu, dass die Zinkplatten, nachdem sie einige Zeit in der Lösung rerweilt hatten, (ob zum Kreise geschlossen, oder nicht, wird nicht gesagt) im Allgemeinen gleichartig an seinem Multiplicator erschienen, der, wie man ans anderen Versuchen schliessen kamn, eine hinreichende Empfindlichkeit für den Iuskelstrom hesass. Demnoch ward es, wie es scheint, manchmal nöthig, auf die Unschädlichmachung eines übrig bleibenden beständigen Unterschiedes der beiden Platten bedacht zu sein. Dies gelang Hrn. Regnadlo, in seinen schätzharen Versuchen über die absolnte Stärke des Muskelstromarmes im Multiplicator unter verschiedenen Umständen, beiläufig den ersten messenden Versuchen in diesem Gebiete, mit Hülfe einer in entgegensetztem Simne in den Kreis eingeführten thermoëlektrischen Kupfer-Wismuth-Kette, deren eine Löthstelle auf $0^{\circ}$, die andere auf der erforderlichen Temperatur erhalten wurde. ${ }^{1}$

Zwei Jahre darauf machte Hr. Matreucci ähnliche Angaben. Er empfahl als ganz umpolarisirbare Combination Platten aus destillirtem Zink, oder auch aus verquicktem gewalzten Zink in nentraler gesïttigter schwefelsanrer Zinkoxydlösung. Nan bringe, sagt er, an dem einen Ende der Multiplicatornadel eine Hemmung an, welche die Nadel verhindert, nach der einen Seite auszuschlagen, und sende durch den Multiplicator den Strom mehrerer nach Art einer Sänle angeordneter Wadenmuskehn rom Frosch in der Richtung in der die Nadel gehemmt ist. Nach wenigen Augenblicken entferne man die Säule und schliesse den Kreis zwischen den Bänschen (die Hr. Matтeuccr nämlich jetzt nach meinem Vorgange anwendet). Dabei bleibe die Nadel röllig unbewegt, zum Zeichen, dass keine Ladung stattgefunden habe. ${ }^{2}$

[455] Das Jahr darauf kam Hr. Natteucci auf diesen Gegenstand zurück, indem er diesmal nur verquickte Zinkplatten in gesättigter schwefelsaurer Zinkoxydlösung oder Chlorcalciumlösung als unpolarisirbare Combination empfahl. Dabei rühmte er namentlich die grosse beständige Ablenkung, die der Inskelstrom bei Ableitung mittels solcher Elektroden erzenge. Mit Platinplatten in Kochsalzlösung als Elektroden bringt ein Gastroknemius oder halber Oberschenkel rom Frosch an dem Multiplicator von 24000 Windungen, den er sich nach dem Vorbilde des

1 Comptes rendus ete. 15 Mai 1854. t. XXXVIII. p. 891 ; - l'Institut. vol. XXII. Nr. 1067. p. 206; - Cosmos. Revue encyclopédique ete. par M. l'Abbé Morgno. t. IV. p. 599.

2 Comptes rendus etc. 28 Juillet 1856. t. XXIII. p. 234 ; - Ibid. 1 Décembre. p. 1054 ; - l'Institut. 1856 . t. XXIV. Nr. 1178. p. 267. 
meinigen hat bauen lassen, einen Ausschlag ron $30-40^{\circ}$ hervor, der binnen wenigen Secumden nur $2-1^{0}$ beständiger Ablenkung hinterlässt. Mit rerquicktem Zink in Zinklösung hingegen erhielt er, nachdem die Platten gleichartig geworden, einen Ausschlag ron $90^{\circ}$ und eine beständige Ablenkung ron $70-80^{\circ}$, welche sehr langsam abnahm. Entfernte er den Muskel und brachte er, sobald die Nadel sich beruhigt hatte (in Ermangelung eines Schliessungsbausches), die Zuleitungsbäusche zur Berührung, so gab sich keine Spur ron Ladung kund. ${ }^{1}$

Mir mussten diese Angaben selır bedenklich erscheinen. Zwar ist von vorn herein nicht so unwahrscheinlich, dass Zink in Zinklösung sehr geringe Ladungsfïhigkeit besitze. Allerdings nicht aus dem Grunde, aus welchem Hr. Regnadud die vollkommene Unpolarisirbarkeit dieser Combination ableiten zu können meint. Hm. Regnauld's Betrachtung passt ebensogut auf jedes andere Metall in einer Lüsung eines Salzes desselben Metalls, woraus sich letzteres gut galvanoplastisch niederschlägt. oder, wie man der Kürze halber sagen kann, auf alle galranoplastischen Combinationen. In der That pflegt man auch an die Unpolarisirbarkeit solcher Combinationen ganz allgemein zu glauben, ${ }^{2}$ und ich selber habe deshalb früher die Anwendung ron Kiupferelektroden in schwefelsaurer Kupferoxydlösung, ron Silberelektroden in Cyansilberkaliumlösung zur Ableitung der [446] thierisch-elektrischen Ströme vorgeschlagen. ${ }^{3}$ Allein Hr. Heumholtz fand, dass diese Combinationen noch immer ein Maass ron Polarisation zulassen, welches keine sicheren Strombestimmungen erlaubt. ${ }^{+}$Möglicherweise könnte nun beim Zink dieser Rest ron Polarisation besonders klein ansfallen wegen der geringen Condensationsfähigkeit für Gase, welche die Oberfläche der positiven Metalle besitzt. Demgemäss hatte ich selber schon bei verschiedenen Gelegenheiten, wo mir die Polarisation besonders lästig war, die jetzt von Hrn. Regnauld empfohlene Combination, Zink in schwefelsaurer Zinkoxydlösung, wirklich versucht, mit dem Unterschied allerdings, dass ich mich des im Handel vorkommenden Materials bediente. Ich rerband die Zinkelektroden in Zinklösung erst mit einer Grove'schen Kette, dann durch eine Wippe plötzlich mit dem sogenannten Museums-Multiplicator, dessen Nadel 12" schlug. Es geschah, im Simne negativer Ladung, ein Ausschlag bis auf $20^{\circ}$, während bei Anwendung von Platin in Kóchsalzlösung die Nadel

1 Philosophical Transactions etc. For the Year 1857. P. I. p. 131. 132.

2 Vergl. z. B. E. Becquerel, Annales de Chimie et de Physique. 3 me Série. 1846. t. XVII. p. $271 ;-1847$. t. XX p. 68.

3 Untersuchungen u. s. w. Bd. I. S. 243.

4 Untersuchungen u. s. w. Bd. II. Abth. I. S. 149. 
an die Hemmung geworfen wurde. ${ }^{1}$ Ich komte mich demnach nicht bewogen finden, für gewöhnlich meine zwar höchst polarisirbaren, aber auch höchster Gleichartigkeit fähigen Platinelektroden gegen weniger polarisirbare, aber in Bezug auf Gleichartigkeit durchans unzurerlässige Zinkelektroden zu rertauschen.

Hr. Regnauld hatte sich freilich chemisch reinen Materials bedient, zum Beweise der Unpolarisirbarkeit der ron ihm empfohlenen Combination aber keinen Versuch mitgetheilt. Was Hrn. Млtтeucci's Angaben betrifft, so war es eimmal a priori wohl sehr wenig wahrscheinlich, dass rerquicktes Zink in Zinklösung unpolarisirbar sei, da man nicht begreift, wie die an der Oberfläche liegenden Quęcksilbertheilchen nicht mit dem daran ausgeschiedenen Wiasserstoff elektromotorisch wirken sollten. Wie sodam Zink in Chlorealciumlösung eine unpolarisirbare Combination abgeben könne, ist gar nicht zu verstehen. [447] Hrm. Matreucci's Versuche endlich sind bei weitem nicht strenge genug, um darauf eine Behauptung ron so grosser praktischer Wichtigkeit für den Fortschritt der Wissenschaft zu gründen, wie die des Daseins einer wirklich unpolarisirbaren Combination. Erstens besass sein Multiplicator, obschon ron 24000 Windungen, nur sehr mässige Empfindlichkeit. Bei uns führt eim mit Längs- und Querschnitt aufgelegter Ischiadners rom Frosch die Nadel eines solchen Nultiplicators an die Hemmung, und hält sie beständig auf 40-50 $0^{\circ}$. Einen Ausschlag, wie Hr. Mitteucer ihn an seinem Multiplicator ron 24000 Windungen bei Ableitung des Muskelstromes mit Zinkelektroden in Zinklösung erhält, bekomme ich an meinem alten Multiplicator für den Muskelstrom ron nur 4650 Windungen mit Platinelektroden in Kivehsalzlösung. ${ }^{2}$ Damn aber ist an seiner Versuchsweise auszusetzen, dass während der Zeit, die nothwendig ist, um die Nadel auf Null zu bringen und den thierischen Erreger durch einen unwirksamen feuchten Leiter zu ersetzen, die während der Daner des Stromes vorhandene Polarisation bereits unmerklich geworden sein kam. Bei dem, übrigens ron Hrn. Faraday herrührenden Kunstgriff, ${ }^{3}$ die Nadel einseitig zu hemmen, wird zwar dieser Zeitverlust rermieden. Dafür tritt jedoch der Verdacht ein, dass die Nadel an der Hemmung geklebt, oder dass sich, in Folge des Abhebens der Glocke beim Anbringen der Hemmung, die

I Untersuehungen u. s. w. Bd. II. Abth. I. S. 409.

2 Poggendorff's Aunalen u. s. w. 1843. Bd. LVIII. S. 2; - Untersuehungen u. s. w. Bd. I. S. 464 ff.; - Bd. II. 1. Abth. S. 492.

${ }^{3}$ Experimental Researches in Electrieity. Reprinted from the Philosophieal Transactions. vol. I. Seeond Edition. London 1849. Series IX. Dec. 1834. p. 332. 333. No. 1087. p. 338. No. 1103. „Blocking the needle“; - Poggendorff's Annalen u. s. w. 1835 . Bd. XXXV. S. 428. 436. 
Gleichgewichtslage der Nadel während des Versuches im Sinne des ursprünglichen Stromes verrückt habe, oder endlich dass die Hemmung zu weit im Sinne der Ladung verschoben worden sei.

Wie dem auch sei, ich durfte natürlich nicht anstehen, die Angaben der Hrn. Regnauld und Matteucci einer Prüfung von solcher Schärfe zu unterwerfen, wie die Bedeutung des Gegenstandes sie erheischt. Ich theile in dem Folgenden das, wie ich [448] glaube, nicht unwichtige, jedenfalls überraschende Ergebniss meiner Untersuchung mit. Ich bemerke übrigens hinsichtlich der Art, wie sie geführt ist, dass ich dabei weniger rom Standpunkt des Physikers ausging, der die Polarisation um ihrer selber willen erforscht, als von dem des Elektrophysiologen, dem es zunächst nur darauf ankommt, sich für seine besonderen Zwecke gewisse Kenntnisse und Hülfsmittel zu verschaffen. Daher man manche Frage, die sich hier darbot, unerledigt, ja unberührt finden wird.

Ich begann damit, einige Vorversuche mit käuflichem Zinkdraht in käuflicher Zinklösung ${ }^{1}$ anzustellen. Die Drähte hatten $0.5^{\mathrm{mm}}$ Durchmesser, und wurden, damit sie ja gleichartig sein sollten, so geschnitten. dass die beiden zum Eintauchen bestimmten Enden im Draht aneinanderstiessen. Sie wurden geputzt, indem ich sie an dem zum Einklemmen bestimmten Ende mit einer Zange fasste, und sie durch feines Sandpapier hindurchzog, bis sie überall eine gleichmässig blanke Oberfläche zeigten. Dies liess sich am leichtesten erkennen, indem ich das freie Ende in Schwingungen versetzte. Sodamn zog ich die Drähte so oft durch die Falten eines reinen Leintuches, bis sie keinen schwarzen Strich mehr hinterliessen. In diesem Zustand eingetaucht, verhielten sie sich am Muskel-Nultiplicator meist leidlich gleichartig. Am Nerven-Nultiplicator hingegen war kaum etwas damit anzufangen. Es gehörte eine übermenschliche Geduld dazu, um abzuwarten, dass die hier noch stets beträchtlicher Wirkungen fähigen und dabei im höchsten Grade wandelbaren Ungleichartigkeiten der Drähte eimmal in einer glücklichen Stunde eine Beobachtung erlaubten. Die Nadel wurde dadurch bald anf dieser, bald auf jener Seite des Nullpunktes oft auf $20-25^{\circ}$ beständiger $\mathrm{Ab}$ lenkung gehalten, oder sie wanderte langsamer oder schneller über den Nullpunkt fort zwischen diesen Grenzen hin mol her, so dass an Compensireu dieser der Grösse und Richtung nach röllig unbeständigen Wirkungen durch eine in den Kreis eingeführte elektromotorische liraft auch nicht füglich zu denken [449] war. Die geringste Erschütterung

1 Mit Zinklösung ist vor der Hand stets gesättigte schwefelsaure Zinkoxydłösung gemeint. Die käufliche Lösung ist die des Zincum sulphuricum Pharm. Bor. (nicht des renale). 
eines der beiden Drähte, anch wemn dabei die Benetzung neuer Punkte der Oberfläche vermieden wurde, machte den erschütterten Draht negativ gegen den anderen, wie mir schon von früherher bekamnt war. ${ }^{1}$ Ueberhaupt aber schien es, als ob hier das Geschlossenhalten der eingetauchten Drähte zum Kíreise, wodurch ursprünglich ungleichartige Platindrähte bald nahe oder ganz gleichartig werden, nicht mur wenig untzte, was sich ans der vergleichsweise geringen Ladungsfähigkeit erklärt, sondern sogar schädlich wirkte. Streifen von Zinkblech statt der Drähte angewandt erwiesen sich rollends als unbrauchbar.

Was die Ladungsfïhigkeit anlangt, so gelangen mir mit diesen Elektroden zwar sehr leicht ähnliche Proben wie die, durch welche $\mathrm{Hr}$. Matreuccr die Unpolarisirbarkeit des destillirten oder verquickten Zipks in Zinklösung bewiesen zu haben glaubt. Liess ich z. B. den Muskel $5^{\prime}$ lang die mit Zinklösung getränkten, mit Eiweisshäutchen bekleideten Bäusche mit Längs- und Querschnitt berühren, hob ihn dann ab, brachte die Nadel mittels des Beruhigungsstäbehens anf Null, was kaum länger danert, als eine halbe Schwingung, und legte den Schliessungsbausch auf, so gab sich keine Spur von Ladung zu erkennen. Man würde sich also für gewöhnlich, wenn es sich bloss darum handelte die Ladmng nicht zu sehen, zu Versuchen am Muskel-Multiplicator der käuflichen Zinkdrähte in käuflicher Zinklösung bedienen können. Dass aber demmoch diese Combination nicht unpolarisirbar sei, zeigte sich sofort, als ich die Zinkdrähte ein paar Secunden lang mit einer Grove'schen Kette, dann durch Umlegen einer Wippe schmell mit dem Muskel-Multiplicator verband. Jetzt erfolgte, wie es nach jenen älteren, oben S. 44.45 angeführten Versuchen nicht anders zu erwarten war, ein heftiger Ausschlag im Sime negativer Ladung. Und es ward mir nicht schwer, denselben Erfolg anch mit Strömen von der Ordnung des Muskelstromes wahrnehmbar zu machen, indem ich der Wippe solche Eimrichtung gab, dass Schliessung des Multiplicatorkreises möglichst rasch auf Oeffinung des Kettenkreises folgte. Die Ströme erzengte ich theils [450] mit Hülfe einer SäureAlkali-Kette, da ich damals noch nicht auf Anwendung der Nebenschliessung zur Erzeugung passend abgestufter Ströme bei thierischelektrischen Versuchen verfallen war; theils diente mir dazu der Muskelstrom selber. Ich brachte nämlich zwischen den Zinkdrähten, als Nebenschliessung zum Multiplicator, noch eine metallische Leitung an, deren Widerstand gegen den des Multiplicators rersehwand, so dass die Nadel

1 Vergl. Monatsberichte u. s. w. 1854. S. 297; - MoLeschoтr's Untersuchungen u. s. w. 1858. Bd. IV. S. 11 ; - Untersuchungeu u. s. w. Bd. II. Abth. II. S. 328. 
auf Null blieb. Unmittelbar nachdem ich den Muskel entfernt hatte, ̈̈ffnete eine eigenthümlich gebaute Wippe diese Nebenschliessung und lrückte unmittelbar darauf den Schliessungsbausch auf die Zuleitungshäusche. Unter diesen Umständen erhielt ich am Nerven-Multiplicator eine zwar sehr kleine, aber deutliche Spur ron Ladung. Man bemerkt leicht, dass die zum Inultiplicator angebrachte Nebenschliessung mir hier denselben Dienst leistete, wie Hrn. Matteucc die einseitige Hemmung der Multiplicatornadel, ohne zu denselben Bedenken Anlass zu geben.

Wurden noch schwächere Ströme angewandt, so gelang es auch mit Hülfe clieser Vorkehrungen nicht, deutliche Spuren negativer Polarisation wahrzunehmen. Hingegen gab sich, bei lange dauernder Schliessung solcher Ströme, die sonderlare Erscheinung einer positiven Polarisation kund, welche schon früher ron Hrn. Beetz und Hrn. Martess an Eisen in verdünnter Schwefelsäure und von mir selber an rerquicktem Zink in Brumnenwasser beobachtet wurde. ${ }^{1}$ So beständig war hier diese Erscheinung, dass ich zur Vorstellung geführt wurde, die Polarisation des Zinks in Zinklösung sei bei schwachen Strömen positiv, über eine gewisse Stromstärke hinaus negativ. Die positive Polarisation bei schwachen Strömen würde erklären, warum bei dieser Combination das Geschlossenhalten der Elektroden zum Kreise, statt die Gleichartigkeit zu befördern, sie rielmehr geführde. Der ursprünglich vorhandene Strom würde sich selber allmählich durch positive Polarisation rerstärken, statt sich durch negative Polarisation zu schwächen.

Dadurch dass ich unter denselben Umständen, wo Hrn. Matteucci reines und rerquicktes Zink in Zinklösung keine Ladung [451] gaben, auch mit unreinen keine erhielt, während ich unter besseren Bedingungen mit diesem letzteren allerdings Ladung beobachtete, musste mir die angebliche Unpolarisirbarkeit des reinen und des rerquickten Zinkes natürlich doppelt verdächtig werden. Ich beharrte indess, der Wichtigkeit der Sache halber, in meinem Entschluss, ihr auf den Grund zu gehen; und glücklicherweise bot sich mir die Gelegenheit, dies auf einem viel rollkommneren Wege, als dem bisher betretenen, zu versuchen.

Durch die Güte meines Freundes Werner SIEnexs stand mir nämlich die ron diesem in Poggexdorffy's Annalen u. s. w. 1857. Bd. CII. S. $70 \mathrm{ff}$. beschriebene und Taf. I. Fig. $1-3$ ebendaselbst abgebildete ${ }^{2}$

1 Untersuchungen u. s. w. Bd. I. S. 236, 610, - Vergl, oben Abh. I. S. 6.

2 [Sie findet sieh auch dargestellt in WiEDEnaxN's Lehre vom Galvanismus und Elektromagnetismus. 2. Aufl. Braunsehweig 1872. Bd. I. S. 653. - Eine noch viel zweckmässigere selbstthätige Wippe, die von den Hrn. Siemexs und Halske seitdem gebaut wurde, und von der ich ihrer Freundsehaft ein Exemplar verdanke, ist meines Wissens noch unbeschrieben.] 
automatische Wippe zu Gebot, welche für Erforschmng solcher Latungserscheinungen, die nach einer kurze Zeit dauernilen Durchströmung hinterbleiben, sehr geeignet ist, ta sie Wirkungen wahrzunehmen gestattet, welche inrer Kleinheit halber bei eimmaliger Einwirkung auf die Nadel völig spurlos vorübergehen. Ich muss tiese Wippe hier als bekamt voraussetzen. Der Plau, mach dem ich verfuhr, war folgender. Der Schieber der Wippe sollte, indem er sich an die eine der Anschlagschrauben $m^{\prime}$ und $n^{\prime}$ (s. die angeführte Figur) anlegte, ten ursprünglichen Strom durch tie auf ihre Ladungsfähigkeit zu prüfenden Elektroden hindurchlassen. Indem er sich an die andere ter beiden Schrauben anlegte, sollte er der Larlung Gelegenheit zur Abgleithung in secm dären Strome geben. Beide Kreise, der primäre und der secundäre, sollten gleichen Widenstand haben, unt rergleichbare Bussolen enthalten. F.s sollten die beständigen Ablenkungen bestimmt werden, in denen die beiden Bussolnadeln gehalten würden durch tie sich in gleichen, sehr kurzen Zwischenräumen wiederholenden gleichen, sehr kurzen Stösse beziehlich des secundären und des primären stromes. Das Verhältniss beider (anf eine und lieselbe Einheit zurückgeführten) Ablenkungen $S: P=\alpha$ kamn man als den Polarisationscoëfficienten der betreffenden Combination für die durch den Mechanismus der Stenexs'schen Wippe betingten Zeitverhältnisse bezeichmen, und ans ter Vergleichung der Polarisationscoëfficienten [ 452 ] verschiedener Combinationen einen Schluss anf deren rergleichsweise Ladungsfähigkeit ziehen.

Bei der Ausführung dieses Planes handelt es sich natürlich zunächst darum, die Anwendung der beilen rergleichbaren Bussolen zu umgehen. Das Mittel dazu bestand darin, nur eine Bussole zu beobachten, diese aber abwechselnd in den secundären und primären Kreis einzuschalten.

Als Bussole wendete ich die von Hrn. Wredeusax mit Hrn. W. WebER's Stahlspiegel und dïmpfender Ḱuferhülse versehene Lavont'sche Bussole ${ }^{1}$ mit rerschiebbaren Gewinden an, wie sie Hr. Saverwald hierselbst in gewohnter Tollkommenheit anfertigt. Die Entfermung der Scale rom Spiegel betrug 2285 $\mathrm{mm}$. Das Rollempar, tessen ith mich bediente, hat 12000 Windungen eines ganz feinen Kupferdrahtes, und die Bussole zeigt tlamit, wem beide lollen über der Kúpferhülse zusammengeschoben sind, ohne dass dem spiegel etwas von seiner Richtkiaft genommen wird, eine Empfindlichkeit, welche sich der des Nerven-Multiplicators nähert, indem dieser, zwei seiner Grade auf einen Scalentheil gerechnet, immerhalb der ersten $55^{\circ}$ allerdings die grössere relative, mul immerhalb

1 Poggendorff's Amnalen u. s. w. 1853. Bd. LXXXVIII. S. 230 ; - Bd. LXXXIX.

S. 504. Anmerk.

E. du Bois-Reymond, Ges. Abh. I. 
der ersten $65^{0}$ die grössere absolute Empfindlichkeit besitzt, darüber hinaus jedoch der Bussole mehr und mehr nachsteht. Leider schwang der Spiegel etwas zu schnell, so dass er die kleinen Unvollkommenheiten im Gange der Wippe nicht hinlänglich durch seine Trägheit ausglich, sondern bei starken Strömen in fortwährenden kleinen Schwankungen blieb, aus deren Beobachtung auf die wahrscheinliche Gleichgewichtslage des Spiegels geschlossen werden musste.

Da die Bussole eimen sehr bedeutenden Widerstand darbietet, so lenchtet ein, dass es nicht genügte, sie einfach abwechselnd in beide Ḱreise einzuschalten. In dem Fall, dass die Bussole sich im primären Ḱreise befand, wäre der primäre Strom geschwächt, hingegen die Entladung der Elektroden begünstigt gewesen; im anderen Falle wäre der primäre Strom stärker gewesen, und der Polarisationsstrom hätte einen sehr [453] grossen Widerstand zu überwinden gehabt. Um diesem Uebelstande vorzubengen, mass ith an einem Siemens-Hatske'schen Rheostat, wie er sich in dem oben angeführten Aufsatz des Hrn. Sienens S. 75 beschrieben, Taf. I. Fig. 4. abgebildet findet, mittels des Wheatstone'schen Strommetzes einen Widerstand gleich dem der Bussole ab, und traf solche Anordnung, dass jedesmal, wemn sich die Bussole in dem einen Kreise befand, dieser Widerstand, nämlich 80 Meilen Telegraphendraht, in den anderen Kreis eingeschaltet war.

[454] Fig. 2 ist bestimmt, eine Uebersicht der Finrichtung des Versuches zu geben. Um sich darin zurechtzufinden, sehe man zuerst ron den punktirten einfachen Limien ab. Dieselben kommen erst später in Betracht.

$E, E^{\prime}$ sind die auf ihre Ladungsfähigkeit zu prüfenden Elektroden. $k^{\prime}$ ist der Schieber der SiEmexs'schen Wippe, der während der Ruhe der Wippe durch die Feder wider den leitenden Anschlag $m^{\prime}$ gedrückt wird, während des Ganges, unter dem abwechselnden Einfluss der Feder und des Elektromagnetes, bald $m^{\prime}$, bald den gegenüberliegenden, ebenfalls leitenden, Anschlag $n^{\prime}$ trifft, $^{1}$ und beziehlich an jedem so lange liegen bleibt, bis der Hebel seinen Hub in der anderen Richtung nahe vollendet hat.

$B$ ist die Bussole, $R h$ der an Widerstand ihr gleiche Rheostat. $D$ ist eime Danielische oder Grove'sche Kette grösserer Art, für deren Beständigkeit stets die äusserste Sorgfalt getragen wurde. Von dieser Kette wurde durch Nebenschliessung der ursprüngliche Strom in folgender Art abgeleitet. NS ist ein gleich einer Clariersaite auf einem Brett

1 Die Bezeichnungen $k, m^{\prime}$ und $n^{\prime}$ sind der leichteren Vergleichung halber aus Hrn. Siemexs' Beschreibung seiner Wippe beibehalten. S. a. a. 0. 
ausgespannter Messingdraht ron $1 \cdot 75^{\mathrm{mm}}$ Durchmesser und beiläufig $1 \cdot 6^{\mathrm{m}}$ Länge. Dieser Draht heisst der Nebenschliessdraht. Das Ende $S$ des Nebenschliessdrahtes steht durch einen Schlüssel $S$ in Verbindung mit der Kette sowohl als mit den Elektroden. Hier also spaltet sich, bei geschlossenem Schlüssel $S$, wie man in der Figur sieht, der Strom, und geht zum Theil durch den Nebenschliessdraht, zum Theil durch die

Fig. 2.

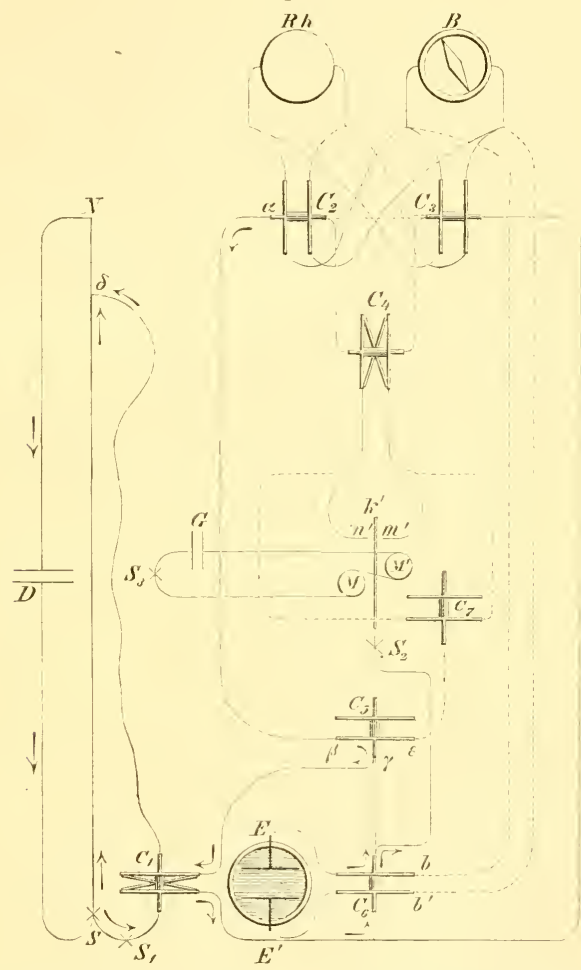

Elektroden weiter. Auf dem Wege zu den Elektroden trifft er auf einen PoнL'schen Stromwender $C_{1}$, der dem Stromzweig zwischen den Elektroden die passende Richtung in Bezug auf eine schon bestehende Ungleichartigkeit giebt, also z. B., wenn negative Polarisation erwartet wird, die Richtung jener Ungleichartigkeit. In der Figur ist solche Lage der 
Wippe des Stromwenders angenommen, dass der Stromzweig geradesweges weiter zur Elektrode $E^{\prime}$ geht. Anch ist hier noch ein Schlüssel $S_{1}$ eingeschaltet, der jenen Stromzweig nach Belieben herstellt oder unterbricht. [455] Aus den Elektroden kehrt der Stromzweig, nachdem er andere Theile der Vorrichtung durchlaufen hat, durch die Leitung $\alpha \beta \gamma \delta$ zurück, um sich bei $\delta$ wieder mit dem Hauptstrome zu vereinigen. Das Ende $\delta$ des Drahtes $C_{1} \delta$ ist beweglich am Nebenschliessirahte, so dass man zwischen $S$ und $\delta$ ein beliebiges Stück des Nebenschliessdrahtes aufnehmen kamn. Die Folge davon ist begreiflich, dass der Stromzweig zwischen den Elektroden rerschiedene Stärke erlangt. Der Yebenschliessdraht ist so gewählt, dass man mittels der Terschiebung ron $\delta$ leicht Ströme von der Ordnung des Muskelstromes erzengen kann. Beim Oeffnen des Schlüssels $S$ aber fält die Nebenschliessung ganz fort, und der Strom der Kette $D$ gelangt ungeschwächt zum Elektrodenpaar. Selbst in diesem Fall aber, kamn man annehmen, bleiben die Widerstände des primären und des secundären Kireises einander hinlänglich gleich, da der Widerstand der Kette $D$ gegen den der Bussole oder des Rheostates, und der Ladungszelle, nicht in Betracht kommt.

$C_{2}$ und $C_{3}$ sind zwei PoHL'sche Stromwender ohne Kirenz, und, wie die ihre Wippen rerbindende punktirte Doppellinie anzeigen soll, nit gekuppelten Wippen. Diese Anordnung ist derselben Dienste fähig, welche die neulich von $\mathrm{Hrn}$. Wпा beschriebene Wippe leistet. ${ }^{1}$ Die Doppelwippe $C_{2} C_{3}$ war es, die, wie man leicht rersteht, wemn sie nach unten in der Figur umgelegt war, den ursprünglichen Strom durch die Bussole und den secundären durch den Rheostat liess, wemn nach oben, die umgekehrten Verbindungen herstellte. Der stromwender mit Ḱreuz $C_{4}$ bewirkt, dass man alwechselnd die Contactstelle $m^{\prime}$ in den Fireis des ursprünglichen, die $n^{\prime}$ in den des secundären Stromes aufnehmen könne, und umgekehrt. $S_{2}$ ist ein Schlüssel, welcher in den dem primären und dem secundären Kreise gemeinsamen Theil der Leitung eingeschaltet, in jedem Angenblick die Nichtrerïnderung des Nullpunktes zu controliren crlaubt. Endlich $M M^{\prime}$ stellt den Elektromagnet der [456] Sivarexs'schen Wippe, $G$ die zugehörige Gangkette, bestehend aus zwei Grove'schen Elementen grösserer Art, $S_{3}$ den Schlüssel vor, der die Wippe in Gang: und in Ruhe setzt.

Sendet man einen beständigen Strom durch die eine oder andere

1 Die Neumanx'sehe Methode zur Bestimmung der Polarisation und des Uebergangswiderstandes, nebst einer Modification derselben. Vierteljahrssehrift der naturforsehenden Gesellsehaft in Zürich. 2. Jahrgang. 1857. S. 213. - Vergl. unten Abh. X. §. II. Die Doppelwippe. 
der beiden Contactstellen $m^{\prime}$ und $n^{\prime}$ der im Gange begriffenen Sremens'schen Wippe, so bleibt ein gewisser Brnchtheil der Stromstärke übrig, den man als Coëfficienten der bezüglichen Contactstelle bezeichnen kamn. Die Wippe arbeitet um so vollkommener, je gleicher und je grösser zugleich die beilen Coëfficienten sind. Im besten Zustande der Wippe unterscheiden sich beide Coëflicienten um keinen in Betracht kommenden Bruchtheil ihrer Grösse von einander, und zwar erreichen sie dabei den Werth ron $\frac{1}{2 \cdot 6}$. Fs stellt sich aber die Nothwendigkeit heraus, die Coëfficienten mit Leichtigkeit öfter revidiren zu können, und kleine Terändermngen ihres Werthes, die sich aus mbekamnten Gründen damn und wamn einfinden, durch etwas veränderte Spannmg der Federn (vergl. die Beschreibung der Wippe a. a. O.) zи berichtigen. Zı dieser Revision diente die in der Figur durch die punktirten einfachen Limien angedentete Anordnung. $C_{5}, C_{6}, C_{7}$ sind Stromwender ohne Krenz. Die Wippen ron $C_{5}$ and $C_{6}$ sind gekuppelt. Wird die Doppelwippe $C_{5} C_{6}$ ron $E^{\prime}, E, \beta$ nach $b^{\prime}, b, \varepsilon$ umgelegt, und die Wippe des stromwenders $C_{4}$ ansgehoben, so geht der von dem Nebenschliessdraht abgeleitete Stromzweig statt durch die Elektroden $E$. $E^{\prime}$ durch die Bussole, und, je nach der Lage der Wippe $\boldsymbol{C}_{\boldsymbol{z}}$, durch die rine oder die andere Contactstelle. War die Simmens'sche Wippe gut im Stande, so durfte der spiegel das schmelle Umlegen der Wippe $C_{7}$ nur durch ein Zncken nach der Ruhelage hin beantworten.

Ansserdem wurden, zu grösserer Sicherheit, die Versuche stets so angestellt, dass jede Contactstelle einmal in den primären und einmal in den secundären Kreis eingeschaltet wurde. Dies gab zwei Paar Ablesungen, $P_{m^{\prime}}, S_{n^{\prime}}$ und $P_{n^{\prime}}, S_{m^{\prime}}$. Da aber anch noch die Richtung des primären Stromes durch das Elektrolenpaar mmgekehrt wurde, so setzte sich schliesslich jede Bestimmung des Polarisationscoüfficienten in dem oben S. 49 gegebenen Simne aus acht Ablesungen zusammen, welche den [457] acht möglichen Combinationen der beiden Lagen der Doppelwippe $C_{2} C_{3}$, der Wippe $C_{4}$, nnd der $C_{1}$ entsprachen.

Sollte die Polarisation nach längerer Daner des ursprünglichen Stromes heobachtet werden, so brachte ich mittels des Schlüssels $S_{3}$ die Sremens'sche Wippe in Ruhe, und legte die Doppelwippe $C_{2} C_{3}$ nach oben. die Wippe $C_{4}$ aber nach unten in der Figur um, wodurch die Bussole und die Contactstelle $m^{\prime}$, gegen welche die Feder den Schieber drückt, in den secundären Kreis geriethen. Dam fixirte ich duch einen Keil den Hebel der Srewexs'schen Wippe in der Lage, die ihm der Elektromagnet zu ertheilen strebt, und hielt so, bei geöffnetem secundären Kreise, den primären Kŕreis dauernd geschlossen. Wurde im gegebenen 
Angenblick der Keil fortgezogen, so fiel der Hebel, der Feder gehorchend, vom Magnet ab, gleich als wäre dieser durch Oeffnen seiner Gangkette entmagnetet worden, nur, da kein magnetischer Rückstand den Fall verzögerte, noch geschwinder, und führte zuletzt mit grosser und stets gleicher Geschwindigkeit den Schieber in die Lage über, wo er den secundären Kreis schloss. Diese Beobachtungsweise der Ladung soll zum Unterschiede ron der erstbeschriebenen, zu der die Sienexs'sche Wippe eigentlich allein bestinmt ist, die zweite heissen. Als dritte endlich gelte die selten angewandte Versuchsweise, wobei die Ladung im prinären Krreise selber nach Aufhören des ursprünglichen Stromes beobachtet wurde. Hiezu genügte es, bei ruhender Wippe und bei Gegenwart der Bussole im primären Kreise, im gegebenen Angenblick einen in dem Hauptkreis DNS der Kette selber angebrachten Schlïssel zu öfnen.

Bemerkt zu werden verdient noch, dass ich es zur Erleichterung des. Vergleiches der primären und secmdären Wirkung bequem gefunden hatte, die Leitungen, wie es sich aus der Figur ergiebt, so anzuordnen, dass negative Ladung im secundären Kreise den Spiegel in derselben Richtung ablenkte, wie der ursprüngliche Strom.

Ich begann damit zuzusehen, wie sich die Ladung einiger in Ansehung ihrer Pularisirbarkeit bereits besser gekannten Combinationen an meiner Vorrichtung gestalten würde. Wo es nicht ausdrücklich anders bemerkt ist, hatten die anf ihre [458] Ladungsfähigkeit zu prüfenden Elektroden die Form von Drähten ron $0.5 \mathrm{~mm}$ Durchmesser und tauchten bei $1^{\mathrm{cm}}$ Abstand ron einander $2^{\mathrm{em}}$ tief in die Flüssigkeit.

1) Platin in rerdünnter Schwefelsäure $\left(\mathrm{SO}_{4} \mathrm{H}: \mathrm{HO}\right):: 1: 5$ dem Volum nach). Die elektromagnetischen Wirkungen des primären und des secundären Stromes ergaben sich als völlig gleich, so dass rasches: Umlegen der Doppelwippe $C_{2} C_{3}$, oder Vertanschen beider Wirkungen mit einander an der Bussole. sich im Fermrohr nur durch ein Zucken des Spiegels nach der Ruhelage hin bemerklich machte. $\alpha$ (s. oben S. 49) war also hier $=1$. In Uebereinstimmung damit sah man, bei der dritten Beobachtungsweise, den primären Strom beim Schliessen des Schlüssels $S_{2}$ angenblicklich bis anf einen sehr kleinen Bruchtheil rerschwinden, und beim Oeffnen des im Haupthreise befindlichen Schlüssels, auch nach kürzester Frist, einen negatiren Ausschlag ron sehr nahe. gleicher Grüsse mit dem primären erfolgen. Die Gleichheit der primären und secundären Wirkung hörte übrigens, wie sich nach den bekannten Gesetzen der Polarisation erwarten liess, auf, wenn die Stärke des primären Stromes eine gewisse Grenze überschritt. Schon bei Anwendung eines einzigen, nicht durch Nebenschliessung geschwächten Daniells fing die primäre Wirkung zu überwiegen an; hei fünf DAxteLL'schen Gliedern 
war $\alpha$ nur noch etwa $=1 / 2$, wozu noch kommt, dass jetzt der secundäre Kreis dem primären an Widerstand bedentend nachstehen musste.

Platinplatten, die sich in $1^{\mathrm{cm}}$ Abstand 2 Quadratcentimeter benetzter Oherfläche zukehrten, zeigten ganz dieselben Erscheinungen.

2) Platin in gesättigter Kochsalzlösung. Drähte und Platten. Ganz dieselben Erscheinmgen.

3) Platin in rauchender Salpetersäure. Diese Combination gilt allgemein für unpolarisirbar, und ich selber habe früher einen Versuch beschrieben, der dies zn beweisen scheint. Die durch den Strom einer Grove'schen Kette, in deren Kreis Platinelektroden in rauchender Salpetersäure eingeschaltet waren, in beständiger Ablenkung gehaltene Nadel zeigte keinen merklichen positiven Ausschlag, als der Strom im Elektrodenpaare mittels einer Wippe so rasch wie möglich um- [459] gekehrt wurde; ${ }^{1}$ eine Beobachtungsweise der Ladungen, die wir im Gefolge der bereits früher anfgezählten hier beiläufig noch als die vierte bezeichnen kömnen. Hr. Pfü̈GER hat nenerlich, bei Wiederholung dieses Versuches, unter denselhen Umständen nur $1^{\circ}$ Ansschlag beobachtet, wo Kupferelektroden in schwefelsaurer Kupferoxydlösung $20^{\circ}$ Ausschlag gaben. ${ }^{2}$ Indessen ist nicht zu übersehen erstens, dass bei dieser Tersuchsweise die Empfindlichkeit der Nadel nothwendig vermindert ist, selbst wemn man sich, wie Hr. Pfrüger that, in den empfindlichen Breiten der Theilung hält; zweitens, dass, in meinem Falle bestimmt, in Hrn. PfoüGer's Falle höchst wahrscheinlich, Elektroden von grösserer Oberfläche angewendet wurlen. Mit Drähten als Elektroden zeigt die Sienens'sche Wippe, dass diese Combination noch einen gewissen und zwar gar nicht so geringen Grad ron Ladungsfähigkeit besitzt. Ich bemerke, dass die Säure tief braumroth gefärbt war, stark ranchte, und bei $26 \cdot 9^{\circ} \mathrm{C} .1 \cdot 49$ Dichte besass. Democh war mit Strömen ron der Stärke des Inskelstromes $\iota=\frac{1}{33}$, mit ungeschwächtem Daniell $=\frac{1}{37}$. Auch als ganz einfach die oben S. 54 als zweite bezeichnete Versuchsweise mit einem solchen Damiell und 2'Durchströmung in's Werk gesetzt wurde, erfolgte cin Ausschlag ron 40 Scalentheilen. Da in dieser Combination der Wasserstoff an der negativen Elektrode auf Kosten der Salpetersäure oxydirt wird, so hat man sich rermuthlich zu denken, dass diese Polarisation von der elektromotorischen Wechselwirkung des Platins und des Sanerstoffs an der positiven Elektrude herrührt, welche das

1 Untersuchungen u. s. w. Bd. II. Abth. I. S. 379.

2 Untersuchungen über die Physiologie des Electrotonus. Berlin 1859. S. 449,450 . 
Platin noch negativer mache, als es schon durch Berührung mit den hohen Oxydationsstufen des Stickstoffs wird.

4) Silber in gesättigter salpetersaurer Silberoxydlösung. Anch diese für unpolarisirbar geltende Combination liess an der Snemexs'schen Wippe unter Umständen bedeutende Ladungen hervortreten, bot aber noch ansserdem eine sehr merkwürdige Erscheinung dar. Ich fand nämlich mit.[460] Strömen von der Ordnung des Muskelstromes $c=$ $\frac{1}{1 \cdot 7} ; \frac{1}{1 \cdot 6}$ : ein Maass der Ladmgsfähigkeit etwa so als ob gar keine Vorkehrung zur Beseitigung der Ladung wäre getroffen worden. Hingegen mit ungeschwächtem Daniell ward $\alpha$ nur $=\frac{1}{125} ; \frac{1}{138}$ gefunden. Dies rührte nicht allein davon her, dass die Stärke des Polarisationsstromes überhaupt langsamer wächst als die ursprüngliche Stromstïrke. Sondern indem ich bei arbeitender Wippe die secundäre Wirkung danernd beobachtete, während ich die Länge der Nebenschliessumg zwischen $S$ und $\delta$ stetig wachsen liess, zeigte sich's, dass die absolute Grösse der secundären Wirkung in Bezug auf die primäre Stromstärke ein Maximum habe. Ich ziehe vor, mich jeder Aeusserung ïher die muthmaassliche Ursache dieser Erscheinumg zu enthalten, erlaube mir aher, sie der Aufmerksamkeit derjenigen zu empfehlen. welche die Elektrolyse zum Gegenstand ihrer Untersuchungen machen.

5) Kupferdrähte in verdünnter Schwefelsäure von der unter (1) angegebenen Concentration waren zu ungleichartig, um einigermaassen genanere Beobachtungen zu gestatten. Als sie nur mit den Spitzen eintauchten, gelangen einige Ahlesumgen, wonach bej Strömen von der Ordnung des Muskelstromes $\alpha$ hier etwa $=\frac{1}{1.5}$ sein würde.

6) Kupferelektroden in schwefelsaurer Kupferoxydlösung verhielten sich anch nur selten gleichartig genug für meinen Zweck. Es zeigte sich, dass mit dieser Combination die Polarisation für Ströme von der angegebenen Ordnumg an der Stenexs schen Wippe fast unmerklich war. Sie ward erst messhar, als die ganze Länge des Nebenschliessdrahtes in den primären Kreis anfgenommen worden war. Unter diesen Umstïnden hestimmte ich $a$ zn höchstens $\frac{1}{15 j}$. Nicht erheblich kleiner fiel « bei Anwendung eines ungeschwächten Daniells aus. Während demnach bei der oben S. 55 als vierten bezeichneten Beobachtungsweise Kupfer in Kunferlösung viel stärkere Ladung gieht, als Platin in Salpetersäure, übertrifft an ter Snevexs'schen Wippe die secundäre Wirkmng ler letzteren Combination die der ersteren mm etwa das Fünffache; ein Widerspruch zwi- [461] sehen den Ergebnissen beider Methoden, auf den 
wir unten werden zurückzukommen haben. Schon hier kömnen wir ihm entnehmen, dass die gewöhnlichen Beobachtungsweisen nicht ausreichen, wemn es sich darum handelt, einer Combination die Larlungsfähigkeit abzusprechen, sondern dass man in dieser Beziehnng mindestens noch eine Vorrichtung nach Art der SiEmexs'schen Wippe zu befragen habe.

7) Käufliches Zink in käuflicher Zinklösung. In ter That lehrt denn auch die Siemexs'sche Wippe sofort, dass diese Combination nicht allein, den oben $S .47$ berichteten Erfalırungen entgegen, durch Ströme von der Ordnung des Muskelstromes Ladung im gewöhnlichen, negativen Simn annimmt, sondern dass diese Ladung sogar, unter übrigens gleichen Umständen, die des Kupfers in Kunferlösung ganz ungehener übertrifft. $\alpha$ nümlich ward hier, so genau als die Ungleichartigkeiten es gestatteten, zu $\frac{1}{5 \cdot 5}, \frac{1}{3 \cdot 3}$, ja eimmal zu $\frac{1}{2 \cdot 3}$ bestimmt. Wit dem Strome des ungeschwächten Daniells war $\iota n u r=\frac{1}{79 \cdot 3}$, also relatir sehr viel kleiner, jedoch nicht, wie beim Siller in Silberlösung, auch absolut kleiner als mit den schwachen Strömen.

Es fragte sich nun natürlicherweise vor Allem, wie es komme, dass ich früher bei langer Schliessung schwacher Ströme durch die Zinkelektroden positive, mit starken Strömen aber negative Polarisation beubachtet habe. Die Wiederholung des Versuches an der Bussole, statt am Multiplicator, liess vermöge der geringen Schwingungsdauer des Spiegels einen Umstand herrortreten, welcher den Sehlüssel hierzu gab. Es zeigte sich nämlich, bei der zweiten Beobachtungsweise, zuerst stets ein kleiner negativer Ausschlig, ron etwa einem Scalentheil, und dann erst wurde der Spiegel im Sinn der positiven Polarisation abgelenkt. Das unreine Zink in Zinklösung besitzt also wohl beide Arten von Polarisation zn gleicher Zeit, die gewöhnliche negative, und die mregelmässige positive, so dass man in Wihrheit stets mur den Unterschied beider zu sehen bekommt. Die beiden Polarisationen befolgen aber in Bezug auf ihr Wachsthum mit der Dauer des ursprünglichen. Stromes und auf ihre [462] Abnahme nach dessen Aufhören ein rerschiedenes Gesetz, wie dies in Fig. 3 rorgestellt ist. Die Abscissen $0 t$ bedeuten die Zeiten, die aus-

Fig. 3.

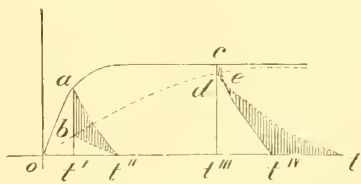


gezogenen Curven gehören der negativen, die punktirten Curven der positiven Polarisation an. Die negative Polarisation wächst mit der Dauer der Schliessung his zu einer gewissen Grenze rascher als die positive, nimmit aber auch nach Unterbrechung des primären Stromes schneller ab. Wird dieser taher, wie es in der Sienexs'schen Wippe der Fall ist, bereits nach sehr kurzer Zeit, z. B. bei $t^{\prime}$, unterbrochen, so erhält man eine durch den schraffirten Flächenraum $a b t^{\prime \prime}$ gemessene, rein negative, secundäre Wirkung. Wird dagegen die Kette erst bei $t^{\prime \prime \prime}$ geöfnet, so fällt die secundäre Wirkung doppelsinnig aus, indem ein kleiner negativer Vorschlag, gemessen durch $c$ de, der grösseren positiven Hauptwirkung vorangeht, die durch $e t^{\mathrm{IV}} t$ vorgestellt wird. Ja es scheint, obwohl es mir nicht gelang diesen Zustand künstlich herbeizufülnren, lass hei fortgesetzter Schliessung eines Stromes ron gewisser Schwäche die positive Pularisation die negative sogar an Grösse übertreffen kann, so dass die beiden Curven zuletzt einander schneiden. Man würde sonst nicht rerstehen, wie Zinkelektroden in Zinklösung durch Geschlossenstehen zur Kette ungleichartiger statt gleichartiger werden kömnen. Ausserdem findet allem Anschein nach auch noch eine rerschiedene Abhängigkeit der beiden Arten von Polarisation ron der Stärke des ursprünglichen Stromes statt, der Art, dass die positive Pularisation viel langsamer mit der Stromstärke wächst. So wird es erklärlich, dass bei grösserer Stärke des ursprünglichen Stromes, bei Anwendung z. B. eines ungeschwächten Daniells, die positive Polarisation nicht heobachtet wird. Die unregelmässigen Wirkungen, welche nach Abgleichung der starken negativen Polarisation in diesem Falle meist hinterbleiben, gestatten keine sichere Aussage darüber, ob [463] die positive Polarisation dabei noch spurweise wahrnehmbar sei oder nicht.

Wie dem anch sei, hält man zunächst nur die Empfänglichkeit des unreinen Zinks in Zinklösung für die gewöhnliche, bei weitem wichtigere negative Ladung im Auge, so haben wir also gefuntlen, dass diese Combination kaum weniger polarisirbar ist als Kupfer in verdümnter Schwefelsäure. Es ist danach wohl hinlänglich klar, dass Elektroten, welche, bei der gewöhnlichen Art der Untersuchung, wie sie ron Hrn. Matredccr in's Werk gesetzt wurte, gar keine, und bei den oben ron uns angewandten, schon etwas schärferen Prüfungen nur eine äusserst schwache Spur ron Ladung wahrnehmen lassen, demnoch in sehr hohem Grade ladumgsfähig sein können; und nicht minder klar, nach diesen Torgängen, dass die Untersuchung über das dem reinen oder rerquickten Zink in Zinklösung zukommende Maass von Polarisation völlig von vom anzufangen habe.

8) Reines Zink in reiner Zinklösung. Das reine Zink, dessen 
ich mich bediente, hatte Hr. Apotheker Vorgt die Güte gehabt, durch wiederholte Destillation darzustellen. Zuletzt war es, was besser wäre vermieden worden, in einer eisemen Höllensteinform, ohschon allerdings bei möglichst niedriger Temperatur, in Stangen gegossen worden. Aus einem Theile dieser Stangen wurden in einer Form aus sogenamntem Blaustein (worin zimmerne Soldaten gegossen werden), später, da der Blanstein, obschon rorgewärmt, absplitterte, in einer Gypsform, Platten ron $25^{\mathrm{mm}}$ Breite und $60^{\mathrm{mm}}$ Länge gegossen. Allein ich musste auf den Gebranch so grosser Platten verzichten, weil es schlechterdings mmöglich war, mit den Ungleichartigkeiten fertig zu werden. Ich hrach daher die an den Stangen haftenden flügelförmigen Lappen, welche sich durch das Eindringen des geschmolzenen Metalls zwischen beide Hälften der Form gebildet hatten, in schmale Leistchen, und schahte deren Oberfläche mit der scharfen Kante einer gesprungenen Glasscheibe rein. Diese möglichst reinen Zinkoberflächen tauchte ich in gesättigte reine schwefelsaure Zinkoxydlösung, die ich Hm. Heinnich Rose rerdankte. Auch so liess die Gleichartigkeit riel zu wünschen übrig, jedoch war sie genügend, um gute Beobachtungen an der Siemexs'schen Wippe zn gestatten. Es zeigte sich aber, [464] mit Strömen ron der Ordnung des Muskelstromes, negative Polarisation eben so stark, wie beim käuflichen Zinkdraht, welche eben so schneil wie dort mit wachsender Stärke der Ströme abmahm. Mit den schwächsten Strömen nämlich fand ich $\alpha=\frac{1}{2 \cdot 9}$, mit den stärksten, die der Nehenschliessdraht bei Anwendung eines Daniells zuliess, $=\frac{1}{3 \cdot 4}$, mit dem ungeschwächten Strom des Daniells aber nur noch $=\frac{1}{i 8 \cdot 3}$. Anch hier überzengte ich mich daron, dass die absolute Grösse der secundären Wirkung nicht, wie beim Silber, ein Maximum in Bezug auf die Stromstärke besitzt.

Dagegen war bei dem reinen Zink im Gegensatz zum käuflichen keine dentliche Spur von positiver Polarisation zu bemerken. Bei der zweiten Beobachtungsweise gab sich nach langem Schlusse der primären Kette unter denselben Umständen, wo das umreine Zink die doppelsinnige Polarisation zeigt, nur eine lebhafte und nachhaltige negative Wirkung kund.

Es war danach klar, dass die positive Polarisation nicht dem Zink selber, sondern einer Terunreinigung des Zinks angehöre, und zwar wahrscheinlich dem Eisen, da nämlich Eisen bisher das einzige bekannte Metall ist, welches positive Polarisation besitzt. Doch ist unter den Flüssigkeiten, in denen Hr. BEETz diese Erscheinung beobachtete, schwefelsaure Zinkoxydlösung nicht genannt, die zu prüfen er keinen Grund 
hatte. Ich versuchte deshalb, wie sich Eisenelektroden in dieser Flüssigkeit verhalten.

9) Eisen in Zinklösung. Ich fand, dass zwei Stücke nsenburger Eisendraht darin sehr gut gleichartig wurden; dass sie an der Siemens'schen Wippe, mit Strömen von der Ordnung des IIuskelstromes, starke negative Polarisation zeigten $\left(\alpha=\frac{1}{1 \cdot 7} ; \frac{1}{2 \cdot 6}\right)$; dass sie aber bei der zweiten Beobachtungsweise nach langer Durchströmung genau wie das unreine Zink einen doppelsimnigen Ausschlag gaben, zuerst einen deutlichen negativen Vorschlag, damn eine lang anhaltende positive Wirkung.

Die chemische Analyse des mureinen Zinkdrahtes, die Hr. Heinnich liose die Güte hatte, in seinem Laboratorium ans- [465] führen zn lassen, wies demn anch darin eine gewisse Menge Eisen nach. Auch das destillirte Zink ward bei derselben Gelegenheit nicht ganz frei ron dieser Vermureinigung gefunden. Möglich, dass diese Verunreinigungen es waren, ron welchen anch die negative Polarisation meines destillirten Zinks herrührte. Möglich, dass Hrn. Matтeucci’s Zink einen Grad der Reinheit besass, bei dem es anch an meinen Vorrichtungen keine negative Polarisation gezeigt haben würde. Indessen fehlt der chemische Beweis für jene Reinheit, so gut wie der physikalische für diese Nichtladungsfühigkeit, und was jene Möglichkeiten in hohem Grade unwahrscheinlich macht, ist der Umstand, dass sich in meinen Versuchen zwischen der Empfänglichkeit des käuflichen und der des gereinigten Zinks in Zinklösung für die negative Ladung gar kein Unterschied ergeben hat.

Wie dem anch sei, bei der ungemeinen Schwierigkeit, sich Zink in diesem Zustande vollkommener Reinheit zu verschaffen, würde den Elektrophysiologen mit dem Vorschlage des Hrn. Jules Regrautu nicht geholfen sein, da sie immer erst der Sremexs'schen Wippe bedürfen würden, um sich zu überzeugen, dass ihre Zinkelektroden nicht ladungsfähig seien, und es in dieser Ungewissheit riel bequemer für sie sein würde, sich des käuflichen Küufers in käuflicher Kíuferlösung zu bedienen, welche Combination, nach meinen Versuchen, eine ohne Vergleich kleinere Ladungsfähigkeit besitzt, als jedenfalls schon sehr sorgfïltig gereinigtes Zink.

Vielleicht würde die galvanoplastische Darstellung des Zinks ein Mittel abgeben, sich ein minder ladmosfïhiges Metall zu verschaffen, als das meinige war. Ich habe keine Veranlassung mehr gehabt, diesen Versuch anzustellen, auch micht mich um chemisch noch besser gereinigtes Zink zu bemühen, da die folgenden Ergebnisse diese Bemühungen von dem praktischen Standpunkte ans, den ich erwähntermaassen hier einnahm, als überflüssig erscheinen liessen.

10) Verquicktes Zink in Zinklösung. Ich ging nun nämlich 
auch noch," und zwar, wie ich schon oben S. 44. 45 andeutete, mit sehr geringen Erwartungen, an die Untersuchung der Ladungsfähigkeit des rerquickten Zinkis in Zinklösung. Wie gross war mein Erstamen, als ich zunächst fand, dass zwei beliebige Stücke Zink auf beliebige Art reichlich [466] rerquickt, sich in Zinklösung nicht allein an der Bussole, sondern sogar am Nerven-Multiplicator absolut gleichartig verhielten. Zuerst reinigte ich die Zinkdrähte oder -Bleche sorgfïltig mit Sandpapier, rerquickte sie mit reinem Quecksilber mittels chemisch reiner Schwefelsäure, und tauchte sie in die chemisch reine Zinklösung. Damn dreister werdend erkannte ich Schritt für Schritt, dass alle diese Vorsichtsmaassregeln unnütz seien, und dass zwei beliebige Stücke ganz gemeinen Zinkbleches, wie es zu Klempnerarbeiten gebraucht wird, mit altem schmierigem Quecksilher und roher Salzsäure verquickt, mit Wasser abgespült und mit Fliesspapier ahgetrocknet, sich in käuflicher Zinklösung bei einer benetzten Oberfläche ron mehreren Quadratzollen nach wenigen Augenblicken am Nerven-IIultiplicator absolut gleichartig verhalten. So rollkommen ist diese Gleichartigkeit, dass ich, ehe ich mich an den Anblick gewöhnt hatte, immer in Versuchung kam zu prüfen, ob denn auch der Kreis wirklich geschlossen sei, da beim Schliessen und Oeffnen durchaus keine spur ron Bewegung, sei's des Spiegels, sei's der Nadel, bemerklich wurde, nicht anders als ob der Kreis entweder an einer zweiten Stelle offen oder rein metallisch gewesen wäre. Nit wie geringer Sorgfalt diese Gleichartigkeit erzielt werde, die das Beste weit hinter sich lässt, was nach meiner Torschrift mit allem Fleiss zubereitete Platinelektroden leisten, geht wohl am deutlichsten aus folgendem Versuch hervor. Aus einer DaxtelL'schen Süule griff ich auf's Gerathewohl zwei Zinkcylinder von beiläufig $33^{\mathrm{mm}}$ Durchmesser heraus, von denen, wie sich ergab, der eine schon mehrmals, der andere noch nicht gebraucht worden war, und tauchte diese, nachdem sie, um an dem gebrauchten Cylinder etwa haftendes Kupfer zu entfernen, mit Wasser abgespült und mit Fliesspapier abgetrocknet worden waren, einander möglichst nahe $50 \mathrm{~mm}$ tief in Zinklösung, wobei also die benetzte Oberfläche jedes Cylinders über 50 Quadratcentimeter betrug. Es erfolgte zwar im ersten Augenblick ein ziemlich starker Ausschlag am Nerven-Multiplicator, sehr bald aber kam auch hier die Nadel absolut auf Null, und blieb daselbst, auch wemn der Krreis minutenlang geöffnet und dann wieder geschlossen wurde.

Die Abgleichung dieser im Anfang vorhandenen Ungleichartigkeiten beruht demmach, wie rlie Folge noch deutlicher leh- [467] ren wird, nicht auf Polarisation, wie die Abgleichung der Platinelektroden in Kochsalzlösung, welche bis zu einem gewissen Grade deshalb stets nur eine 
scheinbare ist. Die Abgleichung des etwa beim ersten Eintauchen sich kundgebenden Unterschiedes findet denn auch hier ebensowohl bei offenem wie bei geschlossenem Kreise statt. Die so umbegreiflich leicht erreichte rollkommene Gleichartigkeit wird eben so leicht, ohne alle besonderen Vorsichtsmaassregeln, in's Unbegrenzte erhalten. Zwar beobachtet man an Nerven-Multiplicator, wem von zwei rerquickten Zinkplatten die eine um die andere tiefer in die Zinklösung getaucht wird, jedesmal bei Benetzung neuer Punkte der einen Platte einen Ausschlag von wenigen Graden, der diese Platte als negativ gegen die andere anzeigt, und etwas stärker negatir wird ron zweien rerquickten Zinkelektroden, die man zwischen den mit Zinklösung benetzten Fingern beider Hände hält, diejenige, auf welche man einen Druck ausübt oder ausüben lässt. ${ }^{1}$ Dies ist aber auch Alles, was hier noch von den zahlreichen Umständen übrig ist, wodurch sonst gleichartige Elektroden ungleichartig werden. Man kann die eine der beiden Platten, nachdem sie einmal vollständig benetzt worden, an die Luft heben und wieder eintauchen, man kamn sie in der Zinklösung schütteln, wie man will, sie zwischen den Lagen eines mit Zinklösung getränkten Bausches drücken: ${ }^{2}$ das Gleichgewicht am Nerven-Mnltiplicator wird nicht gestört. Das Wasser der Zinklösung verdunstet, Krystalle schiessen in der Flüssigkeit an den Platten an oder bekleiden sie über deren Spiegel, und nach Wochen findet man die Platten in der zurückbleibenden nichtleitenden Krystallmasse eingewachsen, ohne dass während dieser ganzen Zeit die Nadel den Nullpunkt auch nur um eimen Grad verlassen hätte. Diese, ich wiederhole es, jede Vorstellung übersteigende Gleichartigkeit findet in ganz gleicher Weise statt, ob die beiden Zinkplatten erst eben verquickt seien und die Tropfen flüssigen Amalgams noch daran herunterfliessen; ob sie seit Wochen in den krystallinischen Zustand übergegangen seien; endlich gar, was wohl als das Wunderbarste erscheint, ob deren eine [468] sich in dem einen, die andere in dem anderen dieser Zustände befinde.

Schon durch diese Eigenschaft einer unübertroffenen mit leichtester Mühe zu erzielenden und zu erhaltenden Gleichartigkeit würde diese Combination, wie ich nicht zu bemerken brauche, eine höchst werthrolle Bereicherung nicht bloss des elektrophysiologischen. sondern des galranischen Apparates überhaupt sein. Allein meine Ueberraschung steigerte

1 Vergl. Monatsberiehte u. s. w. 1854. S. $288 \mathrm{ff.}$; - Mоцеsснотт's Untersuchungeu u. s. w. 1858. Bd. IV. S. 1 ff.; - Untersuchungen u. s. w. Bd. II. Abth. II. S. 321.

2 Vergl. Monatsberiehte u. s. w. 1854. S. 293; - MoLeschotт's Untersuchungen u. s. w. 1858. Bd. IV. S. 6 ; - Untersuchungen u. s. w. Bd. II. Abth. II. S. 324 . 
sich noch, als ich num ferner fand, dass die mit Hülfe der Siemess'schen Wippe bestimmte Ladungsfähigkeit dieser Combination in der That rerschwindend klein, jedenfalls unsergleichlich kleiner sei, als die irgend einer anderen bisher bekamnten Combination. Mit Strömen von der Ordnung des Muskelstromes liess die Wippe keine Spur daron erkemen. Noch als bei rerminderter Empfindlichkeit der Bussole und Anwendung eines ungeschwächten Daniells $P_{m^{\prime}}, P_{n^{\prime}}$ etwa 300 Scalentheile betrugen, waren $S_{n^{\prime}}, S_{m^{\prime}}$ schlechterdings nicht wahmehmbar, d. h. sie betrugen ganz gewiss nicht $0 \cdot 2$, ja schwerlich $0 \cdot 1$ Scalentheil. Ich fahndete darauf mittels eines Verfahrens, bei dem mir auch eine so kleine Spur ron Ladung nicht entgehen konnte, nämlich indem ich, bei arbeitender Wippe und geschlossenem secundären Kreise, in dem die Bussole befindlich war, das Ange am Fernrohr, den primären Kreis mittels des Schlüssels $S_{1}$ abwechselnd öffnete und schloss, oder gar den primären Strom zwischen den Elektroden mittels des Stromwenders $C_{1}$ ab und zu umkehrte. Erst als ich die Nebenschliessung fortliess, und mit beiden Rollen im Abstand ron $0^{\mathrm{mm}}$ eine Grove'sche Kette grösserer Art als Quell des primären Stromes benutzte, erschien negative Ladung der Zinkdrähte in bestimmbarer Grösse, nämlich etwa $1 \cdot 2$ Scalentheil betragend. Die primäre entsprechende Wirkung, mit nur einer Rolle in $100^{\mathrm{mm}}$ Abstand beobachtet, während die andere an einer anderen Stelle des Kreises eingeschaltet war, betrug 120 Scalentheile. Die Wirkung einer Rolle bei $100^{\mathrm{mm}}$ rerhält sich zu der bei $0^{\mathrm{mm}}$ Abstand : : $1: 26 \cdot 85$. Daraus ergiebt sich

$$
c=\frac{1.2}{2 \times 26 \cdot 85 \times 120}=\frac{1}{5370^{\circ}} .
$$

Diese Zahl wird sich, für den vorliegenden Fall, nicht weit ron der Wahrheit entfernen. Indessen soll sie rorzugsweise dazu [469] dienen, eine Vorstellung ron der Ordnung der Grösse zu geben, um die es sich hier handelt. Denn erstens lag aus mancherlei Gründen die Messung einer so kleinen Ablenkung an der Grenze meiner Beobachtungsmittel, zweitens schien der Werth von $\boldsymbol{c}$ Schwankungen unterworfen zu sein, da ich es einigemal nicht unbeträchtlich grösser $(1 / 3000)$, anderemale aber auch wieder sehr viel kleiner gefunden habe, so dass die secundäre Wirkung der Grove'schen Kette bei voller Empfindlichkeit der Bussole ganz ummerklich war. Nimmt man an, dass mir $0 \cdot 2$ Scalentheil secundïrer Wirkung entgangen seien, so komte doch $c$ in diesen Fällen nicht riel grösser als $1 /{ }_{50000}$ sein. Ich glaube bereits mit Bestimmtheit sagen zu kömnen, dass diese Schwankungen von dem Zustande der verquickten Zinkfläche so abhangen, dass die grösseren Werthe ron a schon üfter 
gebrauchten, die kleinsten frisch, oder von Neuem rerquickten Drähten zukommen.

Als die Drähte durch Platten ersetzt wurden, die einander 6-7 Quadratcentimeter benetzter Oberfläche zukehrten, wurde die secundäre Wirkung, selbst mit ungeschwächtem Strom der Grove'schen Kette und bei voller Empfindlichkeit der Bussole, unter allen Umständen ganz unwahrnehmbar.

Am Nerren-Multiplicator erfolgten mit den Drähten durch die secundäre Wirkung eines Daniells $4^{0}$, durch die zweier $7^{0}$ beständiger Ablenkung.

Bei Anwendung der zweiten Beobachtungsweise mit einem Daniell und $5^{\prime}$ Durchströmung erfulgten mit den Drähten an der Bussole bei voller Empfindlichkeit etwa 5 Scalentheile Ausschlag im Sime negativer Ladung. Iit den Platten betrug unter denselben Umständen der Ausschlag keinen ganzen Scalentheil, und als ich die Daxmelische Kette durch eine fünfgliederige Grove'sche Säule ersetzte, auch mur $3 \cdot 5$ Scalentheile. Erst als aus dem primären Kireise der Widerstand entfernt wurde, der darin zn dem Zweck angebracht war, den Gesammtwiderstand des primären und des secundären Kreises gleich zu machen (s. oben S. 50), wurden dentlichere Wirkungen erhalten.

Die Terquickung rernichtet also, kann man sagen, die bedeutende negative Ladungsfähigkeit des Zinks in Zinklösung. Aber auch die pusitive Ladungsähigkeit dieser (ombination [470] ist dadurch beinahe gänzlich aufgehoben. Nach 15--20' langer Durchströmung mit Strömen ron der Ordnung des Muskelstromes erfolgte höchstens ein halber Scalentheil Ausschlag im positiven Sime.

11) Verquicktes Zink in Chlorealeiumlösung. Ehe wir an diese Thatsachen weitere Folgerungen knüpfen, sollen noch einige andere Punkte bclenchtet werden. Hr. Мıттеucce führt rerquicktes Zink in Chlorealciumlösung als eine seinen Erfahrungen nach eben so mmpolarisirbare Combination wie das verquickte Zink in Zinklösmng an. Es ist nicht leicht zu rerstehen, wie er zu diesem Ausspruch gelangt ist, der theoretisch michts für sich hat, und ron dessen Unrichtigkeit es leicht ist, sich im Versuch zu üherzengen. Erstens rerhalten die rerquickten Zinkclektroden in gesättigter Chloralciumlösung sich sehr schlecht gleichartig. Für's zweite fand ich $\alpha$ für diese Combination mit primären Strömen ron der Ordnumg des Muskelstromes $=\frac{1}{4 \cdot 1}$. Drittens warf bei der zweiten Beobachtmgsweise, nach wenigen Minnten Durchströmung mit dem Strum des ungeschwächten Damiells, die secundäre Wirkung das 
Bild der Scale aus dem Gesichtsfelde. Positive Polarisation war bei dieser Combination nicht wahrnehmbar.

12) Verquicktes Zink in Chlorzinklösung rerhält sich dagegen nahe, aber, wie mir schien, doch nicht ganz so gleichartig, wie in schwefelsaurer Zinkoxydlösung. Die Chlorzinklösung enthielt noch ungelöstes ('hlorzink, und stellte eine syrupöse Flüssigkeit von 2.008 Dichte bei $27^{\circ} \mathrm{C}$. dar. Die etwas geringere Gleichartigkeit rührt vielleicht daher, dass die Lösung sich an der Oberfläche durch Wasser verdümnt, welches sie aus der Atmosphäre anzieht. Jedenfalls scheint aber die Ladungsfähigkeit dieser Combination nicht grösser zu sein, als die des Zinks in der schwefelsauren Lösung, dem auch hier wurde an der SiEmens'schen Wippe die Ladung erst merklich, als ich Drähte im primären Kreise dem Strom eines ungeschwächten Daniells aussetzte, und die secundäre Wirkung bei voller Empfindlichkeit der Bussole beobachtete. Auf dieselbe Art, wie dies oben S. 63 beschrieben wurde, bestimmte ich dabei $a$ zu $\frac{1}{5815}$; auf den Unterschied zwischen diesem Werth und dem in der [471] schwefelsauren Lösung gewomnenen ist natürlich nichts zu geben. Auf positive Polarisation nach langer Schliessung schwacher Ströme komte hier wegen der geringeren Gleichartigkeit nicht mit derselben Schärfe wie bei der schwefelsauren Lösung geprüft werden; indessen kann daron höchstens eine ganz unbedeutende Spur zngegen sein. Die gesättigte Chlorzinklösung leitete beiläufig nach meinen Versuchen dreimal schlechter als die schwefelsaure Lösung bei gleicher Temperatur. Verdünnung mit dem gleichen Volum Wassers erhühte aber ihr Leitrermögen auf das Fünffache, so dass sie nun um zwei Drittel besser als die gesättigte und auch noch $u m$ ein Drittel besser als die ebenso verdümnte schwefelsaure Lösung leitete.

Diese Wahrnehmung ist geeignet, uns daran zu erimnern, dass Hr. Jules Regnauld das reine Zink nicht in gesättigter, sondem in so verdünnter Zinklösung als umpolarisirbar empfohlen hat, dass die Lösung das Haximum ihres Leitvermögens besitze (s. oben S. 42). Obschon, wie bemerkt, $\mathrm{Hr}$. Regnauld seine Aussage durch keine Versuche gestützt hat, und obschon es höchst unwahrscheinlich war, dass die Verdünnung der Zinklösung bis zu jener Grenze die Ladungsfähigkeit der Combination aufheben solle, so habe ich doch nicht unterlassen, auch hierüber noch den Versuch zu befragen, indem ich Hrn. DE LA Rive's Angabe zu Grunde legte, wonach das Maximum des Leitrermögens dler Zinklösung bei deren Verdümnung mit dem gleichen Volum Wassers eintritt. Ich prüfte demgemäss noch $(13-16)$ reines Zink in reiner, käufliches, reines und verquicktes Zink in käuflicher Zinklösung von der

E. du Bois - Reymond, Ges. Abh. I. 
angegebenen Verdünnung. Das rerquickte Zink - es wurden in beiden Flüssigkeiten dieselben Drähte benutzt - lieferte ein etwas grösseres $\alpha$ als in der gesättigten Lösung. Dagegen fand ich allerdings, was sehr sonderbar ist, dass mit dem reinen und käuflichen Zink in der verdünnten käuflichen Lösung $\alpha$ erheblich kleiner ausfiel, als ummittelbar vor- und nachher mit denselben Elektroden in der gesättigten Lösung. Indessen blieb $\alpha$ hier noch immer bedeutend grösser als mit Kupfer in Kupferlösung; und mit dem reinen Zink in der verdünnten reinen Lösung betrug es, bei schwachen Strömen, sogar $1 / 8$. Der Widerspruch zwischen unseren Ergebnissen und [472] Hru. Regnauld's Behauptung beruht also nicht darauf, dass wir uns bisher stets der gesättigten Zinklösung bedient haben.

(19-24) Verquicktes Zink in verdünnter Schwefelsäure, in Serum ron Pferdeblut, in Brunnenwasser und in destillirtem Wasser. Da ich früher gerade bei Anwendung verquickter Zinkelektroden auf die räthselhafte Erscheinung positiver Ladung gestossen war, so versuchte ich, um diese Beobachtung zu erneuern, noch die in der Aufschrift genannten Combinationen. Serum hatte ich unter die mit dem verquickten Zink zu prüfenden Flüssigkeiten aufgenommen, um zu erfahren, wie sich letzteres bei unmittelbarer Berührung mit den thierischen Theilen, z. B. beim Ueberbrücken zweier daraus gebildeten Elektroden mit einem Nerven, in Bezug auf Gleichartigkeit und Ladungsfähigkeit verhalten würde. Es zeigten sich in der verdünnten Schwefelsäure, dem Serum und dem Brunnenwasser aber so ungeheure Ungleichartigkeiten der verquickten Zinkdrähte, und von solcher Unbeständigkeit zugleich, dass jede feinere Beobachtung der Ladung dadurch unmöghich gemacht wurde. Bei der leisesten Erschütterung sah man die Scale pfeilschnell. im Gesichtsfelde hin- und herschiessen. ${ }^{1}$ In diesen drei Flüssigkeiten wurde deshalb nur die gewöhnliche oder negative Ladung beobachtet. Bei Brunnenwasser konnte auch kein annähernder Werth von $\alpha$ gewomnen werden. Bei der verdünnten Schwefelsäure gelang es einmal, $\alpha$ zu etwa $1 / 100$ zu bestimmen. Sehr viel grösser schien $\alpha$ im Serum zu sein, denn ich erhielt mit Strömen von der Ordnung des Muskelstromes Quotienten wie $\frac{1}{2 \cdot 3} ; \frac{1}{3 \cdot 6}$, und bei der zweiten Beobachtungsweise warf die secundäre Wirkung des ungeschwächten Daniells nach 5‘ Durchströmung das Bild der Ścale aus dem Gesichtsfelde. Ganz ähnliche

1 Verquicktes Zink in verdünnter Schwefelsäure wird nach Hrn. PoggendonfF durch Schütteln negativ. Vergl. Monatsberichte, 1854. S. 297; - MoLeschotr's Untersuchungen u. s. w. 1858. Bd. IV. S. 11; - Untersuchungen u. s. w. Bd. II. Abth. II. S. 326. 
Werthe ron $a$ lieferten Kupferdrähte im Pferdeserum; mit Platindrähten war $\alpha$ auch hier $=1$. Was nun die positive Ladung des rerquickten Zinks betrifft, so nahmen im destillirten Wasser die Ungleichartigkeiten eine etwas mildere Gestalt an, und es zeigte sich mit einem Da[473] niell an der SiEmens'schen Wippe folgende merkwürdige Erscheinung. Beim Schliessen des Schlüssels $S_{1}$, während die Bussole im secundären Kreise beobachtet wurde, entstand zuerst ein Ausschlag im Sinne negativer Ladung. Darauf fingen positive Ladungen sich zu entwickeln an, dergestalt, dass die secundäre Wirkung durch Null hindurch ihr Zeichen wechselte, wobei das sonst negative, hier positiv gewordene $a$ zu etwa $1 / 55$ bestimmt wurde. Wurde dann $S_{1}$ geöffnet, so nahm, trotz dem Aufhören des primären Stromes, anfangs noch die positive secundäre Wirkung an Stärke zu; unstreitig, und in Uebereinstimmung 'mit dem, was wir oben S. 57. 58 über die gleichzeitige positive und negative Ladung des käuflichen Zinks in eben solcher Zinklösung angenommen haben, weil die schneller entstehende, aber auch schneller vergehende negative Ladung jetzt fortfiel, die sich während der Dauer des primären Stromes von der secundären Wirkung im positiven Sinne abgezogen hatte. Bei der zweiten Beobachtungsweise wurde leicht sehr starke positive Ladung beobachtet, die im Falle schwacher Ströme ganz rein zur Erscheinung kam, während im Fall eines ungeschwächten Daniells dem positiven Hauptausschlage ein negativer Vorschlag voransging.

Wir kehren nun zum verquickten Zink in den Zinklösungen zurück. $\mathrm{Zn}$ der unschätzbaren Gleichartigkeit, die wir an diesen Combinationen zu rühmen gefunden haben, gesellt sich also, nach den Versuchen an der Sremens'schen Wippe, auch noch eine bei weitem geringere Ladungsfähigkeit, als die irgend einer anderen bekannten Combination. Es ist leicht, sich von demselben Ergebniss noch auf eine andere Art zu überzeugen. Man lässt zuerst den primären Strom im nämlichen Kreise nach eimander durch die Zinkzelle und durch die damit $\mathrm{zu}$ vergleichende Combination gehen, und setzt dann plötzlich die beiden letzteren einander im Multiplicatorkreise dergestalt entgegen, dass die Richtung des Ausschlages anzeigt, welcher ron beiden Combinationen die grössere secundärelektromotorische Kraft zukomme. In Ermangelung der eigens von Hrn. PoggendorfF hierzu angegebenen Wippe ${ }^{1}$ gelingt dies leicht mittels einer Doppel- [474] wippe, wie sie in Fig. 2 in $C_{2} C_{3}$ und in $C_{5} C_{6}$ angedeutet ist. Ich stellte dergestalt folgende Vergleiche an.

1) Verquickte Zinkdrähte in gesättigter käuflicher schwefelsanrer Zink-, und Kupferdrähte in schwefelsaurer Kupfer-

1 Annalen u. s. w. 1844 . Bd. LXI. S. 612. 
oxydlösung. Nachdem der Strom eines ungeschwächten Daniells 1-2 hindurchgeschickt worden, erfolgte an der Bussole, bei voller Empfindlichkeit, ein kräftiger Ausschlag im Sinne der negativen Ladung der Kupferzelle. Mit Strömen von der Ordnung des Muskelstromes sah ich anfänglich zu meinem nicht geringen Befremden einen kleinen Ausschlag (2—3 Scalentheile) im Sinne negatirer Ladung der Zinkzelle erscheinen. Bei näherer Untersuchung zeigte sich indess, dass, wie es nach den oben S. 63. 64 beschriebenen Versuchen nicht anders sein konnte, die Polarisation der Zinkzelle schlechterdings unmerklich war, dass aber die Kupferzelle unter diesen Umständen eine geringe Spur positiver Polarisation besass, welche den Anschein überwiegender negativer Ladung der Zinkzelle bewirkt hatte.

2) Kupferzelle wie vorher, und reines Zink in gesätigter reiner schwefelsaurer Zinkoxydlösung. Mit Strömen ron der Ordnung des Muskelstromes wurde nichts deutliches wahrgenommen, indem die Ungleichartigkeiten sich feineren Wahrnehmungen widersetzten. Mit dem Strome des ungeschwächten Daniells erfolgte ein ansehnlicher Ausschlag im Sinne negativer Ladung der Zinkzelle.

3) Kupferzelle wie rorher, und Silberdrähte in silberlösung wie oben S. 56. Bei schwachen Strömen hat die Silberzelle ein sehr bedentendes, bei starken die Kupferzelle ein geringes Uebergewicht. Nach den oben bestimmten Werthen ron $\alpha$ für die Silberzelle hätte Letzteres nicht der Fall sein sollen.

4) Kupferzelle wie vorher, und Platindrähte in rauchender Salpetersäure wie oben S. 55. Erfolg wie beim vorigen Versuch. Mlit schwachen Strömen überwiegt die Platin-Salpetersäure-, mit starken die Kupfer-Zelle.

Wie man sieht, spricht anch diese Beobachtungsweise dafür. dass das verquickte Zink in Zinklösung die am wenigsten la- [475] dungsfähige Combination sei. Was aber die beiden letzten Versuche betriftt, so giebt sich darin abermals ein Widerspruch kund, gleich dem bereits oben S. 56. 57 bemerkten, zwischen dem an der SrEvexs'schen Wippe gewonnenen Ergebniss und dem des gewöhnlichen Verfahrens, die Ladung durch Umlegen der Wippe eines Stromwenders zu beobachten. Auf doppelte Art kann man die Erklärung dieses Widerspruchs versuchen.

Entweder nämlich braucht die Kunferladung längere Zeit, um sich zu entwickeln, und dies ist der Grund, weshalb $\iota$ an der Sizmexs'schen Wippe für das Kupfer kleiner ausfällt als für die beiden anderen Combinationen. Oder die Kupferladung ist nachhaltiger als die dieser letzteren, so dass, wenn der Wechsel der Verbindungen mittels der Wippe eines Stromwenders, d. h. verhältnissmässig ziemlich langsam, geschieht, die 
Ladung des Silbers in Silberlösung, des Platins in Salpetersäure, schon Zeit gehabt hat, sich zu zerstrenen, während sie zur Zeit, wo die Sienens'sche Wippe den secundären Kreis nach Oeffnung des primären schliesst, in der That die des Kupfers übertrifft. Beide Voraussetzungen lassen, whne Hinzunahme weiterer Muthmaassungen, unerklärt, weshalb der Erfolg mit den schwachen Strömen ein verschiedener sei ron dem mit den starken Strömen beobachteten.

Weder hierauf, noch auf die Frage, welche von beiden Annahmen der Wirklichkeit entspreche, wollen wir indess näher eingehen. Uns interessirt an dem in Rede stehenden Verhalten vorzugsweise das Licht, welches es auf den Werth des hisher ron uns zur Bestimmung der Ladungsfähigkeit der Combinationen angewandten Verfahrens zu werfen geeignet ist. Man sieht, dass wir aus der Grösse, in der die Ladung nach Aufhören des primären Stromes erscheint, keinen sicheren Schluss auf die Ladungsfähigkeit einer Combination machen kömnen. Ein ähnliches Verhältniss, wie zwischen der Ladung der galvanoplastischen Kupfercombination und der des Platins in Salpetersäure, kömnte zwischen der des rerquickten Zinks in Zinklösung, und der der galvanoplastischen Kupfercombination, stattfinden. Zwar schliessen die bei der zweiten Beobachtungsweise und auch so eben bei der Entgegensetzung der Zinkund Kupferzelle [476] nach längerer Durchströmung gemachten Wahrnehmungen die Höglichkeit aus, dass das rerquickte Zink in Zinklösung an der Sienexs'schen Wippe deshalb ein so kleines a geliefert habe, weil dessen Polarisation wegen der kurzen, durch den Gang der Wippe bedingten Schliessung des primären Stromes nicht Zeit gehabt habe, sich zu entwickeln. Sehr wohl denkbar wäre es dagegen wegen der geringeren Fähigkeit der positiven Metalle, Gase an ihrer Oberfläche zu verdichten (rergl. oben S. 44), dass die Ladung des rerquickten Zinks in Zinklösung bedeutend flüchtiger wäre, als die des Kupfers in Kúupferlösung, und dass darauf der erstaunlich kleine Werth von $\alpha$ bei ersterem beruht habe.

Mit einem Worte, den Curren, in denen während des Schlusses der primären Kette die Polarisation bis zu einer gewissen Grenze wächst, um nach Oeffnung der Kette wieder abzufallen, sei’s dass der secundäre Kreis offen bleibe, oder nach kürzerer oder längerer Zeit geschlossen werde, diesen Curren darf bei rerschiedenen Combinationen gewiss nicht ohne Weiteres ein gleiches Gesetz untergelegt werden. Ich kann nicht umhin, in der Nichtberücksichtigung dieses Umstandes einen gewichtigen Einwurf gegen den von Hrn. WILD (s. oben S. 52 Anm.) reröffentlichten Vorschlag zur gesonderten Bestimmung der Polarisation und des Uebergangswiderstandes zu erblicken, wonach zuerst die durch Polarisation und 
Uebergangswiderstand gemeinschaftlich bewirkte Stromschwächung in eine Gleichung gebracht, und dann daraus die Polarisation mit Hülfe eines Werthes eliminirt werden soll, der aus deren Beobachtung nach Oeffnung des primären Kreises herrorgeht. Ich weiss sehr wohl, dass die Polarisation nach Oeffnen des primären Kreises, so lange der secundäre Kreis nicht geschlossen ist, bei weitem langsamer sinkt, als nachdem dies geschehen. Oeffnet man den Hauptkreis einer Kette, in deren Nebenleitung, wie in unserer ersten Figur, Platinelektroden in verdünnter Schwefelsäure oder Kochsalzlösung eingeschaltet sind, auf wenige Augenblicke, wobei der secundäre Kreis geschlossen bleibt, und die Ladung sich abgleichen kann, so geht der durch die Ladung geschwächte Strom der Kette sofort wieder zeitweise bedentend in die Höhe. Dies ist nicht der Fall, [477] mit anderen Worten, die Polarisation bleibt rerhältnissmässig unverändert, wenn man statt des Hauptkreises die Nebenleitung selber eben so lange öffnet, weil nun der Ladung zwar wie vorher der sie auf steter Höhe erhaltende primäre Strom entzogen, allein diesmal keine Gelegenheit zur Abgleichung gegeben ist. Nichtsdestoweniger muss ich darauf bestehen, dass, bis nicht für jeden einzelnen Fall das Gegentheil erwiesen ist, keine andere Bestimmung der Polarisation oder der Ladungsfähigkeit einer Combination Vertranen verdient, als solcbe die während der Dauer des primären Stromes in dessen Kreise selber gemacht, oder wenigstens mit Hülfe von dergleichen Beobachtungen controlirt sind.

Es bleibt uns also schliesslich übrig, auch noch auf diese Art die Unpolarisirbarkeit unserer Combination darzuthun. Ich hatte einen parallelepipedischen Trog aus gefirnisstem Eichenholz von $125^{\mathrm{mm}}$ Länge, $53^{\mathrm{mm}}$ Breite und $40 \mathrm{~mm}$ Tiefe, in dessen Wände und Boden, ehe sie zum Troge zusammengefügt wurden, in Fわenen senkrecht auf die Längsrichtung des Troges und in $15 \cdot 6^{\mathrm{mm}}$ Abstand von einander, neun $5 \mathrm{~mm}$ tiefe Sägeschnitte angebracht waren. Diese dienten dazu, Bleche aufzunehmen, welche sich alsdann als Zwischemplatten auf der Bahn eines den Trog der Länge nach durchfliessenden Stromes eingeschaltet fanden, indem die Leitung durch die im Falz um das Blech herum übrigbleibende capillare Flüssigkeitsschicht nicht in Betracht kam. Dieser Trog wurde $5^{\mathrm{mm}}$ hoch mit gesättigter schwefelsaurer Zinkoxydlösung gefüllt, und mit zwei verquickten Zinkblechen als Elektroden in den beiden äussersten Falzen, in den Kreis einer Grove'schen Kette und der Bussole gebracht. Während das Bild der Scale im Fernrohr beobachtet wurde, schob ich nach einander verquickte Zinkbleche anch in die sieben übrigen Falze. Da die Flüssigkeitssäule im Troge dabei nicht allein um $5^{\mathrm{mm}}$ verkürzt wurde (su viel betrug die Gesammtdicke der sieben Bleche, deren Widerstand remachlässigt werden kann), sondern zugleich, wegen der durch die 
Bleche verdrängten Flüssigkeit, an Querschnitt zumahm, so nahm der Widerstand des Troges durch das Eimsenken der sieben Bleche um 1/10 ab. Ich hatte [478] aber, hierauf rechnend, einen so bedeutenden metallischen Widerstand in den Kreis eingeführt, dass eine Verkürzung des Troges um $7 / 8$, wie sie die Folge des Versenkens der äussersten, als Elektroden dienenden Bleche in zwei einander zunächst befindliche Falze war, den Widerstand des Kreises nur um 1/196, das Einsenken der sieben Bleche denselben folglich nur um 1/1666 verminderte. Bei einer Ablenkung ron 150 Scalentheilen musste also die durch Verminderung des Widerstandes beim Einsenken der Bleche erzeugte Vermehrung der Stromstärke unter $0 \cdot 1$ Scalentheil bleiben, und es hätte mir nicht entgehen kömnen, wenn die sieben Bleche, deren jedes ein Elektrodenpaar von nur 2-65 Quadratcentimeter Oberfläche vorstellte, durch eine der des primären Stromes entgegengesetzte elektromotorische Kraft, eine Verkleinerung der Ablenkung anch nur um $0 \cdot 2$, oder eine Schwächung des Stromes um $1 / 750$, d. h. also jedes Blech eine Schwächung $u m$ etwa $1 / 5000$, hervorgebracht hätten. Ich konnte aber mit dem Strome der zwar nicht durch Nebenschliessung, wohl aber durch die eingeführten Widerstände sehr geschwächten Grove'schen Kette nichts der Art wahrnehmen. Mit sehr schwachen Strömen traten beim Einsenken und Herausnehmen jeder einzelnen Platte Spuren von Wirkung, bald in der einen, bald in der anderen Richtung auf, die aber sichtlich micht auf Polarisation, sondern auf leichter Ungleichartigkeit der heiden Seiten der Platten beruhten.

Da bei dieser Versuchsweise die Oberfläche der Elektroden, obschon im Vergleich zu der, die man in thierisch-elektrischen Versuchen anwenden kann, nur klein, mit Rücksicht auf den Zweck, die Ladungsfähigkeit zu prüfen, immerhin eine grosse zu nennen war, so änderte ich die Anordnung noch in folgender Art ab, wobei ich zwar eine beliebig kleine Oberfläche, jedoch nur noch ein Elektrodenpaar anwenden konnte.

In den Kreis einer zweigliederigen Grove'schen säule und der Bussole wurden zwei verquickte Zinkbleche eingeschaltet, die in zwei Gefässe $A$ und $B$ mit derselben Zinklösung; wie oben, tauchten. $A$ und $B$ waren durch ein $250^{\mathrm{mm}}$ langes zweimal rechtwinklig gebogenes, mit derselben Lösung gefülltes Thermometerrohr verbunden. Neben $B$ stand ein drittes ähnhiches Gefäss $C$ mit [479] Zinklösung. In $B$ und $C$ tauchten verquickte Zinkdrähte von $0 \cdot 5^{\mathrm{mm}}$ Durchmesser $5^{\mathrm{mm}}$ tief, also mit einer Oberfläche von 7-8 Quadratmillimetern, ein. Diese waren metallisch verbunden und stellten das plötzlich in den Kreis einzuführende Elektrodenpaar vor. Die Einführung geschah einfach so, dass das Thermometerrohr, während sein eines Ende in $A$ stecken blieb, mit seinem 
anderen Ende ans $B$ in $C$ übertragen wurde. Natürlich rerschwand unter diesen Umständen jeder andere Widerstand im Kreise, auch der etwaige Uebergangswiderstand, gegen den des capillaren Flüssigkeitsfadens im Thermometerrohr, und die Einführung des Gefässes $C$ liess demnach auch zuerst die Stromstärke durchaus unverändert. Jedoch durfte dabei das Rohr nicht mit den Fingem angefasst werden, sondern es ward nothwendig, es mittels einer Handhabe zu berregen, weil die durch die Finger bewirkte geringe Temperaturerhöhung des Rohres wegen des dadurch verminderten Widerstandes des Flüssigkeitsfadens sofort einen Ausschlag um mehrere Scalentheile herrorbrachte, so dass man sich einer solchen Vorrichtung als eimes höchst empfindlichen Thermoskops bedienen könnte. Wenn aber $C$ eine Zeit lang im Kreise gewesen war und damn plötzlich wieder durch Zurückführung des entsprechenden Endes des Thermometerrohrs nach $B$ daron ausgeschlossen wurde, fand allerdings in einigen Fällen eine geringe Termehrung der Stromstärke statt, die sich jedoch höchstens auf $1 / 300$ belief. Mit frisch rerquickten Drähten aber habe ich auch gesehen, dass bei über 200 Scalentheilen Ablenkung der Faden sich genau an derselben Stelle der Scale wieder einfand, die er mit dem Elektrodenpaar im Kreise zuletzt imne hatte. Die Stromstärke war in diesem Versuche trotz der bedentenden elektromotorischen Kraft, wegen des ungeheuren Widerstandes, nicht viel grösser, als die des Mnskelstromes.

Mit Zinklösung, die mit einem gleichen Tolum Wassers verdünnt worden war, gaben frisch rerquichte Zinkdrähte, die in gesättigter Lösung keine Spur von Schmächnng erzengt hatten, etwa 1/400 Stromabnahme. Dies scheint zwar mit dem zu stimmen, was wir an der SrEmens'schen Wippe mit dem verquickten Zink in verdümnter Zinklösung beobachtet haben (s. [480] oben \$. 65. 66), doch möchte ich vor der Hand nichts darauf geben. Wie dem auch sei, man sieht, dass sich auf diesem Wege, wie mit der Sremens'schen Wippe, die Ladung des rerquickten Zinks in schwefelsaurer Zinkoxydlösung im günstigsten Falle nur eben spurweise darthun lässt.

Als aber die rerquickten Zinkdrähte durch Elektroden aus reinem Zink ersetzt wurden, betrug die Stromschwächung mit der gesättigten Lösung $1 / 30$, mit der rerdünnten, gleichfalls in Uebereinstimmung mit dem an der Sremens'schen Wippe Wahrgenommenen (s. oben S. 66) sogar $1 / 20^{*}$

Jetzt wiederholte ich dieselben Tersuche, sowohl die eben beschriebenen, als den mit dem Trog voll Zwischenplatten, mit Kupferelehtroden in Kupferlösung. Der Tersuch im Troge konnte indess wegen der Ungleichartigkeiten der Platten nur mit so starken Strömen angestellt 
werden, dass gegen die ihnen zu Grunde liegende elektromotorische Kraft die jener Ungleichartigkeiten rerschwand. Es ergab sich, dass bei dieser Art der Prüfung das Kupfer in Kupferlösung ungefähr dasselbe höchst geringe Naass ron Polarisirbarkeit zeigte, wie zuweilen das rerquickte Zink in Zinklösung. Im Troge war die Polarisation unwahmehmbar, mit einem Paar Drahtelektroden betrug sie ungefähr $1 / 500$. Es hat also, wenn man ron den so eben erwähnten Fällen absieht, wo das frisch rerquickte Zink durchaus keine bemerkbare Stromschwächung bewirkte, in der That den Anschein, als ob an der Siemexs'schen und an der PoggendorfF'schen Wippe die Polarisation des Kunfers die des rerquickten Zinks nur deshalb übertroffen habe, weil erstere minder flüchtig sei. Indessen ist es doch unmöglich, dass die elektromotorische Gegenkraft des Kupfers in Kupferlösung während der Dauer des primären Stromes nur etwa $1 / 500$ betrage, und nach dessen Aufhören an der SIEMEss'schen Wippe eine Wirkung erzeuge, der im Mittel eine elektromotorische Kraft ron $1 / 155$, wegen der sofort beginnenden Abgleichung anfangs also noch eine riel bedeutendere, zu Grunde liegen muss. Ich rermuthe deshalb, dass die oben S. 68 bemerkte positive Polarisation des Kupfers in Kupferlösung sich hier in der Weise eingemischt habe, dass die wahrgenommene [481] Wirkung nur der Unterschied der negativen und der positiven Ladung war, während an der SiEvexs'schen Wippe, ganz wie es bei dem käuflichen Zink der Fall ist (s. oben S. 57 . 58), allein die negative Ladung zur Erscheinung kommt.

Nach alledem kann keine Frage mehr sein, welcher Combination wir, um bei thierisch-elehtrischen und bei Reiz-Tersuchen die Polarisation zu rermeiden, den Vorzug zu geben haben werden. Ton dem reinen Zink in Zinklösung kam begreiflich dabei die Rede nicht mehr sein. Was das Kupfer in Kupferlösung betrifft, so wird bei Anwendung grösserer Elektrodenflächen dessen Polarisation zwar auch unmerklich, bei kleineren hat sie sich uns, im geschlossenen primären Kreise, als ron gleicher Ordnung mit der des nicht mehr ganz frisch rerquickten Zinks gezeigt. Abgesehen indess von der Unsicherheit, die noch über diesem letzteren Ergebniss schwebt, rersteht es sich doch ron selber, dass dem rerquickten Zink in Zinklösung der Vorzug gebührt wegen jener wunderbaren Gleichartigkeit, wodurch sich diese Combination vor allen anderen auszeichnet.

Wir haben uns bis jetzt ausschliesslich mit der Beseitigung der an der Grenze der metallischen IIultiplicatorenden und der zuleitenden Flüssigkeit auftretenden elektromotorischen Gegenkraft beschäftigt. Es könnte scheinen, als ob nun auch noch der Uebergangswiderstand eine eben so sorgfältige Berücksichtigung rerlange. Indessen ist zu erwägen, 
dass erstens der Uebergangswiderstand im Allgemeinen mit der Polarisation gleichen Schritt hält, so dass beide gleichzeitig unmerklich werden dürften; zweitens, dass dieser Widerstand gegen den der Muskeln, vollends der Nerren, der Eiweisshäutchen, der übrigen flüssigen Theile des Kreises, endlich des Multiplicatorgewindes, bei Reizversuchen der PFLÜGER'schen Eiweissröhren, ${ }^{1}$ nothwendig rerschwinden müsse.

Worauf die Gleichartigkeit des verquickten Zinks in Zinklösung beruhe, weiss jich nicht. Wo Hr. FARADAY von dem von KEMrP angegebenen und so wichtig gewordenen Kunstgriff handelt, die Zinkplatten der galvanischen Ketten durch [482] Verquickung vor dem örtlichen Angriff der Säure zu schützen, sagt er: „It is probable that the mercury ,acts by bringing the surface, in consequence of its fluidity, into one „uniform condition, and preventing those differences in character between "one spot and another which are necessary for the formation of the "minute voltaic circuits referred to. If any difference does exist at the „first moment, with regard to the proportion of zine and mercury, at ,one spot on the surface, as compared with another, that spot having „the least mercury is first acted on, and, by solution of the zinc, is soon „placed in the same condition as the other parts, and the whole plate "rendered superficially uniform." 2 Diese sinnreiche Betrachtung passt aber schwerlich auf unseren Fall. Zugegeben, dass in den angewandten Zinklösungen jene Ausgleichung der mit rerschiedenen Mengen Zinks und Quecksilbers behafteten Stellen noch möglich sei, würde doch zu erinnern sein, dass gerade in verdünnter Schwefelsäure rerquickte Zinkelektroden ungeheure Ungleichartigkeiten offenbaren; dass man leicht an ihrer Oberfläche Ungleichartigkeiten mittels JÄGER's Verfahren (durch aufgelegtes, mit destillirtem Wasser befeuchtetes Lakmuspapier) entdeckt; ${ }^{3}$ endlich dass, wie oben S. 61.62 berichtet wurde, rerquickte Zinkplatten unter Umständen gleichartig erscheinen, wo Zink und Quecksilber ganz gewiss nicht gleichförmig an ihrer Oberfläche rertheilt sind. Zwei Quecksilberkuppen unter verdünnter Schwefelsäure als Elektroden benutzt, liessen bedentende Ungleichartigkeiten hervortreten.

Ebensowenig weiss ich über die Ursache der Unpolarisirbarkeit unserer Combination etwas beizubringen. Wie wenig zu erwarten dies

1 Untersuchungen über die Physiologie des Electrotonus. Berlin 1859. S. $98 \mathrm{ff}$.

2 Experimental Researches in Electricity. Reprinted from the Philosophical Transactions etc. London 1839. Vol. I. 1. 304. Ser. VIII. 1834. No. 1000; Poggendorff's Annalen u. s. w. 1835. Bd. XXXV. S. 238.

3 Untersuchungen u. s. w. Bd. I. S. 613. 
Verhalten ron rorn herein war, habe ich schon oben S. 45 angedeutet. Da es dennoch stattfindet, so muss man sich vielleicht denken, dass die Quecksilbertheilchen als solche nicht mehr in elektromotorische Wechselwirkung mit dem [483] Wasserstoff zu treten vermögen, sondern nur als Bestandtheile der Atomgruppen von Zinkamalgam. Quecksilber muter verdünnter Schwefelsäure gab an der Sremexs'schen Wippe $\iota=$ $\frac{1}{1 \cdot 3}$. Es ist also nicht daran zu denken, dass die geringe Ladungsfähigkeit des rerquickten Zinks von der Flüssigkeit der Oberfläche herrühre, vollends nicht, da bereits krystallinisch gewordenes Amalgam dieselbe Eigenschaft zeigt. Verquicktes Zink rerhält sich nach J. W. RitTeR's Entdeckung positiv gegen nicht rerquicktes, ${ }^{1}$ und mag deshalb mit Wasserstoff weniger stark elektromotorisch wirken. Wemn dies aber auch, was schwerlich der Fall ist, die Vernichtung der so bedeutenden negatiren Ladungsfähigkeit des rohen Zinks durch die Verquickung ansreichend erklärte, so bliebe noch immer das Räthsel übrig, wie auch die an und für sich so geheimnissvolle positive Polarisirbarkeit zugleich ein Ende nehmen könne.

Es ist klar, dass zum Verständniss dieser Vorgänge ein sehr viel eingehenderes Studium erforderlich wäre. Es müsste die Polarisation jeder einzelnen Elektrode, die Abhängigkeit der Gleichartigkeit und Polarisation von der Concentration der Lösung innerhalb weiterer Grenzen, der Einfluss der Verquickung anf Gleichartigkeit und Polarisation anderer Netalle und rieles Andere erforscht sein, ehe man daran denken könnte, hier zur Einsicht zu gelangen. ${ }^{2}$ Es lag, wie gesagt, nicht in meinem Plane, mich mit der Lösung solcher Aufgaben zu befassen, sondern ich durfte nunmehr durch Auffindung einer unpolarisirbaren und überdies von Natur gleichartigen Combination mein Ziel für erreicht, ja meine Wünsche für übertroffen halten.

Die thierisch-elektrischen und die Reizrersuche werden ron num an eine andere Gestalt annehmen. Jenes Heer ron Schwierigkeiten, welches, wenigstens am Nerren-MInltiplicator, stets noch aus Ungleichartigkeiten auch der am sorgfältigsten behandelten Platinplatten erwächst, und gegen welches ich in früherer Zeit so manchen qualrollen Tag rergeblich gestritten, hatte [484] ich nun freilich schon längst dadurch zu besiegen gelernt, dass ich den Multiplicatorkreis zur Nebenschliessung einer

1 Gilbert's Annalen der Physik. 1804. Bd. XVI. S. 303 ff.

2 [Ueber die bisher bekannt gewordenen Fortsetzungen dieser Untersuchung liefert eine vollständige Uebersicht die kürzlich erschienene kritische Abhandlung von Hrn. W. BeEtz: „Ueber die Electricitätsleitung in Electrolyten“, in den Sitzungsberichten der Münchener Akademie, Mathematisch-physikalische Classe, 1875. S. 59.] 
DanteLL'schen Kette in der Art machte, wie dies oben in Fig. 2 für den die Elektroden enthaltenden Kreis rorgestellt ist, und jeder auftauchenden Ungleichartigkeit sofort mit einer gleichen und entgegengesetzten, dem Daniell mittels einer passenden Länge des Nebenschliessdrahtes entlehnten elektromotorischen Kraft begegnete. Allein viel besser wird es sein, ohne jede Vorbereitung, Vorsichtsmaassregel und Hülfsvorrichtung, ohne Waschen, Ausglühen, Einhüllen in den Fliesspapiermantel, Firnissen, Geschlossenstehenlassen, Compensiren u. s. w., in jedem Augenblick über röllig gleichartige und unter allen Umständen anch gleichartig bleibende Elektroden zu gebieten, die man sich noch dazu, da sie keinen in Betracht kommenden Geldwerth haben, in beliebiger Anzahl verschaffen kamn. Man brancht die Zuleitungsgefässe nicht mehr zum Kreise geschlossen, ja nicht einmal mehr zusammengesetzt zu halten, sondern man hat nur dafür zu sorgen, dass in der Zwischenzeit der Versuche die Lösung in den Bäuschen nicht krystallisire. Die ganze Vorrichtung wird übrigens jetzt passend dahin abzuändern sem, dass die Zuleitungsgefässe selber aus Zink gegossen, auswendig lackirt, inwendig rerquickt, zur Isolirung anf ein paar Glasstreifen gekittet, und ummittelbar mit der Ḱlemmschraube zur Anfnahme der Iultiplicatorenden rersehen werden. Ich habe zur Anfertigung dieser nenen Znleitungsgefässe bereits die Einleitung getroffen.

Ton dieser Seite also werden nun die bisher so beschwerlichen thierisch-elektrischen Versuche plötzlich zu den leichtesten, die es geben kann. Aber durch den Fortfall der Polarisation in irgend in Betracht kommendem Maasse wird jetzt zugleich eine Menge ron Versuchen möglich gemacht, auf deren Ausführung man früher zu verzichten hatte, und eine Menge anderer nimmt eine einfachere Gestalt an, in der sich der den thierischen Erregem zukommende Antheil an der Erscheinung klarer ausspricht als bisher. Der Vorschlag des Hrn. Bewss, hei den thierisch-elektrischen Tersuchen einen Depolarisator nach Art der von Hrn. Becquerei d. V. [485] angegebenen anzuwenden, ${ }^{1}$ ist num überflüssig gemacht. Mit den absolut gleichartigen, unpolarisirbaren rerquickten Zinkelektroden zur Ableitung; mit dem Princip der Nebenleitung zur Erzeugung auf's Feinste abgestufter elektromotorischer Kräfte jeder Ordnung; endlich mit der Spiegelbussole, die, bei gleicher Empfindlichkeit

I Verhandeling over de Galvanisehe Polarisatie met betrekking tot de Leer der dierlijke Eleetrieiteit, ete. Groningen 1858. - VAN DEEN, Vergelijking tussehen het door H. BEINs uitgevonden werktuig tot onderzoek van dierlijke Electrieiteit en den tot hetzelfde doel gebezigden toestel van E. Du Bors-Reymoxd. (SeparatAbdruek.) - Vergl. Becquenel in Amales de Chimie et de Physique. 3 me Série. 1854. T. XIII. p. 389 et suiv. 
mit dem Nerven-Multiplicator (s. oben S. 49.50) keiner schwierigen und vergänglichen Graduirung mehr bedarf: steht jetzt nichts mehr in diesem Gebiete der Ausführung messender Versuche entgegen, und eine neue Bahn wichtiger Untersuchungen ist eröffnet.

Die Erfahrung hat noch zu lehren, welcher Zinklösung bei den thierisch-elektrischen Versuchen der Vorzng zu geben sei. Die gesättigte Chlorzinklösung dürfte, wegen ihrer Wassergier, ihres geringen Leitvermögens, vorzüglich aber deshalb von vorn herein zu verwerfen sein, weil sie nach den Angaben des Hrn. F. Schulze in Rostock, und der Hrn. Barreswil und Rilliet, auf die Cellulose der Bäusche ähnlich wie Schwefelsäure wirken, d. h. sie auflösen würde. $O b$ nicht auch verdünnte Chlorzinklösung bei monatelanger Berührung zuletzt die Consistenz des Papiers zu beeinträchtigen rermöge, ist noch unbekannt. Jedenfalls richtet sich unter diesen Umständen die Aufmerksamkeit zunächst mehr auf die schwefelsaure Zinkoxydlösung, und es würde sich nur noch fragen, ob die gesättigte oder die mit dem gleichen Volum Wassers rerdünnte Lösung für den Gebranch die bessere sei.

Für die Anwendung der letzteren würde sprechen, dass sie erstens die thierischen Theile minder heftig anätzen würde, und dass sie zweitens besser leitet.

[486] In der That erscheint das schlechte Leitrermögen der Zinklösungen überhaupt ${ }^{2}$ hier zuerst als kein ganz ungewichtiger Uebelstand. Zwar nicht so sehr wegen der dadurch bedingten Vermehrung des Widerstandes des Multiplicatorkreises. Demn durch Fortfall der Polarisation wird doch die Stärke wenigstens der dauernden Wirkung der thierischelektrischen Ströme im Multiplicatorkreise sehr erhöht sein. Allein erstens kann man, wie ich gefunden habe, num nicht mehr durch einen neben dem Muskel über die Zuleitungsbäusche gebrückten Schliessungsbausch den Muskelstrom im Multiplicator zum Verschwinden bringen, oder, wie ich es nemne, abblenden, was in vielen Fällen ein nützlicher Kunstgriff ist. Zweitens besitzt Fliesspapier mit Kupferlösung getränkt, wegen ihres geringen Leitrermögens, ein gewisses, wenn auch sehr kleines

1 Journal für praktische Chemie. 1852. Bd. LVI. s. 58.

2 Nach Hrn. E. Becquerel (s. oben S. 42. Anm.) leitet nämlich gesättigte $\mathrm{Na}$ Cl lösung besser als

- gesättigte $\mathrm{Cu} \mathrm{SO}_{4}$ lösung . . . . . . . . . 5.81 mal

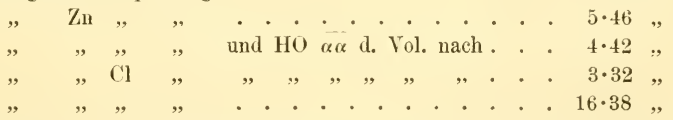

(für $\mathrm{Zn} \mathrm{Cl}$ mit Zugrundelegung meiner oben S. 65 angeführten Bestimmung.) 
Maass imnerer Polarisirbarkeit. ${ }^{1}$ Unzweifelhaft wird ihm ein solches auch mit den Zinklösungen zustehen.

Inzwischen wird man sich, was das Abblenden des Stromes betrifft, nummehr dazu, anstatt des Schliessungsbausches, einer verquickten Zinkplatte bedienen können. In Ansehung des zweiten Punktes ist nicht zu vergessen, dass, um am Nerven-Multiplicator Spuren der inneren Polarisation mit Kupferlösung getränkten Fliesspapieres wahrzunehmen, balkenförmige Bäusche von viel grösserer Länge und viel kleinerem Querschnitt als Zuleitungsbänsche sie darbieten, ${ }^{2}$ dem Strom einer dreissiggliederigen Grove'schen Säule ausgesetzt wurden. Die innere Polarisation dürfte folglich hier ummerklich sein. Ohnehin wird man, [487] bei Anwendung auch der mit verdünnter Zinklösung getränkten Bäusche, die gleichfalls innerlich polarisirbaren Eiweisshäntchen nicht entbehren können. Sollen auch diese Spuren nicht dem thierischen Erreger angehöriger innerer Ladung ans dem Kreise verbannt werden, so bleibt michts übrig, als eine Eimrichtung, ähnlich den von Hrn. Pfuügre angegebenen Eiweissröhren, die in ihrer jetzigen Gestalt für die Ableitung der thierischelektrischen Ströme einen viel zu grossen Widerstand haben. Und selbst alsdann wird man noch nicht aller Ladung ausserhalb des thierischen Erregers ledig sein, da an der Grenze der Zinklösung und des Eiweisses unzweifelhaft eine, wemn anch ihrer Richtung und Grösse nach noch nicht erforschte Polarisation stattfindet. ${ }^{3}$

Da nun zudem der Unterschied zwischen dem Leitrermögen der gesättigten und der verdünnten Lösung anch nur klein ist, so wird ratürlich Alles darauf ankommen, ob letztere gleich ersterer dauernd und sicher den Vortheil der vollkommenen Gleichartigkeit der ableitenden Vorrichtung gewähre. Hierüber zu urtheilen bin ich nach meinen jetzigen Erfahrungen noch nicht im Stande. Thatsache ist nur, dass von zwei verquickten Zinkplatten, deren eine in gesïttigter, die andere in verdünnter Lösung steht, während ein mit verdünnter Lösung gefülltes, mit Goldschlägerhant überbundenes Schliessungsrohr die Verbindung herstellt, letztere sich so stark positir gegen erstere zeigt, dass die Nadel des Nerven-Ifultiplicators dadurch dauernd an der Hemmung gehalten wird. Danach ist zu besorgen, dass anch schon solche Unterschiede in der Concentration der in beiden Zuleitungsgefässen enthaltenen Lösungen, wie sie sich im Lanfe der Versuche einstellen können, bereits merklich elektromotorisch wirken dürften. In diesem Falle würde natürlich, trotz

1 S. oben Abh. II. S. 16. 22.

2 S. oben Abh. I. S. 7.

3 S. oben Abh. I. S. 1. 
ihrem geringeren Leitvermögen, der gesättigten Lösung der Vorzug zu schenken sein, welche nur durch Verdünnung, wozu jkeine Gelegenheit ist, nicht aber durch Verdunstung, ungleichartig werden kann. Jenen Uebelstand, der bei der gesättigten Kochsalzlösung so lästig fällt, nämlich das Effloresciren des Salzes, ${ }^{1}$ hat man [488] hier nicht zu fürchten, da einmal, wie bemerkt, nicht mehr nöthig sein wird, die Vorrichtung dauernd zusammengesetzt zu baltén, und da für's zweite die gesättigte schwefelsaure Zinkoxydlösung sehr viel weniger als die Kochsalzlösung efflorescirt.

1 Mit Kochsalz ist hier das käufliche Salz der Königl. Preussischen Salinen gemeint, wie es vor der Erbohrung der Stassfurter Steinsalzlager im Handel vorkam. Hr. Prof. Funke hat mir mitgetheilt, dass nach seinen Erfahrungen bei thierischelektrischen Versuchen, die nach meiner Vorschrift angestellt wurden, chemisch reine Chlornatriumlösung jene lästige Erscheinung nicht zeigte. Wie sich Lösung des Stassfurter Steinsalzes in dieser Beziehung verhalte, weiss ich noch nicht. 
V.

\section{Ueber den secundären Widerstand, ein durch den Strom bewirktes Widerstandsphänomen an fenchten porösen Körpern.}

(Gelesen in dẽr Gesammtsitzung der Königl. Akademie der Wissenschaften zu Berlin am 20. December 1860. $)^{1}$

\section{§. 1. Einleitung.}

In meiner ersten Mittheilung über innere Polarisation poröser, nit Elektrolyten getränkter Halbleiter ${ }^{2}$ habe ich zweifelhaft gelassen, ob diese Polarisation im Kreise der Säule selber, die sie hervorrief, mit gewöhnlichen Hülfsmitteln bemerkt werden könne. Ich hatte damals besondere Beobachtungen über den Gang des ursprünglichen Stromes während des Polarisirens, nach dem Entladen u. s. f. noch nicht angestellt. Meist hielt ich den Strom nicht länger geschlossen als nöthig war um zu entscheiden, ob der ihm ausgesetzte feuchte poröse Körper imnere Polarisation in bemerkbarem Grade annehme oder nicht, wozu wenige Minnten ausreichten. Anch befand sich im ursprünglichen Kreise, zur Aufsicht über die Säule, nur ein Vertical-Galvanoskop von Siemens und HaLske, wie sie in Telegraphenbureaus angewendet werden. Allein mir war unter diesen Umständen bereits eine räthselhafte Erscheinung aufgestossen, die zu weiteren Nachforschungen aufforderte. Es zeigte sich nämlich häufig, bei Gegenwart der innerlich polarisirbaren Körper im Ḱreise, dass der ursprüngliche Strom, trotz den sorgfältigsten Vorkehrungen, nicht beständig blieb. Sobald ich die Kette irgend länger geschlossen liess, sank die Ablenkung an dem Vertical-Galvanoskop um einen oft sehr ansehnlichen Bruchtheil, näherte sich aber wieder ihrem ursprünglichen Werthe, wemn die Kette einige Zeit uffen gehalten wurde. Die Schwächung des Stromes, die bei lüngerer Schliess- [847] ung eintrat, war meist riel zu beträchtlich, um sie auf die elektromotorische Gegenkraft der inneren Polarisation

I Monatsberichte u. s. w. 1860. S. 816 ; - Auch abgedruckt in MoLeschotт's Untersuchungen u, s. w, 1862 . Bd. VIII. S. 354.

2 S. oben S, 13. Abh. II. 
beziehen zu kömmen, wollte man nicht dieser Kraft, während der Daner des ursprünghichen Stromes, eine beispiellose Grösse, unł nach dessen Aufhören, eine ebenso beispiellose Flüchtigkeit beimessen. Und duch war nichts leichter, als sich daron zu überzengen, dass die Unbeständigkeit des Stromes allein von Gegenwart der feuchten porösen Körper im Kreise herrührte. Wurden die mit gesättigter schwefelsaurer Kupferoxydlösung gefüllten Zuleitungsgefässe, worin die Kupferelektroden der Säule tauchten, unmittelbar durch ein mit derselben Lösung gefülltes Schliessungsrohr, oder die mit jener Lösung getränkten Zuleitungsbäusche durch einen eben solchen Śchliessungsbausch verbunden, so sah man die Nadel, so lange und so genau als nur zu erwarten war, auf dem Theilstrich verharren, auf den sie sich nach ihren ersten Schwingungen eingestellt hatte.

Um diesen Umstand aufzuklären und um zugleich der immeren Polarisation in dem ursprünglichen Kreise selber nachzugehen, wurde jetzt in diesen Kreis, anstatt des Vertical-Galvanoskops, die früher ${ }^{1}$ erwähnte Wiedemans'sche Bussole mit magnetischem Spiegel, dämpfender Kupferhülse und verschiebbaren Rollen aufgenommen. Diese Art von Bussolen eignet sich, der darin stattfindenden starken Dämpfung halber, ganz besonders dazu, den Gang eines unbeständigen Stromes zu verfolgen, während der grosse Spielraum ihrer Empfindlichkeit hier gleichfalls von Nutzen wird. Auch ist gelegenthich ron grossem Tortheil, dass man beiderseits rom Spiegel eine Rolle, ja, wemn man will, mehrere Rollen hintereinander anbringen, und so, ohne das Auge rom Fernrohr zu wenden, mittels einer passenden Schaltung abwechselnd den Strömungsrorgang in zweien, beziehlich mehreren Kreisen überwachen kann. Die Bussole war bei diesen Versuchen gewöhnlich mit nur wenigen Windungen (53 oder 106) versehen. Ein PoHL'scher Stronwender wurde ferner so angebracht, dass er die Richtung des Stromes in den Zuleitungsgefässen und den dazwischen befindlichen feuchten porösen Körpern umkehrte, während sie in der Bussole die- $[8+8]$ selbe blieb. Er war an den Tisch befestigt, und seine Wippe drehte sich, wie stets an meinen Stromwendern, um eine feste Achse, so dass die Zeit zwischen dem Oeflnen des Stromes in der einen und dessen ernentem Schliessen in der anderen Richtung nicht nur durch passende Anfüllung der Quecksilbernäpfe, sondern auch durch rasche Bewegung der Wippe möglichst klein gemacht werden konnte. Bei der langen Dauer vieler der folgenden Versuche war es nothwendig, sich überzengen zu können, dass die Säule an sich beständig geblieben sei. Dies geschah mit Hülfe einer Schaltung, welche an Stelle der Zuleitungsgefässe und des zwischen ihnen befindlichen feuchten porösen

1 S. oben, Abh. IV. S. 49.

L. du Bois-Reymond, Ges. Abh. I. 
Körpers, enen solchen metallischen Widerstand in den Kreis der Säule und der Bussole und zugleich eine solehe Nebenschliessung zu letzterer anbrachte, dass die Ablenkung eine angemessene Grösse besass.

Mit diesen vollkommneren Mitteln bestätigte ich nun zunächst die Thatsache, dass bei Abwesenheit eines feuchten porösen Körpers im Kreise, wenn entweder die Bäusche einander berührten, oder ein Schliessungsrohr die Züleitungsgefässe verband, der Strom ganz beständig blieb. Nicht nur sank die Ablenkung nicht, auch bei noch so langer Dauer der Schliessung, innerhalb der durch die Natur der Dinge gesteckten Grenzen, sondern man sah sie anfangs sogar bis zu einem gewissen Punkte wachsen, unstreitig in Folge der mit der Hand fühlbaren Erwärmung des Schliessungs-Rohres oder -Bausches. Wurde die Wippe umgelegt, so sah man den Spiegel um ein paar Scalentheile zurüickweichen, und dann äusserst nahe wieder seine vorige Stellung eimnehmen. Kupfer in gesiittigter schwefelsaurer Kupferoxydlösung ist zwar der Polarisation nicht ganz unfähig; ${ }^{1}$ allein diese Polarisation ist doch kleiner, als dass der

Fig. 4 .

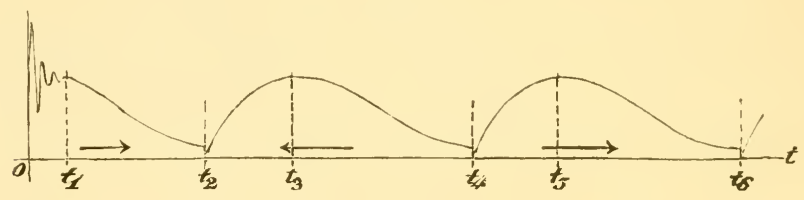

daraus entspringende Zuwachs an elektromotorischer Kraft in den ersten Augenblicken nach der Umkehr des Stromes in den Zuleitungsgefässen, selbst bei nur Einer Grove'schen Kette im Kreise, vermocht hätte, den Ausfall an ablenkenden Kräften während des Umlegens der Wippe zu decken. geschweige zu über- [849] wiegen.

Um die Erscheinung. um die es sich im Folgenden handeln wird, sofort in dentlichster Ausprägung und in ihrer ganzen Grösse kennen zu lernen, denke man sich jetzt zwischen die Zuleitungsbäusche ein Prisma aus hart gesottenem Eiweiss ${ }^{2}$ von den üblichen Mlaassen ${ }^{3}$ gebracht, und eine zwanziggliederige Grove'sche Säule dadurch geschlossen. Fig. 4 ist bestimmnt, den Gang der Erscheinungen unter diesen Umständen zu ver-

1 S. oben, Abh. IV. S. 56.

2 Ieh verschaffe mir ein solehes, indem ich Eiweiss in geölten Reagirgläsern im Wasserbade zum Gerinnen bringe, den Boden des Glases zertrümmere, und den Eiweisseylinder mittelst eines Stempels ausstosse. (Vgl. oben Abh. II. S. 22. 23.)

3 s. oben. Abh. II. S. 17. 
sinnlichen. Die Abscissenaxe $0 t$ stellt darin die Zeit vor, die Ordinaten bedeuten in Scalentheilen ausgedrückte, der Stromstärke proportionale Spiegelablenkungen.

Bei der Abscisse Null wird die Kette geschlossen. Nachdem der Spiegel sich beruhigt hat, erscheint die Ablenkung in den ersten Augenblicken manchmal beständig, anderemale wächst sie sogar, meist jedoch findet man sie sogleich im Sinken begriffen. Dies Sinken ist entweder anfangs noch langsam, und wird erst mit der Zeit geschwinder, oder es geht gleich von vorn herein mit reissender Schnelle vor sich. Allmählich indess wird in allen Fällen das Sinken langsamer, und endlich, oft erst nach $10-20$ und noch mehr Mimuten ist eine beständige Ablenkung erreicht. Jetzt ist von der ursprünglichen Stromstärke, wie man sie aus dem ersten Hin- und Hergang des Scalenbildes folgern kamm, oft nicht mehr als der zehnte Theil übrig, wie man bei $t_{2}$ in der Figur ungefähr sieht.

Wird nun die Wippe umgelegt, wie der Pfeil in der Figur andeutet, so könnte man erwarten, einen mächtigen Aus- [850] schlag erfolgen zu sehen, da es scheint als habe sich in dem Ḱreise eine bedeutende elektromotorische Gegenkraft entwickelt. Man sagt sich indessen schon, wie umwahrscheiulich es sei, dass diese in einer $50^{\mathrm{mm}}$ langen Strecke geronnenen Eiweisses der Kraft von achtzehn Grove'sehen Gliedern gleichkommen solle. Der Versuch liefert demn auch ein ganz anderes Ergebniss. Man beobachtet nämlich im Augenblick des Umlegens nur einen kleinen negativen Ausschlag, der von dem Ausfall an ablenkenden Kräften während des Unlegens herrührt (s. die Figur bei $t_{2}$ ). Ton der inneren Pularisation wird also, trotz der langen Dauer der Durchströmung, nichts bemerkbar, was sich leicht erklärt, wenn man die grosse elektromotorische Krraft der Säule erwägt. Unmittelbar daranf aber ist die Ablenkung in langsamem Wachsen begriffen, der Art, dass, wenn die ursprüngliche Ablenkung einige Hundert Scalentheile betrug, in der Secunde anfangs etwa 10, zuletzt nur noch in der Minute so viel Scalentheile am Faden vorbeiziehen. In Folge dieses Wachsens erreicht die Ablenkung bei $t_{3}$ zuletzt ungefähr die nämliche Grösse wieder, die sie bei $t_{1}$, unmittelbar nach der ersten Schliessung des Kreises, besass. Allein abermals verweilt sie nur einen Augenblick auf dieser Höhe. Sofort beginnt das Sinken von Neuem, und findet zuerst langsam, dann schnell, damn wieder langsam statt, bis abermals die Ablenkung (bei $t_{4}$ ) einen unteren Grenzwerth erreicht hat, wo dem abermaliges Umlegen abermals langsames Wachsen der Stromstärke hervorruft. Und so kamm man, so oft als die Natur der Dinge es zulässt, diesen Wechsel der Erscheinungen beobachten. Ihre nähere Ursache ist nicht schwer auzugeben. Was das in einigen 
Fällen anfänglich bemerkbare Steigen der Ablenkung betrifft, welches sich andere Male nur als eine Verzögerung des bald überhànd nehmenden Sinkens kundgiebt, so ist es wohl einerlei mit dem Steigen, welches man auch ohne das Eiweissprisma, beim Schliessen des Kreises durch ein mit der Kupferlösung gefülltes Rohr, wahrnimmt, $d$. h. es ist auf die Verminderung des Widerstandes der Elektrolyte durch Erwärmung zu schieben. Das darauf folgende Sinken aber, die Erscheinung also, die uns ursprünglich aufgefallen ist, kann von nichts herrühren, als ron einem Widerstand, den der Strom in [851] der einen Richtung in dem Eiweiss entwickelt und den der Strom in der anderen Richtung wieder aufhebt. Dies folgt unwiderleglich aus der Wirkung des Umlegens der Wippe. Jenes so höchst sonderbare langsame Wiederanwachsen der Stromstärke lässt sich nur auf diese Art begreifen, während, wie schon bemerkt, der Erfolg im Fall einer elektromotorischen Gegenkraft, die den Grund des Sinkens enthielte, ein ganz anderer sein müsste.

Wir wollen diesen durch den Strom erzengten Widerstand der Kürze halber den secundären Widerstand nemnen, womit gar nichts über seine weitere Ursache ausgesagt, sondern nur sein Auftreten unter denselben Umständen angedeutet wird, unter welchen in manchen feuchten porösen Körpern secundär-elektromotorische Kräfte entstehen. Man begreift, ron welcher Wichtigkeit diese Erscheinung im Gebiete der Elektrophysiologie werden kann, da sie, unter gewissen Voranssetzungen, die Möglichkeit beständiger Ströme in den thierisch-elektrischen und in den elektrischen Reiz-Versuchen ausschliessen würde. Ich habe mich daher genöthigt gesehen, wie schon die Polarisation an der Grenze der Elektrolyte und die innere Polarisation der fenchten porösen Halbleiter, auch noch den secundären Widerstand, soweit es für diesen Zweck erforderlich war, zu ergründen: ein Geschäft, welches sich leiler als eines der schwierigsten und, wegen der Dauer und Einförmigkeit der Versuche, auch der mühseligsten unter allen erwies, die mir im Lauf meiner Untersuchungen zugefallen sind. Nur die praktische Bedentung der schliesslich hier aufgedeckten, an sich sehr unscheinbaren Thatsachen für die Elektrophysiologie kann mich mit den Opfern an Zeit und an Arbeitskraft, die ich diesem widerspenstigen Gegenstande habe bringen müssen, etwas aussöhnen.

§. II. Von den feuchten porösen Körpern, welche secundären Widerstand zeigen.

Wir beginnen damit, uns eine Uebersicht über die feuchten porösen Körper zu verschaffen, die den secundären Widerstand zeigen. Den zu untersuchenden Körpern wurde die Ge- [852] stalt eines Prisma's, wo 
es anging, von den schon erwähnten Maassen (s. oben S. 17) ertheilt. Dies Prisma wurde zwischen die mit schwefelsaurer Kupferoxydlösung getränkten Zuleitungsbänsche gebracht, und ron Grundfläche zu Grundfläche dem Strome der zwanziggliederigen Grove'schen Säule ausgesetzt. Auf die Fähigkeit der Substanz, secundären Widerstand anzunehmen, wurde stets erst geschlossen, wenn das charakteristische langsame Wachsen der Stromstärke nach dem Umlegen der Wippe mindestens eimmal bei jeder Richtung des Stromes beobachtet worden war.

Der Gesichtspunkt, der sich hier für die Untersuchung darbietet, ist der, ob sich eine Beziehung feststellen lasse zwischen der Empfänglichkeit der Körper für den secundären Widerstand und der für die innere Polarisation, oder ob die beiden Erscheinungen ganz gleichgültig neben einander her gehen. Wir schliessen uns demgemäss, bei der jetzt vorzunehmenden Musterung feuchter poröser Körper, der Reihenfolge an, welche sich uns bei Erforschung der immeren Polarisation an die Hand gegeben hat. Gleich beim ersten Schritte findet sich, dass zwischen dem secundären Widerstande und der imneren Polarisation vermuthlich gar kein Verhältniss besteht.

I. Unorganische Körper. Kreide und Bimsstein zwar, lange in destillirtem Wasser gesotten, zeigten den secundären Widerstand spurweise. Modellirthon dagegen, welcher gleichfalls innerlich polarisirbar ist, liess nichts davon wahrnehmen, wie lange auch Stäbe von den verschiedensten Maassverhältnissen dem Strom ausgesetzt blieben. Quarzsand oder Schwefelblumen, mit Wasser zu einem Brei angemacht, geben keine innere Polarisation, und können grundsätzlich keine geben, weil das Verhältniss der Leitungsfähigkeit des porösen Gerüstes zu der des Elektrolyten ein zu ungünstiges ist. Dies gilt namentlich für den Schwefelbrei, der lebhaft sauer (von Schwefelsäure) reagirte, und deshalb auch sehr viel besser leitete als das Wasser, womit er angerieben wurde. Dennoch liessen diese Körper, in Röhren gestopft, deutlich secundären Widerstand erkennen. Ja der Quarzsand fuhr fort dies zu thum, selbst als ich ihn, statt [853] mit Wasser, mit verdünnter Schwefelsäure ${ }^{1}$ zu einem Brei anrührte. Hingegen mit einem Brei aus dem geschlämmten Sande der Königl. Porzellan-Manufactur ${ }^{2}$ und destillirtem Wasser ward kein secundärer Widerstand beobachtet.

II. Organische, nicht organisirte Körper. Gleich dem hartgesottenen Eiweiss, von dem bereits die Rede war, verhielt sich auch der durch Schlagen des Rinderblutes erhaltene Faserstoff, und der Blutkuchen

$1 \mathrm{sO}_{4} \mathrm{H}: \mathrm{HO}:: 1$ : 19 und :: 1 : s dem Volum nach.

2 S. oben, Abh. II. S. 18. 
rom nämlichen Thiere, sowie erstarrter Leim, dieser jedoch nur in gewissen Fällen, deren Bedingungen mir nicht klar geworden sind. Blutkuchen und Leim hatten keine immere Polarisation gegeben. Anch die Speckhant ron Pferdeblut zeigte secundären Widerstand.

Ein sonderbares Verhalten war das der Seife. Um regelmässige Stromwirkungen durch Seife hindurch zu erzielen, ward es nöthig, Bögen daraus zu schnitzen und deren Enden in die Kupferlösung der Zuleitungsgefässe zu tauchen. Beim Einklemmen von Prismen aus Seife zwischen die Zuleitungsbäusche entstanden nämlich stets Störmgen, durch, wie es schien, sprungweise Veränderung des Widerstandes der Berührungsstellen der Seife mit den Bäuschen. Bei der angegebenen Anordnung sieht man die Stronıstärke schnell um einen sehr ansehnlichen Bruchtheil abnehmen. Legt man die Wippe um, so erfolgt ein positiver Ausschlag, so lebhaft als ob es sich um Polarisation handelte, und ohne dass sich danach langsanies Wachsen einstellte. Nan hat sich also wohl rorzustellen, dass unter dem Einfluss des umgekehrten Stromes der secundäre Widerstand der Seife in einem Zeitraum schwinde, der kleiner ist als die Schwingungsdauer des Spiegels, da man der inneren Polarisation der Seife im ursprünglichen Krreise nur ungem die elektromotorische Kraft von vielen Grove'schen Gliedern, und zugleich eine solche Flüchtigkeit zuschreiben wird, dass daraus erklärlich würde, weshalb nach Entfermung aus dem ursprünglichen Kreise die Seife keine ungewöhnlich starke imnere Polarisation zeigt. [854]

III. Organisirte Pflanzentheile. Prismen geschnitten aus Kartoffeln, Mohrrüben, Petersilienwurzeln, Aepfeln, Birnen, der saftige Stiel von Begonien, zeigten die Erscheinmg in sehr ansgesprochener Weise. Hinder schön trat sie an gesottenen Hölzern, Eichen-, Kíen-, MahagonyHolz, hervor, und noch weniger deutlich an einem in vollem Safte stehenden holzigen Zweige des Zuckerahorns, obschon solche Zweige gerade die heftigste imere Polarisation geben, die sich denn anch hier wirklich im ursprünglichen Kreise durch einen kleinen positiven Ausschlag beim Umlegen der Wippe bemerklich machte.

Mit destillirtem oder mit Brumnen-Wasser getränkte balkenförmige Fliesspapierbänsche nehmen secundären Widerstand in geringem Grade an. Tränkt man solche Bäusche mit der gesättigten Lösung von schwefelsaurem Zinkoxyd, schwefelsamem Natron, Alaun, Chlornatrium, Chlorammonium, Quecksilberchlorid, oder mit käuflicher Kaliḥ̣dratlösung, so wird auch beim längsten Durchströmen und bei irgend welchen Maassrerhältnissen der Bäusche kein secundärer Widerstand bemerkbar, so wenig als wären sie mit der Kupferlösung der Zuleitungshäusche selber getränkt (s. oben s. s1). Denselhen Gegensatz im Verhalten des 
Fhesspapiers, je nachdem es mit Wasser oder mit dergleichen Lösungen getränkt wird, haben wir in Bezug auf innere Polarisation beobachtet. Allein diese Uebereinstimmung ist nicht durchgreifend. Tränkt man nämlich das Fliesspapier mit verdünnter Schwefel- oder Salpetersäure, wodurch es jede Spur innerer Polarisirbarkeit einbüsst, so ist der secundäre Widerstand gleichwohl sehr deutlich wahrnehmbar. Ausnehmend stark erscheint er beim Tränken des Papiers mit neutraler chromsaurer Kalilösung, wobei an der Grenze der Kupferlösung ein brauner Niederschlag, wie mir Hr. Rammexsberg sagt, von basisch chromsaurem Kupferoxyd entsteht.

IV. Thierische Gewebe. Die Versuche wurden an frischen Gewebetheilen von Rindern oder Kälbern angestellt. Als Vertreter des Knochengewebes bei Versuchen dieser Art ist am bequemsten ein Stück Rippe, des Knorpelgewebes ein Stück Rippenknorpel, des Sehnengewebes eine der Beugesehnen an der Mittelhand, des elastischen Gewebes das Nackenband, der Nerven ein Stück Rückenmark. Ausserdem wurden geprüft [855] Streifen der Haut und prismatische Stücke Muskelfleisch, letztere sowohl roh als gekocht, und sowohl in der Faserrichtung als senkrecht darauf. Alle diese Theile zeigen die oben am hartgesottenen Eiweiss beobachteten Erscheinungen auf's Dentlichste ausgeprägt und im grössten Maassstabe; mit Ausnahme des Knochens, der nur damn eine sichere Spur secundären Widerstandes zu entfalten scheint, wemn er ein mehr schwammiges Gefüge besitzt.

Diese Versuchsreihe genügt um zweierlei darzuthum, 1. dass die Fähigkeit, secundären Widerstand anzunehmen, den feuchten porösen Körpern sehr allgemein zukomme, 2. dass, wie schon bemerkt, keine Beziehung zwischen ihr und der inneren Polarisation obwalte.

\section{§. III. Vom äusseren secundären Widerstande.}

Wir wollen jetzt den Versuch machen, in die Natur des secundären Widerstandes etwas tiefer einzudringen. Im Folgenden sollen, der Kürze halber, die Hälfte und das Ende des feuchten porösen Körpers, wo der Strom, ferner der Bausch, durch den er eintritt, die Eintrittshälfte, das Eintrittsende, der Eintrittsbausch, die entsprechenden Theile der anderen Seite die Austrittshälfte, das Austrittsende, der Austrittsbauseh genannt werden.

Es bietet sich vor Allem die Frage dar, wo der Sitz des secundären Widerstandes sei. Ist es, was jetzt kaum wahrscheinlich däucht, wie bei der inneren Polarisation, jeder durchströnte Querschnitt des porösen Körpers? Oder sind es nicht vielmehr, wie bei der Polarisation an der 
Grenze ungleichartiger Elektrolyte, die Berührungsstellen dieses Körpers mit den Zuleitungsbäuschen?

Es ist, wenigstens in allen von mir geprüften Fällen, leicht sich zu überzengen, dass das letztere, wemn auch rielleicht nicht ausschliesslich, doch in überwiegendem Maasse stattfinde, und dass namentlich das Eintrittsende unstreitig den bei weitem grössten Theil des secundären Widerstandes beherberge. Hat man den secundären Widerstand z. B. in einem Eiweissprisma (s, oben S. 82) sich entwickeln lassen, schneidet man das Prisma in der Mitte quer durch, und prüft man [856] die beiden Hälften einzeln auf ihren Widerstand, so zeigt die Eintrittshälfte einen viel grösseren Widerstand als die Austrittshälfte. Schneidet man ron dem Austrittsende ein Stück ron einigen Millimetern Länge ab, während das Eintrittsende an dem entsprechenden Bausch möglichst unverrückt liegen bleibt, so bleibt die Stromstärke nahe dieselbe. Sie erscheint nur vorübergehend sowohl als danernd etwas gewachsen, das erstere, weil während der zum Abschneiden erforderlichen Zeit ein geringer Theil des secundären Widerstandes sich zerstreut hat, das letztere wegen der Verkürzung des Eiweissprisma's, als des am meisten widerstehenden Theiles des Kreises. Schneidet man aber ein gleich langes Stück rom Eintrittsende ab, so erreicht die Stromstärke plötzlich ihre ursprüngliche Grösse ungefähr wieder, und es ist klar, dass der hauptsächlichste Theil des secundären Widerstandes beseitigt ist, demn das Sinken begimnt ron Neuem ganz als ob der Kreis zum erstemmal geschlossen würde, oder als ob der secundäre Widerstand in Folge des Umlegens der Wippe geschwunden wäre. Sogar wenn wirklich in Folge des Umlegens der Wippe der secundäre Widerstand vollständig aufgehoben scheint und das Sinken eben wieder beginnen will, erhält man durch Abschneiden des Eintrittsendes noch eine ansehnliche Verstärkung des Stromes. Bringt man, an Stelle des rom Eintrittsende befreiten Prisma's, dies abgeschnittene Ende selber zwischen die Zuleitungsbäusche, so zeigt sich, dass es den Strom fast ebenso sehr schwächt, als das ganze noch damit versehene Prisma that. Dass durch die blosse Berührung der Zuleitungsbäusche mit den Enden des Prisma's ohne Mitwirkung des Stromes, nichts dem secundären Widerstande Aehnliches herbeigeführt werde, versteht sich aus mehrfachen Gründen von selbst, und wird durch die Erfahrung bestätigt.

Hat man, anstatt den Grunitlächen des Eiweissprisma's die Zuleitungsbänsche, zweien Punkten der Seitenflächen des Prisma's Keilbänsche ${ }^{1}$

1 Die Keilbäusche haben schon in frïheren Mittheilungen (S. oben Abh. II. S. 15 ; - Abh. IIl. S. 34) eine thnsehnliche Rolle gespielt, und ihre Bedeutung in dieser Abhandlung und in einigen folgenden wird so gross, dass ich nicht länger 
angelegt, und rückt man, nach entwickel- [857] tem secundären Widerstande, den Austrittsbausch von der Stelle, so findet keine bemerkenswerthe Veränderung der Stromstärke statt. Dagegen erscheint der secundäre Widerstand alsbald beseitigt, und das Sinken beginnt ron Neuem, wenn man den Eintrittsbausch einer neuen stelle anlegt. Innerhalb gewisser Grenzen, die ron dem Verhältniss des Widerstandes der Eiweissstrecke zwischen den Keilbäuschen zum Widerstande des übrigen Krreises abhangen, ist es dabei gleichgültig, ob die neue Stelle, der man den Ausoder Eintrittsbausch anlegt, nach aussen oder nach innen liegt, d. h. ob man die Eiweissstrecke zwischen den Keilbäuschen verlängert oder verkürzt.

Durch ähnliche Versuche habe ich mich überzeugt, dass auch beim Leim und der Seife; beim Knorpel, der Haut und dem Mnskelfleisch des Rindes; beim Gewebe der Kartoffel und der Birne; endlich bei den mit verdümnter Schwefelsäure oder [\$58] mit gesättigter chromsaurer Kalilösung getränkten Büuschen das Eintrittsende der vornehmste Sitz des secundären Widerstandes ist. Es kann sich also nur noch darum laandeln, ob, wie es oft den Anschein hat, hier wirklich der ganze secundäre Widerstand hause, so dass er nur ein äusserer sein würde, oder ob ein Theil daron vielleicht auch noch über das Imnere des feuchten porösen Körpers verbreitet sei.

zögern darf, sie dem Leser zu versinnlichen. Man sieht in Fig. 5 einen Keilbausch einem gewöhnlichen Zuleitungsbausch aufsitzen. Er ist daran befestigt mittels eines

Fig. 5.

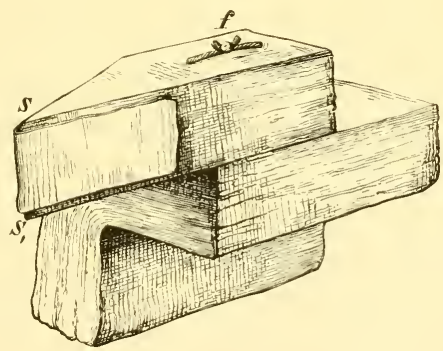

Fadens, den man in $f$ unterscheidet, und der durch zwei den Keil- und Zuleitungsbausch durchbohrende Löcher geführt ist. Die etwa $15 \mathrm{~mm}$ lange Schneide des Keilbausches ss, ist mit einem Eiweisshäutchen bekleidet vorgestellt. Damit dies in der dadurch bedingten scharfen Krümmung verharre, muss es den Seiten des Keils in einiger Länge auhaften. Ich pflege die Eiweisshäutehen für diesen Zweck $40 \mathrm{~mm}$ lang zu schneiden. 


\section{§. IV. Tom inneren secundären Widerstande.}

Um hierüber zu entscheiden, wollen wir uns zunächst an zwei dergleichen Körper heften, welche beide den Vortheil bieten, dass man sie sich jederzeit leicht von wesentlich gleicher Beschaffenheit und in passender Gestalt rerschaffen kann; an das hartgesottene Eiweiss, welches uns schon vorher als Typus eines des secundären Widerstandes fähigen Körpers gedient hat, und an das Gewebe der Kartoffel. Letzteres kommt zwar dem Eiweiss an secundärem Widerstande nicht gleich, da die Stärke des Stromes damit nur auf etwa $1 / 3$ ihres ursprünglichen Werthes sinkt; die Folge wird aber lehren, dass die Wahl eines Pflanzengewebes als zweiten Vertreters der mit secundärem Widerstande behafteten Körper hier von besunderer Bedentung ist.

Ich verfuhr nummehr folgendermaassen. Den Seiten des wie gewöhnlich von Grundfläche zu Grundfläche durchströmten Prisma's legte ich mit gesättigter schwefelsaurer Zinkoxydlösung getränkte und mit doppelten Eiweisshäutchen bekleidete Keilbäusche in solcher Entfermung ron den Enden an, dass der besondere Torgang, dessen Sitz das Eintrittsende ist (s. unten §. VII), sich nicht bis zwischen ihre Schneiden erstreckte. Die Keilbäusche sassen den mit der nämlichen Flüssigkeit getränkten Zuleitungsbäuschen eines Paares meiner neuen Zuleitumgsgefässe aus verquicktem Zink ${ }^{1}$ auf, welche mit einer DaxisuL'schen Kette rerbunden waren. Die Grove'sche Säule soll hinfort die Hauptkette, ihr Strom der Hauptstrom, dessen Kreis der Hanptkreis, die Dantell'sche Kette die Hülfskette, ihr Strom der Hülfsstrom, dessen Kreis der Hülfskreis heissen. [859] In dem Krreise der Hauptkette befand sich die eine, in dem der Hülfskette die andere der beiden verschiebbaren Rollen der Wredemann'schen Bussole, beide in passendem Abstande rom Spiegel, letztere gemeiniglich ron 3000, manchmal von 6000 Windungen. Ich beobachtete nun zuerst bei offener Hauptkette die Stärke des Hülfsstromes bei dem ursprünglichen Zustande des Eiweisses oder des Kartoffelgewelbes. Dann schloss ich, bei geöffneter Hülfskette, die Hauptkette, liess den secundären Widerstand sich entwickeln, und beobachtete abermals, bei geöffneter Hauptkette, die Stärke des Hülfsstromes. Damn legte ich die Wippe des Hauptstromes um, liess den secundären Widerstand, unter dem Einfluss der neuen Stromrichtung, sich zerstrenen, öffnete die Hauptkette im Angenblick, wo das Sinken sich wieder einstellte, las abermals die Stärke des Hülfsstromes ah, n. s. f. Mit einem Worte, ich

1 Vergl. oben, Abh. IV. S. 76. Sie sollen nächstens beschrieben und abgebildet werden. (S. unten, Abh. VIII. §. III.) 
prüfte jedesmal mittels des durch das Prisma, mit Ansschluss des Eintrittsendes, hindurchgesandten Stromes der Hülfskette, die Veränderungen des Widerstandes, welche etwa darin durch den Hauptstrom hervorgerufen waren.

Bei dieser Versuchsweise zeigt sich, dass der Hülfsstrom, in kleinerem Naassstabe zwar, jedoch vollkommen regelmässig und deutlich, die Schwankungen mitmacht, denen der Hauptstrom unterliegt. Ist der Hauptstrom, in Folge der Entwickelung des secundären Widerstandes, gesunken, so ist anch der Hülfsstrom klein; hat der Hauptstrom, in Folge der Zerstreuung des secundären Widerstandes durch den umgekehrten Strom. seine ursprüngliche Grösse wieder erreicht, so ist auch der Hülfsstrom gross. Es hat also den Anschein, als gebe es, ausser dem an dem Eintrittsende sich entwickelnden äusseren secundären Widerstande, wirklich noch einen inneren secundären Widerstand, der seinen Sitz in jedem durchströmten Querschnitt des Prisma's habe. Es fragt sich indess noch, ab es nicht möglich sei, diesen inneren secundären Widerstand auf bereits bekannte Ursachen zurückzuführen.

Vor Allem sei bemerkt, dass nicht daran zu denken ist, die Schwankungen des Hülfsstromes alozuleiten rom Hereinbrechen eines Theiles des Hauptstromes in den Hülfskreis, während der Hülfsstrom beobachtet wurde. Fin solches Hereinbrechen wurde ummöglich gemacht durch die Anordnung, die ich in der $A b-[\$ 60]$ handlung über Polarisation an der Grenze ungleichartiger Elektrolyte ${ }^{1}$ beschrieben und schematisch abgebildet habe, indem nämlich eine Wippe den einen Kreis, während sie den anderen schloss, an zwei passend gelegenen Stellen zugleich unterbrach.

Ebensowenig ist daran zu denken, dass der Hauptstrom, indem er an den Keilbäuschen der Hülfskette vorüberfloss und sich rielleicht schleifenförmig in sie hineinbog, an den Berührungsstellen der Keilbäusche mit dem Prisma äusseren secundären Widerstand entwickelt habe. Diesem Einwand zu begegnen, wurde das Eiweiss- oder Kartuffelprisma an einem Glasstabe wagerecht schwebend ${ }^{2}$ zwischen zweien Paaren ron Keilbäuschen aufgestellt, deren eines dem Haupt-, das andere dem Hülfskreise angehörte. Der Abstand zwisehen dem einen und dem anderen Paare von Keilbäuschen war grösser als der wagerechte Durchmesser des Prisma's. Indem das Prisma in wagerechter Ebene senkrecht auf seine Axe hinund herbewegt wurde, konnte es abwechselnd dem einen und dem anderen

1 S. oben, Abh. I. S. 2 ff.

2 Im Fall des Eiweisses war der Glasstab in der Axe des Reagirglases befestigt worden, in welchem das Eiweiss gerann. 
Paare von Keilbäuschen angelegt werden. Anch so zeigten sich die den Schwankungen des Hauptstromes entsprechenden Schwankungen des Hülfsstromes, obschon jetzt der Hauptstrom die Keilbäusche der Hülfskette gar nicht mehr berührte.

Dann könnte man rersucht sein, um die Schwankungen des Hülfsstromes zu erklären, an die innere Polarisation zu denken, deren elektromotorische Kraft im Kreise der Hülfskette (eines einzigen Daniells) nicht mehr als verschwindend anzusehen sei. Diese Deutung setzt roraus, dass Haupt- und Hülfsstrom einerlei Richtung im Prisma haben, da sonst die durch den Hauptstrom bewirkte innere Polarisation, anstatt den Hülfsstrom zu schwächen, sich rielmehr zu ihm hinzufügen würde. Es zeigt sich aber, dass die Schwankungen des Hülfsstromes bei jeder Richtung des letzteren in Bezug auf den Hauptstrom nahe gleich stark ansfallen. Allerdings erhält man in den ersten Augenblicken nach Oeffnung des Haupt- und Schliessung des Hülfskreises einige Scalentheile mehr Ablenkung, wenn man [861] das Prisma so in den Hülfskreis bringt, dass der Hülfsstrom darin ebeuso fliesst, wie vorher der Hauptstrom; im anderen Falle einige Scalentheile weniger. Diese Erscheinung ist unzweifelhaft anf Rechnung der inneren Polarisation zu bringen, allein im Vergleich mit den Schwankungen des Hülfsstromes, ron denen hier die Rede ist, kommt sie nicht in Betracht.

Es giebt num noch eine rierte Ursache, auf die man diese Schwankungen zurückführen kamn. Dies ist die Wärmeentwickelung durch den Hauptstrom. Es ist klar, dass je stärker der Hauptstrom ist, um so wärmer wird das Eiweiss- oder Kartuffelprisma, um so besser muss es leiten. Umgekehrt, je mehr sich der Hauptstrom durch Entrickelung secundären Widerstandes geschwächt hat, um so kälter wird das Prisma, und um so grösser folglich dessen Widerstand. Es kamn sich nur darum handeln, ob diese Ursache ausreiche, um die beobachteten Schwankungen des Hülfsstromes zu erklären, oder nicht.

Um hierüber Gewissheit zu erlangen, steckte ich in ein in das Eiweissprisma senkrecht auf seine Axe gebohrtes Loch den schlanken cylindrischen Behälter eines für Beobachtungen über thierische Wärme bestimmten, in Zehntel Grade C. getheilten Thermometers, und las durch eine BRückE'sche Arbeitslupe die durch den Strom bewirkte Temperaturerhöhung ab. Sie belief sich im Ganzen auf etwa $10^{\circ}$, und die Temperaturschwankungen, welche den Schwankungen des Hauptstromes entsprachen, auf volle $6^{0}$.

Sodam erwärmte ich ein Eiweissprisma ron dem gewöhnlichen Querschnitt in einem Reagirglase bis zu einer Temperatur. welche die höchste im vorigen Versuche durch den Strom erreichte um mehrere 
Grade übertraf, und brachte dann das Prisma in Berührung mit den im gewöhnlichen Abstande von einander befindlichen Keilbäuschen der Hülfskette. Während das in dem Prisma steckende.Thermometer abwärts das Temperatur-Interrall durchlief, welches den im rorigen Versuch durch den Strom bewirkten Temperaturschwankungen entsprach, wuchs der Widerstand des Eiweisses, nach der Stärke des Hülfsstromes bemessen, um ebensoriel, als wenn der Hauptstrom das Eiweissprisma lange genug durchkreist, um sich auf's Aensserste zu schwächen. [862]

Diese Versuche laufen, wie man sieht, darauf hinaus, die Annahme eines besonderen inneren secundären Widerstandes im Eiweiss unnöthig zu machen. Nicht so was das Gewebe der Kartoffel betrifft. Dies leitet nämlich ansserordentlich riel schlechter als das hartgesottene Eiweiss. In Folge davon erreicht der Hauptstrom im Kartoffelprisma eine viel geringere Stärke als im Eiweissprisma, und die Temperaturerhöhung im ersteren ist so gering, dass sie oft gar nicht bemerkbar wird, und jedenfalls nicht in Betracht kommt. Gleichwohl fallen die den Schwankungen des Hauptstromes entsprechenden Schwankungen des Hülfsstromes in der Kartoffel nicht kleiner, sondern, im Vergleich zu den ersteren, sogar noch grösser aus als im Eiweiss. Wir hahen also noch immer Grund, im Kartoffelprisma einen imneren secundären Widerstand anzunehmen. Doch scheint es wünschenswerth, dessen Dasein noch auf anderem Wege gegen den Verdacht zu sichern, als handele es sich dabei um Temperaturschwankungen. Die folgenden Ermittelungen erfüllen diesen Zweck.

Betrachtet man genauer die den Schwankungen des Hauptstromes entsprechenden Schwankungen des Hülfsstromes im Falle des Eiweisses und in dem des Kartoffelgewebes, so zeigt sich bald ein wesentlicher Unterschied. Bei dem Eiweiss nämlich liegen die kleinsten Werthe der Hülfsstromstärke, die man beobachtet, wenn der Hauptstrom im Eiweiss durch Entwickelung des secundären Widerstandes seine unterste Grenze erreicht hat, niemals unter, sondern stets noch über dem ursprünglichen Werthe der Hülfsstromstärke, den man vor jeder Einwirkung des Hauptstromes erhielt. Der Hauptstrom bringt also im Eiweiss keine absolute Verminderung der Leitungsfähigkeit hervor. Die Verminderung ist rielmehr nur relativ, d. h. sie stellt sich als solche dar im Vergleich zu der Vermehrung der Leitungsfähigkeit, welche der Strom in seiner vollen, durch den secundären Widerstand ungeschwächten Grösse thermisch erzengt. Anders bei dem Kartoffelgewebe. Hier liegen jene kleinsten Werthe der Hülfsstromstärke unter dem ursprünglichen, es hat also eine wirkliche Verminderung der Leitungsfähigkeit durch den Hauptstrom stattgefunden, welche nie die Folge der thermischen Wirkung sein kann. 
Diese absolute [863] Verminderung der Hülfsstromstärke kaun sich bis auf $1 / 5$ ihres ursprünglichen Werthes belaufen.

Beobachtet man den Gang der Hülfsstromstärke unmittelbar nachdem man den auf's Aeusserste geschwächten Hauptstrom geöffnet hat, so giebt sich abermals zwischen den Erscheinungen, die das Eiweiss, und denen, die das Kartuffelgewebe bietet, ein bedeutsamer Unterschied zu erkennen. Beim Eiweiss ist nämlich die Hülfsstromstärke im Sinken begriffen. unstreitig, weil, wie das Thermometer bekundet, das Eiweiss kälter wird. Wie schwach anch der Strom geworden war, immer erhielt er das Eiweiss doch noch auf einer höheren Temperatur, als ihm sonst zukommen würde. Beim Kartuffelgewebe beobachtet man im Gegentheil, dass die Hülfsstromstärke nach Unterbrechung des Hauptstromes ziemlich rasch wächst. Dies kann ron nichts herrühren, als davon, dass ein durch den Hauptstrom entwickelter innerer secundärer Widerstand anfängt sich zu zerstreuen, sobald der Hauptstrom aufhört. Der Hauptstrom selber erscheint in beiden Fällen nach dem Offenstehen seines Kreises etwas verstärkt, bei dem Eiweiss darum, weil auch der äussere secundäre Widerstand sich sofort, obschon riel langsamer, zu zerstreuen beginnt, wenn der Strom aufhört, der ihn hervorrief.

Um nun auch den Einfluss der Stromumkehr auf den inneren secundären Widerstand zu erforschen, dient folgender Kunstgriff. Man denke sich ein Eiweiss- und ein Kartoffel-Prisma durch zwei möglichst senkrecht auf die Axe geführte Schnitte in drei Stücke getheilt, von denen das mittlere das längste ist, solamn die drei Stücke wieder genau zusammengefügt, und zwischen den Zuleitungsbäuschen des Hauptstromes dergestalt angebracht, dass man das Mittelstück heransnehmen kam, ohne dass die Endstücke an den Bäuschen verschoben werden. Der Hauptstrom wird bis zur äussersten Schwächung durch den äusseren secundären Widerstand hindurchgeschickt. Dann wird so rasch wie möglich das Mittelstück heransgenommen, in verkehrter Lage wieder eingesetzt, und der Erfolg am Fernrohr beobachtet. Mit dem Eiweiss ist dieser Erfolg nichtig; der Faden stellt sich, wenn der Versuch gut gelingt, sobald die unvermeidlichen Schwankungen wegen Oeffnens und Wiederschliessens der Kette vorüber sind, fast genau auf den Theilstrich wieder ein, auf dem [86t] er sich vor dem Umkehren des Mittelstückes befand. Mit dem Kartoffelgewebe hingegen zeigt sich die Ablenkung, wemn der spiegel zur Ruhe gekommen ist, im langsamen Wachsen begriffen, und dies lässt sich sogar in Fällen beobachten, wo ein in dem Mittelstïck steckendes Thermometer aus anderen Gründen sinkt, nicht steigt. Das langsame Wachsen hat eine Grenze. bei welcher angelangt die Stromstärke einige Angenblicke beständig bleibt, und dann wieder zu sinken beginnt, ganz, nur in 
kleinerem Maassstabe, als ob es sich um den äusseren secundären Widerstand handelte. Wird das Mittelstück nur heransgenommen und wieder eingesetzt ohne umgekehrt zu werden, so ereignet sich nichts der Art.

Nach diesen Versuchen ist es als ausgemacht anzusehen, dass das Kartuffelgewebe wirklich inneren secundären Widerstand besitzt. Vom Eiweiss hätte man bis zum letzten Versuche noch glauben können, dass die durch thermische Wirkung darin erzeugten Hülfsstromschwankungen rielleicht auch noch solche Schwankungen in sich bärgen, die auf innerem secundären Widerstande beruhten. Nach diesem Versuch aber steht es fest, dass dem Eiweiss keine nachweisbare Spur inneren secundären Widerstandes zukommt. Zwar lässt sich dagegen noch einwenden, dass wir, der Natur der Sache nach, das Eiweiss auf den inneren secundären Widerstand nur haben prüfen können mittels eines Stromes, der durch den äusseren secundären Widerstand um den grössten Theil seiner Stärke gebracht war. Allein die Folge wird uns Mittel an die Hand geben, diesen Einwand zu beseitigen, wie auch den inneren secundären Widerstand des Kartoffelgewebes noch auf einem vierten Wege darzuthun (s. unten, §. XI).

Wir werden dergestalt auf die Aufgabe geführt, zu ermitteln, welche unter den feuchten porösen Körpern, die wir oben als des secundären Widerstandes überhaupt fähig erkannt haben, neben dem äusseren secundären Widerstande, der ihnen allen in grösserem oder geringerem Grade zuzukommen scheint, auch noch gleich dem Kartoffelgewebe inneren secundären Widerstand besitzen. Das Ergebniss dieser Prüfung hat etwas Befremdendes. Ich habe nämlich den inneren secundären Widerstand bisher nur an frischen Pflanzengewebetheilen, an [865] Stücken Kartoffel, Nuhrrübe, Petersilienwurzel, Begoniastiel. Apfel, Birne, nachweisen kömen. Hält man Kartoffeln oder Begoniastiele zehn Minuten lang in siedendem Wasser, so leiten sie sehr viel besser, haben aber die Fähigkeit, inneren secundären Widerstand anzunehmen, eingebüsst. Was die anderen feuchten porösen Körper betrifft, so habe ich ausser dem Eiweiss auf diese Fähigkeit vergeblich untersucht folgende Vertreter der vier Klassen: Kreide und Bimsstein; Seife; Stäbe aus Eichen- und Weissbuchenholz, Bäusche aus Fliesspapier und Streifen Pappe, sämmtlich mit Wasser getränkt; endlich Muskelfleisch, in der Faserrichtung und senkrecht darauf durchströnt, Rückenmark, Sehnen- und elastisches Gewebe, Haut und Knorpel rom Rinde. Sieht man von der Seife ab, an der sich aus gewissen Gründen nicht mit der Hülfskette experimentiren lässt, so findet bei keinem dieser Körper eine absolute Verminderung der Hülfsstromstärke in Folge des lurchganges des Hauptstromes, oder ein Ansteigen derselben in Folge des Oeffnens der Säule statt. Die Hölzer nehmen eine so starke 
Polarisation an, dass der Hülfsstrom dadurch, je nach der Richtung des Hauptstromes, ansehnlich verstärkt oder geschwächt wurde. (Tergl. oben S. 92.) Diese in raschem Sinken begriffene Polarisation setzt der Bestimmung des Widerstandes der Hölzer wach dem Durchgang des Hauptstromes grosse Schwierigkeiten entgegen. Es gelingt jedoch auszumachen, dass der Widerstand nicht vermehrt, sondern, unstreitig durch thermische Wirkung des Hauptstromes, rermindert ist. Bei den porösen Körpern unorganischen Ursprungs, Kreide und Bimsstein, habe ich mich auf die Beobachtung jener beiden Merkmale der Abwesenheit des imneren secundären Widerstandes beschräuken nüssen. Hier ist somit noch die Möglichkeit da, dass eine Spur imneren secundären Widerstandes durch die themische Wirkung des Hauptstromes verdeckt wurde. Was aber die übrigen so eben genannten feuchten porösen Körper. die Hölzer, die Pappe, insbesondere die thierischen Gewebe betrifft, so habe ich damit noch den zuletzt angegebenen Umkehrrersuch angestellt, und dabei nie langsames Wachsen gesehen. Ebensowenig war dies der Fall bei der Seife, wo nur dieser Versuch angestellt werden komnte. Von diesen Körpern können wir also mit derselben Gewissheit wie rom Eiweiss sa- [866] gen, dass sie keine Erscheinung zeigen, welche zur Annahme eines immeren secundären Widerstandes zwänge.

\section{§. V. Nähere Untersuchung des inneren secundären Wider- standes.}

Abgesehen daron, dass wir noch nicht wissen. ob nicht die noch im Besitz ihrer Lebenseigenschaften rerharrenden thierischen Gewebe des inneren secundären Widerstandes fähig sind, erscheint dieser an sich als ein Phänomen ron hinlänglicher Bedeutung, um ein etwas näheres Eingehen darauf an dieser Stelle zu rechtfertigen.

Zunächst versuchte ich zu erfahren, ob sich dieser Widerstand auch kundgeben würde, wenn man den Hülfsstrom, statt dem Hauptstrom parallel, senkrecht darauf durch das Pflanzengewebe leitete. Zn diesem Zwecke stanzte ich mittels eines Blechdeckels kreisrunde Scheiben aus einer durch zwei parallele Ebenen begrenzten Kartoffelschnitte, und zeichnete darauf mit Tinte rier einander unter $45^{\circ}$ schmeidende Durchmesser. Dem Endpunkte eines dieser Durchmesser legte ich die Keilbäusche der Hauptkette an, die der Hülfsbäusche folgweise den Endpunkten der drei anderen Iurchmesser. Kleiner als $45^{\circ}$ oder grösser als $135^{\circ}$ liess sich der Winkel zwischen beiden Strömen nicht machen, weil über diese Grenzen hinaus kein Platz für die Zuleitungsgefïsse, welche die Keilbäusche trugen, übrig blieb. Innerhalb dieser Grenzen aber erwies sich 
die absolute Verminderung des Hülfsstromes in Folge der Einwirkung des Hauptstromes als gleich gross, es mochte nun der Hülfsstrom den Hauptstrom senkrecht, oder unter einem Winkel von $45^{\circ}$ oder von $135^{\circ}$ schneiden. Demnach scheint es als sei der innere secundäre Widerstand unabhängig von der Richtung des Stromes, der ihn hervorrief.

Dann wollte ich wissen, wie dieser Widerstand im Inneren des Kartoffelprisma's rertheilt sei; ob er in allen Querschnitten des Prisma's gleich gross gefunden werde, oder ob er vielleicht rom Eintrittsende nach dem Austrittsende zu abnehme, was so zu deuten gewesen wäre, dass der innere secundäre Widerstand eine in der Richtung des Stromes in den feuchten porösen Körper hineinragende Fortsetzung des änsseren secundären [867] Widerstandes bilde. Vergeblich suchte ich zuerst diese Frage dadurch zu entscheiden, dass ich die Keilbäusche der Hülfskette in beständigem Abstande von einander verschiedenen Strecken des Prisma's anlegte und die Veränderungen verglich, welche der Hauptstrom in dem Widerstande dieser Strecken hervorbrachte. Es zeigten sich keine deutlichen Unterschiede, allein das Verfahren erwies sich als zu unsicher, um sich bei diesem Ergebniss beruhigen zu dürfen. Zur schärferen Prüfung beschloss ich, zwei gleich lange Strecken des Kartoffelprisma's zu Schenkeln eines Wheatstone'schen Stromnetzes ${ }^{1}$ zu machen, in dessen ungespaltener Strecke eine Hülfskette von hinlänglicher Kraft befindlich, und dessen beiden anderen Schenkeln ein solcher Widerstand ertheilt wäre, dass bei dem ursprünglichen Leitvermögen des Kartoffelgewebes der Strom in der Brücke verschwände. Wenn dann durch die Einwirkung des Hauptstromes die beiden Strecken des Prisma's verschiedenen Widerstand annähmen, müsste sich dies dadurch kundgeben, dass beim Schliessen der Hülfskette nach dem Oeffnen der Hauptkette ein Strom in der Brücke entstände.

Dieser Versuchsplan wurde in's Werk gesetzt, indem ich dem Kartoffelprisma in gleichen Abständen drei mit Zinklösung getränkte Keilbäusche anlegte, welche auf rerquickte Zinkplatten gebunden und passend aufgestellt waren. Das mittlere Zinkblech führte zum einen Ende der Hülfskette, die beiden anderen waren durch die Brücke verbunden, und hingen ausserdem mit dem anderen Ende der Hülfskette zusammen durch metallische Leitungen von angemessenem Widerstande, welche die beiden anderen Schenkel des Stromnetzes ausmachten. Der Widerstand der einen dieser Leitungen konnte hinreichend fein abgestuft werden, und mit Hülfe

1 Philosophical Transactions etc. For the Year 1843. P. II. p. 323 ; - PogGENDORFF's Annalen u. s. w. 1844. Bd. LXII. S. 535. - Kirchnoff, ebendas. 1845. Bd. LXIV. S. 512.

E. du Bois-Reymond, Ges. Abh. I. 
daron wurde der Stromzweig in der Brücke, worin die eine Rolle der Bussole eingeschaltet war, leicht zum Verschwinden gebracht. Die Empfindlichkeit der Anordnung war so gross, dass einer Veränderung des Widerstandes eines der Schenkel um $1 / 200$ etwa ein Scalentheil Ausschlag entsprach. [868]

Nun liess ich, bei geöffneter Hülfskette, ${ }^{1}$ den Hauptstrom sich durch Entwickelung des secundären Widerstandes auf's Aeusserste schwächen, prüfte den Brückenstrom, legte die Wippe im Hauptkreise um, liess den umgekehrten Hauptstrom den secundären Widerstand zerstreuen, prüfte abermals den Brückenstrom, liess ron Nenem durch den Hauptstrom den secundären Widerstand in entgegengesetzter Richtung ron rorhin hervorrufen, prüfte zum drittenmal den Brückenstrom, u. s. f. Der Erfolg war in mehreren wohlgelungenen Versuchen, dass zwar der Strom in der Brücke nicht gerade Null blieb, was bei der Dauer der Beobachtungen nicht zu rerlangen war, dass sich aber, in Sinn und Grösse der auftretenden Ablenkungen, keine Spur eines Gesetzes blicken liess. Und doch bringt, wie man leicht bemerkt, das angewendete Terfahren es mit sich, dass bei einem beständigen Unterschiede zwischen dem Widerstande der Ein- und dem der Austrittshälfte, die Ausschläge in der Brücke bald die eine, bald die andere Richtung gehabt. mit anderen Worten, dass ihre Grössen sich summirt haben würden. Gleichgültig war dabei, ob der mittlere Bausch mit dem positiven oder mit dem negativen Ende der Hülfskette rerbunden war, d. h. ob der Hülfsstrom in der Eintrittshälfte dieselbe Richtung wie der Hauptstrom hatte oder nicht. Dadurch ist dem Verdacht vorgebengt, als habe vielleicht der in der Eintrittshälfte zufällig stets dem Hauptstrom entgegengesetzte, in der Austrittshälfte aber gleichgerichtete Hülfsstrom in der ersteren Hälfte den immeren secundären Widerstand zerstreut, in der letzteren bestehen lassen, und als sei so durch die Prüfung selber die durch den Hauptstrom bewirkte Ungleichheit der Widerstände wieder verwischt worden.

Aus diesen Versuchen ist somit zu schliessen, dass der Widerstand des Kartoffelprisma's in allen seinen mittels der Keilbäusche zugänglichen Querschnitten unter dem Einfluss des Hauptstromes gleichmässig steigt und fällt, und dass keine nachweisbare Abstufung des imneren secundären Widerstandes rom [869] Eintritts- nach dem Austrittsende zu stattfindet,

1 Die Oeffnung geschah natürlich an zwei Stellen, nämlich in den beiden Drähten, die von den beiden äussersten Zinkblechen ausgingen, und zwar bevor diese Drähte sich in die Brïcke und in die beiden metallischen Sehenkel des Stromnetzes spalteten. Anderenfalls hätte ein Theil des Hauptstromes seinen Weg durch die Brïcke genommen. 
welche auf eine Beziehung zwischen dem inneren und dem äusseren secundären Widerstande hinwiese. Wenn folglich die Maxima und Minima des Haupt- und Hülfsstromes in den obigen Versuchen einander zu entsprechen schienen, so ist darauf nichts zu geben. War dies wirklich der Fall, so war es nur ein zufälliges Zusammentreffen. Allein jenes Entsprechen kann ebensogut nur ein Anschein gewesen sein, erzeugt durch eine Reihe ron Möglichkeiten, deren ausführliche Zergliederung sich hier nicht der Mühe lohnen würde.

Wie mit der Dauer der Durchströmung, so nimmt der innere secundäre Widerstand in einem gegebenen Kartoffelprisma natürlich auch mit der Stärke des Hauptstromes zu. Schon bei fünf GrovE'schen Gliedern und den gewöhnlichen Maassen des Prisma's trat die Erscheinung in sehr grosser Stärke hervor. Wurden noch fünf Glieder in die Hauptkette genommen, so wuchs auch der innere secundäre Widerstand, und so fort bis zu zwanzig Gliedern. Doch geschah das Wachsthum immer langsamer, so dass durch die Vermehrung der Gliederanzahl von fünfzehn auf zwanzig nur noch eine ganz unbedentende Verstärkung des inneren secundären Widerstandes herbeigeführt wurde.

Es rersteht sich ron selber, dass es sich hierbei nicht um die absolute Stromstärke, sondern, wie bei ähnlichen Wirkungen des Stromes im Inneren von Leitern, un die Stromdichte handelt. Es würde indess wünschenswerth sein, dies so zu zeigen, dass bei beständig bleibender Stromstärke der Querschnitt des Kartoffelprisma's verändert würde. Da, wie wir sehen werden, der äussere secundäre Widerstand mit der Verkleinerung der Berührungsfläche zwischen Bausch und feuchtem porösen Förper rasch zunimmt, so kann dies nicht ohne Weiteres in der Art geschehen, dass man, im Hauptkreise beobachtend, Prismen von verschiedenem Querschnitt einem Strome ron stets gleicher Stärke aussetzt und die durch den secundären Widerstand in den verschiedenen Fällen herbeigeführten Schwäuhngen des Stromes miteinander vergleicht. Es würde ror der Hand an jedem Mittel fehlen, um den Antheil an der Schwächung des Stromes, der dem imneren, von dem zu sondern, der dem äusseren secundären Widerstande zukommt. Es ist vielmehr klar, dass zu einer tadel- [870] freien Versuchsweise hier gehört, dass sowohl die ursprüngliche Stärke des Stromes, als der äussere secundäre Widerstand beständig gehalten werden, welches letztere nur so möglich ist, dass die Enden des Prisma's unverrückt an den Bäuschen liegen bleiben. Daraus ergiebt sich folgendes Verfahren.

Man bezeichnet sich an dem Prisma durch Tintenpunkte zwei gleich lange Strecken, $A$ und $B$, welche einen möghichst grossen Theil seiner Länge einnehmen, an jedem Ende des Prisma's jedoch, und zwischen. 
sich, noch ein etwa $1^{\mathrm{cm}}$ langes Stück übrig lassen. Der einen dieser Strecken, $A$, legt man die Keilbäusche der Hülfskette zuerst so an, dass sie dessen ganze Länge umfassen, und bestimmt die absolute Verminderung des Hülfsstromes, welche der Hauptstrom hervorbringt. Dann verjüngt man in der Strecke $A$ das Prisma um die Hälfte, rückt die Keilbäusche der Hülfskette einander $\mathrm{mm}$ die Hälfte näher, und schneidet die Strecke $B$ ans dem Prisma ans. Sieht inan davon ab, dass die Leitung des Hülfsstromes zwischen den Keilbäuschen, und des Hauptstromes da wo der Querschnitt des Prisma's sich plötzlich um die Hälfte ändert, keine lineare sein kann, so lässt diese Reihe von Operationen den Widerstand sowohl in Haupt- als im Hülfskreise, und folglich beide ursprüngliche Stromstärken, unverändert, verdoppelt hingegen die Stromdichte in der verjüngten Strecke. Wächst folglich der innere secundäre Widerstand mit der Stromdichte, so muss sich eine Vergrösserung der durch die beiden secundären Widerstände im Hauptkreise bewirkten Schwächung

Fig. 6 .

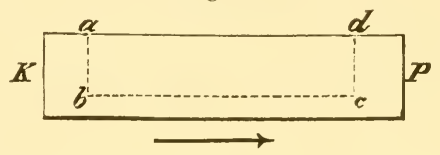

der Hauptstromstärke, noch leichter aber eine solche der durch den imneren secundären Widerstand allein bewirkten Schwächung der Hülfsstromstärke nachweisen lassen.

Ich habe diesen Versuchsplan mehrmals in's Werk gesetzt, jedoch ohne klaren Erfolg. Es ist in Wirklichkeit, aus Gründen, deren Ausführung zu weitläufig werden würde, unmöglich, die Bedingungen zu erfüllen, auf denen er beruht. Ebensowenig ist mir dies mit einem einfacheren Versuchsplan gelungen, den ich dann zu demselben Zweck erdachte. Er besteht darin, ein Kartoffelprisma $K P$ (s. Fig. 6) zwischen die Zuleitungsbäusche zu bringen, an welchem ein Stück $a \quad b \quad c \quad d$ ausgeschnitten, und wieder eingesetzt ist. Ich liess den secundären Widerstand sich so weit entwickeln, dass der Strom beständig erschien, [871] und entfernte damn plötzlich das Stück $a b c d$. Natürlich geschah, unter heftigen Schwankungen des Scalenbildes, eine plötzliche Verminderung der Stromstärke. Ich hoffte aber nach Beruhigung des Spiegels die Stromstärke noch langsam abnehmen zu sehen, zum Zeichen, dass der erhöhten Stromdichte in der verjüngten Strecke ein höherer Grad inneren secundären Widerstandes entspreche. Allein auch diese Versuchsweise schlug fehl, weil entweder, bei kleinem Widerstande im Kreise ausserhalb des 
Prisma's, die Stromdichte in der verjüngten Strecke nicht hinlänglich wuchs, oder, bei grossem Widerstande, in Folge der Schwäche des Stromes sogar bei dreissig Grove'schen Gliedern der Säule die Erscheinungen undentlich wurden.

Unsere Bemühungen, das Wachsen des inneren secundären Widerstandes mit abnehmendem Querschnitt bei beständiger Stromstärke nachzuweisen, bleiben somit für jetzt vergeblich. Die Folge wird uns indess in den Stand setzen, diese Frage mit besserem Erfolg wieder aufzunehmen (s. unten §. XI).

Wollte man den inneren secundären Widerstand in den Ausdruck für den Widerstand des Kartoffelprisma's einführen, so würde er, nach den Untersuchungen dieses Paragraphen, durch einen von der Stromdichte und der Dauer der Durchströmung abhängigen Summanden zu dem Coëfficienten darzustellen sein, der den Widerstand des Gewebes für die Einheit der Länge und des Qnerschnittes bedeutet.

\section{§. VI. Abhängigkeit des äusseren secundären Widerstandes} ron Stromstäre und Querschnitt.

Wir kehren num zurück zu dem äusseren secundären Widerstande, der aus mehreren Gründen bei weitem die wichtigere Erscheinung für uns ist. Gleich dem inneren secundären Widerstande wächst der äussere in einem gegebenen fenchten porösen Körper rasch mit der Stromstärke. Bei nur einer Grove'schen [872] Kette im Kreise zeigt sich an einem Eiweissprisma von den gewöhnlichen Maassen keine sichere Spur daron. Bei fünf Grove'schen Gliedern dagegen sind schon alle oben beschriebenen Erscheinungen am Eiweiss, dem Muskelfleisch, dem Knorpel, dem elastischen und dem Sehmen-Gewebe, dem der Kartoffel, deutlich wahrzunehmen, nur dass das Sinken sowohl als das Wiederanwachsen der Stromstärke nach dem Umlegen der Wippe riel langsamer vor sich gehen als bei den hohen Stromstärken, und dass sich leicht Unregelmässigkeiten einstellen, z. B. der secundäre Widerstand nur oder vorzugsweise bei der einen Stromrichtung auftritt.

Die Ursache, weshalb wir uns bisher stets einer Säule ron so grosser Gliederanzahl bedient haben, und dies für gewöhnlich auch fernerhin thum werden, ist also nicht etwa, dass es solcher Mittel bedarf, um den inneren oder äusseren Widerstand sichtbar zu machen. Sondern aus demselben Grunde, aus dem diese Anordnung vielleicht für den einen unserer Zwecke nicht die günstigste war. nämlich um die innere Polarisation im ursprünglichen Kreise zn beobachten, eignet sie sich zur Untersuchung des secundären Widerstandes. Sie hat gerade den Vortheil, dass wir uns dabei 
um die verschiedenen secundär-elektromotorischen Kräfte, welche im: Krreise rege werden mögen, nicht zu kümmern brauchen: so wenig wieum die innere Polarisation, um die der Kupferelektroden, um die Polarisation an der Grenze der Elektrolyte, und um die Hydrothermoströme, zu denen die thermische Wirkung des Säulenstromes rielleicht Anlass giebt. ${ }^{1}$ Alle diese Störungen rerschwinden unstreitig gegen die elektromotorische Kraft ron zwanzig Grove'schen Gliedern, und jede merkliche Stromschwankung darf ohne Weiteres auf eine Teränderung des Widerstandes bezogen werden.

Lässt man den secundären Widerstand durch den Strom von fünf GrovE'schen Gliedern sich vollständig entwickeln, so dass bei einer ursprünglichen Ablenkung ron etwa 200 Scalentheilen mehrere Minuten rergehen, bis ein Sinken um einen Scalentheil erfolgt ist, und geht man dann plötzlich zu einer grösseren Stromstärke, z. B. zu der ron zehn Gliedern über, so beobachtet man in den ersten Augenblicken wieder rasches Sinken, welches auf eine er- [873] neute Entwickelung secundären Widerstandes hinweist. In der That kann man sich, mit Hülfe leichț zu ersinnender Gegenversuche, überzeugen, dass das erneute Sinken nicht etwa darauf beruht, dass der secundäre. Widerstand sich zum Theil zerstreut hat, während man, um die neuen Glieder aufzunehmen, die Kette eimen Augenblick öffnete. Wartet man abermals einen nahezu beständigem Zustand $a b$, und steigert man wieder die Gliederanzahl der Säule um fünf, so beobachtet man den nämlichen Erfolg, und so habe ich ihn, wenn auch in immer kleinerem Maassstabe, bis zu dreissig Gliedern eintreten sehen.

Für den äusseren secundären Widerstand hat es keine Schwierigkeit, dessen Abhängigkeit rom Querschnitt, oder rielmehr ron der Berührungsfläche zwischen feuchtem porösen Körper und Bausch, nachzuweisen. Sie ist erwähntermaassen (s. oben S. 99) der Art, dass dieser Widerstand um so beträchtlicher erscheint, je kleiner die Berührungsfläche, oder je. grösser die Stromdichte darin. Dies spricht sich besonders darin ans, dass wenn man dem Eiweissprisma statt der auf die Axe senkrechten Grundflächen jederseits eine keilförmige Schneide oder eine Spitze ertheilt und es damit die Bäusche berühren lässt, man statt fünf Grove'scher Glieder nur noch einer einzigen DaxienL'schen Kette bedarf, um alle Erscheinungen des äusseren secundären Widerstandes vollkommen deutlich wahrzunehmen. Dasselbe ist natürlich der Fall, wem man umgekehrt die Berührungsfläche dadurch rerkleinert, dass man das Prisma mit Keilbäuschen berührt. Da die schwefelsaure Zinkoxydlösung sich der Kupfer-

1 Vergl. Wild in Poggendorff's Annalen u. s. w. Bd. (III. S. 353. 
des äusseren secundären Widerstandes von Stromstärke und Querschnitt. 103

oxydlösung in diesen Versuchen ganz gleich rerhält, so wurde deshalb bei der obigen Anwendung der Hülfskette mit ihren Kieilbäuschen die Vorsicht gebraucht, die Kette nie länger als nöthig geschlossen zu halten und den Strom oft umzukehren.

Bemerkenswerth ist der Erfolg, wenn man, bei nur einem Damiell im Kreise, ein Eiweissprisma zwischen die Bänsche bringt, das nur an einem Ende keilförmig zugeschärft ist. Alsdann nämlich beobachtet man den secundären Widerstand nur, wemn die Schneide dem Strome zum Eintritt dient. Hat der Strom die andere Richtung, so erscheint er ganz beständig.

Oeffnet man den Kreis, in welchem ein Eiweissprisma das Maximum des äusseren secundären Widerstandes angenommen [874] hat, ein paar Minuten lang, so findet man, wie schon bemerkt, die Stromstärke etwas gewachsen, obgleich während des Offenstehens die Temperatur des Eiweissprisma's nothwendig gesunken ist. Doch lïsst diese ron selber eintretende Zerstremung des änsseren secundären Widerstandes auch nach sehr langer Zeit noch immer den grössten Theil daron bestehen.

Selbst der umgekehrte Strom hebt übrigens den einmal rollständig entwickelten äusseren secundären Widerstand nicht ganz auf, wie schon oben S. 88 gezeigt wurde und wie abermals aus folgendem Versuch erhellt. Man richte sich so ein, dass man mit Leichtigkeit abwechselnd mit dem Strom der vielgliederigen Grove'schen Säule, dem Hauptstrom, den einer Daxielu'schen Kette als Hülfsstrom durch die Zuleitungsgefässe und das Eiweissprisma schicken könne. Das Prisma muss die Bäusche mit hinreichend grossen Flächen berühren, damit der Hülfsstrom für sich keinen secundären Widerstand herrorrufe. Man bestimmt nun zuerst die Stärke des Hülfsstromes ehe der Hauptstrom durchgegangen ist. Dann lässt man diesen durch Entwickelung secundären Widerstandes sich auf's Aeusserste schwächen, kehrt ihn um, und ersetzt ihn wieder durch den Hülfsstrom in dem Angenblick, wo das langsame Wachsen sein Ende erreicht hat und der Hauptstrom wieder zu sinken beginnt. Man findet zwar den Hülfsstrom jetzt ansehnlich stärker als zu Anfang, allein dies rührt nur her von der durch den Hauptstrom entwickelten Wärme. Hat man ein Thermometer im Eiweiss stecken, und wartet man bis die Temperatur wieder auf den Punkt gesunken ist, wobei die erste Beobachtung geschah, so zeigt sich eine geringere Stärke des Hülfsstromes, so dass es klar ist, dass auch unter dem Einfluss des umgekehrten Stromes das Eiweissprisma seine ursprüngliche Leitungsgüte nie ganz wiedererlangt. Nur durch das Abschneiden des Eintrittsendes kamn dies erreicht werden. 
§. VII. Nähere Untersuchung des Eintrittsendes des feuchten porösen Körpers, welches der Sitz des äusseren secundären Widerstandes ist.

Es ist nun an der Zeit dieses Eintrittsende etwas genauer zu betrachten, um dadurch womöglich zu einer Vorstellung [875] von der Natur des äusseren secundären Widerstandes zu gelangen.

Bei fast allen feuchten porösen Körpern, welche man zwischen die Zuleitungsbäusche bringt, beobachtet man, dass das Eintrittsende sich nach kürzerer oder längerer Zeit, bis zu grösserer oder geringerer Tiefe, blau färbt in der Farbe des Kupfersalzes der Bäusche, während das Austrittsende diese Farbe nur oberflächlich annimmt, so dass man mittels dieses Kennzeichens die Stromrichtung bestimmen kann.

Das Eintrittsende eines Eiweissprisma's oder -Cylinders zeigt jedoch noch eine andere bemerkenswerthe Eigenthümlichkeit. Man findet es nämlich nahe der Grundfläche nach Art einer Rakete eingeschnürt, oder, wie es in der Feuerwerkerei heisst, gewürgt (s. Fig. 7). Von der Grund-

Fig. 7. ,

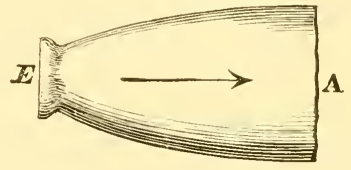

fläche $E$, die dem Brandloch entspricht, bis zur Würgung ist das Eiweiss hellblau, die Kehle der Würgung dagegen sieht dunkelblaugrün aus, als ob ein abfärbender Faden zum Würgen gedient hätte. Diese Färbungen erstrecken sich, wie man auf Längsschnitten sieht, mehr oder minder ausgesprochen durch die ganze Masse des Eiweisses. Die Strecke ron der Grundfläche bis zur Würgung fühlt sich sehr fest und derb, die Würgung selber hart wie Horn an. Die Würgung erscheint zuerst ganz nahe der Grundfläche als eine seichte dunkle Furche. In dem Maasse wie der Strom länger einwirkt, wird sie tiefer und breiter, und rückt sie weiter in der Richtung des Stromes fort. Hat der Strom seine unterste Grenze erreicht, so bleibt sie in einer Entfernung ron $2-4^{\mathrm{mm}}$ von der Grundfläche stehen.

Am Austrittsende zeigt sich nichts der Art. Die dort durch Diffusion entstandenen blauen Stellen bleiben weich, wie dies anch der Fall ist, wemn man Eiweiss noch so lange in Kupferlösung tauchen oder auf einem damit getränkten Bausche [876] stehen lässt. Hat aber der Strom lange in derselben Richtung angehalten, so macht sich am Austrittsende eine 
leichte Anschwellung in Gestalt eines abgestumpften Kegels bemerkbar, dessen Grundfläche die vergrösserte blaugefärbte Grundfläche $A$ des Eiweisscylinders ist, während seine abgestumpfte Spitze mit dem unveränderten mittleren Theile des Cylinders verschmilzt. In Fig. 7 ist diese Anschwellung, mit Rücksicht auf sogleich zu Erwähnendes, zu stark ausgeprägt.

Trägt man mit einem scharfen Messer die zwischen Grundfläche und Würgung gelegene Strecke des Eintrittsendes in dünnen Scheiben ab, so bleibt dies ohne Wirkung auf den äusseren secundären Widerstand. Dieser rerschwindet erst, und der Strom erreicht erst wieder seine ursprüngliche Stärke (s. oben S. 88. 103), nachdem man mit dem schichtweisen Abtragen des Eintrittsendes an die Würgung gelangt ist. Nicht das ganze Eintrittsende also, sondern die der Würgung entsprechende Scheibe des Endes ist der eigentliche Sitz des änsseren secumdären Widerstandes.

Die Würgung lässt sich ganz wie beim Eiweiss auch beim Leim, dem Knorpel, dem elastischen Gewebe, dem Rückenmark, dem Muskelfleisch und anderen feuchten porösen Körpern der Art wahrnehmen, wenn sie dem Strom hinreichend lange zwischen den Kupfersalz-Bäuschen ausgesetzt blieben.

Im Widerspruch mit früher von mir mitgetheilten Versuchen ${ }^{1}$ muss ich endlich bemerken, dass sich mir nenerdings öfter ein Temperaturunterschied des Ein- und Austrittsendes, und zwar stets zu Gunsten des ersteren, dargeboten hat, jedoch ohne dass ich bis jetzt Gelegenheit genommen hätte, mich ausdrücklich und in Strenge davon zu überzengen. Z. B. eine Dampfsäule stieg nur ron dem Eintrittsende des feuchten porösen Körpers auf, ron einem Leimprisma schmolz nur dies Ende u. d. m.

§. VIII. Tom äusseren secundären Widerstande bei Tränkung der Zuleitungsbäusche mit verschiedenen Flüssigkeiten.

Demnächst obliegt uns, um unsere Kenntniss des äusseren secundären Widerstandes zu erweitern, der Versuch, wie sich [877] dieser Widerstand gestalten werde, wemn wir den Strom dem Eiweiss durch Bäusche zuführen, die, statt wie bisher mit Kuuferlösung, mit verschiedenen Flüssigkeiten getränkt sind.

Dass schwefelsaure Zinkoxydlösung sich dabei im Wesentlichen gleich der Kupferlösung rerhalte, ist schon bei Gelegenheit der Anwendung der Hülfskette erwähnt worden. deren Zuleitungsgefässe und -Bäusche jene

1 S. oben, $\Lambda$ bh. I. S. 10. 
Lösung enthielten (s. oben S. 102. 103). Um aber unsere Erfahrungen in dieser Richtung zu vervielfältigen, überziehen wir jetzt die Zuleitungsbäusche mit Sicherheitsbäuschen, die gleichfalls mit Kupferlösung getränkt sind, und diese wiederum mit Hülfsbäuschen, welche die zu rersuchenden Elektrolyten enthalten sollen; zwischen die Hülfsbäusche wird das Eiweiss gebracht.

Wählen wir zuerst Kochsalzlösung, wegen der bedeutenden Rolle, die sie in der Elektrophysiologie spielt. Man ist nicht wenig überrascht zu finden, dass Eiweiss zwischen zwei Kochsalz-Hülfsbäuschen noch so lange Zeit dem Strom ausgesetzt, keine Spur änsseren Widerstandes wahrnehmen lässt. Die Ablenkung wächst bei dieser Anordnung stetig, in Folge der Erhitzung des Eiweisses, bis das dynamische Gleichgewicht zwischen Wärmeerzeugung und -Abgabe erreicht ist. Umlegen der Wippe hat keine bemerkenswerthe Folge. Das Abschneiden des Eintrittsendes verstärkt den Strom nicht mehr als das des Austrittsendes. Das Eintrittsende zeigt übrigens ganz wie mit der Kupferlösung die Würgung, nur natürlich nicht blau, sondern gelbgrau. Indem das Eintrittsende fast bis auf die Hälfte seines Durchmessers einschrumpft, während das Austrittsende mehr und mehr anschwillt, nimmt ein Eiweisscylinder hier zuletzt die abenteuerliche Gestalt an, die Fig. 7 S. 104 zeigt. In Folge des Umkehrens des Stromes geht diese Gestalt wieder in die cylindrische über; die nicht ganz verschwindende Würgung am alten Eintrittsende rerhindert aber, dass sich die Kegelgestalt in der anderen Richtung rein auspräge, und der Cylinder erhält mehr die Form einer Birne, deren stiel am neuen Eintritts- und deren sogenannte Knospe an neuen Austrittsende läge. Als ich am Eintrittsende keilförmig zugeschärfte Eiweissprismen zwischen die Kochsalz-Hülfsbäusche brachte, erhitzte sich die Schneide dermaassen, dass die Leitung unter Ḱnisteru plötzlich ganz unterbrochen wurde. Nur indem [878] ich den Strom der zwanziggliederigen Grove'schen Säule dem Eiweiss durch Kochsalz-Keilbäusche zuführte, gelang es mir zuletzt mit dieser Flüssigkeit äusseren secundären Widerstand in geringem Naasse, theils durch langsames Wachsen der Stromstärke nach dem Umlegen der Wippe, theils durch den rerschiedenen Erfolg beim Verrücken des Ein- und des Austrittshausches nachzuweisen.

Da für gewöhnlich mit der Kochsalzlösung durchans kein secundärer Widerstand auftritt, so lange nicht die Kupferlösung durch die Kochsalzbänsche hindurch zum Eiweiss dringt, so bietet sich jetzt eine bequeme Art dar, verschiedene Flüssigkeiten auf die Fähigkeit zu prüfen, mit Eiweiss secundären Widerstand zu geben, ohne für jede Flüssigkeit die Zuleitungsbäusche mit neuen Sicherheits- und Hülfsbäuschen überziehen, und ohne darauf Rücksicht nehmen zu müssen, ob die Grenze des mit 
der zu prüfenden Flüssigkeit getränkten Hülfsbausches und des Sicherheitsbausches ein Sitz secundären Widerstandes werde. Man bekleidet. nämlich die Sicherheitsbäusche znerst mit einem mehrere Millimeter dicken Blatt Modellirthon, damn mit einem Hülfsbausch, der mit Kochsalzlösung getränkt ist. Der Thon setzt keinen secundären Widerstand (s. oben S. 85) und rerzögert die Diffusion der Lösungen, so dass man nicht so. bald einer Eneuerung der Anordnung bedarf. Zwischen die Hülfsbäuschebringt man das Eiweissprisma, das man mittendurchschneidet, und seine beiden Hälften durch den mit der zu prüfenden Flüssigkeit getränkten Bausch von einander trennt. Ich habe dergestalt eine ziemliche Anzahl von Versuchen angestellt, zu dem Zweck, die Eigenschaft zu entdecken, wodurch eine Flüssigkeit befähigt wird, mit Eiweiss secundären Wilerstand zu geben. Das Ergebniss dieser Versuche, verbunden mit dem der früheren, ist in folgender Uebersicht enthalten. Die Lösungen waren, wo nicht das Gegentheil gesagt ist, gesättigt.

Secundären Widerstand gaben:

* Schwefelsaure Kupferoxydlösung.

* Schwefelsaure Zinkoxydlösung.

* Salpetersaure Silberoxydlösung.

*Neutrale essigsaure Bleioxydlösung.

*Chlorzinklösung.

* Alaunlösung. [879]

*Verdümnte Schwefelsäure ( $\left.\mathrm{SO}_{4} \mathrm{H}: \mathrm{HO}:: 1: 19\right)$.

*Verdünnte Salpetersäure (Käufliche $\mathrm{NO}_{5}: \mathrm{HO}:: 1: 9$ ).

Dagegen versagten secundären Widerstand:

Chlornatriumlösung.

Dieselbe verdümnt mit dem dreifachen Volum Wassers.

Dieselbe verdünnt mit dem nemfachen Volum Wassers. Chlorammoniumlösung.

Chlorealciumlösung.

*Qnecksilberchloridlösung.

Schwefelsaure Natronlösung.

Neutrale chromsaure Kalilösung.

Doppelt chromsaure Kalilösung.

Kohlensaure Kalilösung.

Kialihydratlösung.

Brmnnenwasser.

*Absoluter Alkohol.

*Derselbe verdümnt mit dem halben Volum Wassers.

Essigsäure.

Bei vielen der letzteren Flüssigkeiten, welche gleich der Kochsalz- 
lösung keinen secundären Widerstand geben, wurde wie dort gleichwohl die Würgung am Eintrittsende des Eiweisscylinders beobachtet. Umgekehrt bot die Höllensteinlösung das Beispiel einer Flüssigkeit dar, mit welcher der stärkste secundäre Widerstand auftrat, olme dass eine deutliche Spur von Würgung bemerkbar wurde. Der Strom sank nämlich damit riel zu schnell auf eine sehr niedere Stufe, als dass die Erscheinung Zeit gehabt hätte sich auszubilden.

Vielleicht ist es nicht umnütz zu bemerken, dass es im Wesentlichen gleichgültig ist, ob man das Eiweissprisma zwischen Bäusche bringt, welche mit einer bestimmten Flüssigkeit getränkt sind, oder ob man es bogenförmig mit seinen beiden Enden in dieselbe Flüssigkeit taucht. Die ron uns bis jetzt angewendete Versuchsweise hat keine andere Bedeutung, als dass sie eine grössere Bequemlichkeit gewährt und die Berührungsfläche des Eiweisses mit dem zuführenden Elektrolyten sicherer abzugrenzen erlaubt.

Sehr sonderbar ist aber, dass anch an einem flüssiges Eiweiss enthaltenden heberförmigen Rohr, wetches in die mit Kunpfer- [880] oder Zinklösung gefüllten Zuleitungsgefässe umgestürzt ist, alle Erscheinungen des äusseren secundären Widerstandes, zwar langsam, aber in vollkommener Ausprägung und in grösstem Naassstabe, anftreten. Dabei bildet sich in dem Rohr, rom Eintrittsende her, ein mit der Dauer der Schliessung bis zu einer gewissen Grenze fortschreitendes Gerimnsel, das der Sitz des secundären Widerstandes ist, da der Strom sich hebt wenn es entfernt wird. In das Austrittsgefäss rerbreitet sich kein entsprechendes Gerinnsel. Nit Kochsalzlösung bleibt der Strom beständigg.

\section{§. IX. Tom äusseren secundären Widerstande bei Zuleitung des stromes durch metallische Elektroden.}

Ehe wir eine Erörterung dieser Thatsachen rersuchen, wird es zweckmässig sein, unsere Versuche auch noch dahin abzuändem, dass wir den Strom dem Eiweiss statt durch Elektrolyte, durch metallische Elektroden zuführen, um zu sehen, ob sich dabei gleichfalls secundärer Widerstand nachweisen lasse. Es wird daranf ankommen, ob wir in dieser Bemühung nicht durch die Polarisation allzusehr gehemmt werden, die, wenigstens bei den negativeren Metallen, jetzt anch gegen die elektromotorische Kraft der zwanziggliederigen GrovE'schen Säule nicht mehr verschwinden dürfte.

Bringt man einen Eiweisscylinder mit seimen beiden Grundflächen 
zwischen Platinelektroden, die mit dieser Säule verknüpft sind, so sinkt unter lebhafter Gasentwickelung die Stromstärke rasch auf einen kleinen Bruchtheil ihrer Grösse, während sich am Austrittsende ein Kegel in der oben S. 105. 106 beschriebenen Art ansbildet, der aber hier eine eigenthümliche Beschaffenheit hat. Er besteht nämlich ans einer durchsichtigen, von vielen (Wasserstoff-) Blasen erfüllten, äusserst weichen Masse, die wie hartgesottenes Kiebitzeiweiss aussieht, und aussen und innen stark alkalisch reagint. Am Eintrittsende bewahrt das Eiweiss sein porzellanartiges Ansehen und fühlt sich härter an als in der Mitte, wo es unverändert bleibt; die harten Theile reagiren lebhaft sauer. Eine Würgung findet nicht statt. Legt man die Wippe um, so geht der Strom zuerst in einem Sprunge, dann aber so langsam in die Höhe, dass es ganz so aussieht, als habe man [881] es mit dem Verschwinden secundären Widerstandes zu thun. Auf der Höhe verweilt der Strom nur einen Augenblick und sinkt dann wieder, und dieser Vorgang wiederholt sich so oft wie man die Strömungsrichtung ändert, ohne dass auch bei langer Dauer des Stromes in der der ursprünglichen entgegengesetzten Richtung, der Eiweisscylinder seine Gestalt wieder annähme, geschweige ein Kegel am nenen Austrittsende sich bildete.

Sind die Platinoberflächen nur klein, wie es der Fall ist, wenn man Platindrähte als Elektroden einer fünf- bis zwanziggliederigen Säule in das Eiweiss einsticht, so verlaufen die Erscheinungen, was die Schwankungen der Stromstärke betrifft, ähnlich, nur dass das langsame Wachsen nach dem Umlegen rermisst wird. Es fragt sich, ob dies Wachsen hier auf secundären Widerstand zu deuten sei. Es könnte nämlich auch dadurch, dass sich der Polarısationsstrom plötzlich, statt sich rom ursprünglichen Strom abzuziehen, dazu hinzufügt, des letzteren thermische Wirkung wachsen, und den Widerstand des Eiweisses herabsetzen. Inzwischen ist erstens die Schwächung des Stromes zu beträchtlich, um sie allein der Polarisation zuzuschreiben, zweitens der positive Ausschlag beim Umlegen nicht so gross, wie er sein müsste, wemn diese Schwächung allein von Polarisation herrührte. Drittens endlich zeigt sich, dass anch hier das Eintrittsende eine besondere Rolle bei der Schwächung des Stromes spielt, indem dem Abschneiden des zeitigen Eintrittsendes stets eine ungleich grössere Hebung des Stromes folgt als dem des zeitigen Austrittsendes. Hat man Platindrähte als Elektroden des geschwächten Stromes im Eiweiss stecken, und zieht man die Kathode heraus um sie wo anders einzustechen, so bleibt Alles beim Alten. Verfährt man ebenso mit der Anode, so erreicht der Strom auf Augenblicke seine ursprüngliche Grösse wieder. Dies zeigt um so sicherer, dass es sich hier um äusseren secundären Widerstand, und nicht um Polarisation handelt, als bei der Polari- 
sation es bekanntlich gerade umgekehrt die Kathode ist, deren Erschütterung die Stromstärke wieder belebt. ${ }^{1}[882]$

Mit Zinkelektroden folgt auf das Umlegen der Wippe, nachdem der Strom bis auf einen kleinen Bruchtheil geschwunden ist, keine Hebung der Stromstärke, sondern räthselhafterweise ernentes Sinken. Bei abermaligem Umlegen der Wippe (zur ursprünglichen Richtung) geht der Strom plötzlich in die Höhe bis etwa zu seiner anfänglichen Stärke, sinkt aber bald wieder eben so tief wie das erstemal. Ein drittes Umlegen hat wieder erneutes Sinken, ein viertes rasches Emporsteigen zur anfänglichen Höhe zur Folge, und so fort mit jedem ungeraden und jedem geraden Umlegen. Die änsseren Erscheinungen am Eiweisscylinder sind dabei dieselben wie mit dem Platin, der Kegel schien mir aber in derselben Zeit noch rascher zu wachsen als dort. Verquicktes Zink verhielt sich wie unverquicktes, Kupfer anfangs wie Zink, später mehr wie Platin.

Hier schliessen sich einige Wahrnehmungen verwandter Natur an Bäuschen, statt an Eiweiss, an. Auf ein Kupferelektrodenpaar bringe man Bäusche mit gesättigter schwefelsaurer Kupferlösung getränkt, und verbinde sie mittels Fliesspapierstreifen, die mit derselben Lösung getränkt sind; oder man treffe die gleiche Anordnung mit f̧erquicktem Zink und Zinklösung. In beiden Fällen glanbt man alle Bedingungen für die Beständigkeit des Stromes erfüllt zu haben. Mit nichten; bei zwanzig Gliedern im Kreise fast augenblicklich, noch bei fünf nach nicht allzulanger Zeit sieht man den Strom plötzlich bis auf einen kleinen Rest verschwinden. Legt man um, so stellt er sich im Nu wieder her, ohne dass langsames Wachsen folgt, und das Sinken beginnt von Nenem, früher oder später, je nach der Stromstärke. Aehnlich wirkt Oeffnen des Kreises während einiger Minuten. Die Besichtigung der Elektroden lehrt übrigens, dass der galvanoplastische Process nicht ordentlich ron statten geht. Bei gleicher Stärke des Stromes ist seine Unbeständigkeit um so grösser, je kleiner die Elektroden, je trockener die Bäusche und je fester sie den Elektroden anliegen. Nicht einmal wem man die Elektroden mit darauf gebundenen Bäuschen in Gefässe taucht, die ein Schliessungsrohr überbrückt, oder wenn mur der einen ein Bausch anliegt, wird der Strom beständig. Nur der Theil des Stromes verhält sich so, der von den frei umspülten Kanten u. s. w. beider Metallplatten ausgeht. [883]

Man sieht leicht, wie gefährlich diese Erscheinung in manchen Versuchen werden kann, wemn man nicht darauf rorbereitet ist. Dass es sich dabei im Wesentlichen nicht um Polarisation handelt, geht abermals

1 Die Literatur hierzu s. in meinen Untersuehurgen u. s. w. Pd. I. S. 212. 
aus dem Betrage der Stromschwächung und der beim Umlegen stattfindenden positiven Wirkung hervor, dann aber, in diesem Fall, auch noch daraus, dass dieselben Elektroden, von denselhen Elektrolyten frei umspült, überhaupt keine hier in Betracht kommende Ladung annehmen. Die Erscheinung beurkundet sich vielmehr als dem Gebiete des secundären Widerstandes angehörig dadureh, dass man durch verstärkten Druck auf den Eintritts-, nicht auf den Austrittsbausch, die Stromstärke auf Augenblicke wiederherzustellen vermag.

\section{§. X. Zur Theorie des äusseren secundären Widerstandes.}

Dies sind die wichtigsten Thatsachen, die ich über den äusseren secundären Widerstand ermittelt habe. Eine sichere Deutung dieser Erscheinung darauf zu gründen, muss ich mich leider zur Zeit noch bescheiden.

Klar ist zunächst, dass der Unterschied im Verhalten des Ein- und Austrittsendes, wie er beim Eiweiss, dem Knorpel u. s. w. zwischen Kupfersalzbäuschen sich uns dargeboten hat, zu bringen ist auf Rechnung jener überführenden, oder. wie ich sie gern nenne, kataphorischen Wirkung des Stromes, deren Bedeutung in diesem Gebiete mit jedem Tage wächst, seit Hr. WIEDEmans sie der Vergessenheit entriss und ihre Gegenwart überall da wahrscheinlich machte, wo der elektrisehe Strom in CapillarAggregaten eingeengte Elektrolyte ergreift. ${ }^{1}$ Sobald der Strom begomnen hat, von Bausch zu feuchtem porösen Körper, von diesem zu Buusch überzugehen, reisst er auch die Flüssigkeiten darin mit sieh, und treibt die Kupferlösung des Eintrittsbausches in das Eiweissprisma oder das Stück Rippenknorpel, das Wasser oder den Saft aus diesem in den Austrittsbausch hinein.

Es scheint beim ersten Blick, als müsse clie Folge hiervon gerade das Umgekehrte rom äusseren secundären Widerstande [884] sein. Man sollte meinen, das mit der besserleitenden Kupferlösung durchdrungene Eintrittsende, und somit der ganze feuchte poröse Körper. müsse an Widerstand verlieren.

Es giebt aber noch etwas anderes zu bedenken. Die rerschiedenen Elektrolyte unterliegen der Fortführung im Strome bekanntlich um so mehr, je schlechter sie leiten. Die Feuchtigkeit im Eiweiss wird also schneller nach dem Austrittsbausch zu wandern, als die Kupferlösung

I [Hr. G. Quincke hat seitdem über diese Erscheinung, wie auch über das von Hrn. Jüngedsen entileckte reciproke Phänomen (s. unten §. XII) folgenreiche Untersuchunge nangestelit.] 
darin ihr Platz machen kann. Daher rührt die kegelförmige Anschwellung am Austrittsende, welche um so grössere Dimensionen annimmt, je länger der Strom, wie dies beim Kochsalz u. s. w. der Fall ist, ungeschwächt, oder gar durch die von ihm selber ausgehende Erwärmung des Eiweisses verstärkt, seine kataphorische Wirkung übt. Ebenso wird die Eiweissfeuchtigkeit das Eintrittsende schneller räumen, als die Kupferlösung aus dem Eintrittshausch ihr folgen kann. Daher muss hier, an der Grenze beider Flüssigkeiten, eine an Wasser verarmte und deshalb geschrumpfte und hornig verhärtete Stelle entstehen, die sich aussen als Würgung bemerklich macht. Die Würgung muss, wie die Erfahrung lehrt, mit der Dauer des Stromes an Tiefe und Breite zunehmen, dem mit dieser Dauer muss der Vorsprung wachsen, den die Eiweissfeuchtigkeit vor der Kupferlösung gewinnt. Aber auch die Eiweissstrecke zwischen der Grundfläche und dieser Stelle muss, ganz wie wir es gefunden haben (s. oben S. 104), härter erscheinen als eine durch Diffusion entstandene, weil das Wasser aus dem Eiweiss rertrieben wurde, ehe die gesättigte Lösung eindrang, welche das Eiweiss nicht wie Wasser aufzuweichen rermag.

So weit scheint Alles deutlich, und was liegt näher, als folgendermaassen weiter zu schliessen. Die an Wasser rerarmte Strecke muss nothwendig fast nichtleitend werden, und wirklich haben wir darin den eigentlichen Sitz des secundären Widerstandes erkannt. Die Würgung scheint also selber daran Schuld zu sein, dass sie nicht weiter vorsehreitet, sondern auf einer gewissen Stufe der Ausbildung und in einer gewissen Entfernung rom Eintrittsende stehen bleibt. Dies geschieht, wenn der Strom dadurch so geschwächt ist, dass er den Widerstand nicht mehr zu überwinden rermag, der sich der Bewegung der Flüss- [885] igkeiten im Eiweiss entgegenstellt. Je kleiner übrigens der Querschnitt des Eiweissprisma's am Eintrittsende, um so schwächere Ströme werden dem Wasser über die Kupferlösung einen Torsprung von gegebener Grösse verschaffen, oder in um so kürzerer Zeit wird bei gleicher Stromstärke der gleiche Vorsprung erreicht werden. Hört der Strom auf, so zieht das getrocknete Eiweiss rasch wieder Feuchtigkeit an. Darauf beruht die theilweise Wiederherstellung des Stromes durch das Oeffnen der Kette. Legt man die Wippe um, so wird die ausgedörrte Scheibe durch die mit dem Strome wiederkehrende Feuchtigkeit des Eiweisses bewässert, und der Strom geht schneller und viel weiter in die Höhe, ohne jedoch ganz die ursprüngliche Stärke wiederzuerlangen (s. obeu S. 88. 103): demn in der That verändert die Würgung am alten Eintrittsende ihr Aussehen nur wenig unter dem Einfluss des umgekehrten Stromes, während man sofort eine solche auch an Stelle der früheren Anschwellung am alten Austritts-, dem neuen Eintrittsende, entstehen sieht. 
Mit dieser Theorie stimmt es zwar, dass mit Salzlösungen getränkte balkenförmige Bäusche, als feuchte poröse Körper zwischen die Zuleitungsbäusche gebracht, keinen secundären Widerstand zeigen, insofern jene Lösungen etwa ebenso schnell wandern mögen, wie die Küuferlösung der Zuleitungsbäusche. Die nentrale chromsaure Kalilüsung machte hiervon eine Ausnahme (s. oben S. 87); man müsste aber, um diesen Fall gehörig zu beurtheilen, erst noch mehr Versuche mit Lösungen angestellt haben, die mit Kupferlösung einen Niederschlag geben. Dagegen passt es entschieden nicht zur Theorie, dass geschlämmter Sand (s. oben S. 85) und Modellirthon keinen secundären Widerstand annehmen, dass letzterer, ohne eine Spur davon zu zeigen, die Kupferlösung mit der Zeit zu einem anderen feuchten porösen Körper, etwa Eiweiss, durch sich hindurch lässt, wo dann secundärer Widerstand erscheint. Anch passt es nicht dazu, dass das flüssige Eiweiss, oder vielmehr das darin durch die Metallsalzlösung erzengte Gerinnsel, secundären Widerstand giebt. Das Fortschreiten der Gerinnung im Rohr rom Eintrittsende her hat man sich dabei wohl so zu denken, dass ursprünglich an der Berührungsfläche des Eiweisses mit der Metallsalzlësung eine Schicht gerimnt, in der dam die kataphorische Wirkung vor [886] sich geht. Weshalb nicht dasselbe auch am Austrittsende stattfinde, muss im Dunkel bleiben. Wie dem anch sei, man würde sich hier vergebens, scheint es, nach den Bedingungen umsehen, auf die wir die Theorie des äusseren seeundären Widerstandes gegründet haben.

Und wirklich. wie wohlgelungen sie auch heim ersten Anblick sich ausnehmen mochte, in der Form, wie sie hingestellt wurde, ist die Theorie unhaltbar. Liessen auch jene beiden schwierigkeiten sich wegerklären. sie fällt rettungslos vor der Thatsache, dass es mehrere Flüssigkeiten giebt, welche besser leiten und daher langsamer wandern als Kupferlösung, und welche keinen secundären Widerstand geben, wohl aber die Würgung; und dass es umgekehrt eine Flüssigkeit giebt, die Höllensteinlösung, bei der, trotz dem sehr starken secundären Widerstande, die Würgung vermisst wird. Die Würgung kamn also ohme secundären Widerstand, und dieser kann ohne jene bestehen. Da aber die Würgung, wo sie mit secundärem Widerstande zusammen vorkommt, sich als dessen eigentlicher Sitz erweist, so muss sie gleichwohl irgendwelche Beziehung dazu haben. Die Frage scheint nur zu sein, weshalb die Würgung bei gewissen Flüssigkeiten nichtleitend werde, bei anderen nicht.

Eine Musterung der Flüssigkeiten, welche secundären Widerstand geben und rersagen, führt in dieser Hinsicht zu keinem Ergebniss. Einen Augenblick glaubte ich, die Flüssigkeiten der letzteren Art seien vor denen der ersteren, wie die Kochsalzlösung vor der Kupferlösung, allgemein

E. $d u$ Bois=Reymond, Ges. Abh. I. 
durch grössere Wassergier ansgezeichnet, und ich dachte mir den Znsammenhang so, dass, wo kein secundärer Widerstand stattfinde, die durch den Strom getriebene Feuchtigkeit des Eiweisses die Lösung nach sich ziehe, und deshalb die Würgung immer himreichend gut leite. Allein erstens giebt auch eine verdünnte Kochsalzlösung keinen secundären Widerstand, obschon sie noch immer riel besser leitet, oder langsamer wandert, als die Eiweissfeuchtigkeit, während ihre Wassergier nur noch gering sein kamn; für's Zweite hat, bei grüsserer Vervielfältigung der Versuche, die Vertheilung der Flüssigkeiten in solche die Widerstand geben und die ihn versagen, überhaupt nicht mehr [S8i] deren kleinerer und grösserer Wassergier entsprochen, wie denn unter die ersteren Flüssigkeiten anch die so höchst wassergierige Chlorzinklösmng zı stehen gekommen ist.

Eime andere Bemerkung ist vielleicht thatsächlich besser begründet, allein für das Verständniss ist damit nichts gewonnen. Die Sternchen bezeichnen nämlich unter den oben S. 107 angeführten Flüssigkeiten die, welche in dem filtrirten Hühnereiweiss einen undurchsichtigen Niederschlag bewirken. Wie man sieht, sind merkwürdigerweise alle Flüssigkeiten, welche secundären Widerstand geben, solche, welche das Eiweiss fällen; doch stehen auch einige Flüssigkeiten der Art in der Reihe derer, welche secundären Widerstand rersagen. Ich rermag keine Hypothese zu ersimnen, wodurch das Vermögen einer Flüssigkeit, das Hühnereiweiss undurchsichtig zu fällen, verknüpft würde mit dem, in Berührung mit dem geronnenen Eiweiss unter dem Einfluss des Stromes secundären Widerstand zu erzeugen. Um zu ermitteln, ob wirklich eine solche Beziehung stattfinde, würden rielleicht ähnliche Tersuchsreihen mit Glutin und Chondrin einen WTeg abgeben.

Was die Erscheinungen bei Anwendung metallischer Elektroden betriffit, so kann man die Unbeständigkeit des Stromes, wenn umpolarisirbare Elektroden nicht frei ron dem Elektrolyten mmspült sind, sondern dieser in den Capillarräumen eines Bansches seiner Beweglichkeit beranbt ist, zwar zunächst so auffassen, als verschliesse sich der Strom gleichsam selber die Thüre durch seine kataphnrische Wirkung, indem er die an die Anode grenzende Lage des Bausches austrockne. Damit stimmt es, dass Anpressen des Bausches an die Anode den Strom auf Angenblicke wiederherstellt. Unerklärt bleibt aber dabei, dass der Strom anch unbeständig ist, wemn nur der Kathode ein Bausch anliegt. Man kann nur muthmaassen, dass dabei Aehnliches vergeht, wie wenn bei frei umspülten Elektroden deren eingetanchte Fläche zu klein im Verhältniss zur Stromstärke ist. Bei dem Eiweiss wird der Vorgang noch dadurch verwickelt, dass die von der Zersetzung der Salze des Eiweisses stammen- 
den Anionen und Kationen sich in's Spiel mischen, wie sich dies in der Beschaffenheit des Ein- und Austrittsendes ausspricht. Dass die kegelförmige Anschwellung sich hier nicht durch Umlegen der [888] Wippe von dem alten an das neue Eintrittsende rerlegen lässt, rührt gewiss davon her, dass die alkalische Flüssigkeit nicht mehr hinlänglich der kataphorischen Wirkung gehorcht. Die Umregelmässigkeiten, welche die positiveren Metalle zeigen, bleiben vollends räthselhaft.

Unter solchen Umständen gebrach es mir vor der Hand an jedem Fingerzeig, um diese Untersnchung zu gutem Ende zu führen, und ich habe $\mathrm{mm}$ so mehr geglaubt, sie anf sich beruhen lassen zu dürfen, als mit der Einsicht, dass der äussere secundäre Widerstand auf rein örtlicher Wirkung an der Grenze der zuleitenden Theile der Vorrichtung und der feuchten porösen Körper beruht, die Erscheinung überhaupt das - allgemeine Interesse eingebüsst hat, das ihr anfangs zuzukommen schien. Nun löst sich das Problem, welches sich uns darin darbot, zu ebenso vielen Einzelaufgaben mehr untergeordneter Art auf, wie sich Zusammenstellungen ron Elektrolyten denken lassen, womit man die Bäusche und den porösen Körper tränken kann. Es ziehen uns unter diesen Aufgaben nur noch diejenigen an, deren Behandlung verspricht, zugleich die Bedingungen der elektrophysiologischen Versuche ummittelbar aufzuklären. Ich habe mich deshalb auch nicht weiter bemüht, die Art und Weise zu zergliedem, wie der äussere secundäre Widerstand am Eintrittsende anderer feuchter poröser Körper entsteht.

Nur über den äusseren secundären Widerstand, den mit verdümnter Schwefelsäure getränkte Bäusche zwischen den gewöhnlichen Zuleitungsbäuschen annehmen (s. oben S. 87), habe ich noch Versuche angestellt. Ich dachte mir nämlich, im Simn obiger Theorie, dass hier, wo der Elektrolyt in fenchten porösen Körper besser leitet, also langsamer wandert, als der in den Bäuschen, der äussere secundäre Widerstand seinen Sitz statt am Eintritts- rielmehr am Austrittsende haben werde. Ich führte deshalb den Strom der Säule einem balkenförmigen Schwefelsäure-Bausch durch Keilbänsche zu, und rückte, nachdem der Strom sich selber so stark wie möglich geschwächt hatte, bald den Eintritts-, bald den Austrittsbausch, und zwar deren jeden bald nach Immen, bald nach Aussen von der Stelle. Das Verrücken beider Bäusche nach Aussen brachte eine Schwächumg, das Verrücken beider nach Innen eine Verstärkung des Stromes [889] hervor, allein die Stromveränderung, welche dem Verrücken des Eintrittsbausches entsprach, übertraf in beiden Fällen die, welche dem des Austrittsbausches folgte. Jene Voraussicht fand sich also nicht bestätigt, und auch hier erscheint, wie schon oben S. 89 gezeigt wurde, das Eintrittsende als Sitz des secundären Widerstandes. Inzwischen ist 
wohl der Vorgang hier ein ganz anderer als beim Eiweiss. Offenbar hatte der Schwefelsäurebausch in der ganzen Umgebung des Eintrittsbausches, d. h. auch nach Anssen davon, wo gar kein Strom hingelangt, grösseren Widerstand angenommen, als in der des Austrittsbausches. Ich vermuthe, dass dies ron der thermischen Wirkung des Stromes herrührt. Der ganze Bausch wird nämlich sehr heiss, und man sieht demgemäss den Strom anfangs stets erst eine Zeit lang ansehnlich wachsen, bis die Stromabnahme erfolgt, die wir als Entwickelung äusseren secundären Widerstandes aufgefasst haben. Das vom Eintrittsbausch aus in den Schwefelsäurebausch eindringende Kupfersalz krystallisirt dort aus, verklebt die Lagen des Bausches mit einander und überzieht seine Oberfläche mit einem weisslichen Anfluge. Dies trockene Salz scheint es mir zu sein, welches den äusseren secundären Widerstand im Fall des Schwefelsämrebausches bedingt.

Ob der oben S. 105 erwähnte muthmaassliche Temperaturunterschied des Ein- und Austrittsendes nicht rielleicht anch eine Rolle bei Erzengung des äusseren secundären Widerstandes spiele, muss ich dahingestellt sein lassen.

§. XI. Noch Einiges über den inneren secundären Widerstand.

Wir sind jetzt aller Wahrscheinlichkeit nach in den Stand gesetzt, unserer Kenntniss des inneren secundären Widerstandes noch Einiges hinzuzufügen. Das Mittel dazu wird uns in Aussicht gestellt durch die Entdeckung der Möglichkeit, fenchten porösen Körpern den Strom zuzıführen, ohne dass äusserer secundärer Widerstand sich eimmische. Beim Eiweiss wird dies, wie wir gefunden haben, dadurch erreicht, dass man es von der Kupferlösung der Zuleitungsbäusche durch Kochsalz-Hülfsbäusche tremnt. Es steht aber zu vermuthen, und findet sich glücklicherweise bestätigt, dass dieselbe Anordnung uns anch in Be- [\$90] zug auf ähnliche lenchte poröse Körper den gleichen Dienst leisten werde.

Bringt man zwischen jene Hülfsbäusche ein Prisma ans einer gekochten Kartoffel geschnitten, oder einen gekuchten Begoniasticl, so zeigt sich in der That, dass der äussere secundäre Widerstand beseitigt ist. Die Ablenkung erscheint wegen der thermischen Wirkung des Stromes in stetigem Wachsen begriffen, und erreicht erst spät einen beständigen Werth. Legt man um, so kommt das Scalenbild sehr nahe in derselben Lage, meist in etwas grösserer Ablenkung, wieder zur Ruhe; langsames Wachsen findet nicht statt. Stellt man den gleichen Versuch mit den frischen Gewebetheilen an, so sinkt die Ablenkung sofort, und nähert 
sich allmählich einer unteren Grenze, wie vorher einer oberen. Dem Umlegen folgt langsames Wachsen bis zu einem gewissen Punkte, dann ernentes Sinken, u. s. w. Es ist kein Grund vorhanden, anzunehmen, dass an der Grenze der frischen Pflanzengewebe und der Kochsalzlösung sich secundärer Widerstand einstelle, wenn dies nicht mit den gekochten der Fall ist. Ueberdies lässt sich dessen Ausbleiben so darthum, dass man den Strom durch Tieilbänsche zuführt und zeigt, wie das Verrücken weder des Ein- noch 'des Austrittsbausches anders auf die Stromstärke wirke, als durch Veränderung der Länge der zwischen beiden begriffenen Strecke. Die Schwankungen, die der Strom in den frischen Pflanzengeweben zwischen Kóchsalzlïsung zeigt, sind also nur zu erklären durch einen inneren secmuären Widerstand dieser Gewebe, dessen Dasein somit rersprochenermaassen (s. oben S. 95) noch auf einem vierten Wege beglaubigt ist.

Bei dieser Versuchsweise hat man Gelegenheit zu bemerken, was wegen des äusseren secundären Widerstandes früher nicht sicher anging, dass die Schwankungen des Stromes in Folge des immeren secundären Widerstandes, je länger man sie beobachtet, $\mathrm{mm}$ so kleiner werden.

Jetzt kann es keine Schwierigkeit mehr haben, die Frage nach dem Einfluss der Stromdichte auf diesen Widerstand, die uns oben S. 99 ff. vergeblich beschäftigte, zu erledigen. Man brancht dazu nur zwischen die Kochsalz-Hülfsbäusche abwechselnd ein Kartoffelprisma von grossem, und ein solches von kleinem [891] Querschnitt zu bringen, indem man zugleich dafür sorgt, dass die ursprüngliche Stromstärke in beiden Fällen die gleiche, oder mit dem dickeren Prisma etwas grösser sei als mit dem dümneren. Fallen alsdann die Schwankungen der Stromstärke mit dem dickeren Prisma absolut kleiner ans als mit dem dümneren, so kamn dies nur daher rühren, dass der dichtere Strom in letzterem einen stärkeren inneren secundären Widerstand entwickelt. Ich habe diesen Erfolg mehrmals deutlich beobachtet, wobei ich es bequem fand, gewissermaassen als Rheostat, um damit die Stromstärke beständig zu erhalten, einen Stab aus Modellirthon zwischen Bänschen im Kreise zu haben, dessen Dimensionen sich leicht jeden Augenblick ändern lassen.

Wie schon oben S. 95 bemerkt wurde, ist gegen den bis jetzt gelieferten Beweis der Abwesenheit des inneren secundären Widerstandes in vielen feuchten porösen Körpern einzuwenden, dass dieser Beweis mittels eines Stromes geführt wurde, der durch den äusseren secundären Widerstand sehr geschwächt war. Immer würde ein bedentender Unterschied in dieser Beziehung zu Gunsten der frischen Pflanzengewebe bestehen bleiben. Denn diese Gewebe leiten um so viel schlechter als z. B. das Eiweiss, dass der durch den äusseren secundären Widerstand auf das 
Aeusserste geschwächte Strom in einem Eiweissprisma noch immer grössere Dichte besitzt als in einem Kartoffelprisma von gleichen Maassen. Allein es wäre möglich, dass mit Kochsalz-Hülfsbänschen sich jetzt Spuren des inneren secundären Widerstandes da entdecken liessen, wo sie mit den Kupfersalz-Zuleitungsbäuschen vermisst wurden.

Bei den gekochten Pflanzengewebetheilen ist dies indess nicht eingetroffen, und ebensowenig bei dem Eiweiss, in Bezug worauf der entscheidende Versuch sich schon oben S. 106 angestellt findet. Ist ein Eiweissprisma zwischen Kochsalz-Hülfsbäuschen dem Strom ausgesetzt, so folgt dem Umlegen der Wippe kein langsames Wachsen; also ist kein innerer secundärer Widerstand da. Dies ist nämlich die Gestalt, welche jetzt hier der Umkehrversuch annimmt, der oben S. 94.95 als für das Dasein des imneren secundären Widerstandes entscheidend erkannt wurde, indem bei der Geringfügigkeit der inneren Polarisation das Bedenken nicht stattfand, dem wir oben S. 109, [892] wo es sich um Polarisation metallischer Elektroden handelte, allerdings Gehör geben mussten. Man kamn aber auch, wemn man vollends sicher gehen will, den Umkehrversuch in seiner ursprünglichen Form beibehalten. Auf beiderlei Art habe ich mich überzengt, dass auch nnter dem Einfluss des durch äusseren secundären Widerstand ungeschwächten Stromes der zwanziggliederigen Grove'schen Säule, Sehne, Rückenmark und Muskelfleisch rom Rinde, letzteres längs der Faser sowohl als senkrecht darauf durchströmt, keinen inneren secundären Widerstand ammehmen.

Nun aber erhebt sich eine Frage ron wesentlichem Interesse. Die Pflanzengewebe büssen durch Kochen die Empfänglichkeit für den secundären Widerstand ein. Das todte Holz, die im Papier und der Pappe verarbeitete Pflanzenfaser nehmen keinen solchen Widerstand an. Die thierischen Gewebe, die wir bisher darauf geprüft haben, waren zwar so frisch, wie man sie aus dem Schlachthause bekonmen kann, da sie aber von Warmblütern stammten, unstreitig als todt anzusehen. Es ist also die Möglichkeit da, dass thierische Gewebe, die noch im Besitz ihrer Lebenseigenschaften verharren, jenes Widerstandes fähig seien. Unterstützt wird diese Vermuthung durch die Wiahnehmung, dass Inskeh, ganz wie Kartoffehn und Begoniastiele, durch Kochen sehr an Leitungsgüte zunehmen. Obwohl es vielleicht nicht unthunlich wäre, Versuche über den imneren secundären Widerstand an lebenden Warmblütern, ja am Menschen selbst, anzustellen, habe ich mich in dieser Rücksicht bisher auf die uns zunächst angehenden Muskeln und Nerven des Frosches beschränkt.

Das beste Versuchsobject, was die Muskeln betrifft, wird durch die Gruppe der beirlen ziemlich parallelfaserigen starken Muskeln des Oher- 
schenkels, des Adductor magnus und Semimembranosus Cuv., geboten. Man lässt dem oberen Ende der Gruppe die Symphyse, dem unteren das obere Ende der Tibia, und spannt die Muskeln in der früher' ${ }^{1}$ von mir beschriebenen kleinen Spanmvorrichtung wagerecht so stark aus, dass bei [893] Znckungen keine in Betracht kommende Verschiebung der Muskeloberfläche an den ihr anzulegenden Kochsalz-Keilbäuschen stattfinden kann. Es ist deshalb zweckmässig, den zwischen dem Addnctor magnus und dem Semimembranosus gelegenen, aus zwei kurzen Köpfen bestehenden Semitendinosus Cuv. zu entfernen. Dem wenn man den langfaserigen beiden anderen Muskeln die obenbezeichnete Spannung ertheilt, läuft man Gefahr, den Semitendinosus so stark zu spannen, dass er entweder rasch abstirbt, ${ }^{2}$ oder gar zerreisst. Die Schneiden der Keilbäusche bekleidet man, um das Anätzen zu verhindern, mit Rücksicht auf die lange Dauer der Versuche, mit doppelten Eiweisshäntchen. Man legt der Muskelgruppe die Schneiden imnerhalb der Elfenbeinplatten der Spannvorrichtung, und letzteren so nahe wie möglich an. Dazu ist es vortheilhaft, dem Keilbausch auf dem Zuleitungsbausch die mugekehrte Lage ron der gewöhnlichen zn geben, wie sie Fig. 5 (s. oben S. 89) zeigt, nämlich die, wobei die Abschrägung des Keiles nicht nach der hinteren, sondern nach der vorderen Seite des Znleitungsbausches sieht. Zwischen den Kochsalz-Keilbäuschen des Hauptstromes legt man der anderen Seite der Mnskelgruppe die gleichfalls mit doppelten Eiweisshäutchen bekleideten Schneiden der mit schwefelsaurer Zinkoxydlösung getränkten Keilbäusche der Hülfskette an.

So kann man nunmehr mit den lebenden Iuskeln die nöthigen Versuche anstellen, um zu erfahren, ob sich in deren Innerem secundärer Widerstand entwickele, oder nicht. Es zeigt sich, dass der Hauptstrom, abgesehen ron der thermischen Verminderung des Widerstandes, beständig bleibt, er stamme von fünf oder ron zehn Grove'schen Gliedern, welche hier, wegen des kleineren Querschnittes, gewiss eine gleiche Dichte erzeugen, wie zwanzig in den bisherigen Versuchen. Umlegen bringt, bei nur kleiner Gliederanzahl der Säule, einen leichten positiven Ansschlag hervor, der von innerer Polarisation herrührt, und dem kein langsames Wachsen folgt. Den Hülfsstrom findet man, unter Berücksichtigung der immeren Polarisation (s. oben S. 95. 96) und der Erwärmumg der Mnskehı [894] durch den Hauptstrom, nach dem Durchgang des letzteren so stark wie vorher. Nach dem Oeffnen des Hauptstromes steigt der Hülfsstrom nicht an. Ob der Hauptstrom in den Mnskeln auf- oder absteige,

1 Untersuchungen u. s. w. Bd. II. Abth. I. S. 67. Taf. I. Fig. 86. 87.

2 Ebendas. S. 70. 
oder quer durch eine grössere Muskelmasse, z. B. durch die Dicke der beiden Oberschenkel, fliesse, ist für den Erfolg gleichgültig. Nach den Versuchen waren meist die Muskeln noch zuckungsfähig.

Was die Nerven betrifft, so ist man natürlich an die Ischiadnerven gewiesen. Man bereitet sich rasch deren acht, legt sie mit ihren centralen und ihren peripherischen Enden zusammen, so dass sie ein Bündel bilden, welches der Austrocknung himreichend lange widersteht, und spannt sie wagerecht zwischen zwei an einem Glasstabe verschiebbaren, passend geformten Korkstücken aus, auf deren Oberfläche man sie mit Insectemmadeln feststeckt. Damn legt man ihnen ganz wie den Muskeln die beiden Paare von Keilbäuschen an. Der Erfolg ist der nämliche, wie bei den Muskeln, nur dass die Störungen durch innere Polarisation minder fühlbar sind.

Es ergiebt sich also schliesslich, dass Iuskeln und Nerven inneren secundïren Widerstand im Leben so wenig wie im Tode in merklichem Grade annehmen, und die frischen Pflanzengewebetheile sind nach wie vor die einzigen fenchten porösen Körper, die ihn uns gezeigt haben.

§. XII. Was sich zur Zeit über die Natur des inneren secundären Widerstandes sagen lasse.

Es würde übrig bleiben über die Natur der Erscheinung, wenn es angeht, eine Vermuthung aufzustellen. Leider sind uns die Flügel hier noch viel mehr als beim äusseren secundären Widerstande beschitten.

Zunächst nämlich ist zu bemerken, dass das Mikroskop in den dem Strome der zwanziggliederigen Grove'schen Säule unterworfenen Pflanzengeweben durchans keine Veränderung zeigt, die als Ursache des secumdären Widerstandes zu deuten wäre. Ich habe vergeblich danach gesucht bei der Kartuffel, der Mohrrübe, der Petersilienwurzel und dem Begoniastiel. Das Einzige, was sich darbietet, ist gelegentlich die merkwürdige, von Hrn. Jürgensen beschriebene Bewegung fester Theilchen in der [895] dem Strom entgegengesetzten Richtung. ${ }^{3}$ Ich habe diese namentlich in sehr auffallender Weise an den Stärkekörnchen im Inneren der Kartoffelzellen gesehen, welche, wo sie hinreichend lose lagen, mit der vollkommensten Regelmässigkeit, sobald der Strom geschlossen wurde, sich an die Eintrittswand drängten, sobald er umgelegt wurde, sich nach der nenen Eintrittswand begaben, kurz mit der Wippe, so zu sagen, hin und her pendelten; so dass man so gewiss, wie aus der Ablenkung der

1 Reichert's und DU Bois-Rexmond's Archiv für Anatomie und Physiologie u. s. w. 1860 . S. 673. 
Nagnetnadel, die Richtung des negativen Stromes ans seiner anaphorischen Wirkung auf die festen Theilchen würde bestimmen kömen.

Hier also gebricht es uns von vorn herein an jedem Anhaltspunkt, um daran eine Erklärung der Erscheinung zu knüpfen. \an kamm nun zwar leicht mehrere Vermuthungen darüber aufstellen, wie der Strom innerhalb eines feuchten porösen Körpers einen Widerstand hervorrufen könne. Мan kann sich z. B. den inneren secundären Widerstand als in dem nämlichen Verhältniss zur imneren Polarisation denken, wie den Uebergangswiderstand an der Grenze metallischer Elektroden zur Polarisation dieser letzteren. Ich erwähne diese Hypothese nur, weil sie mich zu einer Zeit, wo ich noch nicht im Stande war ihre Unhaltbarkeit zu durchschanen, zu einem Versuch veranlasste, dessen nutzlose Wiederholung, wenigstens in derselben Form, ich gern Anderen ersparen möchte.

Ich tränkte eine ansehnliche Masse Platinschwamms, deren Benutzung ich der Güte des Hrn. Dr. Qunckese verdankte, mit destillirtem Wasser, ferner Holzkohle mit derselben Flüssigkeit oder mit Kochsalzlösung, setzte sie in passender Weise einem starken Strom ans, in dessen Kreise sich die Bussole befand, und versuchte ob es gelingen werde, beim Umkehren des Stromes in den feuchten porösen Körpern, langsames Wachsen der Stromstärke zu beobachten. Dies wäre unter gewissen Voraussetzungen zu deuten gewesen anf Verschwinden des Uebergangswiderstandes, und hätte für das Dasein eines solehen einen mehr unmittelbaren Beweis abgegeben, als die bisher vorhandenen. [896] Ich bekam aber mit Sicherheit nichts zu sehen, als die gewaltigen Wirkungen der gewöhnhichen Polarisation.

Jene Hypothese scheitert, wie jetzt leicht ersichtlich, erstens an dem IIangel an Proportionalität zwischen immerer Polarisation und innerem secundären Widerstande, zweitens daran, dass dieser Widerstand bis jetzt nur am frischen Pflanzengewebe beobachtet ist. Letzterer Umstand bricht überhaupt den Stab allen solchen Vermuthmgen hinsichthich des inneren secundären Widerstandes, die auf beliebige, mit Elektrolyten getränkte Capillar-Aggregate passen. Es ist vielmehr klar, dass es hier zunächst einer Annahme bedarf, wodurch wenigstens diese Art feuchter poröser Körper vorweg ausgeschlossen werde. Eine solche Annahme würde jetzt z. B. sein, dass der innere secundäre Widerstand auf der häufigen Wiederholung der Bedingungen des äusseren secundären Widerstandes im Inneren eines Körpers beruhe, insofern man nämlich als allgemeinste Vorbedingmug des äusseren secundären Widerstandes irgend welche Discontinuität der Leitung hinstellen kann. Allein es möchte schwer sein, in den frischen Pflanzengeweben eine sich oft wiederholende Discontimuität der Leitung zu entdecken, welche sich erstens auch nur einigermaassen dem vergleichen 
liesse, was wir zur Erzeugung des äusseren secundären Widerstandes als nöthig erkannt haben, und welche sich zweitens nicht auch in den des inneren secundären Widerstandes unfähigen Thiergeweben nachweisen liesse.

Der Fingerzeig endlich, den man darin hätte sehen kömnen, dass die Pflanzengewebe, wenn sie durch Kochen die Fähigkeit einbüssen, inneren secundären Widerstand anzunehmen, zugleich besser leitend werden, hat seine Bedentung dadurch verloren, dass auch die Muskeln durch Kochen an Leitungsgüte gewinnen, ohne darum im Zustande des Lebens inneren secundären Widerstandes fähig zu sein.

§. XIII. Anwendung der Erfahrungen über den secundären Widerstand auf die elektrophysiologischen Versuche.

Doch kümmert uns der schlechte Erfolg dieser theoretischen Bemühungen für jetzt nicht. Für uns ist, was den secundären Widerstand betrifft, Alles damit gewomnen, dass wir die Muskeln [897] und Nerren ron dem Verdacht gereinigt haben, damit behaftet zu sein. Es wäre dadurch, bei unzähligen Gelegenheiten, den thierisch-elektrischen und elektrischen Reiz-Versuchen eine Verwickelung mehr aufgebürdet worden, welcher wir num glücklich überhoben sind.

U'm so mehr Beachtung verdient bei manchen dieser Tersuche der äussere secundäre Widerstand. Gleich den todten Geweben der Warmblüter sind die lebenden Muskeln und Nerven des Frosches dafür empfänglich; ja die Kleinheit der Flächen, die sie stets nur der Berührung bieten, lässt sie sogar in hohem Grade so erscheinen.

Wird der Strom von zehn bis zwanzig Grove'schen Gliedern dureh mit schwefelsaurer Kunferoxydlösung getränkte Keilbäusche der wie oben S. 119 aufgestellten Muskelgruppe zugeführt, so findet man ihn fast unmittelbar nach der Schliessung in rasehem Sinken begriffen, und es bleibt zuletzt nur wenig daron übrig. Wo der Eintrittsbausch den Muskeln anlag, bemerkt man eine blangrüne, verhärtete Stelle, die der Würgung beim Eiweiss entspricht. Eiweisshäutchen wie Thonschilder sind unvermögend dem Sinken Einhalt zu thun. Unter dem Einfluss des Stromes durchdringt das Salz bald den Thon, die Eiweisshäutchen aber werden, wie sich erwarten liess, selber ein Sitz secundären Widerstandes. Rückt man am Austrittsbausch, oder entfernt man dessen Eiweisshäutchen, so bleibt Alles beim Alten. Rückt man am Eintrittsbausch, so erfolgt eine Hebung der Stromstärke, jedoch nur um einen Theil des Verlustes, den sie durch Entwickelung des secundären Widerstandes erlitt. Mrren ursprünglichen Werth erlangt sie erst wieder, mit anderen Worten, der übrige Theil des secundären Widerstandes wird erst beseitigt, wenn man 
den Eintrittsbausch, indem man ihn verrückt, zugleich von seinen Eiweisshäutchen befreit.

Noch mit nur drei Grove'schen Gliedern erfolgen diese Erscheinungen, nur minder scharf ansgeprägt, langsamer verlaufend, und nicht selten in der Art unregelmässig, dass nur wemn der eine Bausch dem Strome zum Eintritt dient, secundärer Widerstand erscheint, bei der anderen Richtung nicht, ein Verhalten, welches wir beim Eiweiss künstlich zu erzeugen rermochten (s. oben S. 103). Mit zwei Gliedern sind nur noch Spuren [898] rom secundären Widerstande da, mit einer einfachen Kette ist der Strom beständig, wenn man ron der inneren Polarisation absieht.

Ganz ähnliche Erfolge beobachtet man an den Nerven; wemn sie gleiche Länge mit den Muskeln haben, wegen ihres geringeren Querschnittes, trotz der kleineren Berührungsflächen, jedoch erst bei grösserer Gliederzahl der Säule. Endlich die schwefelsaure Zinkoxydlösung verhält sich auch hier, wie wir dies schon beim Eiweiss erfahren haben, gleich der Kunferlösung.

Aus diesen Thatsachen fliesst die wichtige Regel, dass wenn man Muskeln oder Nerven beständige Ströme von einiger Stärke zuzuführen wünscht, man bei Gefahr, secundären Widerstand zu erwecken, und ganz abgesehen von der der Anätzung, die thierischen Theile nicht ummittelbar mit der Metallsalzlösung der unpolarisirbaren Combination berühren darf, deren man sich zur Zuleitung bedient. Ebensowenig darf man sich den mit solchen Lösungen getränkten Bäuschen anvertranen, nachdem sie mit Eiweisshäutchen bekleidet sind. Nicht einmal auf die von $\mathrm{Hrn}$. PFLÜGER ${ }^{1}$ angegebenen Eiweissröhren in der Form, wie er sie angewendet hat, dürfte unbedingter Verlass sein. Das Gerimnsel, welches sich an der Grenze des Eiweisses und der Metallsalzlösung bildet, kamm, wie wir oben S. 108 gesehen haben, der Sitz eines sehr ansehnlichen secundären Widerstandes werden.

Durch diesen Umstand würde die Anwendbarkeit der unpolarisirbaren Elektroden eine sehr empfindliche Beschränkung erleiden, wenn nicht die vorigen Untersuchungen uns auch sogleich das Mittel böten, ihm erfolgreich zu begegnen, freilich auf Kosten der Einfachheit der Anordnung. Dies Mittel haben wir bereits oben S. 119, 120 in Gebrauch gezogen. Es besteht darin, die thierischen Theile oder das sie vor der Anätzung schützende Eiweiss, es möge nun aufgeweichte Blase befenchten oder in Röhren enthalten sein, von der Metallsalzlösung der unpolarisirbaren Combination durch eine Schicht [899] einer der Salzlösungen zu trennen, die wir oben S. 107 als unfähig erkannt haben, in Berührung

1 Untersuchungen über die Physiologie des Electrotonus, Berlin 1859. S. $98 \mathrm{ff}$. 
mit den Thiergeweben und mit Eiweiss secundären Widerstand zu erzeugen, am bequemsten ron Kochsalzlösung.

Auf dem mit schwefelsaurer Zinkoxydlösung getränkten Zuleitungsbausch der verquickten Zinkgefässe wird also, um Muskeln orler Nerven den Strom mehrerer Grove'schen Glieder ohne Besorgniss vor Stürungen durch den secundären Widerstand zuzuführen, ein mit Eiweisshäutchen bekleideter Kochsalz-Keilbausch anzubringen sein. Nan trennt ihn von dem Zuleitungsbausch, um diesen vor Verunreinigung zu schützen, durch einen mit Zinklösung getränkten Sicherheitsbausch und ein mehrere Villimeter dickes Blatt Iodellirthon. Da auch rerdünnte Kochsalzlösung, ja sogar Brumnenwasser, keinen secundären Widerstand giebt. und da ein geringer Unterschied in der Concentration der Kochsalzlösung der beiden Keilbäusche hier von keiner Bedeutung sein kann, so braucht die Lösung nicht gesättigt, sondern nur eben so concentrirt zu sein, wie es die Rücksicht auf die Leitungsfähigkeit des Kreises erheischt. Dies hat den Vortheil, einerseits die Anätzung der thierischen Theile, andererseits die Verunreinigung der Zinkbäusche, mehr zu verzögern, als dies beziehlich die Eiweisshäutchen und die Thonschicht allein thun würden.

Die oben S. 119. 120 beschriebenen Versuche genügen, um die gute Wirkung dieser Maassregeln darzuthum. Bei deren Befolgung bleibt, abgesehen von der imneren Polarisation und ron der Verminderung des Widerstandes durch die thermische Stromwirkung, auch wohl durch das Eindringen der Salzlösungen in Thon und Eiweisshäutchen, die Stromstärke beständig, selbst bei zwanzig Grove'schen Gliedern im Kreise, und bei noch so langer Dauer der Sehliessung. Es zeigt sich somit auf doppeltem Wege, das eine Mal bei sehr schwachen Strömen und Metallsalz-Keilbäuschen. das andere bei beliebig starken Strömen und Kochsalzbäuschen, dass die hier in Rede stehenden, uns vorzugsweise interessirenden Combinationen dem hartgesottenen Eiweiss an Empfänglichkeit für den secundären Widerstand doch glücklicherweise nicht ganz gleichkommen. [900]

Wo man grosse Widerstände nicht zu schenen braucht, und deshalb die Pfü̈ger'schen Eiweissröhren anwenden kann, wird man das Eiweiss gleichfalls noch durch Kochsalzlösung von der schwefelsauren Zinkoxydlösung zu tremnen haben, die jetzt wohl, in Verbindung mit rerquickten Zinkelektroden, an Stelle der Kupferlösung mit Kupferelektroden treten wird, wie $\mathrm{Hr}$. Pflüger sie anwendete. Dies wird, wenn man die PFLÜGER'sche Einrichtung sonst unverändert beibehalten will, einfach so geschehen können, dass man das heberförmige, an beiden Enden mit Blase überbundene Rohr. welches einerseits in das weite Endt der Eiweissröhren, andererseits in das die metallische Elektrode enthaltende Gefäss 
mit der entsprechenden Metallsalzlösmig taucht, statt gleichfalls mit dieser Lösung, mit Kochsalzlösung füllt. Es trifft sich dabei glücklich, dass sogar die gesättigte Kochsalzlösmng (Dichte $1 \cdot 207$ ) gut auf der gesättigten schwefelsauren Zinkoxydlösung (Dichte 1-441) schwimmt. In der Blase entsteht kein secundärer Widerstand; an der Grenze des Eiweisses und der Nerren und Muskehn kamn dies doch wohl ebensowenig der Fall sein.

Bei den thierisch-elektrischen Versuchen, insofern es sich dabei nur um Ableitung der in den thierischen Theilen erzengten Ströme, nicht zugleich um Erregung dieser Theile auf elektrischem Wege handelt, dürfte der äussere secundäre Widerstand so wenig in Betracht kommen. als, wie wir jetzt wissen, der immere. Immerhin kam es als ein glücklicher Zufall erscheinen, dass fast in allen bisherigen Versuchen eine zuleitende Flüssigkeit angewendet wurde, welche vollends den Verdacht auf eime Eimmischung des secundären Widerstandes ausschliesst, die Kochsalzlösung. So z. B. giebt es eine räthselhafte Erscheinung, die bei den Versuchen mit künstlichem Querschnitt fortwährend auftritt, und die man, wemm nicht jener Umstand wäre, wohl geneigt sein kömnte, dem secundären Widerstande zuzuschreiben. Dies ist die schwächende Wirkung, welche die zunächst an den Querschnitt grenzende Schicht nach kurzer Zeit auf den Strom ausübt, so dass die Entfernung dieser Schicht eine bedentende Hebung der Stromstärke bewirkt. ${ }^{1}$ In der That entspricht, [901] wie man sieht, in Bezug auf den Muskel- oder den Nervenstrom der künstliche Querschnitt dem Eintrittsende des durchströmten Eiweissprisma`s. Nach dem, was wir über den secundären Widerstand ermittelt haben, hat es jetzt kaum den Anschein, als ob dieser Muthmaassung noch irgend ein Werth beiznlegen wäre. Ich habe mich ansdrücklich daron überzeugt, dass der künstliche Querschnitt nicht etwa eine besondere Empfänglichkeit für den secundären Widerstand besitzt.

Der Kóchsalz-Keilbäusche, der Pfü̈ger'schen Eiweissöhren mit der bezeichneten Abänderung, wird man sich bedienen, wo es immer geht,

1 Untersuchungen u. s. w. Bd. I. S. 71t; - Bd. II. Abth. I. S. 19. 145. 150. 179. 2\$3. 557; - Abth. II. S. 108. 113. 122. - [Dies wurde seitdem von mir mittels der unpolarisirbaren Elektroden als eine dureh Polarisation bewirkte Täuselıung erkannt, und im Januar 1862 in dem Abdruck gegenwärtiger Abhandlung in MoLEsснотт's Untersuchungen u. s. w. (a. a. O. s. 409) als solche bezeichnet. Ausführlicher findet sich diese Täuschung besprochen in den Abhandlungen: Ueber das Gesetz des IIuskelstromes mit besonderer Berücksichtigung des M. gastroknemius des Frosches, im Archiv für Anatomie u. s. w. 1863. S. 662, und: Ueber die Erscheinungsweise des Muskel- und Nervenstromes bei Anwendung der neuen Methoden zu deren Ableitung, ebenda, 1867. S. 306. 307. - S. diese Abhandlungen im zweiten Bande dieser Sammlung.] 
um den Nerren und Muskeln Ströme zuzuführen. Doch können Fälle eintreten, wo man, z. B. durch die räumlichen Verhältnisse einer Anordnung, genöthigt ist, metallische Elektroden anzuwenden. Alsdann liegt, um sowohl die ursprünglichen Ungleichartigkeiten, als die Polarisation, unschädlich zu machen, der Rathschlag nahe, bei so grussen Widerständen im Kreise, dass man die gewünschte Stromstärke erhält, so grosse elektromotorische Kräfte aufzubieten, dass jene Störungen dagegen rerschwinden. Wo es sich nur darum handelt, rasch vorübergehende Eimwirkungen zu erzielen, so dass man Inductionsschläge anwenden kann, ist dieser Rathschlag untadelhaft, da er nicht eimmal die Unbequemlichkeit bedingt, die stets ans der Handhabung rielgliederiger Säulen erwächst, sondern nur gewisse Rücksichten wegen der unipolaren Zuckungen auferlegt. Sollen aber die Ströme anhaltend und zugleich beständig sein, so sind durch die Versuche, die wir oben mit Eiweiss zwischen verschiedenen Arten metallischer Elektroden angestellt haben. die Aussichten für diesen Fall sehr getrübt. Die Wiederholung dieser Versuche mit Nerven und mit Muskeln, die ich auf Korkstegen mittels Insectennadeln über verschiedene Elektrodenpaare, ron Platin, Kupfer. Zink, verquicktem Zink, ausspannte, ergab unmittelbar, dass an Beständigkeit des Stromes unter diesen Umständen nicht zu denken sei, und zwar nicht, wie man bisher glaubte, wegen der Ungleichartigkeiten oder der. Polarisation, die man leicht gegen die elektromotorische Líraft der Säule verschwinden machen kann, sondern wegen des secundären Widerstandes. Bei den positiveren Me- [902] tallen stellen sich überdies leicht Lnregelmässigkeiten gleich den oben S. 110 beschriebenen ein. ${ }^{1}$

\section{§. XIV. Ueber Elektrotransfusion am erregbaren Muskel.}

Bei den vorigen Versuchen drängte sich mir an den Muskeln fortwährend die merkwürdige Erscheinung auf, die kürzlich $\mathrm{Hr}$. Kü̈HNE beschrieben hat, ${ }^{2}$ und ich kann nicht umhin, hier schliesslich Einiges darüber zu sagen.

Wird ein dümner regelmässig gefaserter Fruschmuskel, etwa der II. sartorius, über die Platin- oder Zink-Elektroden, oder über die Tíeilbausch-Schneiden einer fünf- bis zwanziggliederigen Grove'schen säule

1 [Ueber den secundären Widerstand hat Hr. Prof. Musk weitere Untersuchungen angestellt, durch welche meine Ergebnisse in mehreren Punkten berichtigt und erweitert worden sind. S. Archiv für Anatomie u. s. w. 1873. S. $241 \mathrm{ff}$.]

2 Ueber das Ponret'sche Phänomen am Muskel. Archiv für Anatomie u. s. w. 1860. S. $5+2$. 
ausgespannt, so sieht man nach der Schliessungszuckung eine fluthende Bewegung, gleich einem Strömen des Muskelbündelinhaltes, in der Richtung des positiven Stromes. Wellenartige Verdickungen kurzer Strecken einzelner Bündel oder Bündelgruppen laufen mit grosser Geschwindigkeit von der Anode zur Kathode. Diese Geschwindigkeit ist noch nicht gemessen, auch ist noch nicht ermittelt, welche Beziehung sie mit der Stromstärke verknüpfe. Die Bewregung ändert ihre Richtung augenblicklich mit der des Stromes. Hält man die Kette danernd geschlossen, so wird die Bewegung schwächer und hört zuletzt ganz auf. Ausserdem sieht man bei der Schliessung die Muskelmasse selber scheinbar der Kathode zustïrzen, bei der Oeffnung davon zurückweichen, beim Umlegen von der einen zur anderen Elektrode hinfahren. Lässt man den Muskel zwischen metallischen Elektroden lange in derselben Richtung durchströmen, so findet sich da, wo er die Kathode berührte, eine gallertartige Anschwellung, während er nach der Anode zu verjüngt, dicht unterhalb ihrer aber weiss und undurchsichtig erscheint.

In diesen danernden Veränderungen, denen anch ein abgestorbener Muskel unterliegt, erkennt man leicht die vereinte Wirkung der kataphorischen Thätigkeit und der Elektrolyse wieder, wie wir ihr beim Eiweiss begegnet sind (s. oben S. 104-106). Es fragt sich aber, was ron jenen bald vorübergehenden Bewe- [903] gungserscheinungen am noch erregbaren Muskel zu halten sei. Hr. KüHNE fasst, wenn ich ihn recht verstehe, in seiner vorläufigen Mittheilung diese Erscheinungen so auf, als sei das scheinbare Strömen während des Säulenschlusses der Ausdruck des Porrex'schen Phänomens am Muskel. Er betrachtet die einzelnen Wellen, die von der Anode nach der Kathode lanfen, als ebensoviele Ueberführungsacte, wodureh contractile Substanz an den negativen Pol befördert werde. Beim Oeffnen kehre diese Substanz zurück, die Rückbewegung könne durch die überführende Kraft des entgegengesetzten Stromes unterstützt werden, u. s. f.

Ich kam dieser Deutungsweise meines geehrten Freundes nicht beistimmen. Ton vorn herein ist dagegen zu sagen, dass das scheinbare Strömen zu rasch geschieht, um die geringe Anschwellung an der Kathode als dessen Ergebniss gelten zu lassen. Dann sieht man nicht, weshalb die kataphorische Wirkung stets nur einzelne Theile einzelner Bündel, anstatt gleichzeitig die ganze intrapolare Muskelmasse, ergreife; auch nicht, warum mit der Erregbarkeit zugleich die Bewegung aufhöre, da die gröberen physikalischen Verhältnisse dieselben bleiben, die bei der Ueberführung allein in Betracht kommen. Seit Hrn. Küune's Mittheilung ist durch Hrn. JüngExsex bekannt geworden, dass die festen Körper, unter anderen auch Froschblutzellen, statt wie Elektrolyte mit dem posi- 
tiven Strome, gegen ihn wandern. Danach ist zn erwarten, dass auch die Disdiaklasten stromaufwärts wandern werden.

Ich habe mir, jedoch rergeblich, riel Mühe gegeben, eine mikroskopische Anschanung von dem Vorgange im Huskel bei jenem scheinbaren Strömen zu gewinnen. Am besten gelang mir dies noch am Platysma myördes des Frosches. Der Muskel war mit Blutserum befenchtet und mit einem Deckgläschen zugedeckt. Die Vergrösserung wechselte von der 15- bis 500fachen, die Zahl der Säulengheder von fünf bis zwanzig. Der Strom wurde dem Iuskel einerseits durch em anhängendes Stück Kehlhaut, andererseits durch ein Stïck des geraden Bauchmuskels zugeführt. Stets indess stellten sich die Wellen nur als rasch über das Gesichtsfeld fliegende Schatten dar, und ich halte es für ummöglich das Terhalten der Querstreifen darin anders als etwa bei augenblicklicher Beleuchtung zu erkemen, was seine [904] grossen Schwierigkeiten haben möchte. Hingegen ist es leicht, während das scheinbare Strömen noch fortdanert, an solchen Strecken der Bündel, die gerade ruhig liegen, sich zu überzeugen. dass auch bei der ansehnlichen Stromdichte, wie zwanzig Grove'sche Glieder sie in dem kurzen und dümnen Platysma erzeugen, keine Bewegung der contractilen Substanz stattfindet. Hat das Strömen aufgehört, so erscheint das Gesichtsfeld rollends ruhig, da doch die Elektrotransfusion ihren Gang geht.

Ich habe auch Schnitte erstarrten Leimes, geronnenen Eiweisses. und Speckhaut ron Pferdeblut wiederholt unter dem Mikroskop betrachtet. während ein lebhaftes Ueberführen durch sie hindurch stattfand, jedoch nichts von Bewegung darin unterscheiden können, als gelegentlich, z. B. an rothen und weissen Blutzellen in Lücken der Speckhant, das Jürgexsex'sche Phaenomen.

Meine Ueberzengung ist demnach, dass auch im erregbaren Muskel, wenn er der Sitz der kataphorischen Wirkung wird, nichts stattfinde als ein unsichtbarer Ortswechsel ron Wassertheilchen in der Richtung des Stromes; unsichtbar weil nirgends die zum Unterscheiden einer sich rerschiebenden Grenze nöthige optische Discontimuität eintritt. Das scheinbare Strömen halte ich für den Ansdruck örtlicher Zusammenziehmngen eimzeher Bündel oder Bündelgruppen, welche von der Anode zur Kathode laufen. Man könnte sich denken, dass diese Zusammenzichungen an der Anode örtlich erregt werden, und sich nur scheinbar nach der Kathode hin ausbreiten, weil nach der anderen Richtung kein Muskel vorhanden sei. Diese Vermuthung trifft nicht zn. Bringt man die Kathode an dem einen Ende des Muskels, die Anode in dessen Mitte an, so sieht man wohl in der an die Anorle grenzenden extrapolaren Muskelhälfte ein 
heftiges Wogen der Muskelbündel, aber kein scheinbares Strömen wie in der intrapolaren Hälfte.

Was die Bewegungen im Augenblicke des Schliessens, Oeffnens und Unlegens der Kette betrifft, so ist vor Allem zu erimnem, dass es sich dabei nicht um die contractile Substanz allein handelt, sondern um den ganzen Muskel. Sarkolemma, Perimysium, Alles nimmt an der Bewegung Theil. Wenn man an zwei Punkten der intrapolaren strecke in der Nähe der [905] Elektroden von unten her Fäden durch den Muskel zieht, die mit einem Knoten rersehen sind, um das völlige Durchgleiten zu verhindern, jeden Faden über die benachbarte Elektrode zurückschlägt, und ihn an einem meiner Zuckungstelegraphen ${ }^{1}$ befestigt, so hebt sich beim Umlegen der Wippe stets die Fahne, woran der in der Nähe der neuen Anode befestigte Faden zieht. Steckt man durch den Muskel in gleichen Abständen eine Anzahl Borsten, oder bestrent man ihn mit einem farbigen Pulver, Russ oder Drachenblut. so sieht man denthich, wie sich beim Schliessen der Muskel scheinhar nach der Kathode hinschiebt, beim Oeffnen zurückprallt u. s. f.

Der erste Eindruck, den ich ron dieser Erscheinmug erhielt, war der, dass der Muskel an der Kathode in örtlichen Tetanus gerathe. Da er zwischen seinen beiden Endpunkten ausgespannt ist, so muss, wenn eine Strecke des Muskels sich verkürzt, der ruhende Theil ausgedehnt werden, und scheinbar sich nach dem Orte der Zusammenziehung hin verschieben, in Wirklichkeit aber dorthin gezogen werden. Ich glaubte um so mehr, dass dies die richtige Deutung sei, als bereits Beobachtungen anderer Forscher vorliegen, wonach bei unmittelbarer elektrischer Erregung des Muskels die Kathode eine bevorzugte Rolle spielen würde. ${ }^{2}$ Allein jedenfalls sind die Dinge verwickelter. Verhielten sie sich nämlich einfach wie eben gesagt wurde, so müsste bei der Anordnung: wo die eine Elektrode die Länge des Muskels hälftet, wenn diese, statt wie vorher zur Anode, nunmehr zur Kathode gemacht wird, beim Schliessen das Verschieben nach der Kathode hin, beim Oeffnen das Zurückweichen von der Kathode fort in der extrapolaren wie in der intrapolaren Strecke stattfinden. Zu Anfang einiger Versuche schien mir dies auch wirklich der Fall zu sein, die Bewegung zu beiden Seiten der Kathode war beim Schliessen ziemlich symmetrisch auf die Kathode zu, beim Oeffnen daron fort gerichtet. Sehr bald aber konnte ich mir nicht abläugnen, dass

1 s. unten, Abh. VIII. \&. XV.

2 Vergl. KüHNe im Archiv für Anatomie u. s. w. 1859. \$. 632; - Myologische Untersuchungen. Leipzig 1860. S. 128. - A. v. BEZOLD in den Monatsberichten der Berliner Akademie. 1860. S. $760 \mathrm{ff}$.

E. du Bois-Reymond, Ges. Abh. I. 
beim Schliessen die Muskelmasse in der Richtung von der Anode zur Kathode über letztere [906] fort wogte, und dass beim Oeffnen, als Rückschlag auf diese Bewegung, die extrapolare Muskelmasse nach der Kathode hinfuhr.

Eine vollständige Zergliederung dieser schwierigen Phaenomene liegt hier nicht in meinem Plan. Ich will mir nur die Frage stellen, ob zwischen Bewegungen, wie sie eben beschrieben wurden, und der Elektrotransfusion, ein Zusammenhang für jetzt denkbar sei. Diese Frage muss ich verneinen. Die Elektrotransfusion ist nicht an den Zustand des Lebens gebunden; sie hat mit Schliessung und Oeffnung nichts zu schaffen, sondern hält mit gleicher Stärke während des Säulenschlusses an. Die kataphorische Kraft haben wir bisher nur in Capillar-Aggregaten thätig gesehen, Elektrolyte vor sich hertreibend, denen eine benetzte Wand als Stützpunkt dient. Nichts berechtigt uns noch zu der Annahme, die eine völlige Umgestaltung unserer Vorstellnngen über den elektrischen Strom bedingen würde, dass er hier die Masse des Muskels, gleich einem Balle, von der Anode zur Kathode werfe. Dazu kommt jetzt abermals die JÜrGENSEN'sche Thatsache, welche auch deren Bedeutung sei, wonach die Substanz des Muskels, wenn der Strom ihr wirklich einen Anstoss ertheilte, im Gegensatz zum Wasser in seinen Poren, vielmehr zur Anode streben würde. 
VI.

\title{
Ueber ein Verfahren um feine galvanometrische Versuche einer grösseren Versammlung zu zeigen. ${ }^{1}$
}

\author{
(Aus einem Schreiben an Hrn. G. Magnus.)
}

London, im Mai 1855.

- Wir haben so oft mit einander von der Schwierigkeit gesprochen, feine galvanometrische Versuche eimer grösseren Versammlung zu zeigen, dass ich glaube, es wird Sie interessiren zu hören, wie es mir jetzt gelungen ist, diese Schwierigkeit vollkommen zu besiegen. Ich bin im Stande gewesen, in dem Thnen bekannten Hörsaal der Royal Institution, meine feinsten thierisch-elektrischen Versuche, wie die über den Nervenstrom und über die negative Schwankung des Muskelstromes im lebenden menschlichen Körper, zahlreichen Zuhörern auf einmal zur Anschauung zu bringen.

Das Mittel, dessen ich mich bedient habe, liegt sehr nahe. Es besteht darin, das magnetische System mit einer spiegelnden Fläche zu versehen, durch diese ein Bündel paralleler Lichtstrahlen zurückwerfen zu lassen, und das auf einem Schirm aufgefangene Bild statt der Nadel selber zn beobachten. Dies kann natürlich bei hinreichender Stärke des Lichtes einer beliebigen Anzahl von Zuhörern sichtbar gemacht werden; und ausserdem ist es klar, dass man bei diesem Verfahren über eine fast unbegrenzte Empfindlichkeit gebietet. Sollte das Maass davon nicht ausreichen, welches man in Folge der Verdoppelung des Ablenkungswinkels und durch die Verlängerung des zurückgeworfenen Strahles erhält, so kann man eine beliebig kleine Winkelbewegung des Spiegels in eine [608] beliebig grosse Ortsverrückung des Bildes anch noch dadurch verwandeln, dass man die Ebene des Schirmes gegen den Strahl neigt.

Von diesem Verfahren war schon früher zwischen HeLмноцтz und mir die Rede gewesen, und Hexmhoutz hat es, wie er mir schrieb,

1 Poggendorff's Annalen der Physik und der Chemie. 1855. Bd. XCV. S. 607. - Uebersetzt in: The Philosophical Magazine etc. Fourth Series. 1856. Vol. XI. p. 109. 
bereits vor mehreren Jahren mit Erfolg angewendet, $1 \mathrm{~m}$ in seinen Vorlesungen meine Versuche zu zeigen. Er bediente sich einer nach seiner Angabe gebauten Tangentenbussole mit zahlreichen Windungen, welche im Wesentlichen nach dem seitdem von GAUGaL empirisch gefundenen, ron Bravars entwickelten Princip angeordnet sind. Eine spiegelnde Stahlscheibe ersetzt nach WEBER den Magnetstab und Spiegel der ursprünglichen PoGgendorfF'schen Einrichtung. Unter Anwendung ron Sonnenlicht gelang es HeLmhoutz mit diesen Hülfsmitteln die hauptsächlichsten Erscheinmmgen des Muskelstromes sichtbar zu machen.

Mir stand hier ein ron SAUERWaLd in Berlin für meinen Freund Dr. Bence Jones hierselbst nach meiner Angabe gebauter Multiplicator von 28780 Windungen zu Gebot. Für diesen Ifultiplicator hatte ich mir ron demselben Künstler ein astatisches System mit etwas dickeren Nadeln und einem Zwischenstück ans Messing anfertigen lassen, statt des leichten mit Schildpatt-Zwischenstück, wie ich es sonst anzuwenden pflege. Eine Verlängerung des Zwischenstücks oberhalb der oberen Nadel, trägt eimen äusserst leichten Messingring, an dessen oberstem Punkte sich die Oese zum Aufhängen des Systems befindet. Innerhalb des Ringes bewegt sich $\mathrm{mm}$ eine wagerechte Axe ein mit einer äusserst leichten Messingfassung rersehener Spiegel. Der Spiegel, den ich der Güte des Hrn. Schieck verdanke, besteht einfach aus einem, auf der einen seite verquickten, runden Deckgläschen für mikroskopische Zwecke ron $19 \cdot 5^{\mathrm{mm}}$ Durchmesser. Zwei einfache Coconfäden reichen hin, das Ganze sicher zu tragen. Der Ring, in dem der Spiegel sich gegen den Horizont neigen lässt, gestattet seinerseits eine Drehung um das obere Ende des Zwi- [609] schenstücks als um eine senkrechte Axe, so dass man bei einer beliebigen freiwilligen Ablenkung des Systems einen in beliebiger Richtung einfallenden Strahl in beliebiger Richtung zurückwerfen kann. Dabei ist indessen zu berücksichtigen, dass mit wachsender Neigung des Spiegels gegen den Horizont die Empfindlichkeit der Vorrichtung abnimmt.

Als Lichtquell diente eine elektrische Lampe ron Dubosq in Paris, gleichfalls Dr. Bexce Jones gehörig. Sie wurde durch die vierziggliederige Grove'sche Sänle der Institution gespeist, und unser Fremnd Prof. Trndaul batte die Gefälligkeit, sich der Regulirung des Lichtes und der Einstellung des Strahles auf den Spiegel anzunehmen, die beide im Lauf einer Stunde mehrfacher Berichtigmien bedurften. Anfangs wurde eine Blendung vor der Sammellinse der Lampe angebracht, so dass das Licht nur den Spiegel selber traf, indem ich anders fürchtete $\mathrm{zu}$ starke Luftströmungen unter der Glocke des Galvanometers und dadurch heftige Schwankungen der Nadel herbeizuführen. Fs zeigte sich indess, dass diese Vorsicht unnütz war, und dass man, ohne in Betracht kommende 
Störungen, den vollen Schein der Lampe auf den Multiplicator fallen lassen konnte. Dies gewährte den Vortheil, dass es dabei sehr viel leichter war, stets eine himreichende Menge Licht auf den Spiegel zu werfen, was bei Anwendung der Blendung seine Schwierigkeiten hatte. Deun obschon ungefähr in der Ebene des Systems aufgestellt, musste doch die Lampe in einer gewissen Entfernung rom Mnltiplicator gehalten werden, damit ihre eigenen magnetischen Kräfte keime Wirkung auf die Nadel ausübten. Mit jener Entfernung aber wächst begreiflich in gleichem Maasse die Schwierigkeit, den Strahl anf den Spiegel einzustellen.

Auf dem ungefähr $2 \cdot 5^{\mathrm{m}}$ langen Schirm bezeichnete ein senkrechter schwarzer Streif den Nullpunkt oder die Stelle, wo sich bei der Ruhelage der Nadel das Spiegelbild aufhalten sollte. Der Abstand des Schirmes vom Spiegel betrug ungefähr $3^{\mathrm{m}}$. Die Empfindlichkeit, die die Vorrichtung gewährte, war eher zu gross als zu klein, [610] da der Muskelstrom die Nadel mitsammt dem Spiegel wider die Hemmung warf, während bereits bei etwa $11^{\circ}$ Ablenkung das Bild den Schirm rerliess. Es war ein schöner Anblick, unter dem Einfluss der elektromotorischen Kräfte eines winzigen Nerven oder einiger Muskelbündel rom Frosch, den elektrischen Lichtschein weit durch den Saal fliegen zn sehen .... 
VII.

\section{Zur Theorie der astatischen Nadelpaare.}

(Vorgetragen in der physikalischen Gesellschaft zu Berlin am 16. November 1860.) ${ }^{\text {I }}$

Hierzu Taf. IV: Fig. 1-3.

Als ich vor acht Jahren in London einen Multiplicator für thierischelektrische Versuche von Hrn. SAuERWaLd's Arbeit aufstellte, stiess ich beim Astatischmachen des Nadelpaares auf eine Schwierigkeit, die mir neu war. Das Merkmal der erreichten grössten Astasie eines gegebenen Nadelpaares besteht bekanntlich darin, dass es sich senkrecht auf den magnetischen Meridian stellt. ${ }^{2}$ Es gelang mir nun damals auch bei grösster Vorsicht nicht, das Nadelpaar dahin zu bringen, dass es diese Lage annähernd eimnahm. Hatte sich z. B. der bezeichnete $\mathrm{Pol}$ der stärkeren Nadel um höchstens etwa $25^{\circ}$ rom magnetischen Meridian entfernt, und versuchte ich durch weitere Schwächung dieser Nadel die freiwillige Ablenkung zu rergrössem, so misslang dies stets insofern, als sofort das System durch die aequatoriale Stellung hindurchschlug, so dass jetzt der unbezeichnete Pol derselben Nadel nur noch etwa um eben so viel vom Norden abstand. Mit anderen Worten, es schien nun bereits die stärkere Nadel die merklich schwächere geworden zu sein, ein Zustand, bei dem man sich nicht gern beruhigt, da alsdamn die Summe der Producte aus den magnetischen Momenten der beiden Nadeln in die ablenkende Stromkraft nicht so gross wie möglich ist. Und doch zeigte dies Nadelpaar, trotz seiner geringen oder seiner zu gro- [2] ssen freiwilligen Ablenkung, sowohl ausserhalb des Multiplicators ${ }^{3}$ die erforderliche Schwingungsdauer, als anch imnerhalb desselben die grösste nur zu erwartende Empfindlichkeit. Es übertraf in letzterer Beziehung. und unstreitig auch an Schwingungsdauer, sonst ganz ähnliche Nadelpaare, denen ich stets ohne alle Mühe die aequatoriale Stellung ertheilt hatte. Eben

1 Poggendorfy's Annalen u. s. w. 1861. Bd. CXII. S. 1.

2 Untersuchungen u. s. w. Bd. I. S. 169.

3 Untersuchungen u. s. w., a. a. O. S. 167. 192. 
so wenig schien es an Stabilität seines magnetischen Zustandes hinter den besten Systemen, die ich noch gehandhabt hatte, zurückzustehen.

Die letzteren Umstände liessen mich schliessen, dass die Eigenthümlichkeit dieses Nadelpaares, so leicht durch die Aequatorialebene hindurchzuschlagen, nicht wohl daher rühren könne, dass die stärkere Nadel, etwa wegen ungenügender Härtung, allzu empfindlich für den demagnetisirenden Einfluss der Streschnadel sei. So ward ich zu der Vorstellung geführt, dass jene Eigenthümlichkeit in nichts ihren Grund haben könne, als in dem vollkommneren Parallelismus, den der Künstler in diesem Falle erreicht habe, da dies der einzige Unterschied war, den ich, für die gewöhnliche Wahrnehmung verborgen, zwischen dem neuen Nadelpaar und den älteren noch voraussetzen konnte. Eine genauere Untersuchung hat diese Meinung gerechtfertigt.

Die Gleichgewichtslage eines astatischen Systems wird bekanntlich ${ }^{1}$ bestimmt durch die Gleichung

$$
U \sin \alpha=I^{\prime} \sin \alpha^{\prime} .
$$

Hier bedentet $\boldsymbol{M}$ das magnetische $\mathbf{M}$ oment der stärkeren Nadel, $\boldsymbol{\alpha}$ den (spitzen) Winkel, den diese Nadel mit dem Meridiane macht, $\boldsymbol{M}^{\prime}$ und $\boldsymbol{a}^{\prime}$ haben die gleiche Bedeutung für die andere Nadel. Es ist aber $u^{\prime}=\alpha+\varphi$, wo $\varphi$ den an $\alpha$ stossenden spitzen Winkel vorstellt, den die magnetischen Axen der beiden Nadeln einschliessen, folglich

$$
M \sin \alpha=M^{\prime}(\sin \omega \cdot \cos \varphi+\cos \alpha \cdot \sin \varphi) .
$$

[3] Diı $q$ nur ein sehr kleiner Winkel ist, können wir setzen:

Daraus folgt

$$
\cos \varphi=1, \sin \varphi=\varphi \sin 1^{\prime} \text {. }
$$

$$
\operatorname{tg} \alpha=\frac{M^{\prime}}{M-\mu} \cdot \varphi \sin 1^{\prime}
$$

Die Tangenten der freiwilligen Ablenkung, als Ordinaten aufgetragen auf den Unterschied $\boldsymbol{M}-\boldsymbol{M}^{\prime}=d$ der magnetischen Homente als Abscissenaxe, bilden also eine auf ihre Asymptoten bezogene gleichschenklige Hyperbel, deren Potenz dem spitzen Winkel zwischen den magnetischen Axen proportional ist. Construirt man aber die Gleichung

$$
\angle \alpha=f(d)
$$

für verschiedene Werthe von $\mathcal{f}$, su erhält man Curven gleich denen in Fig. 1 Taf. IV, wo die gestrichelte Curve einem kleineren, die ausgezogene einem grösseren Werthe ron $\varphi$ entspricht. Die Curren schliessen

1 Vergl. Moser im Repertorium der Physik, Bd. I. Berlin 1837. S. 260. Humphrey Lloyd in: The Transactions of the Royal Irish Academy. Vol. XXII. Dublin 1849.40 . P. I. p. 249. 
sich asymptotisch einerseits den positiren Abscissen, andererseits einer der Abscissenaxe parallelen Geraden an, deren Ordinate dem Winkelwerth ron $180^{\circ}$ entspricht. Sie schneiden die Ordinatenaxe in dem Punkte, der $90^{\circ}$ entspricht; hier liegt zugleich ein Wendepunkt der Curven.

Aus dieser Figur erhellt die Nothwendigkeit des beschriebenen Verhaltens.

Man sieht sugleich, dass in dem Bereich der Curven, wo sie sich der Abscissenaxe anschliessen, grosse Unterschiede ron $d$ nur kleinen Aenderungen ron $\boldsymbol{c}$ entsprechen, in der Nähe des Nullpunktes dagegen grosse Aenderungen ron $\alpha$ kleinen Unterschieden ron $d$. Das System wird sich daher, wie auch die Erfahrung lehrt. wenn man die stärkere Nadel folgweise um gleiche, oder. wegen der abnehmenden Intensität der rerkehrt gebrauchten Streichnadel, sogar um abnehmende Grössen schwächt, anfangs stets nur langsam rom Meridian entfernen, während, wenn sich die Nadeln schon mehr der Gleichheit nähern, selbst einem viel kleineren Sprunge im Unterschiede der Momente ein riel grösserer Sprung in der freiwilligen Ablenkung folgen [4] kann. Hat sich der Unterschied der Nadeln umgekehrt, so kehren dieselben Erscheinungen symmetrisch wieder.

Nan sieht ferner, dass, je kleiner $\varphi$, für um so kleinere positive wie negative Werthe ron $d$ wird das System am Meridian zu kleben scheinen, und in um so grösseren Sprüngen wird es, wenn $d$ unter einen gewissen Werth gesunken ist, schliesslich den Aequator überschreiten. Die Wahrscheinlichkeit, dass es gelingen werde, $d=0 \mathrm{zu}$ machen, ist natürlich von $q$ unabhängig und für alle Werthe von $\varphi$ gleich klein. Je kleiner aber q ist, oder je vollkommener parallel die Nadeln sind, um so grösser wird für den kleinsten, für gewöhnlich herstellbaren positiven Werth ron $d$ die Ergänzung der freiwilligen Ablenkung zu $90^{\circ}$, um so kleiner folglich diese selher, um so grösser hingegen für den kleinsten demnächst herstellbaren negativen Werth ron $d$ die freiwillige Ablenkung. um so kleiner folghich deren Ergänzung zu $180^{\circ}$ sein.

Was die Richtkraft des Systemes betrifft, so ist deren Maass bekanntlich die Diagonale des Parallelogramms, ron dem man zwei Seiten erhält, wenn man auf die beiden magnetischen Axen ron ihrem Kreuzungspunkt aus Stücke im Werthe der zugehörigen magnetischen Momente aufträgt. Es bedarf kaum der Erwähnung, dass der Werth dieser Diagonale von $q$ und $d$ so abhängt, dass er für $d=0$ durch Wachsen ron $\varphi$ bis $180^{\circ}$ jede Grösse bis zu $2 M_{0}$ annimmt, und dass folglich ein nahe winkelrecht zum Meridian stehendes System durch grösseres $千$ an Richtkraft einem solchen überlegen sein kann, welches bei gleichem, 
oder gar geringerem $d$, wegen kleineren $\varphi$ 's, sich kaum rom Meridian entfernt.

Ich habe es nicht unterlassen, diese Folgerungen durch den Versuch zu prüfen, und an einem zur Demonstration bestimmten astatischen Systeme, dessen $14^{\mathrm{em}}$ lange Nadeln eine hinlänglich feine Drehung um die sie verbindende Axe gestatten, mich davon überzeugt, dass mit dem spitzen Winkel zwischen den Nadeln, bei beständigem Unterschiede ihrer Momente, die freiwillige Ablenkung wächst [5] und die Schwingungsdauer abnimmt. Genauere Maassbestimmungen würden nicht leicht ausführbar sein wegen der Schwierigkeit, den kleinen Winkel zwischen den magnetischen Axen scharf zu beobachten. Sie würden übrigens keine vollkommene Uebereinstimmung mit der Rechmung ergeben. In der That hat Hr. SAUERWALD seitdem noch eine andere Eigenschaft der astatischen Nadelparre wahrgenommen, welche jedenfalls zu ihrer Erklärung ein Princip beansprucht, das in der obigen Entwickelung noch fehlt.

Man denke sich ein Nadelpaar, dessen rollkommen parallele Nadeln rollkommen gleich stark magnetisch seien. In welcher Lage wird solches Nadelpalar, frei aufgehängt, in Ruhe verharren? Abgesehen von der Torsion, ron Luftströmungen u. d. m., in jedem Azimuth, lautet die Antwort, die, so viel ich weiss, seit Aupk̀ne ganz allgemein anf diese Frage gegeben worden ist. In Einklang damit wird tg $c$, wemn man in (I) $\boldsymbol{M}-\boldsymbol{M}^{\prime}$ und $\boldsymbol{\phi}=0$ setzt, unbestimmt.

Hr. Sauerwald hat mir gezeigt, dass sich diess nicht so verhält. Von ihm selber gestrichen, befinden sich seine Nadelpaare vielmehr auf dem Aequator in labilem Gleichgewicht, und haben zwei stabile Gleichgewichtslagen in geringer Entfernmng vom Meridian, in deren einer die obere, in deren anderer die untere Nadel ihren bezeichneten Pol gen Norden kehrt.

Die Erklärung hiervon ist, wie mir scheint, leicht, und man hätte bei einigem Nachdenken die Erscheimung vorhersehen können. Es ist eine altbekamnte, in neuerer Zeit vorzüglich durch Hrn. Poggendorfa ${ }^{1}$ bei seinen Versuchen über die doppelsimige Ablenkung wieder hervorgehobene, endlich ganz neuerdings von Hrn. Bewtz ${ }^{2}$ genauer untersuchte Thatsache, dass auch sehr harter und scheimbar bis zur Sättigung magnetisirter Stahl unter dem Einfluss äusserer magnetischer Kräfte vorübergehender Magnetisirung und Demagnetisirung fähig ist. Als sol- [6] che äussere Kraft muss auf die beiden Nadeln des Systems, so-

1 Poggendorff's Annalen u. s. w. 1838. Bd. XLY. S. $363 ;-1841$. Bd. LIV. S. 191.

2 Ebendas. 1860. Bd. CXI. S. 107. 
bald es nicht die aequatoriale Lage inne hat, die horizontale Componente des Erdmagnetismus wirken, so zwar, dass von beiden Nadeln stets die gestärkt wird, deren bezeichneter Pol nach Norden sieht, während die andere geschwächt wird. Die Stärkung, beziehlich Schwächung, jeder Nadel wird übrigens um so beträchtlicher sein, je grösser der Cosinus des Winkels ist, den sie mit dem Meridiane macht. Ohne Weiteres sieht man nun schon ein, dass, wenn es sich um ein Paar in aller Strenge paralleler und gleich starker Nadeln handelt, durch die Wirkung der Erde das bewegliche Gleichgewicht aufgehoben, die beiden Aequatorialstellungen zu labilen, und die beiden Meridianstellungen zu stabilen Gleichgewichtslagen werden müssen. Um aber zu beurtheilen, was geschehe, wenn $\boldsymbol{M}-\boldsymbol{M}^{\prime}$ und q nicht rerschwinden, ist eine mehr eingehende Betrachtung nöthig.

Jener Umstand wird in die Theorie der astatischen Nadelpaare aufgenommen, indem man in dem allgemeinen Ausdruck für die auf das System wirkenden Kräfte,

$$
X[M \sin \alpha-M \sin (\alpha+\varphi)],
$$

wo $\boldsymbol{X}$ die horizontale Componente der Erdkraft, statt $\boldsymbol{M}$ und $\boldsymbol{M}$ beziehlich setzt

$$
M+m \cos \alpha, M-m^{\prime} \cos (\alpha+q) .
$$

Hier drücken $m, m^{\prime}$ die Grösse der secundären Momente aus, welche durch die vertheilende Wirkung der Erde, gemäss der Natur des Stahles und anderen Umständen, in jeder der Nadeln für den Fall hervorgerufen werden, dass die zugehörige Nadel im Meridian einsteht. Man erhält, $X$ bei Seite gelassen,

$$
[M+m \cos \alpha] \sin \alpha-\left[\boldsymbol{M}^{\prime}-m^{\prime} \cos (\alpha+\varphi)\right] \sin (\alpha+\varphi)
$$

Dieser Ausdruck gestaltet sich bequemer für die Discussion, wenn man bei Betrachtung des Vorganges, statt, wie Hr. Mosen und Hr. LLoyd, von der Lage des Systems, wo die stärkere Nadel im Meridian einsteht, d. h. $\alpha=0$ ist, vielmehr ausgeht von der aequatorialen Stellung, wo [7] $\alpha=90^{\circ}-\frac{q}{2}$ ist; und wenn man demgemäss, an Stelle ron $\alpha$, als Veränderliche, nach deren fortschreitenden Werthen die Discussion geschehen soll, einen Winkel $\beta=90^{\circ}-\left(\alpha+\frac{q}{2}\right)$ einführt, der für die Aequatorialstellung $=0$, in entgegengesetzter Richtung wie $\alpha$ wächst, und als Subtrahend von $90^{\circ} \mathrm{zu} \frac{\text { \% }}{2}$ hinzutritt. Man hat

$$
\alpha=90^{\circ}-\left(\beta+\frac{\varphi}{2}\right), \alpha+\varphi=90^{\circ}-\left(\beta-\frac{\varphi}{2}\right) \text {. }
$$


Der Ausdruck (II) wird dadurch zu folgendem:

$$
\begin{aligned}
\left(\boldsymbol{M}-\boldsymbol{U}^{\prime}\right) \cos \frac{\varphi}{2} \cdot \cos \beta-\left(\boldsymbol{M}+\boldsymbol{U}^{\prime}\right) & \sin \frac{\varphi}{2} \cdot \sin \beta \\
& +\frac{\left(m-m^{\prime}\right)}{2} \sin \varphi \cdot \cos 2 \beta \\
& +\frac{\left(m+m^{\prime}\right)}{2} \cos \varphi \cdot \sin 2 \beta .
\end{aligned}
$$

Setzt man der Einfachheit halber $m=m^{\prime}=m_{0}$, so behält der Ausdruck nur noch die drei Glieder

$$
\begin{aligned}
\left(\boldsymbol{M}-\boldsymbol{U}^{\prime}\right) \cos \frac{\varphi}{2} \cdot \cos \beta+2 m_{0} \cos \varphi \cdot \cos \beta \cdot \sin \beta \\
\\
\quad-\left(\boldsymbol{M}+\boldsymbol{M}^{\prime}\right) \sin \frac{q}{2} \cdot \sin \beta,
\end{aligned}
$$

die wir in der Reihenfolge, wie sie dastehen, mit $D, \mathfrak{M}, \Phi$ bezeichnen wollen. Hiervon stellt $D$ die Kraft vor, die von der Ungleichheit der Nadeln, $\mathfrak{M}$ die, welche von der vertheilenden Wirkung der Erde, endlich $\boldsymbol{\Phi}$ die, welche ron dem mangelhaften Parallelismus der Nadeln herrührt. In der That rerschwindet $D$ mit $d, \mathfrak{M}$ mit $m_{0}, \Phi$ mit $\psi$. Das positive Vorzeichen eines der drei Glieder bedeutet, unserer Herleitung gemäss, dass die dadurch vorgestellte Krraft in dem Simne wirkt, wie die stärkere Nadel auf der Seite des Meridians, wo deren bezeichneter Pol dem Norden näher ist, als der unbezeichnete $\mathrm{Pol}$ der schwächeren Nadel, oder so, dass $\beta$ dadurch rergrössert werde, das negative Vorzeichen das Gegentheil. Erinnert man sich sodann, dass eine stabile Gleichgewichtslage dadurch bedingt [8] ist, dass bei jeder Ablenkung daraus Kräfte rege werden, die das System darin zuräckzuführen streben, während für das labile Gleichgewicht das Umgekehrte geschieht, so hat es schon so keine Schwierigkeit mehr, den Gang der drei Functionen um den Kreisumfang zu verfolgen, und die aus ihrem Conflict entspringenden stabilen und labilen Gleichgewichtslagen für rerschiedene relatire Werthe von $d, \varphi$ und $m_{0}$ anzugeben.

Erleichtert wird dies indess noch durch die in Fig. 2 Taf. IV angedeutete graphische Darstellung. Die Abscissenaxe stellt den in die rier Quadranten getheilten Krreisumfang, ron $\beta=0^{\circ}$ bis zu $\beta=360^{\circ}$, geradlinig ausgestreckt vor. Die ausgezogene Curve bedeutet den Gang der Function $\mathfrak{M}$, die punktirte den der Function $D$, die gestrichelte den der Function $\boldsymbol{\Phi}$. Pfeile an den Curren geben die Wirkungsrichtung ihrer Ordinaten an. Stabile Gleichgewichtslagen finden statt, so oft die Curre, die man als allein, oder die Resultirende der Curren, die main als zusammen bestehend betrachtet, in der Richtung der positiven Ab- 
scissen verfolgt, das positive Zeichen ihrer Ordinaten mit dem negativen vertauscht; labile Gleichgewichtslagen, so oft das Gegentheil geschieht. Stabile Gleichgewichtslagen werden überdies durch Hinzutreten einer positiven Kŕraft zu denjenigen, aus deren Conflict sie entspringen, im Simne der positiren Abscissen, durch Himzutreten einer negativen Kuraft im entgegengesetzten Sime verschoben. Für labile Gleichgewichtslagen gilt das Gegentheil.

Von den sieben denkbaren Fällen des Einzeln- und Zusammenrorkommens der drei Functionen sind physikalisch möglich nur die vier, bei denen die Function $\mathfrak{M}$ betheiligt ist. Diese sollen jetzt nach einander betrachtet werden. Erste und zweite Aequatorialstellung heissen im Folgenden die Stellungen des Systems für $\beta=0$ und $\beta=180^{\circ}$, erste und zweite Meridianstellung die für $\beta=90^{\circ}$ und $\beta=270^{\circ}$.

In Fig. 3 Taf. IV finden sich die jenen vier Hauptfällen und ihren Unterfällen entsprechenden Gleichgewichtslagen [9] des Systems in der Art angegeben, dass die labilen Lagen durch gestrichelte, die stabilen durch ausgezogene Radien bezeichnet sind, welche der den Winkel $\varphi$ hälftenden Geraden entsprechen. Die zwischen sämmtlichen Kúreisen durchgezogene Gerade $\boldsymbol{W O}$ ist der Aequator, den Meridian hat man sich in jedem Kreis senkrecht darauf zu denken, den Norden wie in einer Landkarte nach oben. Bei Fig. 3, II- $-V$. (in den übrigen Fällen kommt darauf nichts an) ist angenommen, dass der bezeichnete Pol der stärkeren Nadel sich in der ersten Meridianstellung westlich befindet. In der ersten Aequatorialstellung ist dieser Pol alsdann nach Osten gekehrt; $\beta$ wächst oder die Quadranten folgen aufeinander, wie es Fig. 3, I. zeigt, in der umgekehrten Richtung der Zeiger einer U'hr.

I. $d=0$ und $\varphi=0$; Mi allein ist übrig. Im Einklang mit dem bereits oben der Anschanung Entnommenen zeigt sich, dass in der ersten und zweiten Aequatorialstellung labiles, in der ersten und zweiten Meridianstellung stabiles Gleichgewicht herrscht (Fig. 3, I). Für $\beta=$ $45^{\circ}$ : $=135^{\circ} \mathrm{u}$. s. f. finden, wegen $\sin 45^{\circ}=\cos 45^{\circ} \mathrm{u}$. s. f. beziehlich positive und negatire Maxima der hraft statt.

II. $\varphi=0$; zugleich mit $\mathfrak{M}$ tritt die Curve $D$ in Ĺraft. Die erste und zweite Aequatorialstellung sind keine labilen Gleichgewichtslagen mehr, sondern das System unterliegt darin einer Kraft beziehlich $= \pm(\boldsymbol{M}-\boldsymbol{M})$. Die erste Heridianstellung ist unter allen Umständen eine stabile Gleichgewichtslage, indem die im ersten Quadranten durchweg positive Kraft im zweiten Quadranten durchweg negatir wird, wie sie es darin überhaupt stets ist, gleichriel welche Combination der drei Functionen man amnehme, und welchen Werth man den Constanten 
beilege. Was im dritten und vierten Quadranten und in der zweiten Meridianstellung stattfindet, hängt davon ab, ob

$$
2 m_{0} \cos \varphi \cdot \sin \beta>\left(\boldsymbol{M}-\boldsymbol{M}^{\prime}\right) \cos \frac{\boldsymbol{f}}{2}
$$

werden könne oder nicht. Ist letzteres der Fall, so bleibt-auch im dritten Quadranten die Kraft durchweg negativ, [10] im vierten wird sie, im Anschluss an den ersten, wieder durchweg positir, die zweite Meridianstellung ist eine labile Gleichgewichtslage (Fig. 3, I, a). Kann dagegen jene Bedingung erfüllt werden, so ist das Gleichgewicht in der zweiten Meridianstellung stabil, und zu beiden Seiten dieser Stellung findet sich symmetrisch eine labile Gleichgewichtslage (Fig. 3, II, b). Dieser Fall unterscheidet sich also hinsichtlich der Gleichgewichtslagen von dem I. nur insoferm, als die beiden labilen Gleichgewichtslagen, deren Ort dort der Aequator war, hier sich der zweiten Meridianstellung um gleiche Bögen genähert haben; die stabilen Lagen sind dieselben auf dem Meridian.

III. $d=0$ oder $\boldsymbol{M}=\boldsymbol{M}^{\prime}=\boldsymbol{M}_{0}$. $\mathfrak{M}$ und $\boldsymbol{l} \boldsymbol{l}$ kommen miteinander in Betracht. Es stellen sich sofort zwei Fälle dar.

a. Entweder nämlich ist der Unterschied

$$
m_{0} \cos \mathscr{f} \cdot \cos \beta-\boldsymbol{M}_{0} \sin \frac{\mathscr{f}}{2}
$$

schon für den kleinsten denkbaren Werth ron $\beta$ negativ, d. h.

$$
m_{0} \cos \varphi<\boldsymbol{M}_{0} \sin \frac{\varphi}{2} \text {. }
$$

Alsdann ist die erste Aequatorialstellung eine stabile Gleichgewichtslage; die Kraft bleibt in den beiden ersten Quadranten negatir, und wird für $\beta=180^{\circ}$ positiv, so dass daselbst labiles Gleichgewicht herrscht. In den beiden anderen Quadranten kehren die Erscheinumgen symmetrisch wieder (Fig. 3, III, a). Die Krraft, welche bei Störung des Systems aus seinem labilen Gleichgewicht in der zweiten Aequatorialstellung um einen kleinen Winkel rege wird, ist um $2 \cdot m_{0} \cos \varphi$ grösser als die, welche bei Störung des Systems aus seinem stabilen Gleichgewicht in der ersten Aequatorialstellung $n$ m denselben Winkel entsteht.

b. Oder $m_{0} \cos q>\boldsymbol{H}_{0} \sin \frac{\varphi}{2}$; in diesem Fall ist das Gleichgewicht in der ersten Aequatorialstellung labil. Dies wird um so leichter eintreten, je grösser $m_{0}: \boldsymbol{M}_{0}$ und je [11] kleiner $\sin \frac{\mathscr{f}}{2}: \cos \boldsymbol{q}$, oder je kleiner $\varphi$. Da aber für $90^{\circ}$ das mit $\cos \beta$ hehaftete Glied rerschwindet, so muss im ersten Quadranten eine stabile Gleichgewichtslage stattfinden, je kleiner \&, um so näher dem Meridian, mit dem sie für 
$\varphi=0$ zusammenfällt (I. Hauptfall). Die Kraft im zweiten Quadranten ist durchweg negativ, in der zweiten Aequatorialstellung herrscht labiles Gleichgewicht, in den beiden anderen Quadranten kehrt Alles symmetrisch wieder. Man hat also zwei labile Gleichgewichtslagen auf dem Aequator, und zwei stabile im ersten und vierten Quadranten (Taf. I Fig. 3, III, b).

IV. Weder $d$ noch $\varphi=0$. Alle drei Curven gelten. Weder die Aequatorial-, noch die Meridianstellungen sind ferner Gleichgewichtslagen der einen oder anderen Art, sondern in der ersten Aequatorial- und der zweiten Meridianstellung erreichen $D$ und $\Phi$ beziehlich ihr positives, in der zweiten Aequatorial- und der ersten Meridianstellung ihr negatives Maximum. Für $\beta=0$ findet demgemäss eine positive Kraft $\left(\boldsymbol{M}-\boldsymbol{M}^{\prime}\right)$ $\cos \frac{\varphi}{2}$, für $\beta=90^{\circ}$ eine negatire Kraft $\left(M+M^{\prime}\right) \sin \frac{\varphi}{2}$ statt. Dazwischen muss die Gleichung $D+\mathfrak{N}-\boldsymbol{\Phi}=0$ einmal erfüllt sein, man hat also eine stabile Gleichgewichtslage im ersten Quadranten, und zwar wegen des hinzugekommenen positiven Gliedes $D$, wenn sonst Alles unverändert blieb, näher dem Meridian als in dem Falle III, $b$. Im zweiten Quadranten herrscht durchweg negative Kraft; unter Umständen kann hier ein Maximum rorkommen. Im dritten Quadranten findet labiles Gleichgewicht statt, an einem Punkte, welcher um weniger als $180^{\circ}$ ron der stabilen Gleichgewichtslage im ersten Quadranten absteht (Fig. 3, IV, a). Im vierten Quadranten kamn die Kraft durchweg positiv sein, und zwar kamn sie ein Maximum oder ein Minimum besitzen. Es kann aber anch das Minimum soweit gehen, dass die Curve die Abscissenaxe zweimal schneidet, wo denn zwischen den Schneidepunkten die Kraft negativ, der erste Schneidepunkt eine [12] stabile, der zweite eine labile Gleichgewichtslage wird (Fig. 3, IV, b). Alle Symmetrie hat also jetzt aufgehört: nur für

$$
\left(\boldsymbol{M}-\boldsymbol{M}^{\prime}\right) \cos \frac{\varphi}{2}=\left(\boldsymbol{M}+\boldsymbol{M}^{\prime}\right) \sin \frac{\varphi}{2}
$$

sind die stabilen und labilen Gleichgewichtslagen wieder symmetrisch angeordnet in Bezug auf den Durchmesser, der den $135^{\circ}$-Punkt mit dem $315^{\circ}$-Punkt verbindet. Die Bedingung für das Auftreten der beiden Gleichgewichtslagen im vierten Quadranten heisst alsdann

$$
2 m_{0} \cos \varphi \cdot \cos 45^{\circ}>\left(M-M^{\prime}\right) \cos \frac{\varphi}{2}+\left(M+I^{\prime}\right) \sin \frac{\varphi}{2} .
$$

Lässt man $d$ oder $\varphi$ oder beide in der Vorstellung kleiner werden, so nähert sich der Zustand dem entsprechenden unter denen, die wir schon unter den einzelnen Nummern betrachtet haben. Wichtiger ist die Erwägung, was sich ereigne, wenn $m_{0}$ im Vergleich zu $\boldsymbol{I}-\boldsymbol{M}$ 
und $\sin \frac{\varphi}{2}$ sehr klein wird, da, wenn auch $m_{0}$, wie bemerkt, physikalisch nicht $=0$ werden kann, dieser Fall doch, wegen des unvollkommenen Parallelismus der Nadeln und ihres im Vergleich zu $m_{0}$ allzu beträchtlichen Unterschiedes, in Wirklichkeit gerade der am häufigsten vorkommende ist, ja bis zu Hm. SAUERWaLd der allein beobachtete war. Wie man leicht erkennt, bestehen alsdann die beiden Gleichgewichtslagen im vierten Quadranten nicht, und die beiden anderen entfernen sich, unter sonst gleichen Umständen, je kleiner $m_{0}$, um so mehr, die stabile von der ersten Meridian-, die labile von der zweiten Aequatorialstellung, um sich dem nämlichen Durchmesser zu nähern, mit dem sie für $m_{0}=0$ zusammenfallen (Fig. 3, V). Die Lage dieses Durchmessers, zu dessen beiden Seiten die Kräfte symmetrisch vertheilt sind, wird bestimmt durch die Gleichung

$$
\operatorname{tg} \beta=\frac{M-M^{\prime}}{M+M^{\prime}} \cot \frac{\varphi}{2},
$$

welche mit der von Hrn. LLOYD gegebenen (I) gleichbedeutend ist, und mit Hülfe einer ähnlichen Construction [13] die nämlichen Schlüsse zulässt, wobei aber die Grösse von $\varphi$ unbeschränkt bleibt.

Versucht man nunmehr das Ermittelte auf Hrn. Saukrwald's Beobachtung anzuwenden, so lässt sich so viel sagen, als dass jedenfalls an seinen Nadelpaaren $\varphi$ noch nicht ganz $=0$ gewesen sei, weil nämlich die beiden stabilen Gleichgewichtslagen nicht in den Meridian fielen. Ob $d=0$ war oder noch einen endlichen Werth besass, würde davon abhangen, ob die stabilen Gleichgewichtslagen in gleichem oder in ungleichem Abstand rom Meridian, und dem entsprechend die labilen genau oder nicht genau auf dem Aequator stattfanden (vergl. Fig. 3, III, $b$ und IV, $b$ ), worüber es an Bestimmungen gebricht. Unter allen Umständen setzt das Bemerkbarwerden der vertheilenden Wirkung der Erde voraus, dass $d$ und $q$ beide äusserst klein seien, und Hrn. SAuErwaLD's Wahrnehmung liefert einen neuen Beweis dafür, dass es ihm gelungen sei, wenn nicht die magnetische Gleichheit, doch den Parallelismus seiner Nadelpaare weiter zu treiben, als irgendwer vor ihm.

Diese Wahrmehmung lehrt uns, ohne Messung der Schwingungsdauer, die bei sehr astatischen Nadelpaaren nur unsichere Ergebnisse liefert, beurtheilen, nicht allein, ob ein gegebenes Nadelpaar den höchsten Grad der Astasie erreicht habe, dessen es vermöge des Parallelismus seiner Axen fähig ist, sondern auch, ob dieser Grad so hoch sei, s wie man ihn wirklich herzustellen vermag.

Eine messende Untersuchung so hoch astatischer Nadelpaare zur Prüfung obiger Theorie würde unter anderen fast unbesiegbaren Schwierig- 
keiten noch ganz besonders auf die stossen, dass es an einem Mittel fehlt, eine labile Gleichgewichtslage scharf zu bestimmen. Eine solche Untersuchung würde sich übrigens $u m$ so weniger der Mühe verlohnen, als man auch jetzt noch nicht auf einen vollkommenen Einklang der Erfahrung mit der Theorie rechnen dürfte. Noch immer ist diese nur als eine erste Amnäherung zu betrachten, wobei mindestens zwei Umstände [14] vernachlässigt sind, welche scheinen bei hinreichend genauer Beobachtung zu Abweichungen Anlass geben zu müssen.

Erstens haben wir $m=m^{\prime}=m_{0}=$ const. gesetzt. Dies hätte wenig zu sagen, insofern dadurch nur die Natur des Stahls u. d. m. als in beiden Nadeln imnerhalb gewisser Grenzen identisch antgefasst wäre. Allein die Einführung solcher constanten Coëfficienten überhanpt, um die Stärke der durch die Erde erzengten secundären Momente für ein gegebenes Azimnth zu bemessen. ist nicht in aller Strenge zulässig. Sie setzt rorans, was in Wirklichkeit nicht zutrifft, dass eine noch so stark magnetisirte Nadel durch eine äussere magnetische Kraft einen stets dieser Kraft proportionalen positiven oder negativen Zuwachs erhalte. Bei Berücksichtigung dieses Umstandes rerwickelt sich die Sache ausserordentlich, da an Stelle ron $m, m^{\prime}$ nene und unbekannte Functionen der Ablenkung der Nadehn aus dem Meridiane treten.

Für's zweite ist zu bedenken, dass auch die beiden Nadeln auf einander eine vertheilende Wirkung ausüben, durch welche sie sich gegenseitig in astatischer Anordnung rerstärken, in umgekehrter schwächen. ${ }^{1}$ Dies würde nicht bloss zur Folge haben, dass MIessungen von $\boldsymbol{M}, \boldsymbol{U}^{\prime}$ an den einzehen Nadeh, ron $\boldsymbol{M}-\boldsymbol{U}^{\prime}$ am astatischen, oder ron $\boldsymbol{M}+\boldsymbol{M} \boldsymbol{I}^{\prime}$ am verkehrt zusammengefügten Nadelpaar nicht mit einander stimmen könnten, sundern es würde anch die Stärke der Wirkung, welche die eine Nadel auf die andere ausübt, soriel es sich ohne Rechmmng übersehen lässt, abermals eine verwickelte Function des Azimuths sein. In der That würde für $\varphi=0$ und $d=0$ in den beiden Aequatorialstellungen die eine Nadel die andere eben so sehr rerstärken, wie diese jene; hingegen in einer der Meridianstellungen würde die durch die Erde rerstärkte Nadel die dadurch geschwächte unstreitig mehr stärken, als diese jene, so dass der Unterschied der Nadeln in dieser Stellung kleiner als in jener anstiele.

1 Vergl. Poggendorff in seinen Annalen. 1838. Bd. XLY. S. 375 ff. 
TIII.

\section{Beschreibnug einiger Vorrichtungen und Versuchsweisen zn elektrophysiologischen Zwecken.}

(Im Anszuge gelesen in der Gesammtsitzung der Königh. Akademie der Wissenschaften zu Berlin am 30. Мai 1s61.) ${ }^{1}$

Hierzu Taf. I-III.

Ich habe, seit dem Erscheinen meiner 'Untersuchungen über thierische Elektricität, zu dem, was dort über Vorrichtungen und Versuchsweisen zu elektrophysiologischen Zwecken gesagt ist, allerlei himzuzusetzen gefunden, woron ich Einiges hier zusammenstellen will, nm mich gelegentlich darauf beziehen zu können. Ein Theil daron hat zwar bereits anf anderen Wege, durch meine Vorträge, durch persönlichen Verkehr, durch die aus meinem Laboratorium hervorgegangenen Arbeiten, eine ansehnliche Verbreitung, ja einige Becleutung für den Fortschritt unserer Wissenschatt erlangt. Ich erfülle aber einen oft gegen mich ausgesprochenen Wumsch, indem ich ausilrücklich mo im Zusammenhang eine Schilderung auch dieser schon bekannteren Hülfsmittel gebe.

\section{§. I. Tom Multiplicator.}

Die Multiplicatoren für thierisch-elektrische Versuche, wie sie $\mathrm{Hr}$. SAUERWALD auf meine Amregung zul balten begomen hat, weichen in mehreren Punkten von dem ron mir a. a. O. Bil. II. Abth. I. S. 477 beschriebenen Instrument ab. Sie sind aber in Dentschland, ja im Auslande, jetzt so rerbreitet, dass eine Beschreibnng derselben für überflüssig gelten darf, und die Art sie zu behandehn kam anch als so allgemein bekamnt rorausgesetzt werden, dass höchstens einzelne minder auf der Hand liegende Rathschläge noch am Platze scheinen möchten.

1 Abhandlungen der Königl. Akademie der Wissenschatten zn Berlin 1562. Berlin 1863. 40. Physikalische Klasse. S. 75.

E. du Bois-Reymond, Ges. Abh.I. 
Folgendes Terfahren beim Aufstellen des Multiplicaturs führt schnell und sicher zum Ziel. Ich nehme an, dass der einfache Coconfaden mit seinem Häkchen bereits eingebracht ist. Man giebt dem Theodolitenfuss [76] des Instrumentes einen beliebigen, durch Rücksichten der Symmetrie oder Bequemlichkeit empfohlenen Stand anf einem Wandeonsol, bei dessen Befestigung man nicht ängstlich Eisen zu rermeiden braucht. Cnter jede Stellschraube legt man eine der auf ein quadratisches Stück Spiegelglas angekitteten Messingplatten, und befestigt das Stück Glas an das Consol, indem man es mit Kolophoniumkitt umgiesst. Man entfernt die Theilung, und stellt das Instrument wagerecht mittels einer auf den Rahmen aufgesetzten Dosenlibelle. Jan hängt an das Häkchen des Coconfardens eine einfache Nadel, und stellt die Windungen ihr parallel. Un diese Stellung künftig wieder zu finden. liest man sie an der unteren Theilung ab.

Nun streicht man die Nadeln bis zur Sättigung auf die a.a. O. S. 484 beschriebene Art, und hängt sie unter einer Glocke über einer Theilung auf, deren Nulllinie im Meridian steht. Man sieht zu, jwenn man das Nadelpaar nicht bereits kennt, ${ }^{1}$ welche Nadel die stärkere ist, und schwächt diese mittels der Streichnadel bis zu dem Maasse der freiwilligen Ablenkung, das Geschick und Gläck, und, wie ich unlängst in Poggendorff's Amnalen gezeigt habe, ${ }^{2}$ der Parallelismus der Nadeln zu erreichen gestatten. Die Theorie verschiedener Fälle stabilen und labilen Gleichgewichtes der Nadelpaare, auf die man dabei stossen kann, habe ich dort, mit Rücksieht auf eine Beobachtung des Hrn. SAUERWaLd, entwickelt. Beim Handhaben der Nadeln rergesse man nicht, dass man das Zwischenstück aus Schildpatt besser nicht mit der Hand berührt. durch deren feuchte Wärme es leicht rerkrümmt werden könnte, ${ }^{3}$ die Nadeln selber aber nicht mit Metallen, auch scheinbar ganz unmagnetischen, weil im Augenblick der Berührung mit einem Magnete, oder der Tremmung ron demselben, jedes Metall, wegen der darin erzeugten Inductionsströme. sich magnetisch rerhält. Einige [77] rülmmen das Ver-

1 Zur Kenntniss eines Nadelpaares gehört, dass man wisse: 1. welche Nadel die stärkere, 2. welehes der Sim der freiwilligen Ablenkung des Nadelpaares sei. - Wenn man sich in der Lage befindet, einen unbekannten Streichmagnet anwenden zu müssen, versäume man nicht, zuerst dessen Pole anf die Richtigkeit ihrer Bezeichnung zu prüfen. Sonst läuft man Gefahr, wie es mir einst begegnete, im ferneren Verlaufe der Operation, die schwächere statt der stärkeren Nadel zu schwächen, und rergeblich auf das Eintreten der Astasie zu warten.F

$2 \mathrm{~S}$. die vorige Abhandlung.

3 Aluminium würde als Material für das Zwisehenstiick jetzt vielleicht den Torzug vor dem schilipatt rerdienen. 
fahren, der Nadel die letzten Striche durch Papier oder Glimmer hindurch zu ertheilen. Leider kamn man sich nicht auf Astatischmachen eines bestimmten Nadelpaares mittels einer bestimmten Streichnadel einüben, weil durch das Verkehrtstreichen auch die Streichnadel selber an Magnetismus rerliert. Es ereignet sich wohl, dass man mit der Streichnadel keine Schwächung der stärkeren Nadel mehr erhält, wemn man sie an bestimmten Punkten ihres Umfanges, die sich am bequemsten zur Berührung bieten, verkehrt streicht. Alsdann genügt es, die Nadel an einem anderen minder zugänglichen, und deshalb bisher verschont gebliebenen Punkte zu berühren, um einen neuen Fortschritt der Astasie zu bewirken.

Ist das Nadelpaar so astatisch wie möglich, so stellt man die Windungen des Multiplicators mit Hülfe der unteren Theilung in die Ebene der freiwilligen Abłenkung, und hängt das Nadelpaar ein. Es folgt die Compensation der Ablenkungen durch die Drahtmassen, wenn dergleichen vorhanden sind, nach den in meinem Werke ${ }^{1}$ gegebenen Regeln, zu denen ich nichts hinzuzufügen wüsste, als dass man zum Compensator statt der Spitze der dort empfohlenen Perhnadeln, die nicht ans hartem Stahl bestehen, besser die der Aachener Nähnadeln Nr. 12 (lang) benutat.

Hr. Trndalu hat kürzlich die Bemerkung gemacht, dass die gewöhnlich zum Bespinnen angewendete grüne Seide Eisen enthalte und magnetisch wirke, und es ist ihm gelungen, völlig anziehungsfreie Drahtmassen herzustellen, indem er weisse Seide zum Bespinnen nahm. ${ }^{2}$ Ich hatte, als ich im Beginn meiner Multiplicatorversuche mit den Ablenkungen durch die Drahtmassen kämpfte, keinen Grund auf die Seide einen Verdacht zu werfen, da ich nicht unterlassen hatte, mich durch chemische Analyse zu überzeugen, dass mein Draht, selbst nach dem Auflösen der vielleicht durch das Ziehen rerunreinigten Schicht, Eisen enthielt, und dass Stücke ron demselben Kupfer, aus dem er gezogen war, stark magnetisch wirkten. ${ }^{3}$ Der Kupferdraht, den Hr. SAUERwatid neuerdings zu seinen Multiplicatoren ver- [78] wendet hat, ist durch Stein gezogen, und trotzdem magnetisch, auch wenn er mit weisser Seide besponnen wird. Es würde also Tänschung sein, wenn man hoffte, fortan

1 Bd. II. Abth. I. S. 485 ff. - Auf S. 494 ist ein verwirrender Druckfehler stehen geblieben. Es ist nämlich daselbst der Satz ,Sie bleibt gestaltet etwa wie die kurzpunktirte Curve in Fig. 126" (Z. 14 und 15 von oben) zu streichen, da diese Curve, um die Figur nicht noch mehr zu verwickeln, fortgelassen wurde.

2 Philosophical Transactions ete. For the Year 1861, p. 2; - Poggendorff's Annalen u. s, w. Bd. CXIII. 1861. s. 2.

3 Untersuchungen u. s. w. Bd. I. s. 164.187. 
durch blosse Anwendung weisser Seide zum Bespimmen sich ror den Ablenkungen durch die Drahtmassen zu schützen. Sondern die nächste Aufgabe wird bei uns noch immer sein, sich eisenfreies Kunpfer zu rerschaffen. Nach Hrn. MLagnus' Versuchen ${ }^{1}$ ist galvanoplastisches Kunfer keinesweges ohme Weiteres als eisenfrei anzusehen; es kamn erst durch ein so mühseliges und kostspieliges Verfahren eisenfrei erhalten werden, dass es rermuthlich in jeder Beziehung vortheilhafter wäre, Silber zn rerwenden. Die Schwierigkeiten, auf die Hr. Magnus bei Herstellnng eines eisenfreien Gewindes zu thermoëlelitrischen Zwecken stiess, dürften sich aber noch steigern, wem es sich darum handelte aus dem galvanoplastischen Kupfer so feine Drähte zu ziehen, wie man ihrer zu thierisch. elektrischen Versuchen bedarf. Unter diesen Umständen wird das Gerathenste sein, den Draht ans England zu beziehen, wo von elf Proben neun sich Hrn. Trxdalu diamagnetisch zeigten.

Das Nadelpaar muss gut centrirt sein, nicht allein wegen der Fehler der Ablesung, die ans der mangelhaften Centrirnng entspringen, sondern anch ans folgenden Gründen. Hängt es excentrisch, so wird es erstens bei starken das Gewinde durchkireisenden Strömen leichter nach einer Seite hin gezogen und dadurch in Pendelschwingungen versetzt. Zweitens ist zu bedenken, dass die Anziehungen. welche nicht eisenfreie Drahtmassen und das Berichtigungsstäbchen anf das Nadelpaar ausüben, von der Höhe abhangen, in der dasselbe im Rahmen schwebt, oder von der Länge des Fadens. Diese Länge unterliegt, wenn nicht besondere Maassnahmen getroffen sind, wegen der wechsehnden Feuchtigkeit der Luft, fortwährenden Schwankungen, deren grössere Werthe man bei einiger Aufmerksamkeit leicht beobachten kann. Num aher kommt das Gleichgewicht des Nadelpaares im Azimuth zu Stande durch Znsammensetzung jener beiden Krräfte mit der Richtkraft der Erde. Aendern sich also jene Kräfte in Folge einer Höhenschwankung der Nadelı, so muss anch im Allgemeinen die Gleichgewichtsstellung der Nadeln eine andere werden. Abgesehen ron anderen denkbaren Fällen, die kein [79] praktisches Interesse haben, trifft dies nur dam nicht zu, wenn 1. die magnetischen Axen beider Nadehn in einer Ebene liegen, und wemn 2. diese Ebene zusammenfällt mit der, welche das in sich vällig gleichartig gedachte Gewinde der Lünge nach hälftet. Alsdam nämlich werden die obigen drei Kr räfte gleichzeitig in jeder Höhe Null. und folglich die Stellung des Nadelpaares unabhängig von der Länge des Fadens. Allem dies setzt,

1 Physikalische Abhandlungen der Königl. Akademie der Wissenschaften zu Berlin. Aus dem Jahr 18j1. 4. S. 6. (s); - Poggendorff's Annalen u. s. w. 1־51. Bd. LXXXill. S. 474 . 
wie man sieht, wiederum roraus, dass das Nadelpair centrisch hänge. Bei der schwierigkeit, die hier rorgeschriebenen Bedingumgen in Strenge zu erfüllen, und der verhältnissmässig geringen Sorgfalt, die wohl darauf rerwendet worden ist, bin ich überzeugt, dass dies der wahre und einfache, wenn auch ziemlich verborgene Grund jener ewigen Schwankungen der Gleichgewichtslage des Nadelpaares ist, welche den früheren Beobachtern, und rormals mir selber, so viel zu schaffen machten, und die man sich durch Luftströmungen, durch thermisch bewinkte Aenderungen in der Intensität der Nadehn u. d. m. stets nur dürftig erklärte. ${ }^{1}$ Man sehe z. B. die Hypothesen, in denen sich darüber MELboni ergeht, der übrigens die freiwillige Ablenkung astatischer Nadelpaare, deren Theorie schon Noвı richtig gegeben hatte, unbegreiflicherweise ron der Torsion des Fadens ableitete. ${ }^{2}$

Natürlich wird man sich jetzt nicht damit begnügen, die Nadeln möglichst zu centriren, sondern man wird zugleich suchen, die Länge des Fadens beständig zu erhalten, indem man die Luft unter der Glocke anstrocknet. In der That habe ich, seit ich dies thue, ron jenen Schwankungen nichts mehr rerspürt, obschon ich den erhabenen Rand um die Theilung, den ich zum Schutze der oberen Nadel gegen Luftströmungen empfahl, ${ }^{3}$ längst aufgegeben habe. Die Austrocknung kann übrigens nur einen günstigen Einfluss auf den Isolationszustand des Gewindes ausüben. Als Austrocknumgsmittel gebe ich aus rerschiedenen Gründen dem Kali kausticum fusum (in baculis) den Torzug. Um das Káali zu beherbergen, habe ich Porzellangefässe ron geeigneter Gestalt anfertigen lassen, die jederseits rom Rahmen zwischen demselben und dem die Nadehn tragenden Bügel Platz finden. Wemm längere Zeit nicht gearbeitet wird, thut man wohl, die [S0] Gefässe zu entfernen, damit nicht überkletterndes kohlensaures Kali Schaden stifte.

Ховші wollte bekanntlich, dass die untere Nadel die stärkere sei, weil dabei die Summe der elektrodynamischen Wirkungen, die das System erführt, grösser ausfalle. ${ }^{4}$ Man kömnte einwenden, dass dafür die Astasie des Systemes dadurch rermindert werde, dass die ohnehin stärkere untere Sadel meln als die schwächere obere durch den strom gestärkt werde. Auf alle Fälle glaube ich, dass wemn ja ein Terlust an Empfindlichkeit daraus entspränge. dass die obere Nadel die stärkere ist, er durch den Vortheil aufgewogen würde, dass man gelegentlich, ohne das Nadelparr

1 Untersuchungen u. s. w. Bd. I. S. 192.

2 La Thermochrôse ou la Coloration calorifique etc. Naples 1850. p. 33 et suiv.

3 Untersuchungen u. s. w. Bd. II. Abth. I. S. 455.

4 Untersuchungen u. s. w. Bu. I. S. 173. 
aus dem Rahmen zu entfernen, der Astasie nachhelfen kann. Dazu braucht man unr den Faden herabzulassen, so dass die obere Tadel auf der Theilung ruht, und diese Nadel wieder mit der Streichnadel rerkehrt zu streichen. Während man die eine Hälfte der Nadel streicht, hält man die andere mittels eines anfgedrückten Haarpinsels fest.

Schliesst man einen Multiplicator durch einen Draht ron rerschwindendem Widerstande, so üben die Windungen auf die schwingende Nadel eine dämpfende Wirkung aus, die im Allgemeinen mit der Masse der Windungen wächst, aber unabhängig daron ist, ob die Windungen zu halber Länge und doppelter Dicke, oder zu ganzer Länge und einfacher Dicke rerbunden sind. Bei den Nerren- und anch schon bei den Muskel-Lultiplicatoren erreicht diese Wirkung einen solchen Grad, dass die Nadel dadurch ziemlich eben so schnell beruhigt wird, als man dies, selbst bei ansehnlicher Uebung, durch ein Magnetstäbchen zu thun rermag, ${ }^{1}$ Lasse ich die Nadel meines Inltiplicaturs ron 24160 Windungen ron $90^{\circ}$ fallen, das einemal bei offenem, das anderemal bei geschlossenem Multiplicatorgewinde, so erhalte ich folgende Reihe ron Ausschlägen:

$$
\begin{aligned}
& \text { Gewinde } \\
& \text { offen: }+90-60+26-18+10 \text { u. s. w. } \\
& \text { geschlossen: }+90-28+8-6+2 .
\end{aligned}
$$

Der nächste negative Ansschlag kann wegen des Ansschnittes in der Theilung zum Durchlassen der unteren Nadel nicht mehr abgelesen werden. Bei Versuchsreihen, wo man rasche Beruhigung der Nadel braucht und ander- [81] weitig zu thun hat, namentlich aber in Vorlesungen, ist dies Verfahren sehr nützlich.

Hr. Sauerwald giebt, auf meine Teranlassung, seinen grossen Multiplicatoren einen Stromwender bei, der mit Leichtigkeit rerschiedene Combinationen der beiden Multiplicatordrähte mit der Kette und mit einer Nebenschliessung herzustellen erlaubt. Mit Hülfe daron kamn man 1) die Kette, mit Ausschluss des Multiplicators, in sich schliessen. 2) den Strom nur durch eine bestimmte Windung. 3) durch beide Windungen hintereinander oder 4) zugleich hindurchlassen, 5) eine Nebenschliessrulle aus Neusilberdraht zum Multiplicator anbringen, wodurch er, bei ganzer Länge und einfacher Dicke, die passende Empfindlichkeit für den Muskelstrom erlangt; endlich 6) den Strom im Multiplicator bei irgend einer dieser Combinationen umkehren. Ich selber rerdanke den Hrn. SizuExs und HaLske einen noch vollständigeren Strommender, welcher nämlich den strom auch noch beliebig durch die eine orler die andere der beiden

1 Untersuchungen u. s. w. Bd. I. S. 192. 
Windungen zu senden erlaubt. Ton Wichtigkeit unter diesen Combinationen sind indess nur die mit $1 ., 3 ., 5$. und 6 . bezeichneten. Mit Hülfe geeigneter Nebenschliessungen lïsst sich dem Mnltiplicator jeder gewünschte Grad ron Unempfindlichkeit geben. Die Terminderung des Widerstandes des Multiplicators durch gleichzeitige Benutzung beider Drähte kommt bei thierisch-elektrischen Tersuchen kaum jemals vor. Ja, da nenerdings mehrmals Mnltiplicatorgewinde dadurch unbrauchbar geworden sind, dass die beiden Drähte sich irgendwo im Imeren metallisch berührten, die Anwendbarkeit des Multiplicators als BECQuereL'sches Differentialgalranometer aber rollends entbehrlich erscheint, so habe ich Hrn. Sautrwatd gerathen, das einst ron Noвm eingeführte Bewickeln der Rahmen mit zwei Drähten überhanpt ganz anfzugeben. Freilich wird das Bewickeln mit nur einem Drahte insofern mühsamer, als doppelt so riele Windungen aufzutragen simd. Dafür legt sich indess ein Draht leichter zurecht als zwei, und man hat die sicherheit, dass durch einen etwa entstehenden Isolationsfehler nie mehr als höchstens zwei Lagen ausser Wirkung kommen.

Der Stromwender muss nicht anf dem Consol angebracht sein, da das Handhaben der Torreiber die Nadeln erschüttern könnte.

Unter den Combinationen des Stromwenders fehlt zwar die, deren man bedarf, um die Beruhigung der Nadehn durch Dämpfung möglichst roll- [82] kommen zu bewerkstelligen, nämlich das Schliessen des Mrultiplicators durch einen kurzen metallischen Bügel. Inzwischen leistet das Schliessen durch die Nebenschliessrolle (Combination 5) fast das Nämliche, da es an meinem Inttiplicator, heim Fallenlassen der Tadel ron der Hemmung, folgende Reihe ron Ansschlïgen liefert: + $90-32+$ $8 \cdot 5-6+3$, die, wie man sieht, mit der ohme Rolle gewommenen so zusammenfällt, dass es auf den Lnterschied nicht ankommt. ${ }^{1}$

Um die Uebersicht der Versuche zu erleichtern, ist es rortheilhaft, die Terbindungen so herzustellen, dass das beobachtete Ende der Nadel sich im gleichen Sinne bewegt, wie der Strom zwischen den Zuleitungsgefässen.

Sollen Ablenkungen, oder Teränderungen derselben, von nur wenigen Graden beobachtet werden, so wird es, um Täuschungen durch die Parallaxe der Nadel in Bezug auf die Theilung zu remmeiden, nothwendig, sich eines Fermrohres zu bedienen, welches so aufgestellt sein muss, dass es der Nadel in ziemlich hohe Ablenkungen folgen kamm. Statt anf die in meinem Werke, a. a. 0. S. 484. 485, beschriebene Art,

1 [Bei der zuletzt angenommenen Form des stromwenders wird der Multiplicator beim Schliessen der Kette in sich stets zugleich anch in sich geschlossen.] 
kann dies auch so geschehen, dass das Fernrohr auf einem kreisförmigen Schlitten um den Inltiplicator läuft. Fine solche Einrichtung hatte Hr. Halske die Güte, für mich auszuführen. Beiden Anordnungen. wobei das Fernrohr die Nadel schräg durch die Glocke betrachtet, ist wohl die schon vor langer Zeit von Hrn. Lexz angewendete vorzuziehen. bei der über der Spiegelplatte, die oben die Glocke schliesst, ein passend geneigter Spiegel oder ein Prisma angebracht wird, worin ein wagerechtes Fernrohr das Bild der Nadel erblickt. ${ }^{1}$

Schliesslich stelle ich die Literatur über Hydro- und Thermomultiplicatoren, seit dem Eingangs bezeichneten Zeitpunkte, so weit sie uns angeht und in dem Vorigen noch nicht berührt wurde, hier zusammen.

1. Lenz, Poggendonff's Amnalen u. s. w. 1849. Bd. LXXTI. s. 500.

2. Reubex Phirss, The Philosophical Magazine etc. 1549. Vol. XXXII. p. 51); - L'Institut. 1549. t. XVII. No. 519.

3. Doxovax, Transactions of the Royal Irish Academy. Vol. XXII. Dublin 1549. t. P. III. p. 233.

4. Buff, Ammalen der Chemie und Pharmacie. 1854. Bd. XC. S. 186.

5. De la Provostaie. Annales de Chimie et de Playsique. Octobre 15.55. 3 me Série. t. LII. p. 129.

[83] 6. Wredencaxx, Die Lehre ron den Wirkungen des galranischen Stroms in die Ferne. Bramschweig 1861. S. 210.

7. Doв, Der Elektromagnetismus. Berlin 1861. S. 27.

8. Magncs. Monatsberichte der Akademie. 1861. S. 248.

§. II. Tom Gebrauch der Spiegelbussolen zu thierischelektrischen Tersuchen.

Schon in meinen 'Tntersuchungen' rom Jahr $1848^{2}$ habe ich die Termuthung ausgesprochen, dass man zur messenden Beobachtung der thierisch-elektrischen Ströme sich der PoggexdorfF'schen, von Gatss und Hrn. WEBER rervollkommneten Methode der Spiegelahlesung würde bedienen kümen. Anch habe ich bereits im April 1851 im plysikialischen Cabinet zu Leipzig mit Hrn. Haxkes den Muskelstrom am Elektrodynamometer beobachtet, und Hr. Heisnoutz hat das Jahr daranf in Königsberg seinen Zuhörem meine Versuche an einer Spiegelbussole mittels des später ron mir beschriebenen Verfahrens gezcigt, wobei die Ahlenkung des Spiegels durch die Bewregung eines daron zurückge-

1 Poggendorff's Amalen u. s. w. 18.35. Bd. XXXIY. S. 38;.

2 A. a. O. Bit. I. S. 197. 
worfenen Lichtbündels sichtbar wird. ${ }^{1}$ So lange indessen die Larlungen der Platinelektroden messende Versuche in diesem Gebiet überhaupt vereitelten. fehlte es an einer bestimmten Veranlassung: den Multiplicator für die Spiegelbussole anfzugeben. Als aber durch Erfindung der unpolarisirbaren Elektroden dies Hinderniss beseitigt war, wies ich sogleich auf den Tortheil hin, den jetzt die Spiegelablesung hier rerspreche. ... Wit den absolut gleichartigen, umpolarisirbaren rerquickten Zinkelektroden .zur Ableitung; mit dem Princip der Nebenleitung zur Erzengung auf's „Feinste abgestufter elelitromotorischer Kräfte jeder Ordnung; endlich ,.mit der Spiegelbussole, die, bei gleicher Empfindlichkeit mit dem Yerren..Multiplicator, keiner schwierigen und rergïnglichen Graduirung mehr , hedarf: steht jetzt nichts mehr in diesem Gebiete," sagte ich damals. , der Austührmg messender Tersnche entgegen, und eine nene Balnu ,.nichtiger Untersnchmeen ist eröthinet.. 2

[84] In demselben Aufsatz, \$. 49.50, führte ich an, dass meine ron Hrn. Saderwatd nach Hrn. Wiedenaxy's Modell gehaute Bussole, mit 12000 Windnngen feinen Drahtes rersehen, bei $2285 \mathrm{~mm}$ Abstand der Scale rom spiegel, ohne dass diesen etwas ron seiner Richtkraft genommen werde, bereits eine Empfindlichlieit zeige, die sich der des Nerren-Mnltiplicators nähere, indem dieser, zwei seiner Grade anf einen Scalentheil gerechnet, inmerhalb der ersten $55^{\circ}$ allerings die grössere relative, und imerhalh der ersten $65^{\circ}$ die grössere absolnte Empfindlichkeit besitze, darüber hinaus jedoch der Bussole mehr und mehr nachstehe. ${ }^{3}$

1 S. oben S. 131. Abh. IT.

2 S. oben Abh. IV. S. 76. 77.

$3 \mathrm{Um}$ dies zu prüfen, hatte ich durch beide Instrumente hintereinander einen von einer beständigen Kette abgeleiteten Stromzweig geschickt, dessen Stärke dureh Verlängern der Nebensehliessung schrittweise erhöht wurde. Nit gleieher absoluter Empfindlichkeit ist im Obigen gemeint, dass die beiden Instrumente um dieselbe Zahl gleichwerthiger, d. h. also z. B. dureh Schätzung gleich sicher in Zehntel zu theilender Abschnitte ihrer Theilung abgelenkt werden, mit gleicher relativer Empfindlichkeit, dass ein gleicher Stromzuwaehs einen gleichen Ablenkungszuwachs bewirkt. Trägt man auf eine Abseissenaxe, welehe die wachsenden Stromstärken bedeutet, die entsprechenden Ablenkungen des Multiplicators und der Spiegelbussole als Ordinaten auf, so liegt die stark gegen die Alseissenaxe coneave Multiplicatorcurve anfangs über der Geraden, welehe den Gang der Bussolenablenkungen darstellt, bei etwa $55^{\circ}$ ist die Tangente an der Multiplieatoreurve dieser Geraden parallel, d. h. die relativen Empfindlichkeiten sind gleich, bei etwa $65^{0}$ schneiden sich die Curve und die Gerade, oder die absoluten Empfindlichkeiten sind dieselben, endlich bei $90^{\circ}$ sehliesst sich die ('urre einer der Abeissenaxe parallelen Geraden asymptotisch an. während die Gerade bis zu den Grenzen der Scale. 1000 Graden oder 500 Scalentheilen entsprechend, ihre Richtung behält. 
Für die meisten Versnche über den Mnskelstrom reicht die Empfindlichkeit der Bussole in dem bezeichneten Zustand aus. Ein Adductor magnus rom Frosch, anf die Thonschilder der sogleich zn beschreibenden nenen Znleitungsgefïsse mit Längsschnitt und künstlichem Querschnitt aufgelegt, giebt gegen 300 sc (Scalentheile) beständiger Ablenkung. Für den Nervenstrom dagegen ist die Bussole, wegen der linearen Gestalt ihrer Intensitätencurve, unter denselben Umständen noch nicht empfind-

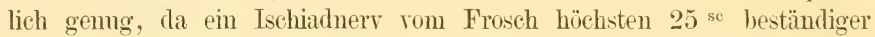
Ablenkung giebt; mol ebensowenig würde sie für die negative Schwankung des Muskelstromes des einen Armes ansreichen. Um die Empfindlichkeit zn erhöhen, gebietet man über rerschiedene Mittel. Man kann die Anzahl der Windungen, die Entfermung der Scale rom Spiegel, die Tergrösserung des Fermrohres steigern; man kam [85̃] endlich anch die Richtkraft des Spiegels rermindern, indem man die Wirking der Erde durch die eines passend genäherten Magnetes zum Theil aufhebt. Bei dem letzteren Verfahren gelingt es sehr leicht, anch für die Versuche an Nerven überflüssige Empfindlichkeit herzustellen.

Welch grosser Vortheil ans dem linearen Gange der Intensitätencurve an der Spiegelbussole entspringe, anch wemn man keine Messungen bezweckt, hedarf nicht der Erwähnmmg. Die relative Empfindlichkeit bleibt bei jeder noch rerwendbaren Ablenkung die nämliche, und ron dem Verhältniss grosser mo kleiner Stromstärken erhält man mmittelbar eine richtige Vorstellung, statt des mehr oder remiger verzenten Bildes, welches jede andere galvanometrische Vorrichtung davon entwirft. Die Spiegelbussole erfüllt ohne Weiteres das Bedürfniss der Elelitrophyssiologie nach einem Galranoskop ron grosser Empfindlichkeit bei kileiner Schwingungsdaner des magnetischen Systems. Die starke Dïmpfung der Schwingungen durch die Kiupferhülse ist in unseren Tersnchen, wo es sich, wie ich zeigen werde, anch bei umpolarisirbaren Zuleitungsgefässen noch stets nm unbeständige Ströme handelt, ron unschätzbarem Nutzen. Nimmt man hinzu, dass die Spiegelbussole ron allen Schwierigkeiten der Handhabung, die dem Mnltiplicator mit astatischem Narlelpaar stets anhaften werden, frei ist, und dass ihr Preis, mit Inbegriff eines StersHEI'schen Fermohrs, den eines Multiplicaters ersten Ranges linge nicht erreicht, so drängt sich die Frage anf, ob nicht überhanpt der Ifnltiplicator ganz für die spiegelbnssole aufzngeben sei. Wirklich muss ich sagen, dass ich selber mich seit jenem Zeitpunkte mit grossem Vortheil der Bussole fast ansschliesslich zu meinen Untersuchmmen bedient habe.

Inzwischen hat diese anch ihre Mängel. Sie rerlangt zu ihrer Anfstellung Räumlichkeiten, über die nicht Jeder verfügt; mol obschon ein Inltiplicator, wie eben hemerkt wurde, thenrer sein kamn, als Bussole 
und Fernrohr, so kamn er doch auch weit billiger hergestellt werden. In dem Stübchen, wo ich den grössten Theil meiner Untersuchungen gemacht habe, hätte ich keine Spiegelbunssole aufstellen können, selbst wemn meine Mittel mir damals erlaubt hätten, eine solche anzuschaffen, anstatt mir einen Inultiplicator zu banen. Dies sind Verhältnisse, die heute, wo jede Universität ihr physiologisches Laboratorium hat, nicht wiederkehren [86] können. Aber Anderes bleibt zum Truste derer zu erwägen, die sich jetzt vielleicht ungern anf den Gebranch des Multiplicators angewiesen sehen. Das leichte Nadelpaar eines Multiplicators ist für Erschüttermingen viel weniger empfindlich als der Spiegel. Die Störungen durch die elektromagnetischen Eisenkerne, z. B. des Magnetelektromotors, des Fallhammers, machen sich an der Bussole auf riel grössere Entfermungen sichtbar als am Multiplicator. Die Unstetigkeit des Nullpunktes an der Bussole ist lästig, selbst wenn dem Magnet nichts ron seiner Richthraft genommen wird. Sie wächst mit wachsender Astasie zuletzt zu einem umerträglichen Missstande. ${ }^{1}$ Nachts bleibt Belenchtung der Scale in solcher Auslehnung, wie sogenamnte qualitative Versuche es erheischen, bei denen man oft nicht rorher weiss, in welcher Richtung und Grösse der Ausschlag erfolgen wird, stets eine missliche Anfgabe. Namentlich aber ist an der Spiegelablesung anszusetzen, dass man dabei nicht, während man mit einem Versuch beschäftigt ist, zugleich aus der Ferne und mit einem Blick übersieht, was im Kreise vorgeht. Die Stellung der Nadel aut der Multiplicatortheilung, der Sinn ihrer Bewregung, verrathen selbst im indirecten Sehen sofort den elektrischen Vorgang; die Spiegelbussole dagegen rerlangt immer eine mit dem Ange am Fermrohr gemachte Ablesung. Ist der Tersuch der Art, dass man ihn erst rollständig eimrichten, und damn ohne hinzusehen durch eine einfache Handbewegung die beabsichtigte Wirkung herbeiführen kamm, so hat dies nichts zu bedenten. Viele Versuche erlauben aber nicht solches Terfahren, und alsdamn braucht man zum Ablesen der Bussole einen Gehülfen, was namentlich hei qualitativen Versuchen unbequem ist, wo die Beobachtungen sich nicht regelmässig folgen, sondern jeden Augenblick durch Ueherlegungen und durch Torbereitungen, deren Bedürfniss sich einstellt, unterbrochen werden kömnen. Anch zur Demonstration ist die Spiegelbussole nicht geeignet, wemn man nicht schon für zwei Personen zu dem ziemlich umständlichen Verfahren greifen will. dessen oben S. 152. 153 gedacht wurde.

Es bleiben somit den Multiplicatoren für jetzt anch noch einige Vorzinge, und da sie ohnehin zur Zeit die am meisten verbreitete

1s. unten, Abh. XV. 
galranometrische Torrichtung sind, so habe ich nicht für ummütz gehalten, hier noch eimmal auf deren Handhabung zurückzukommen.

[87] Die Theorie der Spiegelbussolen findet sich an rerschiedenen Stellen so rollständig entwickelt und ihre Behandlung ist so einfach. dass darüber nichts weiter zu sagen ist. Doch will ich bemerken, dass ich mich bei lïngerem Gebranch der Spiegelablesung zu elektrophysiologischen Zwecken nicht in die von den magnetischen Beobachtungen herstammende Gewohnheit habe finden künnen, eine in $1000^{\mathrm{mm}}$ getheilte Scale so anzuwenden, dass der Faden ungefähr mit der Nitte ibrer Länge zusammenfällt. Bei messenden Versuchen nach vorher bestimmtem Plane, deren Ergebnisse rechnend rerwerthet werden sollen, mag dieses Verfahren am Platze sein. Bei qualitatiren Versuchen dagegen, wo es darauf ankommt, das Ergebniss' augenblicklich zu fassen um darauf weiter zu bauen. ziehe wenigstens ich die mmittelbare Anschanmg einer Zahl, deren Gewinnung durch Subtraction zweier vierstelligen Zahlen ron einander vor. Meine Scale hat daher den Nullstrich in der Mitte, und ich rerschiebe sie ror jedem Versuch mittels Zahn und Trieb so, dass der Faden den Nullstrich deckt. Entsprechend der oben S. 151 für die Aufstellung der Multiplicatoren gegebenen Regel ist die Anordnmo getroffen, dass der Faden sich im Fermrahr über die Scale scheinbar in der Richtung bewegt, wie der Strom zwischen den Zuleitungsgefässen auf dem Tisch ror mir. Um aber auch, wenn das Scalenbild unbeweglich abgelenkt ist, den Sinn sofort zu erkennen, in dem dies geschah, sind die Zahlen der im Fernrohr rechts erscheinenden Scalenhälfte roth, die der anderen wie gewöhnlich schwarz mit der schablone aufgetragen. ${ }^{1}$

1 Zu meiner Frende erfuhr ich, nachdem der vorliegende Paragraph im Wesentlichen druckfertig war, auf der Reise durch Göttingen gegen Ende April d. J., ron Hrm. Professor Meissner, dass er sich mit dem im Bau der Instrumente mit Spiegelablesung so erfahrenen Hm. Inspector Merensters verbunden habe, um ein für elektrophysiologische Zwecke geeignetes Galvanometer der Art zu Stande zu bringen. Dasselbe ist seitdem unter dem vielleicht nicht ganz bezeichnenten Namen eines Elektrogalvanometers in Hence's und Pfeuffer's Zeitschrift (3. Reihe. Bd. XI. S. 193) und in Poggendorfy's Annalen (1861. Bd. (XIV. S. 132) besehrieben worden, und seine Leistungen lassen, wie es seheint, kaum etwas zu wünschen ibrig. Der Magnetstab, mit dessen Hülfe clie Richtkiaft des beweglichen Magnetes verkleinert wird, ist hier gleich an dem Instrument in passender Weise angebracht, wodureh die Anfstellung sehr erleichtert wird.

Sinnreich, und den Verfassern eigenthümlich, ist die spaltung dieses Hülfsmagnetes in einen stärkeren nnverrïekt bleibenden, und einen schwächeren verschiebbaren, wolureh erreicht wird, dass man, um cine hinreiehend kleine Abänderung der Wirkung auf den aufgehängten Magnet auszü̈ben, nicht, wie es sonst der Fall sein würde, einer ausserordentlich feincn Einstellung des festen Magnetes bedarf 
Das cylindrische Glasgefäss, mit inmen angekitteter Holznase zum Unterstützen der Bäusche, wie es in meinen 'Untersuchungen' als Zu-

Die Verfasser irren jedoeh, wemn sie die Anwendung eines festen Magnetes zum Astatischmachen eines beweglichen für etwas Nenes halten, und Hrn. W. Weber zuschreiben, da dies allbekannte und längst zum Gemeingut gewordene Verfahren nicht nur der Anwendung der Doppehnadel im Multiplicator dureh Nobici, sondem sogar ihrer Erfindung durch Aupène vorherging. HAur gab dies Verfahren 1817 an, um die Compassnadel der Mineralogen zu befähigen, schwache Spuren von Magnetismus sichtbar zu machen. (Mémoires du Muséum d'Histoire naturelle etc. 4. t. IIl. 1817. p. 172; - Amnales des Mines ete. 1817. t. II. p. 329; - GiLbert's Amualen der Physik. 1819. Bd. LXIII. S. 104.) Dieses Kiunstgrifies bedienten sich sjdann Hr. Biot und Savart im Jahr 1820 bei ihrer Untersuchung über das Gesetz, wonach die Wirkung des Stromes auf die Magnetnadel mit der Entfernung abnimmit, um die sehwingende Nadel der Erdkraft zu entziehen. (Annales de Chimie et de Physique. 1820. t. XV. p. 222; - Anpère et Babinet, Exposé des nouvelles Déconvertes sur l'Électricité et le Maguétisme. Paris 1822. p. 59; - Fechner's Bearbeitung von Bıт's Lehrbuch der Experimental-Physik u. s. w. Leipzig 1829. Bi. IT. S. 158.) In der Abhandlung vom Jahr 1825, worin er den Multiplieator mit Doppelnadel beschreibt, führt Nobıl selber an, dass die Physiker sich bisher, um die Empfindlichkeit des SchweIgGer'sehen Galvanometers zu erhöhen, eines darunter angebrachten Magnetstabes bedient luätten, weleher die richtende Kraft der Erde verminderte. (Memorie ed Usservazioni ec. Firenze 1834. vol. I. p. 2.) Als Melloni 1841 vorsehlug, die Astasie eines Nadelpaares auf diese Weise zu vergrössern (Arehives de l'Électrieité. 1841. t. I. 656), erinnerte Hr. Poggendorff sogleich wieder daran, dass in Deutschland dieses Nittel bei einfachen Nadeln längst angewandt worden. (Poggendorff's Annalen u. s. w. 1st2. Bd. LVI. S. 370.) lch selber habe mich desselben, seit ich den Multiplicator mit der Bussole vertauseht habe, stets bedient, um, wo es nöthig war, die Richtkraft des Spiegels zu schwächen; wie aus meinen oben S. 153 angeführten Worten erhellt, mit denen nicht gemeint sein konnte, dass ich dem Spiegel selber Magnetismus nahm, da bekanntlich die Stärke des Magnetisnus einer Nadel aus dem Ausdruck für die Grösse ihrer Ablenkung dureh den Strom verschwindet (Untersuehungen u. s. w. Bd. I. S. 166. 167).

Bei dem Verdammungsurtheil, welehes sie über das astatisehe Nadelpaar fällen, scheinen die Verfasser die eigentliche Spitze der Noвılı'schen Erfindung zu übersehen, den glïeklichen Umstand nämlich, lass die Wirkung der oberen Windungen anf die obere Nadel die ablenkende Kraft un fast die Hälfte vermehrt, während überlies die eine Nadel die andere verstärkt, statt dass bei ihrem Verfahren die Nadel durch den festen Magnet geschwächt wird. Da es gerade die Aufgabe ist. möglichst grosse Empfindlichkeit bei mögliehst kleiner Astasie (d. h. Sehwingungsdauer des systemes) zu erzielen, so bin ich gar nicht so gewiss, ob es an Stelle der von den Hrn. Meissner und Meyerstein getroffenen Einrichtung nicht vortheilhafter wäre, wie Gauss selber es vor bald dreissig Jahren vorsehlug (Göttingische Gelehrte Anzeigen. 1832. St. 206. 207. S. 2055; - PoggendorfF's 
leitungs- [89] gefäss bei thierisch-elektrischen Versuchen beschrieben und abgebildet ist, habe ich längst mit einlenchtendem Vortheil ersetzt durch ein riereckiges Porzellangefäss, dessen rorderer immerer Wand ein Karnies aus demselben Stoffe angeformt ist.

Was die Behandlung der Platimplatten betrifft, so hat so mancherlei Nenes, was ich darüber sagen kömnte, sein Interesse eingebüsst durch die Entdeckung der merkwürdigen Eigenschaften des rerquickten Zinkes in schwefelsaurer Zinkoxydlösung. ${ }^{1}$ Ich wüsste keinen Fall, wo nicht diese Combination dem Platin in Kochsalzlösung unbedingt vorzuziehen wäre, und begnüge mich daher mit der Berichtigung eines Irrthums, in den ich bei meinen früheren Aeusserungen über diesen Gegenstand verfallen hin.

Ich habe mir nämlich immer vorgestellt, dass wemn an die Grenze der Messingklemmen und der Platimplatten an meiner Torrichtung Salzlösung hingelangt, das Platin der betroffenen Seite positiv erscheine. ${ }^{2}$ Die beiden einander berührenden Metalle mit dem die Berührungsstelle benetzenden Elektrolyten dachte ich mir als flaches Erregerpar in dem ron mir aufgestellten Sinne, ${ }^{3}$ und glaubte, dass wemn man die beiden Metalle durch den Multiplicator rerknüpfe, der Stromzweig sichtbar werde, der sich bei dieser Anordnung, trotz der Nebenschliessung durch die Berührungsstelle selber, doch auch durch den Multiplicator ergiessen muss. Der ummittelbare Versuch hat mich aber des Gegentheiles belehrt. Ich löthete einen Kupfer- und einen Zinkidraht, beide ron $1.3^{\mathrm{mm}}$ Durchmesser, aneinander, brachte sie in den Multiplicatorkreis, und benetzte die Löthstelle mit rerdümnter Schwefelsäure. Es gab sich selbst mit halber Länge und doppelter Dicke des Muskel-MIultiplicators keine Spur ron Wrirkung zu erkennen. An der Spiegelbussole erschien, bei nur 53 Windnngen dicken Drahtes, eine Ablenkung ron etwa 1 se. Da aber dadurch das Kupfer, statt negativ, positir gegen das Zink angezeigt [90] wurde. so war sie wohl thermoëlektrischen Ursprunges. Temn also durch ein scheinbar die Grenze der Messingklemmen und Platimplatten benetzendes Tröpfchen Salzlösung eine Ungleichartigkeit

Ammalen u. s. w. 1833. Bd. XXVIII. S. 251. Anm.), eine Doppelnadel von kräftigen Verhältnissen mit Dämpfung und Spiegelablesung zu versehen, wobei Einem immer noch unbenommen bliebe, die Astasie nach Nencoxı's Vorsehlag mittels des HAur'schen Verfahrens zu erhöhen. Auch würde so die lästige Empfindlichkeit gegen magnetische Fernwirkungen vermindert sein. (Nachträgliche Ammerkung [rom Jahr 1,62].)

1 S. oben S. 42. Abh. IT.

2 Untersuchungen u. s. w. Bd. I. s. 21s, 220.

3 Ehendas. S. 581 . 
entsteht, so geschieht dies rermuthlich so, dass die Lösung in dem Capillarspalt zwischen den Metallen bis zu Stellen eindringt, die ron solchen Punkten, wo die Metalle einander wirklich berühren, hinreichend weit entfernt sind, damit der Widerstand der dadurch gebotenen Bahn nicht völlig rerschwinde gegen den des Multiplicatorkreises.

Man kann natürlich die allgemein rerbreiteten riereckigen Zuleitungsgefässe aus Porzellan mit ihren Ständern, Messingklemmen und Sicherheitsplatten, wie sie zur Aufnahme zweier Platimplatten bestimmt waren, jetzt auch mit einer rerquickten Zinkplatte anwenden, und wird dies in den Versuchen ohne Bäusche, z. B. über die negative Schwankung des Muskelstromes des einen Armes, mit allem Vortheil thun. Tiel bequemer zu den Tersnchen mit Bäuschen ist die in Fig. 1. Taf. I dargestellte, ${ }^{1}$ von Hrn. Saderwadd nach meiner Angabe verfertigte. kleine Vorrichtung; ja wer sie bisher gehandhabt hat, ist einig mit mir darüber, dass sich wohl nur noch wenig daran rerbessern lasse.

Auf einen isolirenden Fuss ron Kammmasse ist das aus Zink gegossene Zuleitungsgefäss geschraubt. Ausser dem eingetanchten Theile des Bausches fasst es nur wenige Cubikcentimeter Lösung. Innen wird es mit BERJot's Flüssigkeit ${ }^{2}$ verquickt, anssen und an den Rändern, welche aber vorher gleichfalls rerquickt worden sind, mit Lack überzogen. Der der Hinterseite des Gefässes angegossene Hals trägt einen Knopf aus Kammmasse zum Stiitzen des Ballens bei feinen Verrichtungen auf den Bänschen; auch dient er als Henkel zum Anfassen des Gefässes beim Terquicken, Lackiren, Ansspühlen u. d. m. $k$ ist eine Doppelklemme zor Aufnahme erforderlichenfalls zweier Drähte. Der Bausch nimmt wie bei den Porzellangefässen die ganze Breite des Gefässes ein. Mit dem unteren Ende seines senkrecht in das Gefäss himabragenden Theiles stützt er sich ummittelbar auf dessen Boden, mit der unteren Fläche seines wagerecht vorgestreckten Theiles ruht er auf der rerquickten Fläche eines Karnieses, welches [91] eine Terbreiterung des vurderen Randes des Gefässes vorstellt. Ton den seitlichen Rändern des Gefässes erheben sich Wangen, welche den Bausch vollends gegen seitliche Verschiebung sichem und die Zinkoberfläche rergrössern, die auf möglichst kurzem Wege durch die Lösung ron den dem Bausch aufliegenden thierischen Theilen aus erreicht wird. Das Gleiten des Bausches nach rückwärts wird verhindert durch ein Schild aus Kammmasse, welches mittels eines in die Hohlkehle des Karnieses gelegten Kantschukringes gegen den Rücken des Bausches

1 Der Maassstab von 0.66 bezieht sich auf die dem Beschauer zugekehrte senkrechte Kante des Gefässes.

2 Comptes rendus etc. 9 Aoút 185.8. t. XLWII. p. 273. 
federt. Der hintere hand der Wangen ist nach der Gestalt dieses Rückens ansgesthnitten. Der Bausch muss so dick sein, dass er das schild überall ron diesem hande abhält und so den Druck des Schildes vollstïndig erfïhrt. Das Schild ist in Fig. $2 a$ von hinten besonders dargestellt. Anschnitte $a, a^{\prime}$ am seitlichen Rande des Schildes rerhüten das Auspringen des Kautschnkringes. Der untere Rand des Schildes rerschiebt sich auf dem oberen Rande des Gefässes, den die Figur im Durchschnitt zeigt $\left(r, r^{\prime}\right)$, und zwei ron jenem unteren Rande in's Gefäss ragende Zapfen $\left(z, z^{\prime}\right)$ rerhindem, dass das Schild seitlich answeiche. Diese Eimrichtung bietet gegen die ältere den Vortheil, dass die ohere Fläche des Bausches ron allen Seiten her zugänglich ist. Sonst nämlich wurde dem Rückwärtsgleiten des Bausches dadurch rorgebeugt, dass man die Platimplatten ans der Flüssigkeit hob und gegen den Rücken des Bansches drückte, ${ }^{1}$ wo damn die den Bansch überragenden Messingklemmen dessen obere Fläche nach hinten oft störend beschränkten.

Der wesentliche Unterschied zwischen der Handhabung der neuen und der der alten Zuleitungsgefässe besteht darin, dass während diese. um gleichartig zu bleiben, ansser der Arbeitszeit, ja zwischen je zwei Versuchen, sorgfältig musten geschlossen gehalten werden, diese Nothwendigkeit bei den nenen Gefässen fortfällt. Subald und so oft man die Vorrichtung zusammenstellt, ist sie gleichartig; sollte sie mit der Zeit etwas ungleichartig werden, so genügt ernentes Verquicken, um den besten Zustand wieder herzustellen. Die einzige Sorge ist also die, dass die Flüssigkeit in den Bünschen und Crefässen gleichartig bleibe, am sichersten gesättigt. jedoch ohne lass das Zinksalz auskirystallisire. Dazu ist nur nöthig die Vorrichtung, mit einem Vorrath ungelöster Kirystalle am Borlen der Gefässe, in rer fenchten Kammer anfzubewahren.

\section{§. IV. Von den Bäuschen.}

Ein anteres Material zım Ersatz der Fliesspapierbäusche ist mir zu finden noch nicht gelungen. Doch giebt es einen himnstgriff, der ihre Anfertigung sehr erleichtert, nämlich sie im feuchten Zustande mit einer langen geraden und breiten Klinge (einem Tischmesser) zu schneiden, wobei das durch Capillaranziehung berirkte Haften der Blätter aneinander den Druck der Presse ersetzt. Das Messer schärft man jedesmal, nachdem man eine Fläche am Bausth hergestellt hat, mit einer sthmirgelfeile, welche genan die passende Art ron Schneide erzengt. Ferner pflege ich die Bäusche jetzt an dem Ende, womit sie in die Lïsung tauchen,

1 Untersuchungen u. s. w. Bd. I. S. 222. Taf. 1. Fig. 12. 
zusammenzuähen, wie ich dies zur Befestigung des Keilbausches an den Zuleitungsbansch angegeben habe. ${ }^{1}$ Dies erlaubt sie gelegentlich, wemn sie längere Zeit ruben sollen, mter Lösung anfzubewahren, ohne dass ihre Blätter sich verschieben, anch wohl gänzlich ron einander lösen. Das Anfbewahren geschieht am besten in weiten und niedrigen standgefässen mit aufgeschliffenem Glasdeckel, wie man sich ihrer zu Gehirnpräparaten u. d. m. bedient.

\section{§. V. Tom Modellirthon als Ersatzmittel der Eiweisshäutchen.}

Mit den von mir sogenannten und früher empfohlenen Eiweisshäutchen hatte ich längst Ursache wenig zufrieden zu sein. Die Blase ist oft ungleich dick, fett, fault leicht und steckt das zum Aufweichen benutzte Hühnereiweiss an, so dass man die aufgeweichten Häutchen nicht rorräthig halten kamn. Das Eiweiss selbst ist anch nicht immer von gleicher Beschatfenheit, unangenehm zu handhaben, und es ist sehr fraglich, ob dessen organische Substanz irgend einen Dienst leiste. Die Eiweisshäutchen schmiegen sich nicht gehörig den Bäuschen an, so dass sich Luftblasen darunter fangen u. d. m. Was aber mehr zu bedenten hat als dies Alles, ihr Widerstand ist kein beständiger, vielmehr ist er, wenn sie mit Zinklösung getränkten Bäuschen aufliegen, in raschem Wachsen begriffen, wie ich beim Untersuchen des Muskelstromes mit umpolarisirbaren Elektroden an der Spiegelbussole bald erfuhr.

[93] Es zeigte sich nämlich, dass trotz der Beseitigumg der Polarisation der Elektroden der Strom stets rasch sank. Nit Hülfe des unten zu beschreibenden ,Compensatur's" (§. XI) stellte ich fest, dass dabei die elektromotorische Kraft in viel geringerem Maass abnahm, als die stromstärke. Es hatte also jedenfalls auch der Widerstand des Kreises zugenommen, und dass die Zunahme die Eiweisshäutchen betraf, ging daraus herror, dass bei derer Emenermng der Strom ansehnlich in die Höhe ging. ${ }^{2}$ Diese Widerstandszunahme der Eiweisshäntchen rührt nicht ron secundärem Widerstand her, ron dem bekaunt ist, dass er zu seiner Entstehung grösserer Stromstärken bedarf; anch tritt sie, obschon in

1 s. oben Abh. V. S. 89. Anm.

2 Der Theil der Stromabnahme, der sich nicht auf diese Weise erklärt, sondern auf einer Vermindernng der elektromotorischen Kraft beruht, rïhrt von innerer Polarisation des Mnskelgewebes her, wie ich anderswo darthun werde. [Terg]. hieriiber die Abhandlung: Ueber die Erscheinungsweise des Muskel- und Nervenstromes bei Anwendung der neuen Methoden zu deren Ableitung, im Archiv für Anatomie u. s. w. 1s67. S. 270. - s. diese Abhandlung im zweiten Bande dieser Sammlung.]

E. du Bois-Reymond, Ges, Abh. I. 
geringerem Naass, ein. wenn man die Häutchen durch mehrere mit Kochsalzlösung getränkte Fliesspapierlagen von der Zinklösung trennt. ${ }^{1}$ Ebensowenig stammt sie ron Austrocknumg an der Luft her, da sie im feuchten Raume nicht ausbleibt, und überdies gerade die rom Iuskel berührten Stellen der Häutchen vor der Trockniss aus diesem Grunde geschützt sind. Sondern ihre Ursache ist zu suchen in der Wasserentziehung durch die Zinklösung, die sich auch darin ausspricht, dass die Häutchen hornartig trocken und durchscheinend werden und sich stark einrollen.

Da, wie gesagt, auch die Dazwischenkunft ron Kochsalzlösung diesen Uebelstand nicht ganz beseitigt, so bin ich neuerdings dazu gelangt, die Fiweisshäutchen ganz zu verwerfen. Den Ersatz, den ich dafür gefunden habe, betrachte ich als eine der glücklichsten Bereicherungen der elektrophysiologischen Technik. Hr. Dr. Rosenthal hatte mich schon darauf aufmerksam gemacht, dass an Stelle des Eiweisses der Eiweisshäutchen sich rermuthlich eine Kochsalz- oder phosphorsaure Natron-Lösung ron solcher Concentration mit Tortheil würde anwenden lassen, dass die Nerven oder Muskeln nicht daron leiden. ${ }^{2}$ Seine Absicht war, damit, statt der [94] Blase, sogenanntes regetabilisches Pergament ${ }^{3}$ zu tränken. Ich kam auf den Gedanken, den mir bereits von meinen Studien üher secundär-elektromotorische Erscheinungen und den secundären Widerstand der feuchten porösen Leiter wohl rertrauten Modellirthon damit anzukneten, der eine sehr geringe innere Polarisation besitzt, keinen secundären Widerstand annimmt, jeder Form sich schmiegt, stets in gleicher Beschaffenheit erhalten, vor Trockniss geschützt so lange man will brauchbar aufbewahrt werden kann, endlich für Salzlösungen sich in den Fristen, die hier in Betracht kommen, so gut wie undurchdringlich rerhält. In der Abhandlung über den secundären Widerstand gab ich an, man solle, um letzteren zu rermeiden, die thierischen Theile und Eiweisshäutchen ron den mit Zinklösung getränkten Bäuschen stets noch durch Kóchsalzbäusche trennen, zwischen diesen und den Zinkbäuschen aber, um die Diffusion der Salzlösungen zu verzögern, ein mehrere Millimeter dickes Blatt Modellirthon aubringen. ${ }^{4}$ Die Torschrift, die ich jetzt gebe, ist riel einfacher; sie besteht darin, die Eiweisshäutchen und Kochsalz-

1 s. oben Alh. V. S. 123.124.

2 KöLlıke, Verhandlungen der Würzburger phrsikalisch-medizinischen Gesellschaft. Bd. VII. 1856. S. 145 .

3 A. W. Hofmaxx, Report on Vegetable Parehment, auressed to Messrs. Tromas de la Rue and Co. London 15.5-

4 s. oben Alh. Y. \&. 124 . 
bäusche fortzulassen, und die thierischen Theile unmittelbar mit dem Thon in Berührung zu bringen, diesen aber, um seine Leitungsfähigkeit zu erhöhen, statt mit Wasser, mit einer $0 \cdot 75-2 \%$ igen Kochsalzlösung zu tränken. Man knetet aus dem Thon eine Platte von der angegebenen Dicke, legt sie auf eine Glastafel, und schneidet daraus mittels einer langen und geraden Kilinge (abermals eines Tischmessers) Stücke von etwa $20^{\mathrm{mm}}$ Länge und $15^{\mathrm{mm}}$ Breite, die man wie früher die Eiweisshäutchen verwendet, um die Bäusche an den Stellen, wo man Muskeln oder Nerven aufzulegen beabsichtigt, damit zu bekleiden. (S. Fig. 1.) Diese Anordnung lässt in der That wenig zu wünschen übrig. Der Widerstand ist gering und beständig; man kann den Thon leicht in viel bequemere Formen drücken, als die Eiweisshäutchen sie darboten, welche die an sich nicht scharfen Formen oft gebrauchter Bäusche nur noch mehr abstumpften; der Thon lässt sich rorräthig halten, so dass man nicht mehr nöthig hat, ehe man einen Versuch anstellen kann, auf das Aufweichen der Blase im Eiweiss zu warten; endlich die thierischen Theile werden weniger angegriffen, da, wie ich mich überzeugt habe, eine so verdünnte Kochsalz- [95] lösung auf die parelektronomische Schicht am natürlichen Querschnitt ron Gastroknemien nicht merklich entwickelnd wirkt, was das Hühnereiweiss thut, ${ }^{1}$ welches auch häufig eine Zuckung auslöst, wemn ein Muskel mit frischem künstlichem Querschnitt damit in Berührung gebracht wird. ${ }^{2}$

\section{§. VI. Ton den Zuleitungsröhren mit Thonspitzen. ${ }^{3}$}

Um das elektromotorische Verhalten sehr beschränkter Stellen eines thierischen Theiles, z. B. der verschiedenen Punkte des Querschnittes eines Muskels, zu erforschen, reichen die gewöhnlichen Zuleitungsbäusche nicht aus, und ich habe früher, wo dieser Fall eintrat, dieselben mit spitzen Fortsätzen aus mehreren Lagen Fliesspapier versehen, wie es in Fig. 37. Taf. IT. des ersten Bandes meines Werkes dargestellt ist, was aber mehrere Unbequemlichkeiten hatte.

1 Vergl. meine 'Untersuchungen' v. s. w. Bd. II. Abth. II. S. 49 ff.; - Monatsberichte u. s. w. 1851. S. $38 \%$.

2 [Ueber den Wassergehalt des Modellirthones in dem Zustande, wie er zu thierisch-elektrischen Versuchen dient, und über dessen Leitungswiderstand vergl. §. $V$ der Abhandlung: 'Ueber den Einfluss körperlicher Nebenleitungen auf den Strom des M. gastroknemius des Frosches' im Archiv für Anatomie u. s. w. 1871 und im zweiten Bande dieser Sammlung.]

3 Nachträglich [1862] eingerückter Paragraph. [Nan nennt die Zuleitungsröhren nit Thonspitzen in den Laboratorien mit einem ihnen von A. v. BEzoLD, damals in Jena, ertheilten Namen häufig kurz ,Thonstiefelelektroden." ] 
Hr. Czermak hat kürzlich eine Vorrichtung empfohlen, welche den nämnlichen Zweck zu erfüllen bestimmt ist. "Meine Zuleitungsgefässe": sagt er, „werden durch zwei Glasspritzen dargestellt, wie man sie zu „medicinischen Zwecken gebraucht, mur wird der Stempel durch eine ..Glasröhre ersetzt, welche rorn mit einem Fliesspapierpfropf oder einem .,Goldschlïgerhäutchen, hinten mit einem Kork rerschlossen ist. In ..Imnern der Röhre befindet sich concentrirte Zinkvitriollösung, durch den „Kork geht ein amalgamirter Zinkdraht, der sich zu einer langen Spirale ,aufrollt, und aussen ist die Röhre mit Baumwollenfäden umwickelt, so „dass sie als Stempel wirken kam. Die Spitze der Spritze wird durch ..Zurückziehen des Röhrenstempels mit frischem Hühnereiweiss gefüllt, ..jede Luftblase sorgfïltig entfernt, und auf diese Weise eine ableitende ,Vorrichtung hergestellt, welche gleichartig und umpolarisirbar ist, und „mit freier Hand, oder in ein nach allen Richtungen bewegliches Stativ „eingespamnt, ganz genan bestimmten Punkten angelegt werden kamm."1

Hril. Czermak's spritzen 'sind, wie man sieht, eine geschickte Abänderung der PfuÜger’schen Eiweissröhren, wodurch diese, abgesehen [96] rom Ersatz des Kunfers in Kinpferlösung durch verquicktes Zink in Zinklösung, beweglicher und besser leitend gemacht werden. Ich glaube, dass es nir seitdem gelungen ist, das Nämliche, in mancher Rücksicht noch vollkommener und einfacher, zu erreichen.

Meine Zuleitungsröhren, deren man eine, mit der Art ihrer Aufstellung, in Fig. 2 Taf. II. im $2 / 3$-Maassstabe abgebildet sieht, wie sie Hr. SAUERwaLd liefert, sind aus plattgedrückten Glasröhren-geschnitten, deren Querschnitt Fig. $2 a$ in natürlicher Grösse zeigt. Das untere Ende der Röhre wird mit dem oben erwähnten Thon wasserdicht rerschmiert, und es wird daran eine Spitze geknetet, die zum Berühren der thierischen Theile bestimmt ist. Dieser Spitze kann man in jedem Augenblick jede gewünschte Gestalt, Richtung und Feinheit ertheilen. In die mit Zinklösung gefüllte Röhre taucht ein verquickter Streifen Zinkblech. Der einen schmalen Seite der Rühre ist ihrem oberen Ende nahe auf der Hütte ein Stiel angeschmelzt, dessen Axe, nach einer kurzen Biegung, der Axe der Röhre parallel läuft. Der Stiel ist in eine Hülse gekittet, die bei * in ein Messingstäck geschranbt ist, welches sich in die eine Kugel eines Kugelscharniers fortsetzt. Dadurch wird es möglich, der Rühre jede erforderliche Lage im Raum zu ertheilen. Ton dem Messingstück erstreckt sich ein Fortsatz $f f$, wem die Rühre darin festgeschraubt ist, über diese fort, in einer Ebene mit der Längsaxe ihres Querschnittes.

1 Allgemeine Medicinische Central-Zeitung rom 5. Juni 1861. XXX. Jahrgang. 45. Stiick. \$. 353 . 
Das ohere Ende des Zinkstreifens ist hakenförmig gehogen, und wird äber jenen Fortsatz gehängt und daran mittels der Schranbe $s$ festgeklemmt. An das Messingstïck ist ausserdem noch ein besponnener Kinpferdraht geschraubt, der zur Fortführung des Stromes bestimmt, in gewolnter Art zunïchst nm einen Elfenbeinknopf an der das Kngelschamier tragenden Hülse gewickelt wird, damit eine Zerrung am Drahte nicht rmmittelbar die Röhre treffe. Die Hülse ist an einer Messingsänle beweglich, die sich anf dem einen Brempunkt eines elliptischen Bleifusses erhebt. Die Säule hat nnr gerade die nöthige Höhe, so dass eine fenchte Kammer. in der man ein oder zwei Pare solcher Vorrichtmogen aufstellt, deshalb noch nicht so gross wird, dass sich ihr Raum nicht leicht mit Wasserdampf sättigte.

Nichts Leichteres giebt es mit einem Paar dieser Röhren als, was sonst mmnöglich schien, am Frosch das elektromotorische Verhalten der verschiedenen Punkte des künstlichen Querschnittes eines einzehnen Oberschen- [97] kelmuskels, oder, wie es die Figur zeigt, der Achillessehnen-Ausbreitung zn prüfen. Es rersteht sich, dass man sich der Röhren ebensowohl zum Znleiten fremder Ströme, als zum Ableiten der thierischelektrischen Ströme bedienen kann, und es hält nicht sehwer, die Thonspitzen ron rier Röhren einem Nerven anf einer Strecke ron kaum ebensorielen Millimetern anzulegen.

Die plattgedrückte Gestalt des Querschnittes der Röhren ist zwar nicht wesentlich, gewährt aber mehrere Vortheile. Erstens ist es leichter, solche Röhren wasserdicht mit Thon zu schliessen, als runde Röhren von gleichem Querschnitt. Zweitens brancht man den Streifen Zinkblech nicht, wie es bei gleicher Breite desselben und bei runder Röhre von gleichem Querschnitt erforderlich wäre, zu einer Rimne zu biegen. Drittens kann man wegen der Capillarität die platten Röhren wagerecht stellen ja hintenüberneigen, ohne dass die Lösung ausfliesst. ${ }^{1}$ Viertens and hanptsächlich nehmen mehrere, in einer Reihe anfgestellte, die platten Seiten einander zukehrende Röhren weniger Platz ein, als wemn sie rund wären, mo man hat weniger Schwierigkeit, die Thonspitzen zwei einander sehr nahen Punkten anzulegen.

Die Gleichartigkeit nnd Unpolarisirbarkeit der Röhren ist gefährdet, wenn das verquickte Zink den nicht mit Zinklösung getränkten Thon berührt. Bei der beschriehenen Form der Vorrichtung ist dem dadurch rorgebengt, dass die Zinkplatte durch die Ḱlemme in gegebener Höhe

${ }^{1}$ [Vergl. die Abhandlung über das Gesetz des Muskelstromes mit besonderer Berücksichtigung des M. gastroknemius des Frosches. Archiv für Anatomie u. s. w. 1863. S. 545. Anm. - S. diese Abhandlung im zweiten Bande dieser Sammlung.] 
festgehalten wird. Yan kann dasselbe aber auch erreichen, indem mare vor dem Verquicken das Zinkblech so biegt, dass es sich in der Rühremit Reibung rerschiebt. Auf alle Fälle bleibt es gerathen ron unten her in die Röhre, ehe man sie mit Thon rerschmiert, einen mit Zinklösung getränkten Fliesspapierpfropf zu schieben, welcher nicht nur das Zink rom Thone trennt, sondern auch die Diffusion der Zinklösung mit der rerdümnten Kochsalzlösung im Thone rerzögert. ${ }^{1}$

Ganz bestïndig ist natürlich der Widerstand der Röhren nicht, weil der Thon theils an der Luft austrocknet, theils durch die Zinklösung ausgesogen wird. Der erstere Umstand kommt indess weniger in Betracht, weil man feinere Versuche in diesem Gebiete doch nicht mehr anders. als in der feuchten Kammer anstellen wird, und der letztere Vorgang wird durch den mit Zinklösung getränkten Fliesspapierpfropf sehr rerzögert. Ja man kamn die zum Gebrauch fertigen Röhren mehrere Tage. lang in tauglichem Zustande in der feuchten Kammer bewahren, wenn man die Thonspitzen lose mit feuchtem Fliesspapier umhüllt. ${ }^{2}$ Auch der Widerstand der Czermak'- [98] schen Spritzen kann übrigens kein ganz beständiger sein, da die Zinklösung mit dem Wasser des Eiweisses diffundirt, und sie sind nicht frei rom Verdacht auf secundären Widerstand.

Um Anderen rergebliche Mühe zu sparen, sei noch bemerkt, dass ich versucht habe, aussen und an ihrem unteren Ende auch innen gefirnisste rerquickte Zinkröhren, statt der, Zinkbleche enthaltenden Glasröhren, anzuwenden. Dies scheint nicht zu gehen wegen der Unsicherheit, dass nicht die rerdünnte Kochsalzlösung des Thones durch Sprünge im Lack demnoch zur Berührung mit dem rerquickten Zink gelange, wo es dann mit der Gleichartigkeit und Unpolarisirbarkeit zu Ende ist. ${ }^{3}$

1 [Ungleich vortheilhafter ist es, die Röhre zuerst mit Thon zu versehmieren, der mit gesättigter schwefelsaurer Zinklösung angeknetet ist. Ueber diesen Verschluss kommt dann erst der zur Berührung der thierisehen Theile bestimmte, mit der verdünnten Kochsalzlösung angekuetete Thonstiefel. Vergl. die in der vorigen Anmerkung angeführten Stellen.]

2 [Nach längerer Erfahrung muss ich doch gegen dies Verfahren warnen. Die Thonspitzen fallen häufig ab, und durch ungleiche Wasseranziehung in den beiden Röhren wird die Vorrichtung ungleichartig. Man bringt es übrigens leicht dahin, zwei Paar Zuleitungsröhren in zehn Minuten zusammenzusetzen und sie in derselben Zeit auseinanderzunehmen und zu reinigen, so dass sie zu neuem Gebrauche fertig sind.

3 [Man bat sich oft bei mir ïber mangelhafte Gleichartigkeit der unpolarisirbaren Zuleitungsröhren besehwert. Folgende Zahlen beweisen, dass die von Anderen wahrgenommenen Ungleichartigkeiten nicht meinen Einrichtungen und Vorsehriften zur Last zu legen sind.

Die. am runden Compensator (s. unten §. XI) gemessene elektromotorische Kraft 


\section{§. VII. Vom feuchten Arbeitsraume.}

Wie bei den Reizversuchen ist es auch bei den thierisch-elektrischen Versuchen gerathen, soviel wie möglich in einem mit Wasserdampf gesättigten Raume zu arbeiten. Für die Versuche, wobei Terven in's Spiel kommen, rersteht sich dies ron selbst; aber auch für die Versuche an Nuskeln ist es oft des Thones halber wünschenswerth, einen feuchten Arbeitsraum zu besitzen.

Mir dient als solcher eine aus Glas und Holz gefugte Kammer ron $350^{\mathrm{mm}}$ Länge, $250^{\mathrm{mm}}$ Breite und $230^{\mathrm{mm}}$ Höhe. So ist sie gross genug, ım die Zuleitungsgefässe, und was ron Hülfsvorrichtungen gewöhnlich gebraucht wird, aufzunehmen, und nicht zu gross, um sich nicht noch leicht mit Wasserdampf zu sättigen, weun man ron ihren Wänden die, an deren Durchsichtigkeit gerade nichts liegt, mit feuchtem Fhesspapier belegt, und ausserdem darin ein paar por̈̈se Thontröge als Alkarazzas aufstellt.

Das Grundbrett, auf dem die Krammer steht, ist sorgfältig geebnet, und ruht mit seinen kurzen Seiten auf $25^{\mathrm{mm}}$ hohen Leisten, sodass darunter Drähte, die durch das Brett in die Kammer treten, isolirt verlaufen.

Die Kammer ist auf dem Grundbrett befestigt, aber die dem Arbeiten-

eines Paares Zuleitungsröhren, deren Thonspitzen einander berïhrten, betrug an zehn aufeinanderfolgenden Versuchstagen:

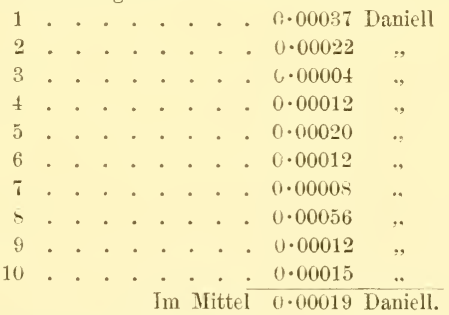

Die mittlere elektromotorische Kraft des Nervenstromes beträgt bekanntlich etwa das 100 fache des Mittels, nämlich 0.02000 , nicht weniger als das 500 fache des kleinsten, und noch immer das 36 fache des grössten unter den obigen Werthen (Vergl. §. IV der Abhandlung ,Ueber die elektromotorische Kraft der Nerven und Mnskeln" im Archiv für Anatomie u. s. w. 1567 und im zweiten Bande dieser Sammlung).

Den Widerstand eines Paares unpolarisirbarer Thonstiefelelektroden hat $\mathrm{Hr}$. RaNke je nach dem Fenchtigkeitszustande des Thones zu 105-112 Meilen Telegraphendraht, die Meile zu 64 SiEmexs'schen Einheiten, also zu etwa 6720-7168 S. E. bestimmt (Tetanns. Eine physiologische Skizze. Leipzig 1865. S. 26)]. 
den zugekehrte Wand lässt sich ganz oder theilweise entfernen, wodurch das Innere zugänglich wird. Diese Wand besteht nämlich aus zwei Spiegelscheiben, welche in der Mitte senkrecht aneinanderstossen, und sich seitlich rerschieben. Da die Länge der einen Scheibe drei Viertel ron der der Kammer beträgt, so kann man leicht bewirken, dass sie irgendwo zwischen sich einen Schlitz lassen, breit genug $10 \mathrm{~m}$ die Hand einzuführen, ohne dass die [99] feuchte innere Luft zu einem erheblichen Theile durch trockene äussere ersetzt wird.

Die feuchte Kammer mit abzuhebendem Gehäuse, das in einer mit Wasser gefüllten Rimne steht, wie ich sie zum"Aufbewahren der Zuleitungsgefässe empfahl, ${ }^{1}$ kann man auch als Arbeitsraum benutzen. Sie hat jedoch den Nachtheil, dass sich über die Rinne fort den imnerhalb befindlichen Gegenständen schlecht beikommen lässt, und dass der Rand des Gehäuses beim Ahheben trieft. Die geringe Wasseroberfläche der Rimne macht zudem das feuchte Fliesspapier und die Alkarazzas kaum überflüssig. Das Abheben des Gehäuses geschieht beiläufig am besten, indem man es auf eine seiner langen Seitenflächen umlegt. Man macht es dazu mit Scharnieren am Grundbrett beweglich, deren Axe man möglichst weit abrückt. Die Zarge des Gehäuses muss eisenfrei sein, um unbedenklich in der Nähe des Multiplicators oder der Spiegelbussole gehandhabt zu werden. ${ }^{2}$

\section{§. VIII. Von den Vorrichtungen zum elektrischen Tetanisiren. ${ }^{3}$}

Der Schlitten-Nagnetelektromotor ist, seit ich ihn im Jahre 1849 beschrieb, ${ }^{4}$ so vielfach ron Physiologen und Aerzten angewendet worden,

1 Untersuchungen u. s. w. Bd. I. S. 219.

2 [Noch besser ist es die feuchte Kammer an zwei Schnïren aufzuhängen und sie durch Gewichte zu aeguilibriren.]

${ }^{3}$ Nachträglich [1562] eingeriickter Paragraph.

4 Ich habe seitdem gefunden, dass schon 1 $1839 \mathrm{Hr}$. Jos. Hexry (damals in Princeton, New-Jersey, später in Washington) vorsehlug, durch Entfernung der beiden Rollen von einander die Stärke der Inductionsschläge zu ärztlichen Zwecken abzustufen (Transactions of the American Philosophical Societr, held at Philadelphia, ete. New Series. 4. 1839. vol. VI. p. 315. \$. 52; - The ... Philosophical Magazine ete. New and united Series. vol. XV1. p. 256; - Poggendorff's Annalen u. s. w. Ergänzungsband (I). 1842. S. 291). Um so sonderbarer ist es, dass man in Frankreich noch immer, statt dieses einfachsten und zweckmïssigsten Mittels, sich zum Abstufen der Ströme eines Kupferrohres bedient, das man zwisehen die Haupt- und die sie umgebende Nebenrolle sehiebt, wobei eimmal der Strom nicht Null, zweiteus der zeitliche Verlauf auch des Endstromes so verändert wird, dass dic Ordinaten nicht 
dass ihm von allen elektrophysiologischen Vorrichtmgen wohl die grösste Verbreitumg zukommt.

[100] Eine wichtige Veränderung des Magnetelektromotors ist nenerdings von Hrn. Heumholtz angegeben worden. Da ich diese in den Monatsberichten der Akademie ausführlich besprochen habe, so rerweise ich auf jene Stelle. ${ }^{1}$ Dort findet sich auch das Nöthige gesagt für den Fall, dass man congruenter Wechselströme hedarf. Hier bleibt mir danach nur wenig zu erwähnen übrig.

Bei fortgesetzter Erfahrung hat es sich gezeigt, dass die Länge des Geleises, wie ich sie ursprünglich für physiologische Zwecke angab, wobei die Mittelpunkte der Axen beider Rollen höchstens $35^{\mathrm{cm}}$ ron einander entfernt wurden, nicht ausreicht, indem der Oeffuungsschlag oft noch weit über diesen Abstand hinaus Zuckung erregt. Die HH. SIEMENs und HaLske liefern die Magnetelektromotore für physiologische Zwecke daher jetzt mit einem Geleise, welches jenen Mittelpunkten etwa $90^{\mathrm{cm}}$ Abstand zu geben gestattet. Da dies Geleise für gewöhnlich unbequem wäre, so besteht es aus zwei durch ein Scharnier verbundenen Hälften, von denen die von der Hauptrolle entferntere, wemn sie nicht gebrancht wird, unter die vordere geklappt wird. Eine auf Papier gedruckte Millimetertheilung ist der einen Schiene des Geleises entlang geklebt, und ein darüber gleitender Zeiger am Schlitten erlaubt mit ausreichender Schärfe dessen Stellung abzulesen.

$\mathrm{Zu}$ den Vorrichtungen, die im elektrophysiologischen Laboratorium unẹntbehrlich sind, gehört der HaLske'sche Unterbrecher. ${ }^{2}$ Er dient als elektromagnetische Maschine um den Nerren mechanisch zu tetanisiren. ${ }^{3}$ Fr lässt sich in jedem Augenblick mit jedem beliebigen Paar Rollen verknüpfen, und stellt alsdann einen Magnetelektromotor dar. Als solcher erlaubt er eine viel langsamere Folge der Inductionsströme, als der mit dem gewöhmlichen Iagnetelektromotor rerbundene Unterbrecher, was manchmal von Wichtigkeit ist. So gewährt er z. B. die Möglichkeit, das Verschmelzen einzelner Zuckungen zu einem stetigen Tetanus zu veranschaulichen, indem man ihn bei ganz freier Hülfsfeder und schwach

dasselbe Verhältniss zu einander behalten, was bein Entfernen der beiden Rolleu von einander nur für den Anfangsstrom der Fall ist, dessen physiologische Wirkung neben der des Endstromes verschwindet. S. den in der folgenden Anmerkung angeführten Aufsatz, S. 387. - Vergl. auch Fortschritte der Physik im Jahre 1850 und 1 ऽ51 u. s. w. VI. und VII. Jahrgang. Berlin 1855. S. 736.

1 Sitzung vom 26. Juni 1×62. ..Ueber den zeitlichen Verlauf der Inductionsströme“. - S. unten Abh. X.

2 Poggendorff's Annalen u. s. w. 1856. Bil. XCVII. s. 641.

3 Heidenhain, Physiolngische Studien. Berlin 1856. S. 129. 
gespannter Hauptfeder zuerst mit möglichst gehobenem Contactstift gehen lässt, wobei die Zahl der Cnterbrechungen nur etwa fünf in der Secunde beträgt, und dann den Contactstift allmählich senkt. Um die Zahl der Unterbrechun- [101] gen einer grösseren Zuhörerschaft zu vergegenwärtigen, bringe ich an Stelle des Elfenbeinhammers, der zum mechanischen Tetanisiren dient, einen metallischen Hammer an, und lasse diesen eine Glocke treffen. Die Art, die Zuckung selber weithin sichtbar zu machen, wird später beschrieben werden (s. unten $\S$. XT).

Eine besonders schöne und lehrreiche Weise, den Muskel mittelbar durch Wechselströme zu tetanisiren, ist die ron Hrn. R. Grossucasi ersonnene, ${ }^{1}$ die man den akustischen Tetanus nennen kann. Man spannt einen stark magnetisirten Stahlstab, ron etwa $250^{\mathrm{mm}}$ Länge, $10^{\mathrm{mm}}$ Breite und $3^{\mathrm{mm}}$ Dicke, in der Mitte seiner Länge in ein Gestell ein, wie es zu Versuchen mit Ḱlangscheiben üblich ist. Tnter dem einen Pol des Magnetes stellt man die aus dem Geleise genommene Nebenrolle des Magnetelektromotors so auf, dass ihre Axe die flache Seite des Magnetes in der Gegend des Pols senkrecht trifft; die Rolle muss so nahe gebracht werden wie möglich, ohne die Schwingungen des Magnetes zu stören. Die Enden der Rollen führen in gewohnter Art zum Nerrmuskelpräparat. Wird nun die freie Hälfte des Magnetstabes mittels des Violinbogens in tönende Schwingung rersetzt, so geräth der Muskel in Tetanus, bei einem Stabe ron den angegebenen Maassen jedoch nur, wenn der Stab, algesehen ron seiner eingespannten Mitte, ohne Ḱnoten schwingt. Bilden sich Knoten, was die schrillende Erhöhung des Tones rerräth, so bleibt der Iuskel in Ruhe. Hr. Grossunsx hat bereits die Gründe entwickelt, aus denen sich ergiebt, dass alsdamn die inducirten Ströme schwächer sind. Doch wäre es nicht überflüssig, darüber das Elektrodynamometer zu rernehmen. Auch ist jetzt hier noch an einen Umstand zu denken, nämlich daran, ob bei dem Schwingen mit Kunoten die ströme sich nicht zu schnell folgen um zu tetanisiren. ${ }^{2}$

1 Amtlicher Bericht über die 32. Versammlung deutscher Naturforscher und Aerzte zu Wien im September 1856 . Wien 185\%. 4. \$. 221.

2 Vergl. Untersuchungen u. s. w. Bd. I. 1s4s. s. $418 \mathrm{ff}$; - HARLEss, in den Gelehrten Anzeigen der $K$. bayerischen Akademie der Wissenschaften. 10. Juli 1857. Nr. 5. S. 4i; - Heidexhalx, Studien des physiologischen Instituts zu Breslan. Heft 1. Leipzig 1861. \$. 64- c6. - Bei dem höchsten Tone. den der Stab giebt, zeigt er ausser der queren Knotenlinie an der stelle, wo er eingespannt ist, eine seine Seitenfläche der Länge nach hälftende Knotenlinie. Er schwingt also dann so dass seine Flächen windschief werden. Da seine Pole sich dabei kaum ron der Stelle bewegen, und die Wirkung der einen Längshälfte nothwendig die der anderen aufhelut, so bedarf man keines weiteren Grundes, mu das Ausbleiben des Tetanus unter diesen Umständen zu erklären.] 
Seit der Erfindung der Schranbenklenmen statt der Quecksilberverbindungen zur Verknüpfung von Leitungsdrähten ${ }^{1}$ pflegte man wenigstens da, wo der Kreis öfter geüffinet und wieder geschlossen werden sollte, noch immer ein Näpfehen mit Quecksilber anzubringen, das eine Ende des Kreises darin zu befestigen, und durch abwechselndes Heransziehen und Eintanchen des anderen jenen Zweck zn erreichen. Viel hequemer ist dazu die nachstehend abgebildete Vorrichtung, ${ }^{2}$ deren Form ich mit Hrn. Halske festgestellt habe, und die ich im Vergleich mit

Fig. :

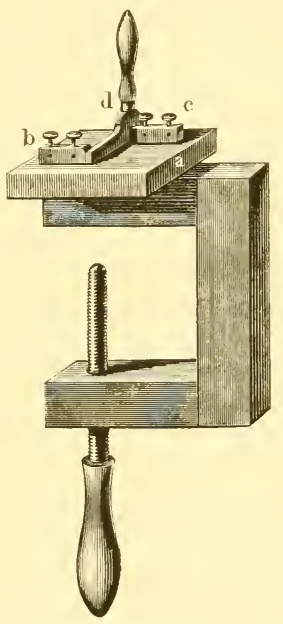

dem bekannten Organ des MorsËschen Telegraphen den schlüssel nenne, obgleich für beide der Name Śchloss passender wäre, da man in den bedenklichen Fall kommt, rom Schliessen oder Oeffnen des Schlüssels zu sprechen. Sie hesteht aus zwei Doppelklemmen $b$ und $c$, welche auf einer Platte ans Kammmasse $a$ isolirt sind, und zwischen denen der tedernde Vorreiber $d$ mit Elfenbeingriff spielt. Mittels einer

1 Poggendorfy in seinen Aunalen u. s. w. 1840. Bd. XLIX. S. 39.

2 Der Holzschnitt ist aus Hrn. Wiedexaxx's „Lehre vom Galvanismus" (Braunschweig 1861) entlehnt, indem ein Abklatsch davon mir durch die Güte des Verlegers dieses Werkes zur Benutzung überlassen wurde. 
Tischlerzwinge lässt sie sich überall und in jeder Lage anbringen. Hat $b$ das eine, $c$ das andere Ende eines Krreises aufgenommen, so schliesst und öffnet der Schlüssel den Kreis. Die Doppelklemmen erlauben aber anch ihn so anzuwenden, dass $b$ und $c$ an zwei Stellen des Kreises eingeschaltet sind, zwischen denen der Vorreiber eine gut leitende Nebenschliessung herstellt und abbricht.

Der Schlüssel gewährt den Vortheil, erstens, dass er stets bereit ist, keiner Reinigung und Ernenerung bedarf, wie die Quecksilber-Torrichtung, nnd zweitens, dass man damit rollkommen sicher und auf ammähernd gleiche Weise öffnen und schliessen kann, olme hinzusehen. Beim Gebrauche des Schlüssels ist indess wohl zu beachten, dass sein Widerstand [103] nicht ganz beständig ist. Ist der Schlüssel in einen Kreis von geringem Widerstande eingeschaltet, und man drückt den Vorreiber entweder stärker gegen die Kilemme $b$, oder daron fort, so dass seine Berührung beziehlich eine mehr oder minder imnige wird, so schwankt der Widerstand des Kreises ab und auf um eine kleine Grösse. Wo dies von Belang ist, thut man besser daran, beim Quecksilber zu bleiben, ${ }^{1}$ es sei denn, dass man ohne Schaden den Widerstand des Kreises so vergrössern kamn, dass der veränderliche Theil des Widerstandes des Schlüssels dagegen verschwindet. Bei galvanischen Reizrersuchen darf man sich deshalb, wo grössere Sorgfalt erheischt wird, in der Hauptleitung des Rheochords (s. unten §. XII) und im primären Kreise ron Inductionsvorrichtungen des Schlüssels nicht ohne Weiteres bedienen, um die Kette zum Zweck der Reizung zu schliessen und zn öffnen. Die Schwankung der Stromdichte, die dadurch entsteht, dass der Vorreiber beim Schliessen nach der ersten Berührmng noch in grösserer Ansdehnung oder stärker, beim Oeffnen ror dem letzten Abreissen znerst in kleinerer Ausdehnung oder schwächer angedrückt wird, verschwindet nicht gegen die beim Schliessen durch die erste Berührung, beim Oeffnen durch das letzte Abreissen bewirkte Schwankmo, und die Stärke der Reizung wird so von der Geschwindigkeit beeinflusst, womit man den Vorreiber bewegt. ${ }^{2}$

1 S. dic Beschreibung eines Qnecksilberschliissels in der Abhandlung X. §. I.

2 Die ersten Galvanisten pflegten bekauntlich das Stück Wirbelsäule des ächten Galvan'schen Präparates (Untersuchungen u. s. w. Bd. I. S. 467) mit Stanniol zu armiren, wie sie es nannten, und dann zwisehen den Muskeln oder Nerven einerseits und der Armatur andererseits mit einem Bogen ans einem anderen Netalle zu schliessen. Dabei zeigte sich, dass die Zuckungen stärker und sicherer auftraten, wenn man den Bogen erst an die Muskeln oder Nerven, dam an die Armatur anlegte, als wenn man umgekehrt verfuhr. (Vergl. Moscati und Galvani in Al. GaLVAsi de Viribus Eleetricitatis in Notu nuseulari ('ommentarius etc. Mutinae 1792. 4. p. $26 ;-$ A. Galrani, Abhandlung über die Kräfte đler thierischen Elektricität 
[104] Der Schlüssel wird auch sehr nützlich, indem man ihm an das Galvanometerconsol befestigt, und seine beiden Klemmen statt der sonst üblichen, mit Holzschrauben in das Consol eingebohrten Klemmen benutzt; der Vorreiber dient alsdamn zum I)ïmpfen. Ebenso kamn man den

u. s. w. Eine Uebersetzung u. s. w. von Johann Maxer. Prag 1793. s. IX; VALL1 in Gren's Journal der Physik. 1792. Bd. VI. S. 393; - Derselbe in Rozier, Journal de Physique. 1792. t. XLI. p. 72. 73; - Derselbe in Reinhold's Gesehichte des Galvanismus u. s. w. Leipzig 1^03. S. 31; - Grex in seinem Journal der Physik. 1792. Bd. VI. S. 405; - R. Fowlen, Experiments and Observations relative to the Influenee lately diseovered by M. Galvanı ete. Edimburgh 1793. p. 36; - Alex. Monro's und R. Fowler's Abhandlung über thierische Elektricität u. s. w. Leipzig 1796. S. 75. 76; - PfaFF, Commentatio de Electricitate sie dicta animali. Stuttgardiae 1793. p. 13. 14. 41. 67; - Derselbe in Grex's Journal der Physik. 1794. Bt. VIII. S. 202-204. 230. 254. 272. 276; - Derselbe, Ueber thierische Elektricität und Reizbarkeit. Leipzig 1795. S. 10. 22; - v. HumboLdt, Yersuche über die gereizte Muskel- und Nervenfaser u. s. w. Posen und Berlin 1797. Bd. I. S. 101. [Subjectiv, an Blasenptlasterwunden]; - Rernhold, De Galvanismo Speeimen II. ete. Lipsiae 1798. 4. p. 38; - Bericht der Commission des National-Instituts von Frankreich u. s. w. in Rirter's Beiträgen u. s. w. Bd. I. St. I. 1800. S. 55. 102. 103; - P. Ermax in den Abhandlungen der Königl. Akademie der Wissenschaften in Berlin. Aus den Jahren 1812-1813. S. 158. 163. 164. Fig. 2. 3; Bellingeri, Memorie della Reale Aceademia della Scienze di Torino. t. XXIII. 1518. p. 160. 161; - Fechner, Lehrbuch des Galvanismus und der Elektrochemie u. s. w. Leipzig 1829. S. 497; - Cima in Zantedeschis Raceolta fisico-chimica italiana ec. 1848. vol. III. p. 449. §. 57. [1844].) Als Hr. Pflüger im Jahre 1857 anfing sich mit Elektrophysiologie zu beschäftigen, forderte ich ihn auf, die Erklärung jenes räthselhaften Unstandes zu versuchen. Hr. PrLǘger gelangte bald zu einer sehr scharfsinnigen Lösung der Aufgabe, wodurch sie zu dem im Texte Gesagten in nahe Beziehung tritt. Nach ihm würde nämlich der Unterschied in der Stärke der Zuckungen wesentlich darauf beruhen, dass das einemal die Ket'e rein metallisch, das anderemal durch Berührung eines Metalls mit einem feuchten, d. h. mit einem ausserordentlich viel schlechteren Leiter geschlossen wird. Im letzteren Falle nimmt der Widerstand des Kreises vom Augenblick der ersten Berührung bis zum vollendeten Schlusse noch merklich ab, im ersteren Falle erlangt der Strom sofort die ganze Stärke, deren er nach den sonstigen Umständen des Versuches fähig ist. Diese Stärke wird also hier in raschem sprunge erreicht, dort in vergleichsweise langsamer Steigung; und nach dem allgemeinen Gesetze der Nervenerregung lureh den Strom wird so der Reiz zur Zuckung bei rein metallischem Kettenschluss stärker als bei gemischtem ausfallen. - Mit der so erledigten Frage ist die nicht zu verwechseln, was an der in der älteren Literatur der Reizversuche öfter wiederkehrenden Behauptung sei, dass bei sich gleichbleibender Art der Schliessung deren Ort einen Einfluss auf die Zuckung übe. (Vergl. v. Hunboldt, a. a. O. \$. 36; Ritter in Gilbert's Annalen der Physik. 1801. Bd. VII. S. 452. 456. 457; Bellingeri, Ivi p. 18s; - Person in Becquerel's Traité de l'Électricité et du Magnétisme ete. t. IV. Paris 1836. p. 240; - Moser in Dove und Moser, Repertorium der Physik. Bd. I. s. 190.) Hier bleibt etwas aufzuklären übrig. 
Schlüssel anwenden, wo von einer Vorrichtung zur anderen Drähte durch das Zimmer zu führen sind, um zu verhüten, dass durch Zerren an den Drähten die Torrichtungen erschüttert oder herabgerissen werden. ${ }^{1}$

\section{§. X. Tom Gebrauch des Schlüssels beim Tetanisiren [105] durch Inductionsströme.}

Besondere Erwähmung verdient der Gebrauch des Schlüssels beim Tetanisiren durcll Inductionsströme. És handelt sich darum, die Ströme des Magnetelektromotors oder der Saxtox'schen Maschine in einem gegebenen Augenblick auf Nerr oder Muskel möglichst bequem und ohne die Gefahr einwirken zu lassen, dass unipolare Zuckungen den wirklich beabsichtigten voraufgehen. $\mathrm{Zn}$ rerwerfen ist im Allgemeinen das Verfahren, die beiden Enden des inducirten Kreises, während die Feder des Magnetelehtromotors spielt oder das Rad der Maschine gedreht wird, den thierischen Theilen anzulegen. Nicht allein, weil dabei unipolare Zuckung stattfinden kann, sobald das Anlegen beider Enden nicht rollkommen gleichzeitig oder innerhalb eines stromlosen Zeitabschnittes geschieht, sondern auch, weil man die Enden nicht sofort in die Lage an den thierischen Theilen zu bringen rermag, in der man die Wirkung der Ströme zu beobachten wünscht, und weil man die Freiheit der Hände für andere gleichzeitige Verrichtungen, und die der Aufmerksamkeit für den Erfolg des Tetanisirens selber, einbüsst. Man wird also, wie ich dies ron Anfang an empfohlen habe, die thierischen Theile zuerst sicher auf den Elektroden einrichten, und dann die Ströme in sie einbrechen lassen. Dies darf aber nicht etwa so geschehen, dass man, während die Feder spielt .oder das Rad gedreht wird, den inducirten Krreis schliesst. Dabei würden

1 Um den Verkehr nieht zu hemmen, werden die Drähte dabei von den Vorrichtungen zuerst steil empor und dann erst wagerecht Schnüren entlang geführt. die in Reichhöhe in den nöthigen Richtungen dauernd ausgespannt sind. Man hängt die Drähte daran mittels Haken aus Glas oder Guttapereha auf.

Ein Fehler, der beim Zusammenstellen elektrophysiologiseher Vorrichtungen oft begangen wird, und der grosse Unbequemlichkeiten verursacht, ist der Gebrauch zu dicker Leitungsdrähte. Abgesehen von dauernden Leitungen, wozn mit Kautschuk и. d. m. isolirte Telegraphendrähte au besten sind, werden in meinem Laboratorium drei Drahtdicken geführt: Draht von $0.6 \mathrm{~mm}$ Durchmesser für primäre Inductionskreise; von $0.4 \mathrm{~mm}$ für die Fälle, wo thierische Theile im Kreise sind; und soleher von nur etwa $0 \cdot 1.5 \mathrm{~mm}$ für sehr bewegliche Verbindungen. Die beiden ersten Sorten sind mit Baumwolle yon versehiedener Farbe besponnen, und diese mit Wachs getränkt; die dritte ist der zn thierisch-elektrischen Multiplicatoren übliche mit Seide bespomene Draht. Von grösster Wichtigkeit ist, dass sämmtliche Schraubenklemmen auch ilen feinsten Draht sofort sicher fassen. 
unipolare Wirkungen nur durch sehr vollkommene Isolation der thierischen Theile $u$. s. w. zu vermeiden sein. Besser schon ist es, bei geschlossenem inducirtem Kreise das Rarl der SAxтon'schen Maschine, oder am Magnetelektromotor die Feder in Gang zu setzen. Letzteres kamn entweder durch Anstossen an die Feder, oder durch Senken des Stiftes, oder endlich durch Schliessen des primären Kreises an einer anderen Stelle geschehen. Allein das Rad hat [106] nicht sofort die passende Geschwindigkeit, und der Magnetelektromotor rersagt manchmal in den ersten Angenblicken seine Dienste. Weit vorzüglicher ist es daher, während die Feder spielt oder das Rad gedreht wird, die in der inducirten Rolle entstehenden Ströme von den thierischen Theilen durch eine so gute Nebenschliessung abzublenden, dass kein merklicher Stromzweig diese Theile trifft, und die Nebenschliessung im geeigneten Augenblick hinwegzuräumen. wo dann die Ströme in der Stärke, welche durch die übrigen Umstände des Versuches bedingt ist, in die Theile eimbrechen. Die erste Art, wie ich dies in's Werk setzte, bestand darin, dass ich in jeden der beiden ron der secundären Rolle kommenden Drähte ein Quecksilbernäpfchen einschaltete, und zwischen beiden Näpfchen mittels eines an beiden Enden rerquickten Kupferbügels schloss. Sollten die Ströme zugleich umgekehrt werden, so war es sehr bequem, während die Drähte der Folle zu den Gefässen $a$ und $b$ des Stromwenders führten, zwischen den Gefässen $c$ und $\beta$, oder $A$ und $B^{1}$ den nebenschliessenden Bügel anzubringen. Der Bügel schwächt die Ströme in den thierischen Theilen dergestalt, dass auch bei ganz aufgeschobener secundärer Rolle der empfindlichste Froschschenkel, dessen Nerr jenseits des Bügels die Enden der Rolle überbrückt, in Ruhe verharrt. In dem Augenblicke, wo man den Bügel entfernt, was man ohne hinzusehen thun kann, ist der Tetanus da.

In dieser Form hatte ich das Verfahren schon seit 1851 bei meinen Untersuchungen und Vorträgen angewendet, und ist es von Hm. PFuüger, dem es bei seinen Versuchen îber den $\mathrm{X}$. splanchnicus grossen Vorschub leistete, in seiner Dissertation bekannt gemacht worden. ${ }^{2}$ Inzwischen liegt Einem häufig ebensoviel daran, in einem gegebenen Angenblick das Tetanisiren aufhören, wie daran, es begimnen zu lassen, und dazu ist jene Anordnung ungeeignet. weil man ohne hinzusehen nicht wohl den Bügel

1 Untersuchungen u.s. w. Bd. II. Abth. II. S. 343.

2 De Nervorum splanchnicorum Functione. Berolini 1555. p. 9. 10; - Ueber das Hemmungs-Nervensystem für die peristaltischen Bewegungen der Gedärme. Berlin 1857. S. 17; - Untersuchungen über die Physiologie des Electrotonus. Berlin 1859. S. 124. - Vergl. A. v. Bezocd, Ueber den Einfluss der Wurali-Vergiftung auf die Rami carliaci des Nervus vagus. Allgemeine Medicinische Central-Zeitung. Berlin, 19. Juni 185ธ. 27. Jahrgang. 4?. Stück. S. 386.387. 
wieder über die Näpfchen brücken kamm: Der Schlüssel in der oben beschriebenen [107] Gestalt leistet aber in diesem Fall Alles, was man brancht, wemn man jede seiner Doppelklemmen mit dem einen Ende der inducirten Rolle und mit der einen Elektrode rerknüpft, und sich des Vorreibers an Stelle des Kunferbügels zwischen den Quecksilbernäpfchen bedient. Soll die Richtung der Inductionsströme umgekehrt werden, so muss man freilich noch ausserdem vor oder hinter dem Schlüssel einen Stromwender einschalten.

§. XI. Vom Compensator, einer Vorrichtung zum Messen der elektromotorischen Kraft der Nerven und IIuskeln.

Auf einem Brett, einer Latte, u. d. m., denke man sich nach Art einer Klaviersaite über zwei Stege mittels eimer Uese an dem einen, eines Wirbels an dem anderen Ende einen Messingdraht NS (s. Fig. 9) ron

Fig. 9.

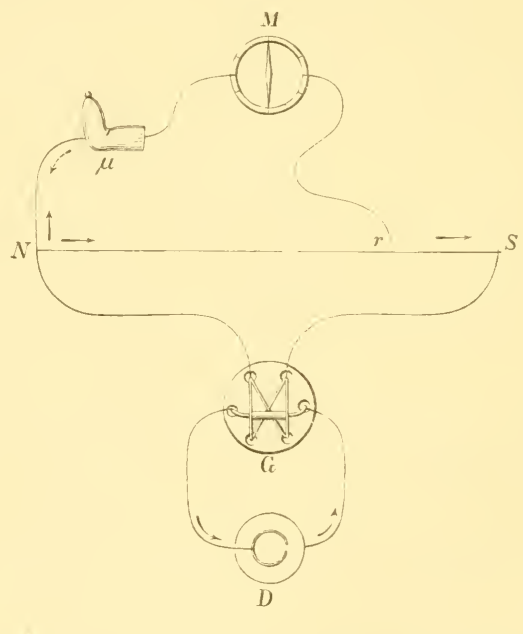

etwa $2^{\text {m }}$ Länge mnd $1 \cdot 75^{\mathrm{mm}}$ Dicke ansgespannt. und dessen Enden durch einen Porl'schen Grotropen $G$ mit dem Zink und Küpfer einer Davmelischen Kette $D$ verknüpft. Dieser Draht heisst der Nebenschliessdraht. In dessen einem Ende $\boldsymbol{N}$ ist das eine Ende des Multiplicatorkreises $N \mu M r$ angelöthet. J)as andere Ende dieses Kreises, $r$, ist an 
dem Nebenschliessdraht irgendwie herreglich gemacht. sei's mit Hülfe des einfachen, von Hru. KímchноғF beschriebenen Kunstgriffes, ${ }^{1}$ wobei aher der Draht wagerecht liegen muss, sei's indem man jenes Ende Draht, ähmlich wie die Basssaiten eines Klaviers bewickelt sind, in einer dichtgewundenen Spirale von etwa $1^{\mathrm{em}}$ Länge aufwickelt, welche gleichsam eine federude, am Drahte mit Reibung rerschiebbare Hülse rorstellt. Irun kann auch an Stelle des Messingdrahtes einen Eisendraht ron gleicher reducirter Länge nehmen, und das Ende $r$ so [108] daran rerschiebbar machen, dass man es mit dem Quecksilber in Inneren eines an jedem Ende durch einen Kiork rerschlossenen Stückes Glasrohr rerbindet, das der Nebenschliessdraht, die Korke durchbohrend, durchsetzt. Mittels der Korke kamn man das Queckillher dem Draht andrücken, auch halten sie die Oberflïche des Drahtes während des Gebranches rein. ${ }^{2}$ Welcher ron diesen Anordnungen man auch den Vorzug gebe, man muss dafür sorgen, dass das bewegliche Ende $r$ iles Ifultiplicatorkreises seinem festen Ende $N$ so nahe gebracht werden könne, dass der Widerstand der zwischen ihnen begriffenen Strecke des Drahtes $N S$ gegen den des Multiplicatorkreises rerschwinde. In dem Falle des zu einer fedemden Hülse an Nebenschliessdraht aufgerollten Endes $r$ muss deshalb die Hülse ron $N$ abgewendet sein, da sie sonst rerhindern würde, $r$ und $N$ mit cinander in Berührung zu bringen.

Dies ist die einfachste Form einer sehr nützlichen Vorrichtung, die ich den Compensator nenne, und die an keinem Galvanometer fehlen sollte. Sie dient, wie man leicht begreift, dazu, ron dem Strome des Daniells einen beliebig gerichteten, und unterhalb einer gewissen Grenze, die durch den Widerstand des Nebenschliessdrahtes bestimmt wird, beliebig starken Zwreig in den Multiplicatorkreis überzuleiten. Mit seiner Hülfe kann man jede beliebige Ablenkung bewirken, deren man bedarf, und umgekehrt jede beliebige rorhantene Ablenkung rernichten, d. h. die Nadel daraus anf Null zurïcliführen. Schon vor Jahren habe ich mich dieser Anordnung bedient, um behufs gewisser Controlversuche im Ifultiplicatorkreise einen Strom ron gleicher Ordmung mit den thierischelektrischen Strömen zu erzengen. ${ }^{3}$ Auch diente sie mir schon längst, um vor Erfindung der gleichartigen Elektroden ans rerquicktem Zink die Ungleichartigkeiten der Platimplatten unschädlich zu machen, die auch

1 Poggendorff's Annalen u. s. w. 1857. Bd. C. S. 180. Taf. II. Fig. 5.

2 Diese Anordnung ist einer ähnlichen von Hrn. Necuasx nachgebildet, die Hr. Kirchhoff und Hr. Wiedemann beschrieben haben. Poggendorff's Annalen u. s. w. 1849. Bd. LXXVI. S. 422; - 1856. Bd. XiTX. s. 226. Anm.

3 Untersuchungen n. s. w. Bd. II. Abth. I. 1849. S. 441.

L. du Bois-Reymond, Ges. Abh. I. 
bei der sorgfältigsten Behandlung theils zurückzubleiben, theils plötzlich aufzutanchen, und den Gang der Versuche auf das Lästigste zu unterbrechen pflegten. ${ }^{1}$ Am Nerren-IInltiplicator kann der Compen- [109] sator in dieser Art auch bei Anwendung des rerquickten Zinks noch gute Dienste leisten. Er hilft ferner noch stets, wo eine Veränderung der Stromstärke am Multiplicator beobachtet werden soll, z. B. die negatire Schwankung des Nerren- oder des Muskelstromes, die Nadel auf Null zu bringen, und so die grösstmögliche Empfindlichkeit, und ein deutlicheres Bild ron der Grösse der Veränderung, zu erzielen. Bei den Tersuchen über negative Schwankung des Muskelstromes am lebenden menschlichen Körper hebt er die Ströme wegen der Hautungleichartigkeiten auf, die dabei so häufig hinderlich werden. Allein noch mehr, der Compensator ist bestimmt, die Rolle eines Messwerkzeuges im Gebiete der thierischelektrischen Ströme zu übernehmen; indem er nämlich gestattet, Tergleichungen des ohne Frage wichtigsten Elementes in jenen Erscheinungen, der elektromotorischen Kíraft ler Nerren und Muskeh., auszuführen.

Es sei

$E$ die elektromotorische Kraft der Daxielischen Kette, an deren Stelle man sich eine beständige Kette irgend welcher Art denken kam, die die Maasskette heissen soll;

$\boldsymbol{W}$ der Widerstand der diese Kette enthaltenden Leitung gemessen bis zum Nebenschliessdraht;

$L$ der Widerstand des ganzen Nebenschliessdrahtes;

$\lambda$ der Widerstand der eigentlichen Nebenleitung, d. h. des Nebenschliessdrahtes zwischen den Enden des Multiplicatorkreises;

$\boldsymbol{I}$ der Widerstand des Multiplicatorkreises; und endlich

y eine in diesem Kŕreise befindliche elektromotorische Kraft, von entgegengesetztem Zeichen wie $F$. z. B. die des in Fig. 9 bei $\mu$ bemerkbaren Muskels, dessen Strom der punktirte Pfeil anzeigt.

Setzen wir $L+\boldsymbol{H}^{\prime}=C$, so hat die Stïrke der beiden sich deckenden Ströme im Inultiplicatorkreise zum Ausdruck:

$$
\frac{E \lambda-y C}{(1 /+\lambda)+M i}
$$

Sie wird also $=0$ wemn $E \lambda=y C$. Ungekehrt wird diese letztere Beziehmmg hergestellt jedesmal, dass man bei entgegengesetzten $E$ und y durch passende Teränderung ron $\lambda$ den Strom im Multiplicatorkreise zum Verschwinden bringt. Ifan hat alsiann

$$
\stackrel{y}{E}=\stackrel{i}{C},
$$

1 s. oben Abh. IV. S. 75. 76. 
[110] und man braucht nur das Verhältniss $\lambda: C$ zu bestimmen, oder, wenn $I$, in Bezug auf $W$ bekannt ist, das ron $\lambda: L, u m$ das Verhältniss $y$ : $E$, oder den Werth ron $y$ als Bruchtheil der elektromotorischen Kraft der Maasskette, zu erfahren.

Dies ist, wie ich kaum zu sagen brauche, nichts als eine leichte Abänderung der ron Hrn. Poggendorff angegebenen Compensationsmethode zur Messung der elektromotorischen Kraft unbeständiger Ketten. ${ }^{1}$ Die Vortheile dieser Methode sind wesentlich folgende. 1. Man umgeht die Schwierigkeiten, die bei jedem anderen Verfahren ans der Polarisation der Elektroden erwachsen, dadurch dass man den Strom gar nicht zustande kommen lässt, sondern, wie Hr. PogGEndorfF sich ausdrückt, gleichsam nur die Tendenz zu seiner Entstehung misst. 2. Eine einzige Bestimmung, wobei die zu messende hraft in Betracht kommt, liefert deren Werth. Die Genauigkeit der Messung selber wird also auch durch solche Schwankungen der Kraft nicht beeinträchtigt, welche unabhängig ron der Herstellung des Stromes eintreten. 3. Der Widerstand des Multiplicatorkreises fällt aus der Bedingungsgleichung für das Verschwinden des Stromes in diesem Kreise heraus. Dieser Widerstand braucht kein beständiger zu sein, und es kommt auf die Widerstands-Schwankungen nicht an, deren Sitz die Berührungsstelle des Nebenschliessdrahtes und des beweglichen Endes $r$ des Ifultiplicatorkreises leicht wird. 4. Die genane numerische Vergleichung der elektromotorischen Kräfte kann dergestalt geschehen ohne einen graduirten Inultiplicator oder sonst eine galvanometrische Vorrichtung, da es sich nicht darum handelt, wie stark ein zu beobachtender Strom sei, sondern nur darum, ob ein Strom rorhanden sei oder nicht.

Da aus den thierisch-elektrischen Versuchen die Polarisation der metallischen Elektroden jetzt rerbannt ist, so könnte es scheinen, als habe der unter 1. aufgeführte Umstand für uns an Gewicht verloren. Wegen der inneren Polarisation sind indess die thierischen Erreger noch immer den Ketten ron unbeständiger Krraft beizuzählen (vergl. oben S. 161. Anm. 2), und die durch das Absterben u. d. m. bedingte Abnahme ihrer Kraft macht auch den zweiten Punkt im höchsten Grade schätzbar. Der Compensationsmethode in einer oder der anderen Furm wird man sich daher noch stets am besten [111] bedienen, um die elektromotorische Kraft der Iuskeln und Nerren mit derjenigen bekannter galvanischer Combinationen. z. B. eines Daniells, in Beziehung zu setzen. ${ }^{2}$

1 Annalen u. s. w. 1841. Bd. LII. S. 161.

$2 \mathrm{Hr}$. Jules Pegrauld hat dies mit Hülfe seines C'ompensationsverfahrens durch thermoëlektrische Ketten zu thun angefangen (Comptes rendus etc. 15 Mai 1854. t. XXXVIII. p. 891). Hr. PoggendonfF hat bereits mit Recht bemerkt, dass 
Inzwischen ist die Frforschung dieses Verhältnisses mehr eine Sache der wissenschaftlichen Nengier, als dass sich ror der Hand wichtige Folgerungen daran knüpften; und besonders stellt sich dies so dar, wemn man die von mir entwickelte Ansicht gelten lässt, wonach die nach Aussen gelangenden elektromotorischen Wirkungen der Nerren und Muskeln nur ein umbestimmbarer Bruchtheil der inneren Wirkungen sind. ${ }^{1}$ Ohnehin werden wenige Messungen genügen, jenes Verhältniss ein für allemal festzustellen; für die wahrhaft lehrreichen Versuche aber, über die Krraft der thierischen Erreger im Vergleich zu der elektrochemischer Combinationen, ist die ummittelbare Entgegensetzung beider Stromquellen im nämlichen Kreise vorzuziehen, woron ich anderswo ein Beispiel gegeben habe. ${ }^{2}$

Dagegen was ron der höchsten Wichtigkeit erscheint, ist, die elektromotorischen Kräfte der Nerren und Muskehn unter rerschiedenen Umständen rasch, sicher und bequem rergleichen zu kömnen, ja die Reihe der Fragen, die sich zudrängen, sobald eimmal die M̈̈glichkeit einer solchen Bestimmung eröfnet ist, hat gar kein Ende. Dies wünschenswerthe Ziel num scheint durch die Methode der Compensation in der oben beschriebenen Gestalt, welche ron der PoggendorfF'schen etwas abweicht, erreicht zu sein.

Diese Abweichung besteht darin, dass, während wir das Ende $r$ des Inttiplicatorkreises am Nebenschliessdraht rerschieben, Hr. Poggendorff dies Ende fest lässt, dafür aber die Länge der eigentlichen Nebenleitung, deren Widerstand wir $\lambda$ namnten, rerändert bis der Strom verschwindet. Bei Hm. Poggexdonff bleibt also der Widerstand des die Maasskette enthaltenden Zweiges beständig. Bei uns wird dieser Widerstand stets um [112] ebensoriel vergrössert oder verkleinert, wie der der Nebenleitung rerkleinert oder vergrössert.

In Folge daron nimmt die Bedingungsgleichung für das Verschwinden des Stromes im Multiplicatorkreise in Hrm. Poggendorff's und in unserem Falle eine wesentlich rerschiedene Gestalt an. In unserem Falle heisst sie

$$
y=\frac{E}{C} \cdot \lambda
$$

derselbe Zweck weit vollkommener und bequemer durch die früher von ihm angegebene Methode erreicht werde (Amnalen u. s. w. 1s5t. Bd. XCI. s. 628).

1 Untersnehnngen u. s. w. Bi. I. s. 689 .

2 De Fibrae muscularis Reactione ut Chemicis visa est acida. Auctore AEm. du Bors-Peymond. Berolini 1559. 4. p. 43. - [S. indess im zweiten Bande dieser Sammlung die Abhandlung über die elektromotorische hiraft der Nerven und Muskeln, §. XI.] 
Da $E$ und $C$ Constanten sind, so ist $y$, die zn messende elelitromotorische Krraft, eine lineare Function ron $\lambda$, und zwar $\lambda$ einfach proportional. Nicht so bei Hrn. Poggendorff. Um seinen Fall mit dem unseren in Vergleich zu bringen, ist mur nöthig, sich zu denken, die Tebenleitung von reränderlichem Widerstande $\lambda$ sei ummittelbar zwischen den Punkten $\boldsymbol{N}$ und $S$ umseres Schema's (Fig. 9) angehracht. Nennen wir diesmal $u$ die zu messende elektromotorische Kraft im Multiplicatorkreise, so hat die Stärke der beiden darin sich deckenden Ströme zmm Ausdruck:

$$
\frac{E \lambda-u\left(\lambda+H^{2}\right)}{\omega^{*}(M+\lambda)+M \lambda}
$$

an Stelle ron $C-\lambda$ in unserer Formel $(\mathrm{I})$ ist $\boldsymbol{H}$ getreten. Die Bedingungsgleichung (II) lautet demgemäss jetzt

$$
u=\frac{E \lambda}{i+\|^{r}}=E-\frac{E W^{r}}{i+\omega^{r}},
$$

d. h. $u$ als Function von $\lambda$ wird dargestellt, indem man die Ordinaten einer gleichschenkligen, auf ihre Asymptoten bezogenen Hyperbel, deren Asymptoten zu Gleichungen haben $u=E$, und $\lambda=-\boldsymbol{I}$, und deren Potenz $\boldsymbol{E} \boldsymbol{W}$, abzieht ron den Ordinaten der den Abscissen parallelen Asymptote. S. die Curve $0 u$ in Fig. 10, worin die Gerade $0 y$ zugleich

Fig. 10 .

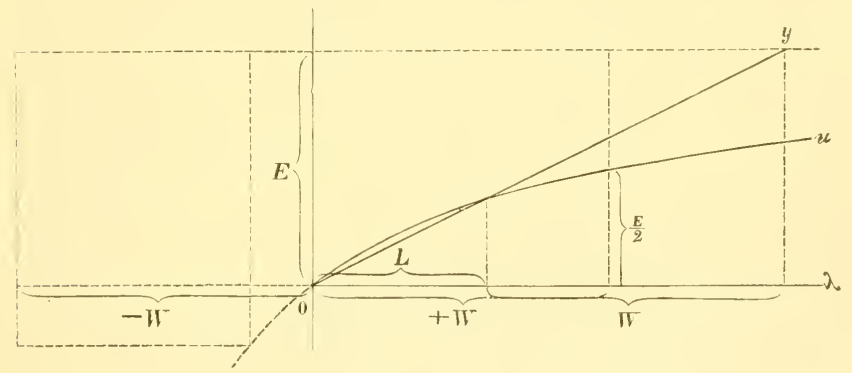

den Gang der linearen [113] Function y in unserem Falle vorstellt. Für $\lambda=W^{r}$ ist $u=\frac{E}{2}$; für $\lambda=C-H^{r}=L$ selmeidet die Gerade unseres schema's die Hyperbel des Pogrendorffschen, remöge einer bekannten Eigenschaft dieser Curve. Für $i_{r}=C$ ist die Ordinate unseres Schema's $=E$, welche Grösse die des PogrendorfF'schen erst für 入. $=\infty$ erreicht. 
Es bedarf also, bei letzterem Schema, noch stets einer gewissen Rechnung, um die relative Grösse der Kraft zu finden, während in unserem Falle dazu nichts gehört, als die Messung der Strecke $\mathrm{Nr}$ (Fig. 9), der Entfermung der Enden des Multiplicatorkreises auf dem Nebenschliessdraht, der ja der Widerstand $\lambda$ proportional ist. Mit einem Wort, am Nebenschliessdraht, wie wir ihn anwenden, misst sich die elektromotorische Kraft, wie das Zeng an der Elle. So viel ich weiss, ist diese merkwürdige Eigenschaft unseres Schema's bisher der Aufmerksamkeit der Elektriker entgangen.

Hr. Poggendorff empfiehlt die Messung so anzustellen, dass man bei einer passenden Länge der Nebenleitung den Multiplicatorkreis einen Angenblick schliesst, um zu sehen, ob und wohin noch ein Ausschlag erfolge, oder ob und in welchem Sinne man jene Länge noch zu rerändern habe um sich dem Gleichgewicht zu nähern, und so tastend fortfährt, bis man die Länge getroffen hat, bei der die Nadel auf Null rerharrt. Zu dieser Vorschrift zwangen ihn die Ladungen der unbeständigen Combination, deren elektromotorische Krraft zu messen er sich rorgesetzt hatte. Bei Abwesenheit merklicher metallischer Ladungen in unserem Falle könnte man jetzt so verfahren wollen, dass man bei geschlossenem Iultiplicatorkreise die Länge der Nebenleitung so lange reränderte, bis die Nadel nach dem Nullpmlt zurückkehrte. Inzwischen bleibt noch immer rathsam, die Ilessung nach der ron Hrn. Poggendonfr angegebenen Art zu leiten, weil man so die innere Polarisation der thierischen Theile vermeidet (s. oben S. 161. Anm. 2). Ausserordentlich bequem zeigt sich übrigens dabei, wegen der Dämpfung der Schwingungen, der Gebrauch der Spiegelbussole, so dass sie dadurch sofort an Bedeutung für dieses Gebiet wiedergewinnt, was ihr der Compensator, indem er die Jessungen von Stromstärken überhaupt in den Hintergrund drängt. daran zu nehmen drohte. Das beste Multiplicatorgewinde wird aber anch hier, wie leicht ersichtlich, das sein, welches sonst für den Terren- oder Muskelstrom das passendste gewesen wäre.

[114] Bereits an der vorher beschriebenen rohen Vorrichtung kann man die Längemmessung des Nebenschliessdrahtes mit einer für die meisten Zwecke hinreichenden Genauigkeit romehmen, wenn man unter den Messingdraht eine gedruckte Millimeterscale klebt. Bei den angegebenen Verhältnissen genügt der Messingdraht, um ron dem Strom eines einzigen Daniells einen Zweig abzuleiten, der den Iuskelstrom im ILultiplicatorkireise ïberwiegt. Nichts rerhindert, wemn dieser Draht gelegentlich nicht ausreichen sollte, ihn durch einen längeren oder dlünneren zu ersetzen, zwei Daniell nebeneinander anzuwenden, oder noch besser, die Daxtell'sche Kette durch die Grove'sche zu ersetzen. 
Mehrere Damiell hintereinander helfen nicht viel, weil der Widerstand des Messingdrahtes schon gegen den eines Dimiells nur klein ist.

Tollkommener und beqnemer wird der vorgesetzte Zweck erreicht durch das in Fig. 6 Taf. I im Aufriss und in halber natürlicher Grösse vorgestellte Instrument, welches die Werkstatt der Hrn. Simuens und Hasske liefert. Diese Figur ist nur bestimmt, eine allgemeine Vorstellung von der Gestalt des Instrumentes zu geben, dessen sïmmtliche Theile im Einzelnen verständlich zu machen, zu viel Abbildungen erfordert hïtte. Der Stromlauf in dem Instrument erhellt aus Fig. 11.

An Stelle des Messingdrahtes tritt hier ein Platindraht ron $1^{\mathrm{mm}}$ Dicke bei gleicher redncirter Länge mit jenem, nämlich nur etwa $370 \mathrm{~mm}$ lang. Anstatt diesen Draht gerade auszuspannen, das eine Multiplicatorende daran verschiebbar, und dessen Entfernung rom anderen an einer Längentheilung messbar zu machen, zog Hr. Hauske es ror, ihn gleichsam in Gestalt einer einzigen, sehr sorgfïltig gearbeiteten Agometer-Windung um den isolirenden Unfang einer kreisrunden Scheibe zu biegen, und an Stelle der Messming jener Entfernung die Messung einer Drehung der Scheibe um ihre Axe zu setzen. Diese Eimrichtmng rerspricht einen dreifachen Vortheil. Erstens nimmt das Instrument keinen grösseren Raum ein, als etwa ein fünfzölliger Azimuthalkreis. Zweitens bewegt sich der Draht, und das daran rerschiebbare Multiplicatorende bleibt stehen. Man hat also diesem nicht mit dem Ange behufs der Ablesung über eine Strecke ron fast vier Decimetern zu folgen, sondern die Ablesung geschieht an einem festen Zeiger. Drittens stellt sich der Preis des Instrumentes niedriger als bei der anderen Gestalt, weil die Anfertigung winkelmessender Instrumente geläntiger, als die von [115] LängenIessvorrichtungen ist, und die meiste Arbeit daran sich anf der Drehbank ausfülıren lüsst.

In Fig. 11 ist $N 0 r^{\prime} r S$ der Nebenschliesstraht. Man sieht ihn in Fig. 6 Taf. I. bei $r r^{\prime}$ in einer Nuth am Unfang eines gut abgedrehten Ringes aus Kammmasse, ron $65^{\mathrm{mm}}$ Halbmesser, anfgewunden, welcher eine Nessingscheibe umgiebt, deren Oberfläche den getheilten Kíreis trägt. Die beiden Enden des Drahtes $N, S$, welche in Fig. 6 unsichtbar sind, stehen ein für allemal in Verbindung mit den Klötzen $\nu$, $\sigma$ eines Stöpselumschalters, der in der Mitte der Scheibe angebracht ist. Die beiden anderen Klötze 1 und 2 des Umschalters stehen ihrerseits durch die in Fig. 11 sichtbaren Schraubenklemmen $1^{*}, 2^{*}$, und durch Drähte, welche in der hohlen Axe des Instrumentes rerlanfen, in Verbindung mit den Ḱlemmen I und II an dessen hölzernem Fussgestell. Diese sind zur Aufnahme der Enden der Maasskette $D$ bestimmt, und der Umschalter wird so gestellt, dass der im Mfultiplicatordraht kreisende Stromzweig der 
184 VIII. Beschreilung einiger Vorrichtungen und Versuchsweisen u. s. w.

Maasskette die entgegengesetzte Richtung des Stromes der in diesem Zweige befindlichen thierischen Kette, also z. B. des Muskels $u$, hat (s. Fig. 11). Am Punkte 0, der in Fig. 6 gleichfalls rersteckt ist, geht der Nebenschliessdraht über einen scharfen Platinsteg, der durch einen abermals in der Axe rerlaufenden Draht mit der Klemme IV und dadurch mit dem einen Ende des Multiplicatorkreises rerknüpft ist. Endlich $r$ ist ein Platinröllchen. dessen Platinaxe an einer Feder befestigt ist, die dasselbe gegen den Nebenschliessdraht drückt. Die Feder ist,

Fig. 11 .

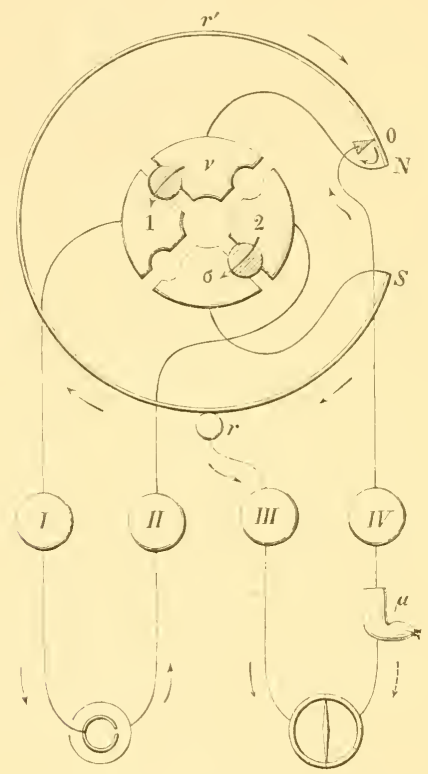

wie Fig. 6 zeigt, an einer säule befestigt, die zugleich den festen Zeiger und darüher die Lupe zum Ablesen der Drehung trägt. Eine hier befindliche Schraubenklemme 3 steht in Ver- [116] bindung mit der Schraubenklemme III am Fussgestell, die das andere Ende des Multiplicatorkreises aufnimmt. Lüst man die Schraube $g$ in der Hauptfigur, so kimn man die Scheibe aus der Hand mittels der vier daran nach unten ragenden Stifte drehen. Zieht man $g$ an, so gewährt in bekannter Weise $f$ cine mikrometrische Einstellung. In Wirklichkeit betinden sich 
übrigens die rier Schrauben I-IV an der Seite des Instrmmentes, wo sich die das Röllchen. den Zeiger und die Lupe tragende Süule erhebt.

Die Theilung ist keine gewöhnliche Kíreis-, sondern eine Decimaltheilung, und zwar ist der Umfang der Scheibe, in der Ansdehnmg in der sie rom Draht umspannt wird, in 1000 Theile getheilt. Um den Nullpunkt dieser Theilıng mit dem Zeiger zusammenfallen zu machen bei der Stellumg des Röllehens, wobei der Stromzweig der Maasskette im Multiplicatorkreise Null ist, oder wobei der Berührungspunlit von Röllchen und Draht mit dem ron Draht umd Platinsteg zusammenfallen würde, wenn der Draht keine merkliche Dicke besïsse, diente mir folgender Kiunstgriff. Es heisse der gesuchte Berührungspunkt 0, so ist klar, dass, wenn das Rüllchen einen Punkt des Nebenschliessdrahtes zwischen $N$ und 0 berührt, der Stromzweig der Maasskette im Multiplicatorkreise die umgekehrte Richtung hat ron der die ilm zukommt, wenn sich das Röllchen ron $\boldsymbol{N}$ ans jenseits 0 befindet. Ich brachte also an Stelle der Maasskette zwei als zusammengesetzte Kette rerbundene Grove'sche Elemente der grösseren Art, rerband III und $\mathrm{T}$ durch einen Mnltiplicator, und suchte die Stellung des Nebenschliessdrahtes am Rüllchen auf, die sich mit äusserster Schärfe bestimmen liess, wobei der Stromzweig im Multiplicator seine Richtung wethselte. Bei dieser Stellung schraubte ich den bis dahin seitlich verschiebbaren Zeiger dergestalt fest, dass der Strich darauf mit dem Nullstrich der Theilung zusammenfiel. In der nächsten Umgebung des Punktes 0 ist es nicht zu rerlangen, dass die, sonst an dem Instrument zu erwartende, einfache Beziehung zwischen y und der Länge der Strecke $0 r$ stattfinde, weil der Platindraht verhältnissmässig zu dick ist, um als linearer Leiter zu gelten. Doch scheint dieser Umstand, wie wir sogleich sehen werden, schon in sehr geringer Entfernung keinen Einfluss mehr zu üben.

Die Leistungen des Instrumentes im Versuch zu prüfen, müsste man eine Anzahl beständiger elektromotorischer Anordnungen nehmen, deren Gesammtkraft der eines Inuskels etwa gleichkänı, ind bei rerschie- [117] denen Widerständen im Maasskettenzweige $1,2,3 \ldots$ davon im Multiplicatorzweige compensiren. Das Verhältniss der dazn nöthigen Längen des Nehenschliessilrahtes müsste dabei stets dasselhe bleiben. Als ich diesen Versuch mittels Sänre-Alkali-Ketten in's Werk setzte, fand sich, dass diese durchans nicht himreichend beständig waren. um sie zur Prüfung eines Messwerkzenges zu verwenden. ${ }^{1}$ Thermoëlemente. gleich denen ron Hrn. Jules Regnactud, deren etwa 6 dem Strum

1 [Vergl. §. VII. der Abhandlung: „Ueber die elektromotorische Kraft der Nerven und Huskeln" im Archiv für Anatomie u. s. w. 1867 und im zweiten Bande dieser Sammlung.] 
zwischen natürlichem Längs- und künstlichem Querschnitt die Wage halten (s. oben S. 179. Anm. 2), würden vielleicht das Richtige sein. Ich habe noch nicht Zeit gehabt, den Versuch mit solchen Ketten zu wiederholen.

Es gab aber noch eine andere, mittelbare Art, sich der Brauchbarkeit des Instrumentes zu rergewissern. Bei der Sicherheit der Theorie, aus der das Princip seiner Construction geschöpft ist, könnte diese Brauchbarkeit nur dadurch beeinträchtigt sein, dass der Widerstand des Nebenschliessdrahtes nicht proportional seiner Länge wüchse. Man braucht also, um das Instrument zu prüfen, nur irgend eine Reihe von Messungen damit anzustellen, bei denen sich ergiebt, ob gleichen Längen des Platindrahtes gleiche Widerstände entsprechen oder nicht. Eine Prüfung der Art beruht auf der Bemerkung Petrisa's, ${ }^{1}$ dass, wem ein Kreis irgendwo in zwei Nebenleitungen $A$ und $B$ gespalten ist, und der Widerstand ron $A$ verschwindet gegen den von $B$ und gegen den der Hauptleitung, wie wir die ungespaltene Stromstrecke nemnen wollen, die Stärke des Stromzweiges in $B$ dem Widerstande von $A$ annähernd proportional sei. Behält man die oben gebrauchten Bezeichnungen bei, so ist die Stärke des Stromzweiges der Maasskette im Multiplicatorkreise

$$
I=\frac{E \lambda}{(C-\lambda)(M+\lambda)+M i}
$$

Lässt man $\lambda$ gegen $C$ und $M I$ verschwinden, so bleibt übrig

$$
I=\frac{E}{C \cdot M} \cdot \lambda
$$

Um diese Beziehung zur beabsichtigten Prüfung zu verwenden, nahm ich zwischen die Klemmen III und IV die Tangentenbussole mit Spiegelahlesung und 12000 Windungen auf, an der die Ablenkungen den Stromstäken so [118] nahe proportional sind, dass die Abweichung zu rernachlässigen ist; zwischen die Klemmen I und II aber eine mehrgliederige Grove'sche Säule und einen angemessenen Widerstand. Es zeigte sich. selbst immerhalb der ersten 5 Tansendtel, einer strecke also ron noch nicht $2^{\mathrm{mm}}$ rom Nullpunkte, die bestmögliche Uebereinstimmung. Dies Ergebniss war um so hefriedigender, als bei dieser Art des Versuches der veränderliche Widerstand zwischen Platinröllchen und Nebenschliessdraht nicht ans der Rechnung füllt, wie bei der Anwendung des Instrumentes zum Compensiren. Es lehrt zugleich, dass, wem man es wünschen sollte, man sich des Compensaturs sehr bequem bedienen liann, um die empirische Gradurung eines Multiplieators nach Petrina auszuführen.

1 Poggendorfy's Amnalen u. s. w. 1s42. Bd. LVI. S. 32s. Anm.; Bd. LVII. s. 111. 
Am Ende $S$ ist der Platindraht wieder über eine scharfe Platin- kante gespannt, welche dem tausendsten Strich der Theilung entspricht. Da man somit das Verhältniss $\lambda: I$. stets ummittelbar abliest, so gehört sich's, um die am Compensator gewomenen Bestimmmgen der elektromotorischen Kraft auf die Krraft der Naasskette als Einheit zu beziehen, nur noch, dass man das Verhältniss $I$, zи $\boldsymbol{W}$ kenne. Dies zu finden hat natürlich im Allgemeinen keine Schwierigkeit, doch ist zu bemerken, dass in gegenwärtigem Falle die Bestimmung der Natur der Dinge nach keine sonderlich scharfe werden kamn, weil das Verhältniss ein zu kleines ist.

Ein Umstand, der beim Gebrauch des Compensators Beachtung verdient, ist die Erwärmung des Nebenschliessdrahtes durch den Strom. Nimmt man als Maasskette eine Grove'sche Kette, so wird die Erwärmung sehr fühlhar, falls man nicht längere Zuleitungsdrähte anwendet; mit einem Daniell ist sie ummerklich. Auf alle Fälle macht man sie, sofern es sich nicht um absolnte Bestimmungen handelt, dadurch unschädlich, dass man den sich bald einstellenden stationären Zustand ahwartet.

Dass man bei allen Versuchen, wobei die Kette dauernd durch eine kurze Leitung geschlossen ist, besondere Sorgfalt auf deren Beständigkeit rerwenden müsse, brancht kaum bemerkt zu werden.

Zuletzt will ich nicht unterlassen, ausdrücklich hervorzuheben, dass durch die ron Hrn. Hewnнontz entwickelte Theorie ${ }^{1}$ der thierischelektrischen Ströme die Bedenken endgültig erledigt sind, die ich am [119] Schlusse des ersten Bandes meines Werkes (\$. 723 ff.) gegen die Anwendung der Methode der Compensation zum Eliminiren des Widerstandes in thierisch-elektrischen Tersuchen erhoben hatte. ${ }^{2}$

§. XII. Tom Rheochord in seiner Anwendung zu elektrophysiologischen Versuchen.

Nachdem mir dergestalt die Anwendung des Princips der Nebenschliessung zur Abstufung schwacher elektrischer Ströme am Multiplicator geläufig geworden war, lag es sehr nahe, dasselbe anch auf den Fall zu übertragen, wo Nerven und Muskeln Strömen von willkürlich beherrschharer Stärke unterworfen werden sollen, wo es sich z. B. darum handelt, Ströme die Nerren treffen zu lassen, welche nicht das Maximum der Zuckung bewirken.

1 Poggendorff's Amnalen u. s. w. 1853. Bu. LXXXIX. S. 211. 353.

2 [Weiteres ïber den Compensator s. in der folgenden Abhandlung (IX).] 
Im Gebiete der Induction gewährt die Veränderung des Abstandes der Nebenrolle von der Hauptrolle ein Mittel, die einzelnen Schläge oder den tetanisirenden Strömungsvorgang mit aller nur wünschenswerthen Feinheit abzustufen. Im Gebiete der beständigen Ströme schlugen die. welche sich Aehnliches vorsetzten, natürlich zuerst den Weg ein, der bei physikalischen Versuchen leicht zum Ziele führte, Veränderung der Stromstärke durch Teränderung des Widerstandes. Allein es fand sich, dass, wegen des grussen eigenthümlichen Widerstandes und der Kileinheit der thierischen Theile, mit metallischen Widerständen hier nichts auszurichten sei, man müsste denn solche in ganz riesigem Maassstabe entwickeln; während die Anwendung feuchter Widerstände, wie Hr. Haruess sie versucht hat, mühsam und zeitraubend ausfällt, und leicht zu Fehlern Anlass giebt. ${ }^{1}$

1 Der feuchte Rheostat des Hrn. Harless (Molekuläre Vorgänge in der Nervensubstanz. I. Abhandlung: Voruntersnchungen. Aus den Abhandlungen der K. bayer. Akademie der Wissenschaften. 1858. II. Cl. VIII. Bd. II. Abth. S. 320. 321 [8. 9]) besteht aus drei mannshohen Glasröhren von 3-4 mm Durchmesser, die mit destillirtem Wasser oder mit verdïnnter schwefelsaurer Kupferoxydlösung gefüllt werden. Die Unständlichkeit dieser Operation, namentlich wenn die Röhren, nachdem sie die Lösung enthielten, mit destillirtem Wasser gefüllt werden sollen, kann nicht klein sein. Nach Bediurfniss werden eine, zwei, drei dieser Röhren in den Kreis aufgenommen. Unterabtheilungen der einen Röhre erhält man, indem man einen Kupferdraht bis zu der erforderlichen Tiefe darin versenkt. Dies geschieht mittels eines Fadens, der über eine Rolle am Gipfel einer etwa elf Fuss hohen Säule geht, woran die Röhre aufgerichtet ist. Auch die Verbindungen der Riohren unter sich und mit dem anderen Ende des Kreises sind aus Kupfer, und somit entbält die Vorrichtung nicht weniger als drei Elektrodenpare, an denen eine dreifache Ungleichartigkeit, und, da gewisse Gründe die Anwendung einer hinlänglich concentrirten Kupferlösung verbieten, dreifache, bei der Kleinheit der Flächen sogar sehr starke Polarisation stattfindet. Wie dabei der Strom habe auch nur einigermaassen beständig bleiben, oder in verschiedenen Versuchen gleiche Stromstärken denselben Rheostatenständen baben entsprechen können; wie der Einfluss der Stromrichtung erforseht werden konnte, da doch beim Umkehren des Stromes die Polarisation sich plötzlich zur Kraft der Kette hinzufïgte statt sich daron abzuziehen, ist sehwer zu begreifen. Wenn die Spitze des Kupferdrahtes, durch dessen Heben und Senken der Strom beherrscht werden sollte, negativ war, musste deren Bewegung nach bekannten Erfahrungen (Untersuchungen u. s. w. Bd. I. S. 212. Anm. 1) von einer Hebung des Stromes begleitet sein. Diese Wirkung, die sich zu der durch Verändernng des Widerstandes erzengten algebraïsch summirte, fehlte hingegen, wenn jene Spitze positiv war. Hr. HARLess beschränkte sich aber nicht darauf, diese Vorrichtung zum Abstnfen der Stromstärke zu benutzen, sondern er maass danit anch Widerstände. In Vergleich mit den bezeichneten Fehlern wird es wenig zu sagen gehabt haben, dass die Röhren nicht eylindrisch waren, und dass Hr. Harless, statt die Röhren zu ealibriren, sich begnïgte, deren mittleren 
[120] Die ron mir eingeführte Abstufung der Stromstärken bei Reizversuchen mittels des Princips der Nebenschliessung ist anzusehen, als sei an Stelle der unthunlichen Veränderung des Widerstandes die der elektromotorisehen Kraft gesetzt. Der Schliessdraht einer Kette bietet uns, rermöge der daranf stattfindenden Anordnung der spannungen, eire Reihe stetig wachsender Spanmmosunterschiede dar, die wir den Enden des Nervenkreises - so soll hinfort der jetzt den Nerren, früher den Multiplicator enthaltende Zweig heissen - ertheilen kömnen. Es kamm sich nur darum handeln. die beste Gestalt zu ermitteln, die zu diesem nenen Zweck der Vorrichtung zu gehen sei. Dabei kommt es auf folgende Punkte an.

Erstens muss die Veränderung des Widerstandes des Nebenschliessdrahtes so geschehen, dass weder, wemn man diese Veränderung durch Verschiebung des einen Endes des Nerrenkreises am Nebenschliessdraht bewerkstelligt, eine Trennung beider, noch. wemm mam den Nebenschliessdraht selber rerlängert, eine Oeffnung der Nebenschliessung zu befürchten sei. Im [121] einen Falle würde eine nicht zum Versuch gehörige, vielleicht schädliche, jedenfalls munütze Erregung stattfinden. Im anderen würde der Nerv plötzlich dem ungeschwächten strom der Kette ansgesetzt sein. Dies sind Rücksichten, die den Physikern bei der Erfindung der beweglichen Verbindungen an den Rheochorden fremd waren, und welche keine Wahl ülrig lassen, als zwischen der von Hrn. Neumaxx herrührenden Quecksilherverbindung, und federnden Schiebern. Letztere lassen sich auf sehr rerschiedene Art eimrichten, sie haben aber immer den Nachtheil, dass sie bei häufigem Gebrauche den Draht angreifen. Ton diesem Fehler ist die Necmaxx'sche Torrichtung verhältnissmässig frei und rerdient schon darum den Vorzug.

Zweitens muss der Widerstand der Nebenleitung im Vergleich zu dem des Nerrenkreises so klein gemacht werden kümnen, dass bei der gewöhnlich angerrendeten elektromotorischen Kraft keine merkliche Erregung des Nerren erfolgt.

Drittens sollte der Widerstand der Nebenleitung auch wiederum so gross gemacht werden kömnen, dass die durch den Draht bewirkte Schwächung des Stromzweiges im Nerrenkreise nicht mehr in Betracht

Qnerschnitt zu bestimmen. Wenn aber Hr. HARLess so gemessene Widerstände thieriseher Theile auf neun, ja auf zehn Stellen genau angiebt, während beim Jessen metallischer Widerstände mittels der Wheatstone'schen Brüeke Hr. Sieyexs z. B. sich mit höehstens fünf Stellen begnügt (Poggendorfy's Ammalen u. s. w. $1>60$. Bd. CX. S. 1 ff.), so ist dies gewiss nieht geeignet, das Misstranen zu mildern, womit jeder Physiker sogar auf die erste Stelle in Hrn. Harless Zahlen blieken wird. 
komme. Dies ist bekanntlich der Fall, wenn der Widerstand der Hauptleitung gegen den der beiden Nebenleitungen rerschwindet. Alsdann nehmen die Enden dieser beiden Leitungen den nämlichen Unterschied der Spannungen an, als ob deren jede allein rorhanden wäre und die elektromotorische Kraft enthielte. ${ }^{1}$ Behalten wir unsere obigen Bezeichnungen mit dem Untersehiede bei, dass wir $N$ für $M$ schreiben, da an Stelle des Multiplicatorkreises jetzt der Nervenkreis getreten ist, und setzen wir $L$ und $N$ sehr gross gegen $\boldsymbol{W}$, so rerschwindet, für $\lambda=L$, das erste Glied des Nenners in (III) gegen das zweite, und die Stromstärke wird im Nerrenkreise

$$
I=\frac{E \lambda}{N i}=\frac{E}{N}
$$

in der Nebenleitung

$$
I_{1}=\frac{E N}{\lambda N}=\frac{E}{\lambda} .
$$

[122] Man wird also, wemn $W$ gegen $N$ und $L$ zum Verschwinden gebracht werden kamn, ohne eine neue elektromotorische Kraft zu Hülfe zu nehmen, den Nerren einem eben so starken Strom aussetzen kömen, als ob gar keine Nebenleitung rorhanden wäre.

Viertens darf bei Stromschwankmngen keine Induction im Nebenschliessdraht stattfinden, wodurch der zeitliche Terlauf' des Stromes geändert würde, auf den in Reizversuchen so viel ankommt. Kamn der Draht, zu grosser Länge halber, nicht gerade ansgestrecht bleiben, so ist er im Zickzack zu führen, oder ein Theil daron ist auf Rollen halb im einen, halb im anderen Simne zu wickeln. So sind bereits wegen der Nachtheile, die anch bei anderen Versuchen aus der Induction erwachsen, die Rollen an dem Stöpselrheostat ron SiEnens und HaLske ${ }^{2}$ gewickelt, den Hr. Моцеsснотт, auffallenderweise ohne dieses wichtigen Umstandes zu gedenken, empfiehlt. ${ }^{3}$ der aber in seiner jetzigen Gestalt für elektrophysiologische 'Zwecke nicht wohl brauchbar ist, weil er nur aus Rollen besteht, folglich den Widerstand nur in Sprüngen abzustufen erlaubt.

Fünftens und schliesslich scheint es nämlich wünschenswerth, dass der Widerstand der Nebenleitung zwischen den unter 2. und 3. angegebenen Grenzen stetig rerändert werden kömne.

1 Untersuchungen u. s. w. Bd. I. S. 572.

2 Siemens in PoggendorfF's Annalen u. s. w. 185\%. Bd. CII. s. 75. Taf. I. Fig. 4.

3 Untersuchungen zur Naturlehre des Menschen und der Thiere. Bd. VII. $1 \times 60$. s. $404 ;-$ Bd. VIII. $1 \times 61$. S. 2. 
Die Form der Vorrichtung, der wir bis jetzt den Vorzug schenkten, wobei die Hauptleitung immer um ebensoriel rerkürzt, wie die Nebenleitung verlängert wird, lässt ans leicht ersichtlichen Gründen die Erfüllung der dritten unter diesen Bedingungen nicht wohl zu. Ohnehin büsst für den gegenwärtigen Zweck unser Schema den Vorzug ein, den es für den Zweek elektromotorischer Krraftmessungen vor dem PograxDORFF"schen Schema besitzt, wobei nur die Nebenleitung verlängert wird. Hr. Pfü̈GER, dem ich im Begimn seiner elektrophysiologischen Forschungen das hier in Rede stehende Verfahren mittheilte, und in dessen Händen es rasch umgestaltend in die Lehre von den Reizrersuchen eingriff, ${ }^{1}$ that deshalh wohl daran, bei dem Bau seines grösseren Rheochords zum PoggendorfF'schen Schema zurückzukehren, wobei jene Bedingung leicht erfüllt wird. [123] Hr. PfLüger bestimmte die Länge eines $0 \cdot 3 \mathrm{~mm}$ dicken Neusilberdrahtes, welcher, bei einer zehngliederigen Grove'schen Säule in der Hauptleitung, als Nebenleitung zum Nerrenkreise den Strom in letzterem um nur etwa $1 / 7$ schwächt, zu etwa $14^{\mathrm{m}}$. Er empfand übrigens das Bedürfniss, zum Zweck feiner Abstufung sehr schwacher Ströme, noch ein kleineres Rheochord zu haben. Diesem liess er ganz meine erste Einrichtung, nur dass er daran mit der spirale, wodurch ich das eine Ende des Tervenkreises am Nehenschliessdraht verschiebbar zu machen pflegte, den Eisendraht rerband, der nur mit dem Quecksilberrohr nöthig wird; was nicht vortheilhaft erscheint, da Eisen schlechter leitet, und leichter rostet, als Messing.

Ich bin, nach rielen Uebcrlegungen, im Verein mit Hrn. SAUERwaLD, bei der Gestalt des Rheochords für elektrophysiolugische Zwecke stehen geblieben, die Taf. II. Fig. 7 im Grundriss und, bis auf die Länge des Kastens, die etwa nuch einmal so stark rerkleinert ist, in 1/3 der natürlichen Grösse zeigt. Es liegt dieser Gestalt, wie dem grösseren Pfuüger schen Rheochord, das Poggexdorff'sche Schema zu Grunde. Die ganze Vorrichtung ist aber zu einem flachen, länglichen Kasten ron nur $1178^{\mathrm{mm}}$ Länge, $175^{\mathrm{mm}}$ Breite und $52^{\mathrm{mm}}$ Höhe zusammengedrängt, so dass alle Handhabungen innerhalb der bequemen Reichweite einer sitzenden Person bleiben.

Auf dem Boden dieses Kastens, den man sich umgestürzt denken muss, verlaufen, der einen langen Seite entlang, zwei Platindrähte $s \sigma u$, $s, \sigma, v$, ron $0 \cdot 3 \mathrm{~mm}$ Durchmesser und etwas über ein Meter Länge. Jeder dieser Drähte ist zwischen einem vorderen Platinsteg $s, s$, und einem hinteren Elfenbeinsteg $\sigma, \sigma$, mittels eines Wirbels $w, w$, ansgeS. $121 \mathrm{ff}$.

1 Untersuchungen über die Physiologie des Electrotonus. Berlin 1559. 
spamnt. Es schien nicht der In̈̈he werth den Einfluss zu berücksichtigen, den die Spamnung ron Drähten auf ihren Widerstand äussert, und den hier nothwendigen Zng an den Platindrähten durch Fewichte ansüben zu lassen. Unter den Platindrähten läuft auf einer Holzleiste ron schwalbenschwanzförmigem Querschnitt ein Messingschlitten, der zwei mit Quecksilber gefüllte Röhren ron polirtem Stahl trïgt, durch welche die Platindrähte hindurchgehen. Man sieht diese Anordnung in Fig. $7 a, b$, in halber natürlicher Grösse abgebildet, und zwar in Fig. $7 a$ im senkrechten Durchschnitt auf die Axe der Rühren. in Fig. $7 b$ im seitlichen Aufriss, bis auf die anch hier im Durchschnitt rlargestellte, dem Beschauer nähere Röhre. An dem hinteren Ende sind die [124] Röhren durch Korke rerschlossen, welche ron den Drähten durchhohrt werden. Torn sind sie nach Art eines zugeblasenen Rohres gewölbt und an der Liuppe mit einer glatten Oeffnumg rersehen, welche die Drähte, indem sie durch sie treten. so ausfüllen, dass das Quecksilher daneben erst unter einem merklichen, auf den Kork ausgeübten Druck herausträufelt.

Durch den Schlitten und die ihm aufgelötheten beiden Stahlröhren wird zwischen den sonst ron einander isolirten Platindrähten eine gut leitende Brücke hergestellt, deren Widerstand nicht in Betracht kommen soll gegen den des Stückes der Drähte zwischen den Stegen $s, s$, und den Röhren. Steg $s$ hefindet sich an einem und demselben Messingklotz mit der doppelten Schraubenklemme $P$, welche das eine Ende der Kette und des Nerrenkireises aufnimmt, wie Fig. 7 zeigt. Steg $s$, steht durch die gleich näher zu betrachtende Leitung $s, Q$ mit der entsprechenden Doppelklemme $Q$ in Verbindung, zu der die anderen Enden der Kette und des Nerrenkreises gehen.

Dass die stählemen Quecksilberröhren rorn nicht dureh einen Kork rerschlossen, sondem in eine metallene Kuppe endigen, hat zur Folge. dass, wemn man sie mit diesen Kúppen gegen die Platịnstege $s, s$, drüekt, die Tebenleitung für den Nerrenkreis durch den Steg $s$, jene Röhren nebst dem Schlitten ummittelbar, den Steg $s$, und die Leitung $s$, $Q$ gebildet wird. In diesem Fall ist der Widerstand der Nebenleitung so klein, dass, wemn nicht die Kette ron ungewöhnlich grosser elelitromotorischer Liraft ist, der Nerr in seinem Kreise keine Erregung erfährt. Auf alle Fälle würde es stets leicht sein, diesen Zustand dadurch herbeizuführen, dass man in die Hauptleitung einen metallischen Widerstand aufnimmt, da für $\lambda$ selır klein gegen $W^{r}$ und $N$,

$$
\begin{gathered}
E \lambda \\
\left(W^{r}+N\right) \lambda+W^{r} N
\end{gathered} \text { ammähernd }=\begin{gathered}
E \lambda \\
W^{r} \lambda
\end{gathered}
$$

d. h. $W$ umgekehrt proportional wird. Längs der Schlittenbahn ist eine $1^{\mathrm{m}}$ lange Villimetersale (Fig. $7,0-1000$ ) aufgeklel,t. Bei der oben 
beschriebenen Stellung des schlittens steht ein daran befindlicher Zeiger $z$ anf dem Nullpunkte der Theilung. Durch Verschieben des Schlittens nach den Stegen $\sigma, \sigma$, am hinteren Ende des Rheochords kamn man $2^{\mathrm{m}}$ des Platindrahtes in die Nebenschliessung aufnehmen. Reicht dieser Widerstand nicht [125] aus, so lässt er sich folgendermaassen noch bis um das zwanzigfache vermehren.

Die Leitung $\sigma, Q$ besteht aus einer Reihe von sechs parallelepipedischen Messingklötzen, die auf einer Platte ron Kammmasse so befestigt sind, dass sie fünf kleine Zwischenräume zwisehen sich lassen. Klotz 1 hängt unmittelbar zusammen mit Steg $s$, Ḱlotz 6 trägt die Doppelklemme $Q$. Die fünf Zwischenräume zwischen den Kiötzen sind für gewöhnlich, wie an den Stöpselumschaltern, mit Stöpschn ansgefüllt, die Fig. 7 im Querschnitt zeigt. Ausser durch die Stöpsel stehen aber die Klötze noch im Inneren des Kastens in Verbindung durch kürzere oder längere Strecken Neusilberdraht, welche an der imneren Fläche des Kastenbodens in Gestalt haarnadelförmiger Oesen, wo es nöthig ist, zickzackförmig ansgespannt sind. Diese Leitungen sind in Fig. 7, gleich der Länge des Káastens in doppelt kleinerem Maassstabe als das Uebrige, punkirt gezeichnet. Die Drähte zwischen Ḱlotz 1 und 2, und 2 und 3 $(I b, c)$ haben denselben Widerstand, wie die Platindrälute, wenn $z$ auf $1000 \mathrm{~mm}$ steht. Zwischen 3 und 4 beträgt der Widerstand das doppelte $(I I)$, zwischen 4 und 5 das fünffache $(V)$, zwischen 5 und 6 das zehnfache $(X)$ ron jenem. Die stöpsel bilden, in Bezug auf die Drähte, Nebenschliessungen ron verschwindendem Widerstande, welche nur entfernt zu werden brauchen, um den Widerstand der Nebenleitung um das ein-, zwei-, fünf- oder zehnfache rom Widerstande der Platindrähte zu erhöhen. Aus diesen Zahlen kann man ron eins bis zwanzig jede beliebige Zahl zusammensetzen.

Die Widerstände werden mittels der WhEatstone'schen Brücke abgestimmt. Um dies mit aller Feinheit thum, und dabei doch den Drähten die gehörige Spannung geben zn kömnen, dass sie nicht im Inneren des Kastens lose werden und mit einander in Berührung gerathen, wird folgendermaassen rerfahren. Das eine Ende des abzupassenden Drahtes ist bereits an den zu seiner Aufnahme bestimmten, von oben in's Innere des Kastens herabragenden Fortsatz des einen Messingklotzes gelöthet; das andere ist an dem entsprechenden Furtsatze des benachbarten Klotzes vorläutig unter einer lose angeschraubten Platte mit Reibung verschiebbar. Biegt der Draht von Klutz zu Kilotz nur in einer Oese um, wie es der Fall ist für $I b, I c, I I$, so wird die Oese in die Hohlkehle eines Elfenbeinscheibchens gelegt, das [126] excentrisch an einem Wirbel sitzt (Fig. 7, 7 a). Der Wirbel wirl so in den Boden eingedreht, dass der E. du Bois-Reymond, Ges. Abh. I. 
Widerstand schon ungefähr der verlangte, nur etwas kleiner ist; durch das Drehen der excentrischen Scheibe wird er damn auf das richtige Haass gebracht, während zugleich der Draht die geeignete Spammung erhält. Steht die Tadel des Galranoskops in der Brücke auf Tull ein, so wirl auch das zweite Ende des Drahtes festgeschraubt und rerlöthet. Hat der Draht zickzackförmig hin und her zu laufen. wie es für die Widerstände $V$ und $\mathrm{X}$ nöthig wird, so geschieht mur die letzte Biegung um eine excentrische Scheibe, die übrigen um Pflöcke, wie man in Fig. 7 unterscheidet.

Zum Gesammtwiderstande des von Hrn. Pfuẗger beschriebenen grösseren Rheochords rerhält sich der des unsrigen etwa wie $1: 0 \cdot 6 .^{1}$ Die vier ersten oben gestellten Bedingungen erfüllt also unsere Einrichtung vollständig genug, um es zunächst dabei bewenden zu lassen. Was aber die fünfte Bedingung betrifft, so ist diese dabei allerdings zum Theil anfgegeben. Man kam zwar an unserem Rheochord den Widerstand imerhalb eines Zwanzigtels seines Gesammtwerthes stetig erhöhen. und, im Gegensatz zum Rheostat ron Siemexs und HaLske, jeden rerlangten Widerstand so genau herstellen, wie die mechanische Tollkommenheit der Vorrichtung es gestattet; grössere Veränderungen jedoch kann man, wie an diesem Rheostit, anch nur in Sprüngen bewirken. Darin steht unser Rheochord dem grösseren Pfiëger'schen nach. Dies enthält vier Paar Drähte, entsprechend unseren Platindrähten, deren jedes einen federnden Schieber besitzt. Man kamn also dort, wem die Länge eines oder mehrerer Drahtpaare nicht ansreicht, den Widerstand um ein beliebiges Stück des nächsten Paares erhöhen, und so ihn stetig ron Yull bis zur äussersten Grenze steigeru. Will man dagegen an unserem Rheochord den Widerstand über ein Tielfaches des Widerstandes der Platindrähte hinaus um einen Bruchtheil dieses Widerstandes rermehren, so muss [127] man jedesmal erst wieder den Widerstand durch Zurückführen des Schlittens auf Noll mm eine Einheit rermindern, und ansserdem die passenden Veränderungen vornehmen, hei denen manchmal der Strom im Nerrenkreise ganz aufhört. Bin ich z. B. beim Widerstand 5, zusammengesetzt aus den beiden Platindrähten $(I a)$. Neusilberdraht $I b, I c$ und $I I$, angelangt. und er reicht nicht ans, so muss ich zuerst den Schlitten auf Null stellen und die drei Stöpsel $I b, I c$ und $I I$ einsetzen, damn erst den Stöpsel $V$ entfernen, und nun noch den Schlitten

1 Der Widerstand meines Pheochords ist seitdem ron Hrn. Dr. JoH. Raxke in meinem Laboratorium zu 1.03 Meilen Telegraphendraht, die Meile zu 64 SieMexs'schen Widerstandseinheiten (Poggendorkf's Annalen u. s. w. 1560. Bd. CX. S. 1). bestimmt worden (Iianke, Der galvanische Leitungs-Widerstand des lebenden Muskels. Ansbach 1×62. S. 19). (Nachträgliche Anmerkung [1862].) 
um die erforderliche Grösse rerschieben. Unstreitig ist dies an und für sich ein Nangel. Auch geht dabei Zeit verloren. Inzwischen hat sich beim Gebranch noch kein ernstlicher Nachtheil als Folge hiervon herausgestellt, während unser Rheochord andererseits seine werthvollsten Figenschaften gerade der Einrichtung verdankt, worauf jener Mangel beruht.

Sobald allein durch Terschiebung jeder beliebige Widerstand zwischen Null und der Gesammtlänge des Rheochords hergestellt werden soll, bleibt nichts übrig, als die Anordnumg, bei der jene Gesammtlänge in eine Anzahl gleichlanger gerade ansgestreckter Drahtpaare abgetheilt wird. deren jedes seine rerschiebbare Brücke hat, und damit steht man. wemn es sich $\mathrm{um}$ die feinere technische Ansführung handelt, vor einer Reihe von Schwierigkeiten. Die bewegliche Brücke macht für jedes Paar Drähte eine Schlittenbahn nebst Scale nöthig. Wählt man als Brücke federnde Schieber, so kann man Nensilberdraht anwenden, allein dann muss der Draht stark genug sein um einige Zerrung und Abnützung auszuhalten, und das Instrument wird sehr umfangreich. Wählt man Quecksilberröhren, wie sie an unserem Rheochord als Brücke zwischen dem einen Paar Platindrähten angebracht sind, so ist man auf Eisenoder Platindraht beschränkt. Jener rostet zu leicht, dieser ist kostspielig und wenig haltbar. Beide leiten im Vergleich mit dem Neusilber so gut, dass, wenn man sie nicht übermässig fein nimmt, abermals der Umfang der Torrichtung ein zu grosser sein wirl. Der Preis wird fast in gleichem Verhältniss mit der Zahl der heweglich überbrückten Drahtpaare wachsen $u$. s. w.

Diese Schwierigkeiten sind an unserem Rheochord dadurch umgangen. dass, wie man an Messinstrumenten, Mikroskopen u. d. m. eine grobe und eine feine Einstellung hat, nur ein kleiner Theil des Nebenschliessdrahtes [128] dazu bestimmt ist, eine feine Abstufung seiner Länge zu gestatten. ${ }^{1}$. Auf diese kurze Strecke und deren Eimrichtung hat alle Sorgfalt rerwendet werden kïmnen, und hier war, als Substanz der Drähte, Platin an seinem Platze. Der bei weitem grösste Theil des Nebenschliessdrahtes dagegen durfte, da er keine andere Bedingung zu erfüllen hat als die einen grossen Widerstand darzuhieten, und im Inneren des Kastens vor jeder Zerrung geburgen werden kamn, aus Nensilher und beliebig fein genommen werden, um so das Instrument zu rerkleinern. Daher dieses bei gleicher Leistung handlicher. einficher, wohlfeiler und dauterhafter nicht leicht möchte herzustellen sein, und dessen Gehranch aus

1 Ein ähnlicher Kunstgriff ist sehon von Hrn. Wiedemans beschrieben worden. Poggendorfy's Amnalen u. s. w. 1856. Bd. XCIX. S. 226. Anm. 
den physiologischen Laboratorien sich sogar schon in die der Physiker auszubreiten begimnt.

Die Platindrähte erleiden ron der glatten Mündung der Quecksilberröhren keinen Schaden. Nur ganz in der Nähe der Stege $s, s$, sind sie bedroht, weil sie hier am meisten gebraucht werden, und sich eine $A b$ weichung der Axe der Qnecksilberröhren von der Gleichgewichtslage der gespannten Drähte hier am meisten fühlbar macht. Vor Verletzungen sind die Platindrähte durch ein darüber angebrachtes Dach geschützt, welches gleichwohl den Schlitten zu rerschieben und dessen Stellung abzulesen erlaubt. In Fig. 7 ist das Dach fortgelassen; man erkennt es aber in Fig. $7 a$ und $b$.

Die kleinen Schwankungen im Widerstande der Strecke $s, Q$ in Folge rerschiedenen Einsetzens der Stöpsel kömnten beim Gebranch des Rheochords zu physikalischen Zwecken rielleicht Bedenken erregen. Diesem Uebelstande wird durch eine in einen Stöpsel anslaufende Doppelklemme abgeholfen. Indem man diese Stöpselklemme statt des ersten Stöpsels braucht, den man, rom Widerstande Null an gerechnet, sonst eingesteckt haben würde, erreicht man, dass ausser ihr und den Quecksilberröhren in der benutzten Strecke des Rheochords keine anderen als feste Terbindungen rorkommen.

[129] §. XIII. Von einem beim Gebranch les Rheochords in Reizrersuchen zu beachtenden Umstande.

Beim Gehrauch des Rheochords in Reizversuchen muss man auf eine besondere Erscheinung vorbereitet sein, welche sonst leicht Täuschmnen reranlassen kann.

Man denke sich in die Hauptleitung und in den Nerrenkreis Schlüssel eingeschaltet, durch deren Schliessung und Oeffnung der Stromzweig im Nerrenkieise hergestellt und unterhrochen werden kamn. Nach den Oнм'schen Grundsätzen muss es, um Zuckung zu erhalten, ganz gleichgültig sein, wo man die Kette schliesst und öfnet, in der Hauptleitung oder im Nerrenkreise, da in beiden Fällen die beständige Stromstärke, die im Nerrenkreise hergestellt und anfgehohen wird, dieselbe ist. Als ich ror mehreren Jahren den Tersuch eimmal anstellte, ward ich überrascht, diese scheinhar so unhestreitbare Folgerung keinewreges bestätigt zu finden. Vielmehr musste ich, um z. B. beim Schliessen und Oeffnen des Nervenkreises Zuckung zu erhalten, der Nebenleitung eine viel grössere Länge geben, als beim Schliessen und Oeffnen der Hauptleitung. Mit anderen Worten, ich musste, $1 \mathrm{~m}$ gleiche Erregung des Nerven zu bewirken, mittels des Schlüssels im Nerrenkreise in diesem 
Kreise eine riel grössere Stromstïrke herstellen oder rernichten, als diejenige, deren Herstellung oder Vernichtung ausreichte, wenn ich mich des Schlüssels in der Hauptleitung bediente. Der Unterschied, um den es sich handelt, war ein sehr heträchtlicher. Als Nebenschliessdraht henutzte ich eine Eisensaite ron $0.8^{\mathrm{mm}}$ Durchmesser und etwa $2^{\mathrm{m}}$ Länge, als Kette eine Daxieli'sche ron mittlerer Grösse. Schloss und öflnete ich die Hauptleitung, so erfolgte Zuckung schon bei wemigen Centimetem Länge der Nebenleitung. während manchmal die ganze Länge des Tebenschliessdrahtes nicht ausreichte, $u m$ beim Schliessen und Oeffinen des Nervenkreises Zuckung zu erlangen. Bei ummittelbarer Erregung der Iuskeln zeigte sich derselbe Untersehied zwischen absolut höheren Grenzen.

Mein erster Gedanke war, dieser Unterschied läge an den Schlüssehn, aber theils intem ich die Schlüssel mit einander vertiuschte. theils indem ich mittels einer geeigneten Schaltung einen und denselben Schlüssel abwechsehnd in Nerrenkieis und Hauptleitung brachte, überzeugte ich mich ron dem Ungrunde dieser Vermuthung. Ebensowenig komnte die Erwär- [130] mung des Nehenschliessdrahtes die Ursache des Lnterschiedes sein, da diese vielmehr im entgegengesetzten simne wirkt. Wird die Hauptleitung ror dem Nerrenkreise geschlossen, so ist der Yebenschliessdraht wärmer und schlechter leitend, und folglich, wie die Rechnung lehrt, der Stromzweig im Nerrenkreise stärker. Auch an Polarisation in der Kette war nicht zu denken, wodurch allerdings die Stromstärke bei geschlossener Hauptleitung ror dem Schliessen des Nerrenkreises rermindert worden wäre, demn die Erscheimmg zeigte sich anch mit einer Grove'schen Kette im besten Zustande. Dagegen ergab es sich bei weiterer Ueberlegung, dass es die Polarisation an den Platinblechen der anfünglich zur Erregung benutzten stromzuführenden Vorrichtung war, worauf jener Untersehied heruhte. In der That wird letzterer ummerklich, sobald man die Platinbleche dureh mupolarisirbare Elektroden aus rerquicktem Zink in Zinklösung ersetzt, ja er kehrt sich sogar zuweilen um, so dass der Schlüssel im Nerrenkreise etras stärkere Erregung giebt, als der in der Hauptleitung. Bringt man aber in den Terrenkreis ein Platinelektrodenpar in rerdümnter Schwefelsäure, so ist der Lnterschied wieder wie gewöhnlich da. Hiernach erklärt sich die Sache folgendermaassen.

Schliesst man clie Hauptleitung nach dem Nerrenkreise, so bricht in letzteren der Zweigstrom in seiner vollen, durch das Verhältniss der Widerstände bedingten Grösse ein. Oeffnet man die Hauptleitung, so hört $\mathrm{m}$ Nervenkreise freilich nur der durch die Polarisation auf das Aensserste geschwächte Strum auf. Allein ihm folgt auf dem Fusse, da 
198 VIII. Beschreibung einiger Vorrichtungen und Versuchsweisen u. s. w.

ihm die Bahn der Nebenleitung" uffen steht, der Polarisationsstrom im umgekehrten Simne, dem im ersten Angenblicke ungefähr die Stärke des primären zukommt, und der also in hohem Grade befähigt ist Zuckung zu bewirken. Im Polarisationsstrome gleichen sich im Nu die Ladungen zum grössten Theile ab, so dass, wenn man den Schlüssel in der Hauptleitung wieder schliesst, dasselbe Spiel ron rorn beginnt.

Schliesst man dagegen den Nervenkreis nach der Hauptleitung. so wird das erste Mal freilich die Stromstärke die nämliche sein wie beim Schliessen der Hauptleitung nach dem Yerrenkreise. Weil aber beim Oeffnen des Terrenkreises den sich alsbald entwickelnden Ladungen die Gelegenheit zur Abgleichung genommen wird, so bleibt erstens die Oeffnung selber rergleichsweise wirkungslos, zweitens wird anch für eine binnen nicht allzu- [131] langer Frist darauf folgende Schliessung die Strumstärke nicht wieder hergestellt.

Dass die Polarisation hier im Stande ist, einen so bedeutenden Unterschied zu bewirken, wird rerständlich ans der grossen absuluten Schwäche der Ströme, die bereits das Jaximum der Zuckumg herbeiführen, im Verein mit dem bekannten Gesetze, wonach die Polarisation mit Zeit und Stromstärke wächst. Es handelt sich also, damit Alles lilar sei, nur noch um den Nachweis, dass, bei rollkommener Gleichartigkeit der Platinelektroden, wirklich die schliessungszuckung rom schlüssel im Nerrenkreise aus bei derselben Länge der Nebenleitung auftrete, wie die rom Schlüssel in der Hauptleitung aus. Dieser Nachweis gelingt, wemm man die Beobachtung darauf richtet, demn anch leicht; weil aber rom Schlüssel im Nerrenkreise ans nur eben die erste schliessungszuckung erfolgt und damn meistens keine wieder, so erhält man bei der ersten rohen L'ntersuchung den Eindruck jener ungeheuren U'eberlegenheit der Reizung rom Schlüssel in der Hauptleitung ans.

Es geht hieraus die Weisung hervor, wemn man es nicht rermeiden kamn, sich bei Reizversuchen am Rheochord polarisirbarer Elektroden zn bedienen, erstens, die Schliessung und Oeffnung im Nerrenkreise rorzunehmen, um nicht Täuschungen durch den Polarisationsstrom ausgesetzt zn sein, zweitens, muter keinen Umständen die Erscheinungen beim Schliessen und Veffnen des Terrenkreises mit denen heim schliessen und Oeffnen der Hanptleitung in Vergleich zu bringen.

§. XIV. Tom schwankungsrheochord, einer Vorrichtung zum Erweise des allgemeinen Gesetzes der Terrenerregung durch den strom.

Mit wie grosser Wahrscheinlichkeit das ron mir sogenannte allgemeine Gesetz der Nerrenerregung dureh den Strom aus der Gesammtheit 
der Thatsachen hervorging, die ich im ersten Bande meiner 'Untersuchnngen' ${ }^{1}$ dafür beibrachte, so hatte ich es doch an einem ganz unmittelbaren Berreise dafür fehlen lassen. In der That gebrach es mir zu jener Zeit an [132] einem Mittel, um eine positive oder negative Strumschwankung ron passender Grösse und nach Willkür zu beherrschender Geschwindigkeit hervorzubringen. Zwar erschien mir schon damals die Ein- oder Ausschaltung ron Widerständen wicht als das einzige brauchbare Mittel zur Veränderung der Stromstärke. Vielmehr übersah ich rollkommen, wie durch Verlängerung oder Yerkürzumg einer Nehenleitung sich die Stromstärke im Nerrenkreise in ausreichende, und unter Curständen jenen Längenveränderungen proportionale Schwankungen versetzen lasse. ${ }^{2}$ Tras mich aber rerhinderte, diesem Gedanken Folge zu geben, war erstens, dass ich mir auch sogleich rorsetzte, die Terlüngermng der Nebenleitung mit gleichförmiger Geschwindigkeit zu bewirken, zum Zweck, eine lineare Stromschwankung mol damit ein wichtiges Hülfsmittel zur Zergliedermo des Erregungstorganges zu gewimnen; zweitens, dass mir ein Kunstgriff abging, um eimen Draht an einem anderen sicher ror Tremung und doch mit himreichender Geschwindigkeit zu rerschieben, wozu ich Rollen, federnde schieber u. d. m. nicht für ausreichend hielt. Ein solcher Kumstgriff scheint nummehr durch Hrn. Neumaxx's bewegliche Qnecksilberterbindung geboten zu sein, und weun man ron der gleichförmigen Geschwindigkeit der Verschiebung absieht, und nicht unvorhergesehene Hindernisse dazwischen treten, müste es glücken, den damaligen Plan zu rerwirklichen. Dies hahe ich jetat mit Hülfe folgender Torrichtung rersucht, die ich das Schwankungsrheochord nenne. Fig. 8. Taf. II zeigt diesen Apparat, wie ihn $\mathrm{Hr}$. SalERwald nach meiner Angabe gebaut hat, im Grundriss und in halber natürlicher Grösse, Fig. 8 a einen Theil daron im seitlichen Aufriss und in $2 / 3$ der natürlichen Grösse.

Ein eichenes Grundbrett trïgt zwei messingene Winkelstücke $O$ und $L$, zwischen denen als Nebenschliessdraht eine $0 \cdot 2^{\mathrm{mm}}$ dicke Eisensaite $n s$ ausgespannt ist.

Daran rerschiebt sich das stählerne Quecksilberrohr $Q R$, dessen Deckel $R$ abzuschrauben geht. Die Oeffuungen für den Nebenschliessdraht an beiden Enden des Rohres sind mit Kork gefüttert. Um das Rohr zu füllen. wird das Grundbrett anfgerichtet, so dass das Ende $Q$ des (necksilberrohres nach unten sieht. Es wird so riel Quecksilber eingefüllt, das [133] es beim Aufschrauben des Deckels $R$ aus den capillaren

1 A. a. O. S. $262-272$.

2 A. a. O. S. 272,273 , Anm. 
Oeftumngen spritzt. Da beim Gebranch Quecksilber verloren geht, muss ron Zeit zn Zeit welches nachgefüllt werden.

Das Quecksilberrohr gleitet anf einem Schlitten zweien stählernen Führungsdrähten $f d, f$, , entlang, die jederseits rom Nebenschliessdraht und ihm parallel zwischen den Winkelstücken ansgespannt sind. An der unteren Fläche des Schlittens ist isolirt ein doppelter Sperrhaken angelnacht, dem ron jedem der Winkelstücke aus ein ähnlicher federnder Haken begegnet. Letzterer greift, wie Fig. 8 a zeigt, in den entsprechenden Haken am Schlitten ein, bei der Stellung. wobei die Kúupe des Quecksilberrohres gerade das Winkelstück berührt, und rerhindert alsdamn den Schlitten, sich rom Winkelstück zu entfernen. An jedem Winkelstïcke kamn mittels eines Stechers $\sigma, \sigma$, der federnde Haken niedergeedrückt, und dadurch der Schlitten freigegeben werden.

Die Bewegung des Schlittens zum Zweck der Stromschwankung erfolgt stets in der Richtung des Pfeiles ron $O$, dem uberen, zu $U$, dem unteren Winkelstück, oder, wie wir jetzt sagen wollen, Anschlag. Sie kommt zu Stande durch die Zusammenziehnng des rorher ausgedehnten Kantschnkschlauches $\boldsymbol{K} \boldsymbol{S}$, der durch eine $\mathbf{n m}$ zwei Rollen laufende Darmsaite an Schlitten zieht. Die Elasticität ist der Schwere als Triebliraft vorgezogen worden, weil es auf die absolute Beständigkeit, welche die Schwere auszeichnet, hier nicht so sehr ankam, während, um durch die Schrere eine solche Geschwindigkeit zu erzengen, wie sie hier gebrancht wird, die Vorrichturg zu umfangreich hätte werden müssen. Auch die Führung der Darmsaite um die Bollen hat zum Zweck, den Umfang der Torrichtung, der selbst beim Gehranch der Federkraft zu gross zn werden drohte, zu remindern.

Das Ende $S$ des Schlauches kimn mittels einer starken, in einem Schlitze des Grundbrettes rerschiebbaren schraube in passender Entfernung rom oberen Anschlage, der Bahn des Znges entlang gemessen. festgestellt werden. Die Spannmg des Schlanches wird bewirkt. indem man den schlitten nach dem oberen Anschlag führt, wo er durch den entsprechenden Haken festgehalten wird. Drückt man anf den Stecher. so fliegt der Schlitten die Bahn des Nehenschliessdrahtes und der Führungsdrälte hinab, je nach der Spannung des Schlauches mit grösserer oder geringerer Ge- [134] schwindigkeit. Ueberschreitet diese eine gewisse Grenze, so wird der Schlitten rom Haken am unteren Anschlage eingetangen. so dass er dem Anschlage gleich fest anliegt. Jene Grenze wird beiläufig schon erreicht, wenn anch der Schlauch ziemlich früh aufhört dem Schlitten Geschwindigkeit mitzntheilen, so dass die übrige Bahn nur kraft der Trägheit durchlaufen wird. Die V'erschiebung des Schlittens ron Anschlig zu Anschlag beträgt $300 \mathrm{~mm}$. Der Ring $r r_{\text {, }}$, in 
welchem der Kautschukschlauch lose spielt, dient dazu, das Schleudern des treien Endes des Schlanches während seiner Zusammenziehung zu rerhindern. Der Schlitten ist durch einen seln dümmen besponnenen Ḱupferdraht, wie er zu thierisch-elektrischen Multiplicatoren dient, mit einer festen Klemmschraube auf dem Grundbrett leitend rerbunden, worunter seine Berreglichkeit gar nicht leidet (rergl, oben S. 180. Amm.). Endlich an jedem der Anschläge ist zu einem gleich zu erwähnenden Zweck ein starker Kupferbolzen $b, b$, angelöthet.

Fig. 12 ist bestimnt, den Stromlauf in den Tersuchen mit dem Schwankungsrheochord, und zwar zunächst in dem Falle zu versimnlichen, wo positive Schwankung stattfinden soll. $S R$ ist schematisirt dies

Fig. 12.

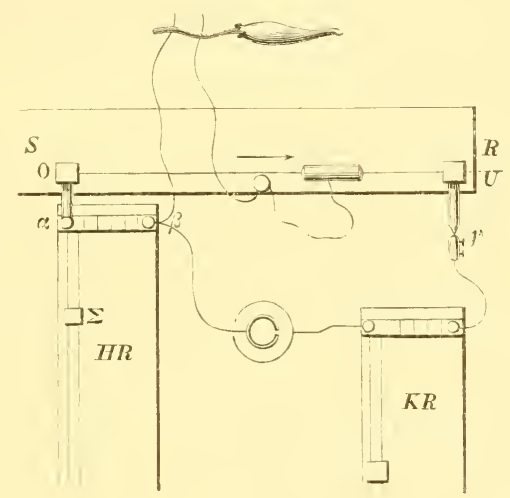

Rheochord, $I I R$ dagegen ein gewöhnliches Rheochord, welches hier das Hülfsrheochord genamnt wird, $\boldsymbol{K R}$ ein zweites solches Rheochord, das Kettenrheochord. Die Kette (einen Grove) und las Terrenmuskelpräparat erkemnt man leicht. Letzteres ist in dem feuchten Raume des Pfü̈Ger'schen Myographions aufgestellt, wo ihm der Strom durch ein Paar meiner unpolarisirbaren Zuleitungsröhren mit Thonspitzen zugeführt wird. Im Nervenkreis hat man sich noch einen Stromwender eingeschaltet zu denken. Die eine Klemme des Hülfsrheochords $\boldsymbol{c}$ ist mit dem Bolzen b, am oberen Anschlag rerbunden. Steht der Schieber I des Hülfsrheochords auf Null. und der Schlitten am oberen Anschlage, so verschwindet die Stromdichte im Nerven, da die Nebenleitung nur ver- [135] schwindende Widerstände, den oberen Anschlag in Berührung 
mit dem Quecksilberrohr, den Kuuferbolzen, die durch den Schieber und die Stöpsel verbundene Reihe der Messingklütze des Hülfsrheochords bis zu dessen zweiter Ḱlemme $\beta$, enthält. Wird also jetzt der Schlitten in der Richtung des Pfeiles losgelassen, so erfolgt eine ron Null anhebende positive Stromschwankung, nach welcher der Strom im Nervenkreise die Stärke behält, die durch den Widerstand des Nebenschliessdrahtes bedingt ist. Ton dem Schliessen einer Kette, wodurch dieselbe Stromdichte im Nerven erzengt würde, unterscheidet sich der Vorgang nur durch die grössere Langsamkeit, mit der jener Grenzwerth erreicht wird, und das abweichende, hier durch die Geschwindigkeit des Schlittens an den verschiedenen Punkten seiner Bahn bedingte Gesetz, wonach das Ansteigen des Stromes erfolgt. Es handelt sich also, damit unser Plan rerwirklicht sei, noch darum, dass die Stromschwankung nicht ron Null, sondern ron einer beliebigen bereits im Yerren vorhandenen Stromdichte ausgehe. Dies geschieht einfach dadurch, dass der Widerstand des Hülfsrheochords entfaltet wird.

Um statt einer positiven eine negative Stromschwankung zu erhalten, ist nichts nöthig, als die beiden Terbindmingen $c$ und $\gamma$ mit einander zu vertanschen. Der ubere Anschlag wird durch das Kettenrheochord mit der Kette, der untere durch seinen Kúuferbolzen $b$ mit der Kilemme $\alpha$ des Hülfsrheochords rerbunden. Steht der Schieber des Hülfsrheochords auf Null, so hebt jetzt die Schwankung bei der Stronstärke an, die dem Widerstande des Nebenschliessdrahtes entspricht, und diese Stromstärke wird durch die Schwankung anf Null gebracht. Die negative Schwankung ist in diesem Falle der Oeffnung einer Kette zu rergleichen, die in dem Yerven die gleiche Stromdichte unterhielte, nur dass die Dichte langsamer und nach einem anderen Gesetze sinkt. Entfaltet man aber den Widerstand des Hülfsrheochords, so lässt die negative Schwankung eine immer grössere Stromdichte im Nerven bestehen, sie beträgt ron der gesammten Stromdichte einen immer kleineren Bruchtheil.

Man kamn also dergestalt eine Stromschwankung ron rerschiedener Geschwindigkeit zwisehen denselben Grenzen, und indem man, was leicht zu machen ist, die Entfernung der Anschläge rerändert, auch zwischen rerschiedenen Grenzen herrorbringen. Aber es bietet sich uns hier zugleich die Gelegenheit zur Behandlung noch einer Anfgabe dar, die ich gleichfalls [136] damals gestellt, aber nicht zu lösen gerrusst hatte, der nämlich zu bestimmen, welchen Einfluss auf die Grüsse der durch eine gegebene Stromschwankung bewirkten Erregung die absolnte Höhe der Ordinaten übt, zwischen denen die Schwankung stattfindet; oder mit anderen Worten, wh die Grösse der Erregung, welche durch eine Veränderung der Stromdichte hewirkt wird, auch noch Function dieser 
Stromdichte selber ist, und wemn sie daron abhängt, ob sie mit wachsender Stromdichte steigt oder fällt. Ich begnügte. mich zur Zeit damit, die Frage dergestalt in's Licht zu stellen, die verschiedenen sich darbietenden Möglichkeiten zu erwägen und die Lrnzulänglichkeit der bereits rorhandenen, darauf bezüglichen Versuche darzuthun. ${ }^{1}$

Diese Frage ist seitdem ron Hrn. Eckhard und ron Hm. Pfü̈ger bearbeitet worden. Hr. EckHARD hat den gnten Gedanken gehabt, die congruente Stromschwankung bei verschiedener bereits im Nerven herrschender Stromdichte dadurch zu erzengen, dass er die Nebenrolle einer Inductionsromichtung in den Kreis aufnahm. ${ }^{2}$ Da ich aber damals noch nicht die Aufmerksamkeit der Elektrophysiologen auf das Rheochord gelenkt hatte, so fehlte ihm ein einfaches Mittel, die beständige Stromdichte im Nerven abzustufen, ohne den Widerstand des Kreises merklich zu verändem. Er half sich, indem er die Hälfte der Säulenglieder in mmgekehrter Richtung in den Kreis brachte, und gelangte so zu dem an und für sich wichtigen Ergebniss, lass bei grösserer absoluter Höhe der Ordinaten die nämliche Stromschwankmug weniger stark erregt.

Hr. Pfö̈GER, der mit dem Rheochord ausgerüstet den Gegenstand aufnahm, änderte Hrn. EckHaRD's Tersuchsweise, dem er bei dieser Gelegenheit, ${ }^{3}$ wie mir seheint, nicht volle Gerechtigkeit widerfahren lässt, dahin ab, dass er die Tebenrolle der Inductionsworrichtung in den Nervenlireis des Rheochords brachte. Es gelang ihm nachzuweisen, dass die Erregung durch eine sich gleichbleibende stromschwankung in Bezug auf die absolute Stromolichte ein Maximum hat. Wählt man eine solche Stromschwankung, dass sie bei der Stromdichte Null im Nerven heine Zuckung bewirkt, so erhält man Znckinng durch dieselbe Stromschwankung, wenn [137] die Stromdichte eine gewisse Grösse erreicht; bei grösserer Stromdichte rerschwindet wieder die Zuckung.

Dies Ergebniss erklärt Hr. Pfü̈Gze darans, dass der Indifferenzpunkt, der nach seiner grossen Entdecknng die intrapolare Strecke in eine Strecke erhöhter und eine solche herabgesetzter Erregbarkeit scheidet, mit wachsender Stromdichte ron der Anode zur Kathode wandert, so dass fast die ganze intrapolare Strecke sich bei geringer Stromdichte im Znstand erhöhter. bei grosser in dem herabgesetzter Erregharkeit befindet. Die totale Erregbarkeit der intrapolaren strecke, d. h. nach Hrn. Pfü̈gen der Integralwerth der Erregbarkeiten sämmtlicher Längendifferentiale jener

1 Untersuchungen u. s. w. Bil. I. S. 293 tit.

2 Beiträge zur Anatomie und Physiologie. Giessen 185\%. 4. .. 28.

3 Untersuchungen über die Physiologie des Electrotonus. Berlin 1859. S. 24.394. 
Strecke, hat somit ein Maximum in Bezug auf die Stromdichte, welchem ein Maximum der Erregung entspricht. ${ }^{1}$

Unstreitig reicht diese Erklärung ans; man kamn jedoch bezweifeln, dass damit die Erscheinmng erschöpfend zerghiedert sei.. Die Erregung, für die mo die Znckung ein ungeführes Maass alogiebt, ist $u m$ so grösser, je grösser die Erregbarkeit und je grïsser der Reiz. Ich hatte mir, als ich die obige Frage stellte, ersteren Factor beständig gedacht. Wir wissen jetzt durch Hrn. PruẗGer, dass er in der beschriebenen Art Function der Stromdichte ist. Er erweist sich als solcher auch bei Anwendung ron Reizen, die, wie der der Kochsalzlösung, unabhängig von der Stromdichte sind. Es liegt also noch immer die Möglichkeit ror, dass, wem man mit einer congruenten Stromschwankung bei rerschiedener Stromdichte reizt, sich, ansser der Erregbarkeit, anch noch der Reiz, oder die Anregumg zur Bewegung, die in dem Uebergang ron der einen Stromdichte zur anderen in gegebener Zeit liegt, nach irgend einem Gesetze ändere. Der Erfolg kömnte dabei der beobachtete sein, wemn nur die Veränderung des Reizes nicht im umgekehrten sinne ron der der Erregbarkeit stattfände und überdies gewisse Grenzen überschritte. Hrn. Pfü̈GER's unschätzbare Versuche scheinen freilich experimentell die ron mir gestellte Frage zu erledigen. Weit entfernt indess sie beantwortet zu haben, zeigen diese Tersuche meiner Neimng nach rielmehr, dass die Frage so nicht zu beantworten sei, weil der andere Factor der Erregung, die Erregharkeit, bei wachsender Stromdichte nicht beständig bleibe. Um jetzt auch noch die Abhängigkeit des Reizes ron der [138] Stromdichte auszumittehn, müsste man untersuchen, ob z. B. die Erhöhung der Erregbarkeit, die man bei einer gewissen Stromdichte beobachtet, für den elektrischen Reiz ebenso gross ansfalle, wie für Reize, die der Natur der Dinge nach ron der Strumdichte mabhängig sind, also für den mechanischen oder chemischen Reiz. Gelänge es nachzuweisen, dass für eine positive Schwankung. während welcher die totale Erregbarkeit noch gesteigert würde, eine geringere scheinbare Erhöhung der Erregbarkeit stattfände, als für den mechanischen oder chemischen Reiz, so wäre der Schluss gerechtfertigt, dass durch die congruente Stromschwankung zwischen höheren Ordinaten eine geringere Anregung zur Bewegung gesetzt sei, als durch die zwischen niederen. Ich begnïge mich damit, den allgemeinen Plan der hier noch offenen Untersuchung anzudenten, deren Austülırbarkeit ich übrigens dahingestellt sein lasse.

Am wenigsten mathen die folgenden Versuche mit dem Schwankungsrheochord Anspruch daranf, diese Angelegenleit zu fördern. Es hat

1. A. (1. ร. 397 . 
zwar, wie hemerkt, keine Schwierigkeit, ihnen eine Gestalt zu geben, wobei sie so gut, ja in gewisser Beziehung besser als die Pfü̈gre'schen Versuche, zur Beantwortung der Frage nach dem Einfluss der Stromdichte anf die Erregung durch congruente Stromschwankungen geeignet scheinen. Dazu ist nur nöthig, dass die Schwankung bei verschiedener Höhe der Ordinaten, zwischen welchen sie stattfindet, dieselbe absolnte Grösse behalte; was dann zutrifft, wemn der Widerstand der Nebenleitung, d. h. des Nebenschliessdrahtes und des Hülfsrheochords, rerschwindet gegen den der beiden anderen Leitungen: des Nervenkreises, was ron selber der Fall sein wird, und des Kettenkreises, was mit Hülfe des Kettenrheochords, nöthigenfalls noch anderer Widerstände, anch stets leicht zn bewirken sein wirl. Der Vorzng unserer Versuchsweise vor der durch Hrn. Pflöger vervollkommneten EckHard'schen könnte aher darin erblickt werden, dass, während es sich dort stets um eine positive und eine negative Schwankumg zugleich handelt, wir im Stande sind, nach Belieben nur eine positive, oder nur eine negative Schwankung zu erzengen, von denen erstere die Stromdichte erhöht, letztere sie erniedrigt zurücklässt; was ein Hülfsmittel mehr zur Zergliederung der Erscheinungen ahgiebt.

Inzwischen hat das schwankungsrheochord die Hoffnumgen, die ich darauf setzte, bisher nicht erfüllt. Die Versuche daran sind ron eigen[139] thümlichen Schwierigkeiten umgeben, die zn überwinden mir erst zum Theil gelungen ist.

Fs zeigt sich nämlich der unerwartete Umstand, dass sehr leicht Znckungen entstehen, wemn bei geschlossener Kette der schlitten irgendwo am Nebenschliessdraht steht und plützlich mit den Führungsdrähten in schwingende Erschütterung rersetzt wird. Durch diese Erschütterungszuckungen, wie wir sie nemen wollen, verlieren solche Znckungen, die man etwa bei schneller Verschiebung des Schlittens zu sehen bekäme, rorläufig jede Bedentung, und unsere Sorge muss vor Allem dahin gehen, den Erschütterungszuckumgen ein Ende zu machen.

Offenbar kömnen diese in nichts ihren Grund haben, als in einer raschen V'eränderung des Widerstandes zwischen dem Qucksilber einerseits, andererseits dem Nebenschliessdraht und der Wand des Quecksilberrohres; obschon dies dabei ron Quecksilber strotzen kann, und obschon man glanben sollte, jener Widerstand, mithin anch dessen Schwankungen, müssten vor dem des Nerrenkreises verschwinden. Auch weiss ich nicht mit Bestimmtheit zu sagen, wie diese Schwankungen zu Stande kommen. Ich kamn nur daran erimnern, dass Hr. SIExexs zwischen eisemen Cylindern, die er in Quecksilher tanchte, und letzterem, einen sehr grossen Widerstand gefunden hat, der wahrscheinlich auf einer an der Ober- 
fläche der festen Metalle condensirten Gasschicht beruhte, da er besonders stark war, wenn die Cylinder nach der Reinigung noch eimige Zeit an der Luft gelegen hatten; ${ }^{1}$ und ich stelle mir ror, dass in unserem Falle eine ähnliche, Eisen und Quecksilber von einander trennende Gasschicht im Augenblick der Erschütterung sehr schnell durchbrochen wird und wieder zusammenfliesst.

Wie dem anch sei, ein sicheres Mittel, die Erschütterungszuckungen zu beseitigen, wäre gewesen. den Widerstand des Yertenkreises so lange zu erhöhen, bis der Widerstand, auf dessen Schwankung sie beruhen. wirklich dagegen rerschwände. Leider musste alsdamn, bei der Kürrze des Nebenschliessdrahtes, um noch hinlängliche Stromdichte im Nerven zu erhalten, in jenem Draht eine solche stromstärke hergestellt rerden, dass er fast erglühte. Es schien mir beiläufig, als ob die Erwärmung des Drahtes an und [140] für sich eine Verminderming der Erschüttermngzuckingen zur Folge hatte. Die Berührungsfläche ron Draht und Quecksilber schien danach der vorzüglichste Sitz des störenden Vorganges zu sein. Ich rersuchte deshalb, den Draht ror den Tersuchen mit feinem Schmirgelpapier zu poliren, und in der That fand sich, dass danach die Erschütterungszuckungen fast ganz rerschwanden. Anch stellten sie sich stets erst oberhalb einer gewissen Stärke des Kettenstromes ein, so dass Entfaltung des Kettenrheochords gleichfalls ein Mittel alogab sich ihrer zu entledigen. Bei alledem sind sie es vorzüglich gewesen, die mich rerhindert haben, die Versuche am Schwankungsrheochord ihrem Ziel zuzuführen. Sie mochten nämlich in einer bestimmten Tersuchsreihe noch so sicher beseitigt scheinen, so tauchten sie aus unbekamntem Grunde plötzlich wieder auf, rerhinderten die Furtsetzung der Tersuche, und rerdächtigten das schon Beobachtete.

Ich habe es deshalb nicht weiter gebracht als bis zu folgenden Ergebnissen. Sowohl bei auf- als bei absteigendem Strom erhält man Zuckung sowohl durch positive als durch negative Schwankung bei geeigneter Stromstärke und Geschwindigkeit des Schlittens. Diese letztere muss sehr bedentend sein. Bei allmählich gesteigerter spannung des Schlauches tritt die Zuckung plötzlich ein. und es hält sehr schwer, eine Abstufung ihrer stärke durch Teränderung der Geschwindigkeit herbeizuführen. Am sichersten erfolgt die Zuckung durch positive schwankung. wenn man diese ron Null ausgehen läst, durch negative Schwankung.

1 Poggendorff's Ammalen u. s. W. 1\$60. Bil. CX. S. 11. Amm. - [Die Hoftnung ist demmach gering, dass vielleicht mit Platindraht die Erschïtterungszuckungen geringer ausfallen der ausbleiben würdon. Doch hätte der Versuch nicht versäumt werden mïsscn. 
wemn der Strom dadurch auf Null zurückgeführt wird. Sehr selten ist es mir geglückt, eine Verstärkung der Zuckung dalurch zu bewirken, dass ich den Schieber des Hülfsrheochords um wenige Centimeter ron seinem Anschlag entfernte. Dagegen gelingt es ausnahmslos, durch weitere Entfaltung des Hülfsrheochords die Zuckung zu schwächen oder zum Terschwinden zu bringen; ein Ergehniss, zu dem ich in der That auch schon im Jahre 1857, ror dem Erscheinen ron Hrn. EckHard's Versuchen. selbständig gelangt war.

Ein Grund für mich, diese Versuche aufzugeben, ist endlich daraus erwachsen, dass ein jüngerer Forscher. Hr. JuL. Benssters, in meinem Laboratorium begomnen hat, sich der Lösung der Aufgabe zu widmen, an die oben erimnert wurle, eine lineare Stromschwankung herzustellen. ${ }^{1}$

[141] Hr. Rosenthal hat mich darauf aufmerksam gemacht, dass das ron Hrn. Hemmнotтz entwickelte Gesetz, wonach der galranische Strom in einem Kreise ansteigt, der eine Inductionsrolle enthält, ${ }^{2}$ ebenfalls benutzt werden könnte, um den Einfluss zu ermitteln, den die rerschiedene Steilheit der Ansteigungscurve auf die Erregung übt.

\section{§. XT. Vom Zuckungstelegraphen.}

Wer über allgemeine Physik der Nerren und Muskeln vor einer grösseren Versammlung rorgetragen hat, weiss, dass es nicht minder schwer hält, Zuckungen eines Gastroknemius auf einige Entferumng hin sichtbar zu machen, als Ausschläge der Multiplicatornadel. Tom Unterscheiden starker und schwacher Zuckungen seitens der Zuhörer ist rollends keine Rede. Ans dem Drange, diesem Mangel alyzuhelfen, entstand während der Vorträge, die ich im Frühjahr 1555 in der Royal Institution hielt, die nachstehend beschriebene, Taf. I. Fig. 9 im seitlichen Aufriss und in halber natürlicher Grïsse dargestellte, sehr einfache aber nützliche Torrichtung, die ich den Zuckungstelegraphen nemne und seitdem in dem betreffenden Theil meiner Vorlesungen fortrährend mit grossem Vortheil angewendet hahe. Diese Vorrichtung ist somit ursprünglich mehr für den Hörsaal, als für das Laboratorium bestimmt, obschon sie auch hier rurtreffliche Dienste leistet.

Das Präparat, worauf die Vorrichtung berechnet ist, ist das in nenerer Zeit so rielfach benutzte, welches aus dem im Hüftgelenk abgelüsten Oberschenkelbcim und dem II. gastrocnemins, je nachdem mittel-

1 Eine vorläufige Anzeige seiner Lntersuchung ist seitdem erschienen im Arehir für Anatomie u. s. w. 1\$62. S. 531. (Nachtr. Anm. [1 \&62].)

2 Poggendorkf's Annalen u. s. W. 14.11. Bd. LXXXiII. S. 510. 511. 
bar oder ummittelbar gereizt werden soll, mit oder whe Ischiadnerr, besteht. ${ }^{1}$

[142] Das Oberschenkelbein dieses Prïparates wird ron einer Messingzange gefasst, die an einer senkrechten Sänle rerstellbar ist. Die Zange ist um die Terlängerung des sie tragenden wagerechten Armes als Axe drehbar, damit, nachdem der Knochen aufs Gerathewohl eingespannt worden, die Insertion des $\mathrm{X}$. tibialis bequem der Seite zugekehrt werden kömne, wo man, aus sonst welchen Gründen, die stromzuführende Vorrichtung angebracht hat. Um die Zange in dieser Lage festzustellen, dient die Schraube $s$.

Der die Zange tragenden sänle gegenüber steht die andlere Hälfte der Torrichtung, Fahne genamnt, auf einem Schlitten $\sigma \sigma_{,}$, der zwischen zwei Leisten läuft, ron denen die Figur zwischen $l$, die eine zeigt; die Schraube $s$, stellt den Schlitten fest.

An der Sänle auf dem Schlitten schiebt sich ein Axenlager anf und ab, in dessen Kémlöchern eine Rolle mit stählernen Spitzen spielt. Die Rolle hat, nach Art des Wirtels einer Drehbank, zwei Hohlkehlen, die eine ron $7 \cdot 5^{\mathrm{mm}}$, die andere ron $15^{\mathrm{mm}}$ Halbmesser, die erstere bestimmt für mser gegenwärtiges Präparat, die letztere für einen anderen, unten zu bezeichnenden Fall. In der gerade benntzten Hohlkehle ist ein Faden um die Rolle geschlungen. Damit er micht gleite, wird er an ein Messinghäkchen geknüpft, das sich dazu in jeder Hohlkehle befindet. An das eine Ende des Fadens ist ein Haken gekuüpft, der durch den Schlitz in der Achillessehne gesteckt wird, und auf den wir sogleich noch zurückkommen werden. Das andere Ende trägt einen ans Messingblech gepressten Eimer mit schrot. An der Rolle ist ein Zeiger befestigt, der eine runde, an der Rückseite roth oder blan angestrichene Glimmerscheibe ron $43^{\mathrm{mm}}$ Durchmesser trägt. Dies ist die Fahne. Sie spielt ror einem gleich breiten Quadranten ron weiss lackirtem Blech, so dass man nicht allein ihre Bewegungen gegen den hellen Grund leichter sehen, sondern

1 Folgendermaassen gewinnt man dies Präparat ám sehnellsten. Znerst legt man den Nerven von der líniekehle ans frei (vergl. Untersuchungen n. s. w. Bd. I. S. 255) und schlägt ihn ïber den Gastroknemins zuriick. Dann ergreift man den Oberschenkel nnd Inrchschneidet mit der Seheere die Oberschenkehmuskeln dicht über dem Kniegelenk quer lois auf den Knochen, fasst num das Präparat an der Fnsswurzel, schabt mit dem Messer das Femur nach anfwärts rein, und löst es ans der Pfanne. Jetzt erst trennt man die Achillessehne unterhalb des Sesamknorpels, schlägt den Gastroknemins, mit dem daranf fencht gebetteten Isehiadnerven, nach oben zurüek, und sehneidet die Tibia dieht unter dem Kniegelenk ab. Zuletzt legrt man die Achillessehne mit ihrer vorderen Fläche anf die Tischplatte [besser eine Korkplatte] mnd bringt mit einem spitzen Sealpell darin einen Längsschlitz an. 
auch ihre Stellung in der Ruhe erkennen kamn. Die Bewegungen der Fahne sind durch zwei Anschläge $a, a$, beschränkt. Unter dem Zuge des Schroteiners liegt sie gegen den Anschlag a, wie es die Figur zeigt, wagerecht, moter dem Zuge des Muskels kann sie sich bis zur Senkrechten erheben und trifft alsdann den Anschlag $u_{,}$. Subald man dem Faden, durch passende Entfernung der Fahne von der Zange, solche Spannung giebt, dass die Fahne den Anschlag $a$, oder die wagerechte Lage, eben rerlässt, wird jeder Znckung des Mnskels eine Hebung der Fahne entsprechen, die Zuckung weithin sichtbar machen, auch nach ihrer [143] Grösse unł Heftigkeit deren Stärke einigermaassen zu beurtheilen erlauben. Beim Tetanus stellt sich die Fahne nubeweglich senkrecht in die Höhe, bei dessen allmählichem Nachlassen sieht man sie ehenso allmählich herabsinken u. s. w.

Mit Vogeldunst gefüllt wiegt der Eimer $75^{\mathrm{grm}}$. Natürlich steht nichts seiner Vergrösserung entgegen. Indem man ihn nur zum Theil anfüllt, oder ihn ganz fortlïsst und anch das Moment der Fahne noch durch das Laufgewicht $\lambda$. aufhebt, kann man die zur Hebung der Fahne nöthige Leistung des Muskels beliebig rerkleinern. Doch ist zu hemerken, dass dies eine durch die wagerechte Stellung des Muskels gebotene Grenze hat, nämlich da, wo das statische Moment der Fahne nicht mehr ausreicht, um Faden und Muskel wagerecht ausgespamnt zu erhalten. In dieser Rücksicht wäre es rielleicht vortheilhafter den Iuskel senkrecht und die Fahne unter ihm an einem und demselhen Stativ aufzustellen. Zu manchen Versuchen ist es auch zweckmässig, Zange und Fahne auf getrennten Gestellen. ähnlich dem allgemeinen Träger, ${ }^{1}$ zu haben.

Soll der Muskel mmittelbar gereizt werden, so wird der eine Draht in die Klemme $s_{\text {, }}$ an der Zange befestigt, und so der Strom durch die Zange selber dem Oberschenkelbein mitgetheilt. Un den anderen Iraht mit der Achillessehne zn rerbinden, dient der in der Figur in natürlicher Grösse, also im doppelten Maassstabe des Uebrigen, vorgestellte Haken. Es ist daran eine Platte und ein Gewinde angebracht, woranf eine Mutter sich wider die Platte schraubt. Zwischen Platte und Mutter wird ein feiner Multiplicatordraht (rergl. oben S. 174. Anm.) eingeklemmt. Dieser führt zunächst zur Schraubenklemme $s_{\prime \prime \prime}$, ron der aus erst der Strom durch gewöhnlichen Draht fortgeleitet wird.

Mit dem Zuckungstelegraphen werden in meinen Vorlesungen alle elektrischen Reizrersuche angestellt, und von den nicht elektrischen die mit mittelbarer Reizung. Ganz sorzüglich lässt sich z. B. daran der mechanische Tetanus nach Hemennas darstellen (s. oben S. 169). Für

1 Untersuchungen u. s. w. Bd. I. S. 448. Taf. III. Fig. 19.

E. du Bois-Reymond, Ges. Abh. I. 
die unmittelbare chemische oder kaustische Reizung bedarf es stärker vergrössernder Mittel, und einer Anordnung, wobei der Querschnitt zugänglich bleibt. Hier tritt an die Stelle des Zuckungstelegraphen die in der folgenden Num- [144] mer beschriebene Vorrichtung. Diese dient auch für die Zuckung durch Zerschneiden des Muskels. Un die Reizung dureh sonstige mechanische Misshandlung zu zeigen, bleibt nichts Anderes übrig, als frisch zugerichtete Froschmuskeln mit Secirnadel und Pincette unter den Zuhörern umhergehen zu lassen.

Es kamn nicht meine Absicht sein, hier auf die Art näher einzugehen, wie rerschiedene Wahrheiten der Elektrophysiologie mittels des Zuckungstelegraphen zur Anschanung zu bringen sind. Es genüge die Bemerkung, dass man dazu häufig zweier solcher Vorrichtungen bedarf, ron deren Fahnen, welche alstamn rortheilhaft zweierlei Farbe haben, die eine nach rechts, die andere nach links in die Höhe gelit. So erweist man z. B. die grössere Erregbarkeit des Nerven im Vergleich zum Muskel bei gleicher Stromdichte nach Hru. Rosenthal's Angabe, ${ }^{1}$ indem man den ummittelbar zu reizenden Muskel, dem der Strom des Schlitten-Magnetelektromotors mittels des eben beschriebenen Hakens zugeführt wird, etwa an eimer rothen, den mittelbar zu reizenden, dessen Nerv dem ersten Muskel entlang gelegt ist, an einer blanen Fahne arbeiten lässt. Nähert man allmählich die Nebenrolle der Hauptrolle, so steht zuerst die blane, und erst bei merklich kleinerem Abstand die rothe Fahne auf; beim Entfernen der Rolle sinkt diese in die wagerechte Lage zurück, während jene noch aufgerichtet bleibt.

Die Hohlkehle von grossem Halbmesser am Wirtel der Fahne dient, um die Abhängigkeit des Hubes und der Kraft der Muskeln von ihrer Länge und Dicke zu reranschaulichen. Man lässt an dem darin befestigten Faden, bei unmittelbarer Erregung bis zum Maximum, abwechselnd einen langen und dümnen Muskel, den Sartorius oder den Rectus internus, und einen kurzen und dicken, den Gastroknemius, arbeiten. Es zeigt sich unter passenden Umständen, dass jene Muskeln den leeren, oder nur wenige Schrotkörner enthaltenden Eimer so hoch heben, dass die Fahne dabei senkrecht zu stehen kommt; während der Gastroknemius zwar leicht den vollen Eimer, sogar mit einer bedeutenden weiteren Belastung, aber auf eine so kleine Höhe heht, dass die Fahne nur eben zuclit. ${ }^{2}$

1 MoLeschотт's Untersuchungen zur Naturlehre des Menschen und der Thiere. 1857. Bd. III. S. 185 .

2 [Hr. Siguund Exner hat neuerlich diesen Versuch in etwas anderer Anordnung gleichfalls als 'Schulversuch aus der Muskelphysiologie' beschrieben. Wiener Sitzmugsberichte, 23. Juli 1874. Bd. LXX. 3. Abth. S. 155.] 
§. 16. Vorrichtung zu Versuchen über chemische Reizung der Muskeln. 211

§. XVI. Ton einer Vorrichtung zu Versuchen über chemische Reizung der Muskeln.

Die in Fig. 10. Taf. III. abgebildete Vorrichtung hat zum Zweck, die Versuche über unmittelbare chemische Reizung der Muskeln, in der Gestalt, welche Hr. W. KüHNE ihnen ertheilt hat, ${ }^{1}$ einer grösseren Versammlung vorzuführen, und mag hier auch Erwähmung finden, obschon sie nicht der Elektrophysiologie angehört. Sie besteht aus drei Theilen, welche an einem messingenen Ständer senkrecht übereinander angebracht sind. $\mathrm{Zu}$ oberst bemerkt man, in einer Hülse am freien Ende eimes wagerechten Messingarmes senkrecht rerschiehbar, eine Stahlstange, welche unten in eine mit einem Klemmringe versehene Pincette ausläuft. Littels der Pincette wird der Sartorius an seinem unteren Ende ergriffen und, sein oberes Ende nach unten, in passender Höhe aufgehängt. Die Flüssigkeit, deren Wirkung auf den am letzteren Ende angebrachten Querschnitt geprüft werden soll, wird in einem Porzellanschälchen auf die Glasplatte gp gesetzt, die dem IIuskel ron unten her schnell mittels der Hülse am Ständer, langsam mittels einer Mikrometerschraube genähert werden kamn. Um die Zuckung sichtbar zu machen, dient ein von Hrn. Rosenthal ersommener Kimstgriff. Quer durch den Muskel, in geringer Entfermung vom Querschuitt, wird ein $20-30^{\mathrm{cm}}$ langer, von einem Ende zum anderen rerjüngter Glasfaden gestossen, der bestimmt ist, fühlhebelartig die Zuckung zu vergrössern. Ein dicht neben dem Muskel am Ständer befestigter gläserner Haken giebt den Drehpunkt des Hebels ab, indem der Glasfaden mittels eines Ringes, zu dem sein dickeres Ende gebogen ist, daran eingelenkt wird, eine Verbindungsart, wobei die Reibung sehr klein ausfällt. Die Bögen, die das entferntere, dünnere Ende des Glasfadens beschreibt, werden durch ein darüber gehängtes, der Leichtigkeit halber durchbrochenes Papierfähnchen sichtbar gemacht.

Wie bemerkt (s. rorige Seite), kann man sich dieser Vorrichtung anch für die kaustische Reizung bedienen; und beim Herstellen eines nenen Querschnittes erfolgt jedesmal eine ansgiebige Bewegung des Fähnchens.

§. XVII. Von der feuchten Reizungsröhre.

In allen Fällen, wo der Gastroknemius mittelbar gereizt werden und das Präparat lange leistungsfähig bleiben soll, ohne dass man zugleich wünscht, mit dem Orte der Erregung am Nerren zu wechseln, und ohne

1 Arehiv für Anatomie u. s. w. 1559. \$. 215. 
dass es auf die Polarisation ankommt, empfiehlt sich die in Fig. 11. Taf. II perspectivisch ${ }^{1}$ dargestellte Vorrichtung, die ich die fenchte Reizungsröhre nenne. Damit das Präparat möglichst lange leistungsfähig bleibe, ist das Wesentliche, wemn nicht schädliche Einflüsse besonderer Art obwalten, bekamtlich nur, dass der Nerr ror dem Vertrocknen geschützt sei. Der Muskel leidet wegen seiner im Vergleich zur Masse so sehr viel kleineren Oberfläche bei weitem weniger mter der Verdunstung, als der Nerv. Die Schwierigkeit, die es oft hat, eine Anordnung $z u$ treffen, wobei der Nerr vor der Trockniss geschützt sei, beruht in rielen Fällen darauf, dass man auch den Muskel in den feuchten Raum aufnehmen will. Bei der feuchten Reizungsröhre ist dies aufgegeben, und nur der Nerv wird vor der Trockniss geborgen.

Die Röhre ist etwa $60^{\mathrm{mm}}$ lang, im Lichten $6^{\mathrm{mm}}$ weit, an dem vorderen Ende aber in eine kuze Spitze ron $n m 1 \cdot 5^{\mathrm{mm}}$ Lichtung ansgezogen. Etwa in der Mitte ihrer Länge, doch der capillaren Spitze näher, hat sie eine mit einem Korke dauernd geschlossene Tubulatur. Hier sind imnerhalb der Röhre, ihrer Wand anliegend, zwei ringförmige Platinelektroden ron $5^{\mathrm{mm}}$ Breite angebracht. Durch Drähte, die neben dem Kork zur Tubulatur hinansgehen, stehen sie in Verbindung mit Ǩlemmen an der isolirenden Fassung der Röhre. Diese Fassung besteht aus einem abgestmmptten Holzkegel, gegen dessen grössere Grundfläche die Rähre durch Drähte geschnürt ist. Die Drähte sind, um die Zeichnung nicht zu verwirren, darin fortgelassen. Die Fassung wird ron einem wagerechten Arme mittels eines Kungelschamiers getragen, wenn die Reizumgsröhre am Mnskeltelegraphen gebrancht wird, an derselben Säule, wie die Zange. Ton den Klemmen an der Fassung gehen die Drähte nicht sogleich weiter zu anderen Vorrichtmgen, sondern um Zerrung zn rermeiden sind sie in gewohnter Art (rgl. S. 16\%) erst noch um einen Elfenbeinknopf an der Hülse des Armes gewickelt. Um die Rei- [147] zungsröhre zum Gebranch fertig zu machen, wird jetzt noch mittels einer Stopfnadel, die an Länge die Rühre ühertrifft, ein langer Seidenfaden hindurch gezogen.

Nun wird die Röhre neben dem Gastreknemins so aufgestellt, dass deren vordere engere Mündung in Einer Höhe mit der Eintrittsstelle des Nerren liegt, und dass, wenn der sie tragende Arm um die Säule gedreht wird, jene Mündung anf diese Stelle trifft, während zugleich die Axe des Rohres mit der des Muskels einen nahezu rechten Winkel macht. Das Ende des Fadens, das zur engen Mündung heraushängt, wird an

1 Der senkrechte Durehmesser der Grunifläche des Holzkegels hat natïrliche Grösse. 
das centrale Ende des Nerren geknüpft. Mittels des zur hinteren Mündnng heranshïngenden Endes des Fadens wird der Nerr in die Röhre gezogen. Er kommt darin, gleich dem Faden, nothwendig innerhalb der Platimringe zu liegen, wie die Figur zeigt, und berührt, falls er nicht gespamnt wird, deren innere Fläehe. In dem Maasse, wie man den Nerven in die Röhre zieht, dreht man sie dem Inskel zu, so dass, wemn der ganze Nerr in der Röhre steckt, die seine Insertion umschliessende engere Mündung an den Muskel stösst und sich in das Bindegewebe der Kniekehle eindrückt. Dadurch ist hier ein ansreichender Terschluss gegeben, und wird die hintere weitere Mündung der Röhre mit einem Kork verschlossen, so ist der Nerv vor Truckniss gesichert, da er ohne merklichen Verlust an Feuchtigkeit den nur etwa $1.5^{\mathrm{cm}}$ betragenden Raum der Röhre bei der gewöhnlichen Temperatur mit Wasserdampf sättigen kamı. Demgemäss erhält er sich in der Röhre stundenlang leistungsfähig. Soll der Versuch abgebrochen werden, so zieht man den Kork von der hinteren Mündung, dreht die Röhre von dem Muskel so weit fort, dass ein hinreichend langes Stück des Fadens heraushängt, um es bequem wieder einem Nerven anzubinden, setzt den Kork wieder anf und schneidet den Faden ab. So ist die Vurrichtung gleich zu neuem Gebrauche fertig.

Die Vertrocknung, der der Muskel ansgesetzt bleibt, übt, wie es scheint, sobald keinen schädlichen Einfluss aus. Erst nach einer Stunde begimnt die Achillessehne, als der dümnste davon betroffene Theil, durchscheinend braun zu werden und, wie man an der in §. XIX beschriebenen Vorrichtung beobachtet, sich zu rerkürzen.

Hr. Rosenthal hat der Reizungsröhre eine Gestalt gegeben, die zwar etwas weniger handlich, den Vortheil gewährt, dass man mit der erregten [148] Strecke wechseln, auch mehrere strecken gleichzeitig erregen kamm. Sie besteht aus einem gestreckt parallelepipedischen Guttapercha-Kästchen, auf dessen Boden mehrere Elektrodenpaare angebracht sind, und dessen eine kurze Seitenwand dem Muskel zugekehrt wird. Durch einen Schlitz in dieser Wand wird der Nerv eingeführt, und imnerhalb des zugedeckten Kästchens leicht vor Truckniss geschützt. ${ }^{1}$

§. XTIII. Tom Frosehwecker, zum Gebrauch bei Versuchen an elektromotorischen Fischen.

Aus der Verbindung des Znckungstelegraphen mit der feuchten Reizungsröhre entsteht der Froschwecker, dessen ich mich bei den

1 [S. unten Abh. XI. §. II. Anm.] 
Versuchen am Zitterwels bediene. ${ }^{1}$ Doch tritt dabei an Stelle eines optischen Signals ein akustisches, indem der Gastroknemius, anstatt einer Fahne, einen Hammer hebt, der an eine Glocke schlägt (s. Fig. 13, S. 218). Die Klemmen der Reizungsröhre sind mit zwei Zimnplatten verbunden, die an einander gegenüber liegenden Punkten des Umfanges der Versuchswanne ${ }^{2}$ rersenkt werden. Ton jedem Schlage, den der Fisch ertheilt, welches anch seine Stellung in der Wanne sei, geht bei dieser Anordnung erfahrungsmässig ein hinlänglicher Stromzweig durch den Nerven, um eine Maximalzuckung, oder nahezu eine solche, auszulösen. Man wird so bei jedem Versuch benachrichtigt, ob der Fisch wirklich geschlagen habe, worüber man keine Gewissheit hat, wenn im Versuchskreise eine erwartete Wirkung ausbleibt, da man nicht weiss, ob man nicht dem Schlag etwas Tnmögliches zugemuthet hat. Durch den Froschwecker erfährt man auch, dass der Fisch nicht selten ohme äussere Veranlassung schlägt, meist wenn er über seine Lage in der geringen Wassermasse der Versuchswanne unwillig, sich in heftigen Anstrengungen gegen deren Wand erschöpft.

Wenn der Fisch unermüdet oder heftig gereizt ist. trifft der Hammer häufig zweimal und öfter die Glocke. Darans ist zu schliessen, dass der Fisch mehr als eimmal geschlagen hat. Wie oft er aher in der That schlug, lässt sich nicht mit Sicherheit bestimmen. Das Ertönen der Glocke zeigt nur an, dass die Zusammenziehnng rasch eine gewisse Grösse über- [149] schreitet und wieder darunter sinkt. Die Gestalt der Dichtigkeitscurve eines Stromes aber, der mehrere solcher Maxima ron bestimmter Lage in der Zeit entsprechen, kamn nach bekannten Grundsätzen eine sehr rerschiedene, mit einer grösseren oder geringeren Zahl von Maxima versehene sein. Bei den Versuchen, die ich am Zitterwels mit der im folgenden Paragraphen beschriebenen Vorrichtung anstellte, hat sich freilich ergeben, dass die Zeitrerhältnisse, die bei dem Schlag in's Spiel kommen, von einerlei Ordnung mit denen sind, welche den Verlauf der Zuckung beherrschen. Danach wird es wahrscheinlich, dass mehreren schnell auf einander folgenden Maximalzuckungen ebensuviele Schläge entsprochen haben. Inzwischen geschieht es, dass man bei subjectiver Prüfung mehr Maxima des Schlages rerspürt, als man Glockenschläge am Froschwecker hört, auf dessen Trene in dieser Beziehung also kein Verlass ist.

1 Monatsberichte u. s. w. 1858. S. 95. - Vergl. die Abhandlung über den Zitterwels im zweiten Bande dieser sammlung.

2 Eine flach eylindrisehe Wanne aus Gesundheitsgeschirr von 11" Durehmesser und $5^{\prime \prime}$ Tiefe, die so viel Wasser enthält, dass der Rücken des Fisches eben bloss liegt. 
Manchmal kommt es vor, dass der Hammer zwar die Glocke trifft, aber nicht sobald wieder herabsinkt, sondern secundenlang daran klebt, wobei natürlich der Ton gedämpft ausfällt. Alsdann ist sichtlich der Nerv tetanisirt. Ton den Umständen des Versuches wird es abhängen, ob man Grund hat, diesen Erfolg der Art zuzuschreiben, wie sich der Fisch entlud, oder darin eine abnorme Reactionsweise des Präparates auf einen einzelnen Schlag zu sehen. dem unter anderen Verhältnissen eine einfache Zuckung entsprochen hätte.

\section{§. XIX. Tom Froschunterbrecher, zum Gebranch bei denselben Versuchen.}

Die erste Schwierigkeit, auf die man bei Untersuchmong des Schlages der elektromotorischen Fische stösst, nachdem man gelernt hat, ihn in annähernd gleicher Art in den Versuchskreis abzuleiten, besteht darin, dass der Fisch, wie soeben gesagt wurde, anf jede Reizmo mit einer umbestimmten Anzahl ron Schlägen antwortet, wodurch die Wirkungen, die er jedesmal hervorbringt, unvergleichbar werden. Ich will beispielsweise erfahren, in welchem von beiden Fällen der Fischschlag durch einen in den Versuchskreis eingeführten Widerstand mehr geschwächt werde, ob bei grösserem, oder bei kleinerem Abstand der Belegungen des dem Fisch aufgesetzten Deckels, ${ }^{1}$ welche Belegungen die Enden des Versuchskreises dar- [150] stellen. Die Beantwortung dieser Frage setzt vier Versuche roraus, bei denen die elektromotorische Thätigkeit des Fisches muss für beständig gelten können, damit ein Schluss aus deren Ergebnissen zulässig sei. Sonderbarerweise findet sich diese Schwierigkeit meines Wissens bei keinem früheren Beobachter erwähnt. Dagegen ist sie Hrn. ЕскнаRD, bei seinen in Triest am Zitterrochen angestellten Tersuchen, fast zur nämlichen Zeit anfgestossen, wo ich hier, im Herbst 1857, damit zu kämpfen begann. Hr. EckHARd hat sie dadurch umgangen, dass er nicht am lebenden Thier, sondern an einem noch im Besitze der Lebenseigenschaften verharrenden Präparat experimentirte, an dem das Organ nur auf Reizung der elektromotorischen Nerven schlug. ${ }^{2}$ Da ich auf das lebende Thier angewiesen war, musste ich mir anders zu helfen suchen. Es handelte sich darum, ein Mittel zu finden, um den Versuchskreis entweder nach erfolgtem ersten Schlage, oder noch während dessen, alsdamn aber nach einer, wenigstens für mehrere anf einander

1 Monatsberichte u. s. w. 1858. S. 97. 103. 104. - Vergl. die Abhandlung ïber den Zitterwels im zweiten Bande dieser Sammlung.

2 Beiträge zur Anatomie und Physiologie. Bd. I. Giessen 1858. 4. S. 166. 
folgente Versuche sich gleich bleihenden Frist, zu öfnen. Yit den gewöhnlichen mechanischen Organen war hier nichts auszurichten, denn durch welches Zwischenglied sollte das Aufsetzen des Deckels, welches nicht einmal genau mit dem. Anfang des Sthlages zusammenfällt, rerknüpft werden mit dem Mechanismus, tem dis Absperren des Entladungsrorganges in einem gewissen Augenhlick anvertrant wäre. Um so näher lag es, hier an tasselbe Hülfsmittel zu denken, das sich im Fruschwecker so gut bewährt hatte, an das Nervmuskelpräparat vom Frosch, welches durch einen verschwindenden Zweig des Fischschlages bis zum Maximum gereizt, in einem kleinen Bruchtheil der Secunde zu jeder hier erforderlichen Leistung bereit ist. Einige Torversuche an einem selhstrerfertigten Iodell beruhigten mich über den Zweifel, ob nicht der Schlag doch zn flüchtig sei, um seiner dergestalt mittels der Znckung Herr im Versuchskreise zu werden; und so entstand die Fig. 12. Taf. III. perspectivisch abgebildete Vorrichtung, ${ }^{1}$ die Hr. SAlERwald nach meiner Angabe ausführte.

[151] Auf einem riereckigen Fussbrett, das auf einem Stift und zwei Stellschrauben ruht, tragen zwei Säulen aus Yeswing ein Tischchen aus demselben Metall empor, indem sie es an seinem hinteren Rand unterstïtzen. An seinem vorderen Rande sind anf einem Vorsprung ron Kammmasse zwei doppelte Schraubenklemmen $k, k$, angebracht. Das Tischchen trägt zwei Axenlager, in denen sich ein Hebel aus Rothguss a a, hp q zwischen stählemen Schraubenspitzen mit Gegenmuttem sehr leicht und sicher dreht.

In der Hitte des Hebels, bei $h$, sind when und unten Haken, der obere für den Muskel, der untere für eine Wagschale, die durch eine Oeffinung im Tischchen herabhängt. Darauf folgen am Hebel, nach dessen freiem Ende zu, zwei Schrauben, die ihn ron oben nach unten durchbohren, und deren Einstellung gleichfalls durch Gegenmuttern gesichert ist. Die erste dieser Schrauben, $p$, läuft unten in einen Platinstift aus, der auf einer Platimplatte ruht, welche durch Kammmasse. isolirt in dem Tisch befestigt, aber mit der Klemme $k$, leitend rerbunden ist. Diese Platte heisst die Stützplatte. Die zweite, am Ende des Hebels gelegene Schraule $q$ endet in eine rerquickte Kupferspitze, die in ein cylindrisches Quecksilbergefïss aus Eisen tancht, welches gleichfalls isolirt in dem Tisch befestigt, und mit der anderen Ḱlemme $k$ leitend rerbunden ist. Die Quecksilberkuppe in dem Gefäss kamn gehoben unt gesenkt werden, indem eine eiserne Schraube $s$, welthe fast die ganze Lithtung des Gefïsses einnimmt, von unten hinein- und herausgeschraubt wird, wie dies Fig. 12a

1 Die dem Beschauer nächste senkrechte Kante des Messingtischehens hat halbe uatiirliche firösse. 
Taf. III. zeigt, worin dieser Theil der Vorrichtung im senkrechten Durchschnitt und im $2 / 3$ - Iaassstahe besonders dargestellt ist. ${ }^{1}$

In der Mitte der hinteren Wand des Tischchens erhebt sich, abermals isolirt, eine senkrechte Messingsäule, an der sich ein kurzer starker Arm auf und ab schiebt. Eine Nuth an der Sänle, in die ein Stift an der den Arm tragenden Hülse eingreift, rerhindert den Arm, sich zu drehen. An dem Arm befindet sich, durch eine Mikrometerschraube auf und ab stellbar, eine Zange zum Einspannen des Oberschenkelbeins, ähnlich der am Zuckungstelegraphen (s. oben S. 208). Die Achillessehne kommt beim Einspamen des gewöhnlichen Präparates in passender Höhe über dem Haken $l$ zu schweben, und wird damit dureh einen Fleischhaken und durch ein isolirendes Zwischenstück $/ i$ aus Sichildpatt rerknüpft.

[152] Der Schlag wird dem Nerren zugeführt durch eine feuchte Reizungsröhre. Diese wird an einem Kugelscharnier getragen durch einen Stiel, welcher an der Zange mittels der Schraube $a$ befestigt wird, so dass sich die Röhre mit der Zange in einem Stück hebt und senkt, mit anderen Worten, dass bei den Bewregungen der Zange zum Einstellen des Muskels die Mündung der Röhre am Muskel und der Nerr anf den Platimringen der köhre unverrückt bleiben.

Für den Fall, dass man den Muskel unmittelbar zu erregen wünschte, würde die Klemme bei $\sigma$ statt des Stieles der Reizungsö̈hre den einen Draht aufnehmen, der andere müsste dünner Multipheatordraht (s. oben S. 174 Anm.) und an Fleischhaken befestigt sein.

Der Gebrauch der Torrichtung im Allgemeinen wird durch Fig. 13 rerständlich, welche das Schema eines Tersuches am Zitterwelse giebt. Man erkennt leicht die Versuchswanne, darin den Fisch mit zwei ihm aufgesetzten, zur Ableitung des Schlages in den Versuchskreis bestimmten Metallsätteln. Ton diesen Sätteln führen Drähte zu den Klemmen $k, k$, und der Tersuchskreis, der bei $B$ die Spiegelbussole enthält, ist durch das Stück $p q$ des um $a$ drehbaren Hebels so lange geschlossen, als der Stift bei $p$ die Stützplatte und die rerquickte Spitze bei $q$ das Quecksilber berührt. Ausser dem Fisch mit seinen Sättehn sieht man in der Wanne die schon beim Froschwecker (s. oben S. 214) erwähnten Zimnelektroden $E, E$, von deren jeder ein gegabelter Draht ausgeht. Ton den beiden Zweigen der Gabelung geht der eine zur Reizungsröhre des Froschweckers, dessen Gastroknemius, Hammer und Glocke man in $G_{I}, H$ und $\Gamma$ erkennt, der andere zu der des Unterbrechers. Schlägt der Fisch, wie er dies im Augenblick zu thun pflegt, wo [153] man ihm die Sättel aufsetzt, so

1 Das Messing im Durehsehnitt ist von rechts und oben nach links und unten, die Kammmasse ist umgekehrt und dichter schraffirt, das Eisen getüpfelt. 
218 VIII. Beschreibung einiger Vorrichtungen und Versuchsweisen u. s. w.

gehen Theile des Schlages, ausreichend um Maximalzuckungen auszulösen, durch die beiden Reizungsröhren. Der Froschwecker schlägt an; die Zuckung des Gastroknemius $G_{I I}$ im Unterbrecher aber trennt den Platinstift $p$ von der Stützplatte und öffnet so den Versuchskreis. Sobald die

Fig. 13.

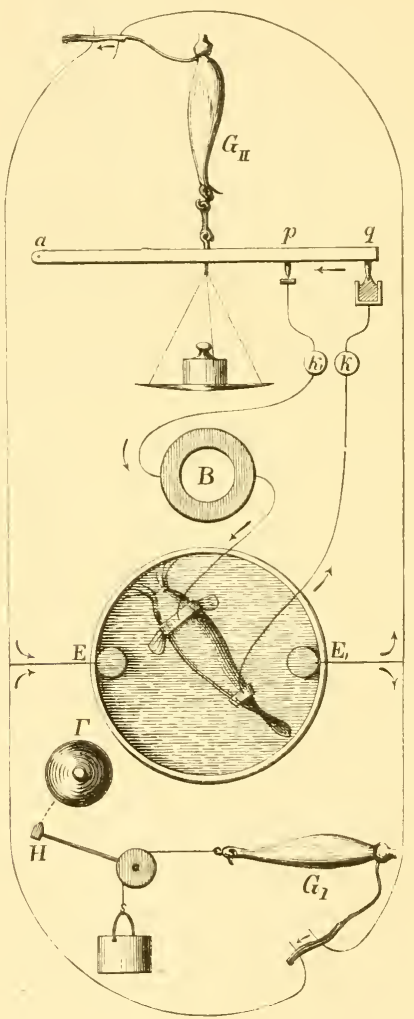

Zuckung nachlässt, sinkt der Stift wieder herab, und wenn jetzt anch die rerquickte Spitze wieder in das Quecksilber tauchte, würde der Kreis wieder geschlossen. Dem wird jedoch rorgebeugt, indem man mittels der Schranbe $s$ die Quecksilberkuppe rorher so tief senkt, dass der durch 
Capillaranziehung getragene Quecksilberfaden bei der geringsten Hebung der Spitze reisst (Fig. $12 a$, Taf. III).

Wie man leicht erkemt, ist nicht allein dieser Kunstgriff der Vorrichtung entlehnt, womit Hr. Heцмногтz die Fortpflanzungsgeschwindigkeit der Reizung im Nerren nach dem PounLLer'schen Verfahren maass, sondern unsere Vorrichtung ist überhaupt nichts als eine bequemere und einfachere Gestalt der von ihm angewendeten. ${ }^{1}$ Der Hebel ersetzt das bei Hrn. Heisholtz sogenannte „stromführende Zwischenstück“, welches frei am Muskel hängt, und den doppelten Vortheil einer rein senkrechten und ganz ungehinderten Bewegung bietet. Dieser Vortheil ist in unserer Vorrichtung anfgegeben, da der Hebel sich im Kreise bewegt und dies nicht ohme eine gewisse Reibung rermag. Dafür ist dessen Handhabung leichter, weil die Pendelschwankungen des Zwischenstücks und die Unsicherheit seiner Lage auf dem es stützenden Querbalken $\boldsymbol{M} \boldsymbol{M}$ (in den HeLmholtz'schen Figuren 1, 2) fortfallen. Die Abweichung von der Senkrechten bleibt bei der Art, wie die Torrichtung gebraucht wird, ohne Einfluss. Selbst am Myographion, wo sie die Curven etwas entstellt, wird sie rernachlässigt. Dass die rerquickte Spitze rermöge ihrer Lage am Hebel einen um ein Drittel längeren Weg beschreibt, als der Stift, und dieser einen um die Hälfte längeren, als der Angriffspunkt des Muskels, sichert einestheils die Zerreissung des Quecksilberfadens, anderentheils die Oeffmung des Kreises zwischen Stift und Stützplatte, bei Verkürzungen, wo an der ursprünglichen Vorrichtung Beides ausgeblieben wäre. Was die Reibung betrifft, so lehrt die Erfahrung am Myographion, wo zu der Reibung an der Hebelaxe noch zwei andere hinzutreten, dass daraus keine namhafte Störung erwächst. Unsere [154] Vorrichtung dürfte sich daher zur Anstellung von Messungen über den zeitlichen Verlauf der Zuckung nach dem PounLLET'schen Verfahren recht gut eignen, nachdem man sich überzeugt hätte, dass sie in ihrem gegenwärtigen Zustande die hinreichende Stabilität besitzt, oder nachdem man ihr solche durch passende Verstärkmng ertheilt hätte. Auch würde sich leicht noch am Ende des Hebels ein Zeichenstift wie am Myographion anbringen lassen, was Gelegenheit zu manchen wichtigen Versuchen böte.

Wie dem auch sei, es ist klar, dass die damals ron Hrn. HeuxHoLTz ermittelten Grundbestimmungen über die bei sich gleichbleibender Länge mit der Zeit wachsende Spannung des Muskels auf unsere gegenwärtigen Versuche Anwendung finden. Indem man den Muskel mittels der Mikrometerschraube senkt, erreicht man, dass der Hebel durch die Platte gerade in der Stellung unterstützt wird, in welcher der Iuskel ihn

1 Archiv für Anatomie u. s. w. 1850. S. 276. Taf. VIII. 
VIII. Beschreibung einiger Vorrichtungen und Versuchsweisen u. s. w.

trägt, wobei also letzterer in den ron Hrn. Нвциноцтz sogenannten $\mathrm{Zu}$ stand der Belastung geräth. Der Augenblick, wo dieser Zustand eintritt, wird mit ansreichender Schärfe daran erkannt, dass bei schnellendem Klopfen mit dem Finger auf die Stiftschraube, wie beim Percutiren zur ärztlichen Exploration, kein Krirren erfolgt. ${ }^{1}$ Um dies besser zu unterscheiden, müssen die Drähte, an denen die Wagschale hängt, an diese gelöthet sein, weil sie sonst an sich schon beim Klopfen ein Klirren erzengen. Es ist vortheilhafter, sich dem Zustand der Belastung durch Herablassen des Muskels zu nähern, als durch Heben, weil im ersteren Falle der Muskel unter dem Einfluss der Belastung die ihm dabei zukommende Länge bereits ammähernd angenommen hat, und daher nach erfolgter Einstellung seine Spamnung besser behält, als wenn er früher unbelastet plötzlich der Reckung durch die Belastmug ausgesetzt wird. ${ }^{2}$

Der Zustand der Belastung bringt es bekauntlich mit sich, dass die kleinste Zunahme des Muskels an Spamung den Stift ron der Stützplatte hebt. Bei verschwindender Daner des erregenden Stromes, z. B. wenn dieser ein durch Oeffnen des primären Kreises erzeugter Inductionsschlag war, erfolgt nach Hrn. HeLnноцтz eine merkliche Zunahme an Spammung erst nach Ablanf zweier Zeiträmme. Der erste Zeitranm ist der, während dessen [155] die Reizmng ron der gereizten Stelle des Nerven zum Mnskel gelangt. Er wächst im Allgemeinen mit der Entfernung zwischen dem Muskel und, sofern es sich nicht um Oeffnungszuckung handelt, der katelektrotonisirten Nerrenstrecke, ${ }^{3}$ und mit sinkender Temperatur. Der obere Rand des unteren Platinringes der Reizungsröhre liegt etwa $27^{\mathrm{mm}}$ rom Inskel. Nach den HewмнoLtz'schen Bestimmungen wirl daher bei mittlerer Temperatur dieser Zeitraum in unseren Versuchen bestenfalls, d. h. wenn der Strom absteigt, nicht unter 1/980 Secunde betragen kömmen. Der zweite Zeitramm ist das Stadium der latenten Reizung, welches über die Vorbereitumgen für die Zusammenziehung im Inskel selber hingeht und sich auf nahe 1/100 Secunde belänft. Die Summe dieser beiden Zeiträume, etwa ${ }^{1} / 93$ Secunde, würde die kleinste Daner sein, die wir dem Strom in einem den Froschunterbrecher enthaltenden Kreise ertheilen kömnten, wemn in demselben

1 Vergl. Henmholtz in Poggendonff's Aunalen u. s. w. 1s51. Bd. LXXXIII. S. 517.

2 Vergl. Helmholtz im Arehiv für Anatomie u. s. w. a. a. 0. S. 312.

3 Vergl. A. v. BEzold, Allgemeine Medieinische ('entral-Zeitung, 26. März 1859. St. 25; - Derselbe in den Monatsberiehten der Akademie, 29. November 1๙60. S. 742; - in MoLeschotr's Untersuchungen zur Naturlehre des Mensehen und der Thiere. 1\$60. Bd. VII. S. 587; - Derselbe, Untersuchungen über die electrische Erregung der Nerven und Nuskeln. Leipzig 1s61. S. 287. 303. 304. 
Augenblick, wo der Strom zu kreisen begimnt, eine Zuckung durch einen Strom ron rerschwindender Daner ausgelöst würde. Dagegen sind wir im Stande, diese Dauer beträchtlich zu verlängem, dadurch, dass wir, nachdem der Mnskel in der angegebenen Weise belastet worden, anf die Wagschale Gewichte, als Ueberlastung in dem von Hrn. Hecmhoctz gebrauchten Simne, legen. Zu den beiden ersten Zeiträumen tritt dam ein dritter hinzu, der im Allgemeinen mit der Ueberlastung wächst, und sich mindestens bis auf das Dreifache der Summe jener ausdehnen kann, so dass die ganze Daner des Vorganges rom Augenblick der Reizung an, bis die Spannung des Muskels der Summe der Belastung und Ueberlastung gleich geworden ist, etwa $0^{\prime \prime} \cdot 04$ beträgt.

Wie pünktlich der Unterbrecher sein Geschäft versieht, oder wie gleich die Zeiten ansfallen, die er unter sonst gleichen Umständen rom Augenblick der Reizung bis zum Heben des Stiftes jedesmal verstreichen lässt, ist leicht zn prüfen, indem man wiederholt den Ausschlag beobachtet, den ein während jener Zeit kreisender beständiger Strom an der Bussole erzengt. Wir kömnten uns hier an Hrn. HeLmholtz' Tersuche zur Bestimmung der Geschwindigkeit der Reizung halten, in denen zwei solche Reihen, [156] die von verschiedenen Nervenstellen ans gewonnen sind, mit einander verglichen werden. Diese Reihen, die in seinen Tabellen je eine Vertical-Columne eimnehmen, lassen eine völlig ausreichende Beständigkeit der Wirkungen ron jeder Nervenstelle ans erkennen. Wir dürfen uns aber nicht hierbei beruhigen, auch abgesehen daron, dass es rathsam erscheint, die neue Vorrichtung ror dem Gebranch anf irgend eine solche Probe zu stellen. Hr. Heцsнoltz liess, wie sein Zweck es mit sich brachte, seine Versuche einander unstreitig so schnell folgen, wie gewisse Umstände es erlaubten; ${ }^{1}$ und er hatte keinen Anlass, sie länger fortzusetzen als nöthig, um daraus auf die Fortpflanzungsgeschwindigkeit der Reizung zu schliessen. Soll dagegen der Froschunterbrecher den ron uns rerlangten Dienst leisten, so muss er mindestens anderthalb Stunden lang gleichmässig arbeiten, während welcher man allerdings nur etwa alle zehn Minuten einen Versuch anstellt: weil dias die Art ist, wie man die Versuche am Zitterwels leitet, um das Thier nicht zu sehr zu ermüden.

Es bedurfte also hier noch einer Prüfung, zu der ich folgendermaassen schritt. Ich brachte in einen Kireis 1. eine Grove'sche Kette, um den zeitmessenden Strom zn liefern; 2. die Spiegelbussole mit 53 Windungen in $15^{\mathrm{mm}}$ Abstand rom Spiegel; 3. den Froschunterbrecher; 4. den ron Hrn. Pflüger in die Elektrophysiologie eingeführten Fall-

1 Archiv für Anatomie u. s. w. A. a. O. S. 312.313. 
hammer mit elektromagnetischer Auslösung, um den Kíreis durch Eintauchen einer Platinspitze in Quecksilber zu schliessen $;^{1} 5$. einen so ansehnlichen Widerstand, dass die im Kreise befindlichen veränderlichen Widerstände, wie der zwischen Stift und Stützplatte, der der Quecksilbergefässe am Unterbrecher und Hammer, dagegen rerschwanden (s. oben S. 172); endlich 6. ein Rheochord, wodurch rom zeitmessenden Strom ein Zweig von angemessener Stärke zur Reizungsröhre des Unterbrechers abgeleitet wurde. Dieser Stromzweig erhielt im Nerven die absteigende Richtung. Im Kreise der elektromagnetisirenden Rollen des Hammers befand sich ein Daniell nebst einem Stromwender zum Fallenlassen des Hammers dureh Umkehren des Stromes. Nachdem bei [157] $100 \mathrm{~mm}$ Entfermung des Multiplicatorgewindes der Bussole rom Spiegel die Stärke des zeitmessenden Stromes $(I)$ war bestimmt worden, um sich am Schluss der Versuchsreihe seiner Beständigkeit versichern zu können, wurde alle zehn Minuten durch Umlegen der Wippe des Stromwenders der Hammer fallen gelassen und eine Schliessungszuckung ausgelöst, welche den Kreis, durch dessen Schliessung sie entstand, sogleich wieder öffnete. Das Multiplicatorgewinde war dabei dem Spiegel wieder so nahe gebracht, dass ein Ausschlag ron angemessener Grösse erfolgte. Die folgende Tabelle zeigt die Ergebnisse, die ich so an rerschiedenen Präparaten bei rerschiedenen Ueberlastungen erhielt. Eine Versuchsreihe ohne Ueberlastung fehlt, da ich, wie schon Hr. Hewsholtz, ${ }^{2}$ fand, dass dabei auf keine Regelmässigkeit zu rechnen sei. Die Zahlen der Tabelle sind unmittelbar abgelesene, den Zeiten proportionale Ansschläge. Die der einen Reihe sind aus verschiedenen Gründen nicht vergleichbar mit denen der anderen, weshalb die Ausschläge nicht regelmässig mit den Ueberlastungen wachsen. ${ }^{3}[158]$

1 Das Spritzen des Quecksilbers, welches Hru. PrLüger zwang, das Quecksilbergefäss auf eine andere Unterlage zu stellen, als den Hammer (Untersuchungen ïber die Physiologie der Electrotonus. Berlin 1859. S. 114. 115), wird vermieden, wenn man das Grundbrett der Vorrichtung an der Stelle, wo der Hammer es trifft, unterstiitzt, so dass es nicht federt.

2 Archiv für Anatomie u. s. w. A. a. O. S. 314.

3 Bringt man an Stelle der Bussole ilas Vertical-Galvanoskop von Sievess und HALSKE und an Stelle des Fallhammers einen Schlitssel, und verstärkt man gehörig den zeitmessenden Strom, so gelingt es leicht mittels der beschriebenen Anordnung in der Vorlesung die Grundlage der HeLmноцтz'schen Versuche vorzuführen. Beim schliessen des Kreises mittels les s'chliussels erfolgt auch ohne Ueberlastung ein kleiner Aussehlag, der von dem Stadium der latenten Reizung herrührt; beim Auflegen wachsender Ueberlastungen erhält man immer grössere Ausschläge. Es ist kein frund da, weshalb man nicht mit Hülfe der Spiegelbussole, bei Inwentung des von mir beschriebenen Verfahrens, um deren Ab- 


\begin{tabular}{|c|c|c|c|c|c|c|c|c|c|c|c|c|c|c|c|c|}
\hline \multirow{2}{*}{\multicolumn{2}{|c|}{ Minuten. }} & & \multirow{2}{*}{10} & \multirow{2}{*}{20} & \multirow{2}{*}{30} & \multirow{2}{*}{40} & \multirow{2}{*}{50} & \multirow{2}{*}{60} & \multirow{2}{*}{70} & \multirow{2}{*}{80} & \multirow{2}{*}{90} & \multirow{2}{*}{100} & \multirow{2}{*}{110} & \multirow{2}{*}{120} & \multicolumn{2}{|c|}{$I$} \\
\hline & & & & & & & & & & & & & & & vorher & nachher \\
\hline \multirow{4}{*}{ 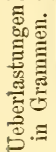 } & 5 & $30 \cdot 0$ & $29 \cdot 6$ & $29 \cdot 0$ & $27 \cdot 0$ & $27 \cdot 3$ & $26 \cdot 8$ & $26 \cdot 9$ & $25 \cdot 8$ & $24 \cdot 0$ & $26 \cdot 7$ & $26 \cdot 6$ & $26 \cdot 0$ & $26 \cdot 0$ & $118 \cdot 2$ & $\overline{116 \cdot 0}$ \\
\hline & 50 & $63 \cdot 6$ & $66 \cdot 2$ & $65 \cdot 2$ & $64 \cdot 4$ & $\overline{65 \cdot 6}$ & $\overline{63 \cdot 5}$ & $62 \cdot 2$ & $63 \cdot 4$ & $62 \cdot 9$ & $63 \cdot 0$ & $64 \cdot 4$ & $62 \cdot 6$ & $\overline{64 \cdot 0}$ & $191 \cdot 3$ & $189 \cdot 7$ \\
\hline & 100 & $58 \cdot 0$ & $56 \cdot 7$ & $56 \cdot 0$ & $56 \cdot 5$ & $55 \cdot 0$ & $54 \cdot 6$ & $55 \cdot 3$ & $55 \cdot 8$ & $56 \cdot 4$ & $56 \cdot 7$ & $56 \cdot 8$ & $59 \cdot 5$ & $60 \cdot 3$ & $191 \cdot 4$ & $193 \cdot 2$ \\
\hline & 150 & $57 \cdot 0$ & $56 \cdot 7$ & $57 \cdot 2$ & 57 & $58 \cdot 5$ & $56 \cdot 5$ & $\overline{56 \cdot 8}$ & $54 \cdot 8$ & $56 \cdot 4$ & $57 \cdot 7$ & $58 \cdot 0$ & $58 \cdot 8$ & $57 \cdot 3$ & $185 \cdot 3$ & $182 \cdot 8$ \\
\hline
\end{tabular}

Ueber zwei Stunden hinaus wuchsen die Ausschläge rasch, und bei den höheren Ueberlastungen wurde bald der Hebel nicht mehr hoch genug gehoben, um den Quecksilberfaden zu zerreissen. ${ }^{1}$

Bei der Betrachtung der obigen Zahlenreihen springt zunächst das

lenkungen Mehreren zugleich sichtbar zu machen (s. oben S. 152), den Zeitverlust im Nerven gleichfalls zur Ansehauung sollte bringen kömen. Hr. CzERMAK hat kürzlich zu diesem Zweck sein Myochronoskop beschrieben (Allgemeine medicinische Central-Zeitung, 5. Juni 1861. XXX. Jahrgang. St. 45. S. 354; - Sitzungsberichte der Wiener Akademie, 4. Juli 1861. Bd. XLIT. S. 231; - Moleschotr's Untersuchungen zur Natur des Menschen und der Thiere. 1862. Bd. VIII. S. 478). So sinnreich dies ist, so scheint es mir für den Vortrag den Nachtheil zu haben, dass seine Wirkungsweise schwerer zu erklären ist, als was es erläuterm soll. Bedenklich ist auch, dass, während Hr. Hexmholtz, worin ich ihm beistimme (s. oben), es unmöglich fand, ohne Ueberlastung regelmässige Ausschläge von der nämlichen Nervenstelle aus zu erhalten, und deshalb nie einen Zeitmessungsversuch ohne Ueberlastung anstellte, am Myochronoskop nicht nur keine Einrichtung zum Ueberlasten vorhanden ist, sondern anch in der Beschreibung der damit angestellten Versuche der Hinweis auf die ungemeine Sorgfalt fehlt, womit das Einstellen auf Belastung alsdann geschehen musste, sollte es nicht völlig dem Zufall überlassen bleiben, welcher der beiden Muskeh zuerst den Kreis öffnete. (Nachträgliche Anmerkung [1862].)

3 Beim Herabsinken des Stiftes auf die Stützplatte wird alsdanı der Kreis wieder geschlossen, was eine neue Zuckung zur Folge hat, ein Vorgang, der sich so oft erneuert, als die Erregbarkeit des Präparates es zulässt. Am frischen Präparat und bei kleiner Ueberlastung kann man dasselbe bewirken, indem man die Quecksilberkuppe so hoch schraubt, dass die spitze beim Herabsinken wieder eintaucht. Dies ist die ausgebildetste Form jenes elektrischen Froschschenkel-Tanzes, den schon Galvani in seinem Commentar mit ungleichartigen Metallen (De Viribus Electricitatis in Motu musculari Commentarius ete. Mutinae 1792. $4^{0}$. p. 19; - Uebersetzt von Joh. Mayer u. s. w. Prag 1793. S. 39; - Opere edite ed inedite ec. Bologna 1841. 40. p. 82), im Trattato dell' Uso aber sogar mit dem Muskelstrom beschrieben hat (Trattato dell' Uso e dell' Attività dell' Areo conduttore nelle Contrazioni dei Muscoli. Bologna 1794. p. 83; - Opere edite ed inedite ec. p. 210). Vergl. meine Untersuchungen u. s. w. Bd. I. S. 63. - Hr. Czermak hat unlängst diese Erscheinung als neu beschrieben (Sitzungsberichte der Wiener Akademie, 4. Juli 1861 . Bd. XLIV. s. 239 ; - Moleschotr's Untersuchungen u. s. w. Bd. VIII.

S. 487. (Nachträgliche Anmerkung [1862].) 
Gesetz in die Augen, rlass die Ansschläge, oder die ihnen proportionalen Sehliessungseiten, zuerst ab- und damn wieder zmmehmen. Die Erörterung dieses Umstandes wird besser in eine Ammerkung rerwiesen, ${ }^{1}$ da [159]

1 Eine Spur desselben Verhaltens lässt sich, wie ich finde, in den HenrHoLtz'schen Versuchsreihen entdecken. Eimmal in der Reihe I. (a. a. O. S. 303), in der zwar mit den Ueberlastungen gewechselt, dieselbe Ueberlastung aber in ziemlich weitem Zeitabstande dreimal nach einander aufgelegt wurde. Der nittlere Ausschlag ist der kleinste. Zweitens in einigen der Reihen, in denen, zur Bestimmung der Geschwindigkeit der Reizung, bei gleicher Ueberlastung bald von einer näheren, bald von einer entfernteren Stelle aus gereizt wurde. Diese Art Reihen kommt, wie bemerkt, ganz mit den unsrigen äberein, bis auf das Wechseln mit der gereizten Stelle des Nerven, und bis auf die Zeiten, die zwisehen den einzelnen Versuchen verflnssen. Demgemäss sieht man in Hrn. Helnholtz' Reihe X. $B$ und XI. $A$ (S. 342.343 ) die Aussehläge in derselben Vertical-Columne. die von der nämliehen Nervenstelle aus erfolgt sind, gleichfalls zuerst ab- und dann wieder zunehmen.

Die sich zuletzt einstellende Zunahme rührt von der Abnahme der Leistungsfähigkeit her, in Folge welcher dieselbe spannung später eintritt, als auf früheren Stufen der Erregbarkeit. Es frägt sich aber, woher die zuerst beobachtete $\mathrm{Ab}$ nahme der Aussehläge stamme.

Sie könnte erstens kommen von einem Sinken der Stärke des zeitmessenden Stromes, dessen Einfluss später durch die Abnahme der Leistungsfähigkeit überwogen würde. Die Tabelle lehrt jedoch, dass die Abuahme der Stromstärke selbst nach zwei Stunden nicht ausreicht, die Abnahme des Ausschlages nach einer Stunde zu erklären. In einem Falle (dem mit $100 \mathrm{gr}$ Ueberlastung) war sogar die Stärke des zeitmessenden Stromes naeh zwei stunden etwas grösser als anfangs, während die Ausschläge das nämliche Gesetz zeigten.

Etwa während der ersten Hälfte jeder Versuehsreihe muss man von Versuch zu Versuch den Muskel etwas heben, um die richtige Einstellung des stiftes auf der Stützplatte zu bewirken. Hingegen während der zweiten Hälfte muss man, um dasselbe zu erreichen, den Muskel etwas senken. Das Erste rïhrt daher, dass der Nuskel durch die dauernile Belastung gedehnt wird und an spannung verliert, das Zweite vom Austrocknen der Sehne (s. oben S. 213). Diese Veränderungen sehreiten auch während des Zeitraumes fort, der zwischen dem erneuten Einstellen des Stiftes auf der Stützplatte, welches jedem Versuch vorhergeht, und dem Versuch selber rerfliesst, und wie klein sie auch während dieses Zeitraumes ausfallen mögen, somüssen sie doeh dahin wirken, die Dehnung, einen Theil der Belastung in Ueberlastung zu verwandeln, und so die schliessungszeit zu vergrössern (Helmholtz, a. a. (). S. 312), die Verkürzung, diese Zeit zu verkleinern. Von diesen beiden Wirkungen nähert sich die erste von Anfang an einer Grenze; die zweite hingegen kann erst in Wirksamkeit treten, nachdem die der Sehne oberflächlich anhaftende Flüssigkeitsschicht verdunstet ist. Es nimmt also von Anfang an eine Wirkung ab, welche die Sehliessungszeiten zu verlängern, und es entwickelt sich mit der Zeit eine Wirkung, welehe jene Zeiten abzukürzen strebt. Nan könnte daran denken, hieraus die Abnahme der Ausschläge zu erklären. Sie würde nur während der ersten Versuchshälfte bemerkbar werden, weil während der zweiten Hälfte die Zunahme wegen sinkender Leistungsfähigkeit die Oberhand erhielte. In Hrn. Hecm- 
sie uns hier zu weit führen würde. Sieht man ab ron einigen ans der Ordnung fallenden Zahlen, welche wohl nur Einstellungstehlern zuzuschreiben [160] sind, so ergiebt sich, dass der Froschunterbrecher volle zwei Stunden lang mit einer für unsere Zwecke genügenden Pünktlichkeit die Aufgabe erfüllt, einen Kreis nach einer durch die Ueberlastung bemessenen Frist zu öffnen.

Demmächst wäre zu zeigen, welchen Einfluss das Einschalten des Froschunterbrechers in den Versuchskreis des Zitterwelses übt. Es ist indess meine Absicht nicht, hier ausführlich darauf einzugehen. I)as allgemeine Frgebniss dieser Versuche habe ich schon anderswo mitgetheilt. ${ }^{1}$ Gemäss dem oben S. 214 Gesagten, besteht es darin, dass kemeswegs der Zitterwelsschlag zu flüchtig ist, um mittels der Zuckung seinen Eintritt in eine stromprüfende Vorrichtung zu regeln; dass vielmehr die Daner des Schlages mit der der Zusammenziehung ron einerlei Ordnung ist; und dass man so mittels des Froschunterbrechers nicht allein bei wiederholtem Schlagen des Fisches den späteren Schlägen den WVeg versperren kamn, sondern es sogar in seiner Gewalt hat, rom ersten Schlage nur einen im Allgemeinen mit der Ueberlastung wachsenden Bruchtheil durchzulassen. Man kam anch nmgekehrt so verfahren, dass man das Stïck $p q$ des Hebels zu einer Nebenleitung zum Tersuchskreise macht, welche durch die Zuckung geöffinet wird. Alsrdam werden die Aus-

HoLtz' Versuchen war indess der Muskel, wenn auch nicht so vollkommen wie der Nerv, vor der Trockniss geschïtzt, und in einem von mir angestellten Controlversuch, wo ex ganz ebenso geschützt war, erfolgte die Abnahme der Ausschläge wie sonst. Von der Trockniss also, als Ursache lieser Abnahme, ist jedenfalls abzusehen. Was die Dehnung betrifft, so ist nicht wohl denkbar, dass ihr Einfluss gross genug ausfalle, in Frwägnng, dass es sich dabei nur um Untersehiede einer sehr kleinen und langsamen abnehmenden Grösse handeln würde.

Mit Erklärungsgründen dieser Art diurfte hier nichts auszurichten sein. Dagegen wöchte Folgendes in Betracht kommen. Hr. Hermans Iunk hat kürzlich gezeigt, dass das Erregungsmaximum des Nerven, gemessen durch die grösste, nach augenblicklicher Reizung erreichte Zuckungshöhe, in der ersten Zeit nach der Zurichtung sehr rasch beträchtlich ansteigt, um dann erst langsamer zu sinken (Archiv für Anatomie u. s. w. 1860. S. 810. \$14. \$15). Einem ähnlichen Gesetze folgen gleichzeitig sämmtliche (rdinaten der Curve der Erhebungshöhen, also auch die der Curve der Spannungen bei gleicher Länge. Dann ist klar, dass eine gewisse Zeit nach der Zurichtung die gleiche sjanmung schneller nach der Reizung eintreten werde, als früher und als später, mit anderen Worten, dass, wie wir es fanden, die Schliessungszeiten ein Minimum haben müssen. ( $\mathrm{Hr}$. Musk ist seitdem zu der Ueberzeugung gelangt, dass das Ansteigen des Erregungsmaximums von einer Temperaturerhöhung des Präparates abhänge. A. a. 1. 1861. S. $425 \mathrm{ff}$; 1862. S. 1 ff. (Nachträglicher Zusatz [1 1862$]$.)

1 Monatsberichte u. s. w. 1 s58. S. 96. 102. - Vergl. die Abhandlung über die Zitterwelse im.zweiten Bande dieser Sammlung. 
schläge un so kleiner, je höher die Ueberlastungen. Man kann also dergestalt mittels der Zuckung beliebige Stücke rom Anfang oder rom Ende der Entladung gleichsam abschneiden, und nur den Rest zur Wirkung im Versuchshreise zulassen.

Man könnte, beim ersten Blick, an diese Versuche die Hoffinung auf noch viel weiter gehende Erfulge knüpfen. Die Dauer der Zuckung eines Froschgastroknemius, die Zeit, deren ein solcher nach der Reizmng bedarf, um eine bestimmte Spannung zu erlangen, ist gleichsam eine Constante der Natur. Warum sollte man nicht, wenn einmal die zum Erlangen einer bestimmten Spannung nöthige Zeit bekannt ist, daraus, dass der Muskel diese Spannung erlangt hat, umgekehrt schliessen, dass jene Zeit rerflossen sei? [161] Es scheint, als böte sich so in passend geleiteten Tersuchsreihen am Froschunterbrecher ein Mittel dar, mit Hülfe der Hewshoutz'schen Curve der Spannungen bei gleicher Länge, ${ }^{1}$ die Dauer des Zitterwelsschlages wahrhaft zu messen, und dessen zeitlichen Verlauf wenigstens ungefähr anzngeben.

Inzwischen latem in diesen Bestimmungen noch mehrere Unbekannte, die einen so raschen Fortschritt rorläufig untersagen.

Ein erster Umstand, der einen solchen Gebrauch der Hesmнoltz'schen Zahlen ummöglich macht, ist der Einfluss der Grösse des Muskels auf die Curve der Spannmingen. Die folgende Tabelle giebt einen Begriff ron diesem Einfluss, den Hr. HeLnнoutz zu berücksichtigen keimen Grund hatte. Sie zeigt das Ergebniss ron Versuchen, welche ganz wie die oben S. 222 beschriebenen mit Gastroknemien ron rerschiedener Länge angestellt wurden. Die Zahlen sind das abgerundete Mittel dreier Versuche, zwischen denen drei Minuten rerflossen.

Ueberlastung $100^{\mathrm{gt}}$.

$\begin{array}{llllll}\text { Länge in MM. } & 19 & 22 & 26 & 33 & 35 \\ \text { Ausschläge in Sc. } & 72 & 60 & 68 & 64 & 52\end{array}$

Wie zu erwarten war, fällt die Schliessungszeit bei gleicher Teberlastung im Allgemeinen um so kleiner aus, je grösser der Muskel; doch nimmt sie langsamer al, als im umgekehrten Verhältniss der Grösse.

Man sieht zweitens, an dem Beispiel des $22^{\mathrm{mm}}$ langen Muskels, dass ansser der Grösse des Muskels anch noch dessen Leistungsfähigkeit in's Spiel kommt, und gelegentlich den Einfluss der Grösse überwiegt.

Drittens aher, und hauptsächlich, setzt der Gebranch der Zuckung zu Zeitmessungen in der angedeuteten Art eine gleichmässige Reizung des Nerren voraus. In Hru. Hewmholtz' Versuchen geschah diese stets mittels eines Oeffinungsinductionsschlages ron rerschwindender Dauer

1 A. a. O. Taf. VIII. Fig. 4. - Vergl. dazu S. 306-309. 
seiner reizenden Theile. In den Fischrersuchen dagegen geschieht die Reizung durch einen Zweigstrom, der auf sehr rerschiedene Weise dem Theil des Schlages entlehnt wird, welcher durch das Wasser der Versuchswanne geht. Insofern der Reiz dabei stets ein Maximalreiz bleibt, kommt darauf weniger an, [162] dass er oberhalb des Maximums bald grösser, bald kleiner ausfällt. Was dagegen sehr in Betracht kommt, ist, dass der Reiz in unserem Falle keine zu vernachlässigendle, ja nicht einmal eine beständige Dauer hat. Nan kann ihn nämlich offenbar als einen an Daner die Schliessungszeit übertreffenden Maximalreiz auffassen; da die späteren Stadien des Vorganges ohne Bedeutung für die Schliessungszeit sind, also gleichsam als würde der Nerv während der ganzen Schliessungszeit, sie sei kurz oder lang, mittels einer stetigen, sehr ausgiebigen Stromschwankung bis zum Maximum tetanisirt. Die Schliessungszeit für eine bestimmte Ueberlastung wird, alles Uebrige gleich gesetzt, in den Fischrersuchen also kleiner sein, als in den HewnHoLTz'schen oder in den oben S. 222 von uns angestellten Versuchen, und die Schliessungszeiten und Ueberlastungen werden dort durch eine andere und mehr verwickelte Beziehung verknüpft sein, als hier. Unter diesen Umständen ist es klar, dass, um aus den Versuchen am Frosehunterbrecher auf Verlauf und Daner des Zitterwelsschlages weitere Schlüsse zu ziehen, zuerst noch Messungen der Zeit anzustellen wären, die beim Tetanisiren in obiger Art zwischen Beginn der Reizung und Heben der Ueberlastung verfliesst.

Bei alledem bleibt noch die Möglichkeit zu erwägen, wodurch auch diese Auskunft entwerthet würde, dass es sich am Zitterwels nicht immer um einen Maximalreiz handele, und dass auch noch so der wechselnde Verlauf des Schlages von Einfluss anf die Schliessungszeit werde. ${ }^{1}$

${ }^{1}$ [Der Froschunterbrecher hat sich noch in anderen Versuchen, als soleher an Zitterfischen, nützlich gezeigt. Indem $\mathrm{Hr}$. RosenthaL zwisehen $k$ und $k$, ein elektromagnetisches Läutewerk cinschaltete, welehes jede Oeffnung des Kreises mit einem Glockenschlage beantwortet, befähigte er den Unterbrecher, so kleine Verkürzungen von Muskeln anzugeben, dass sie anders nicht wohl zu bemerken wären. In dieser Form diente ihm der Unterbrecher zur Bestimmung der Kraft von Froschmuskeln (Comptes rendus etc. 1867. t. LXIV. p. 1143); auch erlaubt er bequem den Hermans'sehen Versuch zu wiederholen, in welehem trotz wachsender Belastung (im Hezmнotтz'sehen Sinne) stets fast dieselbe Stromstärke minimale Zuckung auslöst (Archiv für Anatomie u. s. w. 1861. S. 369).] 
IX.

\section{Ueber den zeitlichen Verlauf voltaëlektrischer Inductionsströme.}

(Gelesen in der Gesanmtsitzung der Königl. Akademie der Wissenschaften am 26. Juni 1862.) ${ }^{1}$

\section{§. I. Abänderung des Magnetelektromotors durch}

Hrn. HeLMHOLTz.

Fast stets, wemn man Nerren oder Muskeln zn tetanisiren hat, ist es wünschenswerth, dass der tetanisirende Strömungsrorgang aus abwechselnd gerichteten, sonst aber gleich beschaffenen Strömen bestehe. Unerlässlich ist dies sogar, wenn es sich um die Beobachtung der negatiren Schwankung des Nervenstromes beim elektrischen Tetanus handelt. Sind nämlich die Ströme nach der einen Richtnng stärker als die nach der anderen, so heben, anch wem in beiden dieselbe Elektricitätsmenge sich abgleicht, die beiden Phasen des Elektrotonus einander nicht völlig anf, sondem es bleibt, abgesehen von der [373] natürlichen Ueberlegenheit der positiven Phase, oder, wie wir jetzt sagen können, des Anelektrotonus, sofern er sich elektromotorisch geltend macht, ${ }^{2}$ ein Unterschied der Phasen zu Gunsten der schwächeren und langsameren Ströme übrig, der sich algebraïsch zur negativen Schwankung hinzufügt, und leicht Tänschungen reranlassen kann, wie dies rermuthlich Hrn. Мoleschotт hegegnet ist. ${ }^{3}$

In der That erfüllen unsere roltaëlektrischen Inductionsvorrichtungen, z. B. der Schlitten-Magnetelektromotor, bei der gewöhnlichen Einrichtung jene Bedingung nicht. Die Schliessungsschläge daran sind physiologisch

1 Monatsberichte u. s. w. 1862. S, 372.

2 Prlüger, Untersuchungen über die Physiologie des Electrotonus. Berlin 1859 . S. 431 .

3 Moleschotr's Untersnchungen zur Naturlehre des Mensehen und der Thiere. 1861. Bd. VIIl. S. 1; - E. DU Bols-Reynovd im Arehiv für Anatomie u. s. w. 1861. \$. $786 ;-$ Јон. Ranke ebendas, 1862 . \&. 241. 
viel weniger wirksam als die Oeffnungsschläge, mit anderen Worten, jene sind viel schwächer aber anhaltender als diese, diese viel stärker aber flüchtiger als jene. In dem Maasse ist dies der Fall, dass an den gewöhnliehen Magnetelektromotoren bei subjectiver Prüfung zwisehen metallenen Handhahen der Sehliessungsschlag unter denselben Umständen kaum verspürt wird, wo bereits der Oeffnungsschlag kaum erträglich ist; und dass beim Versuch am stromprüfenden Schenkel die Zuckung durch den Schliessungsschlag erst bei einem Rollenabstand ron etwa $20^{\mathrm{cm}}$ auftritt, während der Oeffnungsschlag nicht selten noch über den grössten Abstand hinans Zuekung bewirkt, den das Geleise den beiden Rollen zu ertheilen erlanbt.

Hr. Jos. Henny (damals in Princeton, New-Jersey, später in Washington) hat den Grumd dieses Verhaltens sehr früh darin erkamnt, dass sich beim Sehliessen in der Hauptrolle der Extrastrom in entgegengesetzter Richtung des Kettenstromes bildet und das Entstehen dieses letzteren rerzögert, während beim Oeffnen dem entsprechenden Extrastrom der Weg abgeschnitten ist. ${ }^{1}$

[374] Der Unterschied zwischen dem Schliessungs- und dem Oeffnungsschlage wird daher um so kleiner, ans je weniger Windungen und je lockerer die Hauptrolle gewickelt ist, da mit der Zahl und Nähe ihrer Windungen die elektromotorisehe Kraft des Extrastromes wächst; und ieh muss es einen besonderen Glücksfall nemen, wodureh mir manehe Sehwierigkeit und vielleieht manche Täusehung erspart worden ist, dass ich der Hauptrolle der Induetionsvorrichtımg, die ieh mir im Beginn meiner Untersuchungen bante, auf etwa einen Fuss Länge nur einige dreissig Windungen gab. ${ }^{2}$ Inzwisehen würde sogar noch in einem gerade ausgespamnten Drahte dureh Indnetion der prismatischen Fäden, in die man sich den Draht zerlegt denken kamn, auf einander, ein Extrastrom entstehen, während die Induction auf einen benachbarten Draht dabei

1 Transactions of the American Philosophical Society held at Philadelphia etc. New Series. $4^{0}$. t. VIII. 1843. p. 7. \&. §. 19. (1840); - The Philosophical Magazine ete. New and united Ser. ete. 1841. vol. XVIII. p. 488; - PoggenDORFF's Annalen u. s. w. 1841. Bd. LIV. S. 87.

2 Vergl. Untersuchungen über thierische Elektricität. Bd. I. S. 44i; Bd. II. S. 405. 406; - E. DU Bors-Rexmond, Ueber das angebliche Fehlen der unipolaren Zuckung beim Schliessungsinductionsschlage. Im Archiv für Anatomie u. s. w. 1860. S. 857. - S. 858. Z. 11 and 12 von unten muss es hier beilänfig statt: „die jenem Potential nmgekehrt proportionale Steilheit der Curve, in der das Potential u. s. w." heissen: "die mit dem Wachsen jenes Potentials abnehmende Steilheit der Curve, in der die elektromagnetische Resultante u. s. w." 
schwerlich noch stark genng bliebe, um die grossen Widerstände, die in den elektrophysiologischen Versuchen vorkommen, erfolgreich zu überwinden.

Eine andere Art, den Anfangsextrastrom zu rerkürzen, ist auch schon von Hrn. HeNRY in's Werk gesetzt worden. Sie besteht darin, den Widerstand zu erhöhen, den der Anfangsextrastrom zwischen den Enden der Hauptrolle antrifft, und so diesen Strom bis zur Unmerklichkeit zu schwächen. Soll dabei noch die Induction in der Nebenrolle merklich bleiben, so muss der Widerstand dadurch erhöht werden, dass man, statt einer einfachen Kette, eine rielgliedrige Sänle als Stromquell anwendet. Dabei wird, nach Hrn. Hexry's Ter- [375] suchen, der Schliessungsschlag dem Oeffinmmgsschlage nicht bloss gleich, sondern sogar überlegen. ${ }^{1}$ Der letztere Umstand erklärt sich aus den Beobachtungen der Hrm. Eduund ${ }^{2}$ und RrJke, ${ }^{3}$ wonach die Sehliessungsinduction auch bei den sogenamnten beständigen Ketten die Oeffnumgsinduction übertrifft. Wie man sieht, war Hr. Hexrs bereits auf dem Wege subjectirphysiologischer Prüfung zu demselben Ergebuiss gelangt, welches neuerdings Hr. BEeTz ${ }^{4}$ aus der Beobachtung des Hrn. Hrpp gefolgert hat, wonach die Kraft von Elektromagneten bei gleicher Stärke des magnetisirenden Stromes rascher ansteigt, wemn dieser von einer Sänle, als wemn er von einer Kette stammt.

Anstatt den Anfangsnebenstrum auf diese Weise zu rerkürzen, kamn man num aber auch den Cnterschied zwischen beiden Strömen dadurch verringern, dass man den Endnebenstrom rerzögert. Schon Hr. Hexry hatte gezeigt, dass wemn man dem Hauptstrom statt durch Oeffnen der Tíette, durch Schliessen einer Nebenleitung zur Rolle ein Ende macht, der entsprechende Schlag von der Nebenrolle ans ebenso unmerklich werde, wie der durch das Schliessen der Kette oder durch das Oeffnen der Nebenleitumg erlangte. ${ }^{5}$ Alsdamn nämlich kann sich der in der Hanptrolle durch das Verschwinden des Stromes inducirte Strom durch die Tebenleitung ergiessen, was ebenso die allmähliche Abnahme des Stromes in der Hauptrolle zur Folge hat, wie der Anfangsextrastrom das allmähliche Ansteigen des Stromes.

1 Transactions etc. l. c. p. 4. §. 8. 9; - The Philosophical Mlagazine ete. 1. c. p. 484. 485 ; - PoggendorfF's Annalen u. s. w. A. a. O. S. 85.

2 Poggendorfy's Annalen u. s. w. 1849. Bd. LXXVII. S. 182.

3 Poggendorff's Annalen u. s. w. 1857 . Bd. CII. S. 50 s.

4 Poggendorff's Annalen u. s. w. 1857. Bd. CII. S. 557.

5 Transactions ete. l. c. p. 7. §. 18; - The Philosophical Magazine etc. 1. c. p. 487. 488; - Poggendorff's Annalen u. s. w. A. a. O. S. Si. 
Diese Erfahrung hat nenerdings $\mathrm{Hr}$. HeLnholtz bemitzt, um den zeitlichen Verlauf der beiden Schläge des Magnetelektromotors mehr gleichmässig zn machen. Dazn lässt er den [376] Anker, indem dieser rom Elektromagnet angezogen wird, nicht die Kette öffnen, was die ursprüngliche WAGNER'sche Einrichtumg ist, sondern eine Nebenleitung schliessen, die den Strom der Kette in den Windungen des Elektromagnetes und der Hauptrolle schwächt.

Fig. 14 .

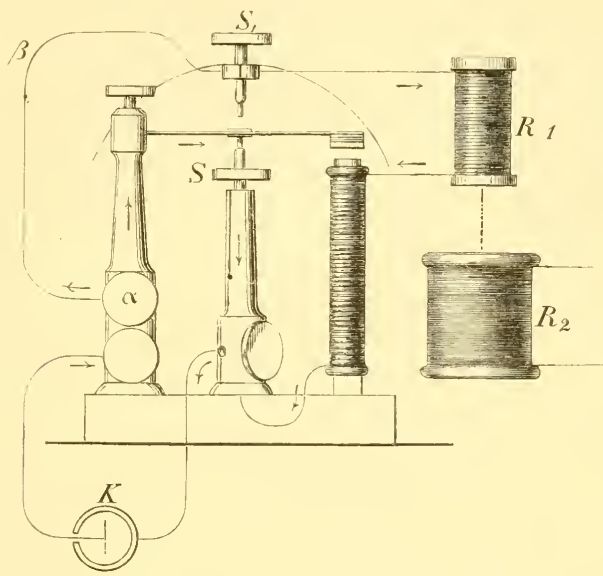

Obige Figur zeigt halb schematisch die nene Einrichtung, wie sie in der Werkstatt der Hrn. SiEmens und Hasske an den SchlittenMagnetelektromotoren fortan stets angebracht wird, auch leicht nachträglich an älteren Exemplaren anzubringen ist. $K$ ist die Kette, $R_{1}$ die Haupt-, $R_{2}$ die Nebenrolle. Die Nebenleitung wird gebildet rurch die Messingsäule, welche die Feder trägt, und nur an ihrem Fuss mit einer zweiten Klemmschranbe $\boldsymbol{c}$ versehen wird, den Theil der Feder bis zu einem ihrer unteren Fläche angelötheten Platimplättchen, das dem schon immer an ihrer wberen Fläche befindlichen entspricht, [377] und eine nene Säule, die gerade mnterhalb des Plättchens dort sich erheht, wo sonst nur die Klemmschrauhe für den Zinkpol der Kette sich befand. Die letztere Säule trägt eine oberhalh in einen Platinstift ausgehende Schranbe $S$ empor, und die Nebenleitung wird geschlossen, indem beim Anziehen des Ankers das mntere Plättchen an der Feder jenem stift begegnet, wie früher die Kette dadurch, dass das obere Plättchen beim 
Zurückschnellen des Ankers den stift an der Schraube $S_{1}$ traf. Das Spiel der Feder geht dabei so gut ron statten, wie sonst, nur etwas langsamer, wegen der, mit deń Strom, jetzt allmählich sinkenden Kraft des Elektromagnetes. Auch ist die Bedingung dafür, dass der Magnetelektromotor bein Schliessen der Kette in Gang komme, ohne dass man die Feder in Schwingung rersetzt, jetzt die umgekehrte ron vorhin, d. h. die Feder darf in der Ruhe dem Stift nicht anliegen, wie es die Figur zeigt, wenn der Anker beim Schliessen des die Kette enthaltenden Umganges angezogen werden soll, da alsdann der Strom rom Elektromagnet abgeblendet ist und die Anziehung des Ankers nur die Feder dem Stift stärker andrückt.

Die nene Einrichtung gewährt bedeutende Vortheile. Erstens sind die beiden Ströme einander in ihrem Verlaufe wirklich sehr nahe gebracht. Der Unterschied der Rollenabstände, bei denen Oeffinen und Schliessen der Nebenleitung Zuckung eines stromprüfenden Froschschenkels bewirkt. dessen Nerr die Nebenrolle schliesst, beträgt nur noch wenige Centimeter. Da es der Endnebenstrom ist, der sich in seinem Verlaufe dem Anfangsstrome genähert hat, so ist die physiologische Wirkung der Induction im Ganzen freilich sehr geschwächt. Beide Zuckungen, die durch den End- wie die durch den Anfangsstrom, erfolgen jetzt erst bei einem Rollenabstand ähnlich dem, wobei früher die letztere Zuckung auftrat, und bei subjectiver Prüfung erhält man gar keinen Schlag mehr bei einem Rollenabstande, wo man bei der älteren Einrichtung sehr ansehnliche Wirkung rom Oeffunngsstrom rerspürte. Immerhin reicht die Stromstärke für die grosse Nehrzahl der elehtrophysiologischen Versuche aus, und sollte dies ausnahmsweise nicht der Fall sein, so bleibt es unbenommen, in jedem Augenblick zur älteren Einrichtung dadurch zurückzukehren, dass man die Verbindung $\alpha_{\beta} \beta S_{1}$ [378] abbricht, und die beiden Schrauben $S$ und $S_{1}$ senlit, um die ubere in den Bereich der Schwingungen der Feder zu bringen, die untere aus diesem Bereich zu entfernen.

Zweitens wird bei der netuen Einrichtung der Funke zwischen Stift und Platte auf den Trennungsfunken einer einfachen Kette beschränkt. ${ }^{1}$ So wird nicht allein die mit der Funkenbildung rerbundene Ahnutzung der Berührungsstelle, sondern auch die Lngleichmässigkeit im Verlauf der

1 Der Funke wird, freilich auf hosten der Stromstärke in der Hauptrolle, ganz vermieden, wenn man zur Hauptrolle eine zweite dauernd geschlossene Nebenleitung von passendem Widerstand anbringt. Vergl. Wundt im Archiv für Anatomie u. s. w. 1s59. S. 53४. - [Heцмноцтz, Die Lehre von den Tonempfindungen. S. 583.] 
Ströme vermindert, welche daher rührt, dass sich dort, unter dem Einfluss des Funkens, die Gestalt der Metalle stets verändert. Während daher somst, wenn bei spielender Feder die Nebenrolle allmählich der Hauptrolle genähert wude, zuerst einzelne Zuckungen auftraten, welche ron besonders raschen Oeffnungen der Kette herrührten, erhält man jetzt, sobald überhaupt Wirkung stattfindet, einen rergleichsweise stetigen Tetanus, so dass man in günstigen Fällen förmlich unter dem Maximum tetanisiren kamn.

Endlich drittens ist die Gefahr, durch unipolare Wirkungen getäuscht zu werden, bei der Hewmнotz'schen Eimrichtung des Magnetelektromotors sehr vermindert, ja unter den gewöhnlichen Umständen. wie sich aus Hru. Pfü̈gen's Versuchen ergiebt, ${ }^{1}$ als ganz beseitigt anzusehen.

[Beachtung rerdient, dass bei dieser Eimrichtung die Fermwirkung der Hauptrolle sehr viel grösser ist als bei der ursprünglichen. Dies ist die nothwendige Folge davon, dass bei der ursprünglichen Eimrichtung das Verhältniss der Zeit, während welcher die Kette geschlossen ist, zu der, während welcher sie offen steht, ein sehr kleines ist, während bei der neuen Einrichtung, bei als gleich voransgesetztem Spiele der Feder. das Terhältniss der Zeit, während welcher die Tebenschliessung den Strom in der Hauptrolle schwächt, zu der, während welcher diese Schwächung nicht stattfindet, ein eben so kleines ist.]

\section{§. II. Bezeichnung der hier noch zu lösenden Aufgabe.}

Beim Anstellen des obigen Versuches über den verschiedenen Rollenabstand, wobei jetzt die Zuckungen auftreten, zeigt sich, dass der Endnebenstrom nicht allein seine Ueberlegenheit in physiologischem Bezuge eingebüsst hat, sondern dass er sogar der minder wirksame, also der ron langsamerem Terlauf, geworden ist. [Beim Tetanisiren eines Nerven überwiegt jetzt die Reihe elektrotonischer Stromzuwachse, welche von den Endströmen herrührt, weil diese die längeren und schwächeren werden.] Da so der Endnebenstrom gleichsam über das Ziel hinaus rerzögert erscheint, entsteht die Frage, ob sich nicht Umstände herstellen lassen, unter denen seine Terzögerung [379] auf dem richtigen Punkte stehen bleibe, und beide ströme ganz gleichen Verlauf nehmen?

Hr. Wund, dem wir die eimzigen bis jetzt über die neue Gestalt des Magnetelektromotors veröffentlichten Nachrichten rerdanken, hat denn auch bereits die Behauptung aufgestellt, dass der inducirende Strom dann

1 Vergl. Arehiv für Anatomie u. s. w. $1 \varangle 60$. S. 857 . 
mit vollkommen derselben Geschwindigkeit falle, mit der er ansteige, folglich auch der Verlauf der beiden Nebenströme vollkommen der nämliche werde, wem der Widerstand der Nehenleitung gegen den der Rolle und den der Kette verschwinde. ${ }^{1}$ Dies wäre eine Thatsache von erheblichem Belang. Eine Reihe der wichtigsten Versuche, die ich oben bereits andeutete, würde dadurch ausnehmend erleichtert und rereinfacht, da es nicht die mindeste Schwierigkeit hätte, die von Hrn. Wund angegebene Bedingung zu rerwirklichen. Hr. Wundt hat indess für seine Behauptung keinen Beweis mitgetheilt, und eine etwas genauere Prüfung lehrt, dass sie nicht richtig ist. Die Bedingung dafür, dass die Induction zu Anfang und zu Ende gleichen Verlauf nehme, oder für die Congruenz der diesen Verlaut darstellenden Curven, ist eine andere, und zwar schwieriger zu erfüllende, als die von Hrn. Wundt bezeichnete.

Den zeitlichen Verlauf von Inductionsströmen zu bestimmen, ist mit Hülfe der von Hrn. Helmholtz aufgestellten und durch den Versuch bewährten Grundsätze ${ }^{2}$ im Allgemeinen leicht thunlich, nur dass man dabei sogar in sehr einfachen Fällen bereits auf ummässig rerwickelte Ausdrücke geführt wird. Zwar wenn wir uns bloss an die Ermittelung jener Bedingung halten wollten, kömnten wir die Aufgabe sehr vereinfachen dadurch, dass wir nur die Induction in der Hauptrolle betrachteten, ohne Rücksicht auf die Gegenwart einer Nebenrolle. Demn es ist deutlich, dass im Fall der Congruenz die Induction der Nebenrolle auf sich selber und deren Rückwirkung auf den Inducenten keimen Unterschied im Verlauf der Ströme herbeiführen können, weil sie nämlich selher gleich verlaufen. Inzwischen schien es mir wünschenswerth, das Problem etwas allgemeiner zu behandeln, um zugleich zu einer klaren Vorstel- [380] lung rom zeitlichen Verlauf der in einer Nebenrolle, wie anch der in der Hauptrolle bei Gegenwart einer Nebemrolle inducirten Ströme zu gelangen. Hr. Hewnнoutz hat wohl bereits ganz allgemein die Aufgabe gelöst, den Verlauf der Induction in einer beliehig verzweigten Leitung anzugeben, worin sich beliebig vertheilt constante elektromotorische Kíräte und auf sich selber wie aufeinander einwirkende Rollen befinden. ${ }^{3}$ Dieser Fall lässt sich auf den unsrigen zurückführen, wenn man sich die Nebenrolle so in eine Zweigleitung eingeschaltet denkt, dass sie ron keinem merklichen Antheil des Kettenstromes durchflossen wird, am einfachsten, wenn man sie als eine am inducirenden Kreise zwischen Kette und Hauptrolle angehrachte Zweigleitung ansieht,

1 A. a. O. und S. 550 .

2 Poggendorff's Annalen u. s. w. 1851. Bd. LXXXIII. S. 505.

3 A. a. O. S. $511-514$. 
und den Widerstand der zwischen ihren Enden begriffenen Strecke $=0$ setzt. Indessen hat bisher weder der Schöpfer jener Theorie, noch meines Wissens sonst jemand, eine solche Anwendung daron veröffentlicht. Unsere Kenntniss des Verlaufes der Inductionsströme in Nebenrollen beschränkt sich zur Zeit noch anf einige ron Hrn. BEETz ausgeführte Messungen, ${ }^{1}$ und auf die ron Hrn. Hzimholtz, ausserhalb seiner allgemeinen Formel, für den Nebenstrom durch Oeffnen der Kette gegebene Bestimmung. ${ }^{2}$ Ich glaube deshalb, dass die folgende Auseinandersetzmng nicht als ganz überflüssig erscheinen werde. Ich habe dabei der angedeuteten Herleitung ans der allgemeinen Formel die selbständige Aufstellung der Gleichungen vorgezogen, indem so eine für uns zwecklose Verwickelung vermieden wird.

Wir betrachten zuerst nur einen inducirenden Kreis, in dem sich eine Kette, dem gegenüber sich ein indueirter Kreis befindet, und durch dessen Schliessung und Oeffnung die Induction geschieht. Es sei

$A$ die elektromotorische Kraft der Kette;

$w$ der Widerstand des inducirenden Kreises (der Hauptrolle und der Kette zusammengenommen);

$w_{0}$ der Widerstand des inducirten Tŕreises (der Nebenrolle [381] und etwa zwischen deren Enden begriffener Leiter zusammengenommen);

$P$ das Potential der Hauptrolle auf sich selber;

II das Potential der Nebenrolle auf sich selber; endlich

$Q$ das Potential der beiden Rollen aufeinander.

Die Potentiale denke man sich überall noch mit der Indnctionsconstanten (Hrn. Neumans's $\varepsilon$ ) multiplicirt, oder, was für uns anf Eins herauskommt, die Widerstände in einer solchen Einheit ansgedrückt, dass die Inductionsconstante $=1$ wird. $^{3}$ Die Inductionskräfte der ausserhalb der Rollen gelegenen Kíettentheile werden vernachlässigt.

Femer wollen wir mit $I$ die Stärke des von der Zeit mabhängig gewordenen inducirenden Stromes, mit $I_{a}, I_{e}$ diese Stärke als Function der Zeit bezeichnen, je nachdem es sich um Anfang oder Ende oder um Steigen oder Fallen des Stromes handelt, gleichviel ob das Steigen oder Fallen die Folge sei des Schliessens oder Oeffnens des Krreises, wie in dem zunächst, oder des Oeffnens oder Schliessens einer Nebenleitung, wie in dem später zu zergliedernden Falle. Ebenso soll $i_{a}, i_{e}$ die Stärke des in der Nebenrolle inducirten Stromes als Function der Zeit bezeichnen,

1 Poggendorff's Annalen u. s. w. 1858. Bd. CV. S. 514.

2 A. a. (). S. 536. 537.

3 Vergl. Kirchhoff in Poggendorfa's Annalen u. s. w. 1849. Bd. LXXVI. S. 426; - Helmholtz ebendas. 1851. Bd. LXXXIII. \$. 508 . 
je nachdem es sich um einen durch Anfang oder Ende, oder durch das Steigen oder Fallen des Hauptstromes inducirten Strom handelt, gleichviel natürlich wiederum wie die inducirende Stromschwankung herbeigeführt wurde; und in derselben Weise wollen wir die entsprechenden Hülfsgrössen, deren wir bedürfen werden, in jenen beiden Zeitabschnitten von einander unterscheiden.

Die Dauer des Schliessens und Oeffinens der Kette setzen wir stets $=0$, d. h. wir nehmen keine Rücksicht darauf, dass in Wirklichkeit, anch ohne dass die Induction sich einmischt, der Strom nicht in einem untheilbaren Augenblick von Null bis zu der ihm durch die Онм'sche Formel vorgeschriebenen Stärke anwächst, oder von dieser Höhe zu Null herabfällt, sondern dass, ganz abgesehen von Verzögerungen, welche im Wesen des elektrischen Vorganges liegen, unstreitig ein allmähliches Ab- [382] nehmen oder Wachsen des Widerstandes der Berührungsstelle die Natur eines solchen Sprunges überhebt.

Fig. 15.

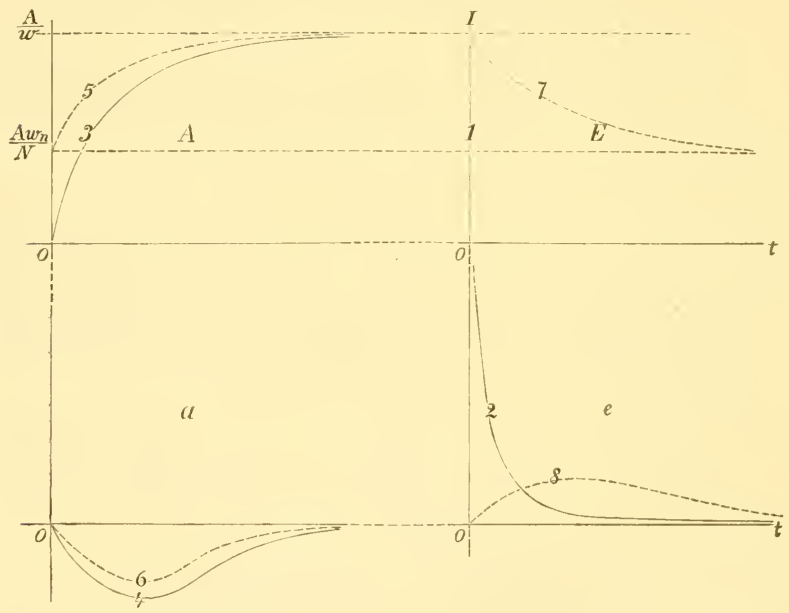

Fig. 15 ist bestimmt, die Verhältnisse, die sich uns im Folgenden darbieten werden, zu versinnlichen. Sie zeigt in ihren beiden oberen Abtheilungen $A$ und $E$ den Verlauf des Hauptstromes zu Anfang und Ende des Stromes, in ihren beiden unteren Abtheilungen $a$ und e den des Nebenstromes in denselben Zeitabsehnitten. Die den einzelnen Curren beigesetzten Zahlen entsprechen den arabischen Orinungszahlen der da- 
durch vorgestellten Gleichmngen. Die ausgezogenen Curven beziehen sich auf den Fall der Schliessung und Oeffnung der Kette, die gestrichelten auf den der Oeffnung und Schliessung der Nebenleitung.

\section{§. III. Induction in der Nebenrolle durch Oeffuen des inducirenden Kreises.}

Was sich bei Oeffunng des inducirenden hreises zutrage, ist, wie bemerkt, schon von Hrm. Hecsholtz selber [383] aus den von ihm anfgestellten Grundsätzen abgeleitet worden. Wir nehmen an, dass der inducirende Strom in der Ordinate $0 I=\frac{A}{w}$, die in Fig. $15 E$ mit 1 bezeichnet ist, zu Null herabfalle. Der indneirte Strom, soferm er die Oeffnung der Kiette überdanert, rührt nur ron secundärer Induction her, die die Nebenrolle auf sich selher ausübt; und da der Kettenkreis geöffnet ist, bleibt die Rückwirkung des inducirten Leiters auf den inducirenden ohne Einfluss anf den Vorgang, soweit wir ihn betrachten. Man hat

$$
i_{e}=-\frac{I I}{w_{o}} \cdot \frac{d i_{e}}{d t} \text {. }
$$

Das Integral ist

$$
i_{e}=C \cdot e^{-\frac{v_{o}}{11} t},
$$

wo $e$ die Basis der natürlichen Logarithmen und $C$ die Integrationsconstante bedenten. Letztere bestimmt sich, wenn man erwägt, dass

$$
\int_{0}^{\infty} i_{e} \cdot d t=\frac{Q I}{w_{o}}
$$

sein solle, zu

$$
C=\frac{A Q}{u l l}
$$

Folglich ist

$$
i_{e}=\frac{A Q}{w \|} \cdot e e^{-\frac{w_{o}}{\Pi} t .}
$$

Der Endnebenstrom heht plötzlich an mit dem endlichen Werthe

$$
\begin{aligned}
& A Q \\
& w \|
\end{aligned},
$$

der, unabhängig rom Widerstande des inducirten Kreises und rom 
Potential der Hauptrolle auf sich selber, nach Umständen kleiner, oder, wie es in der Figur dargestellt ist, grösser ausfällt als die beständige Stärke $I$ des Hauptstromes. Von diesem Anfangswerthe sinkt alsdamn der Endstrom um so lang- [384] samer herab, je kleiner der Widerstand des inducirten Kreises und je grösser das Potential der Nebenrolle auf sich selber, um sich zuletzt asymptotisch der Zeit anzuschliessen. (Curve 2).

§. T. Induction durch Schliessen des inducirenden Kreises.

Beim Schliessen des inducirenden Kreises gestaltet sich die Sache verwickelter. Der Vorgang im inducirenden Kreise setzt sich nämlich jetzt zusammen aus dem Strom der Kette, der Induction der Hauptrolle auf sich selber und der Rückwirkung der Nebenrolle auf die Hauptrolle, oder

$$
I_{a} w=A-P \cdot \frac{d I_{a}}{d t}=Q \cdot \frac{d i_{a}}{d t} .
$$

Der Vorgang im indueirten Kreise setzt sich ebenso zusammen ans der Induction der Hauptrolle auf die Nebenrolle und ans der der letzteren Rolle auf sich selber, oder

$$
i_{a} v_{a}=-Q \cdot \frac{d I_{a}}{d t}-\Pi \cdot \frac{d i_{a}}{d t} .
$$

Han hat also zwei simultane Differentialgleichungen, welche nach gangbaren Regeln behandelt, zuerst die Form annehmen:

$$
\begin{aligned}
& \frac{d I_{a}}{d t}-R_{a} I_{a}+S i_{a}=-T_{a} \\
& \frac{d i_{a}}{d t}+U_{a} I_{a}-V i_{a}=H H_{a}^{r},
\end{aligned}
$$

wo $R_{a}, S, T_{a}, U_{a}, V, W_{a}$, wenn wir $Q^{2}-P \Pi=\Delta$ setzen, constante Coëfficienten von folgender Bedeutung sind:

$$
\begin{aligned}
& R_{a}+\frac{w \Pi}{\Delta}, U_{a}=\frac{w Q}{\lrcorner} \\
& S=\frac{w_{\sigma} Q}{\lrcorner}, V=\frac{w_{\sigma} P}{\Delta} \\
& T_{a}=\frac{A \Pi}{\lrcorner}, H_{a}=\frac{A Q}{\lrcorner} .
\end{aligned}
$$

Nennen wir weiter von den beiden Wurzeln der Gleichung

$$
\Phi_{a}^{2} U_{a}+\Phi_{a}\left(V-R_{a}\right)=S,
$$

[385] nämlich

$$
\Phi_{a}=-\frac{w_{\sigma} P-w \Pi}{2 w Q} \pm \sqrt{w_{\sigma}+\left(\frac{w_{\sigma} P-w \|}{2 w Q}\right)^{2}},
$$


die mit positiver Wurzelgrösse $\varrho_{a} \Phi_{\alpha_{1}}$, die mit negativer $\Phi_{a_{2}}$, und setzen wir

$$
\begin{aligned}
& \Phi_{a_{1}} U_{a}-R_{a}=\frac{w_{\sigma} P+w \Pi-2 w Q \varrho_{a}}{2\left(P \|-Q^{2}\right)}=\Theta_{a_{1}}, \\
& \Phi_{a_{2}} L_{a}-R_{a}=\frac{w_{\sigma} P+w I I+2 w Q \varrho_{a}}{2\left(P \|-Q^{2}\right)}=\Theta_{a_{2}},
\end{aligned}
$$

so erhalten wir das allgemeine vollständige Integral der obigen Differentialgleichungen in folgender Gestalt:

$$
\left.\begin{array}{l}
I_{a}-\frac{\Phi_{a_{1}}}{2 \rho_{a}}\left\{\frac{A}{w}-C_{2} \cdot e^{-\Theta_{a_{2}} t}\right\} \\
i_{a}=\frac{1}{2 \varphi_{a}}\left\{-\frac{\Phi_{a_{2}}}{2 \varphi_{a}} \mid \frac{A}{w}-C_{1} \cdot e^{-\Theta_{a_{1}} t}\right\} \\
C_{2} \cdot e^{-\Theta_{a_{2}} t}-\Theta_{a_{1}} t
\end{array}\right\},
$$

wo $e$ wiederum die Basis der natürlichen Logarithmen und $C_{1}, C_{2}$ die beiden Integrationsconstanten vorstellen. Zur Bestimmung der letzteren dienen die Beziehungen

$$
\begin{gathered}
I_{a}=0 \text { für } t=0 \\
\int_{0}^{\infty} i_{a} \cdot d t=-\frac{Q I}{w_{\sigma}} .
\end{gathered}
$$

Man findet $C_{1}=C_{2}=\frac{A}{w}$, und sehliesslich

$$
\begin{aligned}
& I_{a}=\frac{A}{2 w \varrho_{a}}\left\{2 \omega_{a}+\Phi_{a_{2}} \cdot e^{-\Theta_{a_{1}} t}-\Phi_{a_{1}} \cdot e\right. \\
& i_{a}=-\frac{A}{2 w_{a}}\left\{e^{-\Theta_{a_{1}} t-\Theta_{a_{2}} t}\right\}
\end{aligned}
$$

Die Ordinate des Anfangsnebenstromes ist, wie man sieht, der negatir zu nehmende Unterschied der Ordinaten zweier Expo- [386] nentialcurven von gleichem Anfangswerthe, aber verschiedener Steilheit. Da $\Theta_{a_{1}}<\Theta_{a_{2}}$, ist dieser Unterschied positiv; der Anfangsnebenstrom hat die entgegengesetzte Richtung ron der les Hauptstromes und des Endnebenstromes. Die Form der resultirenden Curve (4, Fig. 15. a) stimmt im Allgemeinen mit den oben S. 235 erwähnten Messungen des Hrm. BeEtz; ein genauerer Vergleich ist natürlich nicht ausführbar. Für $t=0$ ist $i_{a}=0$, und

$$
\text { - } Q \cdot \frac{d I_{\alpha}}{d t}=-\Pi \cdot \frac{d i_{\alpha}}{d t}
$$


die Induction dureh den entstehenden Nebenstrum hebt in dem inducirten Kreise die durch den entstehenden Hauptstrom im ersten Augenblicke gerade auf. Für $t=\infty$ schliesst sich die Curve der Abscissenaxe an. Dazwischen liegt ein Maximum. Setzt man in dem zweiten Differentialquotienten ron $i_{a}$ nach $t t=0$, so erhält man einen positiven Werth; die Curve ist am Nullpunkt conear gegen die Abseissenaxe. Aus ihrem allmählichen Aufsteigen zu einem in endlicher Entfernung vom Nullpumkte gelegenen Maximum im Gegensatz zum plötzlichen Auftreten des Endnebenstromes in endlicher Grösse auf dem Nullpunkt selber erklärt sich die grössere physiologische Wirkung des letzteren.

Setzt man $t=0$ in dem ersten Differentialquotienten ron $i_{a}$ nach $t$, so erhält man

$$
-\frac{A Q}{P \Pi-Q^{2}} .
$$

Dieser Werth, die Anfangssteilheit der Curve, ist absolut genommen um so grösser, je kleiner $P$, das Potential der Hauptrolle auf sich selber. Unter der Voraussetzung, dass bei grösserer Anfangssteilheit das Maximum früher eintrete, ist dies ein analytischer Ausdruck für die Thatsache, dass der Schliessmngs- und Oeffnungsschlag sich um so weniger ron einander unterscheiden, je weniger Windungen die Hauptrolle hat, und je lockerer gewickelt sie ist.

Die ron Hm. Hexny beobachtete Annäherung des Schliessungsschlages an den Oeffnungsschlag durch Vergrössermg ron $w$ (s. when S. 230) erklärt sich dadurch, dass alsclann, für $t=0$, die ne- [387] gative Exponentialgrösse in der Klammer sich der Null, die positive der Einheit, der Coëfficient vor der Klammer aber dem Anfangswerthe des Oeffnungsstromes, $\frac{A Q}{w l l}$, nähert. Man sieht übrigens, dass sich diese Art, die physiologische Wirkung der beiden Schläge einander mehr gleich zn machen, für unsere Zwecke nicht eignet.

In Bezug auf die Abhängigkeit ron Q. welches am Magnetelektromotor durch das Verschieben des Schlittens geändert wird. ist hervorzuheben, dass es nicht als ein blosser Factor in den Ausdruck für $i_{a}$ eingeht, wie in den für $i_{e}$ (Gleichung 2), sondern auf eine viel rerwickeltere Weise. Man schwïht also nicht allein den Anfangsnebenstrom, indem man die Nebenrolle von der Hauptrolle entfernt, sondern man verändert zugleich dessen Verlauf in der Art, dass das Maximum sich rerschiebt; nach welchem Gesetze, werden wir an einem einfacheren Beispiel sehen.

Was den Verlanf des Hauptstromes betrifit, so steigt die ihn vorstellende Curre (Fig. 15. A. Curve 3), nach Aussage ihres zwreiten Differentialquotienten nach $t$ für $t=0$, stets sufort concar gegen die 
Abseissen an, um sich asymptotisch der beständigen Stärke anzuschliessen, die dem Strom unabhängig von der Induction zukommt. Ganz wie in dem einfachen, ron Hrn. Hewshoutz betrachteten Falle des Anfangsextrastromes bei Abwesenheit einer Nebenrolle, ${ }^{1}$ geschieht dies, indem sich ron einem ron der Zeit mabhängigen Gliede, welches jene beständige Stärke darstellt, eine ursprünglich ihm gleiche, mit der Zeit asymptotisch schwindende Grösse abzieht, welche die Induction misst. Während aber in jenem Falle diese Grösse die Ordinate einer einzigen Exponentialcurve ist, haben wir es hier mit der Summe zweier solcher Ordinaten zu thm. Die Exponenten dieser beiden Glieder sind die nämlichen, die in dem Ansdruck für $i_{a}$ rorkommen, allein die beiden Glieder erhalten hier im Allgemeinen rerschiedene Anfangswerthe, indem das negative Glied mit $\Phi_{a_{1}}$, das positive mit $\Phi_{a_{2}}$ multiplicirt ist. Da $\Phi_{a_{1}}$ unter allen Umständen einen positiven, $\Phi_{a_{2}}$ dagegen [388] einen negativen Werth hat, so sind beide Glieder negativ, und ron dem beständigen Gliede alzuziehen. Nan hat übrigens

$$
\int_{0}^{\infty}\left(I_{a}-\frac{A}{w}\right) d t=-\frac{A P}{w^{2}} .
$$

Der Nemner $P$ II $\left.-Q^{2}=-\right\lrcorner$, der in unseren Formeln eine grosse Rolle spielt, verdient eine besondere Berücksichtigung. Für $\Delta=0$ würde für jeden endlichen Werth von $t$ die Ordinate des Anfangsnebenstromes $=0$, und für $t=0$ unbestimmbar, da zwischen $\Delta$ und $t$ keine Beziehung obwaltet. ${ }^{2}$ Für $P \Gamma<Q^{2}$ würde die Klammer negativ, also $i_{a}$ positiv, was auch keinen Simn bietet. Aehnliche Folgermngen ergeben sich für $I_{a}$. Allein schon das Nullwerden von $\Delta$ setzt, wemn man sich der Einfachheit halber beide Rollen als von genan gleicher Beschaffenheit, folglich $P=$ Il denkt, das Unmögliche roraus, dass die beiden Rollen denselben geometrischen Ort eimnehmen. Nur in dem Falle würde dies amähernd rerwirklicht, wo man sich die inducirenden Theile beider Kreise unter dem Bilde zweier congruent gekrümmten, einander überall fast bis zur Berührung genäherten linearen Leiter vorstellt, deren Querschnitt gegen die Dimensionen der ron den Leitern begrenzten Figur rerschwände. Aber völlig gleich, geschweige $>(P=I I)$ kömnte $Q$ selbst

1 A. a. O. S. 510. 511.

2 [Im Text ist übersehen, dass $\Delta=0$ oder $P I I=Q^{2}$ von vorn herein $\mathrm{zu}$ denselben analytischen Folgen führt, die am Schluss des Paragraphen, S. 244, als Folge von $P=\Pi=Q$ sich angegeben finden.] 
in diesem Falle nie werden. Inzwischen bliebe der Beweis zu führen übrig, dass allgemein $Q^{2}$ nie $=$, geschweige $>P I l$ werden kömne.

Kaum bemerkt zu werden braucht endlich, dass so wenig für den Haupt- wie für den Nebenstrom die beiden Exponentialcurren eine andere als eine analytische Bedeutung haben, und dass sie nicht etwa getrennt die beiden Inductionen rorstellen, die in jeder Rolle stattfinden.

Eine grosse Tereinfachung in den Ansdrücken wird dadurch herbeigeführt, dass man $v=w_{\sigma}, P=I I$ setzt, was rerwirklicht 'würde, wenn man zwei gleiche Rollen ron solchem Widerstande nähme, dass der Widerstand der Kette und der ansserwesentliche Widerstand im inducirten Kreise dagegen verschwänden. Alsdann wird $\varrho_{a}=1$. $\Phi_{a_{l}}=+1$, $\Phi_{a_{2}}=-1$, oder rielmehr man bedarf der Hülfsgrösse $\Phi_{a}$ gar nicht mehr, um die Trennung der Variablen zu bewirken. Indem man die beiden [389] Gleichungen (I) und (II) S. 238, in welchen $R_{a}=V$, $U_{a}=S$ wird, das eine Mal addirt, das andere Mal von einander abzieht. und beziehlich $I_{a}+i_{a}, I_{a}-i_{a}=$ einer neuen Variablen setzt, erhält man

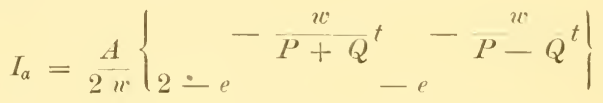

$$
\begin{aligned}
& i_{a}=-\frac{A}{2 w}\left\{\begin{array}{l}
-\frac{w}{P+} Q^{t}-\frac{w}{P-Q} t \\
e
\end{array}\right\}
\end{aligned}
$$

Hier lässt sich leicht zeigen, das mit wachsendem $P i_{\alpha}$ abmimmit, d. h. der Terlauf der Curre ein mehr gestreckter wird; und die Untersuchung des Ausdruckes

$$
t_{\text {max }}=\begin{aligned}
& P^{2}-Q^{2} \\
& 2 w Q
\end{aligned}
$$

welcher $i_{a}$ zu einem Maximum macht, als Function ron $Q$. lehrt, dass für $Q$ sehr nahe gleich $P, t_{\max }$ sehr nahe $=0$, dass mit sinkendem $Q$ das Maximum sich rom Nullpunkt entfernt, und, immer langsamer fortrückend, für $Q=0$ den Grenzwerth $\frac{P}{w}$ erreicht.

Fig. 16 zeigt, abermals in vier Abtheilungen $A, E, a$, e, was sich begiels, wenn man in den rereinfachten Ausdrücken auch noch den Unterschied $P-Q$ immer kleiner werlen lässt. Die gestrichelte Curre stellt in jedem Falle die erste, die punktinte die zweite der beiden Exponentialgrössen in der Kílammer vor. Aus der algebraisschen Summation der Ordinaten dieser beiden Curren, zu denen im Fall des Haupt- 
stromes noch die beständigen Ordinaten $I=\frac{A}{w}$ hinzutreten, entspringen die Ordinaten der ausgezogenen Curven des Stromverlaufes selber. Das Maximum der Curve des Anfangsnebenstromes ist, wie schon bemerkt, dicht an die Ordinatenaxe gerückt, und beträgt sehr nahe $-\frac{I}{2}$. Die Curve, in der der Hauptstrom ansteigt, hat ihrerseits [390] bei $+\frac{I}{2}$ einen stumpfen Knick, keine Discontinuität jedoch, dessen Entstehung aus der Figur deutlich wird. Die beiden Ströme heben also damit an, dass sie mit sehr grosser Steilheit in entgegengesetzter Richtung fast bis zur halben beständigen Stärke des Hauptstromes aufsteigen. Hier fährt zwar der Hauptstrom zu wachsen fort, nähert sich aber fortan viel lang-

Fig. 16.

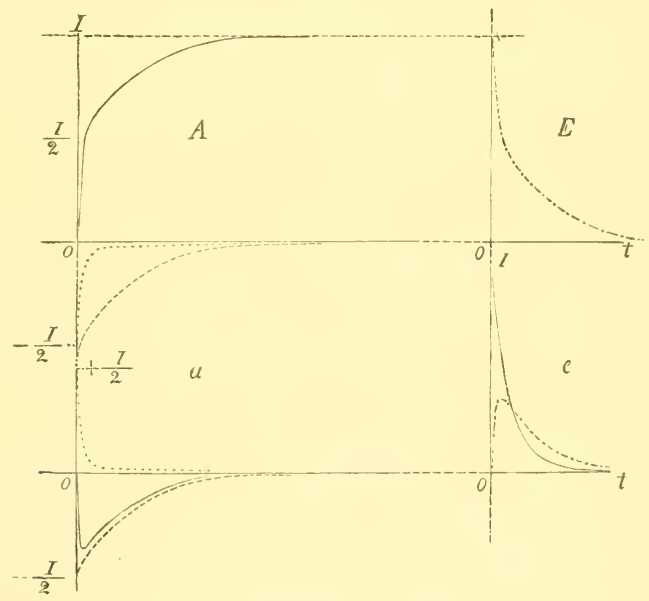

samer seiner Grenze; der Nebenstrom dagegen fällt von seinem Maximum herab. Unter den gleichen Umständen nähert sich der Anfangswerth des Endnebenstromes

$$
\frac{A Q}{w \Pi}
$$

dem Werthe $I$, also dem doppelten des Maximums des Anfangsnebenstromes, so dass in diesem einfacheren Falle der Grund der Ueberlegenheit des Oeffnungsschlages über den Schliessungsschlag klar einleuchtet. 
[391] Um diese durch ihre Einfachheit bemerkenswerthen Beziehumgen zu rerwirklichen, müsste man die beiden oben S. 241 beschriebenen Ringe, in und zwischen welchen die Induction stattfinden soll, einander sehr nahe bringen, und zugleich den Widerstand der übrigen Theile der beiden Kreise gegen den der Ringe rerschwinden lassen. Dies scheint leicht aufführbar, indem man eine Rolle aus zwei dümnen und hinreichend langen Drähten wickelt, etwa wie das Gewinde eines Nervenmultiplicators, und den einen Draht als inducirenden, den anderen als inducirten benutzt.

Setzt man $Q=P=\Pi$, so wird wenigstens die zweite Exponentialgrösse wiederum auf den Nullpunkt unbestimmbar, und die beiden simultanen Differentialgleichumgen kamn man auf eine solche Gleichung und eine Gleichung zwischen den Functionen selber zurücliführen, woraus sich nicht mehr zwei getrennte Gleichungen zwischen den Tariablen und der Zeit mit zwei willkürlichen Constanten herleiten lassen.

\section{§. V. Induction lurch Oeffuen einer Nebenleitung zur Hauptrolle.}

Wir gehen num zur Behandlung des Falles üher, der uns hier eigentlich interessirt, desjenigen nämlich, wo statt durch Schliessen und Oeffnen des inducirenden Kreises, die positiven und negativen Schwankungen in der Hauptrolle dureh Oeffnen und Schliessen einer Nebenleitung bewirkt werden. Wir haben am inducirenden Kreise fortan die Wirlerstände dreier Leitungen zu unterscheiden,

den der Kiette, welcher $u_{k}$,

den der Nebenleitung, welcher $w_{n}$, und

den des Zweiges, der die Hauptrolle enthält, welcher $u_{s}$

heissen soll. Die KínchноF'sche Combination ${ }^{1}$ dieser Widerstände, $w_{k} w_{n}+w_{n} w_{s}+w_{k} w_{s}$, heisse $N$, $\Xi$ aber eine andere häufig auftretende Combination derselben Grössen, nämlich der Unterschied

$$
\frac{1}{w_{k}+w_{s}}-\frac{w_{n}}{N}
$$

[392] der, mit A multiplicirt, die durch das Schliessen der Nebenleitung. in der Hauptrolle bewirkte Stromabnahme misst.

Da das Oeffnen der Nebenleitung dieselben Verhältnisse herstellt, wie das Schliessen der Kette im vorigen Paragraphen, so bleiben unsere Ausdrücke unverändert bis zur Constantenbestimmung, nur dass für $w$

1 Poggendorff's Annalen u. s. w. 1847. Bd. LXXIl. S. 497. 
überall $w_{k}+v_{s}$ zu setzen ist. Für die Constantenbestimmung aber gelten hier die Bedingungen

$$
\begin{aligned}
& I_{\alpha}=\frac{A \cdot w_{n}}{N} \text { für } t=0, \\
& \int_{0}^{\infty} i_{a} \cdot d t=-\frac{A Q \Xi}{w_{o}}
\end{aligned}
$$

Man findet $C_{1}=C_{2}=A \equiv$, und demgemäss

$I_{a}=\frac{A}{2\left(w_{k}+v_{s}\right) \varrho_{a}}\left\{2 \varrho_{\alpha}+\frac{w_{k} v_{s}}{N}\left(\Phi_{a_{2}} \cdot e^{-\Theta_{a_{1}} t}-\Phi_{a_{1}} \cdot e^{-\Theta_{a_{2}} t}\right)\right\}$

$i_{a}=-\frac{A \equiv}{2 \varrho_{a}}\left\{\begin{array}{c}-\Theta_{a_{1}} t-\Theta_{a_{2}} t \\ e\end{array}\right\}$

§. VI. Induction durch Schliessen einer Nebenleitung zur Hauptrolle.

Bei dem Schliessen einer Nebenleitung zur Hauptrolle bleibt der Gang der Rechnung derselbe, aber bereits die Constanten der simultanen Differentialgleichungen werden zum Theil andere. Man hat nämlich zwar noch

$$
i_{e} w_{o}=-Q \cdot \frac{d I_{e}}{d t}-\Pi \cdot \frac{d i_{e}}{d t},
$$

allein die andere Gleichung lautet jetzt

$$
I_{e} N=A w_{n}-\left(w_{k}+w_{n}\right) P \cdot \frac{d I_{e}}{d t}-\left(w_{k}+w_{n}\right) Q \cdot \frac{d i_{e}}{d t} .
$$

Demgemäss wird

[393]

$$
\begin{aligned}
R_{e} & =\frac{N \Pi}{\left(w_{k}+w_{n}\right) \Delta}, & U_{e} & =\frac{N Q}{\left(w_{k}+w_{n}\right) \Delta}, \\
T_{e} & =\frac{w_{n} A \Pi}{\left(w_{k}+w_{n}\right) \Delta}, & W_{e} & =\frac{w_{n} A Q}{\left(w_{k}+w_{n}\right) \Delta} ;
\end{aligned}
$$

$S$ und $V$ behalten ihre Bedeutung. Die Hülfsgrösse $\Phi$ nimmt die Form an:

$$
\begin{gathered}
\Phi_{e}=-\frac{w_{\sigma}\left(w_{k}+w_{n}\right) P-N \Pi}{2 N Q} \\
\pm \sqrt{\frac{w_{\sigma}\left(w_{k}+w_{v}\right)}{N}+\left\{\frac{w_{0}\left(w_{k}+w_{n}\right) P-N \Pi}{2 N Q}\right\}^{2}} .
\end{gathered}
$$


$\Theta_{e_{1}}=\Phi_{e_{1}} U_{e}-R_{e}, \Theta_{e_{2}}=\Phi_{e_{2}} U_{e}-R_{e}$ berechnen sich diesmal beziehlich zu

$$
\frac{N \Pi+w_{o}\left(u_{k}+u_{n}\right) P \mp 2 N Q \varrho_{e}}{2\left(u_{k}+u_{n}\right)\left(P \Pi-Q^{2}\right)},
$$

wo $\varrho_{e}$ die neue Wurzelgrösse vorstellt.

Das allgemeine vollständige Integral heisst:

$$
\begin{aligned}
& \left.I_{e}=\frac{\Phi_{e_{1}}}{2 \varrho_{e}}\left\{\frac{A u_{n}{ }^{t}}{N}-C_{2} \cdot e^{-\Theta_{e_{2}} t}\right\}\left|-\frac{\Phi_{e_{2}}}{2 \varrho_{e}}\right| \frac{A w_{n}}{N}-C_{1} \cdot e e^{-\Theta_{e_{1}} t}\right\} \\
& i_{e}=\frac{1}{2 \varrho_{e}}\left\{C_{2} \cdot e^{-\Theta_{e_{2}} t}-C_{1} \cdot e^{t}\right\}
\end{aligned}
$$

Die beiden Integrationsconstanten $C_{1}$ und $C_{2}$ bestimmen sich durch

$$
\begin{gathered}
I_{e}=\frac{A}{u_{k}+w_{s}} \text { für } t=0, \\
\int_{0}^{\infty} i_{e} \cdot d t=\frac{A Q \Xi}{w_{v}} .
\end{gathered}
$$

Man findet $C_{1}=C_{2}=-A \Xi$, und schliesslich

$$
\begin{aligned}
& I_{e}=\frac{A}{2 N \varrho_{e}}\left\{2 w_{n !} \varrho_{e}+\frac{w_{k} u_{s}}{u_{k}+u_{s}}\left(\Phi_{e_{1}} \cdot e^{-\Theta_{e_{2}} t}-\Phi_{e_{2} \cdot e}\right)\right\}
\end{aligned}
$$

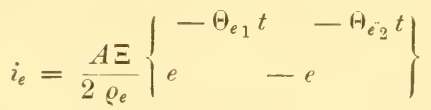

[394] Der Simm dieser Formeln ist folgender. Bei geschlossener Nebenleitung hat der Kettenstrom in der Hauptrolle die Stärke $\frac{A u_{n}}{N}$. Beim Oeffnen der Nebenleitung steigt er von hier zur Stärke $\frac{A}{u_{k}+u_{s}}$ nach eimem ähnlichen Gesetze an, wie früher rom Nullpunkte (Fig. 15. A, Curre 5). Der Verlauf des Nebenstromes (Fig. 15. a, Curre 6) ist auch ähnlich dem beim Schliessen der Kette, nur dass, tda die Stromschwankung kleiner ist, auch der Flächenraum abgenommen hat, den die Curre mit der Abscissenaxe begrenzt. Beim Schliessen der Nebenleitung fügt sich diesmal der Extrastrom, dessen Verlauf durch die beiden Exponentialglieder dargestellt wird, zum bestïndigen strome $\frac{A w_{n}}{N}$ hinzu, so dass 
der Hauptstrom nicht mehr plötzlich, sondern allmählich abfällt und sich asymptotisch der Geraten $\frac{A{ }^{\prime}}{N}$ nähert, von der er ausging (Fig. 15. E, ('urve 7). Der Endnebenstrom aber hat nummehr einen dem des Anfangsnebenstromes ähnlichen Verlauf (Fig. 15. e, Curve 8).

Für $t=0$ findet man

$$
\frac{d i_{a}}{d t}>\frac{d i_{e}}{d t} .
$$

Das Verhältniss, wie es die durch Schliessen und Oeffnen der Kette inducirten Ströme $i_{a}$ und $i_{e}$ bieten, hat sich also hier, nach der Anfangssteilheit zn urtheilen, umgekehrt. Der Anfangsnebenstrom hat den rascheren und steileren Verlauf, wie es in der Figur zu sehen ist. Dies ist, wie man sich erimert, genan der Erfolg. den wir oben S. 233 mittels des stromprüfenden Schenkels beobachtet haben.

\section{§. TII. Bedingungen der Congruenz der Anfangs- mnd Endinduction.}

Es handelt sich num darum, die Bedingungen auszumitteln, unter denen dieser Unterschied zwischen dem Verlanfe der beiden Ströme, wie er durch die Gleichungen (6) und (8) ausgesprochen ist, rerschwindet. Dies wird damn der Fall sein, wemn $\varrho_{a}, \Theta_{a_{1}}, \Theta_{a_{2}}$ beziehlich $=\varrho_{\epsilon}$, $H_{\ell_{1}}, \Theta_{e_{2}}$. Untersucht man diese $[395]$ Ausdrücke, so zeigt sich. dass deren Unterschied daranf himanslänft, dass in $\varrho_{e_{i}} \ldots$ überall $\frac{u_{k}+w_{n}}{V}$ steht, wo $\frac{1}{w_{k}+\frac{1}{w_{s}}}$ in $\varrho_{a} \ldots$ Die Bedingung der Congruenz ron $i_{a}$ und $i_{\epsilon}$ ist also, dass

$$
u_{s}+u_{k}=u_{s}+u_{k} \cdot \frac{u_{n}}{u_{k}+w_{n}}
$$

Man sieht sogleich, dass Hm. Wundт's Angabe entgegen, dieser Gleichung durch $w_{n}=0$ nicht Genüge geschieht. Dagegen $w_{k}=0$ würde "die Gleichung erfüllen. Allein $w_{k}=0$ macht zugleich $\Xi=0$, und in der That würde, wemn der Widerstand der Kette gegen den der Rolle und den der Nebenleitung verschwände, das Anbringen und Entfernen der letzteren nach bekamnten Grmulsätzen gar keine Stromschwankung in der Folle bewirken, so dass̄ alsdann keine Induction stattfände. Setzt man dagegen $w_{k}$ und $w_{n}$ zugleich Null, oder auch $w_{n}$ verschwindend gegen $w_{k}, w_{k}$ rerschwindend gegen $u_{s}$, so ist die Gleichung (III) erfüllt, 
und die Induction besteht fort, demn $\Xi$ nimmt im ersten Falle den Werth an

im zweiten diesen

$$
w_{s}\left(w_{k}+w_{n}\right)
$$

Da aber

$$
\frac{1}{u_{s}}
$$

$$
\frac{1}{w_{s}}>\frac{1}{w_{s}} \cdot \frac{w_{k}}{w_{k}+w_{n}},
$$

so ist die letztere Anordnung vorzuziehen. Sie wird sich übrigens gewöhnlich ganz ron selber hergestellt finden.

Dass auch die Extraströme im inducirenden Kreise durch die nämliche Gleichsetzung einen identischen Verlauf amnehmen, braucht kaum bemerkt zu werden.

Es ergiebt sich zugleich, dass zum Zweck einer bequemeren Untersuchung des rerschiedenen Verlaufes ron $i_{a}$ und $i_{e}$ keine Vereinfachung getroffen werden kann, gleich der, welche uns die Ansdrücke $(3 *)$ und $\left(4^{*}\right)$ lieferte. Damit eine solche [396] Vereinfachung eintrete, müsste, ausser $P=\Pi, w_{o}\left(w_{k}+w_{n}\right)=N$, und anch $w_{o}=w_{k}+w_{s}$, also

$$
w_{s}+w_{k}=w_{s}+w_{k} \cdot \frac{w_{n}}{w_{k}+w_{n}}
$$

werden. Dies ist aber gerade die Bedingung, welche die Congruenz ron $i_{a}$ und $i_{e}$ herbeiführt, so dass es alsdann keinen Unterschied dieser Curren mehr zn untersuchen giebt.

Setzt man in 5, 6, 7, 8P=II, $w_{o}=w_{s}$ und $w_{n}: w_{k}, w_{k}: w_{s}=\infty$, so erhält man

$$
\begin{aligned}
& I_{\alpha, e}=\frac{A}{2 w_{s}}\left\{2 \pm e^{-\frac{w_{s}}{P+Q} t} \pm e^{\left.-\frac{w_{s}}{P-Q} t\right\}}\right\} \\
& i_{a, e}= \pm \frac{A}{2 w_{s}}\left\{\begin{array}{c}
-\frac{w_{s}}{P+Q} Q^{t}-u_{s} \\
P-Q^{t}
\end{array}\right\} .
\end{aligned}
$$

Das obere Zeichen bezieht sich anf die Anfangs-, das untere auf die Endinduction. Die Ausdrücke für $I_{a}, i_{a}$ sind, wie man sieht, einerlei mit $(3 *)$ und $\left(4^{*}\right)$. Für $Q$ sehr nahe $=P$ werden sie daher gleichfalls durch die Abtheilungen $A$ und $a$ der Fig. 16 dargestellt. Für die Endinduction sind die entsprechenden Curren, aus abwechselnden Strichen 
und Punkten zusammengesetzt, in den Abtheilungen $E$ und $e$ eingetragen. So also würden die Ströme verlaufen, wemn man in dem inducirenden Drahte des oben S. 244 erwähnten Doppelgewindes den Strom herstellte und abbräche statt durch Schliessen und Oeffnen der Kette ron verschwindendem Widerstande, durch Oeffnen und Schliessen einer Nebenleitung zu jenem Draht, deren Widerstand wiederum gegen den der Kette verschwände.

§. VIII. Andere Ableitung der Congruenzbedingungen.

Man kamn die analytisch entwickelten Bedingungen der Congruenz von $i_{a}$ und $i_{e}$ anch durch folgende Betrachtung ableiten. Der Anfangsextrastrom von der Stärke $E_{a}$ findet zwischen den Enden der Rolle den Widerstand $w_{k}$, der Endextrastrom ron der Stärke $\boldsymbol{E}_{\ell}$ nur den

$$
\frac{w_{k} w_{n}}{w_{k}+w_{n}} \text {. }
$$

Man hat demgemäss

$$
\begin{aligned}
& \int_{0}^{\infty} E_{a} d t=\int_{0}^{\infty}\left(I_{a}-\frac{A}{w_{k}+w_{s}}\right) d t=-\frac{A P \Xi}{w_{s}+w_{k}}, \\
& \int_{0}^{\infty} E_{e} d t=\int_{0}^{\infty}\left(I_{e}-\frac{A w_{n}}{N}\right) d t=\frac{A P \Xi}{w_{s}+\frac{w_{k} w_{n}}{w_{k}+w_{n}}},
\end{aligned}
$$

wo der erstere Werth der absolut kleinere ist. Die Anfangsordinate des Extrastromes ist aber in beiden Fällen die gleiche, nämlich, ohne Rücksicht auf das Zeichen, $A \Xi$. Wegen seines kleineren Integralwerthes muss also der Anfangsextrastrom steiler abfallen, und deshalb ist der Anfangsnebenstrom in der Nebenrolle gleichfalls der steilere. Sollen die Nebenströme congruent werden, so müssen es auch die Extraströme, und deren Integralwerthe in (IV) und (V) einander gleich. Damit dies geschehe, müssen die Extraströme gleiche Widerstände zu überwinden haben, d. h. es muss

$$
w_{s}+w_{k}=w_{s}+\frac{w_{k} w_{n}}{w_{k}+w_{n}}
$$

sein. Diese Bedingung wird durch $v_{k}=0$ erfüllt, weil es alsdamn für einen von der Rolle ausgehenden Strom gleichgültig ist, ob noch eine andere Bahn $w_{n}$ von beliebigem Widerstand hinzutritt oder nicht. Weshalb dies nicht genüge, sondern nun auch $w_{n}=0$, wo möglich von 
noch höherer Ordnung als $u_{k}$, zu setzen sei, war bereits oben ans allgemeinen Grundsätzen hinreichend klar.

Man kann diese Beziehungen auch noch so zusammenfassen. Der Unterschied zwischen $i_{a}$, $i_{e}$ kommt, wie wir sahen, darauf zurück dass, abgesehen ron dem gemeinschaftlichen Factor $\Xi$,

$$
\frac{1}{u_{s}+\frac{w_{k}}{w_{k}}}
$$

in dem ersten Ansdunck ersetzt ist durch

$$
\frac{u_{k}+u_{n}}{N}=\frac{1}{u_{s}+\frac{w_{k} u_{n}}{u_{k}+w_{n}}}
$$

in dem zweiten. Dasselbe gilt für $E_{a}, E_{e}$. Die Nemner $u_{s}+v_{k}$ und $u_{s}+\frac{u_{k} w_{n}}{w_{k}+w_{n}}$, wodurch sich somit die Ansdrücke für die Anfangsund für die Endindnction unterscheiden, sind aber sichtlich nichts. als die Widerstände auf der Bahn der beiden Extraströme. Nennt man diese Widerstände $\boldsymbol{H}_{a}, \boldsymbol{H}_{e}$, so hat $\operatorname{man} i_{a}, i_{e}=-f\left(\boldsymbol{H}_{a}\right), f\left(\boldsymbol{H}_{e}\right)$. $E_{a}, E_{e}=-F\left(\boldsymbol{H}_{a}\right), F\left(\boldsymbol{W}_{e}\right)$, und für $\boldsymbol{W}_{a}^{*}=\boldsymbol{H}_{e}$ daher $-i_{a}=i_{e}$, $-E_{a}=E_{e}^{d}$.

\section{§. IX. Tersuche zur Bestätigung der Theorie.}

Ich habe nicht unterlassen. mich, so gut ich komnte. durch den Versuch der Richtigkeit des theoretischen Ergebnisses zu rersichern. Ich besass zwar nicht die Yittel, auch lag es nicht in meinem Plane, dies durch förmliche Messungen, gleich denen des Hrn. BeEtz, zu thun. Allein wir haben in dem stromprüfenden Froschschenkel ein Reagens ron ansserordentlicher Feinheit für den zeitbchen Verlanf von Strömen, womit wir freilich nicht diesen Verlanf in jedem Falle scharf bestimmen, bei der gegenwärtigen Sachlage aber doch mit grosser Wahrscheinlichkeit entscheiden kümnen, ob die Ströme, unter den ron der Theorie geforderten Bedingungen, wirklich congruent werden oder nicht. Fallen, hei Herstellung dieser Bedingungen, die Znckmngen durch Schliessen und Oeffnen der Nebenleitung bei gleicher Richtung der Ströme im Nerren gleich stark ans, oder rerschwinden sie bei dem gleichen Rollenabstande, so ist kamm zu zweifeln, dass unsere Theorie richtig sei.

Ich rerfuhr folgendermaassen. Mit dem einen Ende der Hauptrolle eines Schlitten-MIagnetelektromotors, aus der das Drahtbündel entfernt 
war, rerband ich einen Stöpsel-Rheostat ron Sievexs und HaLske, ${ }^{1}$ der eimen Widerstand ron einer bis 99 Meilen Telegraphendraht zn entfalten erlanbt. Das andere Ende der Rolle und des Rheostats rerkmüpfte ich mit einer [399] Grove:chen Kette der grösseren Art, deren verdünnte Schwefelsäure im Terhältniss ron 1:10 gemischt war. Eine möglichst - kurze Nebenleitung zur Rolle und zum Rheostat konnte in Qnecksilber geschlossen und geöffnet werden. Die Nebenströme führte ein Paar meiner umpolarisirbaren Znleitmmgsröhren mit Thonstiefeln, wie man sie in Jena passend genannt hat (s. oben S. 163). im fenchten Raume des Pfrǘger'schen Hyographions dem Nerven eines Gastroknemins zu, der seine Zuckumgen anf der berusiten Glasplatte rerzeichnete. Endlich ein Stromwender erlaubte den beiden Nebenströmen im Nerven die gleiche Richtung zu ertheilen. Dass bei dieser Anordnung zugleich mit $w_{s}$ auch $P$ vergrössert wurde, weil nämlich der Nensilberdraht des Rheostats in Rollen aufgewickelt ist, komnte die Congrnenz, falls sie überhaupt zu Stande kam, nicht beeinträchtigen.

War der Rheostat anf Noll gestellt, und es wurde die Nebenrolle allmählich der Hauptrolle genähert, so erschien, dem oben S. 233 Gesagten gemäss, zuerst bei etwa $20^{\mathrm{cm}}$ Rollenabstand die Anfangsznckung hei anfsteigendem, dam wenige Millimeter näher die bei absteigendem Strome. Der anfsteigende Strom hat rermuthlich die Oberhand, weil nach Hrn. Pfü̈GeR's Ermittelungen die Schliessungszuckung dieses Stromes es ist, die bei allmählich gesteigerter Stromstärke zuerst erscheint, ${ }^{2}$ die Nebenströme aber, weil sie steiler anheben als abfallen, in ihrer zuckungerregenden Wirkung dem Schliessen eines beständigen Stromes rergleichbar sind, wie schon $\mathrm{Hr}$. RosenthaL ans anderen Gründen erschlossen hat. ${ }^{3}$ Etwa $4^{\mathrm{em}}$ näher folgten dann ebenso nahe anfeimander die Entznckung bei anfsteigendem und die bei absteigendem Strome. Wurde der Rheostat anf mehr als 12 Meilen gestellt, so erfolgte selbst bei ganz anfgeschobener Rolle keine Zuckung. Bei 12 Meilen war sie da, und es war sichtlich der Unterschied zwischen der Anfangsznckung und der Endzuckung bei gleicher Stromrichtung sehr rermindert; inzwischen hatte die Anfangszuckung noch ein geringes Uebergewicht.

1 W. Siemers in Poggendorfy's Amalen u. s. w. 1857. Bd. CII. S. 75. Taf. I. Fig. 4. - [Das hier von mir benutzte Exemplar besass noch nicht die oben s. 190 erwähnte Einrichtung der Rollen, daher die Bemerkung am Schlusse des Absatzes.]

2 Untersuchungen über die Physiologie des Electrotouus. Berlin 1 559 . S. 455.

3 Die Fortschritte der Physik in Jahre 1859. Dargestellt von der physikalischen fresellschaft zu Berlin. Berlin 1^61. S. 532. 533. 
[400] Ich ging deshalb zu einem grösseren Magnetelektromotor über, den ich ror mehreren Jahren bei den Hrn. Stemens und Halske hatte bauen lassen, um die Angaben der Hm. Aubert und von Tschischwiтz über die Reizung des centralen Vagusstumpfes zu prüfen. ${ }^{1}$ Die Hauptrolle dieses Apparates hat etwa 200, die Nebemrolle 9845 Windungen. Hier erhielt ich, anch bei 99 Meilen Telegraphendraht im Stromzweig der Hauptrolle, Zuckung noch bei gehörigem Rollenabstande, und unter gewissen Bedingungen nummehr wirklich von völlig gleicher Grösse durch beide Ströme.

Dieser Bedingungen waren im Wesentlichen zwei. Erstens musste die Stromrichtung im Nerven dieselbe bleiben, d. h. also jedesmal zwischen Schliessen und Oeffnen der Nebenleitung die Wippe des Stromwenders umgelegt werden. Sonst machte sich das Gesetz der Zuckungen in der Art geltend, dass gleichviel ob es sich um Anfangs- oder um Endstrom handelte, der aufsteigend gerichtete unter den beiden Strömen früher Zuckung bewirkte als der absteigende; im Gegensatz zu dem Terhalten beim Stande des Rheostats auf Null, wo unabhängig ron der Stromrichtung die Zuckung durch den Anfangsstrom stets um mehrere Centimeter der durch den Endstrom vorhergeht.

Die zweite Bedingung bezieht sich auf die Geschwindigkeit, womit das Schliessen und Oeffnen der Nebenleitung bewerkstelligt wird. Durch rascheres Eintauchen des rerquickten Kuuperhakens in das Quecksilber konnte nämlich der Endzuckmng, durch rascheres Herausziehen der Anfangszuckung das Uebergewicht verschafft werden. Ebenso wirkte rascheres Handhaben des Bügels eines Schlüssels, wemn das Quecksilbernäpfchen mit seinen Kúpferhaken durch einen solchen ersetzt wurde. Es ist somit klar, dass die Veränderungen des Widerstandes, welche der gänzlichen Trennung der Metalle an der Berührungsstelle voraufgehen, oder deren erste Berührung noch folgen, nicht so ganz zu rernachlässigen sind, wie wir es gethan haben. Die oben S. 236 gemachte Voranssetzung, dass diese Veränderungen in einer verschwindend kurzen Zeit ror sich gehen, trifft nicht ohne Weiteres zu. ${ }^{2}$ Ohne Zweifel wird [401] durch diesen Umstand die Ordinate ron $I_{\alpha}$ in der Nähe des Nullpunktes verkleinert, so dass vielleicht die Curve statt concar, zuerst convex gegen die Abscisse anhebt, während die Ordinate ron $I_{e}$ durch denselben Umstand zuerst rergrössert wird, und die Curve anfangs noch conear gegen die Abscisse sein mag. Dadurch wird auch die

1 Vergl. Rosenthal, die Athembewegungen und ihre Beziehungen zum Nervus vagus. Berlin 1862 . S. 32 .

2 Vergl. Helaholtz, a. a. ( ). S. 538. 
Gestalt der Curven $i_{a}$ und $i_{e}$ verändert werden, und deren Congruenz erhalten sein nur unter bestimmten Bedingungen für die Geschwindigkeit des Schliessens und Oeffnens der Nebenleitung, die im Allgemeinen sich nur zufällig, wenn je, erfüllt finden werden. Diese Veränderungen müssen aber deshalb die Zuckung gleich merklich beeinflussen, weil sie den Anfang der Curven, also deren steilsten, und somit physiologisch wirksamsten Theil betreffen. Das beste Mittel, diesem Uebelstande abzuhelfen, wäre, der Tebenleitung einen solchen Widerstand zu ertheilen, dass jene Veränderungen davon nur noch einen verschwindenden Bruchtheil betrügen. ${ }^{1}$ Leider ist dies Mittel hier nicht anwendbar, weil $w_{n}$ gegen $w_{s}$, wo möglich sogar gegen $w_{k}$, rerschwinden soll. Es bleibt also nichts übrig, als jene Veränderungen, da sie der Grösse nach gegeben sind, der Zeit nach zu beschränken, und ihre Daner dem durch die Natur der Sache bedingten Grenzwerth nahe zu bringen, indem man das Schliessen und Oeffnen möglichst rasch vollzieht. Verfährt man so, so erhält man bei gleicher Stromrichtung oft lange Reihen genau gleich hoher Anfangs- und Endzuckungen, zum Zeichen, dass nummehr, allem Ermessen nach, die beiden Ströme wirklich congrnent sind.

Bei Betrachtung des zeitlichen Verlaufes der Induction die Gegenwart von Eisen in der Hauptrolle in Rechnung zu ziehen, gestattet der Zustand unserer Kíenntnisse insofern noch nicht, als wir hinsichtlich der Beziehung zwischen der Stärke eines reränderlichen Stromes und dem dadurch erregten Magnetismus meines Wissens auf die empirischen Bestimmungen des Hrn. BEETz beschränkt sind. ${ }^{2}$ Ieh wollte aber doch prüfen, was ron praktischer Wichtigkeit ist, wie sich die obigen Versuche gestalten würden, wemn ich in die Haupptrollé ein Drahtbündel brächte, womit man sie gewöhnlich anzuwenden ptlegt. [402] Dass die im Eisen als Leiter inducirten Ströme die eimmal hergestellte Congruenz nicht stören würden, war von vorn herein sicher, erstens, weil sie bei hinreichender Dümne und guter Isolirung der Drähte kaum in Betracht kommen, ${ }^{3}$ zweitens aber und rornehmlich, weil sie selber congruent ausfallen. Dagegen war es fraglich, ob auch der Magnetismus der Drähte die Congruenz würde bestehen lassen. Dazu müsste er mit derselben Geschwindigkeit entstehen und rergehen, was zwar bei der Langsamkeit der Stromschwankungen, um die es sich hier handelt, recht grit möglich schien, jedoch zu versuchen stand.

1 Vergl. Helmholtz, a. a. 1). S. 517.

2 Poggendorff's Anmalen u. s. w. 1858. Bd. CV. S. 516 ff.

3 Veril. Helmholtz, a. a. O. S. 535.536. 
Man kaun sich, wegen der durch den Eisenkern rermittelten grösseren Stärke der Wirkungen, dabei wieder eines gewöhnlichen Nagnetelektromutors bedienen. Bei dem Stande des Rheostats auf Null überwiegt die Anfangszuckung durch Oeffnen der Nebenleitung. Bei 50 Meilen Telegraphendraht im Stromzweig der Hauptrolle bleibt selbst bei ganz aufgeschobener Nebenrolle jede Zuckung aus. Bei 40 Meilen waren dagegen die Zuckungen noch in geeigneter Stärke vorhanden, und erschienen, unter denselben Bedingungen wie rorhin, völlig so gleichmässig wie ohne Eisenkern. Dieser schien daher unter den obwaltenden Verhältnissen die Congruenz der Ströme nicht merklich zu beeinträchtigen. Genau genommen folgte dies schon ans den früheren Versuchen, indem auch dabei, trotz der Entfernung der Drähte aus der Hauptrolle, noch etwas Eisen mit im Spiele war, der kleine Elektromagnet nämlich der Magnetelektromotore.

\section{§. X. Schlussbemerkungen.}

Man darf es somit als himreichend gewiss ansehen, dass man mittels des angegebeneu Kunstgriffes sich congruente Wechselströme rerschaffen könne. Was aber dessen Anwendung zum Tetanisiren betrifft, so stösst man dabei auf erhebliche Schwierigkeiten.

Erstens sind, wie wir sahen, die Ströme, die man ohne Eisenkern ron den gewöhnlichen Mlagnetelektromotoren bei Einschaltung solcher Widerstände erhält, dass der der Kette da- [403] gegen rerschwindet, zu schwach um Zuckung zu Dewirken. Zweitens rersagt der Elektromagnet dieser Torrichtungen dabei seine Dienste, d. h. die Feder spielt nicht mehr. Diesen Uebelständen liesse sich allenfalls begegnen. indem man die ganze Drahtlänge, deren man als Widerstand bedart, zu Windungen der Hauptrolle und des Elektromagnetes rerwendete.

Allein drittens fragt es sich, ob unter den Umständen, wo einzelne Schliessungen und Oeffnungen congruente Induction liefern, die Congruenz anch beim Spiel der Feder noch stattfinden würde. Dies setzt. wie sich zeigen lässt, voraus, dass während des Anliegens der Feder am Stift und während ihrer Excursion rom stift fort und zurïck, der Strom jedesmal Zeit habe, sich der ihm dureh die Onм'sche Formel rorgeschriebenen Stärke bis auf eine numerkliche spur zu nähern. Nun wird aber die Feder sich stets früher rom Stift lüsen, als der Elektromagnet seine ganze Krraft eingebüsst hat, oder als der Endextrastrom rorüber ist. Zwischen der Daner des Anfangsextrastromes und der 
einer Excursion der Feder herrscht gar keine Beziehung. Da jedoch unsere Magnetelektromotore, nach einer Bestimmung ron Hrn. HeuxноLтz, $150-300 \mathrm{mal}$ in der Secunde den Kreis öffnen, ${ }^{1}$ der Theil von $i_{a}$ bis zum Maximum in Hrn. BeEtz' Versnchen aber allein $0^{\prime \prime} \cdot 010-12$ danerte, ${ }^{2}$ so ist kaum zweifelhaft, dass auch für den Anfangsextrastrom jene Bedingung nicht erfüllt sei. Jedenfalls müsste man. um mit congruenten Wechselströmen eines Magnetelektromotors zn tetanisiren, diesen su eimrichten, dass man die Zahl der Unterbrechungen in der Secunde bis zu der Grenze rerringern könnte, wo der Tetanus anfhört stetig zu sein, und dass zugleich die Daner des Schlusses der Nebenleitung der ihrer Oeffnung möglichst gleich wäre.

Wie dies am besten zu machen gehe, mag hier unerörtert bleiben. Bemerkt sei nur, dass das Princip des HaLske'schen Unterbrechers, ${ }^{3}$ den man so einstellen kann, dass er die Kette nur etwa dreimal in der Secunde öffnet, sich nicht anf die Unterbrechmo einer Tebenleitung anwenden lässt, weil die [404] Hülfsfeder, anstatt die Wirkumgszeit des Elektromagnets zu verlängern, sie vielmehr abkürzen würrle.

Bei der Schwierigkeit, hinsichtlich der Erfüllung der obigen Bedingung zu einiger Gewissheit zu gelangen, thäte man vielleicht besser, auf den Gebrauch eimer selbstthätig unterbrechenden Torrichtung zu verzichten, und sich der durch ein Uhrwerk gedrehten SAxтos'schen Maschine, oder eines ebenso bewegten Systems ron Unterbrechungsrädem zu bedienen, wodurch ron den Schlägen einer voltaëlektrischen Inductionsrorrichtung die eine Reihe abgeblendet würde, die übrigbleibenden aber abwechselnde Richtung erhielten. Dies wird geleistet durch ein Unterbrechungsad mit einer stetig schleifenden und einer aussetzenden Feder, welches an einer und derselben isolirenden Axe mit einem PogGendorfF'schen Inversorrade angebracht ist. Jenes ist in den indncirenden, dieses in den inducirten Krreis eingeschaltet. Beide haben die gleiche Anzahl leitender und nichtleitender Zähne, sind aber gegen einander $n$ m eine halbe Zahnbreite so verstellt, dass, wenn an dem einfachen Unterbrechungsrade die aussetzende Feder gerade anf Metall geräth oder Metall verlässt, am Inversurrade die beiden aussetzenden Federn auf Holz stehen. Dadurch wird im ersten Falle die Reihe der Schliessungs-, im zweiten die der Oeffinngssehläge abgeblendet,

1 Arehiv für Anatomie u. s. w. 1848. S. 155.

2 Poggendorfy's Annalen u. s. w. 185s. Bd. c'V. s. 516.

3 Poggendorff's Annalen u. s. W. 1856. Bd. XC'VII. \$. 641. 
während das Inversorrad beziehlich den Oeffnungs- oder den Schliessungsschlägen abwechselnde Richtung ertheilt. ${ }^{1}$

1 Vergl. Untersuchungen n. s. w. Bd. II. Abth. I. S. 404, 405. - [Seit Erscheinen dieser Abhandlung machte Hr. J. Bersstein auf eine von mir übersehene Art anfmerksam, wie der Verlauf des Anfangs- und der des Endstromes anch noch gleich gemacht werden kömnen. Sie kommt mit der Helmholtz'schen darin ïberein, dass eine Nebenleitung zur Hauptrolle angebracht wird, unterscheidet sich aber von ihr dadurch, dass Schliessung und Oeffnung nicht in der Nebenleitung, sondern im Kettenzweige geschieht. Bei der Schliessung hat der Extracurrent den Widerstand $u^{\prime} s+\frac{u_{n} n u^{\prime} k}{u_{n}+w_{k}}$, bei der Oeffnung den $u^{\prime} s+u_{n}$ zu überwinden. Es muss $u_{s}+u_{n}=u_{s}+\frac{w_{n} u_{k}}{u_{n}+u_{k}}$ sein, damit Congruenz stattfinde, oder $u_{n}$ muss gegen $w_{k}$ verschwinden. Man muss also $A$ sehr gross wählen, da sonst $\frac{A \cdot u_{n}}{\boldsymbol{N}}$, der Grenzwerth des Stromes in der Hauptrolle, zu klein ansfiele. Naeh Obigem hat es keine Schwierigkeit, diese Combination mathematisch zu behandeln. Ueber deren praktische Ansführbarkeit vergl. im zweiten Bande dieser Sammlung die Abhandlung: ,Ueber die negative Schwankung des Muskelstromes bei der Znsammenziehung." Erste Abtheilung. Anm. 2 zur Einleitung.] 
$\mathrm{X}$.

\section{Anleitung zum Gebrauch des runden Compensators. ${ }^{1}$}

[609] Nachstehende Figur zeigt schematisch den Compensator, und die Art ihn zu gebrauchen. $K_{1}$ ist die Maasskette (ein Grove oder Daniell) mit der elektromotorischen Kraft $E, B_{1}$ eine Bussole, $N S$ der

Fig. 17.

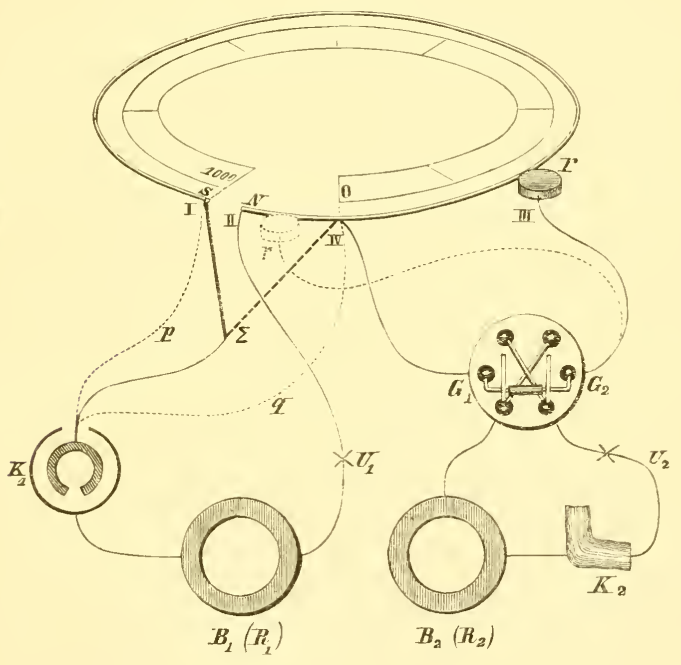

Platindraht. des Compensators (Nebenschliessdraht), $r$ das Platinröllchen des Instrumentes, $G_{1} G_{2}$ ein Stromwender, etwa ein PoHL'scher

1 Aus dem Archiv für Anatomie u. s. w. 1871. S. 608. - Vergl. oben S. 176 ff., §. XI. der Abhandlung VIII.; - ferner die im zweiten Bande dieser E. du Bois-Reymond, Ges. Abh. I. 
Gyrotrop, $B_{2}$ eine zweite Bussole, endlich $\boldsymbol{K}_{2}$ ein wirksam aufliegender Muskel, an dessen Stelle man auch eine beliebige zweite, beständige oder unbeständige Kette sich denken kamn, deren elektromotorische Kraft y gemessen, d. h. als Bruchtheil der Kraft $\boldsymbol{E}$ der Maasskette bestimmt werden soll. $U_{1}, U_{2}$ sind Unterbrechungsstellen der Kreise, wo Schlüssel sich befinden.

Die Strecke $0 N U_{1} B_{1} K_{1}$ ( $p$ oder $\Sigma$ ) $S$ heisst der Maasskettenkreis, ihr Widerstand $\boldsymbol{I}^{r}$; die Strecke $0 G_{1} B_{2} K_{2} U_{2} G_{2} r$ der Messkreis, ihr Widerstand $\boldsymbol{M}$; die Strecke $0 r$ die Nebenleitung, ihr Widerstand $\lambda$; endlich der Widerstand des Nebenschliessdrahtes ron 0 bis $S$ gemessen heisst $L$.

Der Stromwender ertheilt dem Maasskettenstromzweig im Messkreise die entgegengesetzte Richtung vom strome der Kette $\boldsymbol{K}_{2}$. Indem man durch Terschieben des Röllchens $r$ am Nebenschliessdraht in der Richtung ron 0 nach $S$ die Nebenleitung verlängert, rerstärkt man den Maasskettenstromzweig im Mess- [610] kreise. Man kamn ihm so jede Stärke zwischen Null und der Stärke geben, die er rermöge der sonstigen Beschaffenheit der Vorrichtung erreicht, wenn $r$ bei $S$ steht. Wenn diese Grenzstärke die Stärke des Stromes ron $\boldsymbol{K}_{2}$ im Messkreis übertrifft, kann man also durch Verschieben des Röllchens eine Stellumg finden, bei der beide Stärken gleîch sind, und Bussole $B_{2}$ die Stromstärke Null angiebt.

Nach dem Bosschu'schen Satz ${ }^{1}$ ist ein Zweig einer Leitung, in welchem kein Strom kreist, mit den etwa darin wirksamen elektromotorischen Kräften, als nicht rorhanden anzusehen. In Falle des Gleichgewichtes ist also der Strom I, in der Nebenleitung der nämliche, als wäre der Messkreis nicht rorhanden:

Sammlung enthaltene Abhandlung: Ueber das Gesetz des Muskelstromes mit besonderer Berücksichtigung des M. gastroknemius des Frosches, in einer Anmerkung zum §. V.; - ferner die ebenda befindliche Abhandlung: Ueber die elektromotorische Liraft der Nerven und Muskeln, §. II. - S. auch Wiedemann, Die Lehre vom Galvanismus und Elektromagnetismus. Bd. II. Braunsehweig 1863. S. 1068-1069; 2. Aufl. 1072. Bd. I. §. 240. 240b. - Ich bin schriftlich und mündlich so oft ersucht worden, nähere Anfklärung über Theorie und Gebrauch des in Rede stehenden, für thierisch-elektrische Versmehe unentbehrlichen Instrumentes zu geben, dass ich es für gerechtfertigt halte, wemn ich an dieser Stelle ein für allemal und öffentlich diesem Wunseh entspreche, obschon in der Natur der Sache liegt, dass einiges früher Gesagte wiederholt wird. Das Instrument in der Form, wie es hier gedacht ist, unterscheidet sich ron dem früher besehriebenen dadurch, dass der stöpselumschalter aus dem Maasskettenkreis entfernt, und eine Vorkehrung getroffen ist, welche unmittelbare Bestimmung der Ciraduationseonstanten gestattet.

1 Poggendorfi's Annalen u. s. w. 1858. Bu. CIV. S. 460. 


$$
l_{1}=\frac{E}{H^{r}+I^{\prime}}
$$

Nach dem die geschlossenen Figuren hetreffenden KümchноғF'schen Satze ${ }^{1}$ hat man

$$
\begin{aligned}
& \text { Null } \times M+I_{r} \cdot \lambda=y, \\
& \text { also } y=I_{r} \cdot \lambda=\frac{E}{U+L^{r}} . \dot{ }
\end{aligned}
$$

Im Falle des Gleichgewichtes ist also die elektromotorische Kraft der Lette $\boldsymbol{K}_{2}$ der Länge $0 r$ proportional, so dass diese nmmittelbar ein Maass für jene giebt.

Den Grund davon sieht man leicht ein. Da es in Falle des Gleichgewichtes gleichgültig ist. ob der Messkreis mit der Kraft y vorhanden ist oder nicht, so ist dem Nebenschliessdraht entlang das Gefïlle des Elektricitäts-Potentials dasselbe, wie ohne den angehängten Messkreis, gleichriel wo $r$ sich befinde. $r$ wird aher, damit Gleichgewicht herrsche, um so weiter ron 0 entfernt sein müssen, je grösser $y, d$. h. je grösser der Unterschied der constanten Elektricitäts-Potentiale auf den Strecken des Messkreises beiderseits rom Sitze der Kraft $y$ ist.

In dieser den Elektrikern bisher entgangenen Eigenschaft unserer Anordnumg liegt deren Ueherlegenheit über die ursprüng- [611] liche PoggendorfF'sche, ${ }^{2}$ welche anch zmm Messen elektromotorischer Kräfte durch Compensiren dient. Bei der PoggendonfF'schen Anordnung wird die Leitung nicht auf Kosten des Maasskettenkreises rerlängert, sondern durch Einschaltung nener Drahtstrecken. In Folge daron hängt y ron $\lambda$ in rerwickelterer Art ab, als in unserem Fall, und während musere Methode die elektromoturische Kraft wie das Zeug an der Elle misst, findet die Poginndorff'sche Methode sie immer erst dureh Rechnme.

Da y linear mit $\lambda$ sich rerändert, leidet die Bequemlichleit der Messung kaum darunter, dass im Messkreise ausser y vielleicht noch andere elektromotorische Kräfte. z. B. Ungleichartigkeiten einer stromzuführenden Vorrichtung, sich befinden. Sei die Summe dieser Kräfte $= \pm \delta$, und es werde für sie das Cleichgewicht bei $\lambda$. dagegen für $y \pm \delta$ bei $\lambda$ erreicht. Nan hat $\delta=I_{1} \cdot \lambda_{1}, y \pm \delta=I, i$, folglich $y=I,\left(\lambda \mp \lambda_{1}\right)$. Um aher der Constanz ron $\delta$ olme Umsetzen des Maasskettenstromzweiges im Messkreise sich rersichern zu kömmen, empfiehlt es sich. das obere Zeichen zu wählen.

Schreibt man den Ausdruck für die zn messende Krraft

1 Poggexdorff's Annalen u. s. W. 1s45. Bd. IxIl. S. $513 ;-1847$. Bd. IXXII. S. 497 .

2 Poggendorff's Annalen u. s. w. 1841. Bd. LIV. S. 161. 


$$
y=\frac{\lambda}{W+L} \cdot E,
$$

so sieht man, dass es nur der Kenntniss des Verhältnisses $\lambda: W+L$ bedarf, um $y$ als Bruchtheil von $E$ zu bestimmen.

Ist der Nebenschliessdraht ron 0 bis $S$ in $N$ Theile getheilt, und wurde das Gleichgewicht im Messkreise beim $n$ ten Theilstrich erreicht, so hat man

$$
\lambda=\frac{n}{N} \cdot I
$$

und folglich

$$
y=\frac{n}{N\left(1+\frac{W}{L}\right)} \cdot E .
$$

Um den Werth des constanten Nenners der rechten Seite zu kemnen, handelt es sich also nur darum, $W: L$ zu bestimmen. Dazu beobachtet man an der Bussole $B_{1} 1$, indem man die [612] Verbindung $0 N U_{1} B_{1} K q 0$ herstellt, die Stromstärke

$$
I=\frac{E}{W}
$$

2., bei offenem Messkreise, die Stromstärke

$$
I_{1}=\frac{E}{W+L}
$$

im Kreise $0 N U_{1} B_{1} K_{1} p S r 0$. Kann man an der Bussole die Ablenkungen $J, J$, unmittelbar den Stromstärken $I, I$, proportional setzen:

$$
a J=I, a J_{1}=I_{1},
$$

so hat man das Verhältniss $m$ dieser Ablenkungen, welches stets ein unächter Bruch ist,

$$
\begin{gathered}
\frac{J}{J_{1}}=\frac{I}{I_{1}}=\frac{W+L}{W}, \\
\text { folglich } \frac{W}{L}=\frac{1}{m-1}, \text { and } \\
y=n \cdot \frac{m-1}{m N} \cdot E .
\end{gathered}
$$

Der ächte Bruch $\frac{m-1}{m N}$ behält denselben Werth, so lange $W$ und $L$ beständig bleiben, und braucht daher für jede Vorrichtung nur einmal bestimmt zu werden, wofern stets die Maasskette ron gleicher Beschaffenheit ist und ihr Strom dem Nebenschliessdraht in gleicher Art zugeführt wird.

Hat man bei Anwendung eines Daniells, dessen elektromotorische Kraft $D$ heisse, z. B. gefunden 


$$
\begin{aligned}
& J=275 \cdot 2, \\
& J_{1}=247 \cdot 9 \text { Scalentheile, }
\end{aligned}
$$

und ist $N=1000$, so hat man

$$
\begin{aligned}
& \frac{m-1}{m N}=\operatorname{num}\left\{\begin{array}{l}
\log [\operatorname{num}(\log 275 \cdot 2-\log 247 \cdot 9)-1] \\
-(3+\log 275 \cdot 2-\log 247 \cdot 9)
\end{array}\right\}=0,0000991 \\
& \text { oder }=\frac{1}{10091} \text {. }
\end{aligned}
$$

Einem jeden Theilstriche des Nebenschliessdrahtes entspricht also unter diesen Umständen ein Unterschied von $\frac{1}{10091}$, und seiner ganzen Länge ron 0 bis $S$ ein solcher ron $\frac{1000}{10091} D$. [613] Der Bruch $\frac{D}{10091}$ heisst nunmehr die Graduationsconstante der Vorrichtung.

Bei Aenderung ron $m$ ändert sich die Graduationsconstante, und, insofern die Länge des Nebenschliessdrahtes gegeben ist, der durch den Bruch

$$
\text { N. } \frac{m-1}{m N}=\frac{m-1}{m}
$$

bestimmte Umfang der Theilung. Man kamn aber $m$ leicht jeden gewünschten Werth $>1$ dadurch ertheilen, dass man $W$ passend rerändert, d. h. die Zuleitungsdrähte der Kette nach Bedürfniss rerlängert oder verkürzt. Hierron macht man doppelten Gebranch. Erstens nämlich ist vortheilhaft, dass die Gradnationsconstante, mit der man fortwährend zu rechnen hat, einen möglichst bequemen Werth habe. Z. B. damit sie im obigen Falle statt $\frac{D}{10091}$ genau 0,0001 $D$ werde, ist nur nöthig, dass $m$, statt $=\frac{275 \cdot 2}{247 \cdot 9}$ etwas $<\frac{10}{9}$, genau $=\frac{10}{9}$ sei. Dies bewirkt man, indem man $W$ zn $a W$ rerkleinert, wo der Correctionsfactor $\propto<1$ aus

$$
\frac{\alpha W+L}{\alpha W}=\frac{10}{9}=m_{\alpha}
$$

zu berechnen ist. Man findet

$$
c=\frac{m-1}{m_{\alpha}-1},
$$

und erkennt den Schluss der Operation daran, dass das neue $J=J_{\alpha}$

$$
J
$$

ward. In obigem Falle wäre für die Graduationsconstante 0.0001 der Correctionsfactor $\alpha=0.9911 ; J_{\alpha}$ müsste $=278 \cdot 1$ sein, woraus $J_{1 \alpha}=250 \cdot 2$ folgt. 
Natürlich kann man auch ron vornherein sich rorsetzen, der Graduationsconstanten einen gewissen Werth, also z. B. 0·0001 Daniell zu ertheilen, und dazu wäre nur nöthig, $\boldsymbol{W}=9 L$ zu machen. Bei der Schwierigkeit Widerstände abzumessen, wird aber in der Praxis der angegebene Weg der kürzeste sein, [614] die Messung am Apparate selber rorzunehmen, wo die Widerstände gebrancht werden sollen. Ja es empfiehlt sich, nicht erst um den Correctionsfactor e sich zu bemühen, sondern ohme Weiteres $W$ tastend zu verändern, bis $\frac{J}{J_{t}}=m$ den gewünschten Werth zeigt.

Zweitens ist für gewisse Zwecke rortheilhaft, eine kleinere Gradnationsconstante bei kleinerem Umfang der Theilung zu haben, für andere Zwecke, bei grösserer Constanten über grösseren Umfang zu gebieten. Auch dies bewirkt man einfach, indem man in den Maasskettenkreis Drahtlängen einschaltet, beziehlich sie darans entfernt. Am besten hat man kleine Rollen vorräthig, deren Einschaltung, bei sonst unveränderter Anordnung, der Gradnationsconstanten bestimmte Werthe ertheilt, die in einem einfachen Verhältniss zu einander stehen.

Bei dieser Abhängigkeit der Graduationsconstanten ron $\mathrm{W}^{\prime}$ ist natürlich mmgekehrt die grösste Surgfalt darauf zu rerwenden, dass im Laufe der nämlichen Versuchsreihe $W$ constant sei. Die Veränderung von $W$ durch Verändermg des inneren Widerstandes der Kette, wie anch durch Erwärmung der Drähte (welche letztere anch auf $L$ sich erstreckt), ist nicht zu vermeiden, und fällt bei jedem Verfahren zur Bestimmung der Constanten voltaischer Kreise ebenso in's Gewicht. ${ }^{1}$

Dagegen ergiebt sich hier die Vorschrift, den Stromwender, dessen man bedarf, um dem Maasskettenstromzweig im Messkreise geeignete Richtung zu geben, in den Messkreis selber zu verlegen. Des letzteren Widerstand $\boldsymbol{M}$ fällt nämlich ans dem Ausdruck für $y$ heraus, weil im Falle des Gleichgewichtes kein Strom im Messkreise Hliesst. Daher auch die Widerstandsschwankungen an der reränderlichen Berührungsstelle $r$ unschädlich sind. Bei keinem Stromwender aber ist auf ganz gleichen Widerstand in beiden Stellungen zu rechnen, ja der Bau des PoHL'schen Gyrotropes bedingt sugar einen Unterschied des Widerstandes in beiden Lagen der Wippe.

[615] Ans derselben Rücksicht muss Schliessen und Oeffnen des Maasskettenkreises bei $U_{1}$ mittels eines dicken, wohl rerquickten Kínferdrahtes in Quecksilber (eines Quecksilberschlüssels) geschehen, nicht

1 Vergl. über die Art, die Erwärmung so unschädlich wie möglich zu machen. die letzte der drei oben S. $258 \mathrm{Anm}$. angeführten Stellen. 
mittels des gewöhnlichen Schlüssels, dessen Widerstand nicht beständig genug ist. ${ }^{1}$

Als Bussole empfiehlt sich beim Arbeiten mit dem Compensator ganz besonders die WiEdemann'sche Spiegelbussole wegen der Möglichkeit, nach Belieben rerschiedene Rollen aus passenden Entfernmgen auf den Spiegel wirken zu lassen. An Stelle von $B_{1}$ und $B_{2}$ in unserer Figur treten damn zwei Rollen $R_{1}$ und $R_{2}$, welche man abrechselnd in Gebrauch zieht. $R_{1}$ dient zur Messung ron $J$ und $J_{1}, R_{2}$ zur Beohachtung des Stromgleichgewichtes im Messkreise. Wird $R_{1}$ gebrancht, so steht der Messkreis bei $U_{2}$ offen; ist $R_{2}$ an der Reihe, so wird $R_{1}$ ron der Bussole soweit entfernt, dass $R_{1}$ micht mehr merklich auf den Spiegel wirkt. Das Erkennen des Stromgleichgewichtes im Messkreise wird sehr erleichtert durch Anwendung eines Spiegels, der schwingungslos oder dessen Bewegung aperiodisch gemacht ist, ${ }^{2}$ und einer horizontal in ihrer eigenen Ebene rerschiebbaren, auf jeder Seite ron Null ans getheilten Scale. ${ }^{3}$

Rolle $R_{1}$ ist so zu wählen, dass sie hei genügender Wirkung auf den Spiegel möglichst kleinen Widerstand habe, damit $J$ und $J$, hinreichend ron einander sich unterscheiden. Rolle $R_{2}$ ist mit Rücksicht auf den wesentlichen Widerstand der Kette $K_{2}$ so zu wählen. dass sie bei eben gestörtem Gleichgewicht im Messkreise, grösste Wirkung giebt, d. h. nach bekannten Gesetzen muss ihr Widerstand gleich dem Widerstande sämmtlicher im Zustande des Gleichgewichtes zwischen den Enden der Rolle befindlichen Leitungen sein. Ist die Kette $K_{2}$ ein Muskel (wie in der Figur) oder ein Nerv, so wird $R_{2}$ am besten die Beschaffenheit haben, die man dem Gewinde einer für thierisch-elektrische Ströme bestimmten Bussole giebt.

[616] Am Compensator ist der $1^{\mathrm{mm}}$ dicke und etwa $37 \cdot 5^{\mathrm{cm}}$ lange Nebenschliessdraht aus Platin um den Umfang einer kreisrunden Scheibe aus Kammmasse gespamt, und bewegt sich bei Drehung der Scheibe am Röllchen $r$ hin, dessen Axe feststeht. Diese von Hrn. Halske ersonnene Eimrichtung hat ror der zuerst sich darbietenden, bei der das Püllchen einem gerade ausgespanten Draht entlang sich rerschiebt, den Tortheil, dass die Hand, welche die Terschiebung vonimmt, an derselben Stelle und auch der Ort der Ablesung der nämliche bleilht. Anstatt dem Draht entlang suchen zu müssen, wo das Röllchen steht, brancht das Auge

1 S. oben S. 172. - [Ueber den Quecksilberschlüssel vergl, die folgende Abhandilung XI. §. 1. S. 266, 267.]

2 Vergl, unten die Abhandlungen XII-XV.

3 S. oben S. 156. 
nur zwischen Ocular des Fernrohres und Lupe des Compensators hin und her zu gehen.

Nachdem der Compensator solchen festen Stand erhielt, dass dies leicht geschieht, werden zwischen den Ḱlemmschrauben $I$ und $I I$ die Maasskette, die Rolle $R_{1}$ und der Qnecksilberschlüssel angebracht. Die Klemmschrauben $I I I$ und $I V$ werden zunächst mit der Wippe eines Stromwenders rerbunden, jenseit dessen der Schlüssel $U_{2}$, die Kette ron zu bestimmender Kraft und Rolle $R_{2}$ sich befinden. Ton $I, I I, I I I$ und IV gehen Leitungen zu entsprechenden Zahlen am Instrumente. III entspricht dem Röllchen $r, I V$ dem Punkte 0, I dem Punkt $S$ oder rielmehr dem noch zu erwähnenden Punkte $\Sigma$, endlich $I I$ dem Punkt $N$ des Schema's.

Die Scheibe des Compensators trägt eine nicht in Grade, sondern in 1000 Theile (Compensatorgrade, Cgr.) getheilte Theilung; der Nullpunkt dieser Theilung sull dem in der Figur mit 0, der tausendste Theilstrich dem dort mit $S$ bezeichneten Punkt entsprechen. Demgemäss geht beim Theilstrich 0 der Platindraht über eine Platinschneide, beim tausendsten Strich tritt er auf eine Kupfermasse ron rerschwindendem Widerstand, und der Winkelabstand beider Punkte ist möglichst gleich gemacht dem Winkelwerthe der tausend Compensatorgrade.

Es handelt sich aber num darum, die Stellung des Röllchens zu finden, welche dem Punkte 0 entspricht. Dies geschieht mit grosser Schärfe rermöge des Umstandes, dass man dem Röllchen über die Schneide bei 0 hinans die in der Figur punktirte Stellung geben kann. Dabei ist die Richtung des [617] Maasskettenstromzweiges im Messhreise die entgegengesetzte von dem bei der Stellung des Röllchens zwischen 0 und $S$. Indem man in den Maasskettenkreis eine kräftige Kette einführt, dem Messkireise, in welchem keine elektromotorische Kiraft thätig sein darf, möglichst kleinen Widerstand und der Bussole im Messkreise möglichst grosse Empfindlichkeit giebt, kam man sehr genan den Punkt finden, wo der Strom seine Richtung ändert. Ian hat vorher die Schraube, welche den festen Zeiger über dem Röllchen fixirt, mittels eines Stellstiftes so weit gelöst, dass der Zeiger mit sanfter Reibung sich rerschiebt. Jetzt rückt man ihn seitlich bis der Strich darauf mit dem Nullstrich zusammenfällt, und zieht die Schraube wieder an.

Ist die Anfstellung des Instrumentes so weit gediehen, so kamm es schon dazu dienen, das Terhältniss elektromotorischer Kräfte, die in seinem Bereiche liegen, zu bestimmen. Um die Graduationsconstante der Vorrichtung zu finden, ist es num aber noch nöthig. den Maasskettenkreis abwechselnd mit Ausschluss und mit Einschluss der Strecke des Nebenschliessdrahtes ron 0 bis $\mathfrak{S}$ zu schliessen. Es muss also das in der Figur 
an $\boldsymbol{S}$ stossende Ende des Maasskettenkreises mit 0 rerbunden, oder $\boldsymbol{K}_{1} p S$ in der Figur in die Lage $\boldsymbol{K}_{1} q 0$ gebracht werden kömnen.

Natürlich liefe es auf dasselbe hinaus, wemn ein Punkt $\boldsymbol{\Sigma}$ des Maasskettenkreises (s. die Figur) durch eine Leitung ron rerschwindendem Widerstande $(\Sigma 0$ oder $\Sigma S$ ) abwechselnd mit 0 und $S$ rerbunden würde. Dazu dient der am Compensator befindliche drehbare Kupferbügel. Die beiden Enden des Bügels sind an ihrer oberen ebenen Fläche mit Platin bekleidet, und kömnen mittels starker Schrauben den an ihrer unteren ebenen Fläche gleichfalls mit Platin bekleideten Kupfermassen angedrückt werden, von denen die rechts befindliche eine möglichst gute Leitung zum Punkte 0, die andere eine solche zum Punkt $S$ rermittelt.

Indem man den Bügel zuerst nach rechts dreht, welche Stellung in der Figur punktirt ist, erhält man $J$, indem man ihn dann nach links dreht, $J_{1}$. Beim nachmaligen Gebrauche des Instrumentes, falls man während dessen die Graduations- [618] constante nicht zu revidiren beabsichtigt, bleibt der Bügel in letzterer Stellung, welche in der Figur ausgezogen ist.

Ist der Nullpunkt des Compensator's einmal festgestellt, so bedarf es, um die Graduationsconstante zu kennen, wegen der Proportionalität der elektromotorischen Kräfte mit den Abständen $0 r$, nur noch der Kenntniss des Werthes eines einzigen Punktes der Theilung. Solche Bestimmung erlangt man ohne $J$ und $J$, zu messen, indem man $K_{2}$ durch eine Thermokette ersetzt, deren elektromotorische Kraft ein bekannter Bruchtheil der Kraft der Maasskette ist.

Dass in grosser Nähe des Nullpunktes so wie des 1000-Cgr-Punktes die Messumgen fehlerhaft werden, weil die Strömung nicht mehr senkrecht auf die Längenausdehnung des Drahtes geschieht, ist bekanntlich gleichfalls ein Fehler, den sämmtliche galranische Messrorrichtungen mit der beschriebenen theilen.

Excentricität der Scheibe ist gleichgültig, wemn nur Theilung und Draht concentrisch sind. Excentricität des Röllchens bedingt periodische Schwankung des Werthes der Compensatorgrade. 
XI.

\section{Fortgesetzte Beschreibung nener Vorrichtungen für Zwecke der allgemeinen Nerven- und Iluskelphysik. ${ }^{1}$}

\section{§. I. Der Quecksilberschlüssel.}

Hr. Poggendorff war es bekamntlich, der in die galranische Technik an Stelle der bis dahin üblichen Quecksilbernäpfe. in welehe jrerquickte Kupferhaken tauchten, die unter dem Namen Klemmschrauben gebräuchlichen festen Terbindungen einführte: ${ }^{2}$ eine Verbesserung, :die

Fig. 18.

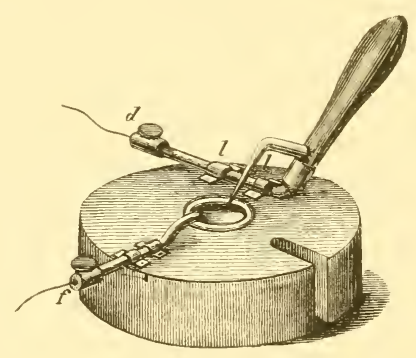

man erlebt haben muss, um den dadurch gemachten Fortschritt zu würdigen. Die Klemmschrauben haben aber den Nachtheil, kein schnelles und regelmässiges Schliessen und Oethinen des Krreises zu erlauben. Man

1 Ans Poggendorff's Anualen der Physik und Chemie. 1573. Jubelband. S. 591. - Vergl. oben die Abhandlung VIII: Beschreibung einiger Vorrichtungen und Versuchsweisen zu elektrophysiologischen Zwecken. Aus den Abhandlungen der Berliner Akademie 1862. Berlin 1 $₫ 63.4^{0}$. - Sämmtliche in gegenwärtigem Aufsatze beschriebene Vorrichtungen liefert die Werkstatt des Hrn. Otto Plath (SauerWALD) in Berlin in gewohnter Vollkommenheit.

2 Poggendorff's Annalen u. s. w. 1<+0. Bd. Xlix. S. 39. 
brancht dazu heide Hände, und muss wenigstens heim Schliessen hinsehen, so dass man nicht zugleich heob- [592] achten kann. Dies führte später zur Construction des nach Analogie des Organs am Monse'schen Telegraphen sogenamnten Schlüssels, ${ }^{1}$ der zum Unterschiede von dem bei chronoskopischen Beohachtungen üblichen Federschlüssel genauer als Vorreiberschlüssel ${ }^{2}$ zu bezeichnen ist. Dieser Schlüssel leistet zwar treffliche Dienste; er hat aber, worauf ich übrigens gleich bei dessen Beschreibung hinwies, den Fehler, dass sein Widerstand schwankt, daher er in gut leitenden Kŕreisen oft nicht anwendbar ist. Alsdam empfiehlt es sich, zum Qnecksilher zurückzukehren, so jedoch, dass anch hier Schliessen und Oeffnen ohne hinzusehen in hinlänglich gleicher Art geschehen kam. Wo beim Schluss in Quecksilber höchste Gleichmässigkeit verlangt wird, ist der elektromagnetische Fallhammer am Platze. ${ }^{3}$ Für riele Zwecke reicht die in Fig. 18 abgebildete Anordnung ans, die ich den Qnecksilberschlüssel nenne. Sie ist minder umstänllich als der Fallhammer, und anch für Oeffnumg des Kreises zu benutzen. In einer kreisrunden Holzscheibe, die man mit einer Flügelschraube am Tisch befestigt, ist ein Porzellannäpfehen eingelassen, und nimmt das Quecksilber auf. Zwei starke Knupferdrähte tanchen mit rerquickter Spitze in's Quecksilber, und endigen andererseits in Klemmschrauben. Einer dieser I)ähte $(f)$ ist fest, der andere $(d)$ lässt mittels eines hebelartig daran befestigten, isolirenden Handgriffes so um seine Axe sich drehen, dass seine rerquickte Spitze in das Quecksilher bald eintancht, bald nicht. Die Drehmig geschieht in den Lagern $l, l$, mit soriel Reibung, dass die Torsion des bei $d$ eingespannten Zuleitungsilahtes den Hebel nicht zu drehen rermag.

\section{§. II. Die Doppelwippe.}

Hr. Poggendorff hat bei seimen simmreichen Versuchen über galvanische Polarisation ${ }^{4}$ meines Wissens zuerst Wippen [593] gebaut, die verwickeltere Aufgaben lüsten, als nur, wie der Avrè̇eE'sche und PoнL'sche Stromwender, den Strom in einer Strecke seiner Leitung umzukehren. Seitdem wurden rieltach Wippen zu besonderen Zweeken angegeben, und jeder Elektriker rerfertigt sich gelegentlich die gerarle nöthige Form.

1 s. oben S. 171 .

2 Levier-clef bei Hrn. Marey, Du Monvement dans les Fonctions de la Vie. Paris 1=68, p. 317. 318 .

3 Vergl. Pruẗger, Untersuchungen ïber die Physiologie des Electrotonus. Berlin 1859. S. 110. - Vergl. oben s. 222. Anm. 1.

4 Poggendorff's Annalen u. s. w. 1844. Bd. LXI. S. 586. 
Eine Aufgabe indess kehrt, gleich der blosser Stromumkehr, so oft wieder, dass es sich lohnt, das Organ zu ihrer Lösung jederzeit bereit zu haben. Es ist die, zwei Stromstrecken mit einander zu rertauschen. Die Bedentung dieser Anfgabe wird klarer in dem besonderen Falle, wo meine sogenaunte Doppelwippe mir in meinen Vorlesungen so gute Dienste leistet, dass ich sie den Fachgenossen als nützliche Bereicherung unseres Apparates empfehlen darf.

Der Einfluss, den Anelektrotonns und Katelektrotonus des Nerren nach Hrn. Pfü̈Ger auf die Erregbarkeit üben, lässt sich bekanntlich nicht leichter als auf die ron Hrn. RosenthaL eingeführte Art nachweisen, nämlich durch den rerschiedenen Abstand der Nebemrolle ron der Hauptrolle des Schlitteninductoriums, bei dem die ersten Zuckungen erscheinen. Nachdem man nun z. B. Anelektrotonus und Katelektrotonus in der centropolaren Strecke gezeigt hat, soll dasselbe in der myopolaren Strecke geschehen, d. h. die vorher elektrotonisirte Strecke ist in den Kreis der tetanisirenden Nebemrolle, die vorher tetanisirte Strecke in den der elektrotonisirenden Kette, zwischen die Endklemmen des Rheochords, aufzunehmen. Da hierbei nicht bloss ein Irrthum, sondern auch eine Verrückung des Nerven auf den Elektroden des RosenthaL'schen Troges ${ }^{1}$ leicht ror- [594] kommt, ist es misslich, den Wechsel aus freier Hand rorzmehmen, und sehr erwünscht, ihn mechanisch mit Eimem Schlage ausführen zu können.

Hr. WID hat bereits, zu einem anderen Zweck, eine Wippe beschrieben, die letateres leisten würde. ${ }^{2}$ Sie lässt im Princip auf zwei in bestimnter Art rerbundene PoHL'sche Stromwender sich zurückführen,

1 Der Rosenthal'sche Trog ist eine nach dem Principe meiner ,feuchten Reizungsröhre“ (S. oben S. 211) gebaute Zuleitungsvorrichtung für Reizversuche, die aber, statt nur Ein Elektrodenpaar, deren vier, jedes mit entsprechendem Klemmenpaare, besitzt. Der Trog ist aus Kammmasse. Denkt man sich ihn als Boot - er gleicht in der That ganz einem sogenannten Einbaum - so stellen die Elektrodenpaare die Ruderbänke vor. Vom Schnabel des Bootes her, der dem Präparat in der Kniekehle angedrückt wird, brückt man den Nerven über die Elektrodenpaare hin, und schützt ihn vor Trockniss durch eine darüber gedeckte Glasplatte. Da indess der mit Wassergas zu sättigende Raum hier grösser ist als bei der Reizungsröhre, so wird ein feuehter Fliesspapierstreif dem Boden des Troges unter den Elektrodenparen entlang gelegt. Die vier Elektrodenpaare liegen in der richtigen Entfernung vom Schnabel, um an mittellangen Nerven die Versuche über verschiedene örtliche Erregbarkeit, deren Aenterung beim Absterben und im Elektrotonus, u. d. m., anzustellen. Mittels eines Kugelgelenkes lässt sich dem Rosenthal'sehen Trog in gewohnter Art jede erforderliche Lage im Raum ertheilen.

2 Vierteljahrsschrift der Naturforschenden Gesellsehaft in Zürich. 2. Jahrgang. 1857. S. 230. 
und in der That erreicht man dasselbe mittels zweier solcher Stromwender ohne Kreuz, die auf gemeinsamer Grundlage so befestigt sind, dass die Axen ihrer Wippen in Einer Geraden liegen, und die Wippen in Einem Stücke sich hewegen. Schon in meinem Aufsatz „Ueber nicht polarisirbare Elektroden" 1 habe ich diese Anordnung schematisch abgebildet. Sie diente mir damals um abwechselnd die Bussole und den Rheostat von gleichem Widerstande beziehlich in den ursprünglichen und den secundären Kreis einzuschalten, und umgekehrt. Jetzt habe ich die Doppelwippe als fertiges Instrument im Laboratorium vorräthig. Sie besteht aus zwei PoHL'schen Stromwendern, die in der angegebenen Art auf ein Grundbrett geschraubt sind. Ihre Wippen sind mittels eines isolirenden Verbindungsstückes gekuppelt, lassen sich aber anch ron einander trennen, und die Stromwender selber können rom Grundbrett entfernt und einzeln gebraucht werden. Eine Flügelschraube befestigt das Grundbrett anf dem Tische. Die vier Klemmen auf der einen Seite der gemeinschaftlichen Axe sind Doppelklemmen, um in jeder die beiden Drähte einspannen zu können, deren Nothwendigkeit für den rorliegenden Zweck aus der angeführten Figur erhellt, und die in Hrn. WILD's Wippe durch das Doppelkreuz dauernd ersetzt sind.

\section{§. III. Die Froschpistole.}

Die Hemmung des im Nerven sich fortpflanzenden Reizes durch Zerstören des organischen Gefüges, z. B. durch Unterbinden des Nerren, einer grösseren Versammlung überzeugend darzulegen, ist nicht so leicht,

Fig. 19.

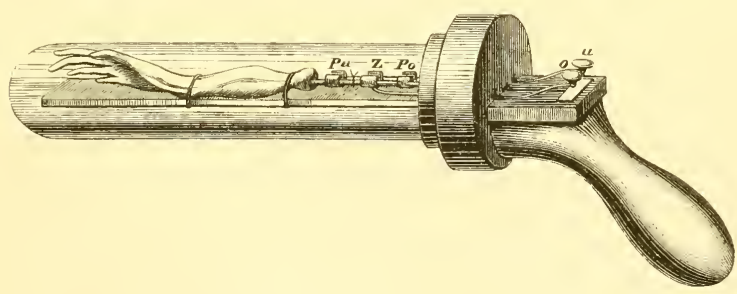

wie es scheinen mag. Ich habe vor langer Zeit eine Vorrichtumg beschrieben, die durch blossen Druck auf einen Hebel, ohme Zerrung und

1 S. oben S. 51. 
Terrückung, einen Nerven unterbindet. ${ }^{1}$ In Terbindung mit dem Zuckungstelegraphen ${ }^{2}$ erlaubt sie sehr schön zu zeigen, dass Reizung oberhalb des Unterbandes unwirksam, unterhalb wirksam ist. ${ }^{3}$ Allein die zunächst Sitzenden ausgenommen muss de Versammlung auf Treu und Glauben sich erzählen lassen, was geschah, den sinnlichen Eindruck der Thatsache erhält sie nicht.

Diesem Mangel hilft die in Fig. 19 dargestellte Turrichtung ab, die meine Zuhörer die Froschpistule nemnen. Ein stromprüfender Schenkel ist auf einem Spiegelglasstreifen befestigt, der. in die der Revolvertrommel entsprechende Holzscheibe an der Fruschpistole gekittet ist. Ueber dem Streifen schweben, durch Drähte, welche die Holzscheibe durchbohren, [596] getragen, und zum Empfang des Nerren bestimmt, hintereinander drei Elektroden. Die unterste, dem Kinie zunächst gelegene, $P_{u}$, besteht ans Platin, die mittlere $\boldsymbol{Z}$ aus Zink, die oberste $\boldsymbol{P}_{\mathrm{o}}$ wieder aus Platin. Die Elektroden sind so gebogen, dass sie eine Rimne bilden, aus welcher der Nerv bei keiner Stellung der Torriehtung heransgleiten kamn. Zwischen $Z$ und $P_{u}$ ist der Nerr unterbunden. Wird $Z$ mit $P_{o}$ metallisch rerbunden, so erfolgt also keine Zuckung; $Z$ mit $P_{u}$ dagegen giebt Zuckung. Ein aufgeschraubtes Glasrohr schützt das Präjarat vor Trockniss. Die Terbindungen werden aussen durch Druck auf zwei federnde Elfenbeinknöpfe bewirkt, die beziehlich mit o (oberhalb) und $u$ (unterhalb des Unterbandes) bezeichnet sind. Wenn man die Vorrichtung wie eine Pistole am Kolben ergreift, trifft der Daumen gerade auf die Knnöpfe. Ist der Frosch gut leistungsfähig, so kamn die Torrichtung durch hundert Hände gehen. ohne dass Zuckung zu erscheinen aufhört. Da die Leitungen dem Biick offen liegen, wird so jedem Einzelnen die MIöglichkeit gewährt, von der Grundwahrheit der allgemeinen Nerrenphysik durch Anschaumg sich zu überzeugen.

Auf den Umstand, dass der Strom in der unteren Strecke ab-, in der oberen auisteigt. kommt es an dieser Stelle des Vortrages noch nicht an. Mit drei Elektroden aus zwei Metallen sind natürlich mancherlei Combinationen möglich, ansser obiger noch fünf. Die ausgenommen, wo Platin in der Mitte, Zink oben und unten sich befindet, und wobei anch der Strom in beiden Strecken umgekehrt fliesst, haben sie alle den Nach-

1 Untersuchungen über thierische Elektricität. Bi. IJ. Abth. I. \&. 341 . Taf. III. Fig. 109. 110. A. B.

2 S. oben S. $20 \%$.

3 Proceedings of the Royal Institution of Great Britain. April 13, 1566. E. DU Bons-Rermoxd, on the Time required for the Transmission of Volition and Sensation throngh the Nerves. 
theil, dass bei Reizumg oberhalb des Unterbandes der Strom der doppelt so langen Nerrenstrecke wegen fast zweimal schwïcher ist als bei Reizung unterhalb, so dass auch so die Reizung nicht beidemal, bis auf das Unterband, in einerlei Art geschieht.

\section{§. IV. Das Federmyographion.}

Die Myographien zerfallen wesentlich in zwei Kilassen. ${ }^{1}$ Die erste Klasse umfasst die beschleunigt oder stetig rotirenden [597] Myographien. Der Art sind das ursprüngliche Hesmнoctz'sche Myographion mit meinen Aenderungen, ${ }^{2}$ das VALExtin'sche Kreisscheiben-Myographion, ${ }^{3}$ und das 'THiRy'sche Iyographion, in welchem, nach Foucault's Vorgange bei seinen Lichtgeschwindigkeitsmessungen, eine sirene das Uhrwerk ersetzt. ${ }^{*}$

Diese Myographien leiden an mehreren principiellen Fehlern. Erstens darf der Stift erst kurz vor der Zuckung der Zeichenfläche angelegt werden, was nur durch verwickelte Vorkehrungen gelingt. Zweitens vergeht zu viel Zeit zwischen je zwei Versuchen. Drittens ist es zu schwer, sowohl den Zeitpunkt zu erkennen, wo die gewünschte Geschwindigkeit erreicht ist, als auch die Geschwindigkeit zu hestimmen, die im Augenblick des Versuches wirklich herrschte. Endlich viertens verwirren sich bei grösseren Geschwindigkeiten, wo sie mehr als einen Cylinderumfang einnehmen, die Myogramme in einer Art, die bei Demonstrationen sehr störend ist, aber auch bei Untersuchungen lästig fällt.

Diese Uebelstände haben die rotirenden Myographien in den Hintergrund gedrängt, und zur Erfindung der zweiten Klasse ron Myographien geführt, in welchen der Zeichenfläche eine bestimmte und ausreichende Geschwindigieit in praktisch rerschwindender Zeit ertheilt, und sogleich ehenso schnell wieder genommen wird. Dies erlaubt in kurzer Frist eine grosse Zahl ron Versuchen anzustellen, und da die Platte vor dem Versuche ruht, kann der Stift ihr schon vorher anliegen. Freilich lassen diese Myographien die schöne, von Hm. Henмnoltz für den Cylinder seines Instrumentes angegebene Art, die Zeichenfläche zu berussen und

1 Das Pflüger'sche Myographion, welches gleichsam nur ein Helmholtz'sches Myographion mit stillstehendem Cylinder ist, kommt hier nicht in Betracht.

2 Vergl. A. v. BEzoLd, Untersuchungen über die electrische Erregung der Nerven und Muskeln. Leipzig 1861. S. \$5.

3 Grundriss der Physiologie. 4. Aut. Braunschweig 1855. S. 529; - Die Zuckungsgesetze des lebenden Nerven und Muskels. Leipzig und Heidelberg 1863. S. 12.

4 Henle's und Pfeufer's Zeitschrift für rationelle Medicin. 3. R. Bd. XXI. 1864. S. 300 . 
die Myogramme abzuklatschen, nicht zu, und man wird kaum einen Ersatz dafür darin sehen, dass sie das Projiciren der Original-Nyogramme mittels der [598] magischen Laterne gestatten. ${ }^{1}$ Sie haben ferner den Nachtheil, dass mit der Geschwindigkeit der Platte deren zur Aufnahme des Myogrammes nöthige Länge wächst. Dennoch zweifle ich nicht, dass dieser Klasse ron Myographien die Zukunft gehört.

Der Art sind das ATwood'sche Myographion von E. Harless, ${ }^{2}$ welches Hr. Jendrássik in Pest neulich wieder hervorgesucht hat, ${ }^{3}$ und Hrn. Fick's Pendelmyographion, ${ }^{4}$ welches von Hrn. Heцsнortz vervollkommnet wurde, ${ }^{5}$ in dieser Form aber meines Wissens noch nicht beschrieben worden ist.

Die Betrachtung, dass man durch Federkraft in kleinerem Raum und kürzerer Zeit dieselbe Summe beschleunigender Kräfte zur Wirkung auf eine Masse bringen kamn, als durch Fallkraft, und dies in behebiger Richtung, führte mich zur Construction eines dritten Myographions dieser Klasse, des Federmyographions. Obschon auf den ersten Blick dies Myographion dem Fall- und dem Pendelmyographion an mechanischer Vollkommenheit nachzustehen scheint, hat es sich doch gut bewährt, und überdies besitzt es gewisse micht $\mathrm{zu}$ verschmähende Vortheile.

Im Federmyographion (s. Fig. 20) wird die Zeichenplatte durch eine Sprungfeder, ähnhich der in den Ḱnabenflinten und Zündnadelgewehren, einer wagerechten Führumg gleichsam entlang geschossen. Der Platte gegenüber sind Schreibewerk und Muskelhalter eines PfuÜGer'schen (Hewsholtz'schen) Myographions aufgestellt. Da dieser Theil der Vorrichtung, mit [599] Ausnahme der später zu beschreibenden Zuleitung für den erregenden Strom, ron dem entsprechenden Theil anderer Myographien nicht wesentlich abweicht, so blieb er in der Zeichnung fort.

Man sieht hier zunächst eine gusseiserne Schiene, auf der zwei kräftige Winkelstücke oder Ständer aus Messing $A, B$ sich erheben. Ein leichter Jessingrahmen nimmt die $160^{\mathrm{mm}}$ lange, $50 \mathrm{~mm}$ breite Zeichenplatte aus $2 \cdot 3^{\mathrm{mm}}$ dickem Spiegelglas auf. Der Rahmen läuft mit mög-

1 Proceedings of the Royal Institution etc. p. 11. (1866). - Vergl. Marey, Du Mouvement dans les Fonetions de la Vie. 1868. p. 191.

2 Abhandlungen der K. Bayerischen Akademie der Wissenschaften. II. Cl. Bd. IX. Abth. II. München 1862. S. 361.

3 Fall-Myographion. Aufgestellt in der Wiener Weltausstellung in der Abtheilung für das Unterrichtswesen von Ungarn. Budapest 1873. $4^{\circ}$.

4 Vierteljahrsschrift der Naturforschenden Gesellschaft in Zürich. 1862. S. 307;

- Frck, die medicinische Physik. 2. Anfl. Braunschweig 1866. S. 86.

5 Verhandlungen der physikalisch-medicinisehen Gesellschaft in Würzburg. N. F. 1872 . Bd. II. S. 147. 
lichst wenig Reibung an zwei zwischen den Ständem $A, B$ parallel ausgespannten Stahldrähten. Der Abstand der Ständer ist gleich der doppelten Länge des Rahmens, so dass die Platte dem Stift in ihrer ganzen Länge vorïbergeht, wenn der Rahmen von Ständer zu Ständer verschoben wird. An den kurzen Seiten des Rahmens sind runde Stahlstäbe eingeschranbt welche die ron ihm zu durchlaufende Bahn etwas an Länge übertreffen, und mit möglichst wenig Reibung durch Löcher in den Ständern $A, B$ gehen. Das Ende $b$ des einen dieser Stäbe ist mit einer stählernen Sprungfeder umgeben. Indem man sie zwischen dem ständer $B$ und

Fig. 20.

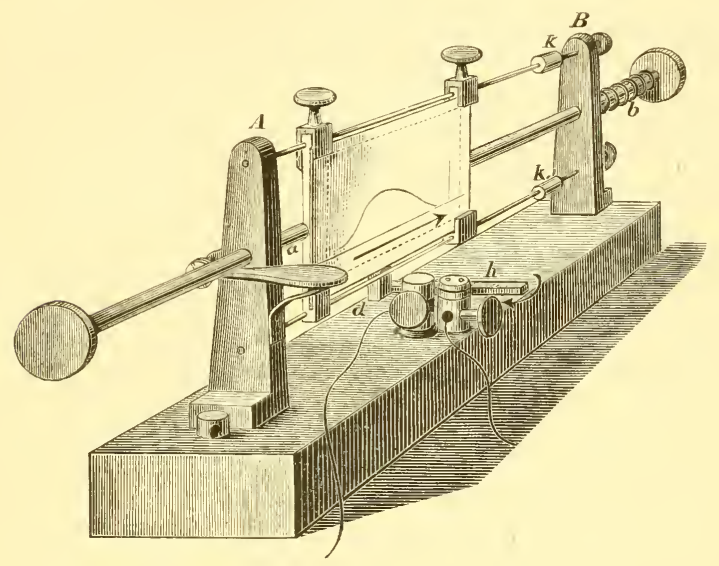

einem Knopf am Ende des Stabes zu- [600] sammendrückt, und so den Rahmen mit den Stäben ron $B$ nach $A$, dem Pfeil anf der Zeichenplatte entgegen (s. die Fig.), hintreibt, kommt ein Punkt, wo der am Ständer A sichtbare, nach oben fedemde 'Abzug' in einen entsprechenden Kerb des Stabes bei $a$ eingreift, und die Wiederauslehmung der Feder verhindert. Sie bleibt also gespannt, bis ein Druck auf den Abzug den Rahmen befreit, der nun mit einer von der Kraft der Feder, der Masse des Systemes, und der Reibung abhängigen Geschwindigkeit den Drähten entlang in der Richtmo rom $A$ nach $B$ oder des Pteiles anf der Platte Hiegt.

Die Geschwindigkeit wächst bis zn dem Punkte, wo die Feder ihre Ruhelage überschreitet. In der diesem Pnnkt entsprechenden Lage des E. du Bois-Reymond, Ges. Abh. I. 
Rahmens schlägt ein an dessen unterem Rande befindlicher Daumen d einen Hebel $h$, der bis dahin den Hauptstrom des Inductoriums geschlossen hielt, in der Richtung des Pfeiles in der Figur ron seinem Anschlage fort, und löst so den reizenden schlag aus. Die Figur stellt diese Lage vor. Der Hebel ist um seine Axe mit soriel Reibung drehbar, dass er, obschon in wagerechter Ebene beweglich, dem Anschlage doch fest genug anliegt, um keine ungehörigen Zuckungen zu reranlassen. Die Kraft des Rahmens ist an dieser Stelle so gross, dass der Stoss, den er durch Fortschlagen des Hebels erhält, keine merkliche Unstetigkeit seines Laufes erzeugt. ${ }^{1}$

[601] Vun hier nimmt die Geschwindigkeit des Rahmens wegen der Reibung ab. Bei Anwendung stärkerer Federn langt er aber noch mit mehr oder weniger Geschwindigkeit am Ständer $B$ an, und es handelt sich darum, diese Geschwindigkeit unschädlich zu machen, namentlich zu verhüten, dass der Rahmen zurückspringe, da er damn den Stift unter stumpfem Winkel trifft und ihm einen heftigen Stoss ertheilt. Das Nittel hierzu ist sehr einfach. Auf die Führungsdrähte sind Korke $k, k$, aufgezogen und daran mit Reibung rerschiebbar. Diese dienen als Bremsen. Je nach der Geschwindigkeit des Rahmens entfernt man sie mehr vder weniger rom Ständer $B$. In der Ueberwindung ihrer Reibung an den Drähten erschöpft sich harmlos die Kraft des Rahmens.

Es fragte sichr, ob, bei dem Spiele, das den Führungsdrähten in den

1 Thiry und Hr. Meyerstein scheinen wegen der geringen hraft ihrer Sirene hier auf Schwierigkeiten gestosseu zu sein, denen sie nur durch verwickelte Hülfsvorrichtungen zu begegnen vermochten (Henle's und Pfeufer's Zeitschrift $\mathrm{u}$. s. w. A. a. O. S. 302), - Hr. Fick hat an Stelle des Schlusses durch feste metallisehe Theile den durch Quecksilber gesetzt (Zürcher Vierteljahrsschrift, a. a. O. S. 312). Ich halte dies für keine Verbesserung, da das Austauchen der Spitze gewiss nicht inmer bei derselben Stellung der pendelnden Platte erfolgt. Viel eher war dies der Grund des Misslingens seiner Versuche über Fortptlanzungsgesehwindigkeit der Erregung, als, wie er meint, die zu geringe Grösse seiner Frösehe, deren Nerven denen norddeutscher Frösche ja nur um $1 / 5$ an Länge nachstanden (a. a. 1). \$. 317). Hr. MAREY, der sich das Verdienst erwarb, die Myographie nach Frankieich zu verptlanzen und nach mehreren Richtungen auszudehmen, hat sich einer neuen Art bedient, die lieizung zu erzengen und leren Augenblick zu verzeichnen. Er reizt durch Schluss einer Kette, und lässt einen Hebel, durch dessen Berïhrung der Schluss geschicht, auf der Zeichentläche den Augenblick der Berührung angeben. (Du Monvement dans les Fonetions de la Vie, p. 422 et suiv.) Hr. Marex sagt nicht, was ihn bewog, dies umständliche nnd in mehrfacher Beziehung bedenkliche Verfahren an Stelle des so einfachen und ganz untadligen HesshoLtz'schen Kun griffes zn setzen. In Deutschland hielten wir letzteren stets für eine der glücklichsten Eingebungen des Erfinders des Myographions. 
Löchern des Rahmens gelassen werden muss, die Führung treu genug sein würde, damit nicht durch Aussetzen des Stiftes Lücken in der Zeichnung entständen. Wirklich lag hierin eine Sthwierigkeit, so lange, wie es am Heцанодтz'schen Schreibewerke der Fall ist, das Andrücken des Stiftes an die Platte der Fallkraft anvertraut wurde. Diese Schwierigkeit rerschwand aber, seit Hr. Prof. Bersstess, der in meinem Laboratorium mit dem Federmyographion arbeitete, statt der Schwere Federkraft, zunächst die eines Kuautschukbändchens, anwandte. Auch hier kommt in Betracht, dass Elasticität in kleinerem Ram und kürzerer Zeit dasselbe leistet, wie Schwere. Hr. Fick hat schon zu demselben Kunstgriff Zuflucht genommen. ${ }^{1}$

Unter einerlei Umständen entworfene Myogramme decken sich am Federmyographion so vollkommen, wie an anderen [602] Myographien. Eine Ausnahme machen nur die letzten Stadien der Zuckung bei kleiner Anfangsgeschwindigkeit, wo die Hemmung durch die Reibung nicht stets genau gleich verläuft. Doch kommt auf diese Stadien nur selten etwas an. Denselben Fall ausgenommen, lassen auch Stimmgabelcurven von einem Nale zum anderen keinen Unterschied erkennen.

Was die an Federmyographion erreichbare Geschwindigkeit der Zeichenfläche betrifft, so erfüllte sich meine Erwartung vollständig. Die Triebfeder des Iyographions lässt sich leicht wechseln. Ich habe deren drei, die, mit einer Köstg'schen Unterbrechungsgabel ron 128 Doppelschwingungen $\left(U t_{2}\right)$ geprüft, folgendes Ergebniss liefern.

Die Maximalgeschwindigkeit, bei der die Reizung geschieht, ist für

$\begin{array}{crrr}\text { Feder } & \text { I. } & 1088 & \mathrm{Mm} . \\ . & \text { II. } & 1536 \quad " \\ , & \text { III. } & 2522 & \end{array}$

in der Secunde. Mit letzterer Feder sinkt die Geschwindigkeit bis zu ihrer Vermichtung durch die Bremskorke im Verhältnisse von 1:0.87; mit Feder II in dem ron $1: 0 \cdot 58$; mit Feder I bleibt die Platte vor den schon ganz an den Ständer geschubenen Korken stehen.

Nimmt man 27 M. in der Secunde als Geschwindigkeit der Reizung in Nerren an, so betrüge bei obigen Geschwindigkeiten, und bei $50 \mathrm{~mm}$ Abstand der Reizstellen, der horizontale Abstand der Zuckungscurven beziehlich $2 \cdot 0 ; 2 \cdot 8 ; 4 \cdot 7^{\mathrm{mm}}$. Um durch Fallkraft diese Geschwindigkeiten zu erzengen, bedarf es im leeren Raum einer Fallhöhe von beziellich $60 \cdot 3 ; 120 \cdot 3 ; 324 \cdot 3^{\mathrm{mm}}$. Damit ein mathematisches Pendel rou

1 Zürcher Vierteljahrsschrift, a. a. O. S. 315.316. 
$1000^{\mathrm{mm}}$ Länge beim Durchgang durch die Ruhelage diese Geschwindigkeiten erlange, muss es ans Ablenkungen von beziehlich etwa 20; 28; $42^{\circ}$ fallen. Die dazı gehörigen Bogenlängen sind beziehlich etwa 175; 244; $366^{\mathrm{mm}}$. Mehr als doppelt so lang müssten, im Bogen gemessen, die Zeichenplatten sein, damit der Stift ihnen schon in der Ruhe anliegen könnte. Noch beträchtlicher wären am ATwood'schen Myographion die zur Erzengung derselben Geschwindigkeiten nöthigen Fallhöhen, da, um die Geschwindigkeit constant [603] zu erhalten, die Fallhöhe in dem Verhältniss vergrössert werden muss, in welchem die Beschleunigung durch Vertheilung auf grössere Masse verkleinert ist. Auch hier wäre also eine sehr unbequeme Länge der Platte nöthig, damit der Stift schon in der Ruhe ilır anliegen könnte. Freilich beschränkt sich Hr. JExDRássik an seinem Fallmyographion auf eine Geschwindigkeit ron $909 \mathrm{~mm}$, und er wagt es, die heranrollende Platte den Stift mit abgeschrägtem Rande treffen und bis in ihre Ebene zurückschieben zn lassen, ${ }^{1}$ was ich für sehr bedenklich halte. Hr. Fıck seinerseits hat eine Hülfsrorrichtung ersumnen, um bei Geschwindigkeiten, die eine Ablenkung des Pendels ïher $15^{0}$ rerlangen, die Platte selber den Stift sich anlegen zu lassen. ${ }^{2}$ Die Nothwendigkeit solcher Verwicklung warfen wir gerade den rotirenden Myographien als principiellen Fehler ror. Nach dem Allen kann kein Zweifel sein, dass in Bezug auf die Leichtigkeit und Bequemlichkeit, womit grosse Geschwindigkeiten der Zeichenfläche sich erzengen mo rerwenden lassen, das Federmyographion obenan steht.

Leider muss num aber bemerkt werden, dass wenigstens bei der dem ursprünglichen Heцмноттz'schen Myographion entlehnten Einrichtung des Schreihewerkes mit den grossen Geschwindigkeiten nicht soriel gewomnen ist, wie man von vornherein zu glauben geneigt sein kömnte. Ganz neu ist diese Einsicht wohl nicht; doch überraschte wenigstens mich das Ergebniss der folgenden Erwägungen, deren Wittheilmng daher vielleicht nicht überflüssig erscheint.

Eine Sache für sich ist es, dass bei grussen Geschwindigkeiten am Federmyographion der dieser Klasse ron Mrographien eigene Uebelstand (s. oben S. 272) hefrortritt, dass nämlich die Platte, $1 \mathrm{~m}$ Raum für das Myogramm zu bieten. ühermässiger Länge bedarf, wozn noch kommt, dass in demselhen Maass ihre Bahn rerlängert werden muss. Mit Feder I erhält man an dem jetzigen Modell vollständige Myogramme. Mit Feder II reicht die Curve schon kaum bis an das Maximmm, [604] mit Feder III

1 Fall-Myographion u. s. w. S. 7. s.

2 Zürcher Vierteljahrsschrift, a. a. O. S. 314.315. 
sieht man nur ihren Anfang. Um für eine gewöhnliche Curve sicher Raum zu bieten, müsste bèi der durch Feder III der jetzigen Platte ertheilten Geschwindigkeit die Platte $0.15 \times 2500=375^{\mathrm{mm}}$ lang sein, ${ }^{1}$ wobei freilich die Abnahme der Geschwindigkeit durch Reibung nicht in Anschlag gebracht ist. Immer würde die nöthige Plattenlänge auch hier Schwierigkeiten bereiten.

Der Punkt, um den es sich hier hauptsächlich handelt, ist aber folgender. Nähere Ueberlegung lehrt, dass mit dem jetzigen Schreibewerke Steigerung der Geschwindigkeit über ein gewisses äusserst geringes Maass, abgesehen von den dadurch bedingten Nachtheilen, auch nicht einmal mehr Vortheil bringt. Merklich vergrössert werden dadurch weder mehr der scheinbare Abstand zweier congruenten Curven, noch die Genauigkeit, womit deren wahrer Abstand sich messen lässt.

Fig. 21 .

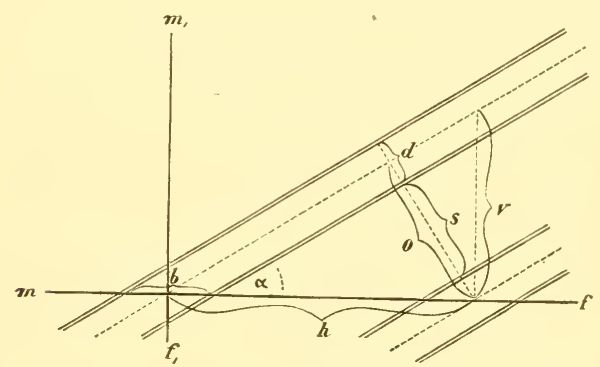

Um dies klar zu machen, denken wir uns zwei congruente Curvenstücke, ẹtwa aus der Mitte des Stadiums der steigenden Energie, als zwei gerade, parallele, von geraden parallelen Rändern begrenzte Streifen, deren Richtung mit der Richtung der Abscissenaxe den Winkel $\alpha$ bildet (s. Fig. 21). In der Figur ist jeder der Streifen, um ihm deutlicher hervortreten zu lassen, durch Doppellinien begrenzt. Von der unregelmässigen Beschaffenheit der Ränder, welche in Russ gezogene Furchen [605] unter dem Mikroskop darbieten, sehen wir ab. Die Dicke der Striche, oder die ron Rand zu Rand senkrecht gemessene Breite der Streifen, sei $d$; ihr von Mitte zu Mitte gemessener orthogonaler, horizon-

1 Vergl. H. Munk's Messungen im Archiv für Anatomie u. s. w. 1860. S. 814. 
taler, verticaler Abstand beziehlich $o, h, v . v$ ist der Weg, den in diesem Zuckungsstadium der Stift in der constanten kleinen Zeit $\tau$ durchläuft, in der die Reizung ron der oberen zur unteren Reizstelle gelangt, und also ein Punkt der Zeichenfläche den Weg $h$ zurücklegt. Die Geschwindigkeit der Zeichenfläche heisse $C$, die des Stiftes, die wir vorläufig uns als gegeben denken, $C_{1}$. Jan hat

$$
C=\frac{h}{\tau}, C_{1}={ }_{\tau}^{v}, \frac{C_{1}}{C}=\frac{v}{h}=\operatorname{tg} \iota,
$$

und folglich

$$
o=\tau C_{1} \cdot \frac{C}{\sqrt{C^{2}+C_{1}^{2}}}
$$

Man sieht sogleich, dass für $C=\propto$ der Quotient $C: \sqrt{C^{2}}+C_{1}^{2}$, den wir kürzehalber $Q$ nennen, $=1, o=v, \alpha=0^{0}$ wird; die Curren fallen zusammen mit der Abscissenaxe. Für $C=C_{1}$ ist

$$
Q=\frac{1}{\sqrt{2}}=0 \cdot 707
$$

für $C=5 C_{1}$ aber schon $=0 \cdot 981$; und da $Q$ die Einheit zur Grenze hat, folglich ron $C=5 C_{1}$ bis zu $C=\infty$ nur noch um etwa $0 \cdot 02$ wachsen kann, so ist deutlich, dass Steigerung ron $C$ uber $5 C_{1}$ hinaus $o$ nicht merklich rergrössert.

Der scheinbare Abstand $s$ der Curven, auf den es bei Demonstrationen rorzüglich ankommt, ist der orthogonale Abstand der einander zugekehrten Ränder der Currenstriche (s. die Fig.). $s$ ist $=0-d$; die Curven rerschmelzen, wemn $d=o$. Durch Steigerung von $C$ über $5 C_{1}$ hinaus wird also $s$ nicht merklich vergrössert. und nach dieser Scite kein Vortheil erreicht.

Ist $C=5 C_{1}$, so ist $\operatorname{tg} \iota=0 \cdot 2=$ etwa $\operatorname{tg} 12^{0}$. Myogramme. die am HeLshoutz'schen Myographion bei einer Geschwindigkeit ron etwa $500 \mathrm{~mm}$ gezeichnet wurden, lassen im Stadium der steigenden Energie bei fast geradem Verlaufe der Curve eine Neigung ron etwa $12^{\circ}$ gegen den Horizont erkemnen. Eine Geschwindigkeit ron etwa $500 \mathrm{~mm}$ genügt also, um [606] den grössten scheinbaren Abstand der Curven zu erhalten, der bei der jetzigen Eimrichtung möglich ist.

Der wahre Abstand der Curven h wächst zwar unbegrenzt mit $C$, nicht aber die Genanigkeit $G$, mit der $h$ sich messen lässt, und auf die es bei Untersuchungen ankommt. Nehmen wir an, ein rerschwintend dümner, horizentaler Mikrometerfaden $m f$ durchschneide das Curvenhild. und nennen wir die Breite, in der dies für jeden der Currenstriche ge- 
schieht, 〉. (S. die Fig.) Denken wir uns ferner das Bild durch eine Mikrometerschraube dem Faden $m f$ entlang bewegt und die Messung. von $h$ dadurch bewirkt, dass der Kreuzungspunkt ron $m f$ mit dem verticalen Faden $m, f$, möglichst genau auf die Mitte von $b$, erst an der einen, dann an der anderen Curve, eingestellt werde. Der bei solcher Einstellung begangene mittlere Fehler ist nach Hrn. Fechner und Hrn. Volkuax der zu hälftenden Grösse proportional. ${ }^{1}$ Da die Fehler eben so gut positiv wie negativ sein kömnen, hat man

$$
G=k \cdot \frac{h}{b}=k \cdot \frac{o}{d},
$$

wo $k$ eine persönliche Constante. Die Genanigkeit der Messung des wahren Abstandes ist proportional dem orthogonalen Abstande der Curven dividirt durch ihre Dicke, und erreicht also in Wirklichkeit mit wachsender Geschwindigkeit ebenso früh eine Grenze, wie der scheimbare Abstand. Bei anderen Nessungsmethoden und mit Berücksichtigung der Unregelmässigkeit der Ränder und der Dicke der Mikrometerfäden oder -Striche, gestalten sich die Dinge etwas anders, insofern der mittlere Fehler nicht mehr einfach $b$ proportional ist; in Wesentlichen wird bei allen das Ergebniss dasselbe sein.

Die Erfahrung bestätigt diese Schlüsse. Wit Feder II und III erhält man, abgesehen daron, dass die jetzige Platte nicht reicht, um das Myogramm rollständig aufzunehmen, keinen grösseren scheimbaren Abstand der Curven, und keine besseren Messungen ihres wahren Abstandes, als mit Feder I. Eine Geschwindigkeit, wie die durch diese Feder erzengte, möchte am Fall- und Pendelmyographion freilich nur als Grenzge- [607] schwindigkeit zu erreichen sein. Aber auch diese Geschwindigkeit ist nach Obigem schon überflüssig gross, und dafür hat das Fallmyographion den Vorzug fast unverzerrter Bilder, das Pemlelnnyographion den höherer mechanischer Vollkommenheit.

Die wahre Ueberlegenheit des Federmyographions liegt daher vorläufig nicht in der grossen Geschwiudigkeit der Zeichenfläche, sundern erstens in seiner Einfachleit. Ein Blick auf Fig. 20 genügt, um zu zeigen, wie weit es hierin alle anderen Мyographien übertrifft. Es nimmt zugleich weniger haum ein als das Fall- und als das Pendelmyographion. Nach Entfernung des einen Stahlstabes beherbergt ein Glassturz von $47^{\mathrm{cm}}$ Länge, $22^{\mathrm{cm}}$ Breite und $40^{\mathrm{cm}}$ Höhe den ganzen Apparat nehst einer unten noch zu beschreibenden Hülfssorrichtung. Eine Folge dieser

1 Elemente der Psychophysik. Bd. I. Leipzig 1 160 . S. 211 ff. 
Einfachheit und geringen Ansdehnung ist die Wohlfeilheit des Federmyographions. Während aber zweitens andere Myographien, meist an eigens dazu vorbereitetem Urte, sorgfältig aufgestellt und justirt sein wollen, ist das Federmyographion jederzeit und überall, in wenigen Minuten auf jedem Tische, rersuchbereit. Diese Schlagfertigkeit empfiehlt es besonders für Vorlesungen und Reisende. Auch habe ich damit sehon 1866 in der Roygl Institution der durch Faraday und Hrm. Tyndali rerwöhnten Zuhörerschaft der Friday Exening Lectures ron zwei Reizstellen aus erzeugte Myogramme vorgeführt, die mein Freund Trndall die Güte hatte, mittels der Dubosq'schen Elektrolampe auf einen Schirm zu projiciren. (S. oben S. 272.)

Sind aber auch die am Federmyographion erreichbaren Geschwindigkeiten unter den bisherigen Voranssetzungen umnütz, so zeigen doch unsere Formeln einen Weg. auf dem wenigstens eine höhere Geschwindigkeit als ron $5 C_{1}$ noch gut zu gebrauchen sein würde. Zmächst bestätigen die Formeln, was ohnehin einlenchtet, dass sowohl der scheinbare Abstand der Curven wie die Genanigkeit der Messung ihres wahren Abstandes mit der Dicke der Striche abnehmen, und dass man also mit möglichst feiner Spitze auf möglichst zarter Russschicht zeichnen solle. Damn aber ist an der Zeit, unser An- [608] gemmerk der Geschwindigkeit des Stiftes zuzuwenden, die wir hisher stets als beständig ammahmen.

Formel (*) S. 278 zeigt, dass der orthogonale Abstand der Curren von der Geschwindigkeit des Stiftes in derselben Weise abhängt, wie ron der der Zeichenfläche. Für $C_{1}=\infty$ wird der Quotient $C_{1}: l C^{2}+C_{1}^{2}$. der $Q_{1}$ heissen mag: $=1, o=h, \sigma=90^{\circ}$; die Curren richten sich auf, so dass sie mit zwei um $h$ von einander abstehenden ()rdinaten zusammenfallen. Für $C=C_{1}$ ist $Q_{1}=Q=0.707$; durch einseitige Vergrösserung ron $C_{1}$ über eine gewisse Grenze hinaus, wemn sie ansführhar wäre, ist für Vergrösserung ron o so wenig zu gewimnen. wie durch solche ron $C$.

Etwas anderes ist es, wenn man $C$ und $C_{1}$ zugleich rerorössert. Ver-n-facht man $C$ und $C_{1}$, so wird

$$
o=n \tau C_{1} Q=n \tau C Q_{1} \text {, }
$$

also gleichfalls ver-n-facht. Es sei $C=C_{1}$, also $o=0.70 \tau \tau C_{1}$ oder $=0.707 \tau C$. Werden $C$ and $C_{1}$ verdreifacht, so wird $o=2 \cdot 121 \tau C_{1}$ $=2 \cdot 121 \tau C$. also über zweimal so gross, als hätte man die eine Geschwindigkeit unrerändert gelassen, die andere unendlich gross gemacht.

Es ist aber, um in der Wirklichkeit $o$ zu rer-n-fachen, nicht nöthig, dies mit beiden Geschwindigkeiten zu thun. Anch durch Ver-n-fachung nur der einen Geschwindigkeit wird o ver-n-facht, wemn deren $n^{2}$-faches 
Quadrat gegen das Quadrat der anderen vernachlässigt werden kann. Damit dies erlaubt sei, muss freilich für jedes $n$ das Verhältniss der constant bleibenden zu der zu ver-u-fachenden Geschwindigkeit mindestens einen gewissen Werth haben. Soll z. B. durch Verfünffachung von $C_{1}$ allein $o$ nahe rerfünffacht werden, so muss schon $C=15 C_{1}$, d. h. etwa $=1500 \mathrm{~mm}$, oder gleich der Maximalgeschwindigkeit bei Anwendung unserer Feder II sein. Man erhält $o=4 \cdot 75 v$, während man allerdings $o=4 \cdot 99 \mathrm{v}$ findet, wemn man bei $C=5 C_{1}$, wo Vergrössern von $C$ allein nichts mehr hilft (s. oben S. 278), $C$ und $C_{1}$ zugleich verfünffacht, was für $C$ etwa $2500^{\mathrm{mm}}$, d. h. die erst dureh Feder III erreichbare Geschwindigkeit gäbe. Anf den Unterschied ron $0 \cdot 05$ in der Grösse von $o$ kommt es indess nicht an; eine [609] Steigerung der Geschwindigkeit der Platte ron 1500 auf $2500 \mathrm{~mm}$ fällt dagegen sehr in's Gewicht.

Aus naheliegenden Gründen wird man in der Wirklichkeit nicht versuchen, was in der Theorie sonst auf dasselbe hinausläuft, $C$ gegen $C_{1}$ rerschwinden zu lassen. Sondern die Art, $o$, und somit auch $s$ und $G$, ausgiebig zu vergrössern, besteht sichtlich darin, bei in obigem Sinn ansreichender Geschwindigkeit der Zeichenfläche, die Geschwindigkeit des Stiftes zn vergrössern. Innerhalb gewisser, ziemlich enger Grenzen hat dies keine Schwierigkeit. Mit Verlängerung des Schreibehebels wächst $v$, wemn auch nicht genia proportional. Man kann num erstens den Hebel relatir verlängem, d. h. den Muskel seinem Drehpunkte näher anbringen, zweitens ihn absolut verlängern. Hr. MLAREY wendet ungleich längere Hebel als die bei uns üblichen an. ${ }^{1}$ Auch Hr. Fick scheint den Hebel des Hewanoutz'schen Schreibewerkes schon rerlängert zu haben, ${ }^{2}$ und ich glaube, dass wir in der Furcht daraus entspringender Fehler zu weit gehen. So werden also grössere Geschwindigkeiten der Zeichenfläche wieder nicht allein nützlich, sondem sogar nothwendig, und die in dieser Rücksicht dem Federmyographion zustehende Ueberlegenheit kommt schliesslich doch noch in Betracht.

Der Grundgedanke unseres Myographions, die Zeichenfläche durch Federkraft zu hewegen, lässt sich übrigens anf andere Formen dieser Fläche übertragen, und mit anderen Arten ihrer Führung rerbinden. Man könnte einer pendelnden Platte durch Federkraft Geschwindigkeit ertheilen, ein Cylinder- oder Kreisscheibenmyographion mit einer Feder gleich der an der Chronometerunruhe oder an dem Fick'schen Spiralrheotom ${ }^{3}$ versehen n. d. m. Solche Torrichtungen wären jeden Grades

1 L. c. p. 422 .

2 A. a. O. S. 309 .

3 Untersuchungen über elektrische Nervenreizung. Braunschweig 1864. $4^{0}$. S. 5. - Die medicinische Physik, 2. Aufl. Braunschweig 1866. S. 425. 
mechanischer Vollkommenheit fähig, und das Pendelmyographion könnte so eingerichtet werden, dass kleinere Geschwindigkeiten, mit kurzem Schreibehebel zu benutzen, durch Fall- [610] kraft, grössere, für den Gebrauch mit langem Hebel bestimmt, durch Federkraft erzengt würden. Der Stift könnte damn schon der ruhenden Platte anliegen, ohne dass diese übermässig lang zu sein branchte (vergl, oben S. 276).

An meinem Federmyographion befindet sich noch eine empfehlenswerthe Einrichtung, die, von dessen eigenthümlichem Bewegungsmechanismus unabhängig, an jedem anderen Nyographion mit gleichem Vortheil angebracht werden kamn. Nach demselben Gedanken, welcher der "fenchten Reizungsröhre" und dem Rosenthal'schen Troge (s. oben S. 268) zn Grunde liegt, habe ich eine Znleitungsvorrichtung für Versuche über Fortpflanzungsgeschwindigkeit der Erregung construirt. ${ }^{1}$ Sie besteht aus einem länglichen Körper aus Kammmasse, der an einem Ende mit Kugelgelenk versehen, am anderen stumpf zugespitzt, und der seiner Axe nach so durchschnitten ist, dass die eine, feste Hälfte mit dem Kugelgelenk in Verbindung bleibt, die andere, bewegliche, von jener abgehoben und anf sie gelegt werden kann. Auf der ebenen Schnittfläche der festen Hälfte ruht der Nerv. Die Schnittfläche der beweglichen Hälfte ist leicht ausgehöhlt; diese Hälfte dient dem Nerven als Deckel und schützt ihn vor Trockniss. Nahe dem zugespitzten Ende, welches der Kniekehle angedrückt wird, überbrückt der Nerv ein Platinelektrodenpaar; $50 \mathrm{~mm}$ daron befindet sich ein zweites, und dahinter eine Höhlung zur Aufnahme eines Stückes Wirbelsänle. Jede Elektrode hat ihre Klemmschraube.

Schon so bietet die Vorrichtung den Vortheil, dass der Inskelhalter, der Muskel selher und die Verbindung zwischen Muskel und Hebel nicht bedeckt werden, und also sichtbar und zugänglich bleiben. Es ist aber daran noch eine Einrichtung angebracht, die sich als sehr nützlich erweist. Zwischen den beiden Elektrodemparen ruht der Nerr in einer Strecke von $40^{\mathrm{mm}}$ auf einer wohlgefirnissten kupfernen Fläche. Sie ist die obere Wand eines in den Kammmasse-Körper einge- [611] lassenen kupfernen Behälters. Durch ein Kautschukrohr ist dieser nit einem Trichter verbunden, der eine Frostmischmng enthält. Durch Oeffinen eines Hahnes erhält die eiskalte Flüssigkeit Zutritt zum Bebälter, aus dem sie durch em zweites Kautschukrohr entweicht. Nachdem man hei

$1 \mathrm{Hr}$. H. Musk hat zuerst eine Zuleitungsvorrichtung mit festen, in passenden Abständen angebrachten Elektrodenpaaren für Versuche ïber Fortpflanzungsgesehwindigkeit der Frregung angewendet. Arehiv für Anatomie u. s. w. 1860 . S. 799 . 
Zimmerwärme eine Curve ron jeder der beiden Reizstellen ans gezogen hat, erkältet man den Nerren und wiederholt den Versuch. Man erhält num mit Feder I einen horizontalen Abstand der Curven von $8-10^{\mathrm{mm}}$, und es gelingt so mit grösster Leichtigkeit, nicht allein die zur Fortpflanzung des Reizes nöthige Zeit, sondern auch deren Ahhängigkeit ron der Temperatur zu zeigen. An heissen Sommertagen bietet die Erkältung des Nerven ein willkommenes Hülfsmittel, um überhaupt dentliche Trennung der Curren zu erreichen. ${ }^{1}$

1 Vergl. H. Munk a. a. O. S. 816. 817. 
XII.

\section{Ueber aperiodische Bewegung gedämpfter Magnete.}

\section{Erste Abhandlung.}

(Gelesen in der Gesammtsitzung der Königl. Akademie der Wissenschaften zu Berlin am 5. August 1569.) ${ }^{1}$

\section{§. I. Einleitung.}

In seiner „Anleitung zur Bestimmung der Schwingungsdauer einer Magnetnadel“2 stellt Gauss für die Bewegung eines in dämpfender Umgebung schwingenden Magnetes die Fundamentalgleichung auf

$$
0=\frac{d^{2} x}{d t^{2}}+n^{2}(x-p)+2 \varepsilon \frac{d x}{d t},
$$

wo $x$ den dem Stand des Magnetes zur Zeit $t, p$ den seinem Ruhestand entsprechenden Scalentheil, $n^{2}$ die magnetische Richtkraft (für die Einheit der Ablenkung) und $2 \varepsilon$ die verzögernde Kraft der Dämpfung (für die Einheit der Geschwindigkeit), beide mit dem Trägheitsmoment des Magnetes dividirt, bedenten. Das Integral dieser Gleichung giebt Gauss unter der Form

$$
x=p+A e^{-t t} \sin \left\{\sqrt{n^{2}-\overline{\varepsilon^{2}}} \cdot(t-B)\right\},
$$

wo $e$ die Basis der natürlichen Logarithmen ist, $A$ und $B$ die beiden durch die Integration eingeführten willkürlichen Constanten vorstellen. Ohne die verzögernde Kraft der Dämpfung ist nach Gauss das Integral

$$
x=p+A \cdot \sin \{n(t-B)\} .
$$

[808] Nachdem Gauss aus Gleichung (I) die Theorie der Schwingungsbewegung gedämpfter Magnete hergeleitet hat, sagt er: „Bei allem

1 Monatsberichte der Akademie u. s. w. 1369. S. 807; - Archives des Sciences physiques et naturelles. Genève 1572. t. XLIV. p. $312 ;-$ t. XLV. p. 84.

2 Resultate aus den Beobachtungen des magnetischen Vereins im Jahre 1837. Güttingen 183๙. S. 58; - C. F. Gauss Werke u. s. w. Göttingen 1867. $4^{0}$. Bd. V. S. 374 . 
„was bisher entwickelt ist, liegt die Toraussetzung zum Grunde, dass $\varepsilon$ „kleiner sei als $n$; im entgegengesetzten Fall nimmt das Integral der „Fundamentalgleichung eine andere Form an. Man erhält nämlich an,statt des Gliedes $A e^{-t t} \sin \left\{\sqrt{u^{2}-\varepsilon^{2}} \cdot(t-B)\right\}$, in dem Fall, „wo $\varepsilon$ grösser ist als $n$, zwei Glieder ron der Form

$$
A e^{-\left(\varepsilon+1 \overline{\varepsilon^{2}-n^{2}}\right) t}+B e^{-\left(\varepsilon-\sqrt{\varepsilon^{2}-n^{2}}\right) t}
$$

,nund in dem Fall, wo $\varepsilon=n$ ist, ron dieser

$$
(A+B t) e^{-t t} \text {. }
$$

„In beiden Fällen findet also in der Bewegung gar nichts perio„disches mehr Statt, sondern der Stand nähert sich asymptotisch dem „Ruhestande. Für unsern Dämpfer ist $\frac{\varepsilon}{n}=0 \cdot 22152$, und es müsste „also ein mehr als $4^{1} / 2$ mal stärker wirkender Dämpfer angewandt werden, „um solchen Erfolg hervorzubringen. Offenbar aber würde es dazu nicht ,himreichend sein, die Metallmenge nur in demselben Verhältniss zu rer..grössern, in sofern diese Vergrösserung nach aussen angebracht werden „müsste, und die äussern Schichten des Metallhahmens vergleichungs„weise weniger zur Inductionswirkung beitragen als die immern. Allein ,es würde nicht eimmal anzurathen sein, eine Dämpfung ron einer „solchen Stärke anzuwenden, dass die Bewegung aufhörte periodisch zu ,sein, theils weil, sobald $\varepsilon$ den Grenzwerth $n$ überschreitet, die An,näherung an den Ruhestand wieder langsamer geschieht, theils weil „man damn den wesentlichen Vortheil verlöre, aus zwei beliebigen, um "T $T_{1} *$ - die Schwingmingdauer des gedämpften Nagnetes — , won ein,ander entfernten Aufzeichmungen den Ruhestand anf eine bequeme Art „berechnen zu können."

So weit Gauss. Er hat den aperiodischen oder schwingungslosen Zustand gedämpfter Magnete, wie man ihn nennen kann, mit geistigem Auge gesehen, ohne ihn wirklich zu beobachten, und seine Andeutungen darüber sind meines Wissens mehr als dreissig Jahre unbeachtet geblieben, obschon [809] sie, wie sich zeigen wird, den Kieim einer interessanten Theorie und, Gauss' Meinung zuwider, eines praktisch wichtigen Verfahrens enthielten. Ich habe gefunden, dass jener Zustand sich leicht rerwirklichen lässt; und noch Jedem, der von der aperiodischen Bewegung meiner Bussolspiegel Zeuge war, sprang der Vortheil in die Augen, der daraus bei vielen Arten galvanometrischer Versuche erwachsen mï̈sse.

Da die Darstellung, deren sich Gauss im Obigen bedient, den Punkt, auf den es hier ankommt, nicht mit voller Klarheit hervortreten 
lïsst, so wird es angemessen sein, die Theorie der aperiodischen Bewegung gedämpfter Magnete zunächst etwas ausführlicher zu entwickeln.

\section{§. II. Allgemeine Gleichung der Bewegung gedämpfter}

Magnete, und periodische Bewegung solcher Magnete.

Der Einfachheit halber nehmen wir an, dass die Ruhelage des Iagnetes dem Nullpunkt der Theilung entspreche, also $p=0$ sei. Indem man sonst die GAuss'schen Bezeichnungen beibehält, aber zur Abkürzung einen der beiden Werthe von

$$
\sqrt{\varepsilon^{2}-n^{2}}=r
$$

setzt, erhält man als allgemeines rollständiges Integral der Differentialgleichung (I) die Gleichung

$$
x=e^{-\varepsilon t}\left(A e^{-r t}+B e^{r t}\right),
$$

deren rechte Seite mit (IV) identisch ist.

Zur Bestimmung der Constanten $A$ und $B$ dienen Ammahmen über Anfangslage und Anfangsgeschwindigkeit des Magnetes. Denken wir uns den Magnet durch eine äussere Krraft, z. B. durch einen beständigen elektrischen Strom, in der Ablenkung $\xi$ gehalten, die aber nicht grösser sei, als dass nicht die Proportionalität zwischen Ablenkung und Richtkraft noch angenommen werden dürfe, und die Dämpfung merklich den gleichen Werth behalte. In Angenblick $t=0$ werde die Kette geöffnet, und der Magnet gleichsam seiner Ruhelage zu fallen gelassen. Für $t=0$ haben wir dann $x=\xi$ und $\frac{d x}{d t}=0$. Wan findet $[810]$

$$
\begin{aligned}
& A=-\frac{\xi(\varepsilon-r)}{2 r}, \\
& B=+\frac{\xi(\varepsilon+r)}{2 r},
\end{aligned}
$$

and Gleichung (VI) wird

$$
x=\sum_{2 r} \cdot \rho^{-t t}\left\{(\varepsilon+r) e^{r t}-(\varepsilon-r) e^{-r t}\right\} .
$$

Die Art der Bewegung des Magnetes, welche durch die Gleichungen (VI) und (VII) dargestellt wird, ist verschieden je nach der Beschaffenheit der Wurzelgrösse $r$.

Ist $\varepsilon<n$, so ist $r=i \varrho$, wemn wir $\sqrt{-1}-1$ mit $i$, und einen der beiden Werthe rou $7^{\top} n^{2}-\varepsilon^{2}$ mit $\varrho$ bezeichmen. Gleichung (VI) geht damn unmittelbar über in

$$
x=e^{-t t}\{(A+B) \cos (\rho t)-i(A-B) \sin (\varrho t)\},
$$


oder, wemn den Constanten $A$ und $B$ ihr Werth ertheilt wird, in

$$
x=\xi \cdot e^{-t t}\left\{\cos (o t)+\frac{\varepsilon}{\varrho} \sin (\varrho t)\right\}
$$

Diese Gleichungen zeigen eine Schwingungshewegung des Magnetes an, bei der die Amplitude der Schwingungen in einer geometrischen Reihe abnimmt, die bekamnte Bewegungsart gedämpfter Magnete. Der Hagnet geht durch den Nullpunkt jedesmal dass

$$
\operatorname{tg}(o t)=-\frac{\varrho}{\varepsilon},
$$

und erreicht seine grösste Elongation jedesmal dass

$$
\sin (\varrho t)=0 .
$$

Bestimmt man eine Winkelgrösse $\phi$ durch die Gleichung

$$
\operatorname{tg}(\varrho \phi)=-\frac{\varrho}{\varepsilon} .
$$

so wird Gleichung (IX)

$$
x=\xi \cdot e^{-t t}\left[\frac{n}{g} \sin \{g(t-\phi)\}\right] .
$$

[811] Der ron der eckigen Klammer umfasste Factor in dieser Gleichung entspricht dem periodischen Factor in (IX), rerschwindet für tg $(\varrho t)=$ $-\frac{o}{\varepsilon}$ und wird $=1$ für $\sin (o t)=0$.

Abgesehen ron der ron uns rorgenommenen Constantenbestimmung. ist Gleichung ( $\mathrm{X}$ ) einerlei mit (II), oder von der Form, in welcher Gauss das Integral der Fundamentalgleichung unter der stillschweigenden Voraussetzung hingestellt hat, dass $\varepsilon<n$ sei; während er der allgemeinen und ursprünglichen Form des Integrals, nämlich der Gleichung (VI), ans der (II) erst durch eine allerdings geläufige Unformung herrorgeht, erst später bei Erwägung der Möglichkeit, dass $\varepsilon>n$ werde, gedenkt. Was Gatss bewog, die umgeformte Gleichung (II) roranzustellen, ist sichtlich der Umstand, dass in dieser Gestalt die Gleichung sich an die (III) anschliesst, welche die Bewegung des Magnetes ohne Dämpfung darstellt. Setzt man in der Fundamentalgleichung $\varepsilon=0$, wodurch der die Dämpfung ausdrückende Term verschwindet, so erhält man als allgemeines vollständiges Integral den von Gauss gegebenen Ausdruck (III). und unter denselben Amahmen über Anfangslage und Anfangsgeschwindigkeit, die wir für den Fall der Dämpfung gemacht haben, und für $p=0$,

$$
\begin{gathered}
A=-\xi, \quad B=\frac{\pi}{2 n}, \\
x=\xi \cdot \sin \left(\begin{array}{l}
\pi \\
2
\end{array} \cdot n t\right)=\xi \cdot \cos (n t),
\end{gathered}
$$


wo $\pi$ in üblicher Bedeutung genommen ist. Die Vergleichung der Ausdrücke (II) und (III), oder ( $\mathrm{X}$ ) und (XI), lässt den Einfluss der Dämpfung auf die Schwingungsbewegung klar übersehen, der sich theils in dem Auftreten des die Amplituden rermindernden Factors $e^{-t t}$, theils in dem langsameren Wachsen des Argumentes der periodischen Function ansspricht, wodurch eine grössere Schwingungsdaner angezeigt wird. Da es Gauss zunächst auf diesen Vergleich ankam, der Fall $\varepsilon>n$ ihm dagegen nur als theoretisches Curiosum vorschwebte, durfte es ihm gleichgültig sein, dass bei seiner Darstellung [812] der ummittelbare Einblick in den Uebergang der periodischen zur aperiodischen Bewegung. der bei $\varepsilon=n$ stattfindet, rerloren ging.

\section{§. III. Aperiodische Bewegung gedämpfter Magnete.}

In dem Falle $\varepsilon>n$, wo also $r$ reell ist, gilt Gleichung (VII), wie sie dasteht. Die Bewegung ist nicht mehr periodisch, sondem die Ablenkung als Function der Zeit wird dargestellt durch den Unterschied der Ordinaten zweier Exponentialcurren, die sich der Abscissenaxe asymptotisch nähern. Der Werth $t=\infty$ ist der einzige mögliche, der $x=0$ macht. Fällt also der Hagnet ron der Ablenkung $\xi$, welche beliebig gross gedlacht werden kann, ohne Anfangsgeschwindigkeit herah, so wird der Nullpunkt nicht überschritten, sondern erst nach unendlicher Zeit erreicht. Die Curve der Ablenkungen hezogen auf die Zeit hebt hei $t=0$ mit der Ordinate $\xi$ und mit horizontaler Tangente an, und hat zuerst einen gegen die Abscissenaxe concaren Verlauf. Die Curre der Geschwindigkeiten

$$
\frac{d x}{d t}=\frac{\xi u^{2}}{2} \frac{r}{r} \cdot e^{-t t}\left(e^{-r t}-t^{r t}\right)
$$

ist am Ursprunge concar gegen die Abscissenaxe, und erreicht ein negatires Maximum für

$$
t={ }_{2 r}^{1} \log \text {. nat. } \frac{\varepsilon+r}{\varepsilon-r} .
$$

welchem $t$ also ein Wendepunkt der Curre der Ablenkungen entspricht. Nach genau der doppelten Zeit folgt der Wendepunkt der Curre der Geschwindigkeiten, die sich gleichfalls der Abscissenaxe asmmptotisch anschliesst. Die Ordinaten beider Curren sind für gleiche Zeiten proportional.

Eine bemerkenswerthe Vereinfachung tritt in rielen Beziehungen ein für den Grenzfall, dass $u=\varepsilon$, vder disss $r=0$ wird. Das Integral der Differentialgleichung ist alsdamn [rergl, uben $\$ .285(\mathrm{~V})]$

$$
x=(A+B t) e^{-t} \text {, }
$$


$A$ findet man $=\xi, B=\varepsilon \xi$, und man hat

$$
x=\xi \cdot e^{-\ell t}(1+\varepsilon t) \text {. }
$$

[813] Diese Gleichung, und die daron abgeleitete

$$
\frac{d x}{d t}=\xi \cdot \varepsilon^{2} t t^{-t t}
$$

lassen sich leichter discutiren als die allgemeineren (VII) und (XII). Einige der sich dabei ergebenden Beziehungen sind in Fig. 22 dargestellt, in welcher $\xi=2, \varepsilon=n=1$ gesetzt sind. Die oberhalb der $\mathrm{Ab}$ scissenaxe verlaufende Curre $(\xi \boldsymbol{v} t)$ ist die der Ablenkungen, die unter-

Fig. 22.

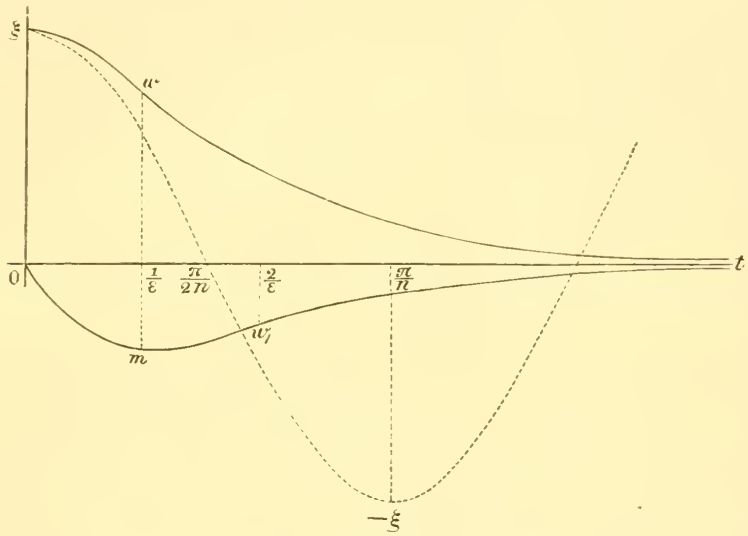

halb $(0 m u, t)$ die der Geschwindigkeiten. Die punktirte Curve $(\xi, \pi)$, — $\xi$ ) ist die Sinuscurre der Ablenkungen ohne Dämpfung, und stellt Gleichung (XI) für $n=1$ dar. Der Wendepunkt der Curve der $\mathrm{Ab}$ lenkungen und das Naximum der Curve der Geschwindigkeiten treten ein zur Zeit

$$
t=\frac{1}{\varepsilon} \text {. }
$$

In der doppelten Entfermung rom Nullpunkt, also zur Zeit

$$
t=\frac{2}{\varepsilon}
$$

tritt anch hier der Wendepunkt der letzteren Curve ein. Die Ordinaten der Curven sind für gleiche Zeiten $\xi$ proportional.

E. du Bois-Reymond, Ges. Abh. I. 
290 XII. Ueber aperiodische Bewegung gedämpfter Magnete. - Abh. I. -

[814] Wird endlich $\varepsilon$ im Vergleich zu $n$ so gross, oder, was rölliger Astasie des Magnetes entspräche, $n$ im Vergleich zu $\varepsilon$ so klein, dass $n$ gegen $\varepsilon$ rerschwinlet und $r$ merklich $=\varepsilon$ ist. so nimmt das allgemeine vollständige Integral unserer Fundamentalgleichung abermals eine andere Gestalt an. Setzt man nämlich $n^{2}=0$, so wird jènes Integral

$$
x=A \cdot e^{-2 \varepsilon t}+B,
$$

wo $A$ und $B$ die beiden willkürlichen Integrationsconstanten bedeuten. Unter denselben Annahmen über Anfingslage und Anfangsgeschwindigkeit wie früher, findet man

$$
A=0, B=\xi, x=\xi .
$$

Der Magnet bleibt also bei $\xi$ stehen, und die der Abscissenaxe parallele Gerade, welche $\xi$ zur Ordinate hat, ist die Grenze, der sich die Curven der Ablenkungen bezogen auf die Zeit nähern, wemn $n$ im Vergleich zu $\varepsilon$ inmer kleiner wird. Erhält aber unter diesen Tmständen der Magnet im Augenblick $t=0$ bei $\xi$ einen Stoss, der ihm eine Geschwindigkeit $\pm c$ ertheilt, so wird

$$
A=\mp \frac{c}{2 \varepsilon}, B=\xi \pm \frac{c}{2 \varepsilon}, x=\xi \pm \frac{c}{2 \varepsilon}\left(1-e^{-2 \varepsilon t}\right) .
$$

Der Magnet bewegt sich also mit abnehmender Geschwindigkeit

$$
\frac{d x}{d t}= \pm c e^{-2 \epsilon t}
$$

dem Punkte $\xi \pm \frac{c}{2 \varepsilon}$ zu, wo er nach unendlicher Zeit stehen bleiht. Der Vorgang ist der Form nach genau der nämliche wie in dem Falle, wo ein Körper nach erhaltenem Stosse sich in einem Mittel bewegt, das ihm einen seiner Geschwindigkeit proportionalen Widerstand entgegensetzt; und dies ist die höchste Stufe des Arago'schen Phaenomens des Rotationsmagnetismus.

§. IV. Uebersicht der Bewegungsformen ungedämpfter und gedämpfter Magnete.

Je nach den Werthen ron $\varepsilon$ und $n$ nimmt also das Integral der Fundamentalgleichung die fünf rerschiedenen Formen an, welche folgende Uebersicht nochmals im Zusammenhange zeigt. 
§. 4. Uebersicht der Bewegungsformen gedämpfter Magnete.

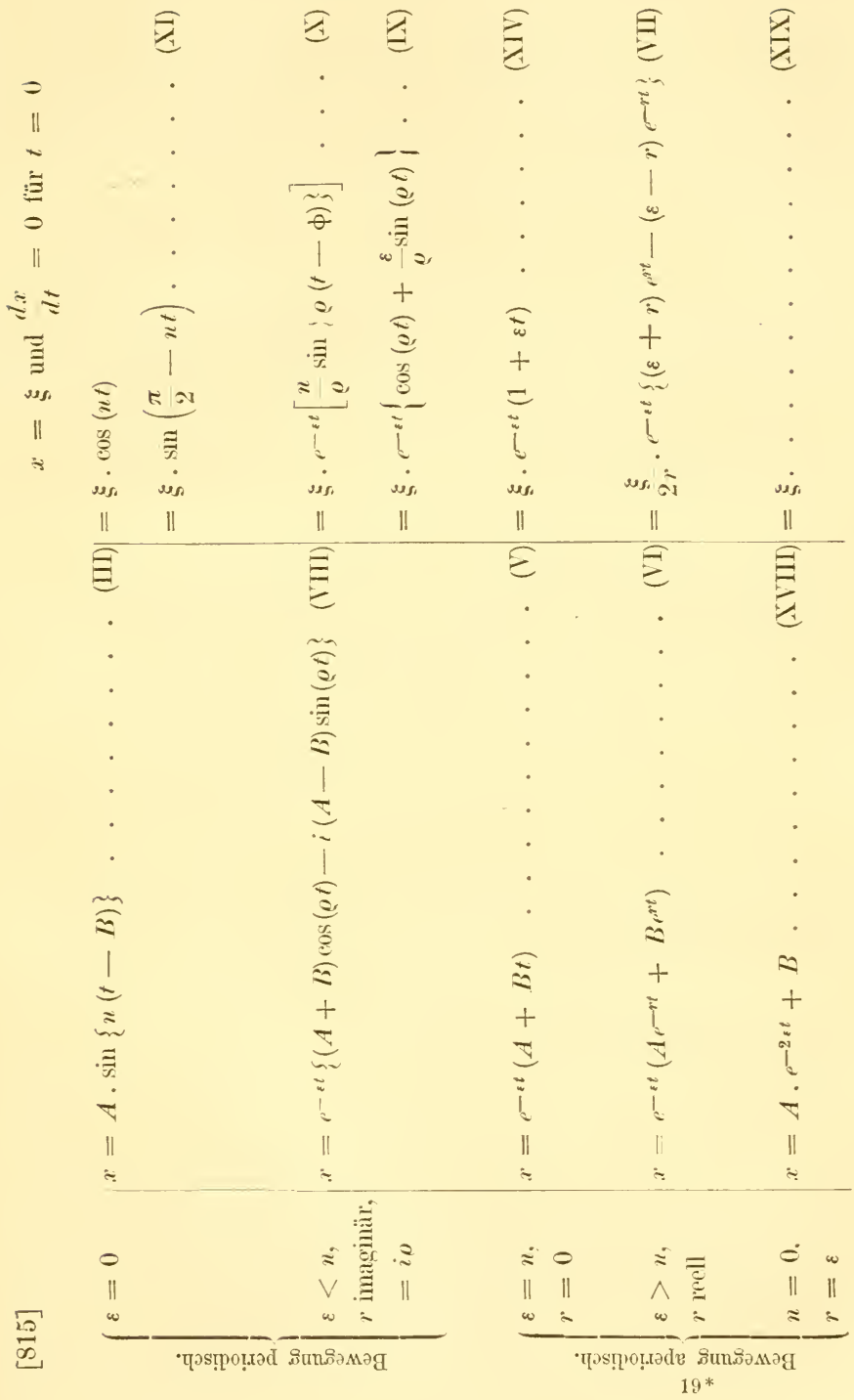


292 XII. Ueber aperiodische Bewegung gedämpfter Nagnete. - Abh. I. -

[816] Aus (IX) wird durch $\varepsilon=0$ (XI), durch $\varepsilon=n$ (XIV); ans (VII) durch $\varepsilon=n$ (XIV), durch $n=0$ (XIX). Dieser Uebergang der verschiedenen Formen in einander ist das analytische Abbild des allmählichen Ueberganges, der in Wirklichkeit ron den Schwingungen des nngedämpften Magnetes bis zur völligen Astasie des gedämpften Magnetes führt.

Die Schwingungsdauer des gedämpften Magnetes ist nach Gadss

$$
T_{1}=\frac{\pi}{\sqrt{n^{2}-\varepsilon^{2}}} .
$$

Wird also $\varepsilon=$ oder $>n$, d. h. die Bewegung aperiodisch, so spricht sich dies darin aus, dass der Ausdruck für die Schwingungsdaner unendlich gross, beziehlich imaginär wird.

Der Ausdruck für das, in natürlichen Logarithmen angegebene logarithmische Decrement der Schwingungen des gedämpften Magnetes ist

$$
\lambda=\varepsilon T_{1}=\frac{\varepsilon \pi}{\sqrt{n^{2}-\varepsilon^{2}}} .
$$

Für $\varepsilon=n$ ist $\lambda$ unendlich, schon die zweite Amplitude verschwindet im Vergleich zur ersten. Für $\varepsilon>n$ ist $\lambda$ imaginär, und auch so giebt sich die eingetretene Schwingungslosigkeit zu erkemnen.

§. V. Aperiodische Bewegung mit Anfangsgeschwindigkeit.

Wir wollen jetzt einen Fall betrachten, dessen Behandlung wesentlich dazu beitragen wird, unsere Kenntniss der aperiodischen Bewegung gedämpfter Magnete zu vervollständigen. Dies ist der Fall, wo die Anfangsgeschwindigkeit nicht Null ist, sondern einen negatiren Werth $-c$, also im Sinne der Richtkraft, besitzt. Die Constanten $A$ und $B$ werden beziehlich in Gleichung (VI)

$$
\frac{c-\xi(\varepsilon-r)}{2 r}, \frac{-c+\xi(\varepsilon+r)}{2 r},
$$

und in Gleichung ( $\mathrm{V}$ )

[817]

die Gleichungen selber

$$
\begin{aligned}
& x=\frac{e^{-t t}}{2 r}\left[\{c-\xi(\varepsilon-r)\} e^{-r t}-\{c-\xi(\varepsilon+r)\} e^{r t}\right], \\
& x=e^{-t t}\{\xi-t(c-\varepsilon \xi)\} .
\end{aligned}
$$

Die Bewegung ist aperiodisch; übersteigt aber $c$ in jedem der beiden Fälle (XXII) und (XXIII) einen gewissen Werth, den wir bald näher betrachten wollen, so wird der Nullpunkt überschritten. Noch ehe $c$ diesen Werth erreicht, werden die Curven der Ablenkungen und der 
Geschwindigkeiten ron $t=0 \mathrm{ab}$ convex gegen die Abscissenaxe. Im Falle (XXII) tritt dies z. B. ein bei $c>1 / 2 \varepsilon \xi$ für erstere, bei $c>1 / 3 \varepsilon \xi$ für letztere Curve, während, wie wir sehen werden, erst von $c>\varepsilon \xi$ ab der Nullpunkt überschritten wird. Dies Ueberschreiten geschieht im Falle (XXII) zur Zeit

im Falle (XXII) zur Zeit

$$
t_{0}=\frac{1}{2 r} \log \frac{c-\xi(\varepsilon-r)}{c-\xi(\varepsilon+r)},
$$

$$
t_{0}=\frac{\xi}{c-\varepsilon \xi^{\circ}} .
$$

Jenseit des Nullpunktes kehrt der Magnet in seiner Bewegung um, im Falle (XXII) zur Zeit

im Falle (XXIII) zur Zeit

$$
t_{\max }=\frac{1}{2 r} \log \frac{(\varepsilon+r)\{c-\xi(\varepsilon-r)\}}{(\varepsilon-r)\{c-\xi(\varepsilon+r)\}},
$$

$$
t_{\max }=\frac{c}{\varepsilon(c-\varepsilon \bar{\xi})},
$$

zu welchen Zeiten $\frac{d x}{d t}$ durch Null geht. Die Curve der Ablenkungen ist vom Nullpunkt der Scale ab concav gegen die Abscissenaxe der Zeiten; es erfolgt aber ein positives Maximum der Geschwindigkeit, sowie ein Wendepunkt der Curve der Ablenkungen im Falle (XXII) zur Zeit

$$
\text { [818] } \quad t_{w}=\frac{1}{2 r} \log \frac{(\varepsilon+r)^{2}\{c-\xi(\varepsilon-r)\}}{(\varepsilon-r)^{2}\{c-\xi(\varepsilon+r)\}},
$$

im Falle (XXIII) zur Zeit

$$
t_{t o}=\frac{2 c-\varepsilon \xi}{\varepsilon(c-\varepsilon \xi)} .
$$

Darauf nähert sich der Magnet von der anderen Seite her asymptotisch dem Ruhestande. Auch die Curve der Geschwindigkeiten nähert sich schliesslich asymptotisch der Abscissenaxe, nachdem sie im Falle (XXII) zur Zeit

im Falle (XXII) zur Zeit

$$
t_{w,}=\frac{1}{2 r} \log \frac{(\varepsilon+r)^{3}\{c-\xi(\varepsilon-r)\}}{(\varepsilon-r)^{3}\{c-\xi(\varepsilon+r)\}},
$$

einen Wendepunkt gehabt hat.

$$
t_{w,}=\frac{3 c-2 \varepsilon \xi}{\varepsilon(c-\varepsilon \xi)}
$$

Die Zeiten $t_{0}, t_{\max }, t_{w}, t_{w}$, bilden also in beiden Fällen Glieder einer arithmetischen Reihe, deren beständiger Unterschied im Falle (XXII)

$$
\frac{1}{2 r} \log \frac{\varepsilon+r}{\varepsilon-r}
$$



im Falle (XXIII) $\frac{1}{\varepsilon}$ beträgt [rergl. wben S. 288. 289, (XII, XVI, XVII)].

In Fig. 23 zeigt $\xi t_{0} m w t$ die durch (XXIII) dargestellte Curve der Ablenkungen bezogen auf die Zeit, nebst der zugehörigen Curve der Geschwindigkeiten (2 $\left.\varepsilon \xi, t_{m} m, v, t\right)$, unter sonst denselben Annahmen wie in Fig. 22; die Curre der Ablenkungen ist ron ihrem negativen Maximum $m$ ab dieselbe wie in Fig. 22, nur mit rerkleinerten Ordinaten. Die Anfangsgeschwindigkeit $c$ ist in der Figur $=2 \varepsilon \xi=4$ gesetzt. [819]

Fig. 23.

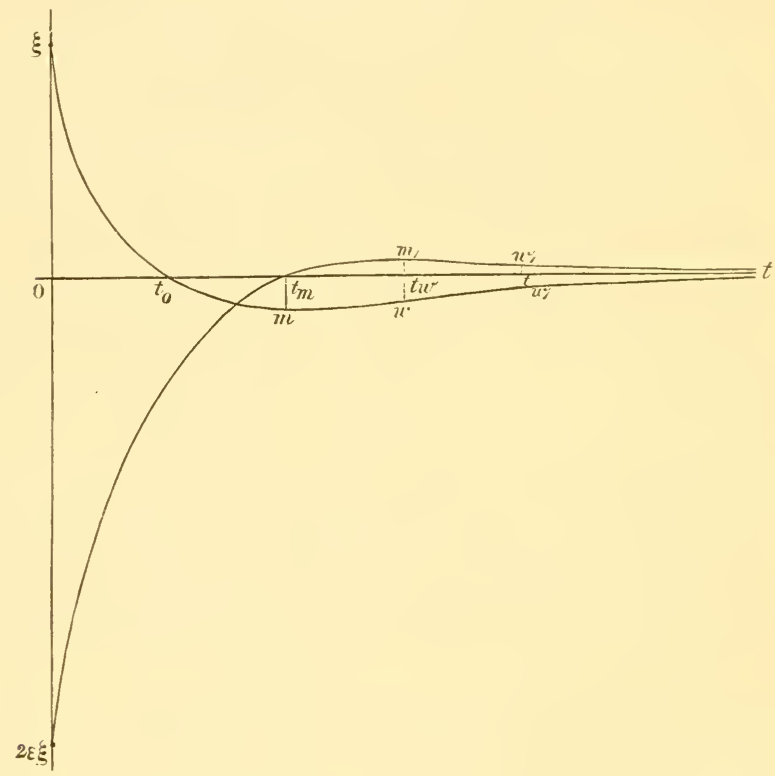

Da die Zeit in ihrem Fortschritt nicht negatir werden kann, haben die Ausdrücke für $t_{0}$ eine wirkliche Bedeutung nur wenn in dem auf den Fall (XXII) bezüglichen Ausdruck die Grösse unter dem Logarithmus positiv und $>1$, also

$$
c>\xi(\varepsilon+r) \text {, }
$$

wo $r$, wie stets ron hier ab, einen positiven Werth hat; oder wemn in dem auf den Fall (XXIII) bezüglichen Ausdruck 


$$
c>\varepsilon \xi
$$

ist. Noch für $c=\xi(\varepsilon+r)$ im ersten, $c=\varepsilon \xi$ in zweiten Falle wird der Nullpunkt erst nach mendlicher Zeit erreicht, und zwar nehmen dabei die Gleichmongen (XXII) und (XXIII) beziehlich die einfachen Formen an

$$
\begin{aligned}
& x=\xi \cdot e^{-(t+r) t} \\
& x=\xi \cdot e^{-t t} .
\end{aligned}
$$

Ist $r=\varepsilon$, oder gilt Gleichung (XX), so muss $c=2 \varepsilon \xi$ sein, damit der Magnet den Nullpunkt erreiche, und $>2 \varepsilon \xi$, damit er ihn überschreite. Ist $c=2 \varepsilon \xi+\delta$, so bleibt er bei $-\frac{\delta}{2 \varepsilon}$ stehen.

§. VI. Herleitung der Bedingung für die zum Ueberschreiten des Nullpunktes nöthige Anfangsgeschwindigkeit.

Der Simn der Bedingnng für die zum Ueberschreiten des Nullpunktes nöthige Anfangsgeschwindigkeit in den durch die Gleichungen (XXII) und (XXIII) dargestellten Fällen ergiebt sich aus folgender Betrachtnng. Es ist offenbar gleichgültig, ob dem Magnete zn einer Zeit $t_{0}$, wo er ans einer Ablenkung $x_{0}$ fallen gelassen wird, eine Geschwindigkeit $-c_{0}$ ertheilt werde, oder ob er zur Zeit $t_{0}$ bei $x_{0}$ anlangend, dieselbe Geschwindigkeit $-c_{0}=\frac{d x_{0}}{d t}$ duch Fallen aus einer höheren Ablenkming $\xi$, gleichsam als Fallgeschwindigkeit, erlange. Kéeine Fallgeschwindigkeit $\frac{d x_{0}}{d t}$, die der Iagnet bei $x_{0}$ durch Fallen von einem beliebig hohen $\xi$ hätte erlangen können, würde also, wemn sie dem Magnete beim Fallenlassen ron $x_{0}$ zur Zeit $t_{0}$ als Anfangsgeschwindigkeit - $c_{0}$ ertheilt würde, ihn über den Nullpunkt führen. Denn obschon in Wirklichkeit die Anwendung unserer Formehn der oben S. 286 erwähnten Beschränkung unterliegt, gelten sie in der Idee für jeden denkbaren Werth ron $\xi$, und wem also der Magnet die Geschwindigkeit $\begin{gathered}d x_{0} \\ d t\end{gathered}=$ - $c_{0}$ durch Fallen von jenem beliebig hohen $\xi$ erlangt hätte, würde er sich asymptotisch der Ruhelage nähern.

Die Rechnung bestätigt diese Schlüsse. Der Einfachheit halber sei die Bewegung nur eben aperiodisch, d. h. $\varepsilon=n$, und demgemäss ihre Gleichung [s. oben s. 289 (XIV)]

$$
x=\xi \cdot e^{-\varepsilon t}(1+\varepsilon t),
$$

[821] $x_{0}$ eine Ordinate zu $t_{0}$. Intem wir den Coordinatenursprung von 
$t=0$ nach $t=t_{0}$ rerlegen, rerwandeh wir der Form nach den Vorgang in den durch Gleichung (XXIII) dargestellten, und haben also

$$
x=e^{-\varepsilon\left(t-t_{0}\right)}\left\{r_{0}-\left(t-t_{0}\right)\left(-\frac{d x_{0}}{d t}-\varepsilon r_{0}\right)\right\}
$$

Es ist aber. nach Gleichung (XIT) und ( $\mathrm{XV}$ ),

$$
\begin{aligned}
& x_{0}=\xi \cdot e^{-\varepsilon t_{0}}\left(1+\varepsilon t_{0}\right) . \\
& d x_{0}=-\xi \cdot \varepsilon^{2} t_{0} e^{-\varepsilon t_{0} .} \\
& d t=
\end{aligned}
$$

Diese Werthe in (XXVIII) eingesetzt liefern wieder die ursprüngliche Gleichung (XIV), d. h. der Nullpunkt wird nicht überschritten, wenn dem Magnete bei $x_{0}$ eine Geschwindigkeit ertheilt wird, wie er sie dort durch Fallen von einem beliebig hohen $\xi$ hätte erlangen können. $x$ kamn erst Null werden, wie Gleichung (XXVIII) uns abermals rorführt, wemn

$$
-\frac{d x_{0}}{d t}>\varepsilon x_{0}, \text { d. h. } c_{0}>\varepsilon x_{0} .
$$

Dieselbe Schlussfolge führt unter der Ammahme $\varepsilon>n$ zur Bedingung

$$
-\frac{d \cdot r_{0}}{d t}>(\varepsilon+r) r_{0} \text { d. h. h. } c_{0}>(\varepsilon+r) x_{0},
$$

entsprechend der Ungleichheit (XXIV) aut S. 294. So werden wir darauf hingewiesen, dass $\varepsilon x,(\varepsilon+r) x$ vielleicht allgemein die Grenzgeschwindigkeiten seien, die beziehlich für $\varepsilon=n, \varepsilon>n$ der Magnet bei $r$ durch Fallen aus einer behiebig hohen Anfangslage erlangen könne. Es handelt sich darum, die Richtigkeit dieser Vermuthung zu prüfen.

Dazu müssen wir von der Betrachtung der Geschwindigkeit als Function der Zeit und Anfangslage $\frac{d r}{d t}=f(t$, §), übergehen .zur Betrachtung der Geschwindigkeit als Function der Ablenkung und Anfangslage $\frac{d x}{d t}=\phi(x, \xi)$. Letztere Function [822] lässt sich nun zwar. nicht explicit darlegen; dies rerhindert aber nicht, den Verlauf der entsprechenden Curve soweit festzustellen, als für unsere Zwecke nöthig ist. Aus Gründen, die hald einlenchten werten, berïcksichtigen wir zunächst nur den Fall $\varepsilon=n$, oder die Bewegmngsgleichung (XIV).

Der Kürze halber setzen wir

$$
x^{\prime}=\frac{d x}{d t}, x^{\prime \prime}=\frac{d x^{\prime}}{d t}, x^{\prime \prime \prime}=\frac{d r^{\prime \prime}}{d t} .
$$

Wir haben dam die Gleichungen

$$
\begin{aligned}
& x=+\xi \cdot e^{-\varepsilon t}(1+\varepsilon t) \\
& x^{\prime}=-\xi \cdot e^{-\varepsilon t} \varepsilon^{2} t
\end{aligned}
$$




$$
\begin{aligned}
& x^{\prime \prime}=+\xi \cdot e^{-\imath t} \varepsilon^{2}(\varepsilon t-1) \\
& x^{\prime \prime \prime}=-\xi \cdot e^{-\ell t} \varepsilon^{3}(\varepsilon t-2) .
\end{aligned}
$$

Nun ist allgemein

$$
\frac{d x^{\prime}}{d x}=\frac{x^{\prime \prime}}{x^{\prime}} \frac{d^{2} x^{\prime}}{d x^{2}}=\frac{x^{\prime} x^{\prime \prime \prime}-x^{\prime \prime 2}}{x^{\prime 3}} .
$$

Hieraus ergeben sich, durch Einsetzen obiger Werthe für $x^{\prime}, x^{\prime \prime}, x^{\prime \prime \prime}$, folgende Beziehungen:

$$
\frac{d x^{\prime}}{d x}=\frac{1-\varepsilon t}{t}, \frac{d^{2} x^{\prime}}{d \cdot x^{2}}=\frac{1}{\xi \cdot e^{-t} \varepsilon^{2} t^{3}} .
$$

Mit Hülfe dieser Gleichungen lässt sich der Verlauf der gesuchten Curve $x^{\prime}=f(x)$ zwischen den Grenzen $x=0, x=\xi$ deshalb discutiren, weil, während $t$ ron Null bis $\infty$ stetig wächst, is stetig von $\xi$ bis Null abnimmt.

Aus dem Werthe von $\frac{d^{2} x^{\prime}}{d x^{2}}$ folgt zunächst, dass die Curve zwischen den angegebenen Grenzen keinen Wendepunkt hat, sundern der Abscisse stets ihre Concavität zukehrt. Aus dem Werthe ron $\frac{d x^{\prime}}{d x}$ folgt ferner, dass die Curve bei $x=0$ ans der Abscissenaxe herabsteigt unter eimem Winkel, dessen Tangente den absoluten Werth $\varepsilon$ hat. Sie hat damn für $t=\frac{1}{\varepsilon}$ (XVI) oder $x=\frac{2}{e} \xi$ ein Haximum im absoluten Betrage von $\frac{\varepsilon}{e} \xi$, und [823] kehrt bei $\xi$ zur Abscissenaxe zurück mit darauf senkrechter Tangente; demn für $t=0$ ist

$$
\frac{d x^{\prime}}{d x^{\prime}}=\infty \text {. }
$$

Unter denselben Annahmen, wie den bei Fig. 22 gemachten, sieht daher unsere Curve etwa aus, wie die ausgezogene Curre $0 \mathrm{~m} \xi$ in Fig. 24, in welcher die Geschwindigkeiten, obschon analytisch negativ, der Anschaulichkeit halber über der Abscissenaxe aufgetragen, und $0 f$, $\xi 0$, die Tangenten an den letzten Elementen der Curve bei 0 und $\xi$ sind. Da wir in der Figur $\varepsilon=1$ gemacht haben, ist der Winkel $00 \xi=45^{\circ}$.

Dies ist der allgemeine Verlauf der Curve für jeden Werth von $\xi$. Es erübrigt sich ein Bild davon zu machen, wie sich die Curve mit $\xi$ ändert. Sowohl die Ordinaten als die Abscissen der Curre sind für ein gegebenes $t$ proportional $\xi$ (s. oben $\mathrm{s}$. 289); die den verschiedenen Werthen des Parameters $\xi$ entsprechenden Curren sind also einander ähnlich. Da die Curven rom Nullpunkte sämmtlich unter dem Winkel 
298 XIl. Ueber aperiodische Bewegung gedämpfter Magnete. - Abh. I. -

[824] ausstrahlen, dessen Tangente $\varepsilon$ ist, während der $\xi$-Punkt auf der Abscissenaxe weiter himans rerlegt wird, so bilden die durch Vergrösserung ron $\xi$ aus $0 \mathrm{~m} \xi$ entstehenden Curren eine Schaar, wie Fig. 24 in den punktirten Curren $0 m_{1} \xi_{1}, 0 m_{2} \xi_{2}, \ldots$ zeigt. Fasst man einen

Fig. 24 .

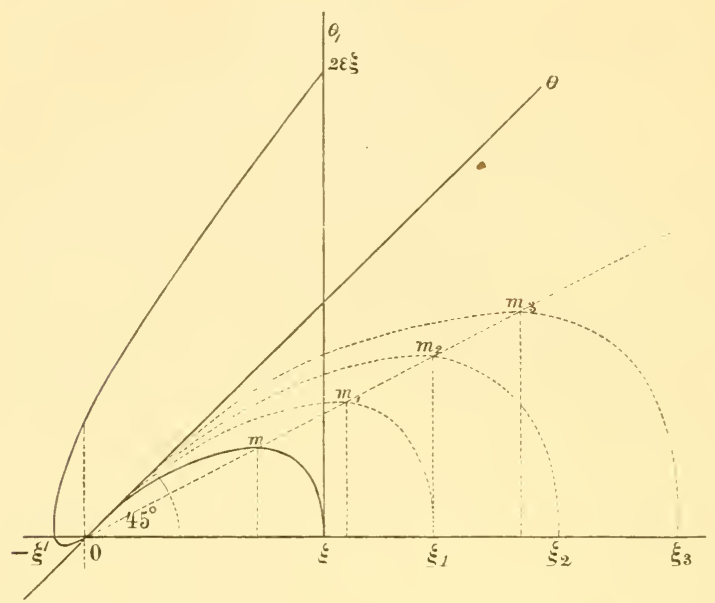

Punkt einer der Curren in's Auge, so rückt in dem Maasse, wie $\xi$ wächst, der Punkt auf der durch ihn und den Nullpunkt gelegten Geraden

$$
x^{\prime}=-\frac{\varepsilon t}{\varepsilon t+1} \cdot \varepsilon v
$$

weiter fort; demn alsdann wachsen Ordinaten und Abscissen des Punktes proportional $\xi$. Z. B. das Maximum unserer Curre $x^{\prime}=\phi(x, \xi)$ bewegt sich wegen $t=\frac{1}{\varepsilon}(\mathrm{X} \backslash \mathrm{I})$ auf der Geraden

$$
x^{\prime}=-\frac{1}{2} \varepsilon x
$$

(s. $0 m m_{1} m_{2} m_{3}$ in der Figur); der dem Wendepunkte der Cure $x^{\prime}=f(t$. $\$$ ) (s. oben S. 296) entsprechende Punkt wegen $t=\frac{2}{\varepsilon}$ (XVII) anf der Geraden

$$
x^{\prime}=-\frac{2}{3} \varepsilon x
$$


ı. s. w.; endlich der dem Nullpunkte nächste Punkt wegen $t=\infty$ auf der Geraden

$$
r^{\prime}=-\varepsilon \cdot x^{\prime}
$$

(s. $0 t)$ in der Figur).

Nacht man zuletzt $\xi$ unendlich, und soll Gleichung (XIV) für ein endliches $d$ erfüllt sein, so muss auch $t$ mnendlich sein. Erst nach unendlicher Zeit trifft der aus dem Unendlichen fallende Magnet im Endlichen ein, wobei seine Geschwindigkeit für endliche Zeit mnendlich ist. Im Endlichen aber besteht, wie wir eben sahen, wegen $t=\infty$ in Gleichmig (XXIX), zwischen seiner Geschwindigkeit und Ablenkung in jedem Augenblicke die Relation

$$
x^{\prime}=-\varepsilon \cdot r \text {. }
$$

Die durch diese Gleichung dargestellte Gerade $0 \%$ in der Figur ist somit die Grenze, der sich im Endlichen [825] unsere Curven nähern, wenn छ in's Unendliche wächst; was schon aus ihrer Aehnlichkeit ohne Weiteres erhellt, übrigens sich den Gleichungen (XIV) und (XV) anch ummittelbar entnehmen lässt. Der durch Division beider Gleichungen erhaltene Werth ron $t$ in (XIV) eingesetzt giebt

$$
\varepsilon \xi=\left(x^{\prime}+\varepsilon \cdot x\right) e^{-\frac{x^{\prime}}{x^{\prime}+t x}}
$$

eine Relation, die für $\xi=\infty$ nur stattfindet, wenn $x^{\prime}=-\varepsilon x$ ist.

Damit sind wir am Ziele. In jeder für uns in Betracht kommenden Entfernung vom Nullpunkte kömnen wir die Gerade $0 \theta$ für die Curve selber nehmen, in der die Geschwindigkeit des aus rerhältnissmässig sehr grosser Ferne fallenden Magnetes abnehmen würde; diese Abnahme geschähe den Ablenkungen proportional. Die Ordinaten der Geraden $0 \theta$ geben folglich für jedes $x$ die grösste Fallgeschwindigkeit an, welche der Magnet dort erlangen kömnte, und mit der er also noch nicht den Nullpunkt überschreiten würde. Setzen wir $x=\xi$, so folgt $-\varepsilon \xi$ als grösste bei §̧ erreichbare Fallgeschwindigkeit. Es muss also im Fall $\varepsilon=n$ dem Magnete bei $\xi$, damit der Nullpunkt überschritten werde, eine Anfangsgeschwintigkeit $c>\varepsilon \xi$ (XXV) ertheilt werden; und so hat in diesem Fall unsere Vermuthung sich bestätigt.

Setzt man wie in Fig. $23 c=2 \varepsilon \xi=4$, so zeigt die Curve $(2 \varepsilon \xi,-\xi, 0)$ in Fig. 24, wie etwa die Curve der Geschwindigkeiten bezogen auf die Ablenkungen sich gestaltet, wenn der Magnet in Folge einex ihm bei $\xi$ ertheilten Anfangsgeschwindigkeit den Nullpunkt überschreitet. Das Stück (- $\left.\xi^{\prime}, 0\right)$ der Curve ist natürlich nach demselben Gesetze gebildet wie die Curven $0 m \xi, 0 m_{1} \xi_{1}, \ldots$, und das rerkleinerte Gegenstück dazu. 
300 XII. Ueber aperiodische Bewegung gedämpfter Magnete. - Abh. I. -

Die Gleichung

$$
x=e^{-t}\{\xi-t(c-\varepsilon \xi)\}
$$

[(XXIII) S. 292], welche im Falle $\varepsilon=n$ die Bewegung des Magnetes mit der Anfangsgeschwindigkeit $-c$ vorstellt, geht für $c=\varepsilon \xi$ über in

$$
x=\xi \cdot e^{-\varepsilon t}
$$

[(XXVII) S. 295]. Anstatt als Anfangsgeschwindigkeit, können [826] wir uns $c=\varepsilon \xi$ jetzt aber auch als Fallgeschwindigkeit, durch Fallen aus dem Unendlichen entstanden, denken, indem wir annehmen, dass die Zeit ron dem Augenblick an, wo der aus dem Unendlichen fallende Magnet durch die Lage $\xi$ hindurchging, nen gezählt werde. Der aus dem Unendlichen nach unendlicher Zeit im Endlichen angelangte Magnet würde den Nullpunkt also erst nach abermals unendlicher Zeit erreichen. Uebrigens stösst hier die Umkehrung der Gleichung zwischen $x$ und $t$ auf keine Schwierigkeit mehr, daher in diesem Falle die Gleichung $x^{\prime}=\phi(x, \xi)$ selber darstellbar wird. Man hat

$$
x^{\prime}=-\xi \cdot \varepsilon e^{-\imath t},
$$

und indem man für $e^{-\epsilon t}$ seinen Werth aus (XXVII) setzt, erhält man dem Obigen entsprechend

$$
x^{\prime}=-\varepsilon i r,
$$

wie umgekehrt Gleichung (XXYII) aus der Integration des letzteren Ausdruckes hervorgeht, wenn man zur Constantenbestimmung $x=\xi$ für $t=0$ setzt.

Wendet man dieselben Betrachtungen auf den Fall $\varepsilon>n$ an, so findet man

$$
\begin{aligned}
\frac{d x^{\prime}}{d x^{\prime}} & =\frac{(\varepsilon-r) e^{r t}-(\varepsilon+r) e^{-r t}}{e^{-r t}-e^{r t}}, \\
\frac{d^{2} x^{\prime}}{d x^{2}} & =-\xi u^{2} e^{-\epsilon t}\left\{\frac{2 r}{e^{-r t}-e^{r t}}\right\}^{3}
\end{aligned}
$$

Die Curve $x^{\prime}=\phi(x, \xi)$ ist also anch in diesem Fall ohne Wendepunkt, concar gegen die Abscissenaxe, mit einem Maximum für den oben (XII) gefundenen Werth von $t$; die Tangente des Winkels am Nullpunkte beträgt $\varepsilon-r$; am $\xi$-Punkte ist der Winkel ein rechter. Die Curren für verschiedene $\xi$ sind einander ähnlich. Für $\xi=\infty$ muss anch hier $t=\infty$ sein, wenn $x$ endlich sein soll; als diesem Fall entsprechende Grenzgestalt der Curvenschaar erhält man aber hier die Gerade

$$
x^{\prime}=-(\varepsilon-r) x \text {; }
$$

$(\varepsilon-r) \xi$ ist die hei $\xi$ erreichbare Grenzgeschwindigkeit. Auch hier folgt dasselbe ummittelbar aus dem durch Eliminiren ron $t$ zwischen (VII) und (XII) erhaltenen Ausdruck 


$$
\xi^{2 r}=\frac{\left(x+\frac{r^{\prime}}{\varepsilon+r}\right)^{e+r}}{\left(x+\frac{x^{\prime}}{\varepsilon-r}\right)^{-r}},
$$

dessen rechte Seite für $x^{\prime}=-(\varepsilon-r) x$ unendlich wird.

Als obere Grenze der Anfangsgeschwindigkeit, welche dem Magnete bei $\xi$ ertheilt, ihn für $\varepsilon>n$ noch nicht über den Nullpunkt führt, fanden wir oben S. 294 (XXIV) den Werth $(\varepsilon+r) \xi$. In diesem Falle trifft also unsere Termuthming hinsichtlich der Bedeutung dieser Grenze in etwas anderer Form zu, als in dem Fall $\varepsilon=n$. Es muss die dem Magnete bei $\xi$ ertheilte Anfangsgeschwindigkeit die bei $\xi$ erreichbare höchste Fallgeschwindigkeit, unstreitig der stärkeren Dämpfung halber, noch um mehr als $2 r \xi$ übertreffen, damit der Nullpmkt überschritten werde.

Eliminirt man mit Hülfe ron Gleichung (XXYI) $t$ in der durch Differenziren derselben Gleichung erhaltenen Gleichung

so ergiebt sich

$$
x^{\prime}=-\xi \cdot(\varepsilon+r) e^{-(t+r) t},
$$

$$
x^{\prime}=-(\varepsilon+r) x
$$

als Gleichung der anf die Scale aufgetragenen Anfangsgeschwindigkeiten, welche den Magnet noch nicht über den Nullpunkt führen. Als Gleichung der ebeuso aufgetragenen Grenzgeschwindigkeiten beim Fall ans dem Unendlichen fanden wir so eben

$$
x^{\prime}=-(\varepsilon-r) r .
$$

Die Integration dieser Gleichung liefert, wemn man für $t=0$ abermals $x=\xi$ macht, zwischen $x$ und $t$ die Relation

$$
x=\xi \cdot e^{-(t-r)} \text {. }
$$

Für $r=\varepsilon$ hat man $x^{\prime}=2 \varepsilon(\xi-x)-c$. Erhielte der völlig astatische Iragnet bei $\xi$ die Geschwindigkeit $-2 \varepsilon \xi$, so nähme diese in der Geralen $x^{\prime}=-2 \varepsilon x^{\prime}$ ab (s. S. 290 (XX), 295).

§. VII. Verhalten aperiodisch sich bewegender Magnete bei kurzer Einwirkung eines Stromes.

Setzen wir jetzt den Fall, zur Zeit Null wirke ein constanter Strom ron der Stärke $I$ eine sehr kurze Zeit $\tau$ ant [828] den in seiner Ruhelage befindlichen Magnet. Der Strom wird dem Iagnet eine, diesmal positive Geschwindigkeit

$$
c=\frac{\mu I \tau}{M}
$$


302 XII. Ueber aperiodische Bewegung gedämpfter Magnete. - Abh. I. -

ertheilen, wemn wir mit $\boldsymbol{M}$ sein Trägheitsmoment, mit $\boldsymbol{u}$ das Drehungsmoment bezeichnen, welches der Strom ron der Stärke Eins in dem Multiplicatordraht auf den Magnet in seiner Ruhelage übt. Die Constanten $A$ und $B$ in der allgemeinen Gleichung (II) findet man, wemn ' man für $t=\tau$ (sehr nahe) $=0, x=0$ und $\frac{d r}{d t}=c$ setzt, beziehlich (sehr nahe)

$$
=-\frac{c}{2 r} \text { und }=+\frac{c}{2 r},
$$

und man erhält als Gleichung der Bewegung

$$
x={ }_{2 r}^{c}\left(e^{-(t-r) t}-e^{-(t+r, t}\right) .
$$

Der Magnet kehrt also um zur Zeit

$$
t_{\max }=\frac{1}{2 r} \log \frac{\varepsilon+r}{\varepsilon-r} .
$$

und nähert sich wieder asymptotisch der Ruhelage. Einfacher gestalten sich auch hier die Dinge für den Grenzfall $\varepsilon=n$. In der allgemeinen Gleichung ( $\mathrm{V}$ ) wird unter den eben gemachten Voraussetzungen $A=0$ und $B=c$, die Gleichung selber wird

$$
r=c t e^{-t t} \text {. }
$$

Die Curve der Ablenkungen ist am Ursprunge concar gegen die $\mathrm{Ab}$ scissenaxe, ihre Ordinate erreicht bei

$$
t_{\max }=\begin{aligned}
& 1 \\
& \varepsilon
\end{aligned}
$$

ein Maximum im Betrage ron

$$
x_{\max }=\frac{c}{\varepsilon e},
$$

dem bei

$$
t_{t c}=\frac{2}{\varepsilon}
$$

[829] ein Wendepunkt folgt. Der Ausdruck für $t_{\max }$ erlaubt durch einen beliebigen dem Magnet ertheilten Stromstoss $\varepsilon=n$ numerisch zu bestimmen. Die Curve der Geschwindigkeiten heht bei $t=0$ mit der Ordinate $c$ an. und ist convex gegen die Abscissenaxe, bis sie diese bei $t_{\max }$ schneidet. Sie erreicht zur Zeit $t_{v}$ ein negatires Haximum und hat einen Wendepunkt bei

$$
t_{w,}=\frac{3}{\varepsilon} \text {. }
$$


Die oben S. 293 bemerkte arithmetische Reihe der Zeiten kehrt also hier wieder. ${ }^{1}$

§. VIII. Verhalten aperiodisch sich bewegender Magnete bei Ablenkung durch einen beständigen Strom.

Bewegt sich der Magnet nnter dem Einfluss eines ihn anf dem Nullpunkte zur Zeit Null treffenden beständigen Stromes von der Stärke $I$, aber von längerer Daner, einer nenen Gleichgewichtslage unter dem vereinten Einflusse dieses Stromes und der Richtkraft zu, so wird die Differentialgleichung der Bewegung

$$
\frac{d^{2} x}{d t^{2}}+2 \varepsilon \frac{d x}{d t}+n^{2} x=k,
$$

wo die Constante $k$ die imnerhalb derselben Grenzen, welche für die Proportionalität der Richtkraft und der Ablenkung gelten, von der letzteren unabhängige ablenkende Trraft, dividirt durch das Trägheitsmoment, vorstellt. Das allgemeine vollständige Integral heisst jetzt

$$
x=\frac{k}{u^{2}}+e^{-\imath t}\left(A e^{-r t}+B e^{r t}\right) .
$$

[830] Indem man, für $t=0, x=0$ und $\frac{d x}{d t}=0$ setzt, erhält man

$$
A=\frac{k}{n^{2}} \cdot \frac{\varepsilon-r}{2 r} \cdot B=-\frac{k}{n^{2}} \cdot \frac{\varepsilon+r}{2 r} .
$$

Bezeichnet man mit $H$ die horizontale Componente der Erdkraft, mit $m$ das magnetische Moment des Magnetes für parallele Kräfte, und benerkt man, dass

$$
n^{2}=\begin{gathered}
m H \\
M
\end{gathered}
$$

so findet man

$$
\frac{k}{n^{2}}=\frac{\mu I}{m H}
$$

1 Für den Fall $\varepsilon<n$ hat Hr. W. Weber die Formel entwickelt

$$
x_{\max }=c \frac{T}{\pi} \cdot e^{-{ }_{\pi}^{\lambda}} \operatorname{arctg} \frac{\pi}{\lambda},
$$

wo $T$ die Schwingungsdauer ohne Dämpfung, $\lambda$ das logarithmische Decrement bedeuten (Elektrodynamische Maassbestimmungen u. s. w. Leipzig 1850. S. 346. Anm.). Diese Formel ist für $\varepsilon=n$ identisch mit unserer Formel (XXXIV). 
Durch Einsetzen der Werthe für $A, B$ und $\frac{k}{n^{2}}$ in (XXXV) wird $x=\frac{\mu I}{m H}\left[1-\frac{e^{-\iota t}}{2 r}\left\{(\varepsilon+r) e^{r t}-(\varepsilon-r) e^{r t}\right\}\right]$.

Die Bewegung erfolgt also, wie zu erwarten, nach demselben Gesetze wie beim Fallenlassen des Magnetes, nur dass an die Stelle von $\xi$ der Nullpunkt, an die des Nullpunktes die beständige Ablenkung $\frac{\mu I}{m H}$ tritt, welche, ohne überschritten zu werden, schwingungslos und in der Theorie erst nach unendlicher Zeit erreicht wird.

Für $\varepsilon=u$ lommt in Gleichung (XXXVII) statt des ron 1 abzuziehenden Termen

$$
e^{-t}(1+\varepsilon t)
$$

zu stehen.

§. IX. Sonstige Combinationen von Lage und Geschwindigkeit des Magnetes und ron ihn treffenden Kräften.

Trifft ein positiver Stromstoss den Magnet im Augenblicke des Fallenlassens, so gelten die Formeln (XXII) und (XXXIII), nur dass $c$ sein Zeichen ändert. Der Magnet schlägt weiter aus, kehrt um und nähert sich asymptotisch dem Nullpunkte.

Wird der im Fallen begriffene Magnet bei $x$, zur Zeit $t$, ron einem Stosse getrotten, der ihm eine Geschwindigkeit $\pm c$ [831] ertheilt, so tritt eine Discontinuität der Bewegung ein. Je nachdem $\varepsilon<$ oder $=n$, gelangt man zu den Gleichungen

$$
\begin{aligned}
& \left.x=\frac{\xi}{2} r(\varepsilon+r) e^{-(\varepsilon-r)(t,+t)}-(\varepsilon-r) e^{-(\varepsilon+r)(t,+t)}\right\} \\
& \pm \frac{c}{2 r} \cdot\left\{e^{-(\varepsilon-r) t}-e^{-(e+r) t}\right\} \\
& \text { (XXIVIII) } \\
& x=\xi \cdot e^{-\cdot(t,+t)}\{1+\varepsilon(t,+t)\} \pm c t e^{-t} \text {. }
\end{aligned}
$$

Hier ist $t$ die rom Augenblicke des Stosses an nen gezählte Zeit. Das rechte Glied von Gleichung (XXXVIII) und (XXXIX) ist die algebraissche Summe der rechten Glieder beziehlich ron Gleichung (VII) und (XXXI), Gleichung (XIV) und (XXXII), nur dass im ersten Term $t,+t$ für $t$ steht: es finclet, wie dies nicht anders sein kann, Superposition der Bewegungen statt.

Ist $c$ negativ, so kam hier wieder der Nnllpunkt überschritten werden; doch muss im Falle (XXXVIII) 
im Falle (XXXIX)

$$
c-\frac{d \cdot r_{1}}{d t}>(\varepsilon+r) x_{1},
$$

$$
c-\frac{d x_{1}}{d t}>\varepsilon x_{1}
$$

sein (vergl. oben §. VI).

Schwankt ein beständiger Strom, der den Magnet abgelenkt hält, so dass seine Stärke von $I$ sich plützlich zu $I$, ändert, so erhält man, je nachdem $\varepsilon>$ oder $=n$, die Gleichungen

$$
\begin{aligned}
& x=\frac{\mu}{m H}\left[I,+\left(I-I_{1}\right) \frac{e^{-\imath t}}{2 r}\left\{(\varepsilon+r) e^{r t}-(\varepsilon-r) e^{-r t}\right\}\right], \\
& x=\frac{\mu}{m H}\left\{I,\left(I-I_{1}\right) e^{-\varepsilon t}(1+\varepsilon t)\right\}:
\end{aligned}
$$

der Magnet geht schwingungslos in die nene Lage über.

Ein Hin- und Hergang des aperiodischen Magnetes ist nur möglich, wie man jetzt auch ohne Rechnung sicher schliessen kann, wemn die Gleichgewichtslage selber bei positiver Schwankung der Stromstärke wieder zurück-, bei negativer Schwankung wieder vorspringt, und wenn entreder dieser zweite Sprung die Gleichgewichtslage wieder auf die andere Seite des Magnetes [832] verlegt, oder der zweite Sprung zu einer Zeit geschieht, wo in Folge des ersten Sprunges der Hagnet noch eine dem zweiten Sprunge entgegengesetzte Geschwindigkeit hat; im letzteren Falle darf aber, soll die neve Gleichgerichtslage überschritten werden, diese Gleichgewichtslage höchstens in solcher Entfernung $\xi$, ror dem ihr entgegenkommenden Magnete stehen bleiben, dass seine Gcschwindigkeit, je nachdem $\varepsilon>$ voder $=n$, beziehlich noch $>(\varepsilon+r) \xi$, oder $>\varepsilon \xi$, ist (rergl. oben $\S$. VI).

§. X. Nähere Bestimmung der experimentellen Bedingungen, unter denen die Bewegung gedümpfter Magnete

aperiodisch wird.

Es wird jetzt nützlich sein, in den Ausdruck

$$
r=\sqrt{\varepsilon^{2}-\overline{u^{2}}} \text {. }
$$

statt der von Gauss aus analytischen Gründen angenommenen und bisher auch ron uns benutzten Symbole $2 \varepsilon$ und $n^{2}$ die wirklichen Grössen zu setzen, die darin eingehen. Für $n^{2}$ haben wir schon oben seinen Werth $\frac{m H}{M}$ eingeführt (XXXVI), den wir aber noch näher so bestimmen wollen, dass wir für $m$ schreiben $\left(\iota+{ }_{\Downarrow} H\right) m^{\prime}$, wo $\iota$ die permanente, E. du Bois-Reymond, Ges. Ahh. I. 
306 XII. Ueber aperiodische Bewegung gedämpfter Magnete. - Abh. I. -

$\eta H$ die durch $H$ inducirte ${ }^{1}$ Intensität des Magnetes, $m^{\prime}$ sein Moment für parallele Kräfte bei der Intensität Eins bedeuten. Man hat also

$$
n^{2}=\frac{(\iota+\eta H) m^{\prime}}{M} H .
$$

Bezeichnen wir sodamn mit $\mathfrak{m}^{\prime}$ das Drehungsmoment, welches für die magnetische Intensität Eins auf den Magnet ausgeübt wird durch eine Strömung im Dämpfer, wie sie der Magnet bei seiner Winkelbewegung erzeugt, und mit $x$ eine Constante, welche unter anderen die Inductionsconstante und das Leitvermögen des Dämpfers zu Factoren hat, so ist

$$
2 \varepsilon=-\left(-\frac{\varkappa \mathrm{m}^{\prime 2}\left(\iota+{ }_{i} H\right)^{2}}{M}\right) .
$$

Durch Einsetzen dieser Werthe wird

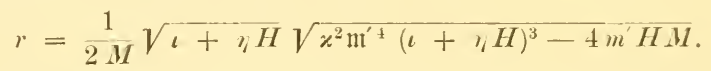

Bei gleicher Dämpfung wird also $r$ um so eher $=0$ oder reell, d. h. die Bewegung des Magnetes um so eher aperiodisch, je kleiner $\boldsymbol{M}$, und je kleiner $H$. Zwar nimmt, durch Terkleinem son $H$, auch der erste Term unter dem Wurzelzeichen ab, doch ist $\eta$ so klein, dass diese Abnahme neben der des zweiten Termen hier nicht in Betracht kommt.

$\mathrm{Da}$ es Gauss bei seinen Zwecken, wie wir sahen (rergl. obęn S. 285), nicht daran lag, den aperiodischen Zustand herbeizuführen, so hat er nicht daran gedacht, statt durch Vergrössern ron $x \mathrm{~m}^{\prime 2}$, dies durch Verkleinern ron $H \boldsymbol{M}$ zu thun, wozu sich zunächst das einfache Mittel bietet, die Wirkung der Erdkraft auf den Magnet zu schwächen, und so $H$ zu vermindern. Dazu wird im Prineip jede der drei Methoden des Astasirens taugen: die Verbindung zweier Magnete zur Doppelnadel, die Aufstellung der Drehungsaxe des Magnetes in der Richtung der Inclinationsuadel, endlich das Haur'sche Verfahren, bei dem ein rerkehrt genäherter Magnetstab der Erde entgegenwirkt, aus einlenchtenden Gründen jedoch am hesten die letztere Methode, deren ich mich zu meinen thierischelektrischen Versuchen längst ausschliesslich bediene. Bei dieser wird, wemn $S$ die horizontale Componente der Kraft des Hacr'schen Stabes bezeichnet,

1 Lamont im Repertorium der Physik. Berlin 1st6. Bu. rI. s. LIV. Vergl. meine Untersuchung über den Einfluss, den die temporäre Magnetisirung der einzelnen Nadeln einer astatischen Doppelnadel durch die Erde auf die Gleichgewichtslage des Systemes übt. Poggendorff's Annalen u. s. w. 1861. Bd. CXII. S. 1. [S. oben Alh. VII., S. 137.] 


$$
\begin{gathered}
\varepsilon=\frac{x \Pi^{\prime 2}\{\imath+\eta(H-S)\}^{2}}{2 M}, \quad \text { (XL) } \\
r=\frac{1}{2 M} \sqrt{\imath+\eta_{(}(H-\bar{S})} \sqrt{x^{2} \mathrm{~m}^{\prime}+\overline{\imath+\eta(H-S)\}^{3}-4 m^{\prime}(H-S) M}}
\end{gathered}
$$

An der Windemaxs'schen Bussole. welche mit einem starken Dämpfer rersehen ist, ${ }^{1}$ gelingt es daher ohne jede [83t] Schwierigkeit, durch fortgesetzte Annäherung des ron mix daran angebrachten Hadr'schen Stabes den Magnetspiegel in den aperiodischen Zustand zu rersetzen. Um bequem darüber zu experimentiren, leitet man von dem Strom einer beständigen Kette mittels des Compensators ${ }^{2}$ einen Zweig durch die Rollen der Bussole und unterbricht den Stromzweig mittels eines Schlüssels im Bussolkreise. Indem man den Magnet stets ans der nämlichen Ablenkung ohne Anfangsgeschwindigkeit fallen lässt, sieht man zuerst in dem Maasse, wie man den Haur'schen Stab nähert, das logarithmische Decrement wachsen. Damn kommt ein Punkt, wo zwar der Nagnet noch über den Nullpunkt hinausschwingt, aber keine dritte Elongation mehr unterschieden werden kann. Die zweite Elongation wird endlich anch ummerklich, und num ist das logarithmische Decrement mendich geworden, und der aperiodische Zustand da. Dieser Punkt lässt sich natürlich nicht mit vollkommener Schärfe bestimmen, wegen der Schwierigkeit zu unterscheilen, ob eine rückgängige Bewegung des Magnetes um wenige Zehntel eines Scalentheiles, welche mehrere Secunden dauert, wirklich als Rückkehr zur Gleichgewichtslage anfzufassen sei. Tebrigens handelt es sich hier zuletzt nm ziemlich kleine Verschiebungen des Haur'schen Stabes. Scheint der aperiodische Zustand eben erreicht und entfernt man den Stab wieder anch nur um $1 \mathrm{~mm}$ bei etwa $300^{\mathrm{mm}}$ Abstand seiner Mitte ron der des Spiegels. so wird bei grösseren Fallhöhen der Nullpunkt sogleich wieder um 1-2 sc überschritten. Es wird sich daher fortan empfehlen, den Stab auch in der Richtung nach dem Magnete zu mit einer mikrometrischen Bewegung zu rersehen.

Lässt man jetzt den Magnet aus sehr hohen Ablenkungen, weit über die Grenzen der Theilumg hinaus, fallen, so wird [835] der Nullpunkt noch mehr oder weniger überschritten. Man bringt es aber. durch

1 In den von Hrn. SAUERWALD vortrefflich gebanten Exemplaren besteht der Dämpfer aus einem kupfernen Cylinder von $60 \mathrm{~mm}$ Durchmesser und $30 \mathrm{~mm}$ Länge. Dieser Cylinder ist seiner Axe nach von einer concentrischen, eylindrischen Höhlung von soleher Weite durchbohrt, dass der $20 \mathrm{~mm}$ im Durchmesser haltende MagnetSpiegel oder -Ping darin eben frei spielt. Vergl. Wiedenans, Die Lehre vom Galvanismns u. s. w. Bd. II. 1. Aufl. 1s63. S. 198; - 2. Aufl. 1873. Abth. I. S. 227. 2 S. oben Abh. VHI., S. $176 \mathrm{ff}$; - Abh. X. 
ferneres Ammähern des Stabes, leicht dahin, dass auch der ron $90^{\circ}$ fallende Spiegel sich schwingungslos auf den Nullpunkt einstellt. Jenes Ueberschreiten erklärt sich rermuthlich so, dass bei weit über die Scale hinansgehenden Ablenkungen zwar die Richtkraft langsamer wächst als die Bögen, noch schneller aber die Dämpfung durch die cylindrische Kupferhülse abnimmt, daher der Nagnet bei dem $\xi$, wo unsere Gesetze merklich zu gelten anfangen, mit einer Geschwindigkeit anlangt, die ihn befähigt, den Nullpunkt zu überschreiten, so lange nicht $r$ einen gewissen Werth übertrifft (rergl. oben §. VI). Bei einer sphärischen Hülse würde aller Wahrscheinlichkeit nach kein solches Ueberschreiten stattfinden.

Nähert man den Stab dem Magnet immer mehr, so schlägt der Magnet um. Vorher kommt natürlich der Punkt, wo er röllig astatisch, $n=0$ und $r=\varepsilon$ ist, wo er also durch den oben S. 290 theoretisch abgeleiteten Znstand lindurchgeht, in welchem er sich gleich einem Kürper bewegt, dem das umgebende Mittel einen seiner Geschwindigkeit proportionalen Widerstand entgegensetzt. Ans Gründen, die keiner Ausführmg bedürfen, vermag die Beobachtung diesen Zustand nicht zu erfassen. Darüber hinaus gehorcht die Bewegung wieder dem durch Gleichung (VII) ausgesprochenen Gesetze, $\mathrm{mm}$ schliesslich durch den Grenzfall (XIV) hindurch von Neuem periodisch zu werden.

Wir werden im Folgenden den Begriff der Beruhigungszeit des Magnetes brauchen. Es ist die Zeit, welche rerfliesst rom Augenblicke, wo der abgelenkte Hagnet fallen gelassen wird, bis zu dem, wo seine Ablenkung ummerklich, d. h. kleiner als eine bestimmte kleine Grösse, etwa ein Zehntel Scalentheil, wird. Die Umstände zn kemnen, welche diese Zeit rerkleinern, ist ron praktischer Wichtigkeit. Zn wahrhaft scharfer Messung eignet sich übrigens die Beruhigungszeit nicht; namentlich bei hoher Astasie ist schwer zu sagen, wann die Bewegung ein Ende hat. Da bei gleichem $t$ die Ablenkmg des schwingungslos zum Nullpunkte zurückkehrenden Magnetes $\xi$ proportional ist (s. oben S. 288. 289), so wächst auch die Be- [836] ruhigungszeit mit $\xi$. Der unten näher zu beschreibende Magnetspiegel I z. B. branchte bei $298 \cdot 5^{\mathrm{mm}}$ Abstand des Haur'schen Stabes, wo seine Bewegung zuerst aperiodisch schien,

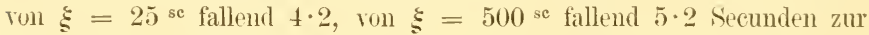
Beruhigmng. Deutlicher wird der Unterschied bei höherer Astasie, wie sie durch Annähern des Stabes erreicht wird, und wobei, wie wir bald näher schen werden, die Beruhigungszeit auch absohut grösser ist. Bei $282 \cdot 5^{\mathrm{mm}} ; 277 \cdot 5^{\mathrm{mm}}$ Alustand des Stabes betrug die Beruhigungszeit des

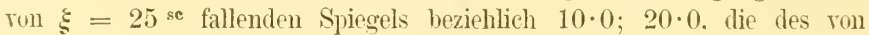
$\xi=500$ se fallenden $17 \cdot 6 ; 29 \cdot 6$ Secunden. 
Wir kehren zu den Bedingungen zurück, unter welchen die Bewegung gedämpfter Magnete aperiodisch wird. Eine zweite Art, unter übrigens gleichen Umständen $r=0$ oder reell zu machen, wäre nämlich die Verkleinerung des Trägheitsmomentes $\boldsymbol{M}$. Es liegt in der Natur der Dinge, dass man, ohne besondere Einrichtungen, diese nicht stetig und nicht am sonst fertigen $\Lambda$ pparate vornehmen kann. Aber je kleiner $M$, je dümner z. B. bei sonst gleicher Gestalt ein ILagnetspiegel ist, bei um so kleinerem $S$, d. h. bei um so geringerer Astasie wird seine Bewegung aperiodisch. Dies ist einer der Gründe, aus denen weder Gauss, noch sonst Einem der vielen Beobachter, die an gedämpften Magneten mit Spiegelablesung thätig waren, der aperiodische Zustand aufgestossen ist, da an den nach Göttinger Vorschrift eingerichteten Magnetometern Stïbe von sehr grossem Trägheitsmomente angewendet wurden, und man überhaupt Magnete ron kleiner Masse wenig gebraucht hat, weil man die schnellere Abnahme ihrer Intensität fürchtete. Der Gebrauch leichterer Magnete empfiehlt sich aber für gewöhnlich hier deshalb, weil, ganz als ob der Magnet noch schwänge, durch Verkleinerumg des Trägheitsmomentes die Beruhigungszeit des aperiodisch sich bewegenden Magnetes verkürzt wird. Setzt man in Gleichung (XIV) $\varepsilon=\frac{\varepsilon}{\boldsymbol{M}}$, wo $\%$ eine Constante, und differenzirt man nach $M$, so erhält man für $\frac{d x}{d M}$ einen positiven Werth: $x$ ist für gleiche Zeiten um so kleiner, je kleiner $\boldsymbol{M}$.

[837] Die Erfahrung bestätigt diesen Schluss. Ich habe den aperiodischen Zustand bisher an drei Magneten beobachtet. Zwei davon sind kreisrunde Stahlspiegel von $20^{\mathrm{mm}}$ Durchmesser, deren einer, der schon erwähnte Spiegel I, nur etwa $0 \cdot 8^{\mathrm{mm}}$, der andere, III, etwa $4^{\mathrm{mm}}$ dick ist; I wiegt $2 \cdot 414^{\mathrm{gr}}$, III $10 \cdot 994^{\mathrm{gr}}$. Der dritte Magnet, II, ist ein kreisrunder Stahlring von gleichfalls $20^{\mathrm{mm}}$ äusserem Durchmesser, der gleichsam aus einem quadratischen Prisma ron $2{ }^{\mathrm{mm}}$ Seite gebogen ist. Ein Schildpattstäbchen verbindet ihn mit einem dünnen Glasspiegel, dessen dümne MIessingfassung sich um die Senkrechte drehen lässt. Das ganze System wiegt $2 \cdot 517^{\mathrm{gr}}$; sein Trägheitsmoment hält nothwendig die Mitte zwischen dem von I und III. Zwar gehört der Ringmagnet zu einer anderen Bussole als die beiden Magnetspiegel, da aber die Dämpfer beider Bussolen wesentlich gleich sind, lassen die Beobachtungen in beiden sich wohl rergleichen. In der folgenden Tabelle ist $l=\lambda m$ das logarithmische Decrement in Briggs'schen Logarithmen, deren Modul $m$; $\mathfrak{I}_{0}$ und $\mathfrak{T}_{m}$ sind in Secunden die Beruhigungszeiten der Magnete beziehlich ohne HauY'schen Stab und mit Stab; $A^{\prime}$ ist in Millimetern die Entfernung 
des Stabes, bei der die Bewegung aperiodisch wurde: bei dieser Bestimmung wurde in beiden Bussulen derselbe Stab angewendet.

\begin{tabular}{|c|c|c|c|c|c|c|}
\hline \multirow[t]{2}{*}{ Magnet } & \multicolumn{5}{|c|}{$\xi=450 \mathrm{se}}$. & \multirow[t]{2}{*}{$\mathfrak{I}_{0}-\mathfrak{T}_{m}$} \\
\hline & $l$ & $\overline{T_{0}}$ & $l$ & $\overline{\mathfrak{T}_{m}}$ & & \\
\hline I & $0 \cdot 72$ & $6 \cdot 8$ & $\infty$ & $5 \cdot 2$ & $298 \cdot 5$ & $1 \cdot 6$ \\
\hline II & $0 \cdot 45$ & $11 \cdot 2$ & $\infty$ & $8 \cdot 8$ & $280 \cdot 5$ & $2 \cdot 4$ \\
\hline III & $0 \cdot 38$ & $22 \cdot 1$ & $\infty$ & $17 \cdot 5$ & $277 \cdot 0$ & $4 \cdot 6$ \\
\hline
\end{tabular}

Das logarithmische Decrement des Magnetes I ist das grösste, welches meines Wissens bisher beobachtet wurde. Wie man sieht, wächst auch an der Grenze der periodischen und der aperiodischen Bewegung die Beruhigungszeit der Magnete schnell mit ihrem Trägheitsmoment, und in einem umgekehrten Verhältniss zu diesem steht die Entfernung, bis zu welcher der Havy'sche Stab genähert werden muss, um die. Schwingungslosigkeit herbeizuführen. [838]

§. XI. Die Beruhigungszeit des gedämpften Magnetes in ihrer Abhängigkeit von dessen rerschiedenen, im Vorigen betrachteten Zuständen.

- Ueber den Einfluss der Dämpfung auf die Beruhigungszeit des Magnetes lernten wir schon eine Andentung ron Gauss kennen. Er sagt (s. oben S. 285), dass ,die Annäherung an den Ruhestand wieder "langsamer geschieht, sobald $\varepsilon$ den Grenzwerth $n$ überschreitet." Setzt man in Gleichung (IX) oder (X) $t=N T_{1}$, wo $N$ die Zahl der Schwingungen, $T_{1}$ die Schwingungsdaner des gedämpften Magnetes bedenten, so ist

$$
x_{m a x}=\xi \cdot e^{-i N T_{1}}
$$

der Ansdruck für die mit wachsendem $N$ abnehmenden Amplituden des ron $\xi$ fallenden Magnetes. $\quad T_{1}$ ist $=\frac{\pi}{\sqrt{u^{2}-\varepsilon^{2}}}[(\mathrm{XXI}), \mathrm{S} \cdot 292)$, und wächst mit $\varepsilon$. Denkt man sich zwei solche Werthe ron $N$ und ron $\varepsilon$, dass $N T_{1}=N^{\prime} T^{\prime}{ }_{1}$, so wird die kleinere Amplitnde zum grösseren $\varepsilon$ und kleineren $N$ gehören: die Beruhigungszeit des nuch schwingenden Magnetes nimmt mit wachsendem $\varepsilon$ ab. Differenzirt man ferner Gleichung (VII) nach $\varepsilon$, so findet man $\frac{d x}{d \varepsilon}$ positiv für jeden Werth ron $t>0$ : die Bernhigumgszeit des schwingungslosen Magnetes nimmt also mit wachsendem $\varepsilon$ zu; und somit ist die Gatss'sche Bemerkung erwiesen. 
Diese Bemerkung passt jedoch nicht auf unseren Fall. Dem während Gauss nur an ein Wachsen von $\varepsilon$ durch Vergrösserung der dämpfenden Metallmenge dachte, verkleinern wir $n$, zugleich aber in geringerem Naasse $\varepsilon$, ohne das Verhältniss zu kennen, in welchem letzteres geschieht. Betrachten wir zunächst den aperiodischen Zustand, und berücksichtigen wir allein die durch Verkleinern ron $n$ bewirkte Vergrösserung von $r$, indem wir Gleichung (VII) nach $r$ differenziren, so ergiebt sich $\frac{d x}{d r}$ für jeden Werth von $t>0$ als positiv. Von dem Grenzfalle $r=0$ an also bis zu $r=\varepsilon$ wächst $x$ für ein gegebenes $t$, oder es findet die Annäherung an die Ruhelage um so langsamer statt, je kleimer $n$, bis endlich der völlig astatische [839] Magnet überall stehen bleibt (rergl. oben S. 290). Berücksichtigen wir num auch die Verkleinerung ron $\varepsilon$, so wird zwar durch diese der Einfluss des Wachsens von $r$ insofern etwas vermindert, als $r$ selber dadurch langsamer wächst. Setzen wir aber $r$ constant, und differenziren (VII) nach $\varepsilon$, so ergiebt sich $\frac{d x}{d \varepsilon}$ diesmal als negativ für jeden Werth ron $t>0$. Die mit der Verkleinerung ron $n$ verbundene Verkleinerung ron $\varepsilon$, soweit es nicht unter dem Wurzelzeichen steht, wirkt also mit jener in gleichem Sinne, d. h. rergrössernd auf $x$, und demgemäss lehrt die Erfahrung, dass mit abnehmender Entfermung $A$ des Haux'schen Stabes die Beruhigmngszeit schnell zunimmt. So war z. B. bei Magnet I für $\xi=450$ sc und

$$
\begin{aligned}
& \text { für } A=A^{\prime}=298.5 \quad \mathfrak{I}_{m}=5 \cdot 2 \\
& \text { für } A=293 \cdot 5 \quad, \quad, 8 \cdot 0 \\
& \text { " " } 288 \cdot 5 \quad " \quad, 12 \cdot 0 \\
& \text { " ", } 283 \cdot 5 \quad \text {, , }, 16 \cdot 4 \\
& \text { " " " } 278 \cdot 5 \quad \text { " } 24 \cdot 4 \\
& \text { " " "273.5 " " } 40 \cdot 0 \text {; }
\end{aligned}
$$

bei weiterer Annäherung wurde der Hagnet unstet und schlug um. Bei Iagnet III war

$$
\text { für } \begin{array}{r}
A=A^{\prime}=277 \cdot 0 \quad \mathfrak{I}_{m}=17 \cdot 5 \\
\text { für } A=272 \cdot 0 \quad " \quad, 40 \cdot 0 .
\end{array}
$$

Darüber hinaus war keine Messung meh ansführbar. Diese Zahlen zeigen auf's Neue, wie der leichte Spiegel schon bei geringer Astasie aperiodisch wird, während beide Spiegel bei ungefähr derselben Nähe des Stabes aufhören brauchbar zu sein; woraus sich für den leichten Spiegel ein ungleich grösserer benutzbarer Spielraum aperiodischer Astasie ergiebt als für den schweren.

Ist die Bewegung noch periodisch, so kann man dieselbe Betrachtung 
anstellen, wie oben. Die abnehmenden Amplituden haben vieder zum Ausdruck

$$
x=\xi \cdot e^{-\varepsilon N T}{ }_{1}=\xi \cdot e^{-\frac{\varepsilon N \pi}{\ln n^{2}-\varepsilon^{2}}},
$$

allein der Exponent rerändert sich jetzt so, dass $n$ kleiner wird, während auch $\varepsilon$, nur in viel geringerem Maasse, abnimmt. Denkt man sich wieder zwei solche. Werthe ron $N$, und ron $u[810]$ und $\varepsilon$, dass $N T_{1}$ $=N^{\prime} T^{\prime}{ }_{1}$, so wird diesmal die kleinere Amplitude dem grösseren $N^{\top}$ entsprechen. Annähermng des Stahes müsste zur Folge haben, dass der Magnet langsamer schwänge, und dass zugleich seine Amplitnden etwas langsamer abnehmen: seine Beruhigungszeit müsste durch den Einfluss des Stabes etwas grösser werden.

So sicher dieser Schluss erscheint, so straft ihn doch die Erfahrmng Lügen. Die Spalte $\mathfrak{I}_{0}-\mathfrak{I}_{m}$ der Tabelle anf $\mathbf{S} .310$ zeigt, dass vielmehr die Beruhigungszeit des eben schwingungslos gewordenen Magnetes um keinen geringen Bruchtheil kleiner ausfällt als die des nicht astasirten. Den Grund dieser Abweichung suche ich in dem Widerstand der Luft. Da dieser mit der Geschwindigkeit wächst, so muss die dadurch bewrite Verzögerung im Falle ron Schwingungen grösser sein als bei schwingungsloser Rï̈kkehr zum Nullpunkte, gleiche Beruhigungszeit in der Luftleere und gleiche Fallhöhe voransgesetzt. Man könnte einwenden, dass dann der Unterschied $\mathfrak{T}_{o}-\mathfrak{T}_{m}$ bei dem schweren Spiegel rerhältnissmässig kleiner sein müsste als bei dem leichten, woron eher das Gegentheil zutrifft. Allein der Hauptsitz des Luftwiderstandes ist unstreitig der ringförmige Spalt zwischen Spiegelrand und Dämpfer, und dieser Spalt ist bei dem schweren, dicken Spiegel, wemn anch nicht ïberall gleich eng, fünfmal so lang als bei dem leichten, dümnen Spiegel. Trotz der gleichen Grösse und Gestalt der Flächen beider spiegel erfährt also der dickere einen grösseren Widerstand, und der Unterschied der Widerstände ist rermuthlich so gross, dass er den Unterschied der Massen überwiegt. Tersnche zur Prüfung dieser Hypothese habe ich noch nicht angestellt. Wie dem anch sei, für den Gebrauch ergiebt sich, dass der Zustand der eben eingetretenen Schwingungslosigkeit des Magnetes zugleich den Tortheil der kleinsten Beruhigungszeit gewälnt, welche die angewandten Torrichtungen gestatten.

§. XII. Bestätigung der für den Fall einer Anfangsgeschwindigkeit theoretisch gefundenen Beregungsgesetze

aperiodischer Magnete.

Lässt man auf den aperiodisch sich berregenden Magnet einen beständigen Strom ron längerer Dauer wirken, der ihn [8+1] immerhalb 
der Grenzen der Theilung, d. h. bei $2300^{\mathrm{mm}}$ Abstand der Scale rom Spiegel um etwa $7^{\circ}$ ablenkt, so sieht man ihn in derselben Art, wie er beim Fallen sich auf den Nullpunkt begiebt, sich der neuen Gleichgewichtslage zu bewegen und schwingungslos dort einstellen. Doch ist zn bemerken, dass wenn $\varepsilon$ nur eben $=n$ und die Ablenkung sehr gross ist, der Magnet sie $m$ m 2-3 se überschreitet, obschon er von ihr herabfallend den Nullpunkt ohne Schwingung erreicht. Anch dies rührt wohl. wie das Ueberschreiten des Nullpunktes bei übergrossen Fallhöhen (s. oben S. 308) von der Verminderung der Dämpfung mit steigender Ablenkung her. ${ }^{1}$

Un die Anfangsgeschwindigkeit $c$ sowohl wie die Ablenkung § gehörig abstufen zu können, traf ich die in Fig. 25 sichtbare Anordnung. Hier ist $\boldsymbol{M}$ der Magnetspiegel an seinem Faden und in seiner im Durchschnitt gezeichmeten dämpfenden Kúpferhülse $D D^{\prime}$. HS der Durehschnitt des Haur'schen Stabes, $K$ die Grove'sche Kette, $S c h$ ein Schlüssel, $R l_{l}$ ein Rheochord, $H$ die Haupt-, $N$ die Nebenrolle eines Schlitteninductoriums grösserer Art, $R_{1}$ eine der Thermorollen, endlich $R_{2}$ eine der gewöhnlichen feinen Hydrorollen der Bussole. Die Theile der Anordnung, die eine merkliche Fernwirkung anf einander übten, sind durch punktirte gerade Linien rerbunden. Die ron Mitte zu Mitte gemessene Entfernung zwischen $H$ und $N$ nemnen wir $B$. Bei geschlossenem Schlüssel $S$ sch hält die Rolle $R_{1}$ deu Magnet abgelenkt; durch Oeffinen des Schlüssels lässt [842] man den Magnet fallen, und ertheilt ihm zugleich eine Anfangsgeschwindigkeit im Simne der Richtkraft durch den in $N$ inducirten Nebenstrom, dem dazu die passende Richtung zu geben ist. Die Ablenkung sowohl wie der Stromstoss lässt sich anf doppelte Art regeln, jene durch das Rheochord und durch Terschieben der Rolle $R_{1}$, diese durch Yerschieben der [843] Rollen $N$ und $R_{2}$; abgesehen ron dem Einlegen von Drähten in $H$, welches aus gleich zu erwähnenden Gründen zu vermeiden ist. So gelingt es leicht, eine hinlängliche An-

1 Da das Ueberschreiten der Ablenkung nicht mehr stattfindet, wenn $\varepsilon$ merklich $>n$, so wird es wenigstens sehr unwahrscheinlich, dass die Erscheinung auf einer Unbeständigkeit der angewandten Grove'schen Kette beruht, woran man nach den Erfahrungen der Hrn. Eduund und RrJke (Poggendorfa's Amualen u. s. w. 1849. Bd. LXXVII. S. 182; - 1857. Bd. CII. S. 508) über die grössere Stärke der Schliessungs- im Vergleich zur Oeffnungs-Induction auch bei den sogenamnten beständigen Ketten deshalb hätte denken köunen, weil meine Hülfsmittel gestatten, durch die Ablenkung der Magnetnadel den Zustand der Kette nach der Schliessung früher zu beobachten, als dies wohl je möglich war. Für diese Deutung liesse sich freilich noch immer sagen, dass bei $\varepsilon>n$ die Zeit innerhalb der die Beobachtung geschieht, vergrössert wird (s. oben S. 311, und unten Abl. XIV. §. II.). 
314 XII. Ueber aperiodische Bewegung gedämpfter Magnete, - Abh. I. -

fangsgeschwindigkeit zu erzengen, damit auch bei $\varepsilon>n$ der Nullpunkt überschritten werde; ron der jenseitigen Ablenkung kehrt der Iagnet schwingungslos zum Nullpunkte zurück. Ausserdem bietet die dargestellte Anordnung auch Gelegenheit, unsere Formeln etwas schärfer auf die Probe zu stellen.

Fig. 25 .

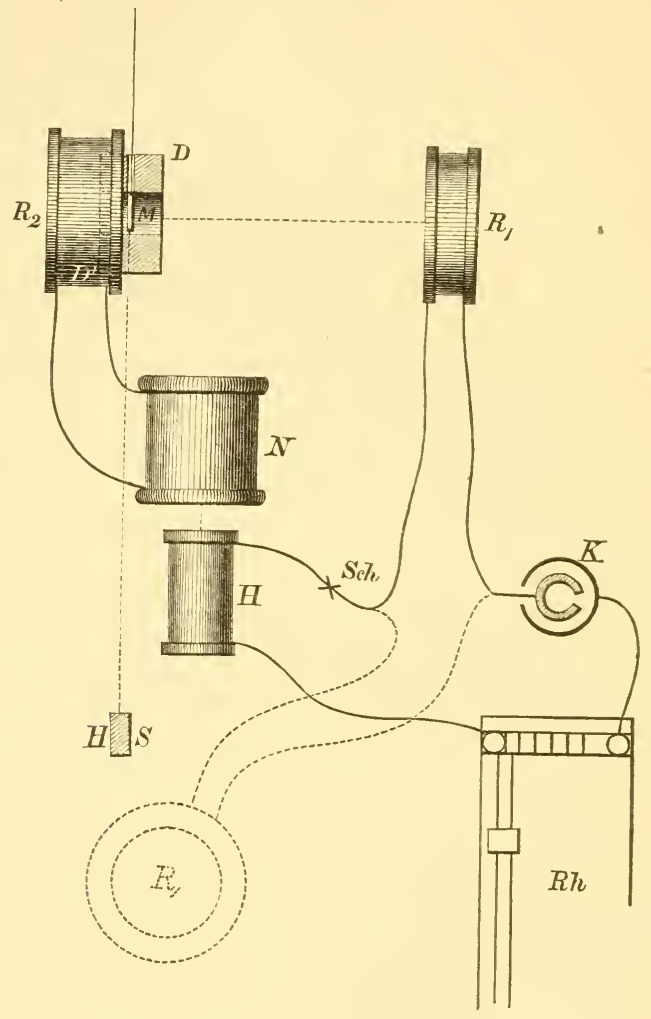

Dazu bringt man zuerst die Rolle $R_{1}$ in solche Lage, dass der Magnet keine merkliche Wirkung mehr von ihr erfährt, wie dies in der Figur durch die punktirte Leitung und Rolle $\operatorname{Sch} R_{1} K$ angedeutet ist. Die Rolle $H$ hat gleichfalls, diese aber dauernd, solche Lage, dass sie nicht merklich auf den Magnet wirkt. Zweitens entfernt man $N$ ron $H$ 
so weit, dass beim Schliessen und Oeffnen bei $S c h$ der Spiegel unbewegt bleibt. Jetzt bringt man $R_{1}$ wieder in solche Lage, und ertheilt dem Strom durch das Rheochord solche Stärke, dass der Spiegel bis an die Grenzen der Scale abgelenkt wird. Indem man ihn aus stets gleicher Höhe durch Oeffnen bei Sch öfter fallen lässt, sucht man die Entfernung des Haur'schen Stabes $A^{\prime}$ anf, bei der die Bewegung des Magnetes eben aperiodisch, oder $\varepsilon=n$ ist. Diese Entfermung muss nach Herstellung der beschriebenen Anordnung ron Nenem bestimmt werden, auch wenn $\varepsilon$ schon früher $=n$ gemacht worden war, weil zur Dämpfung durch die Kupferhülse jetzt noch die durch die Rolle $R_{2}$ tritt, daher fortan die Rolle $\boldsymbol{R}_{2}$ nicht mehr ron der Stelle gerückt werden darf. Anch die Rolle $R_{1}$ erhält von hier ab, sofern sie nicht in die unwirksame Lage gebracht wird, eine mreränderliche Stellung, und die Veränderung der Ablenkung § wird allein mittels des Rheochords bewirkt. Dämpfung sowohl als secundäre Induction im Hauptkreise sind zwar dadurch ausgeschlossen, dass man, der Natur der Dinge nach, mit dem Oeffnmmgsschlage arbeitet; jene Maassnahme hat aber ihren Grund darin, dass die Ablenkung $\xi$ die Stromstärke in dem Ḱreise $K R_{1} \operatorname{Sch} H R h K$ messen soll.

Sind diese Torbereitungen getroffen, so kam man zu folgenden zwei Versuchen schreiten.

\section{Versuch I.}

Bei irgend einer, durch das Rheochord willkürlich bestimmten Ablenkung $\xi$ nähert man die Tebemrolle znerst der Hauptrolle soweit, dass beim Oeffnen der Kette der Magnet den Nullpunkt nur eben um die kleinste bemerkbare Grösse überschreitet; diese Entfermung der Nebenrolle von der Hauptrolle heisse $B^{\prime}$. Alsdam gilt sehr genau (s. oben S. 295 ff.) die Gleichung

$$
c=\varepsilon \xi .
$$

Es ist aber in unserem Falle $c$ sichtlich proportional $\xi$; deun die Elektricitätsmenge, die sich in einem voltaëlektrischen Nebenstrome abgleicht, ist der Stärke des Hauptstromes proportional, ${ }^{1}$ und für eben

1 Es dürfen sich deshalb keine Drähte in der Hauptrolle befinden. Versuche, die ich in dieser Art mit einem kleineren Schlitteninductorium angestellt hatte, mussten verworfen werden, indem sich dabei von dem erwarteten, und wie man sehen wird, richtigen Gesetz Abweichungen ergaben, welche sich aus der An. nahme erklären liessen, dass die in den Inductionsströmen sich abgleichenden Elektricitäismengen schneller wuchsen als die Stärken der inducirenden Ströme. Vergl. Wiedemann, Die Lehre vom Galvanismus u, s. w. 1. Aufl. 1863. Bd. II. S. 297 ; - 2. Aufl. 1873 . Bd. II. Abth. I. S. 338 . 350 . 
dieser Stärke merklich proportional dürfen wir die Ablenkingen des Magnetes nehmen. Man hat also anch $c=a \xi$, wo $a$ eine Constante, folglich $a=\varepsilon$ unabhängig von $\xi$, und demgemäss kann man, wemn eimmal $B^{\prime}$ für ein beliebiges $\xi$ gefunden ist, $\xi$ durch das Rheochord fortan beliebig verändern: gleichviel von wo der Iagnet falle, stets überschreitet er den Nullpunkt nur eben um die kleinste bemerkbare Grösse.

Es versteht sich beiläufig von selber, und Rechnung wie Beobachtung ergeben, dass dabei die Beruhigungszeit kleiner wird als ohne Anfangsgeschwindigkeit.

\section{Versuch II.}

Nachdem dieser Zustand erreicht ist, bringt man, bei einem beliebigen $\xi, R_{1}$ in die unwirksame, in der Figur punktirte Lage, und wiederholt den Versuch. Jetzt trifft der Inductionsstoss, der vorher den Nagnet bei $\xi$ traf, den Magnet auf dem Nullpunkt; es erfolgt ein Ausschlag im umgekehrten Sime von der Ablenkung $\xi$; die Grösse dieses Ausschlages heisse $x$. Man hat

$$
\mathrm{x}=x_{\max }=\frac{c}{\varepsilon e}
$$

[(XXXIV), S. 302]. Abermals ist $c$ proportional $\xi$, also $\xi=$ const $\times \mathrm{x}$, gleichviel wie $\xi$ gewählt wird.

Die fulgenden Tabellen zeigen das Ergebniss der Versuche, die ich zur Prüfung dieses Schlusses anstellte. Die Zahlen $\xi_{c}$ in der ersten Spalte jeder Tabelle sind erhalten, indem ich mittels des Rheochords die Ablenkung von $25^{\text {se }}$ bis 500 se stets $m 25^{\text {sc }}$ steigerte; sie sind das Mittel ans zwei Ablesungen vor und nach zehn Ablesungen von $\mathrm{x}_{b}$; die abgelesenen Tangenten der doppelten Ablenkung sind in die doppelten Tangenten der einfachen Ablenkmng rerwandelt. Die Zahlen $\mathrm{x}_{m c}$ sind das ebenso corrigirte Mittel ans jenen zehn $x_{b}$; die Spalte $x_{m}-x_{b}$ zeigt die grösste, positive oder negative Abweichung des beobachteten nicht corrigirten $x_{b}$ vom mittleren nicht corrigirten $x_{m}$, welche in einem solchen Satze rorkam. Man sieht, dass diese Abweichung sich höchstens auf 0.85 se beläuft. Die Constante ist nach der Methode der kieinsten Quadrate berechnet; die Zahlen $\mathrm{x}_{r}$ sind durch Division ron $\xi_{c}$ mit der Constanten erhalten. Obschon $\mathrm{x}$ bis zu $183^{\text {sc }}$ hinaufgeht, belaufen sich die Abreichungen $\mathrm{x}_{r}-\mathrm{x}_{m c}$ nie auf mehr als den Bruchtheil eines Scalentheiles, mit einer einzigen Ausnahme (Versuch 15 in Tib. 1), wo ein grösserer Fehler durch irgend einen Zufall begangen wurde, wie er bei einer Versuchsreihe, die sich über viele Stunden erstreckt, wohl vorkommen kamm. Erwägt man die Fehler der gedruckten Theilung, die 
§. 12. Experimentelle Bestätigung der Bewegungsgesetze aper. Magnete. 317

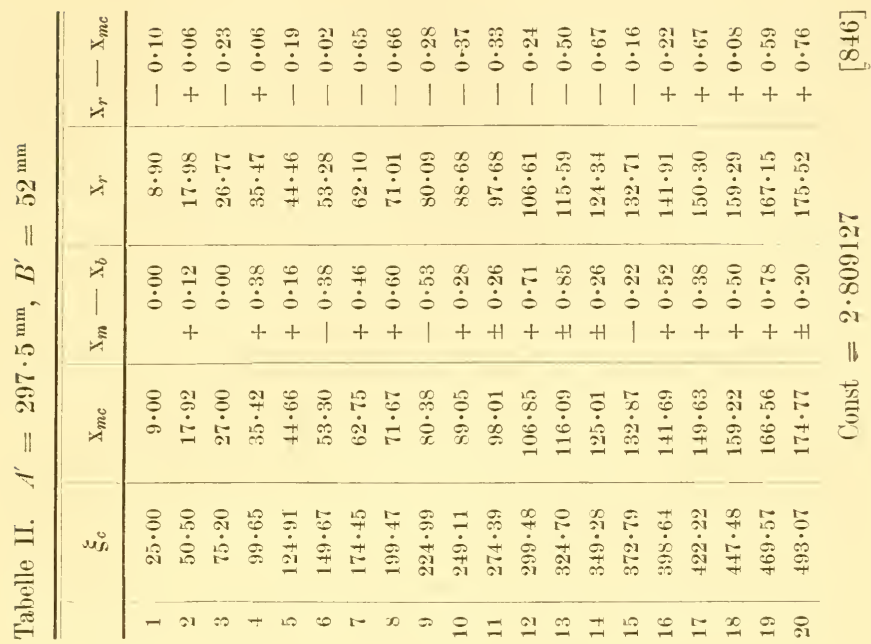

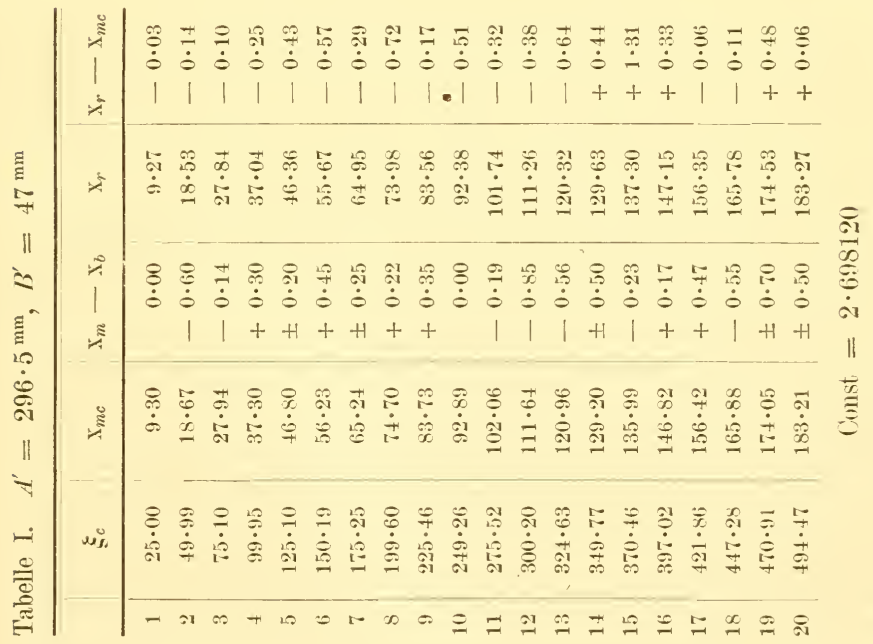


Unbeständigkeit der Kette und die Erwärmung der Drähte, die Schwankungen der Ruhelage des Magnetes und der Länge des ihn tragenden Fadens, die mangelhafte Einstellung des Fermrohrs bei grösseren Ablenkungen und die Schwierigkeit des Ablesens grösserer Ausschläge, den Widerstand der Luft, endlich die unsichere Aufstellung meiner Apparate in dafür ganz ungeeigneten Räumen, so darf die erlangte Uebereinstimmung gewiss für höchst befriedigend gelten. Die Regelmässigkeit in der Vertheilung der Zeichen der Fehler, wonach die grösseren $\mathbf{x}_{m c}$ im Allgemeinen zu klein sind, rührt wohl davon her, dass die Ablenkungen nicht unserer Voraussetzung entsprechend den Stromstärken genau proportional sind, [847] sondern ein etwas abweichendes, und zwar für die beiden Rollen $R_{1}$ und $R_{2}$, wegen ihrer rerschiedenen Entfernung rom Spiegel, verschiedenes Gesetz befolgen. Nicht eimmal die Richtkraft verändert sich genau proportional dem Sinus der Ablenkung, weil der Haur'sche Stab, wenn auch um beinahe $300 \mathrm{~mm}$ entfernt, den Magnet doch nicht mit strenge parallelen Kräften angreift.

Wir wollen jetzt noch der Constanten selber in unserer durch den Versuch bewiesenen Gleichung $\xi=$ const $\times x$ unsere Aufmerksamkeit zuwenden. Aus $c=\varepsilon \xi$ und $x=\frac{c}{\varepsilon e}$ folgt const $=e$, und man hat also die merkwürdige Beziehung

$$
\frac{\xi}{\mathrm{x}}=e .
$$

Würde $\xi=e^{2}$ gemacht, so müsste sich $\mathrm{x}=e$ ergeben; man würde unmittelbar die Basis der natürlichen Logarithmen ablesen. Dies bestätigt sich in der That.

In unserer Versuchsreihe I ist die Constante $=2 \cdot 69812$, in Reihe $I$ ist sie $=2 \cdot 80913$;

$$
\begin{aligned}
\text { Mittel } & =2 \cdot 75362 . \\
\text { Es ist } e & =2 \cdot 71828 ;
\end{aligned}
$$

der Fehler des Mittels ist also nur $=0 \cdot 03534$.

$\varepsilon^{2}$ ist $7 \cdot 3890$; wählt man als Einheit das Centimeter $=10^{\text {se }}$, und macht $\operatorname{man} \xi=7 \cdot 39$, so muss $x=2 \cdot 72$ sein. ${ }^{1}$ Ich stellte eine Anzahl solcher Prüfungen an. indem ich jedesmal ron Tenem $A^{\prime}$ und das zugehörige $B^{\prime}$ bestimmte. Die Ergebnisse dieser Versuche, nach ab-

I Da man die Tangente der doppelten Ablenkung abliest, ist eigentlich $\xi=7 \cdot 39095 \mathrm{zu}$ machen, und sollte $\mathrm{x}=2 \cdot 71838$ sein, doch fällt der Unterschied, wie nicht bemerkt zu werden braucht, weit innerhalb der Grenze der Beobachtungsfehler. 
nehmenden Entfernungen des Hacx'schen Stabes geordnet, zeigt folgende Tabelle in den Tersuchen 1-4; Tersuch 5 und 6. wo der Stab absichtlich zu nah war, wurden hinzugefügt, um das in der Reihe sich kundgebende Gesetz noch deutlicher hervortreten zu lassen.

$[884]$

$\begin{array}{ccccc}\text { Nr. } & A^{\prime} & B^{\prime} & \mathrm{x} & \text { const } \\ 1 & 298 \cdot 5 & 63 & 2 \cdot 26 & 3 \cdot 270 \\ 2 & 297 \cdot 5 & 53 & 2 \cdot 63 & 2 \cdot 810 \\ 3 & 297 \cdot 0 & 48 & \mathbf{2} \cdot \mathbf{7 2} & \mathbf{2} \cdot \mathbf{7 1 7} \\ 4 & 296 \cdot 5 & 46 & 2 \cdot 74 & 2 \cdot 700 \\ & A & & & \\ 5 & 295 \cdot 0 & 28 & 3 \cdot 12 & 2 \cdot 369 \\ 6 & 293 \cdot 5 & 4 & 3 \cdot 53 & 2 \cdot 094\end{array}$

Bei den Versuchen 2 und 4 hatte ich fast genau die Bedingungen der in Tabelle II und I enthaltenen Versuchsreihen wieder getroffen. Man sieht, dass ich ron dem äussersten Terthe ron $A$, wo mir schien, als sei die Beregung aperiodisch, den Stab nur um anderthalb Millimeter mehr, d. h. um 1/199 seines Abstandes, zu nähern hatte, um das theoretisch vorhergesehene Ergebniss zu erhalten. Erwägt man, dass bei diesen Versuchen die oben S. 307 besprochene Schwierigkeit zu sagen, ob der Nullpunkt noch überschritten werde oder nicht, zweimal auftritt, zuerst bei der Bestimmung von $A^{\prime}$, dam bei der von $B^{\prime}$, so wird man die erlangte Uebereinstimmung gewiss als genïgend anerkennen.

Die Tabelle zeigt, dass je kleiner $A$, oder je näher der Stab dem Magnete, um so grösser fällt $x$, und um so kleiner $B^{\prime}$ und die Constante aus. Der Sinn hiervon ist, dass je weniger Richtliraft dem Magnete gelassen ist, um so grösser kann die ihm ertheilte Anfangsgeschwindigkeit sein, ohne dass er den Nullpunkt überschreitet.

Dieser Zusammenhang spricht sich deutlicher aus, wenn man, anstatt $A$ und $B$ zugleich, nur die eine oder die andere Entfernung ändert. Lässt man $A=A^{\prime}$ beständig, und rerkleinert $B$, so wirc bald der Nullpunkt merklich überschritten, $\mathrm{x}$ wächst, die Constante nimmt ab. Terwickelter ist der Torgang, wemn man $B=B^{\prime}$ beständig lässt, und $A$ ändert. Wegen $\mathrm{x}=\frac{c}{\varepsilon e}$ (XXXT) ist zwar $\mathrm{x}$ ron $A$ nux insofern abhängig, als mit $A$ Intensität des Nagnetes, folglich auch Dämpfung und, obschon der Inductionsstoss derselbe bleibt, Anfangsgeschwindigkeit sich ein wenig ändern; allein dies ist nicht zu rernachlässigen. Für $I \tau$ in dem oben S. 301 (XXX) gegebenen Ausdruck

$[849]$

$$
c=\frac{\mu I \tau}{M}
$$


wollen wir $P$ setzen. welches den Integralwerth des Inductionsstromes nach Stärke und Zeit vorstellen soll. Den Werth von $\mu$ entwickeln wir, wie wir dies oben S. 305. 306 mit $m$ und "n gethan haben, zu $\mu^{\prime}\{\iota+\eta(H-S)\}$. Dann ist $e=\mu^{\prime}\{\iota+\eta(H-S)\} \cdot \frac{P}{M}$. Es ist $(\mathrm{XI})$

$$
\varepsilon=\frac{x m^{2}\left\{\imath+\eta\left(H-S^{\prime}\right)\right\}^{2}}{2 M}
$$

und folglich

$$
\mathrm{x}=\frac{c}{e \varepsilon}=\frac{2 \mu^{\prime} \cdot P}{e x \mathrm{~m}^{\prime 2}\{\iota+\eta(H-S)\}} .
$$

Wem man also, bei beständigem $B=B^{\prime}, A$ ron $A^{\prime}$ aus rergrössert, wird $\mathrm{x}$ wegen des abzunehmenden $S$ etwas kleiner, und der Yullpunkt überschritten. Umgekehrt der Nulpunkt wird nur eben erreicht, und $\mathrm{x}$ wächst um ein Geringes, wenn $A$ ron $t^{\prime}$ aus rerkleinert wird. Dies triffit im Versuch ein; als ich bei $B^{\prime}=45^{\mathrm{mm}} A$ ron $A^{\prime}=297 \mathrm{~mm}$ folgweise auf $292 ; 287 ; 277^{\mathrm{mm}}$ rerkleinerte, stieg $\mathrm{x}$ ron dem ihm willkürlich ertheilten Werthe $40 \cdot 3$ se beziehlich auf nur $41 \cdot 2 ; 42 \cdot 7 ; 46 \cdot 5$ se.

Uebrigens ist zu bemerken, dass das $c$ in unserem Tersuch II (s. oben S. 316) dem $c$ in Tersuch I nicht genau gleich ist. Denn in Versuch I, wo man $c=\varepsilon \xi$ macht, wird der Inductionsstoss erzeugt nicht allein durch die Induction ron $H$ anf $N$, sondern auch durch die Induction ron $R_{1}$ anf $R_{2}$ und auf den Dämpfer: welche in $R_{2}$ und dem Dämpfer die rerkehrte Richtung hat ron dem durch die Induction ron $H$ auf $N$ in $R_{2}$ erzeugten Strome. Man kamn also setzen $c=\varepsilon \xi=$ $\{p-(q+s)\} \xi$, wo $p, q, s$ die Geschwindigkeiten sind, welche, für die Einheit der die Stärke des indueirenden Stromes messenden $A b$ lenkung $\xi$, die beziehlich vom $H$ auf $N$, ron $R_{1}$ auf $R_{2}$, und ron $R_{1}$ auf den Dämpfer ausgeübten Inductionen dem Magnet ertheilen. In Tersuch II dagegen erhält der Magnet die Geschwindigkeit $c^{\prime}=p \xi$, und man hat somit statt

$$
\frac{\xi}{\mathrm{x}}=e, \text { vielmehr } \frac{\xi}{\mathrm{x}}=e\left(1-\frac{q+s}{p}\right),
$$

d. h. die Constante muss kleiner als $e$ ansfallen.

Indessen geht ans den Umständen des Versuches herror, dass der Bruch $\frac{q+s}{p}$ nur sehr klein sein komnte. Die Rolle $H$ hat mehrere hundert, die Rolle $N 9845$ Windungen, während $R_{1}$ nur 53 und $R_{2}$ nur 6000 Tindungen besitzt. $B^{\prime}$ war bei dem Versuch 3 der letzten Tabelle, 
wo sich const $=e$ ergab, $=48^{\mathrm{mm}}$, während ron Mitte zu Mitte gemessen der horizontale Abstand zwischen $R_{1}$ und $R_{2}$ 400, zwischen $R_{1}$ und dem Dämpfer $380^{\mathrm{mm}}$ betrug. Die Axen ron $R_{1}$ und die ron $R_{2}$ und dem Dämpfer lagen aber nicht eimmal, wie in der Figur, in einer Geraden, sondem waren einander parallel $u m$ etwa $110^{\mathrm{mm}}$ verschoben. Das Potential der Rollen $R_{1}$ und $R_{2}$, und das der Rolle $R_{1}$ und des Dämpfers aufeinander, mussten also gegen das Potential der Rollen $H$ und $N$ aufeinander nahe rerschwinden.

Für die Indnction ron $R_{1}$ auf $R_{2}$ ist dies leicht zn zeigen. Dazu wird in den Kreis ron $N$ und $R_{2}$ eine dritte Rolle $R_{3}$ ron gleicher Beschaffenheit mit $R_{2}$ (die andere Hydrorolle der Bussole) aufgenommen, und gegenüber der Rolle $R_{1}$ in deren unwirksamer Lage so aufgestellt, wie $\boldsymbol{R}_{2}$ gegenüber derselben Rolle in deren wirksamer Lage anfgestellt ist. Indem man für ein bestimmtes $B$ und $\xi$ die Induction von $H$ anf $N$ mit und ohne Rolle $R_{3}$, dann die Induction ron $R_{1}$ auf $R_{3}$ beobachtet, hat man alle Daten, um $q$ als $\zeta p$, wo $\zeta$ eine Constante, auszudrücken. Es fand sich aber, dass anch bei der grössten inducirenden Stromstärke, welche die Anordnung zuliess, d. l. bei völlig gestöpseltem Rheochord, $q$ neben $p$ nmwahmehmbar blieb. Was $s$ betrifft, so lässt sich dies nicht experimentell bestimmen, doch kam man sicher schliessen, dass, obschon grösser als $q, s$ in Bezug auf $p$ mit $q$ von gleicher Ordnung sei. Der Bruch $\frac{q+s}{p}$ musste also, wie auch aus der Uebereinstimmung unserer Ergebnisse mit der Theorie folgt, nahe $=0$ sein.

\section{[851] §. XIII. Vorzüge der Beobachtung an aperiodischen Magneten.}

Man erreicht mittels des hier beschriebenen Verfahrens vollständiger, bequemer und ohne alle Nachtheile dasselbe, was frühere Experimentatorem, Mohr, ${ }^{1}$ Schilling von Canstadt und Lenz, ${ }^{2}$ Draper, ${ }^{3}$ sich rorsetzten, als sie an die nach unten rerlängerte Axe des Magnetes Flügel von Platin oder Stamiol hefteten, welche in Oel oder Wasser einen die Schwingungen hemmenden Widerstand erfuhren. Keiner, der einmal am aperiodischen Hagnete beobachtet hat, wird ohne besondere Gründe zum schwingenden IIagnete zurückkehren, und die klare und

1 Poggendorfe's Annalen u. s. w. 1836. Bd. XXXIX. S. 131.

2 Ebendas. 1843. Bd. LIX. S. 207; - 1849. Bd. LXXVI. S. 499. 500.

3 Philosophical Magazine ete. 1839. 3rd Ser. vol. XV. p. 266.

E. $d u$ Bois-Reymond, Ges. A th. 1 . 
ruhige Spiegelung der Vorgänge in Multiplicatorkreise, welche jener gewährt, für das rerwirrende Schanspiel des bei jeder Teränderung der Stromstärke hin- und her schiessenden Scalenbildes wieder anfgeben, aus dem sich der Sachverhalt stets erst nach lästiger Ungewissheit entwickelt. Indem man mit der Verminderung der Richtkraft möglichst genan da stehen bleibt, wo $n=\varepsilon$, oder die Bewregung des Magnetes eben aperiodisch geworden ist, geniesst man, wie schon bemerkt, zugleich den Vortheil der schnellsten Beruhigung des Magnetes, welche die angewandten Vorrichtungen gestatten. Von ganz besonderem Nutzen ist der aperiodische Zustand bei dem Compensiren des Stromes zum Zwecke der Messung der elektromotorischen Kraft nach der PoGgendorfF'schen, ron mir abgeänderten Methode, oder des Widerstandes mittels der Wheatstone'schen Brücke. Der schwingende Magnet geräth in Schrankungen, sobald man die Gleichgewichtslage schneller, als der Magnet zu folgen rermag, vor ihm her dem Nullpunkte zu bewegt; der schwingungslose Magnet kann höchstens unter den oben S. 305 bezeichneten Umständen einen Hin- und Hergang machen, so dass man ohne jedes Tasten, mit stetiger Bewegung, den Nullpunkt auf den Faden einstellen kann. Gute [852] Dienste wird auch diese Methode leisten bei Demonstrationsrersuchen vor einer grösseren Versammlung, unter Anwendung des ron mir beschriebenen Verfahrens, die Ablenkungen durch einen rom Spiegel zurückgeworfenen Lichtstrahl sichtbar zu machen. ${ }^{1}$ Dies Verfahren wurde bekamntlich ron Sir Williм Thоusox angewandt, um die schwachen Signale des ersten atlantischen Kabels bequem zu beobachten, und noch heute werden die atlantischen Kabel mit sogenannten Thомsox'schen Galvanometern bedient, an denen die Ablesung auf jene, zuerst ron mir in England gezeigte Art geschieht. Hier, wie überhaupt wo in der Telegraphie Galranometer in Gebrauch sind, wird die Beseitigung der Schwingungen sich als höchst vortheilhaft errieisen.

Nützlich können endlich in ihrer überraschenden Einfachheit die Formeln (XXXIII) und (XXXII) werden. Letztere kann an sich dienen, den Integralwerth kurz danernder Ströme relatir zu bestimmen. Aber auch zur Jlessung kleiner Zeiträume nach der ron Hrn. Heusrнoutz rerbesserten PouLLET'schen Methode ${ }^{2}$ bieten jene Formeln bequeme

1 Poggendorff's Annalen u. s. w. 1855. Bd. XCV. S. 607; - Philosophical Magazine etc. 1\$56. 4 th Ser. vol. XI. 1. 109. - [S. oben S. 131, Abh. II.]

2 JoH. AIÜLLER's Archiv für Anatomie u. s. w. 1850. s. 299; - WiedeMANn, Die Lehre rom Galvanismus u. s. w. Braunschweig 1873. Bd. II. 1. Abth. S. 287 . §. 249. 
Gelegenheit, wenigstens wemn man sich eines Magnetes von solchem Trägheitsmomente bedient, dass er eine scharfe Messung ron

$$
\mathrm{t}=t_{\max }=\frac{1}{\varepsilon}
$$

zulässt. Ist $F$ die Ablenkung durch den zeitmessenden Strom in beständiger Grösse, $x$ der Aussehlag durch denselben Strom während der kleinen Zeit $\tau$, so findet man für diese leicht den Ausdruck

$$
, \tau=\frac{e t}{F} \cdot \mathrm{x} .
$$


XIII.

\section{Ueber aperiodische Bewegung gedämpfter Magnete.}

\section{Zweite Abhandlung.}

(Gelesen in der Gesammtsitzung der Königl. Akademie der Wissensehaften zu Berlin am 23. Juni 1870.) ${ }^{1}$

Hierzu Taf. IV. Fig. $4-8$.

\section{§. I. Einleitung.}

Bei der kürzlich von mir der Akademie mitgetheilten Theorie der aperiodischen Bewegung gedämpfter Magnete bin ich dem rom physikalischen Standpunkte sich darbietenden Wege gefolgt, das allgemeine vollständige Integral der Differentialgleichung für die Bewegung des Magnetes aufzustellen, und die darin rorkommenden willkürlichen Constanten der jedesmaligen Aufgabe gemäss zu bestimmen. Indem ich die Ablenkung zur Zeit Null, $=0$ oder $=$ einer positiven oder negativen Grösse $\xi$, ebenso die Geschwindigkeit zur Zeit Null, = 0 oder gleich einer positiven oder negativen Grösse $c$ setzte, habe ich die Bewegungsgleichungen für die rerschiedenen Combinationen dieser Fälle nacheinander einzeln hergeleitet.

Unter diesen Combinationen erwies sich besonders lehrreich die, wo der Magnet bei $\xi$ im Augenblicke des Fallenlassens eine Anfangsgeschwindigkeit $-c$, also im Simne der Richtkraft, erhält. Die Rechnung zeigte, dass auch damn der Nullpunkt nicht überschritten werde, so lange nicht $c$ grösser als $(\varepsilon+r) \xi$ sei. Es entstand die Frage nach dem Sinne dieser Bedingung. Da es gleichgültig ist, ob der Magnet bei $\xi$ im Augenblicke des Fallenlassens eine Anfangsgeschwindigkeit $c$ in Sinne der Richtkraft erhält, oder ob er diese Geschwindigkeit als Fallgeschwindigkeit

1 Monatsberichte der Akademie u. s. w. 1870. S. 537. - Die Bezeichnungen in dieser Abhandlung sind dieselben wie in der ersten. Die Ordnungszahlen der Formeln sind diesmal arabische, zum Unterschiede von den römischen der ersten Abhandlung. - In den Abhandlungen über aperiodische Bewegung sind mit erster, zweiter ... Abhandlung stets nur diese gemeint. 
$x^{\prime}=-c$ aus einer höheren Ablenkung mitbringt; da, unter der Yoraussetzung umbegrenzter Gültigkeit der Differentialgleichung, der Magnet mit keiner durch Fallen aus noch so hoher Ablenkung erlangten Gesehwindigkeit den Nullpunkt zu überschreiten vermag; endlich da für ein gegebenes $x$ die Fallgeschwindigkeit mit der Fallhöhe wächst: so rermuthete ich, dass $(\varepsilon+r) \xi$ die grösste Fallgeschwindigkeit sei, die der Magnet überhaupt bei $\xi$ erlangen könne, d. h., bei unbegrenzter Gültigkeit der Differentialgleichung, durch Fall aus dem Unendlichen erlangen würde.

Um diese Vermuthung zu prüfen, stellte ich mit Hülfe der bekamnten Relation $x=f(t, \xi)$ den Verlauf der Curve $x^{\prime}=\phi(x, \xi)$ im Allgemeinen fest, und untersuchte, was im Endlichen aus dieser Curve werde, wenn man $\xi=\infty$ setze. Diese Untersuchung lehrte, dass meine Vermuthung genau nur im Grenzfall $\varepsilon=n$ oder $r=0$ zutreffe; $x^{\prime}=-\varepsilon x$ ist wirklich im Endlichen die Gleichung der Curve, deren Ordinaten für jedes $x$ die Geschwindigkeit des aus dem Unendlichen fallenden Magnetes angeben. Für $\varepsilon>n$ aber ist diese Gleichung nicht $x^{\prime}=-(\varepsilon+r) x$, sondern $x^{\prime}=-(\varepsilon-r) x$; und die Geschwindigkeit bei $\xi$ muss diese höchste durch den Fall aus dem Unendlichen erreichbare Geschwindigkeit um noch mehr als $2 r \xi$ übertreffen, damit der Nullpunkt überschritten werde.

Die Differentialgleichung setzt die Proportionalität der Richtkraft mit der Ablenkung, und der rerzögernden Kraft der Dämpfung mit der Geschwindigkeit voraus; die Abweichungen der Beobachtung von der Theorie kömnen also nur so lange innerhalb der Grenze der Beobachtungsfehler bleiben, als die Ablenkung eine gewisse Grösse nicht übersteigt. Vollends hat aus Gründen, die keiner Ausführung bedürfen, eine unendlich grosse Ablenkung des Magnetes keinen physikalischen Sinn. Man sieht aber, dass die mathematische Fiction einer solchen Ablenkumg und der unbegrenzten Gültigkeit der Differentialgleichung dadurch eine wirkliche Bedeutung erhält, dass man eine dem Magnet innerhalb der Grenzen, wo die Bedingungen der Differentialgleichumg noch erfüllt sind, auf andere Art ertheilte Geschwindigkeit als durch Fall aus dem Unendlichen entstanden ansehen kann.

Als ich meinem Freunde, Hrn. Kronecker, die Ergebnisse meiner Untersuchung mittheilte, machte er mich auf eine Behand- [539] lungsweise des Gegenstandes aufmerksam, auf welche rom physikalischen Standpunkte nicht leicht zu kommen war. Sie schlägt gerade den entgegengesetzten Weg ron dem eben angedeuteten ein. Von vorn herein. wird die Gültigkeit der Differentialgleichung für ein unendliches $x$, oder, was das Nämliche ist, für ein unendliches negatives $t$, vorausgesetzt. Indem man überdies bei gewissen ersten Integralen der Differentialgleichung 
stehen bleibt, hat man ohne Weiteres für jede Zeit zwischen $t=-\infty$ und $t=+\infty$ die Beziehung zwischen Geschwindigkeit und Ablenkung vor Augen. Um aber ron dieser ganz allgemeinen und der Wirklichkeit in der That entfremdeten Betrachtung zu den wirklichen Bedingungen zurückzukehren, ist nur nöthig, letztere als gegebene Beziehungen zwischen Ablenkung, Geschwindigkeit und Zeit in den allgemeinen Ausdruck einzuführen.

Wenngleich diese Art der"Betrachtung die frühere nicht wohl entbehrlich macht, hat sie doch ihre eigenthümlichen Vortheile, und erst in ihrem Lichte lassen manche durch die frühere Betrachtung aufgedeckte Beziehungen ihren wahren Zusammenhang erkennen. Dies wird am besten erhellen, wenn wir mit ihrer Hülfe einige der Aufgaben behandeln, deren Lösung scheinbar schon auf dem früheren Wege vollständig erreicht war.

\section{§. II. Die fundamentalen Eigenschaften unserer}

Differentialgleichung.

Indem wir übrigens sämmtliche Bezeichnungen der Abhandlung beibehalten, setzen wir kürzehalber

$$
\varepsilon+r=a, \varepsilon-r=b .
$$

Unsere Differentialgleichung heisst alsdam (vergl. Abhandlung (I), S. 286 und 296)

$$
0=x^{\prime \prime}+(a+b) x^{\prime}+a b x
$$

Die neue Theorie geht ans ron der fundamentalen Bemerkung, dass man durch Differenziren der Ausdrücke

$$
\epsilon^{a t}\left(b x+x^{\prime}\right), \quad e^{b t}\left(a x+x^{\prime}\right)
$$

das rechte Glied der Differentialgleichung beziehlich mit $e^{a t}$ und $e^{b t}$ multiplicirt erhält.

[540] Die Ausdrücke (2) sind also constant; man kann setzen

$$
\left.\begin{array}{l}
b x+x^{\prime}=A^{\prime} e^{-a t} \\
a x+x^{\prime}=B^{\prime} e^{-b t}
\end{array}\right\}
$$

wo $A^{\prime}, B^{\prime}$ willkürliche Constanten sind, welehe zu den Constanten $A, B$ in dem Integral unserer Differentialgleichung, wie es Gleichung (VI) der ersten Abhandlung giebt, in der Beziehung stehen

$$
A^{\prime}=-2 r A, \quad B^{\prime}=2 r B \text {. }
$$

Es folgt weiter, dass man jederzeit setzen kann

$$
\left.\begin{array}{l}
\epsilon^{a t}\left(b x+x^{\prime}\right)=e^{a T}\left(b X+X^{\prime}\right) \\
e^{b t}\left(a x+x^{\prime}\right)=e^{b T}\left(a X+X^{\prime}\right)
\end{array}\right\}
$$

Wird der Verlauf ron $x, x^{\prime}$ als Functionen der Zeit, insofern er von den willkürlichen Constanten abhängt, als bereits bestimmt angenommen, so 
bedeuten $\mathrm{X}, \mathrm{X}^{\prime}, T$ beliebige zusammengehörige Werthe der Functionen $x, x^{\prime}$ und der Zeit. Wird aber jener Verlauf als noch nicht bestimmt angesehen, so bedeuten $\boldsymbol{X}, \boldsymbol{X}^{\prime}, T$ willkürliche Constanten, durch deren Einsetzung der Verlauf bestimmt wird.

Durch $\nu$ malige Differentiation der Gleichungen (3) erhält man, wenn $\frac{d^{\nu} x}{d t^{\nu}}=x^{(\nu)}$ gesetzt wird,

$$
\left.\begin{array}{l}
b x^{(\nu)}+x^{(\nu+1)}=(-a)^{\nu} A^{\prime} e^{-a t} \\
a x^{(\nu)}+x^{(\nu+1)}=(-b)^{\nu} B^{\prime} e^{-b t}
\end{array}\right\}
$$

und folglich

$$
\begin{gathered}
(-1)^{\nu} \cdot 2 r x^{(v)}=-a^{\nu} A^{\prime} e^{-a t}+b^{\nu} B^{\prime} e^{-b t}, \\
a x^{(v)}+x^{(v+1)}=\frac{b^{\nu} B^{\prime}}{a^{\nu} A^{\prime}} \cdot e^{2 r t},
\end{gathered}
$$

oder, wenn man zu den Logarithmen übergehend $\frac{1}{2 r} \log \left(\frac{a}{b}\right)=\Delta$ setzt,

$$
\left.\frac{1}{2 r} \log \left(\frac{A^{\prime}}{B^{\prime}} \cdot \frac{a x^{(\nu)}+x^{(\nu+1)}}{b x^{(\nu)}+x^{(\nu+1)}}\right)=t-v\right\lrcorner .
$$

Hieraus sind folgende Schlüsse zu ziehen:

I. Wenn die Grössen $x$ und $x^{\prime}$ für irgend einen endlichen Werth von $t$ endliche Werthe haben, so sind $A^{\prime}$ und $B^{\prime}$ endlich. Ist einer der beiden Ausdrücke

$$
a x+x^{\prime}, \quad b x+x^{\prime}
$$

[541] für irgend einen endlichen Werth ron $t$ gleich Noll, und ist es also auch $B^{\prime}$ oder $A^{\prime}$ (3), so bleibt der Ausdruck Null für alle endlichen Werthe ron $t$, und es wird demgenäss die Ablenkung $x$ durch eine der beiden Gleichungen

dargestellt.

$$
x=-\frac{A^{\prime}}{2 r} e^{-a t}, \quad x=\frac{B^{\prime}}{2 r} e^{-u t}
$$

II. Wenn, wie es in der Folge stets geschehen soll, ron den erwähnten besonderen Fällen abgesehen wird, so bleiben die Vorzeichen der Ausdrücke

$$
a x^{(\nu)}+x^{(\nu+1)}, \quad b x^{(\nu)}+x^{(\nu+1)}
$$

wie die Gleichungen (5) zeigen, für alle Zeit constant. Wählt man nun, was offenbar erlaubt ist, das Vorzeichen ron $x$ so, dass $a x+x^{\prime}$ und also $B^{\prime}$ positiv ist, so ist $b x+x^{\prime}$ für den ganzen Verlauf der Zeit und also $A^{\prime}$ entweder positiv oder negativ. Demnach sind zwei wesentlich verschiedene Hauptfälle zu unterscheiden, ron denen derjenige stets als der erste bezeichnet werden soll, in welchem $A^{\prime}$ positir ist, also die Ausdrücke (9) einerlei Zeichens sind, und als der zweite der, in welchem $A^{\prime}$ negativ ist, alsu jene Ausdrücke verschiedenen Zeichens siud. 
III. Der Ausdruck $(-1)^{v}\left(a x^{(v)}+x^{(v+1)}\right)$ mimmt, während $t$ von $-\infty$ bis $+\infty$ geht, alle positiven Werthe ron $\infty$ bis 0 wirklich an; ebenso durchläuft $(-1)^{v}\left(b x^{(v)}+x^{(v+1)}\right)$ je nach den beiden soeben unterschiedenen Fällen alle Werthe ron $+\infty$ bis 0 oder ron $-\infty$ bis 0. Der Quotient

$$
\frac{\left.a x^{(\nu)}+x^{\nu}+1\right)}{\left.b x^{(\nu)}+x^{(\nu}+1\right)}
$$

durchläuft, wie Gleichúng (7) zeigt, je nach den beiden Fällen sämmtliche positive oder sämmtliche negative Werthe von 0 bis $\infty$; aber der Quotient

$$
\frac{\left.x^{\prime \nu}+1\right)}{x^{(\nu)}},
$$

welcher für $t=-\infty$ den Werth $-a$ und für $t=+\infty$ den Werth - $b$ hat, durchläuft im zweiten Hauptfalle sämmtliche zwischen - $a$ und $-b$ liegenden Werthe, im ersten Hauptfalle alle übrigen [542] positiven und negativen Werthe. Nur in diesem ersten Hauptfalle werden daher zu gewissen Zeiten $x$ und seine Differentialquotienten gleich Null. Für diese Zeiten und die zugehörigen Werthe der Ablenkung $x$ und ihrer Differentialquotienten führen wir übrigens nachstehende Bezeichnungen ein: der Zeit

$$
\begin{aligned}
& t_{0} \text { entspreche } x=0, x^{\prime}=x_{0}^{\prime} . \\
& \boldsymbol{\tau} \quad, \quad x^{\prime}=0, x=\xi \text {. } \\
& t, \quad x^{\prime \prime}=0, x=x_{1,}, x^{\prime}=x^{\prime} \text {, } \\
& t_{\prime \prime} \quad, \quad x_{\prime \prime \prime}=0, x=x_{\prime \prime}, x^{\prime}=x^{\prime}{ }_{\prime \prime}, \mathrm{u} . \mathrm{s} . \mathrm{W} .
\end{aligned}
$$

IV. Gleichung (6) liefert folgende Bestimmungen für die Ablenkung $(x)$ und deren Differentialquotienten:

wenn $t=-\infty$, so ist $(-1)^{v} x^{(v)}=\mp \infty$ ron der Ordnung $e^{-a t}$; wemn $t=+\infty$, so ist $\quad x^{(v)}=0$ ron der Ordnung $e^{-b t}$. Für $t=-\infty$ ist also $x^{(v)}$ unendlich gross ron derselben Ordnung wie $b x^{(v)}+x^{(v+1)}$, aber ron höherer Ordnung als $a x^{(v)}+x^{(v+1)}$. Für $t=+\infty$ ist $x^{(v)}$ unendlich klein ron derselben Ordnung wie $a x^{(\nu)}+$ $x^{(v+1)}$, aber ron niederer Ordnung als $b x^{(v)}+x^{(v+1)}$.

V. Die Zeitpunkte, in denen der Reihe nach die Quotienten

$$
\frac{x}{x^{\prime}}, \frac{x^{\prime}}{x^{\prime \prime}}, \frac{x^{\prime \prime}}{x^{\prime \prime \prime}}, \ldots
$$

einen und denselben bestimmten Werth annehmen, bilden, wie aus Gleichung (8) herrorgeht, eine arithmetische Reihe mit dem beständigen Unterschiede $\Delta$. Dies findet also namentlich für diejenigen Zeitpunkte $t_{0}, \tau, t_{n}, t_{n} \ldots$ statt, in denen im ersten Hauptfalle folgweise $x, x^{\prime}, r^{\prime \prime}$, $x^{\prime \prime \prime}$. . gleich Null werden (s. oben III.), so wie für diejenigen Zeitpunkte, 
in denen im zweiten Hauptfalle $\frac{x^{(\nu+1)}}{x^{(\nu)}}=-\varepsilon$ wird. Diese beiden Reihen von Zeitpunkten sind zwar je nach den beiden verschiedenen Fällen ganz rerschieden charakterisirt, entsprechen einander aber insofern, als dabei stets

$$
\frac{a x^{(v)}+x^{(v+1)}}{b x^{(v)}+x^{(v+1)}}= \pm 1
$$

wird.

VI. Wemn

$$
A^{\prime}= \pm b \xi e^{a \tau}, \quad B^{\prime}=a \xi e^{b \tau}
$$

gesetzt wird, so nehmen die Gleichungen (3) und (6) die Form an $[543]$

$$
\begin{gathered}
\left.a x+x^{\prime}=a \xi e^{b(\tau-t)}\right\} \\
\left.b x+x^{\prime}= \pm b \xi e^{a(\tau-t)}\right\} \\
x^{(\nu)}=(-1)^{\nu} \cdot \frac{a b}{2 r} \xi\left(b^{(\nu-1)} e^{b(\tau-t)} \mp a^{(\nu-1)} e^{a(\tau-t)},\right.
\end{gathered}
$$

und es bedentet $\tau$ die Zeit, zu welcher

$$
\frac{a x^{\prime}+x^{\prime \prime}}{b x^{\prime}+x^{\prime \prime}}= \pm 1
$$

ist, während aus der zur Zeit $\tau$ stattfindenden Ablenkung $x$ die positive Grösse $\xi$ durch die Gleichung

$$
\xi=\frac{a-b}{a+b} x
$$

bestimmt ist. Hiernach ist im ersten Hauptfalle $\tau$ die Zeit und $\xi$ die Ablenkung, bei der die Umkehr des Magnetes nach Ueberschreiten des Nullpunites erfolgt, bei der also $x^{\prime}=0$ und

$$
x^{\prime \prime}+n^{2} x=0
$$

ist, während im zweiten Hauptfalle $\tau$ die Zeit und $\frac{a+b}{a-b} \xi=\frac{\varepsilon}{r} \xi$ die Ablenkung ist, bei der $x^{\prime}=-\frac{2 a b}{a-b} \xi$ und

wird.

$$
x^{\prime \prime}-n^{2} x=0
$$

VII. Da nach den Gleichungen (11) für irgend welche bestimmte zusammengehörige Werthe $T, X, X^{\prime}$ die Relationen

$$
a X+X^{\prime}=a \xi e^{b(\tau-t)}, b X+X^{\prime}= \pm b \xi e^{a(\tau-t)}
$$

statthaben, so erhält man aus gegebenen Werthen $T, X, X^{\prime}$ die Werthe ron $\tau$ und $\xi$ in folgender Weise:

$$
\begin{gathered}
\tau=T+\frac{1}{2 r} \log \left(\frac{a b X+a X^{\prime}}{a b X+b X^{\prime \prime}}\right) \\
\xi=\left(X+\frac{1}{a} X^{\prime \prime}\right)^{\frac{a}{2 r}} \cdot\left[ \pm\left(X+\frac{1}{b} X^{\prime \prime}\right)\right]-\frac{b}{2 r}
\end{gathered}
$$


VIII. Die Beziehung zwischen Ablenkung und Geschwindigkeit, d. h. zwischen $x$ und $x^{\prime}$, ergiebt sich unmittelbar aus den Gleichungen (11) in folgender Weise:

[544]

$$
a \cdot \log \left(\frac{a \cdot x+x^{\prime}}{a \xi}\right)=b \cdot \log \left(\frac{b x+x^{\prime}}{ \pm b \xi}\right),
$$

wo unter dem Logarithmus-Zeichen nur positive Grössen stehen, oder also

$$
\left(\frac{a x+x^{\prime}}{a \xi}\right)^{a}=\left(\frac{b x+x^{\prime}}{ \pm b \xi}\right)^{b}
$$

§. III. Erster Hauptfall: $a x+x^{\prime}$ und $b x+x^{\prime}$ sind einerlei Zeichens.

Aus (12) ergeben sich in diesem Falle die Gleichmgen

$$
\begin{aligned}
& x=\frac{\xi}{2 r}\left(a e^{b(\tau-t)}-b e^{a(\tau-t)}\right), \\
& x^{\prime}=\frac{\xi a b}{2 r}\left(e^{a(\tau-t)}-e^{b(\tau-t)}\right),
\end{aligned}
$$

welche den Gleichungen (VII) und (XII) der ersten Abhandlung entsprechen. Hier werden gemäss der fünften obigen Schlussfolgerung zu den Zeiten

$$
\begin{gathered}
\left.\left.\left.t_{0}=\tau-\right\lrcorner, \quad \tau, \quad t_{1}=\tau+\right\lrcorner, \quad t_{\prime \prime}=\tau+2\right\lrcorner, \text { u. s. w. } \\
x=0, \quad x^{\prime}=0 \quad x^{\prime \prime \prime}=0, \quad \text { u. s. w. }
\end{gathered}
$$

und zwar müssen, wenn $x$ oder ein Differentialquotient ron $x$ Null werden solll, die Ausdrücke $a x+x^{\prime}, b x+x^{\prime}$ einerlei Zeichens sein. Dies ist nur möglich, wenn entweder $x$ und $x^{\prime}$ selber einerlei Zeichens sind, oder wenn, bei rerschiedenem Zeichen ron $x$ und $x^{\prime}, x^{\prime}$ entweder grösser als $a x$ und also auch als $b x$, oder kleiner als $b x$ und also anch als $a x$ ist.

Für $t=-\infty$ ist gemäss der vierten Folgerung $x=-\infty$, $x^{\prime}=+\infty, \frac{x^{\circ}}{x}=-a$. Was für endliche Werthe ron $t$ geschieht, zeigt Fig. 4 (s. die Taf.). Man erkennt die Curren an den ihnen beigefügten Ordnungszahlen ihrer Gleichungen; Curre (16) ist die der Ablenkungen, Curre (17) die der Geschwindigkeiten. Beide Curven sind anfänglich conrex gegen die Abscissenaxe der Zeiten, denn $x^{\prime \prime}$ ist negativ und $x^{\prime \prime \prime}$ positiv. Dann folgen einander in dem nur von den Constanten der Vorrichtung, nicht von $\xi$ abhängigen Abstande $\lrcorner$ die rier Zeitpunkte $t_{0}, \tau, t_{\mu}, t_{\mu}$. Bei $t_{0}[545]$ schneidet die Curve der Ablenkungen die Axe der Zeiten und wird gegen sie concar, da ihre Ordinate das Zeichen wechselt, $x^{\prime \prime}$ das seinige behält. Dies dauert bis zum Zeitpunkte $\boldsymbol{\tau}$. Hier erreicht die Curre der Ablenkungen das Maximum $\xi$, denn für $t=\tau$ 
ist $x=\xi$ und $x^{\prime}=0$. Die Curve der Geschwindigkeiten schneidet also jetzt gleichfalls die Abscissenaxe der Zeiten und wird gegen sie concar, weil $x^{\prime \prime \prime}$ sein Zeichen behält; bei $t$, erreicht ihre Ordinate das negatire Maximum

$$
x^{\prime},=-\xi \cdot a^{-\frac{b}{2 r}} \cdot b^{\frac{a}{2 r}},
$$

und es findet ein Wendepunkt der Curre der Ablenkungen statt. Endlich für $t_{\prime \prime}$ hat die Curve der Geschwindigkeiten einen Wendepunkt.

In der Figur sind aus Gründen, die später einleuchten werden (s. untell $\S$ VII), $\xi=1, a=1, b=1 / 2$ gesetzt. $\perp$ wird dann $=1 \cdot 38629 ; x_{1}=3 / 4, x_{\prime \prime}=7 / 16 ; x_{0}^{\prime}=2, x^{\prime}=-1 / 4, x^{\prime}{ }_{\prime \prime}=-3 / 16$.

Für $t=+\infty$ werden gemäss der vierten Folgermng $x$ und $x^{\prime}$ $=0, x^{\prime}=-b x, x$ läuft auf der positiven, $x^{\prime}$ auf der negativen Seite der Abscissenaxe asymptutisch aus.

Man kann dergestalt fïr unsere Betrachtung die ganze Zeit ron $t=-\infty$ bis $t=+\infty$ in drei Abschnitte theilen, wie folgendes Schema zeigt (vergl, anch zwischen Fig. 4 und j).

$$
\begin{aligned}
& \text { I. } \\
& \text { II. } \\
& \text { III. } \\
& t=-\infty \\
& \text { - } \infty \text { bis } t_{0} \quad t_{0} \text { bis } \tau \\
& \text { negativ } \\
& \text { positiv } \\
& x^{\prime}=+\infty \\
& \text { positiv } \\
& \text { positiv } \\
& a \text { bis }+\infty \\
& -\infty \text { bis } 0 \quad 0 \text { bis } l \\
& \begin{array}{ll}
\tau \text { bis }+\infty & +\infty \\
\text { positiv } & +0 \\
\text { negativ } & -0
\end{array} \\
& -\frac{x^{\prime}}{x}=a
\end{aligned}
$$

Welche Werthe zu irgend einer Zeit $T$ die Abtenkung $X$ und die Geschwindigkeit $\boldsymbol{X}^{\prime}$ haben mögen, vurausgesetzt nur, dass sie dem ersten Hauptfall entsprechen, stets giebt es, wie oben unter VII. ausgeführt ist, einen Zeitpunkt $\tau$, ror oder nach $T$, in welchem $x^{\prime}=0$ ist, und es lässt sich diese Zeit $\tau$ und die zugehörige Ablenkung $\xi$ aus den gegebenen Werthen $T, \boldsymbol{X}, \mathrm{N}^{\prime}$ berechnen. $\tau$ vorhergegangen ist stets im Zeitabstande $\Delta$ die Zeit $t_{0}$, wo $x=0$ war. Der ganze Vorgang bleibt also, da einzig und allein die Werthe von $\tau$ und $\xi$ variiren können, an sich und im Wesentlichen stets derselbe und namentlich bleibt das Verhalten in positiv und [546] negativ umendlicher Zeit mverändert, wie man auch die Bedingmmgen wählen möge, vorausgesetzt nur, dass die für den ersten Hauptfall bezeichnenden Eigenschaften gewahrt bleiben.

Nimmt man $\xi$ negativ, so ändern die Ausdrücke (9) und in allen drei Zeitabschnitten $x$ und $x^{\prime}$ ihr Zeichen. Alle Torgänge bleiben also dieselben, nur dass die beiden Seiten der Abscissenaxe, oder die beiden Hälften der Scale, mit einander vertanscht sind. 
§. IV. Physikalische Anwendung der gewonnenen Ergebnisse, und Vergleichung dieser Ergebnisse mit denen der ersten Abhandlung.

Wir können die verschiedenen Fälle der Bewegung des Magnetes - von einer Ablenkung oder rom Nullpunkt aus, mit oder ohne Anfangsgeschwindigkeit - ans folgender Fietion herleiten. Vor unendlicher Zeit durchfiel der Magnet Räume unendlicher Ablenkung mit solcher unendlichen Geschwindigkeit, dass diese zur Ablenkung in dem von den Constanten der Vorrichtung abhängigen Verhältniss $-a$ stand. Zur Zeit $t=0$, wo wir den Vorgang zu betrachten anfangen, ist der Magnet in endliche Ablenkung gelangt und es sind, je nach den Bedingungen der Aufgabe, gewisse Zeitpunkte schon rorüber. Ist der Magnet bereits abgelenkt, so kann der Fall aus dem Unendlichen geschehen sein entweder ron der Seite her, auf der er sich befindet, oder ron der entgegengesetzten Seite her.

I. Jedesmal, dass der Magnet zur Zeit $t=0$ ohne Anfangsgeschwindigkeit aus einer endlichen, positiren oder negativen Ablenkung $\xi$ fällt, können wir uns denken, er sei ron der entgegengesetzten Seite her aus dem Unendlichen gefallen, habe den Nullpunkt überschritten, und kehre bei $\xi$ in seiner Bewegung um, daher $x^{\prime}$ hier $=0$ ist. Der Torgang begimnt also in der Idee an der Grenze des zweiten und dritten der oben unterschiedenen Zeitabschnitte. Man braucht in der That nur in (16) $\tau=0 \mathrm{zu}$ setzen, um Gleichung (VII) der ersten Abhandlung zu erhalten, welche diese Bewegung des Magnetes darstellt; und unsere gegenwärtige Fig. 4 fällt ron $\tau$ ab nach wachsender Zeit hin im Wesentlichen mit Fig. 22 der ersten Abhandlung zusammen. ${ }^{1}$ Selbst der Fall aus dem Unend- [547] lichen ohne Anfangsgeschwindigkeit, mit dem sich §. VI der ersten Abhandlung beschäftigt, lässt sich unter denselben Gesichtspunkt bringen, indem man $\xi=\infty$ setzt. Alle endlichen mit $\xi$ multiplicirten Ordinaten, wie $x_{1}, x_{11}, x_{0}^{\prime}, x^{\prime}, x_{\prime \prime}^{\prime}$, werden gleichfalls unendlich; für $t=-\infty$ aber werden $x$ und $x^{\prime}$ unendliche Grössen höherer Ordnung. Man hat sich also vorzustellen, der Hagnet sei aus unendlicher Ferne höherer Ordnung gefallen, habe den Nullpunkt mit unendlicher Geschwindigkeit überschritten und jenseits ausschlagend ein unendliches $\xi$ erreicht, bei welchem er zur nenen Anfangszeit $=0$ eben umkehre.

II. Jedesmal, dass der Magnet auf dem Nullpunkt einen Stoss erhält, der ihm eine Anfangsgeschwindigkeit $+c$ ertheilt, können wir

1 In letzterer ist $r=0$, in der gegenwärtigen Figur $=1 / 4$ gemacht (s. vorige Seite). 
uns denken, er sei in der Richtung des Stosses aus dem Unendlichen gefallen, und überschreite zur Zeit $t_{0}=0$ den Nullpunkt mit einer, jener Anfangsgeschwindigkeit $+c$ gleichen Fallgeschwindigkeit $x^{\prime}$. Der Vorgang beginnt in der Idee an der Grenze des ersten und zweiten Zeitabschnittes. Man erhält Gleichung (XXXI) der ersten Abhandlung, welche diese Bewegung des Magnetes darstellt, indem man in den Gleichmigen (4) $T=0, X=0$ und $X^{\prime}=c$ setzt.

III. Jedesmal dass der Magnet im Angenblicke, wo er in einer gegebenen Ablenkung sich selbst überlassen wird, einen Stoss im einen oder anderen Simm erhält, kömmen wir ebenso für die Anfangsgeschwindigkeit Fallgeschwindigkeit, durch Fall aus dem Unendlichen erlangt, substituiren. Dabei sind drei Fälle zu unterscheiden.

1. Die Geschwindigkeit hat den Sinn der Richtkraft und ist grösser als ax. Es ist als sei der Magnet ron der Seite her, nach welcher er abgelenkt ist, ans dem Unendlichen gefallen, und überschreite eben die gegebene Ablenkung mit der gegebenen Geschwindigkeit - $c$. Daher von $x_{1}^{\prime} t_{1} x_{1}$ nach wachsender Zeit hin unsere gegenwärtige Fig. 4 im Wesentlichen mit Fig. 23 der ersten Abhandlung zusammenfällt, welche die Bewegung des Magnetes mit einer negativen Anfangsgeschwindigkeit $>(-a x)$ rorstellt; nur dass in beiden Figuren die beiden Seiten der Abscissenaxe, also die beiden Scalenhälften, mit einander rertauscht sind, und ausserdem in der Figur der ersten Abhandlung abermals $r=0$, in der jetzigen $=1 / 4$ gesetzt ist. Gleichung (XXII) der ersten Abhandlung entsteht aus den Gleichungen (4), indem man in letzteren $T=0, \quad X^{\prime}=-c, X=$ dem $\xi$ der ersten Abhandlung setzt, welches zum Unterschiede rom [548] jetzigen $\xi$ fortan $\xi_{A}$ heissen soll. ${ }^{1}$ Um $\boldsymbol{X}$ and $\boldsymbol{X}^{\prime}$ rerschiedenen Zeichens, und dabei $\boldsymbol{X}^{\prime \prime}$ grösser als $a \boldsymbol{X}$ zu finden, müssen wir len Anfang des Vorganges in den ersten Zeitabschitt verlegen.

2. Die Geschwindigkeit hat den entgegengesetzten Sinn der Richtkraft. Es ist als sei der Magnet auf der entgegengesetzten Seite ron der, nach welcher er abgelenkt ist, aus dem Unendlichen gefallen, habe den Nullpunkt überschritten, und üherschreite eben die

1 Dass das jetzige und frühere $\xi$ einander nicht stets, wie in Fall I, entsprechen, rührt daher, dass mit dem jetzigen $\xi$ jedesmal der Ausschlag nach Ueberschreiten des Nullpunktes bezeichnet wird, während in der Abhandlung $\boldsymbol{\xi}$ gerade deshalb keine solche gleichmässige Bedentung erhielt, weil es stets die der Anfangszeit $t=0$ entsprechende Ablenkung bezeichnete, wenn nicht diese Null war, wie in dem soeben unter II erwähnten Falle des §. VII der ersten Abhandlung. Daher das $\boldsymbol{\xi}$ der ersten Abhandlung und das jetzige nur bei dem Fallenlassen des Magnetes ohne Anfangsgeschwindigkeit übereinstimmen. 
gegebene Ablenkung $\xi_{A}$ mit der gegebenen Geschwindigkeit $+c$, mit welcher er dem Maximum $\xi$ seines Ausschlages zustrebt; s. bei $\mathfrak{x}_{2}^{\prime} \mathfrak{x}_{2} t_{2}$ in Fig. 4. Analytisch entsteht dieser Fall, indem man in den Gleichungen (4) $T=0, X=\xi_{A}, X^{\prime}=+c$ setzt. Da nur zwischen $t=t_{0}$ und $t=\tau, x$ und $x^{\prime}$ eimerlei Zeichens sind, fällt der Begimn des Forganges in den zweiten Zeitabschnitt; und da zn Anfang dieses Abschnittes $x=0$, $x^{\prime}$ endlich ist, zu Ende das Umgekehrte stattfindet, ist diesmal der Geschwindigkeit kein Grenzverhältniss zur Ablenkung rorgeschrieben.

3. Die Geschwindigkeit hat den Sinn der Richtkraft und ist kleiner als $b x$. Diese Combination kommt nur im dritten Zeitabschnitt ror. Es ist abermals als sei der Magnet auf der entgegengesetzten Seite aus dem Unendlichen gefallen, als habe er aber nicht allein den Nullpunkt, sondern auch das Maximum seines Ausschlages bereits überschritten; s. bei $\mathfrak{x}_{3} \mathrm{t}_{3} \mathrm{r}_{3}^{\prime}$ in Fig. 1 . Analytisch entsteht dieser Fall, indem man in den Gleichungen (4), wie im Falle III. 1., $T=0$, $X^{\prime \prime}=-c, X=\xi_{A}$ setzt; man erhält Gleichung (XXII) der ersten Abhandlung, aber, weil $c$ kleiner ist als $b x$, mit umgekehrtem Zeichen der rechten Seite, daher anch diesmal unsere Figur zur Gleichung erst nach Vertauschung der beiden Scalenhälften passt.

IV. Die in §. IX der ersten Abhandlung behandelten Fälle, in denen der in Bewegung begriffene Magnet zu gegebener Zeit einen Stoss [549] im einen oder anderen Simn erhält, lassen sich gleich den rorigen betrachten, indem man die beiden Geschwindigkeiten, die rorhandene und die hinzutretende, als durch Fall ans dem Unendlichen unter geeigneten Bedingungen entstanden ansieht und algebraisch summirt.

Die nene Behandlungsweise bietet, wie man sieht, den Vortheil, dass sie sämmtliche in der ersten Abhandlung einzeln abgeleitete Fälle auf Einen allgemeinen Fall zurückführt. Die Rolle der merkwürdigen arithmetischen Reihe der Zeiten, ron der sich in jenen Fällen eine grössere oder geringere Zahl ron Gliedern zeigte, ist nun klar. Man versteht auch die Bedeutung der negativen Zeiten, welche dort im Dunkel blieb. Im Fall eines den bei $\xi_{A}$ sich überlassenen Magnet im Simne der Richtkraft treffenden Stosses fanden wir für die Zeit des Durchganges durch den Nullpunkt den Ausdruck

$$
t_{0}=\frac{1}{2 r} \log \left(\frac{c-b \xi_{A}}{c-a \xi_{A}}\right)
$$

(S. oben S. 293). $t_{0}$ ist positiv nur für $c>a \xi_{A}$; im Falle $c<a \xi_{A}$ ist $t_{0}$ reell nur wemn $c$ auch $<b \xi_{A}$, und damn negativ. Dies heisst, wie wir jetzt sehen, soviel als dass unter der Toraussetzung des Falles aus dem Unendlichen, die Zeit des Durchganges durch den Nullpunkt schon seit jener Zeit vorüber war. 
Die beiden Hauptergebnisse, welche im §. VI der ersten Abhandlung hergeleitet worden sind, nämlich sowohl die Bedingung für die zum Ueberschreiten des Nullpunktes nöthige Anfangsgeschwindigkeit, als auch die Grenze der durch Fallen aus beliebig hoher Anfangslage ohne Anfangsgeschwindigkeit zu erreichenden Geschwindigkeit, lassen sich unmittelbar aus dem obigen Schema, S. 331, erkennen. Demn wenn zur Zeit $t$ bei der Ablenkung $x$ der Nullpunkt noch zu überschreiten sein soll, so muss $t$ im ersten Zeitabschnitt liegen, also dem Schema gemäss $-\frac{x^{\prime}}{x}$ $>a$ sein, und dies ist daher die Bedingung für die zum Ueberschreiten des Nullpunktes nöthige Anfangsgeschwindigkeit. Ferner ist die Geschwindigkeit eines ans beliebig hoher Anfangslage ohne Anfangsgeschwindigkeit fallenden Magnetes, der sich also in der ganzen Zeit des Fallens im dritten Zeitabschnitt befindet, nach dem Schema bei jeder Ablenkung $x$ eine solche, dass $-\frac{x^{\prime}}{x}<b$ ist; der Grenzwerth der Geschwindigkeit $x^{\prime}$ ist daher $-b x$.

[550] Während der ganzen Bewegung des Magnetes, insofern dabei der Nullpunkt wirklich oder in der Idee überschritten wird, liegt die Geschwindigkeit $x^{\prime}$ ausserhalb des von den Werthen $-b x$ und - $a x$ eingeschlossenen Intervalls. Es fragt sich num, was die Folge sei, wenn dem Magnete bei $x$ eine Geschwindigkeit grösser als $b x$, aber kleiner als $a x$, zugeschrieben, oder was geschehe, wemn ihm im Augenblicke des Fallenlassens ron $x$ eine solche Anfangsgeschwindigkeit im Sime der Richtkraft wirklich ertheilt werde. Diese Frage ist in der ersten Abhandlung nicht zur Sprache gekommen. Aus den oben roraufgeschickten allgemeinen Sätzen hat man schon erfahren, dass die Discussion unseres zweiten Hauptfalles uns darüber Aufschluss zu geben bestimmt ist.

\section{§. V. Zweiter Hauptfall: $a x+x^{\prime}$ und $b x+x^{\prime}$ sind rer- schiedenen Zeichens.}

Liegt $x^{\prime}$ seiner Grösse nach zwischen $a . x$ und $b x$, und sind $x$ und $x^{\prime}$ verschiedenen Zeichens, so sind anch die Ausdrücke (9) rerschiedenen Zeichens. Da diese Ausdrücke für jede Zeit ihr Zeichen behalten, sie aber für $x=0$ oder $x^{\prime}=0$ einerlei Zeichen, beziehlich das von $x^{\prime}$ oder $x$ erhalten würden, so kömnen unter der Voraussetzung: $x^{\prime}$ grösser als $b x$, und kleiner als $a x$, zu keiner endlichen Zeit $x$ und $x^{\prime}=0$ werden. Erst für $t=+\infty$ tritt dies ein. Dies ist der zweite hier stattfindende Hauptfall, der sich rom ersten also dadurch mterscheidet, dass dabei der Nullpunkt zu keiner Zeit übersehritten wird, sondern Ablenkung und 
336 XIII. Ueber aperiodische Bewegung gedämpfter Magnete. - Abh. II. -

Geschwindigkeit von $t=-\infty$ bis $t=+\infty$ stetig abnehmen. Nimmt man $x$ positiv, so ergeben sich in diesem Falle aus (12), wenn man darin $\xi=\frac{a-b}{a+b} \xi$, $=\frac{r}{\varepsilon} \xi$, setzt, die den Gleichungen (16) und (17) des ersten Falles analogen Bestimmungen

$$
\begin{aligned}
x & =\frac{\xi_{1}}{2 \varepsilon}\left(a e^{b(\boldsymbol{x}-t)}+b e^{a(\tau-t)}\right), \\
x^{\prime} & =-\frac{a b \xi}{2 \varepsilon}\left(e^{a \tau-t)}+e^{b(\tau-t)}\right),
\end{aligned}
$$

wo $\boldsymbol{\tau}$ den Zeitpunkt und $\xi$, denjenigen Werth der Ablenkung $x$ bedeuten, für welche

$$
x^{\prime \prime}=a b x \text { und folglich }(a+b) x^{\prime}+2 a b x=0
$$

[551] ist, für welchen also $\frac{x}{x^{\prime}}$ das arithmetische und $\frac{x}{x^{\prime \prime}}$ das geometrische Mittel jener bezüglichen Grenzwerthe erreicht, zwischen denen die Werthe der beiden Quotienten ron $t=-\infty$ bis $t=+\infty$ variiren. Die Zeitpunkte, in denen folgweise die Quotienten

$$
\overline{x^{\prime \prime}}, \frac{x^{\prime}}{x^{\prime \prime}}, \frac{x^{\prime \prime}}{x^{\prime \prime \prime}}, \ldots
$$

den bezeichneten Mittelwerth - 1/2 $\left(\frac{1}{a}+\frac{1}{b}\right)$ erreichen, bilden gemäss der fünften Folgerung eine arithmetische Reihe, deren Anfangsglied $\tau$ und deren beständiger Unterschied $\Delta$ ist.

Die Reduction aller möglichen Vorgänge auf einen einzigen Typus geschah oben in §. II (sechste Folgermng) dadurch, dass man bei jedem Vorgange einen gewissen Zeitpunkt $\tau$ festsetzte, in welchem das Verhältniss $\frac{x}{x^{\prime}}$ einen bestinmten Werth annimmt. Dieser Zeitpunkt $\boldsymbol{\tau}$ hat aber, wie man sieht, im zweiten Hauptfalle keine so ausgesprochene Bedeutung wie im ersten, wo er der Umkehr des Magnetes entsprach. Es ist deshalb nicht ohne Interesse im vorliegenden zweiten Hauptfalle ron jener Reduction abzusehen und die Betrachtung unmittelbar an die Gleichungen (4) anzuknüpfen.

Es sei $\boldsymbol{X}$ positiv, $\boldsymbol{X}^{\prime}$ negativ. Kürzehalber setzen wir

$$
\begin{aligned}
& a \mathbf{X}+\mathbf{X}^{\prime}=+\mathfrak{U}, \\
& b \boldsymbol{X}+\boldsymbol{X}^{\prime}=-\mathfrak{B} .
\end{aligned}
$$

Da nach unseren Voraussetzmingen $\boldsymbol{X}^{\prime}$ zwischen $b \boldsymbol{X}$ und $a \boldsymbol{X}$ schwankt, und $\mathfrak{A}+\mathfrak{B}=2 r \mathfrak{X}$ ist, so schwanken dementsprechend $\mathfrak{A}$ und $\mathfrak{B}$ zwischen $2 r \mathrm{X}$ und 0 , indem sie sich stets zu $2 r \mathrm{X}$ ergänzen.

Nach Analogie der Gleichungen (16) und (17) für den ersten Hauptfall erhalten wir hier aus (4) 
§. 5. 2. Hauptfall: $a x+x^{\prime}$ und $b x+x^{\prime}$ verschiedenen Zeichens.

$$
\begin{gathered}
x=\frac{1}{2 r}\left(\mathfrak{Q}\left(e^{b\langle T-t)}+\mathfrak{B} e^{a(T-t)}\right)\right. \\
x^{\prime}=-\frac{1}{2 r}\left(\mathfrak{Q}\left(b e^{b(T-t)}+\mathfrak{B} a e^{a T-t}\right)\right.
\end{gathered}
$$

Während $t$ von $t=-\infty$ zu $t=+\infty$ sich verändert, gehen $t$ [552] und $x^{\prime}$, convex gegen die Abscissenaxe der Zeiten, beziehlich ron $+\infty$ und $-\infty$ bis 0 . Wie im ersten Hauptfalle ist für $t=-\infty$

$$
\frac{x^{\prime}}{x^{\prime}}=-u \text {, }
$$

für $t=+\infty$

$$
x^{\prime}=-b e^{2} \text {. }
$$

Setzt man in Gleichung (19) $\mathfrak{Q}=0$, so erhält man

$$
x=e^{a(T-t)} \mathbf{X}
$$

Setzt man umgekehrt darin $\mathfrak{B}=0$, so erhält man

$$
x=e^{b(T-t)} \mathbf{I}
$$

Für $t=T$ aber wird in (19), (23), (24) $r=X$. Gleichung (19) stellt also eine Schaar ron Curven ror, welche durch den Werth ron â und $\mathfrak{B}$ unterschieden und zwischen den Grenzcurven (23) und (24) eingeschlossen, sich mit ihnen im Gipfel der Ordinate $\mathbf{X}$ schneiden.

Setzt man in Gleichung $(20)$ : oder $\mathfrak{R}=0$, so erhält man beziehlich

$$
\begin{aligned}
& x^{\prime}=-e^{(a T-t)} a \boldsymbol{X}^{r}, \\
& r^{\prime}=-r^{(T-t)} \mathrm{b} \mathbf{\boldsymbol { I }} .
\end{aligned}
$$

Für $t=T$ werden (20), (25), (26) beziehlich

$$
\left.\begin{array}{l}
x_{T}^{\prime}=-a \mathrm{X} \\
x_{T}^{\prime}=\mathrm{X}^{\prime}=-a \mathrm{X}+\mathfrak{N}=-b \mathrm{X}-\mathfrak{b}, \\
x_{T}^{\prime}=-b \mathrm{X} ;
\end{array}\right\}
$$

setzt man aber $t=T+\lrcorner$, so werden dieselben Ausdrücke

$$
\begin{aligned}
& \begin{array}{l}
x_{T+\Delta}^{\prime}=-\left(\begin{array}{l}
a \\
b
\end{array}\right)^{-\frac{a}{2 r}} a \boldsymbol{K}, \\
x_{T+a}^{\prime}=-\frac{1}{2 r}\left\{\left(\begin{array}{l}
a \\
b
\end{array}\right)^{-\frac{a}{2 r}} a \mathfrak{B}+\left(\frac{a}{b}\right)^{-\frac{b}{2 r}} b \mathfrak{U}\right\}
\end{array} \\
& x^{\prime} T+A=-\left(\frac{a}{b}\right)^{-\frac{b}{2 r}} b \mathrm{X} .
\end{aligned}
$$

Die drei Ausdrücke (28) sind identisch und die Grenzcurven (25), (26), sowie die zwischen ihmen eingeschlossenen Curren (20), schnciden sich also im Gipfel der Ordinate, die im Abstande $\lrcorner$ auf $S^{\prime}$ folgt.

E. du Bois-Reymond, Ges. Abh. I. 
[553] Während im allgemeinen Falle für $t=-\infty, \frac{x^{\prime}}{x}=-a$ für $t=+\infty, x^{\prime}=-l x$ ist, hat man für $\mathfrak{A}=0$

für $\mathfrak{B}=0$

$$
x^{\prime}=-a x \text {, }
$$

$$
x^{\prime}=-b x
$$

für jede Zeit.

Setzt man $\mathfrak{B}=2 r \boldsymbol{X}+\delta$, $\mathfrak{A}=-\delta$, wo $\delta$ eine beliebig kleine, aber endliche positive Grüsse, so wird alsbald die Axe der Zeiten wieder geschnitten, wenngleich erst zur späten Zeit

$$
t_{0}=T+\frac{1}{2 r} \log \left(\frac{2 r \mathbf{X}+\delta}{\delta}\right) ;
$$

man hat wieder den ersten Hauptfall, und befindet sich in dessen erstem Zeitabschnitt. Setzt man umgekehrt $\mathfrak{P}=2 r \boldsymbol{X}+\delta$, $\mathfrak{B}=-\delta$, so ist diesmal die Axe der Zeiten geschnitten worden zur längst rerflossenen Zeit

$$
t_{0}=T-\frac{1}{2 r} \log \left(\frac{2 r X+\delta}{\delta}\right)
$$

man befindet sich im dritten Zeitabschnitt des ersten Hauptfalles.

Wir wollen num, um die Vorgänge in beiden Hauptfällen ihrer Grösse nach vergleichbar zu machen, $T=\tau$ und $X=\xi$ setzen. Dabei ist zu bemerken, dass, da jetzt nicht wie im ersten Hauptfalle, zu $\tau$ und $\xi$ ein für allemal eine bestimmte Geschwindigkeit $\left(x^{\prime}=0\right.$, s. oben S. 328) gehört, der Verlauf der Curven zwischen den Grenzcurren ein umbestimuter bleibt, so lange nicht die Geschwindigkeit $\xi^{\prime}$ gegeben ist. Es entspricht also jedem $\xi$ jetzt vielmehr ron Ablenkungs- und Geschwindigkeitscurven eine ganze Schaar, deren Steilheit mit $\xi$ wächst, weil $د$ mabhängig von $\xi$ ist.

In Fig. 5 sind die beiden Curven oberhalb der Abscissenaxe die Grenzcurven der Ablenkungscurven, die unterhalb die Grenzenrren der Geschwindigkeitscurven des zweiten Hauptfalles; jede Curve trägt die Ordnungszahl der durch sie vorgestellten Gleichung. Die Amahmen, unter denen die Curven construirt wurden, sind dieselben wie in Fig. 4: $\xi=1, a=1, b=1 / 2$. . Der Maassstab ist derselbe, und gleiche Zeitpunkte stehen in beiden Figuren senkiecht mitereinander. Schreitet man auf der Abscis- [554] senaxe ron $\tau$ aus in beiden Richtungen um Abstände $=\perp$ fort, so bilden die zugehörigen Ordinaten jeder der vier Grenzcurven eine Reihe, deren allgemeines Glied für

$$
\begin{array}{llll}
(23), & (24), & (25), & (26): \\
2^{2 v}, & 2^{v}, & -2^{2 v}, & -2^{v}
\end{array}
$$

ist, wo für $v$ in der Richtung ron $-t$ nach $+t$ die Reihe der positiven 
und negativen ganzen Zahlen zu setzen ist. Die Curven (23) und (25) liegen röllig symmetrisch zur Abscissenaxe, und so dass bei $\boldsymbol{\tau}, \boldsymbol{v}=0$ ist; die Curven (24) und (26) dagegen sind zwar auch symmetrisch, aber gegeneinander in der Richtung der Abscissen um $\Delta$ rerschoben, so dass für (24) " bei $\tau$, für (26) bereits bei $t_{0}$, = 0 ist.

Denkt man sich die Curven beider Hauptfälle, wie Fig. 4 und 5 sie darstellen, auf dieselbe Abscissenaxe aufgetragen, so schneiden sich die Ablenkungscurren des zweiteu Hauptfalles im Gipfel der Maximal-Ordinate

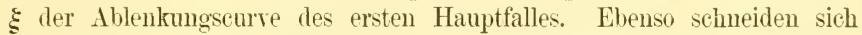
die Geschwindigkeitscurven des zweiten Hauptfalles im Gipfel der Maximal-Ordinate der Geschwindigkeitscurve des ersten Hauptfalles: denn die miteinander identischen Gleichungen (28) sind es anch mit (18). Von den Maximis ab nach den positiven Zeiten hin verlaufen die Curven des zweiten Hauptfalles näher der Abscissenaxe als die des ersten.

Denkt man sich den zweiten Hauptfall auf die andere Scalenseite verlegt, so entstehen in der Kichtung ron $\boldsymbol{\tau}$ nach den negativen Zeiten hin Schneidepunkte seiner Curven mit denen des ersten Hauptfalles. Unter den unseren Figuren zu Grunde liegenden Ammahmen rücken jedoch für die beiden steileren Grenzcurven des zweiten Hauptfalles diese Schneidepunkte in die negative Unendlichkeit.

Im Fall einer dem bei $+x$ losgelassenen Magnet ertheilten, $b x$, aber nicht $a x$ übertreffenden Anfangsgeschwindigkeit $-c$ ist es also, als sei der Magnet von der positiven Seite her aus dem Unendlichen gefallen mit einer Geschwindigkeit, grösser zwar als die grösste Geschwindigheit $b x$, die der Magnet bei $+x$ durch Fall von einem unendlichen positiven $\xi$, d. h. ans negativer Unendlichkeit höherer Ordumng, erlangt hätte (s. oben S. 332), aber nicht gross genug, um den Magnet über den Nullpmnkt zu treiben, wozu die Geschwindigkeit im Endlichen a.r übertreffen muss.

Der Grenzfall $\varepsilon=n$ kann für sich behandelt werden, oder auch indem man in den obigen Formeln $\iota=\varnothing$ setzt.

Man hat zunächst anstatt der beiden Gleichungen (4) hier nur die eine Gleichung

$$
\left(\varepsilon x+x^{\prime}\right) e^{\varepsilon t}=\text { const }=\left(\varepsilon X+X^{\prime}\right) e^{\varepsilon T} .
$$

Diese Gleichung integrirt giebt

$$
x e^{\varepsilon t}=t\left(\varepsilon X+X^{\prime \prime}\right) e^{\varepsilon T}+C,
$$

wo $C$ eine willkürliche Constante ist, die dadurch bestimmt wird, dass für $t=T, x=X$ sein solle. So erhält man 
und durch Division mit (31) in (32)

$$
x=e^{t(T-t)}\left\{X-(T-t)\left(\varepsilon X+X^{\prime}\right)\right\}
$$

$$
\frac{x}{\varepsilon x+x^{\prime}}-t=\frac{X}{\varepsilon X^{\prime}+X^{\prime \prime}}-T=\text { const. }
$$

Gleichung (12) ergiebt für $a=b$ :

$$
x^{(v)}=(-\varepsilon)^{\nu} \cdot e^{\varepsilon(\tau-t)}(1-\nu+\varepsilon t-\varepsilon \tau) \xi,
$$

und daher für $v=0$ und $v=1$

$$
\begin{aligned}
& x=\xi e^{z(\tau-t)}\{1-\varepsilon(\tau-t)\}, \\
& x^{\prime}=\xi \varepsilon^{2} e^{t(\tau-t)}(\tau-t)
\end{aligned}
$$

Diese Gleichungen entsprechen den Gleichungen (XIV) und (XT) der ersten Abhandlung. Da für $a=l$ der beständige Zeitunterschied $\Delta=\frac{1}{\varepsilon}$ wird, so ist für

$$
\begin{aligned}
& t_{0}=\tau-\frac{1}{\varepsilon}, \quad \tau, \quad t_{\prime}=\tau+\frac{1}{\varepsilon}, \quad t_{\prime \prime}=\tau+\frac{2}{\varepsilon}, \text { u. s. } \mathrm{w} . \\
& x=0, \quad x^{\prime}=0, \quad x^{\prime \prime}=0, \quad x^{\prime \prime \prime}=0, \quad \text { u. s. } \mathrm{w} .
\end{aligned}
$$

Wird $\xi$ positiv genommen, so sind für $t=-\infty: x=-\infty$, $x^{\prime}=+\infty$, und zwar, der geringeren Dämpfung halber, beide ron höherer Ordnung, als für ein endliches $r ; \frac{x^{\prime}}{x}$ ist $=-\varepsilon$. Im Endlichen sind die Curven (33), (34) zunächst conrex gegen die Abscissenaxe der Zeiten. Es folgen einander in dem wiederum nur von den Constanten der Vorrichtung, nicht von $\xi$ abhängigen [556] Abstande $\frac{1}{\varepsilon}$ die vier Zeitpunkte $t_{0}, \tau, t_{t}, t_{\prime \prime}$. Für $t=+\infty$ schliessen sich beide Curren asymptotisch der Axe der Zeiten an, und $x^{\prime}$ ist $=-\varepsilon x$.

Die in der ersten Abhandlung aufgestellten Gleichungen für die rerschiedenen Fälle mit und ohne Anfangsgeschwịndigkeit findet man ähnlich wie dies im $\$$. IV für ein endliches $r$ gezeigt wurde, indem man in (32) für $T, X, X^{\prime}$ die Werthe $t_{0}, 0, x_{0}^{\prime} ; \tau, \xi, 0$ u. s. w. einführt und $t_{0}$. $\tau, t_{,}, t_{\prime \prime}=0$ setzt.

Soll zur Zeit $t$ der Nullpunkt noch zu überschreiten, d. h. soll

$$
t_{0}-t=-\frac{x}{\varepsilon r+x^{\prime}}
$$

positiv sein, so müssen $x$ und $x^{\prime}$ rerschiedenen Zeichens, und der absolute Werth ron $x^{\prime}$ muss grösser als der von $\varepsilon x$ sein. Diese Bedingung ist nur für die Zeit $t$ erfüllt, welche dem Zeitpunkt $t_{0}$ rorangegangen ist, da im folgenden Zeitabschnitt $\Delta$, bis zu $\tau$ hin, $x$ und $x^{\prime}$ einerlei Zeichens sind, von $\tau$ ab aber, wo $x$ und $x^{\prime}$ wieder rerschiedenen Zeichens sind, der absolute Werth ron $r^{\prime}$ kleiner als der ron $\varepsilon x$ ist, und diesen erst für $t=+\infty$ erreicht. Das also ist der wahre Simm der in der ersten 
Abhandlung gefundenen Bedingung $x^{\prime}>(-\varepsilon x)$ für das Ueberschreiten des Nullpunktes im Falle $r=0$ (rergl. oben S. 325).

Der zweite Hauptfall findet hier nicht mehr statt, sondern der Nullpunkt wird überschritten, sobald die Geschwindigkeit die Fallgeschwindigkeit aus der negativen Unendlichkeit höherer Ordnung übertrifft, d. l. $x^{\prime}$ grösser ist als $a x$.

§. VII. Die Curven der Geschwindigkeiten bezogen auf die Ablenkungen im allgemeinen Fall $\varepsilon>n$.

Das Ganze dieser Beziehungen wird klarer, wemn wir von $x$ und $x^{\prime}$ als Functionen der Zeit übergehen zur Betrachtung von $x^{\prime}$ als Function von $x, x^{\prime}=\phi(x)$ (vergl. erste Abh. S. 296 und oben S. 325).

In Fig. 6 stellt die Gerade $[-x, 0,+x]$ die beiderseits rom Nullpunkt in's Unendliche sich erstreckende Scale ror, auf welche als Abscissenaxe die Geschwindigkeiten $x^{\prime}$ als Ordinaten aufgetragen sind. Die beiden Geraden $A A^{\prime}, B b^{\prime}$ stellen die béiden Gleichungen (29) und (30):

$$
x^{\prime}=-a \cdot x, \quad x^{\prime}=-b x
$$

[557] ror. Die Curre $t_{0} \tau t_{,} t_{\mu} 0$ ist alsdam für ein positives $\xi$ die Curve des ersten Hauptfilles, welche auf der negativen Seite aus dem Unendlichen kommend im Punkte $x=+\xi$ zur Zeit $\tau$ die Scale schneidet, und bei 0 ron der positiven Seite her physikalisch endet. Die Punkte $t_{0}, \tau, t_{1}, t_{1 \prime}$ bezeichnen die oft erwähnten, eine arithmetische Reihe bildenden Zeitabschnitte $\lrcorner$. Kommt der Magnet ron der anderen Seite, so hat die Curve die Lage $t_{0}^{\prime} \tau^{\prime} 0$. Die Corven des zweiten Hauptfalles liegen wie $0 \zeta, 0 \zeta^{\prime}$ nothwendig zwischen den Geraden $A A^{\prime}, B B^{\prime}$, die selber den Grenzcurren (25), (26) entsprechen; aus dem Unendlichen kommend enden auch die Curven $0 \zeta, 0 \zeta^{\prime}$ und die Geraden $0 A, 0 A^{\prime}$, $0 B, 0 B^{\prime}$ physikalisch am Nullpunkt, und die im rechten unteren Quadranten verlaufenden, $0 A^{\prime}, v \zeta^{\prime}, 0 B^{\prime}$, entsprechen ihrer Lage nach den in unserer Fig. 5 dargestellten Curven.

Wo immer man von einem Punkt irgend einer der Curven parallel der $x^{\prime}$-Axe eine Gerade nach einer der Geraden $A A^{\prime}, B B^{\prime}$ ziehe, wie z. B. $\mathfrak{x}^{\prime} \mathfrak{a}, \mathfrak{x}^{\prime} \mathfrak{b}$ in der Figur, findet man für die Länge der Geraden $\mathfrak{x}^{\prime} \mathfrak{a}$, $\mathfrak{x}^{\prime} \mathfrak{b}$ beziehlich den Ausdruck $a x+x^{\prime}, b x+x^{\prime}$, wo $a x, b x$ und $x^{\prime}$, je nach der Lage des Currenpunktes, positiv oder negativ sind. Wir gelangen so zur Einsicht in die Bedentung der für uns so wichtigen Ausdrücke (9). Sie messen in der Richtung der $x^{\prime}$-Axe die Entfernung des Curvenpunktes ron den Geraden $A A^{\prime}, B B^{\prime}$; und sie sind positiv jedesmal dass der Punkt (in unserer Figur) nach oben und rechts von der 
342 XIII. Ueber aperiodische Bewegung gedämpfter Magnete. - Abh. II. -

Geraden liegt, negativ im anderen Falle; daher sie für die zwischen den Geraden $A A^{\prime}, B B^{\prime}$ liegenden Curvenpunkte, wie der zweite Hauptfall es mit sich bringt, rersehiedenen Zeichens sind.

Eliminirt man die Zeit zwischen den Gleichungen (16) und (17) des ersten Hauptfalles (vergl. die achte Folgerung), so erhält man die mit dem Ausdruck auf S. 301 der ersten Abhandlung identische Gleichung

$$
\left(\frac{a x+x^{\prime}}{a \xi}\right)^{a}=\left(\frac{b x+x}{b \xi}\right)^{b}
$$

welche also die Gleichung der Curre $t_{0} \tau t, t_{n} 0$ ist. Eliminirt man ebenso die Zeit zwischen den Gleichungen (19) und (20) des zweiten Hauptfalles, so erhält man

$$
\left(\frac{a x+x^{\prime}}{\mathfrak{A}}\right)^{a}=\left(\frac{b x+x^{\prime}}{-\mathfrak{b}}\right)^{b}
$$

[558] als Gleichung aller der Curren $0 \zeta^{\prime}$, die für irgend ein $\mathfrak{A}$ und $\mathfrak{b}$ zwischen den Grenzcurren $0 A^{\prime}, 0 B^{\prime}$ liegen.

Setzt man in (36)

$$
\left.\begin{array}{rl}
\mathfrak{H} & =a X+X^{\prime}=a \xi, \\
-\mathfrak{B} & =b \boldsymbol{X}+\mathbf{X}^{\prime}=-b \xi,
\end{array}\right\}
$$

so unterscheiden sich (35) und (36) nur noch durch das negative Zeichen ron $b \xi$ in (36), dem aber auch, nach den Toraussetzungen des zweiten Hauptfalles, ein negativer Werth des Zählers $b x+x^{\prime}$ entspricht. Durch dieselbe Substitution werden die Gleichungen (19) und (20):

$$
\begin{gathered}
x=\frac{\xi}{2 r}\left(a e^{b(T-t)}+\zeta t^{a(T-t}\right), \\
x^{\prime}=-\frac{\xi a l}{2 r}\left(e^{b(T-t)}+\epsilon^{a(T-t)}\right) ;
\end{gathered}
$$

sia nnterscheiden sich also ron den entsprechenden Gleichungen des ersten Hauptfalles (9) und (10)

$$
\begin{aligned}
& x=\frac{\xi}{2 r}\left(a \epsilon^{b(\tau-t)}-b \epsilon^{a(\tau-t}\right), \\
& x^{\prime}=\frac{\xi a b}{2 r}\left(\epsilon^{a(\tau-t)}-\epsilon^{b(\tau-t)}\right),
\end{aligned}
$$

nur noch dadurch, dass in den Gleichungen (38), (39) $T$ für $\tau$ steht und beide Termen in der Klammer positir sind; sie werden identisch mit den Gleichungen $\left(16^{*}\right)$ und $\left(17^{*}\right)$ auf S. 336, wenn man $T=\tau$ und wie dort $\xi=\frac{r}{\varepsilon} \xi$, setzt.

Unter der zu einem bestimmten $\boldsymbol{X}$ und $T$ gehörigen Schaar ron Ablenkungscurven (19) des zweiten Hanptfalles und der entsprechenden Schaar ron Geschwindigkeitscurren (20) giebt es also stets ein Paar zusammengehöriger Curven, deren Gleichungen durch Eliminiren der Zeit 
einen Ausdruck liefern identisch mit dem, welchen gleichfalls durch Eliminiren der Zeit die Gleichungen der zu einem bestimmten $\xi$ und $\tau$ gehörigen Ablenkungscurve und Geschwin- [559] digkeitscurve des ersten Hauptfalles liefern. Es ist jenes Paar das, für welches zur Zeit $t=T$ in (19) und (20)

$$
\left.\begin{array}{l}
x=X=\xi \frac{a+b}{a-b}, \\
x^{\prime}=X^{\prime}=-\xi \frac{2 a b}{a-b}
\end{array}\right\}
$$

.sind $[(37),(38),(39)]$. Wir wollen dies $X$ und $X^{\prime}$, zum Unterschied $\theta$ von dem allgemeinen, $\mathfrak{x}, \mathfrak{X}$, und die zugehörige Zeit $\mathfrak{I}$ nemnen. $\mathfrak{X}$ ist $>\xi$; soll Curve (38) durch den Gipfel der Ordinate $\xi$ gehen, so muss $\mathfrak{I}>\boldsymbol{\tau}$ sein. Weitere Bemerkungen über das gegenseitige Entsprechen der bezüglichen Curren des ersten und zweiten Hauptfalles finden sich oben in der fünften und sechsten Folgerung. Das dortige $\xi$, ist hier xं genannt.

Von dem so bestimmten Curvenpaare werden sich die $x^{\prime}$ des zweiten Hauptfalles, bezogen auf dessen $x$, mit den $x^{\prime}$ des ersten Hauptfalles, bezogen auf die gleichen $x$, für das nämliche $\xi$ in Eine Construction zusammenfassen lassen. Zn dieser schreiten wir nun, indem wir von den übrigen Curren des zweiten Hauptfalles, welche zu der des ersten Hauptfalles nicht in der eben entwickelten, merkwürdigen Beziehung stehen, rorläufig absehen.

Um Gleichung (35) auf eine für die Discussion bequemere Form zu bringen, machen wir die Geraden $A A^{\prime}, B B^{\prime}$ zu $A$ xen eines schiefen Coordinatensystemes; die Gerade $B B^{\prime}$ sei die Alsscissenaxe, die Gerade $A A^{\prime}$ die Ordinatenaxe; die nenen Abscissen eines Punktes $x, x^{\prime}$ der Curve (z. B. des Punktes $\mathfrak{x}^{\prime}$ in der Figur) mögen it, die nenen Ordinaten $\tau_{i}$ heissen. Man hat

1 Wegen der Schwierigkeit, Gleichung (16*) umzukehren, und die Zeit als explicite Function von $x$ darzustellen, lässt sich von der Zeit $T$ nur noch aussagen, dass sie zwischen

$$
\tau-\frac{1}{a} \log \left(\frac{a+b}{a-b}\right) \text { und } t-\frac{1}{b} \log \left(\frac{a+b}{a-b}\right)
$$

liege. Dies sind die Werthe für $T$, die den Gleichungen (23) und (24) der Grenzcurven, zwischen denen die Ablenkungscurven des zweiten Hauptfalles verlaufen, für $x=\xi$ und $\mathfrak{X}=\xi \frac{a+b}{a-b}(40)$ genügen; die Zeiten also, zu welchen die $0 \mathrm{r}$ dinaten dieser Curven den Werth $\xi \frac{a+b}{a-b}$ annehmen. 
344 XIII. Ueber aperiodische Bewegung gedämpfter Magnete. - Abh. II. -

$[560]$

$$
\begin{aligned}
& a x+x^{\prime}=\vartheta \cdot \frac{\sin (\alpha-\beta)}{\cos \omega} \\
& b x+x^{\prime}=\eta \cdot \frac{\sin (\alpha-\beta)}{\cos \beta},
\end{aligned}
$$

wo $\alpha$ und $\beta$ die zu $a$ und $b$ als Tangenten gehörigen Winkel bedenten, und durch Einsetzen dieser Terthe in (35)

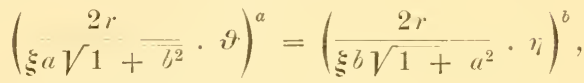

oder, wemn wir kïrzehalber

setzen,

$$
\left(\frac{2 r}{\xi}\right)^{2 r} \frac{\left(b \sqrt{\left.1+a^{2}\right)^{\alpha}}\right.}{\left(a \sqrt{\left.1+b^{2}\right)^{b}}\right.}=C
$$

$$
\eta^{b}=C \cdot \boldsymbol{9}^{\alpha}
$$

Tir haben es also mit einer auf schiefe Coordinaten bezogenen Parabel rom $\frac{a}{b}$ ten Grade zu thum. Sind $a$ und $b$ ganze Zahlen, [561] so bestimmen deren Geradheit oder Ungeradheit und das Zeichen ron $C$, in welchem der vier Coordinatenwinkel Parabelzweige liegen und wie sich diese im Nullpunkte rerhalten, ob sie in einander übergehen, eine Spitze bilden, u. s. w. $C$ würde beiläufig in diesem Falle, wegen des geraden Exponenten $2 r$, auch für ein negatives \& positir sein. Physikalisch hat indess, wie schon hemerkt, ein Zusammenhang der Curren im Nullpunkte

1 Nennt man $x, x^{\prime}, \eta, y$ die geraden und schiefen Coordinaten eines beliebigen, $\boldsymbol{X}, \boldsymbol{X}^{\prime}, H, \Theta$ die eines gegebenen Punktes einer der vier Curven, so kann man stets setzen

also, da nach (4)

$$
\begin{gathered}
a x+x^{\prime} \\
a X+X^{\prime}=\frac{y}{\Theta}, \quad b x+x^{\prime} \\
a x+X^{\prime}
\end{gathered}=\frac{\eta}{H},
$$

$$
\begin{aligned}
\left(\begin{array}{c}
a x+x^{\prime} \\
a X+X^{\prime}
\end{array}\right)^{a} & =\left(\begin{array}{c}
b x+x^{\prime} \\
b X+X^{\prime}
\end{array}\right)^{b}, \\
\left(\frac{\vartheta}{G}\right)^{a} & =\left(\begin{array}{l}
y \\
H
\end{array}\right)^{b}
\end{aligned}
$$

Macht man $X=+\xi, X^{\prime \prime}=0$, so werden $H$ und $\Theta$ die schiefen Coordinaten $H \xi, \Theta \xi$ des $\xi$-Punktes, in welchem die Curve des ersten Hanptfalles die $x^{2}$-Axe schneidet (s. bei $t$ in der Figur). Es ist

$$
\begin{aligned}
& H_{\xi}=b \xi \frac{\cos \beta}{\sin (\alpha-\beta)}=\frac{b \xi \backslash 1+a^{2}}{2 r} \\
& \theta_{\xi}=a \xi \frac{\cos \alpha}{\sin (\alpha-\beta)}=\frac{a \xi \mid 1+b^{2}}{2 r}
\end{aligned}
$$

Durch Finsetzen dieser Werthe in $(41 a)$ erhält man gleichfalls (41). 
keinen denkbaren Simn; auch werden $a$ und $b$ nur ausnahmsweise nicht irrationale Zahlen sein. Ohne die am Nullpunkte möglichen Singularitäten weiter zu ergründen, schreiben wir Gleichung (42) daher besser folgendermaassen:

$$
b \log 3_{1}=a \log i+\log C
$$

it ist ron gleichem Zeichen mit $\xi$, und für jeden der beiden Werthe ron $\vartheta$ kam $\boldsymbol{v}_{\text {; }}$ wiederum positiv oder negativ sein; die Logarithmen sind ron den absoluten Werthen der Grössen zu nehmen. So stellt Gleichung (43) für jede der vier möglichen Zeichencombinationen je einen Curvenzweig vor, der sich rom Nullpunkt in's Unendliche erstreckt.

Beispielsweise betrachten wir num näher das Paar dieser Zweige, welches den beiden Werthen ron $y$ für ein positives $\xi$ und $\vartheta$ entspricht. Der bequemeren Discussion halber kehren wir dabei zu der Gestalt der Gleichung zurück, wie sie (42) zeigt. Der erste Differentialquotient ist

$$
\frac{d l_{i}}{d t}=\frac{a}{l} \cdot C_{b}^{1} \cdot \vartheta^{2 r},
$$

der zweite

$$
\frac{d^{2} y}{d t^{2}}=\frac{2 r^{a} u}{b^{2}} \cdot C_{b}^{b} \cdot v^{b}-2 .
$$

Welchen endlichen Werth man anch $a$ und $\zeta$ beilege, für $\vartheta=0$ sind 3. und auch $\frac{d y}{d y}=0$; die Curven berühren also im Nullpunkte die Gerade $B B$, entsprechend unserem früheren Ergebniss: für $t=+\infty$. $x^{\prime}=-8 x$ in beiden Hauptfällen $[(18)$. (22)]. Beide Zweige steigen convex gegen die Abscissenare rom Nullpunkt in's Unendliche beziehlich anf- und abwärts, wobei der den positiven y entsprechende Zweig den Nullpunkt überschreitet, der [562] den negatiren y entsprechende auf der positiven Scalenseite bleibt. Die Construction lehrt, dass in der Nähe des Nullpunktes die Krömmung der Curve oberhalb der Geraden $B B^{\prime}$ eine stärkere ist als unterhalb. Für $\vartheta=+\infty$ werden $\pm v$ und $\pm \frac{d y}{d \vartheta}= \pm \infty$; beide Zweige entfernen sich also immer weiter von der Geraden $\boldsymbol{d} d$, nehmen aher dabei immer mehr deren Richtung an, entsprechend unserem früheren Ergebniss: für $t=-\infty ._{r}^{x^{\prime}}=-\alpha$ in beiden Hanptfällen.

Die Gleichung einer Tangente an irgend einem Punkte $\boldsymbol{v}_{\boldsymbol{i}}$; $\boldsymbol{v}$, der Curve, auf dieselben schiefen Coordinaten bezogen, lautet

$$
H-\eta_{i \prime}=\frac{a}{b} \cdot \frac{\eta_{1}}{y_{1}}\left(\Theta-\vartheta_{1}\right)
$$

wo $\boldsymbol{H}, \boldsymbol{\Theta}$ die Coordinaten der Punkte der Tangente bedeuten. Setzt 
man für $\boldsymbol{y}_{\boldsymbol{\prime}}, \boldsymbol{4}$, , die Coordinaten $\boldsymbol{H}_{\boldsymbol{\xi}}, \Theta \xi$ des $\boldsymbol{\xi}$-Punktes [(41ל), S. 344 Anm.], so wird die Gleichung

$$
H \cos \alpha=\Theta \cos \beta-\xi .
$$

Dies ist die Gleichung einer Geraden, welche parallel der $x^{\prime}$-Axe durch den $\xi$-Punkt bei $\tau$ geht: die Curve des ersten Hamptfalles schueidet folglich die $x$-Axe senkrecht (vergl. erste Abhandl. S. 300).

Es ist gleichgültig, ob man in (41) $\eta$ und 9 mit einer Constanten $k$, oder ob man $\xi$ mit $\frac{1}{k}$ multiplicirt: Teränderung ron $\xi$ erzengt also eine Schaar ähnlicher Curven.

Bei gleichem $\vartheta$ ist $\eta$ um so kleiner, je grösser $\xi ; \xi=\infty$ macht $\boldsymbol{\eta}=0$ für jedes endliche $\boldsymbol{\imath}$. Bei wachsendem positivem $\xi$ schmiegen sich mithin die Curve des ersten und die des zweiten Hauptfalles, jene ron oben, diese ron unten, rom Nullpunkt her der Geraden $B B^{\prime}$ auf der positiven Seite an; für $\xi=\infty$ verschmelzen sie im Endlichen mit dieser Geraden. Hinsichtlich der Curve des ersten Hauptfalles entspricht dies Ergebniss unserem früheren Ergebniss: für $\xi=+\infty, x^{\prime}=-b x$ für jedes endliche $t$ (s. oben S. 325; erste Abhandl. S. 300); nur denken wir uns jetzt das unendliche $\xi$ entstanden durch Ueberschreiten des Nullpunktes mit unendlicher Geschwindigkeit nach Fall ans unendlicher Ferme höherer Ordnung (vergl. oben S. 332).

[563] $\xi=0$ macht $C=\infty$, also $\vartheta=0$ für jedes endliche ;; die Curve des ersten Hamptfalles fällt zusammen mit den Geraden $\boldsymbol{A} \boldsymbol{A}^{\prime}$ auf der negativen und die Curve des zweiten Hamptfalles mit derselben Geraden anf der positiven Scalenseite, und so geht hier beziehlich der erste Hauptfall in den zweiten, oder der zweite in den ersten über. Dies ist das analytische Abbild dessen was man beobachtet, wenn man für $\varepsilon>n$ dem Magnet im Angenblicke, wo man ihn aus einer stets gleichen Ablenkung fallen lässt, beziehlich einen immer schwächeren oder immer stärkeren Inductionsstoss ertheilt, so dass zuletzt der Nullpunkt nicht mehr überschritten wird, oder eben anfängt überschritten zu werden.

Macht man $\frac{a}{b}=2$, so wird die Curve eine gemeine Parabel,

$$
\eta=C^{\frac{1}{b}} \cdot \vartheta^{2}
$$

welche die $\boldsymbol{\vartheta}$-Axe im Nullpunkte berülırt, deren Axe der $\boldsymbol{r}$-Axe parallel. und deren Parameter

$$
2 p=\frac{\sin ^{2}(\alpha-\beta)}{C_{b}^{1}}
$$

ist. Die Curve des zweiten Hamptfalles auf der negativen Seite ist die 
Fortsetzung der Curve des ersten Hauptfalles anf der positiven Seite und ımgekehrt; man hat zwei Parabeln, die einander im Nullpunkte berühren.

Da die Tangente am Scheitel der Parabel senkrecht steht auf der Parabelaxe, welche mit der Tangente am negatiren Maximum der anf die $x$-Axe bezogenen Parabel den Winkel $\boldsymbol{c}$, mit der Tangente am $\xi$-Punkt den Winkel $90^{\circ}-\alpha$ bildet, so fällt der Scheitel weder nit dem einen, noch mit dem anderen dieser beiden Punkte zusammen, sondem liegt zwisehen ihnen, um so näher dem Maximum, je grösser, um so näher dem $\xi$-Punkte, je kleiner $\%$.

Macht man nun noch $a=45^{\circ}$, also $a=1, b=1 / 2$, so folgt aus den Eigenschaften der Parabel, dass der Scheitel in der Mitte zwischen den beiden Punkten liegt. Die den $\xi$-Punkt und das Maximum rerbindende Gerade geht durch den Brempunkt $F$, ihre Länge $\tau t$, ist der Parameter

[564]

$$
2 p=\frac{1}{212}=0,35355
$$

Das Maximum $x^{\prime}$, ist $=-1 / 4$; die Axe der Parabel schneidet die $x$-Axe bei $x_{1}=3 / 4 ; x_{0}^{\prime}$ ist $=2$ u. s. w. Diese Verhältnisse liegen Fig. 6, und wie schon bemerkt, auch Fig. 4 und 5 zu Grunde (rgl. oben S. 331. 338).

Die übrigen Curven des zweiten Hauptfalles sind jetzt noch genaner zu betrachten. Für eine und dieselbe Vorrichtung, d. h. ein und dasselbe $a$ und $b$ entspricht im zweiten Hauptfalle jedem $\boldsymbol{X}$ eine Sehaar von Curven der Ablenkungen und eine Schaar ron Curren der Geschwindigkeiten bezogen auf die Zeit. Die einzehnen Curven dieser beiden Schaaren unterscheiden sich durch den Werth von $\mathbf{X}^{\prime}$, welcher zwischen $b X$ und $a X$ sehwankt. Da unendiich riele $X$ denkbar sind, giebt es dergestalt unendliehmal unendlich viele Ablenkumgs- und Geschwindigkeitscurven des zweiten Hauptfalles bezogen anf die Zeit. Wird aber die Geschwindigkeit auf die Ablenkung bezogen, so hat man nur noch Eine Currenschaar des zweiten Hanptfalles, welche, mit den sie einsehliessenden Grenzeurven, für alle Werthe ron $\boldsymbol{Y}$ dieselbe bleibt. Demu da die Bewegung des Magnetes durch bestimmte Geschwindigkeit bei bestimmter Ablenkung eindeutig bestimmt ist, kamn durch einen zwischen den Ge' raden $d A^{\prime}, B B^{\prime}$ gelegenen Punkt, als Gipfel einer Geschwindigkeitsordinate, auch nur Eine Curve gehen. Je grüsser $\mathfrak{A}$ und je kleiner folglich $\mathfrak{B}$ (s. oben S. 336), un so näher der Geraden $B B^{\prime}$, je grösser $\mathfrak{B}$ und je kleiner $\mathfrak{A}$, nm so näher der Geraden $\boldsymbol{A} \boldsymbol{d}^{\prime}$ rerläuft die Curve; für $\mathfrak{A}=2 r \boldsymbol{X}, \mathfrak{B}=0$ fällt sie mit $B B^{\prime}$, für $\mathfrak{B}=2 r \mathfrak{X}, \mathfrak{A}=0$ mit $A A^{\prime}$ zusammen. Die zu einem bestimmten $X$ gehörigen Ordinaten 
$-b X,-X^{\prime \prime},-a X$ aber sind jedesmal die nämlichen, die in Fig. 5 bei gleichem Maassstabe zu demselben $X$ und zur Zeit $T$ gehören würden (27).

Für $t \quad \tau$ z. B. schwankt in Fig. 5 die Ordinate sämmtlicher Geschwindigkeitsenren zwischen $x^{\prime}=-\frac{\xi}{2}$ und $x^{\prime}=-\xi$, während sämuntliche Ablenkumgscurven sich im Gipfel der Ordinate + \& schneiden (rergl. oben S. 339). Demgemäss sind in Fig. 6 die Ordinaten - $a \xi$ und $-b \xi$ der Geraden $d d^{\prime}, B B^{\prime}$, beziehlich $=1$ und $=1 / 2$. Dagegen schneiden sich in Fig. 5 sämmtliche Geschwindigkeitscurven bei t, im Gipfel der Ordinate $-\frac{\xi}{4}$, während $[565]$ die Ordinate der $A b$ lenkungscurren zwischen $x=+\frac{\xi}{4}$ und $x=+\frac{\xi}{2}$ schwankt (vergl. oben S. 339). In Fig. 6 stellt sich dies so dar, dass die der $x$-Axe parallele Gerade $x^{\prime}=1 / 4$ die Gerade $d d^{\prime}$ bei $x=+\frac{\xi}{4}$, die $B B^{\prime}$ bei $x=+\frac{\xi}{2}$ schneidet. In Fig. 5 würde mit wachsendem $\xi$ die Steilheit der Curven wachsen (s. oben S. 338); in Fig. 6 bleiben die Curren für jedes $\xi$ die nümlichen, und nur die bezeichneten Schneidepunlte rïcken mit wachsendem $\xi$ weiter rom Nullpunkte fort.

Man vergegenwärtige sich num die Schaar der durch $\xi$ unterschiedenen Curven des ersten Hauptfalles. Mit einer jeden von diesen wird eine der durch $\mathfrak{A}$ und $\mathfrak{B}$ unterschiedenen Corven des zweiten Hauptfalles in der obigen Art gemeinsam construirbar sein; und eine einfache Construction dient, die so zusammengehörigen Curven beider Hauptfälle zu bestimmen. Diese Construction ist in Fig. 7 in kleinerem Maassstabe besonders rorgeführt, da sie für ein so grosses $\xi$, wie es ans anderen Gründen in Fig. 6 nöthig war, zu weite Anslehnung dieser Figur bedingt hätte, wie demn aus demselben Grunde in Fig. 5 die Darstellung der zu $\mathfrak{x}$ gehörigen Curven unterblieben ist.

Aus (36) folgt, dass, wemm $\mathfrak{Y} \mathfrak{A}^{\prime}, \mathfrak{B}$ welches $X^{\prime}=\mathfrak{t}, X^{\prime}=\mathfrak{t}^{\prime}$, man stets haben müsse

$$
\mathfrak{U}^{\prime}: \mathfrak{J}^{\prime}:: a: \ell \text {. }
$$

Ian ziehe irgendwo eine der $x^{\prime}$-Axe parallele Gerade $\mathfrak{t} \cdot t^{\prime}$, und theile die Strecke - $(a-b)$ $\mathfrak{t}=B^{\prime} A^{\prime}$ im Verhältniss ron $a: l$ so ein, dass das a entsprechende grössere Stück an $\boldsymbol{A}^{\prime}$ stosse. Man hat dam

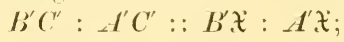

die Punkte $\mathfrak{x}, B^{\prime}, C^{\prime}, d^{\prime}$ liegen harmonisch, und die Geraden $0 . \mathfrak{t}, 0 \boldsymbol{I}^{\prime}$, $0 C^{\prime}, 0 A^{\prime}$ sind harmonische Strahlen. Zieht man ron $C^{\prime}$ nach $\tau$ dem 
Strahle 0 $\boldsymbol{d}^{\prime}$ parallel eine Gerade, so wird diese durch den zugeordneten Strahl $0 B^{\prime}$ in ihre beiden Hälften $+\boldsymbol{y}$ und $-\eta$ getheilt. Da $0 B^{\prime}$ die 4-Axe ist, so sind $C^{\prime}$ und $\tau$ Curvempunkte, und der Strahl $0 C^{\prime}$, der zur Gleichung hat $(40)$

$$
x^{\prime}=-\frac{2 a b}{a+b} \cdot x
$$

[566] ist der Ort aller Curvempunkte des zweiten Hauptfalles, deren y bei gleichem $\boldsymbol{\eta}$ dem $\boldsymbol{y}$ des $\xi$-Punktes irgend einer Curve des ersten Hauptfalles gleich und entgegengesetzt ist. $a \cdot \mathfrak{t}^{\prime}+\mathfrak{t}^{\prime}=\mathfrak{Y}^{\prime}$ ist sichtlich $=a \xi ; b \mathfrak{X}+\mathfrak{x}^{\prime}=-\mathfrak{B}^{\prime}=-b \xi$. In Fig. 7 sind abermals $\xi=1, a=1, b=1 / 2$ gemacht; demgemäss ist $\mathfrak{t}=3$, $\mathfrak{t}^{\prime}=2$; die Gleichung des Strahles $0 C^{\prime}$ ist

$$
x^{\prime}=-\frac{2}{3} x \text {. }
$$

Da für alle Curren des zweiten Hauptfalles, ansgenommen für die Grenzcurve $0 \boldsymbol{A}^{\prime}$, am Nulpunkte $x^{\prime}=-b x[(22),(29)]$, und für alle, ansgenommen für die Grenzeurve $0 B^{\prime}$, im Unendlichen $\frac{x^{\prime}}{x}=-a[(21)$, (23)], so schneiden sämmtliche Curren den Strahl o $C^{\prime}$. Schreibt man Gleichung (36)

$$
\frac{\left(a x+x^{\prime}\right)^{a}}{\left(b x+x^{\prime}\right)^{b}}=\frac{\left(\mathfrak{B}^{\prime}\right)^{a}}{\left(-\mathfrak{B}^{\prime}\right)^{b}}=\frac{a^{a}}{(-b)^{b}} \cdot \xi^{2 r},
$$

so zeigt sich abermals, dass für $\xi=0, x^{\prime}=-a x$, und für $\xi=\infty$, $x^{\prime}=-$ bx wird (rgl. oben S. 346 ); der Anmahme $\xi=0$ genügen aber ferner $\mathfrak{t}$ und $\mathfrak{t}^{\prime}=0$, und der Anmahme $\xi=\infty$ genügen $\mathfrak{t}$ und $\mathfrak{t}^{\prime \prime}=\infty$; für $\xi=0$ also rückt der s'chneidepunkt $C^{\prime}$ auf der Geraden $O C^{\prime}$ an den Nullpunkt, für $\xi=\infty$ in die Unendlichkeit.

§. VIII. Die Curve der Geschwindigkeiten bezogen anf die Ablenkungen im Grenzfall $\varepsilon=n$.

Denkt man sich den Winkel $\boldsymbol{c}-\beta$ immer kleiner bis zum Verschwinden, so hört im Augenblicke, wo die Geraden $d^{\prime} d^{\prime}, B B^{\prime}$ zusammenfallen, der zweite Hauptfall zu bestehen auf, und von den vier Curvenzweigen der Fig. 6 bleiben nur die beiden übrig, welche den ersten Hauptfall vorstellten. Auch die Transformation, bei der jene Geraden als Axen eines schiefen Coordinatensystemes benutzt werden, wird unmöglich. Man kamn aber mit ausreichendem Erfolge diese Transformation durch mehrere andere, z. B. durch die in Fig. 8 sichtbare, ersetzen. Hier ist $0 t_{\prime \prime} t, \tau t_{0}$ wieder die Curve $x^{\prime}=\phi(x)$ für ein positives, $0 \begin{array}{lll}\boldsymbol{\tau}^{\prime} & t_{0}^{\prime}\end{array}$ die für ein negatives $\xi$. 
[567] Die gegenwärtige Construction entsteht aus der rorigen, wenu man sich unter der $\vartheta$-Axe jetzt die Gerade denkt, welche mit der $x$-Axe den zu $\varepsilon$ als Tangente gehörigen Winkel $\omega$ einschliesst, während man in Gedanken die 1 -Axe so weit ron der $v$-Axe fortdreht, dass sie mit der $x^{\prime}$-Axe zusammenfällt. Die Richtungen, in denen die $y$ und $\vartheta$ wachsen, bleiben dieselben.

Ganz wie für ein endliches $r$ die Ausdrücke (9) den Abstand der Currenpunkte ron den Geraden $\boldsymbol{d}^{\prime} \boldsymbol{A}^{\prime}, B \boldsymbol{B}^{\prime}$ in der Richtung der $\boldsymbol{x}^{\prime}$-Axe maassen, misst nun $\varepsilon x+x^{\prime}$ deren in dersèlben Richtung, also anch in der Richtung der $i_{-}$-Axe, genommenen Abstand, z. B. des Currenpunktes ¿z ron der Geraden $x^{\prime}=-\varepsilon x$. Man hat also

$$
y_{i}=\varepsilon \cdot x^{r}+x^{\prime} \text {, }
$$

positiv auf der oberen, negatir anf der unteren Seite der $\vartheta$-Axe. Man hat ferner

$$
\varepsilon x=\vartheta \sin \omega .
$$

Eliminirt man die Zeit zwischen den Gleichungen (33) und (34), so erhält man die mit dem Ausdrnck anf S. 299 der ersten Abhandlung identische Gleichmng

$$
\varepsilon x+x^{\prime}=\varepsilon \xi e^{1-\frac{\varepsilon x}{\varepsilon x+x^{\prime}},}
$$

die hier die Stelle von (35) vertritt. Indem man in (44) für $\varepsilon x+x^{\prime}$, $\varepsilon, r$ die obigen Werthe setzt, kommt

oder

$$
\eta_{i}=\varepsilon \xi e^{1-\frac{\vartheta}{\eta} \sin \omega}
$$

$$
\vartheta=\frac{\eta}{\sin \omega} \log \left(\begin{array}{c}
e \varepsilon \xi \\
\eta
\end{array}\right)
$$

woraus sich das Nöthige ergiebt. Macht man $\xi$ negatir, so rerden $\eta$ und 9 negativ; die Gleichung stellt also beliebig den einen und den anderen der beiden Curvenzweige ror, welche physikalisch nur getrennt Bedentung haben. Wir rerfolgen von diesen Zweigen den oberhalb der t-Axe gelegenen. Bei der Discussion ist es diesmal bequemer, die $\mathfrak{i}_{\text {-Axe }}$ als Abscissen-, die $\vartheta$-Axe als Ordinatenaxe anzusehen.

[568] Es ist

$$
\begin{aligned}
& \frac{d_{i} \vartheta}{d y}=\frac{1}{\sin \omega} \log \left(\frac{\varepsilon \xi}{y_{i}}\right), \\
& \frac{d^{2} \vartheta}{d_{\eta}{ }^{2}}=-\frac{1}{\eta \sin \omega} .
\end{aligned}
$$

Am Nullpunkte fällt die Curre zusammen mit der it-Axe, entsprechend dem obigen Ergebniss: für $t=+\infty, x^{\prime}=-\varepsilon x$. Die Curre steigt dann, conear gegen die $r$-Axe, bis zu einem Haximum am $\$$-Punkte bei 
$\tau$ abwärts, wo $y_{i}=\varepsilon \xi ;$ da hiex $\frac{d \vartheta}{d y}=0$ ist, schneidet die Curre die $x$-Axe senkrecht (rergl. erste Abhandlung S. 297). Ton hier ab steigt sie ohne Tendepunkt in's Unendliche an. Bei $\eta=e \varepsilon \xi$ schmeidet sie die $r$-Axe; fortan ist ihre Ordinate negatir, und sie selber courex gegen die Abscissenaxe; zuletzt für $\boldsymbol{y}_{j}=\infty$ nimmt sie wieder die Richtung der $\vartheta$-Axe an, entsprechend dem obigen Ergebniss: für $t=-\infty$, $\frac{x^{\prime}}{x}=-\varepsilon$.

Es ist gleichgültig, ob man in (45) oder (46) $\vartheta$ und $\vartheta$ mit einel Constanten $k$, oder ob man $\xi$ mit $\frac{1}{k}$ multiplicirt: Teränderung ron $\xi$ erzengt also eine Schaar ähnlicher Curven.

Für $\xi=0$ schmiegt sich die Curre dem negativen, für $\xi=\infty$ dem positiven Schenkel der $\vartheta$-Axe an, und im letzteren Fall ist es als sei der Magnet aus unendlicher Ferne höherer Orduung gefallen und habe den Nullpunkt mit unendhcher Geschwindigkeit überschritten.

Macht man $\xi$ negatir, so rerlegt man dadurch den Vorgang auf die andere Scalenseite, auf der Alles Gesagte symmetrisch wiederkehrt.

In der Figur ist $\omega^{\prime}=45^{\circ}, \xi=1$; das Maximum der Curre $x^{\prime}=\phi(x)$ wird dadurch $=-\frac{1}{e}$, und liegt bei $x=\frac{2}{e}$; die Ordinate des Wendepunktes wird $-\frac{2}{e^{2}}$, und liegt bei $x=\frac{3}{e^{2}}$; endlich die Ordinate $x_{0}^{\prime}$ ist $=e$. Die Fig. 24 der ersten Abhandlung entspricht einem Theile dieser Figur, nur dass dort $\xi$, statt $=1,=2$ gemacht war.

Zusatz von Hrn. Ḱronecker zur vorigen Abhandlung.

[569] Lässt man den Magnet aus einer positiven Ablenkung x̧ ohne Dämpfung fallen, bis er eine Ablenkmung: $\mathfrak{c}$. cos $v$ erreicht, und erst an dieser Stelle die Dämpfung eintreten, was sich durch Schliessen eines Gewindes bewerkstelligen liesse, so kamn man für die weitere Bewegung des Magnetes die Grössen $\mathfrak{x}$ und $v$ als Constanten einführen. Hiernach erhält man, wenn der Nullpunkt der Zeit an den Eintritt der Dämpfung und

$$
v^{b}=1 a \cdot \operatorname{tg} u \quad(0<u<1 / 4 \pi)
$$

gesetzt wird, Ablenkung und Geschwindigkeit durch folgende Gleichungen bestimmt:

$\left(a x+x^{\prime}\right) e^{b t}=n \mathfrak{c} \cdot \frac{\cos (u+v)}{\sin u},\left(b x+x^{\prime}\right) e^{\alpha t}=n \tilde{\varepsilon} \cdot \frac{\sin (u-v)}{\cos u}$ oder: 
352 XIII. Ueber aperiodische Bewegung gedämpfter Magnete. - Abh. II.

$\frac{x}{x} \cos 2 u=\cos u \cdot \cos (u+v) \cdot e^{-b t}-\sin u \cdot \sin (u-v) e^{-a t}$ $-\frac{x^{\prime}}{u x} \cos 2 u=\sin u \cdot \cos (u+v) \cdot t^{-b t}-\cos u \cdot \sin (u-v) e^{-a t} \cdot$ Für $t=0$ wirel:

$$
\begin{aligned}
& x=\mathfrak{r} \cos v, \quad r^{\prime}=-n \underline{x} \sin v
\end{aligned}
$$

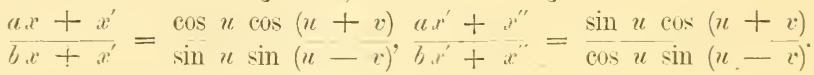

Der Ausdruck $\frac{\cos (u+v)}{\sin (u-v)}$ durchläuft. menn $v$ ron 0 bis $u$ geht, alle Werthe ron cot $u$ bis $+\infty$, hierauf (während $v$ von $u$ bis $\pi$ wächst) stetig zunehmend alle Werthe ron - $\infty$ bis cot $u$. Liegt $v$ zwischen 0 und $u$ orler zwischen $\frac{\pi}{2}-u$ und $\pi$, so findet der erste Hauptfall statt, der zweite aber, sobald $v$ zwischen $u$ und $\frac{\pi}{2}-u$ liegt.

So lange $v \leq \frac{\pi}{2}-u$ ist, d. h. so lange die Dämpfing bei einer Ablenkung eintritt, welche nicht kleiner als $x \cdot \sin \|$ viler $x \sqrt{\frac{b}{a}+\text { b }}$ ist, überschreitet der Magnet nicht seine Ruhelage $x=0$, sondern nähert sich derselben asymptotisch ron der positiven Seite $[570]$ her. Wenn aber $v$ zwischen $\frac{\pi}{2}-u$ und $\frac{\pi}{2}$ liegt und demgemäss die Ablenkung bei Eintritt der Dämpfung positiv und kleiner als $x^{*}$. sin $u$ ist, so überschreitet der Magnet die Ruhelage, kehrt bei der negativen Ablenkung:

$$
-\mathfrak{z} \cdot\left(\begin{array}{c}
-\cos (u+v) \\
\cos u
\end{array}\right)^{\frac{a}{2 r}}\left(\frac{\sin u}{\sin (v,-u)}\right)^{\frac{b}{2 r}}
$$

um und nïhert sich alsdann ron der negativen Seite her wiederum der Ruhelage. Wenn endlich $v$ zwischen $\frac{\pi}{2}$ und $\pi$ liegt, die Dämpfung also erst bei einer negativen Ablenkung beginnt. so bewegt sich der Magnet im Simme wachsender negativer Ablenkungen weiter bis zu dem durch den Ausdruck (A) gegebenen Haximum, kehrt alsdam um und erreicht schliesslich ron der negativen Seite her seine Ruhelage. Der Werth $x=0$ wird also füx positive endliche Werthe von $t$ nur erreicht, wenn ${ }_{2}^{\pi}-u<v$ $<\frac{\pi}{2}$ ist, der Werth $x^{\prime}=0$, wemn $\frac{\pi}{2}-u<v<\pi$ ist. 
XIV.

\section{Ueber aperiodische Bewegnng gedämpfter Magnete.}

\section{Dritte Abhandlung.}

(Gelesen in der Sitzung der physikalisch-mathematischen Klasse der Königl. Akademie der Wissenschaften zu Berlin am 17. November 1873.) ${ }^{1}$

§. I. W. Sremens' aperiodische Magnete ohne Astasirung.

Bei Besprechung der experimentellen Bedingungen, unter denen die Bewegung gedämpfter Magnete aperiodisch wird, sagte ich in der ersten Abhandlung ïber diesen Gegenstand: „Eine andere Art, unter übrigens ,gleichen Umständen $r=0$ oder reell zn machen, wäre Verkleinermng "des Trägheitsmomentes $\boldsymbol{M}$. Es liegt in der Natur der Dinge, dass „man, ohne besondere Eimrichtungen, diese nicht stetig und nicht am „sonst fertigen Apparate rornehmen kamn. Aber je kleiner $\boldsymbol{M}$, je dünner ,z. B. bei sonst gleicher Gestalt ein Iagnetspiegel ist, bei um so ge„ringerer Astasie wird seine Bewregung aperiodisch."2 Seitdem dachte ich oft daran, ob es nicht gelingen würde, durch Verkleinerung des Trägheitsmomentes allein, ohne Astasirung des Magnetes, dessen Bewegung aperiodisch $\mathrm{zu}$ machen. Ich ging damit $\mathrm{Im}$, Nagnete ans dünnstem Stahlblech in silbernen Dämpfern aufzuhängen, wobei nur die Schwierigkeit war, dass solche Spiegel im Fernrohr kein Bild geben, während Verbindung anch mit dem leichtesten Glasspiegel das Trägheitsmoment wieder $\mathrm{zu}$ sehr vergrössert. ${ }^{3}$

Inzwischen ist diese Aufgabe durch meinen Fremnd Hrn. Dr. W. SiEmens in einer Weise gelöst worden, die um so sinnreicher erscheint, je fremdartiger beim ersten Anblicke die Lösung sich darstellt. Hr. Sremers hat ohne Astasirung aperiodisch sich bewegende Magnete zu Stande gebracht, welche, obschon auf Verkleinerung des Trïgheits-

\footnotetext{
1 Monatsberichte der Akademie u. s. w. 1873. S. 748 .

2 S. oben S. 309.

3 Archives des Sciences physiques et naturelles. P. N. t. XLV. 1872. p. 92.

E. du Bois-Reymoud, Ges. Abb. I. 
3.54 XIV. Ueber aperiodische Bewegung gedämpfter Magnete. - Abh. III. -

momentes Rücksicht genommen ist, doch kräftig genug sind, um sie ohne Schaden mit einem Glasspiegel rerbinden zu können. Er hat die Güte gehabt, mir zu gestatten, diese Construction in seinem Namen der Akademie mitzutheilen. [749]

Fig. 26.

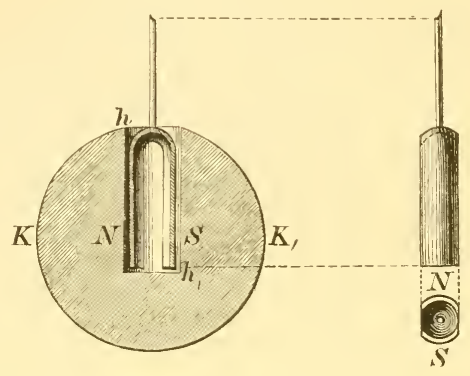

Man sieht sie in Fig. 26 in halber natürlicher Grösse dargestellt. $\boldsymbol{K} \boldsymbol{K}$, ist im Durchschnitt gezeichnet eime Kupferkugel, in der eine eylindrische Höhlung $h h$, ansgebohrt ist, deren Axe mit dem senkrechten Durchmesser der Kngel und der Drehaxe des darin versenkten Magnetes zusammenfällt. Ton letzterem macht man sich am besten einen Begriff, wenn man sich denkt, dass durch einen Fingerhut oder eine Glocke aus Stahl zwei einander und der Axe parallele Schnitte in gleichem Abstande ron dieser geführt seien. Es bleibt ein Bügel übrig, den die Hauptfigur in einem jenen beiden Schnitten parallel durch die Are gelegten Durchschnitt, die Nebenfigur in einer senkrecht anf die erste genommenen Ansicht, sowie im Grundriss von unten gesehen, zeigt. Im Mittelpunkte seiner Wölbung trägt der Bügel in der Verlängerung seiner Axe einen Stiel, mittels dessen er in die cylindrische Höhlung des Dämpfers centrisch herabhängt, und an dem oben der spiegel befestigt ist. Magnetisch gesprochen stellt der Spiegel ein Hufeisen ror, dessen Pole in den Schenkeln $N$, S einander gegenüber liegen. Hr. Simuexs nemnt solche Magnete Glockenmagnete. ${ }^{1}$

1 In anderem Sinne wohlbemerkt, als $\mathrm{Hr}$. WIEDEMAN diesen Ausdruck braucht (Die Lehre vom Galvanismus und Elektromagnetismus. 2. Aufl. Bd. II. Braunschweig 1873. S. 483. §. 423). - Nachricht von den Sremens'schen Glocken- 
[750] Durch diese Anordnung wird erreicht: 1. wegen der Hufeisenform hohe Intensität der Nagnetisirung; 2. verhältnissmässig geringes Trägheitsmoment; 3. grusse Amnäherung der Pole an die dämpfende Metallmasse; 4. Unabhängigkeit der Dämpfung von der Ablenkung.

Diese Umstände haben zur Folge, dass nicht allein der Magnet ohne Astasirung aperiodisch sich bewegt, sondern dass sogar $\varepsilon$ erheblich $>n$ ist. Um den aus bekannten Gründen vortheilhaften Grenzzustand $\varepsilon=n$ zu erreichen, muss man entweder den Haur'schen Stab in umgekehrtem Sinn anwenden, oder den Magnet ein Stück aus dem Dämpfer herausheben. Die SiEmexs'sche Anordnung rerwirklicht also noch treuer als die meinige die ursprüngliche Gauss'sche Conception. Ihre Empfindlichkeit, wemn der Glockenmagnet als Galranometernadel rerwendet wird, lässt nichts zu wünschen übrig. Die Stabilität bei Erschütterungen durch vorüberfahrende Wagen u. d. m. ist ausserordentlich gross. Die Beruhigungszeit des Glockemmagnetes ist nicht bloss in Betracht seiner Hasse, sondern auch absolut genommen sehr klein, noch kleiner nämlich als die meines leichten Spiegels $I^{1}{ }^{1}$ da sie an einem von' mir geprüfteu Exemplare, bei Fall ron den Grenzen der freilich einen sehr kleinen Winkel umfassenden Scale, nur etwa $3^{\prime \prime}$ betrug.

§. II. Verschiedenes Verhalten aperiodischer Magnete bei teleskopischer und bei makroskopischer Ablenkung.

Die ron Gauss aufgestellte Differentialgleichung der Bewegung gedämpfter Míagnete setzt roraus, dass die den Magnet nach seiner Ruhelage bei $p$ treibende Richtkraft der Ablenkung $x-p$ proportional wachse. Die diesem hypothetischen Gesetze gehorchende Kraft heisse $v$; setzen wir wie früher $p=0$, und nemnen das Trägheitsmoment $M$, so haben wir nach der von Gavss eingeführten Bezeichnungsweise ${ }^{2}$

$$
v=M n^{2}, x .
$$

In Wirklichkeit aber wächst die Richtkraft nicht der Ablenkung proportional, sondern deren Sinus. Diese wirkliche Richtkraft heisse y; man hat

$$
y=11 x^{2} \cdot \sin x .
$$

magneten findet sich schon in: Zetzsche, Kurze Mittheilungen über die in Wien 1873 von Siemens und HaLske ausgestellten neuen Telegraphen-Apparate. In Schlömilch's, Kahl's und Cantor's Zeitschrift für Mathematik und Physik. 1873. S. 427.

1 S. oben S. 309 .

2 Hier und S. 359 ist ein Versehen des Originals berichtigt. 
An Stelle der durch diese Gleichung rorgestellten Sinuscurve setzt also die Theorie eine Gerade, nämlich die an die Sinuscurre im Nullpunkte gelegte Tangente, demn diese hat zur Gleichung

$$
v=M n^{2} \cdot x \text {. }
$$

Da die Sinuscurve concar gegen die Abscissenaxe ist, erhebt sich die Gerade rom Nullpunkt aus über sie furt; für $x=90^{\circ}$ beträgt der Unterschied der Ordinaten beider Curren $\boldsymbol{I} / n^{2} \cdot\left(\frac{\pi}{2}-1\right)$; für $x=180^{\circ}$, $\boldsymbol{M} n^{2} \cdot \boldsymbol{\pi}$. S. die Curre $0 y$ und die Gerade $0 v$ in Fig. 27, in welcher $I / n^{2}=2 / 3$ gesetzt ist.

Im Folgenden soll rom rerschiedenen Verhalten solcher Ablenkungen die Rede sein, für welche die Voraussetzungen der Differentialgleichung annähernd erfüllt sind, und solcher, auf welche diese Voraussetzungen nicht mehr passen. Da erstere im Bereiche der Scale bleiben und mit dem Fernrohr abgelesen werden, letztere darüber hinausgehen und mit unbewaffnetem Ange wahmehmbar sind, nemne ich jene teleskopische, diese makroskopische Ablenkungen.

Nach Obigem ist klar, dass, wenn der Magnet aus makroskopischer Ablenkung fällt, an jedem Punkte seiner Bahn, bis in die Nähe des Nullpunktes, eine merklich kleinere Lrraft auf ihn wirkt, als die Theorie annimmt, und dass folglich seine Geschwindigkeit eine kleinere sein wird, als die Theorie verlangt. Die Dämpfung ändert hieran nichts, da sie die Geschwindigkeit nur rerkleinert.

Unter den Toraussetzungen der Differentialgleichung, und für $\varepsilon=n$, würde, wie ich gezeigt habe, der Magnet auch mit der Geschwindigkeit, mit der er aus dem Unendlichen fiele, den Nullpunkt nicht überschreiten. Ist $\varepsilon>n$, so muss, damit der Nullpunkt überschritten werde, die Geschwindigkeit des Magnetes jene Geschwindigkeit bei der Ablenkung $\xi$ sugar noch um $2 r \xi$ übertreffen. Um wie riel weniger wird in beiden Fällen zum Ueberschreiten des Nullpunktes die ungleich kleinere Geschwindigkeit [752] genügen, die der Magnet in Wirklichkeit erlangt, wenn er aus möglichst grosser Ablenkung, von $180^{\circ}$, fällt. Wie gross auch hier der Abstand zwischen theoretischer Toraussetzung und Wirklichkeit sei, diese Folgerung ans der Differentialgleichung, sollte man meinen, muss, weil gleichsam a fortiori bewiesen, in Wirklichkeit dennoch zutreffen.

Stellt man aber den Versuch mit Magnetspiegel und Dämpfer der Wredemaxx'schen Bussole an, indem man der Bequemlichkeit halber den Spiegel sugar nur ans der Ablenkung ron noch nicht ganz $90^{\circ}$ fallen lässt, in der ein kräftiger Strom ihn hält, so ist wenigstens bei $\varepsilon=n$, oder nur mässig $>n$, der Erfolg nicht der erwartete, sondern 
der Nulpunkt wird mehr oder minder, bei $\varepsilon=n$ an meinen Vorrichtungen $\mathrm{um}$ etwa 60 se, überschritten. Der Grund liegt auf der Hand. Zwischen den Toraussetzungen der Differentialgleichung und der Wirklichkeit findet hier noch ein Tuterschied statt. Die Differentialgleichung setzt rorans, dass $\varepsilon$ constant sei. Wegen der Form unseres Dämpfers ist jedoch in Wirklichkeit $\varepsilon$ eine periodische Function ron $x$, die für $x=0, x=\pi, \ldots$ Maxima, für $x=\frac{\pi}{2}, x=\frac{3 \pi}{2}, \ldots$ sehr tief liegende Maxima hat. Der Magnet koumt also in der Gegend, wo die Voraussetzungen der Differentialgleichung merklich erfüllt sind, mit einer Geschwindigkeit an, welche die oben angegebene Grenze übersteigt. Um bei Fall des Magnetes aus so hoher Ablenkung ihn dem Nullpunkt asymptotisch sich nähern zu sehen, muss man daher durch Ammähern des Haur'schen Stabes $n^{2}$ rerkleinem. Nicht bloss nimmt dadurch die Geschwindigkeit ab, welche der Spiegel in der Strecke seiner Bahn erhält, wo die Dämpfung gering ist, sondern es wächst anch die Grösse $2 r \xi$, um welche die Geschwindigkeit des Spiegels die durch Fall aus dem Unendlichen erreichbare Geschwindigkeit bei $\xi$ übertreffen muss, damit der Nullpunkt überschritten werde.

Soweit war, im Wesentlichen, die Untersuchung früher schon gediehen. ${ }^{1}$ Da es aber hier nicht mehr um teleskopische Ablenkungen sich handelt, so ist weder mehr Möglichkeit, noch Nothwendigkeit da, den Ausschlag selber mit Spiegel, Fernrohr und Scale zu beobachten. Vielmehr ist die Beobachtung in der Nähe, [753] am Magnete selber, mit unbewaffneteu Auge vorzunehmen, mit einem Wort, aus einer teleskopischen in eine makroskopische zu verwandeh. Dies hatte ich damals rersäumt. Seitdem habe ich darin ein für Demonstration des aperiodischen Zustandes recht vortheilhaftes Verfahren erkannt, welches üherdies zu einer lehrreichen Wabrnehmung führt.

Es zeigte sich, dass zwar erwähntermaassen durch Amüherung des Haur'schen Stabes ein Punkt erreicht wird, wo beim Oeffinen des Stromes der Magnet von $90^{\circ}$ asymptotisch dem Nullpunkte sich nähert - beilänfig ein wunderbarer Anblick -; dass aber beim Schliessen des Stromes der Magnet nicht ebenso auf $90^{\circ}$ sich einstellt, sondern erst nach ziemlich heftigen Schwingungen zur Ruhe kommt. Bei kleineren makroskopischen Ablenkungen wird die nene Ruhelage nur mehr oder minder überschritten. Tollends bei $\varepsilon=n$ findet das Gleiche statt. Dies ist, nur stärker ausgeprägt, sichtlich dieselbe Erscheinung, die ich bei teleskopischer Beobachtung schon früher spurweise wabrnahm. Ich 
fand, dass, wenn $\varepsilon=n$ und die teleskopische Ablenkung gross ist, der Magnet sie $\mathrm{um} 2-3$ se überschreitet. obschon er von ihr herabfallend asymptotisch dem Nullpunkte sich nähert. Ich brachte dies in Verbindmng mit dem Ueberschreiten des Nullpunktes bei Fall ans makroskopischer Ablenkung und leitete beides ron der Form des Dämpfers her. Doch erwähnte ich nebenher die Möglichkeit, dass das Ueberschreiten grösserer teleskopischer Ablenkungen auf nicht zu beseitigender Unbeständigkeit auch der besten Ketten beruhe. ${ }^{1}$ Auf unsere gegenwärtige, makroskopische Beobachtung würde diese Erklärnng nicht mehr passen, aber anch die Form des Dämpfers ist nicht der wesentliche Grumd der scheinbaren Abweichung, wie sich jetzt leicht ergiebt.

Hrn. Sienexs' Glockemmagnet in seiner cylindrischen Höhlımg ${ }^{2}$ bietet nämlich Gelegenheit, diese Frage zu entscheiden. Hier ist die Dämpfung von der Ablenkung umabhängig.

[754] Wenn also das Ueberschreiten des Nullpunktes bei Fall ron $90^{\circ}$ an der Wredemans'schen Bussole, und für $\varepsilon=n$, ron Abnahme der Dämpfung mit wachsender Ablenkung herrührt, so muss es an der Siemens'schen Anordnung nicht eintreten. Wirklich geschieht es in so geringem Maasse, dass man es füglich auf die Schwierigkeit zurückführen kamn, durch Fallversuche aus teleskopischen Ablenkungen $\varepsilon$ genau $=n$ zu machen.

Wemn zweitens das an der Wtedenaxs'schen Bussule für $\varepsilon=n$ bemerkbare Ueberschreiten grosser teleskopischer Ablenkungen auf demselben Grunde beruht, so muss anch dies an der SiEvexs'schen Anordnung fortfallen. $\mathrm{Zu}$ meiner Ueberraschung fuhr aber trotz der beständigen Dämpfung diese Ahweichung fort sich kundzugeben, und jetzt scheint dafür nur die andere ron mir gegehene Erklärung übrig zu bleiben, dass sie ron Unbeständigkeit der Kette herrühre. Diese Erklärung erweist sich indess bei näherer Ueberlegung als unhaltbar. Die grossen teleskopischen Ablenkungen, bei denen das Ueberschreiten stattfand, waren durch einen rom Compensator abgeleiteten Stromzweig erzengt. $^{3}$ Das Schliessen des Bussolkieises kann keine merkliche Verstärkung des Hauptstromes und demgemäss der Polarisation im Hauptkreise bewirken. An Erwärmung des Bussolkreises ist schwerlich zu

1 S. oben S. 313 .

2 Es wird natürlich nur von sehr geringem Einfluss sein, ob die cylindrische Höhlung in einer Kugel oder in einer sonstwie gestalteten Kupfermasse ausgebohrt ist, wofern nur diese nach allen Richtungen um einen gewissen Betrag ausgedehnt ist.

3 S. oben S. 30 T. 
denken. Es muss für das Ueberschreiten eine andere Ursache geben, und man könnte geneigt sein, sie in Vergrösserung von $n^{2}$ in Folge temporärer Magnetisirung durch den Strom zu suchen, nur dass es wieder kaum glaublich ist, dass diese schon bei teleskopischen Ablenkungen von Einfluss werde. Hrn. Poggendorff's doppelsimnige Ablenkung ${ }^{1}$ zeigt wohl, dass schon nahe dem Nullpunkte temporäre Magnetisirung stattfindet, allein durch Ströme, welche die Nadel senkrecht anf die Windungen stellen. In der That ergiebt sich für das Ueberschreiten noch ein anderer Grund.

Wemn nun nämlich drittens die starken Schwingungen, die an der Wredemann'schen Bussole sogar für $\varepsilon>n$ der auf $90^{\circ}$ abgelenkte Spiegel zeigt, dadurch entstehen, dass an dieser Bussole bei $90^{\circ}$ die Dämpfung vergleichsweise sehr gering ist, so müs- [755] sen bei der SiEurens'schen Anordnung die Schwingungen auf dem 90-Punkt ausbleiben, um so mehr, als zur Dämpfung durch den Dämpfer jetzt noch die durch das Multiplicator-Gewinde tritt. Allein anch hierin sah ich mich getäuscht. Jene Schwingungen bestehen trotz der beständig bleibenden, ja wachsenden Dämpfung fort. Anch sie haben also, wenigstens in der Hauptsache, mit der Abnahme der Dämpfung an der WreDEmaxx'schen Bussole nichts zu schaffen. Tielmehr beruhen sie, zugleich mit dem Ueberschreiten grosser teleskopischer Ablenkungen, auf folgendem naheliegenden, bisher von mir übersehenen Umstande.

In Fig. 27 stellen die Ordinaten der Curren $\left(\frac{\pi}{2}\right) I,\left(\frac{\pi}{2}\right) \dot{I}_{1},\left(\frac{\pi}{2}\right) I_{2}$, $\left(\frac{\pi}{2}\right) I_{\infty}$ für rerschiedene Stromstärken $I, I_{1}, \ldots$ die ablenkende Kraft $z, z_{1}, \ldots$ des Stromes an jedem Punkte des zur Abscissenaxe entwickelten Quadranten vor. Gemäss unseren früheren Bezeichnungen ${ }^{2}$ hat man

$$
z=M k \cdot \cos x, z_{1}=M k_{1} \cdot \cos x, \ldots
$$

Die Ordinaten der Cosinnscurren und die der Sinuscurve $y=M u^{2} \cdot \sin x$ [756] (s. oben S. 355), obschon auf derselben Seite der Abscissenaxe aufgetragen, sind entgegengesetzten Zeichens, wie selbstrerständlich auch jenseit des Nullpuuktes die Ordinaten der Sinuseurve, jenseit des $90^{\circ}$ Punktes die der Cosinuscurren das Zeichen wechseln. Der Schneidepunkt einer Cosinuscurve mit der Sinuscurve entspricht der jedesmaligen Ruhelage des abgelenkten Magnetes $\xi, \xi_{1}, \xi_{2}$ in der Figur.

Für sehr kleine Stromstärken liegt der Schneidepunkt dem Nullpunkte sehr nahe. In der Nähe des Nullpumktes aber fällt die Sinus-

1 Poggendorff's Annalen u. s. w. 1838. Bd. XLV. S. 353.

2 S. oben S. 303. 
curve merklich zusammen mit ihrer Tangente am Nullpunkte $0 v$ (s. oben S. 355), die Cosinuscurve mit der der Abscissenaxe parallelen Tangente an ihrem Maximum im Nullpunkte $I^{\prime}$ I l, (s. die Figur). Das Dreieck $0 I$, $\xi$ stellt somit den Inbegriff der von $\xi$ bis 0 bei offener Kette auf den Magnet wirkenden Richtkräfte vor. Wir wollen dies Dreieck $\boldsymbol{R}$ nemuen. Zieht man $R$ vom Rechtecke $0 I I$, $\xi$ ab, so bleibt ein mit $R$ congruentes Dreieck 0 I I, übrig, welches den Inbegriff der von 0 nach $\xi$ bei geschlossener Kette auf den Hagnet wirkenden ablenkenden Kíräfte vorstellt. Dies Dreieck heisse $A$. Wegen der Congrnenz der Dreiecke $R$ und $A$ fällt unter diesen Umständen bei Schliessung der Kette der

Fig. 27.

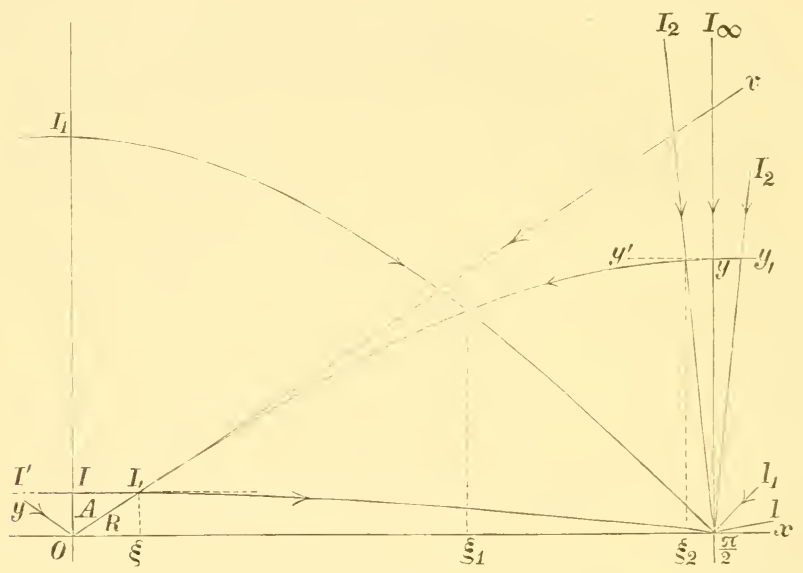

Nagnet rom Nullpunkte dem Punkte $\xi$ nach demselben Gesetze zu, nach welchem er bei deren Oeffinung rom Punkte $\xi$ dem Nulpunkte zu fällt. In beiden Fällen ist bei gleicher Entfernumg rom Ausgangspunkte die Geschwindigkeit dieselbe, nur der Sinn der Bewegung ist umgekehrt, und für $\varepsilon=u$ findet daher ebensowenig Ueberschreiten der neuen Ruhelage wie des Nullpunktes statt. Unsere Construction lehrt so dasselbe wie Gleichung XXXTII der ersten Abhandlung.

Ertheilen wir, im Gegensatze zum Vurigen, dem Strome solche Stärke, dass er den Magnet dem $90^{\circ}$-Punkte nahe in der Ablenkung $\xi_{2}$ hält. An Stelle des Dreieckes $R$ tritt der Flächenraum $0 y^{\prime} \xi_{2}$, an Stelle des Dreieckes $A$ der Flächenraum $0 I_{2} y^{\prime}$, der in der Figur nicht Platz hat. Jener heisse $F_{R}$, dieser $F_{A}$. Es springt in die Augen, dass $F_{A}$ 
$F_{R}$ um eine ungeheure Grösse übertrifft, welche für den $90^{\circ}$-Punkt selber umendlich wird. In gleicher Entfernung rom Ausgangspunkte wirkt also bei Ablenkung des Magnetes stets eine grössere Kraft auf ihn, als bei seinem Falle dem Nullpunkte zu. Unter dem Einflusse der durch $F_{A}$ dargestellten ablenkenden Krräfte wird daher der Magnet eine grös- [757] sere Geschwindigkeit erlangen, als die, welche ihm die durch $F_{R}$ vorgestellten Richtkräfte ertheilen. Er wird nicht allein die neue Ruhelage überschreiten, sondern, wie leicht sich zeigen lässt, auch .um diese Lage schwingen.

In der Nähe des $90^{\circ}$-Punktes kamn man nämlich die Sinuscurve ebenso durch die der Abseissenaxe parallele Tangente $y^{\prime} y y$, an ihrem Maximum ersetzen, wie in der Nähe des Nullpunktes die Cosinuscurre. Die Cosinuscurve dagegen fällt nahe dem $90^{\circ}$-Punkt in langer Strecke mit ihrer Tangente an jenem Punkte merklich zusammen. Es gilt daher hier für den unter dem vereinten Einflusse der Erdkraft, des Stromes und der Dämpfung sich bewegenden Magnet dieselbe Differentialgleichung, wie die auf S. 303 der ersten Abhandlung für den auf dem Nullpunkt unter denselben Einflüssen sich bewegenden Magnet aufgestellte, nur dass jetzt $x$ den Abstand rom $90^{\circ}$-Punkte bedeutet, und dass $k$ und $n^{2}$ die Plätze rertauscht haben, folglich $\varepsilon \geq \sqrt{k}$ Bedingung des aperiodischen Zustandes ist. Dieser Zustand kann aber hier nie erreicht werden. Annähern des Havy'schen Stabes vermindert die, $n^{2}$ proportionale Steilheit der Sinnscurve: $0 y$ sei die Curve, für die $\varepsilon=n$, oder ihre Steilheit die, für die eben Schwingungslosigkeit beginnt. Man braucht nur diese Steilheit mit der, $k$ proportionalen Steilheit der Cosinuscurre $\left(\frac{\pi}{2}\right) I_{2}$ zu vergleichen, um zu sehen, dass der Natur der Dinge nach unter diesen Umständen $\sqrt{k}$ stets riel grösser als $n$, folglich als $\varepsilon$ ist, und also der Magnet um die nene dem $90^{\circ}$-Punkte nahe Ruhelage schwingen muss. Weiteres Amnähern des Havr'scheri Stabes vermag über diese Schwingungen nichts. Denn der Magnet rollzieht sie nicht mehr unter dem Einflusse der anf beiden Seiten der Ruhelage in gleichem Sinne wirkenden Erdkraft, sondern unter dem Einflusse der ihn von beiden Seiten nach dem $90^{\circ}$-Punkt hin treibenden Stromkraft.

Uebrigens versteht es sich von selbst, dass, wemn auch die Schwingungen anf dem $90^{\circ}$-Punkte der Wiedemaxs'schen Bussole nicht allein den zuerst von mir gemuthmaassten Ursprung haben, sie doch dadurch begünstigt werden, dass $\varepsilon$ dort ein Minimum hat, daher sie anch, sorreit ein Vergleich möglich ist, an der WiEdenans'schen Bussole stärker erscheinen, als bei der Sremexs'schen Anordnung.

Lassen wir die Stromstärke abnehmen, so sinkt zwar der Unterschied 
$F_{A}-F_{R}$, in aller Strenge Null wird er aber erst für die [758] Stromstärke Null, wo die Flächenräume $F_{A}, F_{R}$ beziehlich in die congruenten Dreiecke $A, R$ übergehen. Jener Unterschied besteht also, wenn anch in abnehmender Grösse, noch für kleinere makroskopische und grössere teleskopische Ablenkungen. Um zu begreifen, dass für $\varepsilon=n$ auch im letzteren Falle daraus noch Ueberschreiten der nenen Gleichgewichtslage hervorgehe, muss man Folgendes erwägen.

In der ersten Abhandlung zeigt Fig. 24 auf S. 298 die Curven, die, für $\varepsilon=n$, die Geschwindigkeit $x^{\prime}$ rorstellen, mit welcher der Magnet ron rerschiedenem $\xi$ fallend dem Nullpunkte sich nähert. Diese Curren sind einander ähnlich; am Nullpunkte rerschmilzt ihre Schaar mit der Geraden $x^{\prime}=-\varepsilon x$, welche die Geschwindigkeit bei Fall aus dem Unendlichen rorstellt.

Erhält bei irgend einem $\xi$ der Magnet eine grössere Geschwindigkeit, als die, mit welcher er dort aus dem Unendlichen anlangen würde, also absolut $>\varepsilon \xi$, so ïberschreitet er den Nullpunkt (s. oben S. 355). Fällt der Nagnet von $\xi$ aus, so muss ihm also, damit er den Nullpunkt überschreite, gleich anfangs bei $\xi$ durch einen Stoss eine Geschwindigkeit $>\varepsilon \xi$ ertheilt werden. Ist aber der fallende Magnet dem Nullpumkte schon sehr nahe, so reicht die kleinste Beschlemigung ans, um ihn ein wenig über den Nullpunkt fortzntreiben: weil er nämlich, er komme aus Ferne oder Nähe, hier stets schon die Grenzgeschwindigkeit $x^{\prime}=-\varepsilon \xi$ hat.

Bei kleinen teleskopischen Ablenkungen, und für $\varepsilon=n$, ist die Curve der Geschwindigkeit, mit welcher der Magnet seiner neuen Ruhelage zueilt, das seitliche Spiegelbild der Curre der Geschwindigkeit, mit welcher er ron $\xi$ fallend dem Nullpunkte sich nähert. Der IIagnet nähert sich also der nenen Ruhelage, als kïme er aus dem Unendlichen, und die kleinste in ihrer Nähe ihm ertheilte Beschleunigung würde ihn über jene Lage himaustreiben.

Bei grösseren teleskopischen Ablenkungen kommt nun in diesem Sinne in Betracht, dass, wie wir sahen, die ablenkende Kraft Ordinate um Ordinate bereits etwas grösser ist als die Richtkraft. Letztere ist so abgemessen, dass eben der Nullpunkt nicht mehr überschritten wird, also der Magnet ihn erreicht, als käme er aus dem Unendlichen. Ebenso würde er die nene Ruhelage erreichen, wenn die Flächenräume $F_{A}$ und $F_{R}$ genaue Spiegelbilder wären. Der Ueberschuss der Ordinaten der ablenkenden Kraft über die der [759] Richtkraft wirkt aber als Beschleunigung, welche den Iagnet etwas über die nene Ruhelage linausführt.

Für $\varepsilon>n$, und für kleinere makroskopisehe Ablenkungen lassen nach dem Gesagten die beschriebenen Erscheinungen sich leicht ableiten. 
§. III. Von der besten Art, den HAUr'schen Stab anzubringen.

Die Art, den Haur'schen Stab anzubringen, wurde ausführlich noch nie erörtert. Hr. Meissser und Hr. Merenstess brachten an ihrem Elektro-fralranometer nach Hru. Wшн. WEbER's Torgange den Stab mit seinem Mittelpunkte senkrecht über dem des schwingenden Iagnetes an. Sie zerlegten ihn überdies in einen stärkeren, muerrückt in grösserer Ferne bleibenden, und einen schwächeren verschiebbaren Stab. Diese Einrichtung bezweckte, die sehr feine Verstellbarkeit im Azimuth unnöthig zu machen, deren der stärkere Stab bedarf, wenn nu er ta ist. ${ }^{1}$ Ich habe bei früherer Gelegenheit diesen Kunstgriff gelobt, ${ }^{2}$ glaube aber jetzt, dass derselbe Zweck besser erreicht wird, indem man einen recht kräftigen Stab aus entsprechend grosser Ferne wirken lässt. Dabei bleibt die Proportionalität der Richtkraft mit kleinen Ablenkungen sicher gewahrt. Dass dies bei Meissner's und Merenstemn's Anordnung in gleichem Maasse der Fall sei, wäre erst noch zu beweisen. Sobald aber diese Anordnumg nicht umbedingt Nutzen bringt, erscheint sie als nicht zu billigende Verwickelung.

Die Stellung des Stabes senkrecht über dem Magnet hat den Fehler, dass der Stab mit der Aufhängung des Magnetes zusammentrifft, woraus allerlei Schwierigkeiten entspringen. Ich brachte deshalb den Stab senkrecht unter dem Magnet an, ${ }^{3}$ indem ich ihn [760] an einer rom Grundbrett der Bussole herabsteigenden Leiste rerschiebbar machte. Anch diese Anordnung hat ihre Nachtheile. Das Consol muss durchbohrt sein, nm die Leiste durchzulassen, und man kamn die Bussole nicht ans der Hand setzen, wo nicht, wie etwa zwischen zwei Tischen, Raum für die abwärts sich erstreckende Leiste ist.

Aber noch eine andere Rïcksicht macht sich hier geltend. Ist einmal die Entfernung des Stabes gefunden, für die $n=\varepsilon$ ist, so hat man lange Zeit daran nichts zu ändern. Zwar würde bei genaner Beobachtung die tägliche Variation der Intensität sich in einer Schwankmng jenes $\mathbf{A b -}$ standes aussprechen, unter den gewöhnlichen Umständen ist indess ihr Einfluss rerschwindend. Noch weniger kamn Aenderung eines Abstandes des Stabes nöthig werden, für den $n<\varepsilon$. Dagegen an der Stellung des Stabes im Azimuth hat man fortwährend zu ändern, weil wegen der

1 Henle's und Pfeufer's Zeitschrift für rationelle Medicin. 3. R. 1861. Bd. XI. S. 194. - Poggendorff's Annalen u. s. w. 1861. Bd. CXIV. S. 132.

2 S. oben'S. 156.

3 s. die schematische Figur oben s. 31 . 
täglichen Schwankung der Declination Nullstrich der Scale und Faden nur zu bestimmter Tageszeit sich decken. Diese Str̈rung wird um so bedeutender, je kleiner $n$, also je mehr $\varepsilon n$ übertrifft. Innerhalb gewisser Grenzen hilft man sich durch Verschieben der Scale, ${ }^{1}$ doch kommt, wenigstens bei meinen Torrichtungen, ein Punkt, wo dies nicht mehr geht, und wo nichts übrig bleibt, als durch Drehung des Stabes im Azimuth mittels der dazu bestimmten Mikrometerschraube den Spiegel wieder senkrecht auf die durch den Nullstrich der Soale gehende optische Axe des Ferurohres zu stellen. Es empfiehlt sich überhampt, jedesmal bei Beginn der Arbeit diesen Zustand herbeizuführen. Ohne Hülfe ist dies ein sehr mühseliges Geschäft. Man muss zwischen Fermrohr und Bussole vielleicht zehmmal hin- und hergehen, um seinen Zweck doch minder vollkommen zu erreichen, als wenn man vom Fermrohr aus den Stab bewegen könnte.

Ich habe daher die Einrichtung getroffen, dass die Stellumg des Stabes im Azimuth rom Sitzplatz am Fermohr aus durch einen Schnurlauf beherrscht wird, der mittelbar den Kopf der Nikrometerschraube dreht. Es würde nun natürlich nicht angehen, den Zug des Schmurlanfes auf einen langen, mit der Bussole selber verbundenen Hebel wirken zu lassen, wie die den Stab tragende Leiste [761] ihn vorstellt. Man würde die Bussole erschüttern, vielleicht sie ron der Stelle rücken.

Ich trennte deshalb die den Stab tragende Leiste rom der Bussole. und befestigte sie am Consol. Es fehlt in der That an jerlem Grunde dafür, den Stab mit der Bussole zu verbinden. Was aber die Stellung des Stabes zum Magnete betrifft, so zeigt folgende Betrachtung, dass anch hierin die frühere Einrichtung rerfehlt war.

Jede für den Hatr'schen Stah passende Lage muss dreierlei leisten: der Stab muss die Richtkraft des Magnetes um den nöthigen Betrag vermindern, $^{2}$ dabei aber die mittlere Declination, und, wenigstens bei kleinen Ablenkungen, das Gesetz, wonach die Richtkratt mit der Ablenkung wächst, unverändert lassen. Alle diese Lagen kommen darin überein, dass der Stab im magnetischen Meridiane sich befindet; übrigens zerfallen sie in zwei Systeme, und zwar hahen diese die beiden Lagen

1 S. oben S. 156.

2 Da dieser Betrag einen sehr ansehnlichen Theil, keinesweges ein Differential der Richtkraft vorstellt, lassen sich die von Gauss gegebenen „Vorsehriften zur Berechnung der magnetischen Wirkung, welche ein Nagnetstab in der Ferne ausübt* (Resultate aus den Beobachtungen des magnetisehen Vereins im Jahr 1840. Leipzig 1841. S. 26 ; - C. F. Gauss Werke u. s. w. Göttingen 1867. $4^{0}$. Bd. V. S. 427) hier nicht anwenden, wie Hr. Meissner zu glauben scheint (Henle's und Pfeufer's Zeitschrift u. s. w. A. a. O. S. 195). 
über und unter dem Magnet, in denen bisher der Stab sich befand, "mit einander gemein.

Man denke sich Stab und Magnet im magnetischen Meridian, ihre magnetischen Axen horizontal, ihre Mittelpmite in passendem Abstand in einer Senkrechten, den Stab über oder unter dem Nagnet. Das erste System von Lagen entsteht, indem der Stab, sich parallel, um den Magnet geführt wird, so dass sein Mittelpunkt um den des Magnetes einen auf der Dechinationsebene senkrechten Kreis beschreibt. Man sieht leicht, dass das rom Stab auf den Magnet wirkende horizontale Kräftepaar in jedem Punkte des Kreises dasselbe bleibt. Befinden sich Stab und Magnet in der Horizontalebene, so wird der Magnet, durch Abstossung des Stabes, etwas rom Loth abgelenkt; wie er, bei senkrecht über oder unter dem Magnet befindlichem Stabe, gleichsam beziehlich et- [762] was schwerer oder leichter wird. In den Zwischenlagen verbinden sich beide Wirkungen in wechselndem Verhältniss. Die Erfahrung lehrt aber, dass immerhalb der für uns geltenden Grenzen der Genauigkeit überhaupt nichts darauf ankommt.

Es giebt somit für uns keinen Grund, den Stab gerade über oder unter dem Magnet anzubringen, und die darans erwachsenden Schwierigkeiten lagen in einer zufälligen und willkürlichen Lösung der Aufgabe, nicht in dieser selber. Jede Stellung des Stabes, welche einem Punkte des bezeichneten Krreises entspricht, leistet für unseren Zweck dasselbe. Es ist nicht einmal nöthig, dass die Verschiebung des Mittelpunktes des Stabes im Radius jenes Kireises geschehe. Man kamn z. B., ohne irgend einen namhaften Vortheil anfzugeben, die den Stab tragende Leiste auf der Fläche des Consols horizontal so befestigen, dass der Mittelpunkt des Stabes in einer clurch den Aufhängefaden gehenden Aequatorialebene liegt. Dies erreicht man, indem man bei noch nicht fest angezogenen Schrauben die Leiste sich parallel verschiebt, bis im Fernrohr Nullstrich und Faden sich decken, wie ohne Stab. Freilich misst nun die Theilung auf der Leiste nicht mehr unmittelbar den Abstand des Stabes vom Hagnete, sie dient aber ohnehin mehr dazu, den Stab um bestimmite Grössen rerschieben und ihm dieselbe Entfernung wiedergeben zu können.

Anstatt den Mittelpunkt des sich parallelen Stabes einen Kreis in der Aequatorialebene beschreiben zu lassen, kam man anch dem Stab in der Declinationsebene, nördlich oder südlich rom Magnet, darüber oder darunter oder in gleicher Höhe, mit horizontaler oder geneigter Axe jede Stellung geben, bei welcher er auf den Magnet umgekehrt wie die Erde wirkt. So entsteht das zweite, riel mannigfaltigere System für den Stab zulässiger Lagen. Bis das Elektro-Galranometer mich verleitete, den Mittelpunkt des Stabes in eine Senkrechte mit dem des Magnetes 
zu* bringen, arbeitete ich mit einem so aufgestellten Stabe, und neuerlich hat Hr. VIктоR von Lang bei dem von ihm gebauten "Spiegelgalvanometer mit regulirbarer Dämpfung" diese Auordnung vorgezogen. ${ }^{1}$ Einen entscheidenden Grund für Aufstellung des Stabes mit seinem [763] Mittelpunkt in der Declinations- oder der Aequatorialebene giebt es nicht, und man wird sich bei der Wahl zwischen beiden Ebenen durch Rücksichten der Bequemlichkeit leiten lassen, wie die Oertlichkeit sie vorschreibt. Aber auch bei Wahl der Dechinationsebene empfiehlt es sich, den Stab von der Bussole getrennt am Consol zu befestigen, natürlich so, dass jetzt der Stab der Leiste parallel liegt.

Die Befestigung des Stabes am Consol hat den Vortheil, dass der Zug des Schnurlaufes unschädlich wird, da er nur noch das Consol trifft. Die Einzelheiten des Mechanismus, durch den vom Sitzplatz aus der Stab im Azimuthe gedreht wird, lassen sich ohne Abbildungen nicht verdeutlichen. Es genüge zu sagen, dass neben dem Beobachter eine Scheibe am Arbeitstisch sich befindet, deren Drehung mit der Hand durch den Schnurlauf auf den Kopf der Mikrometerschraube mittelbar sich überträgt. Die Bewegung wird dabei so rerkleinert, dass auch für $\varepsilon$ ansehnlich $>n$ Nullstrich und Faden leicht zur Deckung gebracht werden.

\section{§. IV. Sir Wiblam Thomson's aperiodische Magnete ohne Dämpfung.}

Zu den in der ersten Abhandlung aufgezählten Versuchen, Schwingungslosigkeit der Magnete mechanisch herbeizuführen, ${ }^{2}$ ist noch der des Hrm. Neunans in Königsberg zu zählen, welcher an der rerlängerten Axe der Bussolnadel eine in Oel schwimmende Korkscheibe befestigte. ${ }^{3}$ Unter allen denen aber, die mit solchen Versuchen sich befassten, hat wohl den glücklichsten Griff Sir WrLiam Thomson mit seinen nemen aperiodischen Bussolspiegeln gethan. ${ }^{4}$ Dies sind äusserst leichte Glasspiegel, an deren Rückseite ein Stück Uhrfeder klebt. Sie hängen an einem ganz kurzen Faden in einer äusserst engen flacheylindrischen Kammer, [764] in der sie nur zu ganz geringen Ausschlägen Raum

1 sitzungsberichte der Kais. Akademie der Wissenschaften zu Wien. II. Abth. Jahrg. 1873. Bd. LXVII. S. 101.

2 S. oben S. 321.

3 S. Wild, Die Neumann'sche Methode zur Bestimmung der Polarisation u. s. w. In der Vierteljahrsschrift der Naturforschenden Gesellschaft in Zürich. 2. Jahrg. Zürich 1857. S. 236. 237.

4 Vergl. Wiedenaxs, Die Lehre vom Galvanismus and Elektromagnetismus. 2. Aufl. Braunschweig 1872. Bd. I. S. 262 . 
§. 4. Sir William Thomson's aperiodische Magnete ohne Dämpfung. 367

haben. Thre Bewegung wird aperiodisch durch den verhältnissmässig sehr grossen Luftwiderstand, den sie vermöge der Enge der Kammer und ihrer eigenen geringen Masse erfahren. Thre Beruhigungszeit ist nur ein Bruch einer Secunde. Sie sind nicht für Beobachtung mit dem Fernrohre bestimmt, sondern zum Zurückwerfen eines Lichtstrahles auf die von mir beschriebene Art. Es muss also auch dahingestellt bleiben, ob ihre Bewegung streng aperiodisch ist, oder nur dem unbewaffneten Auge so erscheint. Da die Gesetze dieser Bewegung unbekannt sind, wird man für genaue galvanometrische Versuche wohl die durch Dämpfung erzeugte Schwingungslosigkeit vorziehen. Doch zweifle ich nicht, dass Sir Willian Thomson's spiegel durch die ungemeine Geschwindigkeit ihrer Anzeigen, wie bei der Telegraphie, auch in gewissen Gebieten thierisch-elektrischer Versuche vortreffliche, ja kaum anders zu erlangende Dienste leisten würden. 
XV.

\section{Ueber aperiodische Bewegung gedämpfter Magnete.}

\section{Vierte Abhandlung.}

(Gelesen in der Sitzung der physikalisch-mathematisehen Klasse der Königl. Akademie der Wissensehaften zu Berlin am 14. December 1874.) ${ }^{1}$

§. I. Warum es an gewissen Bussolen misslang, den Magnet in brauchbarer Weise aperiodisch zu machen.

Verschiedene Beobachter klagten mir, dass es ihnen nicht gelungen sei, den aperiodischen Zustand der Bussolmagnete, wie ich ihn schildere, herzustellen. Bei fortgesetzter Annäherung des Stabes sei der Magnet² umgeschlagen, ohne dass Schwingungslosigkeit erreicht wurde, oder wenigstens diese sei erst bei einem Abstand des Stabes eingetreten, der sich kaum von dem unterschied, wo der Magnet umschlug; eine Lage, wobei, wenn überhaupt, doch nicht mit Tortheil zu arbeiten war, während ich die Verschiebung des Stabes ron dem Punkt, wo Schwingungslosigkeit eintrat, bis zu dem Punkt, wo der Magnet umschlug, bei meinem leichten Spiegel auf $25^{\mathrm{mm}}$, bei meinem schweren noch auf $5^{\mathrm{mm}}$ angebe. ${ }^{3}$

Um den Fehler aufzudecken, der diesem Terhalten zu Grunde lag, muss man auf die ursprüngliche Bedingung der Schwingungslosigkeit zurückgehen.

Bezeichnet man nach GAuss mit $2 \varepsilon$ die rerzögernde Kraft der Dämpfung für die Einheit der Geschwindigkeit, mit $n^{2}$ die magnetische Richtkraft für die Einheit der Ablenkung, beide diridirt durch das Trägheitsmoment $\boldsymbol{M}$, so ist die Bedingung der Schwingungslosigkeit, dass

1 Monatsberichte der Akademie u. s. w. 1874. S. 767.

2 Unter Magnet sehlechthin verstehe ich liürzehalber hier stets den beweglichen Magnetspiegel, oder Magnetring mit Glasspiegel, unter Stab sehlechthin den festen, der Erdkraft entgegenwirkenden Haux'schen Magnetstab.

3 s. oben S. 311. 
$\varepsilon \overline{>} n$ sei. Entwickelt man die Werthe ron $\varepsilon$ und $n$, so kummt diese Bedingung darauf zurück, dass

$$
x^{2} \mathrm{~m}^{\prime}\{l+4(H-S)\}^{3}>4 m^{\prime}\left(H-S^{\prime}\right) M
$$

sei. ${ }^{1}$ Hier bedeuten

[768] * eine Constante, welche unter anderen die Inductionsconstante und das Leitrermögen des Dämpfers zu Factoren hat;

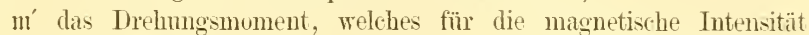
Eins auf den Magnet ansgeübt wird durch eine Strömung im Dämpfer, wie sie der Magnet bei seiner Winkelbewegung erzengt;

$\iota$ die permanente,

" die durch die Einheit einer horizontalen Kraft inducirte Intensität des Magnetes;

$H$ die horizontale Componente des Erlmagnetismus;

$S$ die horizontale Componente des Magnetismus des Stabes;

$m^{\prime}$ das Moment des Magnetes für parallele Krräfte bei der Intensität Eins.

Jene rergeblichen Bemühungen, Schwingungslosigkeit herbeizufülıren, fanden an SACERWALD'schen Bussolen statt. $x, \mathrm{~m}^{\prime}, \boldsymbol{m}^{\prime}, \boldsymbol{M}$ hatten also merklich denselben Werth, wie an meinen Bussolen. $H$ war in den in Betracht kommenten Grenzen anch dasselbe. y ist überhampt kleiner, als dass Schwankungen seines Werthes so grossen Einfluss üben könnten, wie er hier stattfand. Der Fehler, den wir snchen, kamn also nur an $\iota$, oder $\boldsymbol{S}$, oder beilen haften.

Für $S=0$, d. h. ohne Stah, ist an gewrihnlichen Bussolen die linke Seite der Bedingungsgleichmng (1) wohl stets die kleinere. Nur mit SrEvers'schen Glockenmagneten wurde sie bisher grüsser gefunden, als die rechte. ${ }^{2}$ Durch Wachsen ron $S$ nimmt die rechte Seite, wegen Kleinheit von $\imath$, viel schneller ab als die linke, daher beim Annähern eines himreichend kräftigen Stabes die rechte Seite erst gleich der linken, damn kleiner wird. Sind beile Seiten einander gleich, oder ist $\varepsilon=n$, so tritt Schwingnngslusigkeit ein. Wir wollen den Werth $S$, der $\varepsilon=n$ macht, mit $S_{1}$ bezeichnen, den Abstand der Nitte des Stabes ron der Mitte des Magnetes, wobei $S=S_{1}$, mit $r_{1} . \quad S>I I$ bedingt Umschlagen des Magnetes; der Werth $S=I I$ heisse $S_{2}$, der entsprechende Abstand des Stabes $r_{2}$. Wird der Stab noch weiter genähert, so besteht bis zu einem gewissen Werthe ron $S$, der $S_{3}$ heissen mïge, und bei einem Abstande $r_{3}$ stattfindet, Schwingmngslosigkeit fort. Sie hört erst anf, wem die rechte Seite der Bedingungsgleichnng ihrem abso- [769]

1 S. oben S. 306.

2 s. oben S. 354 .

E. du Bois-Reymond, Ges, Abh. I. 
luten Werthe nach wieder die grössere wird. Dies wird rerhältnissmässig früh geschehen, weil jetzt die negativ gewordene inducirte Intensität $\eta$ $(H-S)$ von der permanenten Intensitït $\iota$ sich abzieht. Der ganze Spielramm schwingungsloser Astasie liegt also eigentlich zwischen den Werthen $S_{1}, S_{3}$, oder den Abständen $r_{1}, r_{3}$. In der Ausübung hätte es aber keinen Sim, den Stab dem Magnet über $r_{2}$ hinaus zu nähern, und wir kömnen uns mit der Betrachtung dessen begnügen, was bis zu diesem Punkt, oder bis zu $S=S_{2}=H$, geschieht. Unter Spielraum schwingungsloser Astasie ist daher im Folgenden nur der zwischen den Werthen $S_{1}$, $S_{2}$ oder $r_{1}, r_{2}$ eingeschlossene Spielraum rerstanden.

Der Fehler, den wir zu ergründen streben, bestand nun sichtlich darin, dass der Unterschied $\delta=r_{1}-r_{2}$ zu klein war: denn da beim Annähern des Stabes der Magnet umschlug, lag dieser Fehler keinenfalls darin, dass $S$ nicht gross genug gemacht werden konnte.

Zmuächst ist zu bemerken, dass einem gleichen Unterschiede $S_{1}-S_{2}$ ein rerschiedener Unterschied $\delta=r_{1}-r_{2}$ entsprechen kann.

Stellen wir uns, der Einfachheit halber, ror, die Dimensionen unserer Magnete rerschwänden gegen $r_{1}, r_{2}$, so dass die Gauss'schen Formeln für Fernwirkung ron Magneten anwendbar wären. Dann lässt sich $S$ gleichsetzen einer Constanten $\mathfrak{M}$ (dem Momente des Stabes multiplicirt mit einer trigonometrischen Function), dividirt durch $r^{3}$. Wächst $\mathfrak{M l}$, während

$$
S_{1}=\frac{9 \Re}{r^{3}{ }_{1}}, \quad S_{2}=\frac{\mathfrak{M} i}{r^{3}{ }_{2}}
$$

beständig bleiben, so wachsen auch $r_{1}, r_{2}$. Mit anderen Worten, ein stärkerer Stab bewirkt Schwingungslosigkeit und Umschlagen des Magnetes aus grösserer Ferne als ein schwächerer.

Wir bezeichnen nun ferner mit $r_{1}^{\prime}, r_{2}^{\prime}$ die Abstände, in denen beziehlich Schwingungslosigkeit und Unschlagen des Magnetes durch einen anderen längs derselben Geraden genäherten stärkeren Stab bewirkt werden, für den die Constante $9 \mathfrak{J}^{\prime}$ an Stelle ron $9 \mathfrak{X}$ tritt. Sind $S_{1}^{\prime}, S_{2}^{\prime}$ die zugehörigen $S$, und ist $\delta^{\prime}=r_{1}^{\prime}-r_{2}^{\prime}$, so hat man

und

$$
\begin{aligned}
& S_{1}=\frac{\mathfrak{M} i}{r^{3}{ }_{1}}=S_{1}^{\prime}=\frac{\mathfrak{M} \mathcal{X}^{\prime}}{r_{1}^{\prime}{ }^{3}}, \\
& S_{2}=\frac{\mathfrak{M}}{r^{3}{ }_{2}}=S_{2}^{\prime}=\frac{\mathfrak{M} \mathcal{C}^{\prime}}{r_{2}^{\prime}{ }^{3}}
\end{aligned}
$$

$$
\frac{\delta^{\prime}}{\delta}=\sqrt[3]{\frac{3 \mathfrak{M \ell ^ { \prime }}}{\mathfrak{M \lambda}}}
$$

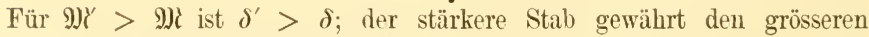
Spielraum schwingungsloser Astasie. 
Unter den vorausgesetzten Bedingungen wird also Schwäche des Stabes einen Einfluss der Art üben, wie wir ihn zur Erklärung des fraglichen Verhaltens brauchen. In Wirklichkeit freilich ist $r$ kleiner, als dass obige Formeln genau zuträfen. Doch ist Grund anzunehmen, dass auch die rerwickelte Function der Entfernung, nach welcher die Wirkung des Stabes in grösserer Nähe wächst, noch die Eigenschaft habe, dass $\delta^{\prime}>\delta$ sei. Andererseits scheint es kaum, als ob dieser Umstand der Grösse nach zur gesuchten Frklärung reiche. Ausdruck (2) lehrt, dass wenigstens bei grösserem Abstand ein $8 \mathrm{mal}, 27 \mathrm{mal}$... schwächerer Stab nur einen beziehlich $2 \mathrm{mal}$, $3 \mathrm{mal}$.... kleineren Spielraum schwingungsloser Astasie gewähren würde. Solche Schwäche des Stabes kommt nicht vor, während jener Spielram an den Vorrichtungen, deren Fehler ums beschäftigt, viel kleiner war, als nur zwei oder dreimal so klein, wie an der meinigen. Es ist nicht wahrscheinlich, dass in grösserer Nähe dies Verhältniss sich um so viel günstiger für unseren Erklärungsversuch gestalte. Doch wird man wohl daran thun, auf möglichst starke Magnetisirung des Hacr'schen Stabes zu achten, schon deshalb, weil bei der grösseren Entfernung, aus der ein stärkerer Stab noch kräftig genug wirkt, die Proportionalität der Tangenten der Ablenkungen mit den Stromstärken besser gewahrt bleibt.

Ein anderer Grund, weshalb $\delta=r_{1}-r_{2}$ zu klein ausfällt, kann nun aber zweitens darin liegen, dass die Werthe $S_{1}, S_{2}$ zu nahe zusammenfallen. Für $S=S_{2}=H$ verschwindet die rechte Seite der Bedingungsgleichung; die linke behält den Werth $\varkappa^{2} \mathrm{~m}^{\prime{ }^{4}} \iota^{3}$, der dem ursprünglichen nur um die kleine Grösse $\eta^{3} H^{3}$ nachsteht. Für $S=S_{2}$ $=H$ ist die linke Seite also die grössere, einen wie kleinen endlichen Werth man auch 'm' und ı zuschreihe. Dies [771] heisst so viel, wie dass bei Gegenwart auch des schwächsten Dämpfers auch der schwächste Magnet durch Ammähern des Stabes nicht zum Umschlagen gebracht werden kann, ohne wenigstens in der Theorie durch den schwingungslosen Zustand zu gehen. Gleichheit beider Seiten der Bedingungsgleichung wird aber durch Wachsen von $S$ schon bei um so grösserem $H-S$, d. h. um so kleinerem $S_{1}$ erreicht, mit anderen Worten, der Spielraum schwingungsloser Astasie wird um so grösser, je grösser die permanente Intensität des Magnetes ı. Un so mehr ist dies der Fall, als deren dritte Potenz in's Spiel kommt.

Natürlich ist stets ein so kleiner Werth von ı möglich, dass, wie gross auch $\varkappa$ und $\mathrm{m}^{\prime}$ seien, die linke Seite der Gleichung die grössere wird, erst wemn $H-S$ fast rerschwindet. Der verschwindenden Intensität ` entspricht aber damn nur ein rerschwindender Unterschied 
372 XV. Ueber aperiodische Bewegung gedämpfter Magnete. - Abh. IV. -

$\delta=r_{1}-r_{2}$, und so wird der schwingungslose Zustand, wenn nicht unfassbar, doch unbranchbar.

Dies ist, mehr oder weniger genan, die Lage, die sich jenen Beobachtern bot. Der Fehler ihrer Vorrichtung bestand wesentlich darin, dass aus irgend einem Grund der Magnet nicht himreichende permanente Intensität besass.

Ohne erst den Tersuch zu machen, Schwingungslosigkeit herbeizuführen, erkennt man schon an der Art, wie bei Abwesenheit des Stabes der Magnet in einem bekamnten Dämpfer schwingt, ob er hinlänglich stark sei. In einer SAUERWALD'schen Bussole sollte das logarithmische Decrement eines Magnetspiegels dünnster Art (ron etwa $0.8 \mathrm{~mm}$ Dicke) nicht kleiner sein als $0 \cdot 7$, das eines Magnetringes mit Glasspiegel nicht kleiner als $0 \cdot 4$, wobei ein Durchmesser des Magnetes rorausgesetzt ist, der ihm nur eben im Dämpfer frei zu schwingen erlaubt. Beim Fallenlassen von 500se ist dann im ersten Falle die vierte, im zweiten die siebente Schwingung kleiner als $1^{\text {se }}$. Ein einziger Ablenkungsrersuch genügt also, um über Brauchbarkeit des Magnetes in seinem zeitigen Zustande sich zu unterrichten. Man hüte sich, mit einem schwächeren, also minder stark sich dämpfenden Magnete zu arbeiten. Je näher $=\boldsymbol{I I}$ man $S$ machen muss, um Schwingungslosigkeit zu erzielen, um so mehr wächst die Beruhigungszeit ${ }^{1}$ des Mag- [772] netes, und un so grösser werden die Schwankungen seiner Gleichgewichtslage bei Tariation des Erdmagnetismus (s. unten §. III).

An anders gebauten Instrumenten könnte einerseits zu grosser $\mathrm{Ab}$ stand des Magnetes rom Dämpfer und sonst mangellufte Beschaffenheit des letzteren, also zu kleiner Werth von $x$ und $m$, andererseits zu grosses Trägheitsmoment $\boldsymbol{M}$ dieselbe Rolle spielen, wie bei passendem Wrerthe dieser Constanten zu geringe Intensität des Magnetes.

\section{§. II. Fortgesetzte Bemerkungen über die beste Art, den HAUY'schen Stab aufzustellen.}

Fig. 2S zeigt die jetzt ron mir angenommene Aufstellumg des Stabes. Der Stab NS ron quadratischem Querschnitt hat $250 \mathrm{~mm}$ Länge und $12 \cdot 5^{\mathrm{mm}}$ Seite. Sein eines Ende $S$ ist mittels der Schranbe $b$ in einer Gabel festgeklemmt, die sich um die Axe as dreht. Sein anderes Ende $N$ ruht zwischen einer Mikrometerschraube ron $0.5 \mathrm{~mm}$ Gangweite, deren Kopf durch die Schmurscheibe IV rorgestellt wird, und einem federnden Knopfe, welcher der Schraube entgegenwirkt. Löst man die Klemm- 
schraube b, so kann man den Magnet innerhalb gewisser Grenzen in der Gabel hin und her schieben, oder ihn ganz aus seinem Lager entfernen, in welehes er natürlich auch umgekehrt passt.

Das Lager des Magnetes rerschiebt sich mit einer Hülse lüngs einer kräftigen Messingschiene, die in aequatorialer Richtung wagerecht rom Consol vorspringt, an welchem sie mittels einer Zwinge aus Rothguss mit zwei Schrauben befestigt wird. Aus räumlichen Rüchsichten musste in

Fig. 28.

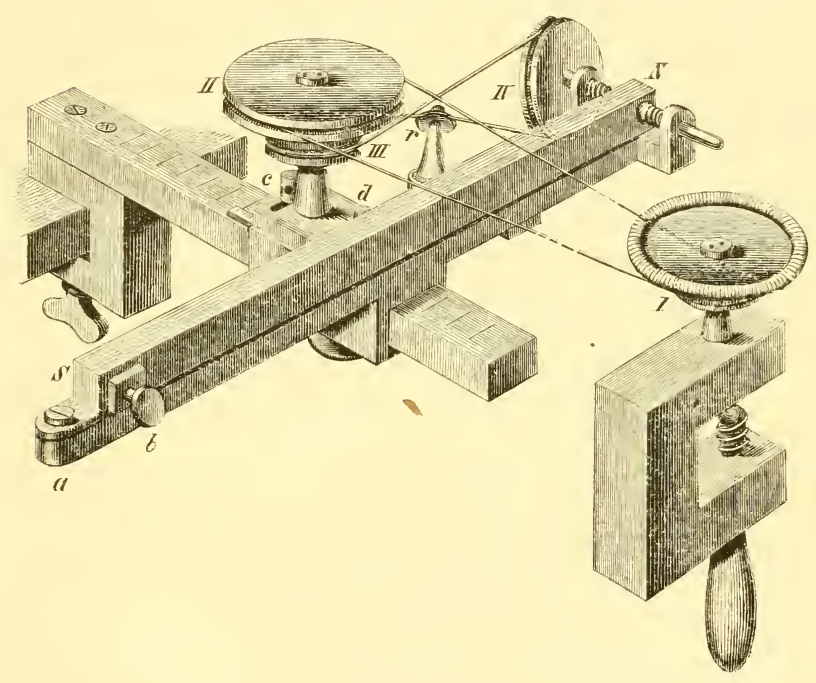

der Zeichnung die Schiene verhältnissmässig zu kurz, das Consol zu dünn und die Zwinge zu klein vorgestellt werden, wie auch ron den beiden Schrauben der Zwinge nur eine abgebildet ist. Die obere Fläche der Schiene ist in Centimeter getheilt, und an dem, dem Consol zugewandten Ende der Hülse befindet sich ein in Millimeter getheilter unächter Nonius; die Hülse kann mittels der unterhalb sichtbaren Schraube festgestellt werden. Un Platz für Befestigung der Schiene am Consol zu haben, 
wird rom Grundbrett der Bussole das Ende mit den zwei Stellschrauben dem Stabe zugekehrt.

Die übrigen in der Figur sichtbaren Organe dienen, von des [773] Beobachters Platz am Fernrohr aus den Stab im Azimuth zu drehen. Die Zwinge mit Schnurscheibe I ist in des Beobachters Reichweite in irgend einer ilm bequemen Lage am Tischrand, einem Tischbein u. d. m. festgeklemmt. Bei der Entferuung zwischen den Scheiben I und II kommt es auf einen mässigen Höhenunterschied der Scheihen so wenig an, wie auf Kreuzung ihrer Ebenen. Damit nicht gegen den durch das Zimmer gespannten Schmurlauf angerannt werde, behängt man ihn mit Papierbögen. Unterhalb Scheibe II trägt dieselbe Axe eine kleinere Schnurscheibe III, die durch einen Schuurlauf mit Scheibe $\mathrm{TV}$ verbunden ist. Der dem Beschaner zugekehrte Schenkel dieses Schnurlaufes liegt in einer gemeinschaftlichen, dem Stabe parallelen Tangente an beiden Scheiben; der Deutlichkeit halber erhielt er in der Zeichnung etwas [75] andere Richtung. Der andere Schenkel läuft über eine Leitrolle $r$, deren unter $45^{0}$ gegen den Horizont geneigte Axe in einer senkrechten Ebene liegt, welche mit der Ebene der Scheibe IV einen Winkel ron $45^{\circ}$ bildet. Dies erlaubt, trotz der Kürze des Schnurlaufes, die Scheiben ohne Schaden zu kreuzen. Löst man Schraube $c$, so kann man den Träger der Scheiben II, III um eine senkrechte Axe bei $d$ drehen, und so die über III und IV gehende Sclmur spamnen.

Die Schmurscheiben bestehen aus Kamimmasse. An meinem Exemplare rerhält sich der Durchmesser von I zu dem ron II etwa wie $1: 2$, der ron III zu dem ron $\Pi$ etwa wie $6: 7$. Um Scheibe I feiner hewegen zu können, ist sie mit einer grösseren ränderinten Scheibe von $54^{\mathrm{mm}}$ Durchmesser versehen. Wird letztere um ein Stäck ihres Umfanges ron $1^{\mathrm{mm}}$, entsprechend einem Winkel von etwas über $2^{0}$ gedreht, so beträgt die Verschiebung der Mikrometerschraube etwas über $0 \cdot 00125^{\mathrm{mm}}$, entsprechend einer Winkelhewegung des Stahes um Axe as ron etwas über $1^{\prime \prime}$.

So sicher und zart arbeitet diese Vorrichtung, ${ }^{1}$ dass die sonst so empfehlenswerthe Verschiebung der Scale in ihrer eigenen Verlängerung dadurch fast entbehrlich wird. Man kömte allein mittels der Schnurläufe Nullstrich und Faden ror jedem Versuche zur Deckung bringen. Es ist aber doch zweckmässig, die Verschiebbarkeit der Scale beizubehalten, weil sie schneller wirkt, als Verstellung des Stabes, was oft wichtig ist.

Die in Abh. III empfohlene seitliche Aufstellung des Stabes hat sich

1 Sie wird von der Plath'schen (Sauerwald'schen) Werkstatt der WiedeMaNN'schen Bussole auf Verlangen beigegeben. 
im Allgemeinen sehr gut bewährt. Doch ist in einigen Fällen ein Uebelstand dabei hervorgetreten, an den ich nicht gedacht hatte. Bei dem Systeme von Lagen nämlich, wo Stab und Magnet in derselben senkrechten Ebene sich befinden, ${ }^{1}$ ist gleichgültig, ob beide Enden des Stabes gleich stark magnetisch sind oder nicht. Auch wemn sie es nicht sind, bleibt der Magnet in der Declinationsebene, wenn der Stab selber darin sich befindet; und nur seine Richtkraft, nicht seine Richtung, wird verändert. Anders ist es bei dem Systeme ron Lagen, wo zwar die Axen des [775] Stabes und des Magnetes einander parallel sind, und die Mitten beider Axen in derselben aequatorialen Ebene, diese Mitten aber nicht in derselben senkrechten Ebene sich befinden. Sobald der Stab nicht symmetrisch magnetisirt ist, und in aller Strenge ist er es nie, macht sich dies durch Ablenkiung des Nagnetes aus der Declinationsebene bemerkbar.

Bleibt diese Ablenkung innerhalb gewisser Grenzen, so hat sie nichts zu bedenten. Ohne Weiteres kamn man sie nicht einmal unterscheiden von den Ablenkungen, die daraus entspringen, dass es unmöglich ist, die magnetische Axe des Stabes durch mechanische Nittel genau in die Declinationsebene zu bringen, und dass, weun dies zufällig gelänge, sie wegen Variation der Declination nur einen Angenblick darin bliebe. Durch passende Drehung des Stabes im Azimuth, nöthigenfalls durch Verschiebung des Stabes in seiner Verlängerung, bringt man Faden und Nullstrich wieder zur Deckung, wie bei Abwesenheit des Stabes.

Es kamn aber zwischen den Wirkungen beider Enden des Stabes anch solcher Unterschied rorkommen, dass die zur Verstellung des Stabes im Azimuth und der Länge nach verfügbaren Wittel nicht reichen, die Wirkungen gleichzumachen. Dam bleibt nur übrig, den Stab besser zu magnetisiren. Sollte bei völliger Sättigung dessen eines Ende eine in der Natur des Stahles begründete Ueberlegenheit zeigen, so müsste man dies Ende durch Verkehrtstreichen schwächen.

Der senkrecht unterhalb des Magnetes befindliche Stab, mit dem ich die Versuche in Abh. I und III anstellte, war $200^{\mathrm{mm}}$ lang, und sein Querschmitt ein Rechteck von etwa $20 \mathrm{~mm}$ Höhe und $10^{\mathrm{mm}}$ Breite. Mit dem jetzigen Stabe, dessen rerlängerte Bahn $80^{\mathrm{mm}}$ unter dem Mittelpunkte des Magnetes hindurchgeht, und dem Magnetspiegel I der Abh. I beträgt der Abstand zwischen den Punkten der Bahn des Stabes, welche den Werthen ron $S_{1}, S_{2}$ entsprechen, über $40 \mathrm{~mm}$. Mit dem alten Stabe betrugen dabei die Entfernungen $r_{1}, r_{2}$ beziehlich etwa 300 und $275^{\mathrm{mm}}$;

1 S. oben S. 364.365 .

2 S. oben S. 311. 
mit dem jetzigen Stab entspricht $S_{1}$ ein Abstand ron $360, S_{2}$ ein solcher ron $325^{\mathrm{mm}}$. Ich brauche kaum zu bemerken, dass letztere Zahlen nicht mehr wie Entfernungen $r_{1}, r_{2}$ anzusehen sind, da die Ter- [776] schiebung des Stahes nicht in der Verbindungslinie zwischen seiner Mitte und der des Magnetes geschieht.

§. III. Ton den Schwankungen der Gleichgewichtslage des Magnetes in Folge der täglichen Variation des Erdmagnetismus, oder den "Variationsschwankungen". ${ }^{1}$

Die tägliche Variation der Declination beträgt in Berlin gegenwärtig im grössten Monatsmittel $15 \cdot 8^{\prime}$. Bei $2 \cdot 5-3^{\mathrm{m}}$ Abstand der Scale rom Spiegel ist $1^{\text {sc }}=41 \cdot 25-34 \cdot 38^{\prime \prime}$. Die tägliche Variation beläuft sich folglich bei uns auf höchstens etwa $25-30^{*}$. In höheren Breiten beträgt sie etwas mehr, in niedrigeren etwas weniger. Sie hätte also wenig zu sagen, würde sie nicht durch Abstossung seitens des iu der ursprïnglichen Declinationsebene rerharrenden Stabes vergrössert, und das bei hoher Astasie in sehr störendem Maasse.

In Fig. 29 ist $n s$ der Nagnet, NS der astronomische, II $\$$ der magnetische Meridian oder die Horizontalprojection der zeitigen Declinationsebene. Der Stab befinde sich in solcher Lage, dass seine Wirkung auf den Magnet gleich der des Erdmagnetismus durch ein der Richtung des Stabes paralleles Kräftepaar vorgestellt wirl. $N \Sigma$ bezeichne die Horizontalprojection der Ebene, der dieses Kräftepaar parallel ist, und mit der, wie wir anmehmen wollen, ursprünglich auch die Declinationsebene zusammenfiel. $\quad I I$ und $S$ stellen beziehlich die horizontalen Kräfte der Erde und des Stabes ror. Winkel $\varphi$ misst dam die Zumahme der Declination, die beispielsweise stattfand, und Winkel $\alpha$ den Betrag, um welchen der Stab die Gleichgewichtslage des Magnetes weiter nach West von der nenen Declinationsebene drängt. Man hat

$$
\begin{gathered}
I \sin \alpha=S \sin (\alpha+\varphi), \\
\operatorname{tg} \alpha=S \sin \varphi \\
H-S \cos \varphi
\end{gathered}
$$

oder, da of klein ist,

$$
\operatorname{tg} \alpha=\frac{S}{H-S} \cdot \varphi \sin 1^{\prime} .
$$

Dieser Ausdruck zeigt erstens, dass die Schwankung der Gleich-

1 Die hier vorkommenden Angaben über die Variationen des Erdmagnetismus verdanke ich der Gefälligkeit des Hydrographen der Kaiserl. Admiralität, Hrı. Dr. Neumayer. 
gewichtslage des Magnetes in Folge der Variation der Declination, der Variation nahe proportional erfolgt. Man sollte zum Aufstellen der Bussole und des Fernrohres mit der Scale daher entweder die Tageszeit wählen, wo man am meisten arbeitet, oder die Stunden, wo mittlere Declination herrscht, also die Zeit zwischen 10 und 11 Uhr Vormittags oder zwischen 8 und 9 Chr Abends.

Uebereinstimmend mit der Erfahrung lehrt zweitens unsere Formel, Fig. 29.

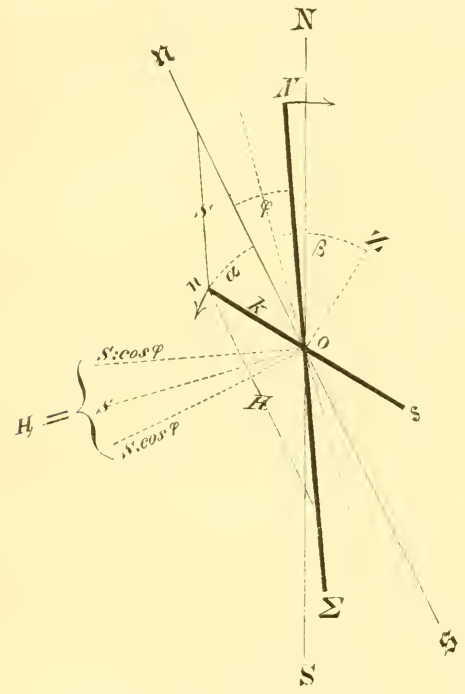

dass die Schwankung um so grösser ist, je grösser die Astasie. Für $H=S$ ist $\alpha=90^{\circ}$ auch für den kleinsten Werth von $\varphi$. Daraus erklärt sich das reissend schnelle Wandern des Null- [778] punktes bei hoher Astasie, welches nichts ist als die im Verhältniss ron

$$
\varphi+\operatorname{arctg}\left(\frac{S}{H-S} \cdot \varphi \sin 1^{\prime}\right): \varphi,
$$

wo $S: H-S$ sehr gross ist, sehr vergrösserte Variation selber.

Man sieht endlich drittens, dass auch die Variation der horizontalen 
Intensität des Erdmagnetismus, welche $\lrcorner H$ heissen möge, nicht ohne Einfluss auf den Stand des Magnetes bleibt. $\Delta H$ beträgt jetzt bei uns höchstens $0.0015 H$. Sobald indess $\Delta H$ nicht gegen $H-S$ rerschwindet, bedingt positives $\Delta H$ Abnahme, negatires Zunahme ron $\%$. Die Intensitätsschwankungen werden also erst bei höheren Graden der Astasie Einfluss üben, dann aber eine rasch wachsende Bedeutung erlangen. Die Stunden, wo die Declination durch ihren Mittelwerth geht, folgen sehr nah auf die, wo die Intensität am kleinsten und am grössten ist, und die Mittelwerthe der Intensität gehen denen der Declination um 3-4 Stunden rorauf. Man kann daher die Aufstellung der Bussole nicht zugleich den besten Bedingungen in Bezug auf Declination und in Bezug auf Intensität anpassen.

Das Zeichen ron $\alpha$ ist dasselbe wie das ron $\varphi$, und für ein negatires oder östliches $q$ stellt sich der Magnet östlich ron der Ebene $N$ 工. Die Intensitätsschwankungen dagegen wirken stets nur im entgegengesetzten Sinne ron den durch Nähern oder Entfermen des Stabes herrorgerufenen Veränderungen ron $S$.

Hr. Prof. Y. Hexsen in Kiel hat mir brieflich den simmreichen Vorschlag gemacht, den Haư'schen Stab in einem starken Dämpfer, der ihn zugleich ror Luftströmungen schützte, aufzuhängen, damit er die Deelinationsschwankungen mitmache. Die Aufhängung müsste so sein, dass trotz der Inclinationsschwankungen der Stab horizontal bliebe. Befände sich der Stab über oder mnter dem Magnet, so kömnte man, um seinen Abstand zu ändern, ihn am Faden oder Draht anf- und abwinden. Der Dämpfer müsste durch andere Mittel entsprechend bewegt werden.

Die durch Variation der Declination bedingten Schwankungen des Magnetes würden so freilich auf das Maass der Variation selber, $d . h$. auf $q$, eingeschränkt. Nennt man die entsprechende Schwankung des Stabes $\psi$, so würde

$$
\operatorname{tg} \alpha=\frac{S}{H-S}(\varphi-\psi) \sin 1^{\prime} .
$$

Für $\psi=$ \& ist $\operatorname{tg} \iota=0$, und also auch die Intensitätsschwankungen hören auf, Einflüss zu üben. Ausgenommen ist nur der Fall $H=S$; dann wird $\alpha$ für $\psi=\varphi$ umbestimmt, und eine Intensitätsschwankung kann wieder den Magnet bewegen, indem sie die Unbestimmtheit anfhebt.

Leider ist zu bemerken, dass die Torsion eines Fadens oder Drahtes, der stark genug wäre, den Stab zu tragen, da man sie nur für eine bestimmte Declination Null machen könnte, $q-\psi$ doch wohl schon einen Werth ertheilen würde, der bei höherer Astasie die alten Störungen mit sich brïichte. Daron abgesehen kann ich für meinen Theil nicht 
nöthig finden, so umfängliche Anstalten zur Bekämpfung der Variationsschwankungen $\mathrm{zu}$ treffen. Ich begnüge mich überhaupt gern mit dem geringsten Maasse schwingungsloser Astasie, da kürzeste Beruhigungszeit (s. oben S. 372) mir wichtiger scheint als grösste Empfindlichkeit. Bei diesem Zustande, wo $\varepsilon=n$, sind die Variationsschwankungen noch recht gut zu ertragen. Bei höherer Astasie, wo ich dieser nicht entbehren konnte, habe ich jene Schwankungen bisher durch Terschiebung der Scale, nenerlich durch Drehung des Stabes im Azimuth von meinem Platz am Fernrohr aus, erfolgreich bekämpft. Zuletzt kommt freilich ein Punkt, wo das Arbeiten mit anderen als kurz danernden Strömen unmöglich wird.

§. IV. Ton der Gleichgewichtslage des Magnetes bei höherer Astasie.

Formel (3) hat noch weiteres Interesse. Setzt man darin $q=0$, $H=s$, so wird $\iota$ mbestimmt, der Magnet ist wahrhaft astatisch; er muss in jedem Azimuth stehen bleiben, in welches änssere Kraft ihn führte.

Versucht man aber, dies zu beobachten, so misshingt es. Nicht bloss in dem Simn, in welchem ich (S. oben S. 308. - Vergl. S. 290. 311.) sagte, die Beobachtung rermöchte aus Gründen, welche keiner Ausführung bedürften, den Zustand völliger Astasie nicht zu erfassen. Ich dachte mir dabei, dass es unthunlich sei, den Magnet durch alle möglichen Stellungen imnerhalb des Kreisumfanges zu führen, und sich zu überzengen, dass er in allen stehen [780] bleibe; unthunlich zu prüfen, ob er im Dämpfer wirklich gleich einem Körper sich bewege, dem das umgebende Mittel einen seiner Geschwindigkeit proportionalen Widerstand entgegensetat.

Allein der Zustand rölliger Astasie entzieht sich der Beobachtung anch noch, weil es in Wirklichkeit nicht dazu kommt. Man kam rielleicht $S$ so nahe gleich $H$ machen, dass die übrig bleibende Richtkraft Luftwiderstand und Torsion nicht mehr zu überwinden vermag. Was man aber nicht kam, ist, die magnetische Axe des Hauy'sehen Stabes der Declinationsebene durch mechanische Mittel parallel stellen. Wemn man anch den Stand des Magnetes ohne Stab abliest, so schnell wie möglich den Stab himzubringt, und mittels der Schmurläufe Faden und Nullstrich wieder zur Deckmng bringt, so hat sich, abgesehen von Fehlem der Ablesung und Einstellung, in der Zwischenzeit die Declination doch rerändert, und $\varphi$ einen endlichen Werth erlangt. Nur mittels des von Hrn. Hexsen angegebenen Kunstgriffes, und selbst damn nur bei absolut verschwindender Torsion, wäre und bliebe $\varphi=0$. 
In der That, obige Betrachtungen über Gleichgewichtslage eines Magnetes, anf den ein der Declinationsebene nicht paralleler Stab wirkt, passen, wie anch Fig. 29 und Formel (3), völlig auf den Fall, den wir uns jetzt denken wollen, dass Winkel $\varphi$ nicht mehr bloss durch Tariation der Declination, sondern zugleich durch mechanische Unvollkommenheit unserer Vorrichtungen entstand.

Um Ausdruck (3) in vielen Fällen leichter zu discutiren, wie auch aus später einleuchtenden Gründen, empfiehlt sich folgende Umformung. Statt des ron der zeitigen Declinationsebene $\| \$$ aus gerechneten Winkels $\alpha$ betrachten wir den Winkel $\beta$ zwischen der $q$ hälftenden Geraden und der in Fig. 29 gleichsam als Zeiger nach Nordost weisenden Senkrechten $0 Z$ auf die Mitte 0 des Magnetes. Man hat

$$
\begin{gathered}
\alpha=90^{\circ}-\left(\beta+\frac{q}{2}\right), \alpha+\varphi=90^{\circ}-\left(\beta-\frac{q}{2}\right), \\
\operatorname{tg} \beta=\frac{H-S}{H+S} \cot \frac{q}{2} .
\end{gathered}
$$

oder am bequemsten für die Discussion

$$
\operatorname{tg} \beta=\left(\frac{2 H}{H+s}-1\right) \cot \stackrel{p}{2}
$$

[781] $H=S$, oder so vollkommene Astasie, wie sie durch absolute Abgleichung der auf den Magnet wirkenden entgegengesetzten Richtkräfte zu erreichen ist, macht $\beta$ nicht unbestimmt, sondern $=0$. Der Magnet stellt sich also dam so ein, dass $0 Z$ den Winkel $\boldsymbol{q}$, seine Axe aber den supplementären Winkel zu $q$, $\mathfrak{H}_{0} \mathbf{\Sigma}$, zwischen den unbezeichneten Polen der Erde und des Stabes hälftet. Setzt man $I I \cos \varphi=S$, so wird $\beta=\frac{\varphi}{2}$, der Magnet steht senkrecht auf dem Stabe. Setzt man $H=S \cos \varphi$, so wird $\beta=-\frac{\varphi}{2}$. der Magnet steht senkrecht auf der zeitigen Declinationsebene, wahrhaft aequatorial. Wächst $S$ weiter, so nähert sich $\operatorname{tg} \beta$ der Grenze $-\cot \frac{\varphi}{2}$, für $S=\infty$ steht der Magnet mit nach Süd gerichtetem bezeichneten Pole dem Stabe parallel.

In der Ausübung wird es sich immer nur um kleine Werthe von of handeln. Doch gelten unsere Formeln natürlich für jeden Werth ron of, und des theoretisehen Zusammenhanges wegen sei Folgendes bemerkt. Für ein endliches of und für $S=H$ ist $\operatorname{tg} \beta=0$, es ist also $\alpha$ dann $=90^{\circ}-{ }_{2}^{q}$, und den Werthen von $f$ ron $0^{\circ}$ bis $90^{\prime}$ entsprechen Werthe ron $\%$ von $90^{\circ}$ bis $45^{\circ}$. Mit anderen Worten, wird bei $S=H$ der Stab aus seiner nahe axialen in die aequatoriale Lage gedreht, so 
weicht der Magnet von seiner nahe aequatorialen Lage bei $\alpha=90^{\circ}$ - $\frac{q}{2}$ zurück auf $\alpha=45^{\circ} . \quad H \cos \varphi=s$, d. h. für $\psi=90^{\circ}$ $S=0$, macht $\alpha=0 ; H=S \cos q$, d. h. für $q=90^{\circ} S=\infty$, macht $\%=90^{\circ}$.

Abh. III. S. 365 wurde gesagt, die richtende Wirkung des Stahes bleibe dieselbe, wem in aequatorialer Ebene die Vitte des Stabes eimen Kreis um die des Magnetes beschreibe, gleichriel also oh der Stab senkrecht muter oder über dem Magnet, oder seitlich in gleicher Hühe mit ihm sich befinde. Dies ist strenge richtig aber nur, wenn die Axe des Stahes der des Magnetes parallel oder $\varphi=0$ ist. Für $q=90^{\circ}$ trifft vielmehr der erste Fall zusammen mit dem ersten, der zweite mit dem zweiten der bekannten Gauss'schen Fälle, ${ }^{1}$ d. h. im zweiten Fall ist $S$ doppelt so [782] gross wie im ersten. Werthen von q zwischen $0^{\circ}$ und $90^{\circ}$, wie auch für $\varphi=90^{\circ}$ Lagen des Stabes zwischen jenen heiden, werden Werthe rom $S$ zwischen dem Einfachen und Doppelten entsprechen.

An jeder Bussole mit rerschiebbarem Haur'schen Stab ist es leicht, den geschilderten Hergang im Groben zu beobachten. Nähert man den Stab über die oben S. 369 mit $r_{1}$ bezeichnete Entfernung, wo $\varepsilon=n$, dem Magnet immer mehr, so kommt ein Punkt, wo der Magnet anfängt, sichtlich rom Meridian abzuweichen. Dies geschieht entweder so, dass der Nordpol durch Ost, oder so, dass er durch West nach Süd sich dreht; hierauf werden wir noch zurückkommen. Bei fortgesetzter Ammäherung, die sich meist nur nach Bruchtheilen eines Millimeters bemisst, stellt sich der Magnet scheinbar aequatorial. Natürlich ist es bei kleinem und überdies umbekanntem, ja wegen der Variation fortwährend sich reränderndem $\varphi$ unmöglich, die Stellmgen $\beta=+\frac{\varphi}{2},=0,=-\frac{f}{2}$ zu unterscheiden. Bei noch mehr genähertem Stabe steht der Magnet mit seinem Nordpol im südöstlichen oder südwestlichen Quadranten, je nach dem simn, in welchem er sich dreht; schliesslich füllt bei rerkehrten Polen seine Lage scheinbar wieder mit dem Meridian zusammen. Es ist daher im Grunde nicht richtig, rom Umschlagen des Magnetes bei fortgesetzter Annähermg des Stabes zu reden. Er schlägt nur um, wenn man beim Annähern des Stabes die Reihe von Lagen dieses letzteren überspringt, für welche der Iagnet eine entsprechende Reihe ron

1 Intensitas vis magneticae etc. In C. F. Gauss Werken u. s. w. Göttingen 1867. 4. Bd. V. S. 107; - Poggendorff's Amalen u. s. w. 1833. Bd. XXVIII. S. 601. 602; - Resultate aus den Beobachtungen des magnetischen Vereins im Jahre 1s:66. Göttingen $1 \times 37$. S. 73. 7 . 
Stellungen durchläuft, die ihn folgweise aus seiner ursprünglichen axialen durch die aequatoriale in die entgegengesetzte axiale Lage führen.

Bei den zahlreichen Anwendungen, die man von der Haux'schen Methode des Astasirens machte, ${ }^{1}$ wurde die Abweichung [783] des hoch astatischen Magnetes aus der Declinationsebene gewiss schon früher wahrgenommen. Man vermuthete aber dabei zufällige Ursachen, welche die Oberhand über die sehr verminderte Richtkraft gewönnen, als da sind Torsion, Luftströmungen, versteckte Mittelpunkte magnetischer Wirkung. Niemand hatte meines Wissens bemerkt, dass bei wachsender Astasie der Magnet röllig regelmässig sich dreht, und dass er aus der aequatorialen Lage abgelenkt langsam, doch treu, in sie zurückkehrt.

Auch ich hatte, wie ich bekemnen muss, rersäumt, mich über das Verhalten, welches der Magnet bei möglichster Gleichheit ron $H$ und $S$ in der Wirklichkeit zeigt, genaner zu unterrichten. Hr. Hensen war es, der mich auf die aequatoriale Stellung des Magnetes bei höchster Astasie aufmerksam machte. Er sah darin einen Widerspruch mit meiner oben S. 308 angeführten Aeusserung in Abh. I, dass der Zustand rölliger Astasie unfassbar für die Beobachtung sei. Doch ist kein solcher Widerspruch da, denn ich setzte damals die idealen Bedingungen wahrhafter Astasie voraus, also auch absoluten Parallelismus der magnetischen Axe des Stabes mit der Declinationsebene. Jetzt wurde es mir um so leichter, das von Hru. Hensen wahrgenommene Verhalten aus mangelhaftem Parallelismus von Stab und Declinationsebene abzuleiten, als ich gerade mit den Variationsschwankungen des Magnetes beschäftigt war.

Auch Hr. Dr. Aron hierselbst hatte jenes Verhalten beobachtet. Er hatte aber auch dessen Beziehung zur freiwilligen Ablenkung astatischer Nadelpaare schon erkamnt. Denn es ist klar, dass die hier auftretende Ablenkung des Magnetes aus dem Meridiane bei höherer Astasie die nämliche Erscheinung ist, wie die einst ron mir so genamnte freiwillige Ablenkung astatischer Nadelpaare, deren Entdecker Nовші sie sogleich auf mangelhaften Parallelismus der Nadeln zurückführte. ${ }^{2}$ Setzt man für $H$ das Moment $\boldsymbol{M}$ der stärkeren, für $S$ das Moment $\boldsymbol{M}^{\prime}$ der schwächeren Nadel, so werden obige Formeln buchstäblich einerlei mit den bekannten Ausdrücken für die Gleichgewichtslage eines astatischen Nadelpaares in der Gestalt, die ich ihnen gab. ${ }^{3}$ In diesen ist $q$ der [784] Winkel zwischen den freundlichen Polen der zum astatischen Paare

\footnotetext{
1 S. oben S. 157. Anm.

2 Untersuchungen u. s. w. Bd. 1. S. 169 ff.

3 S. oben S. 143 .
} 
verbundenen Nadeln, $\beta$ der Winkel, den die $\varphi$ hälftende Gerade mit dem magnetischen Aequator macht.

In der That, die drei Magnete (die Erde und die beiden künstlichen Magnete), deren zwei zu einem festen Systeme verbunden sind, bilden gleichsam eine kinematische Kette. ${ }^{1}$ Das Nadelpaar entspricht dem festrerbundenen Systeme der Erde und des Stabes. Jenes schwingt über der Erde, und stellt sich, wemn dïmpfende Einflüsse zugegen sind, schliesslich zu ihr, wie bei festgehaltenem Magnet, abgesehen von den Trägheitsmomenten, Erde und Stab um den Magnet schwängen, und zu ihm sich stellten. Oder bei festgehaltenem Nadelpaare schwänge unter ihm die Erde und stellte sich schliesslich zu ihm, wie zu Stab und Erde der unter ihrem Einfluss schwingende Magnet.

Um die Einerleiheit der Gleichgewichtshedingungen astatischer Nadelpaare und astatischer Magnete dentlicher hervortreten zu lassen, wurde oben $\beta$ so bestimmt, wie es geschah. Sonst lag es näher, was analytisch auf dasselbe hinanslïuft, hier mit $\beta$ den nach dem Aequator zu gelegenen Complementärwinkel zu $\alpha+\frac{\varphi}{2}(n 0 S$ in Fig. 29) zu bezeichnen.

Auf dem jetzt gewomnenen Standpunkt erscheint es im Grunde falsch, ron Astasie des Magnetes zu reden. Wie man durch Schwächung der im gesättigten Zustande stärkeren Nadel das System beider Nadeln in Bezug auf die Erde astasirt, so astasirt man eigentlich das System von Erde und Stab in Bezug auf den Magnet, indem man den Abstand des Stabes rom Magnet ändert. Je nachdem $H>$ oder $\langle S$, übernimmt im astatischen Systeme von Erde und Stab jene oder dieser die Rolle der Nadel vom grösseren Moment $\boldsymbol{M}$. Anstatt $S$ durch Aenderung des Abstandes zu ändern, könnte man auch, wie bei astatischen Nadelpaaren, das Moment des Stabes ändern, z. B., wie Hr. Hensen mir vorschlug, den Stahlstab durch einen Elektromagnet ersetzen, in dessen Windungen man den Strom abstufte. Dagegen nimmt die Intensität des Erdmagnetismus mit Entfernung von der Erdoberfläche zu langsam ab, $\mathrm{nm}$ anders als in der Idee ein bewegliches astatisches System [785] durch Ortsveränderung abzugleichen, wie dies für das System ron Erde und Stab durch Ortsveränderung des Stabes geschieht. Nichts verhindert sonst sich zu denken, dass man an eine lange senkrechte Axe unten, wo die horizontale Intensität $=\boldsymbol{H}$, eine Nadel vom Moment $\boldsymbol{M}^{\prime}$, und darüber eine Nadel von dem um ein $\frac{\boldsymbol{M}^{\prime}}{n}$ grösseren Moment $\boldsymbol{M}$ in solcher Entfermung von der Erdoberfläche befestigt habe, dass dort die

1 Vergl. Reuleaux, Theoretische Kinematik. Braunschweig 1875. 
Intensität um $\frac{H}{n+1}$ kleiner sei. Das System wäre damn su rollkommen astatisch, wie Winkel of und die temporären Momente es gestatten.

Bei den astatischen Narlelpaaren kommen nämlich, nach Hru. SAuERWALD's Beobachtumg, die durch die Erde inducirten temporären IIomente der Nadeln in Betracht. ${ }^{1}$ Hier sind die temporären Momente, die der Iagnet in Stab und Erde erzeugt, zu vernachlässigen. Das bei höherer Astasie an sich rerschwindende temporäre Moment aber, welches Erde und Stab im Magnet erzeugen, fällt aus dem Ausdruck für seine Gleichgewichtslage ebenso heraus, wie nach GAuss' Bemerkung ${ }^{2}$ sein permanentes Moment. Dasselbe gilt ron den durch das astatische Nadelpaar in der Erle erzengten temporären Moment, abgesehen daron, dass dies rollends zu rernachlässigen ist. Ich rede nicht weiter ron den temporären Momenten, welche Erde und Stab, und welche die beiden Nadeln in einander herrorrufen. ${ }^{3}$ Das Wegfallen der tempurären Momente rereinfacht sehr die Gleichgewichtsbedingungen des astatischen Magnetes, wie wir zu sagen doch fortfahren wollen, gegenüber denen des astatischen Nadelpaares. Man kommt daher hier ohme die graphische Darstellung der auf den entwickelten Kreisumfang aufgetragenen Kräfte aus, die beim astatischen Nadelpaare so gute Dienste leistet. ${ }^{4}$ Wie bei diesem, wenn die temporären Momente als verschwindend betrachtet werden, entspricht der einen stabilen [786] Gleichgewichtslage des astatischen Magnetes eine um $180^{\circ}$ taron entfernte labile Gleichgewichtslage. ${ }^{5}$

Ein zweiter Punkt, in welchem das astatische Nadelpaar und das hier betrachtete System ron einander abweichen, ist der, dass dort y eim für allemal gegeben, hier mit der Declination veränderlich ist. In Folge dessen ist die Gleichgewichtslage des astatischen Nadelpaares auch im Zustand höchster Astasie von den Tariationen des Erdmagnetismus ninder abhängig als die des astatischen Magnetes. Das astatische Nadelpaar emptindet die Variation der Intensität gar nicht, die der Dechination nur deren wirklichem Betrage gemäss. Es sei dem, dass die Gleichgewichtslage des Nadelpaares noch durch andere Kräfte bedingt werde, wie z. B. durch Anzichung der Drahtmassen. Damn kamm Vergrössermmg

1 S. oben S. $137 \mathrm{ff}$.

2 Schummacher's astronomisches Jahrbuch. 1836. S. 25; - Resultate aus den Beobachtungen des magnetischen Vereins im Jahre 1836. Göttingen 1837. S. 75 ; - C. F. Gauss Werke u. s. w. Göttingen 1s67. 4. Bu. V. S. 330.

3 s. oben s. $1+t$.

4 s. Taf. IV. Fig. 2.

5 S. oben S. 143 ; - Taf. IV. Fig. 3. V. 
der durch Tariation der Dechination hedingten S'chwankmo stattfinden, wie auch Variation rer Intensität wieder Einfluss gewimnt.

In Uebrigen kehren die Besonderheiten, welche die freiwilligen Ablenkumgen astatischer Natelpare bieten, bei den astatischen Magneten wieder. Wie dort ist es auch hier, und aus denselben Gründen, um so leichter, den Magnet sich scheimbar aequatorial stellen zu sehen, je grösser $q$ innerhalb gewisser Grenzen ist. Je kleiner $\frac{\text { q }}{2}$, mm so grössere Teränderungen von to $\beta$ entsprechen gleichen Fortschritten der Astasie, so dass der geringsten weiteren Ammäherung des Stabes, wie sie ohne besondere Hülfsmittel müglich ist, schon ein Sprung des Magnetes über den Aequator folgt. ${ }^{1}$ Wird aber of absichtlich über Gebühr gross, $=90^{\circ}$, gemacht, so erreicht, wie wir uben S.380.381 sahen, der Magnet für $\Pi=S$ nm noch die $45^{\circ}$-Stellung, und nur ein mnendliches $S$ kamn ihn bis zum Aequator drängen. Die Schwierigkeit, welche es jetzt hat, den Magnet aequatorial zu stellen, liegt jedoch in etwas Anderem, als die bei rerschwindendem $\varphi$.

Ein astatisches Nadelpaar dreht sich bei wachsender Astasie so, dass der stets rorhandene kleine Winkel $a$ zwischen Meridian und stärkerex Nadel wächst. Dem entsprechend dreht sich bei wachsender Astasie der Magnet so, dass er sich weiter ron der [787] Declinationsebene entfernt. In Fig. 29 dreht sich daher beim Nähern des Stabes der Nordpol des Magnetes im Simme des Pfeiles durch West nach Süd. Die Drehung ändert ihren Simn, und der Nordpol geht hei Nähern des Stabes durch Ost nach Süul, wemn das Nurdende des Stabes westlich ron der Declinationsebene liegt. Durch den Simm, in welchem der Magnet sich dreht. wird man belehrt, auf welcher Seite der Declinationsebene die Wirkungsebene des Stabes liegt, was sonst schwer zu ermitteln wäre. So erfährt man erst durch den Sinn, in welchem ein astatisches Nadelpaar sich dreht, auf welcher Seite der stärkeren Nadel Winkel of liegt.

Befindet sich der Stab in solcher Nähe des Magnetes, dass dieser schon merkich aus dem Meridian abweicht, und dreht man den Stab im Azimuth, ohne seinen Abstand zu ändern, so dreht sich der Magnet mmgekehrt wie der Stab, wie die Pfeile in Fig. 29 zeigen, während er bei Drehung der Declinationsebene gleichsinnig mit dieser sich dreht (s. oben S. 378). Beim Drehen des Stabes durch die Declinationsebene kommt freilich ein Punkt, wo of $=0$ ist und der Magnet für $H>s$ im Meridian bleiben, für $I=S$ überall im Gleichgewicht sein sollte. Allein es braucht kaum wiederholt zu werden, dass menschliche Werk-

1 S. oben S. 136.

E. du Bois-Reymond, Ges, Abh. I. 
zenge und Geduld nicht rermögen, diesen Punkt zu treffen und festzuhalten.

Alles dies lässt sich an jeder SAUERWALD'schen Bussole mit rerschiebbarem Stabe beobachten, an welcher, wie es früher der Fall war, der Stab senkrecht unter dem Magnete sich befindet. Bei der neuen in Fig. 29 abgebildeten Aufstellung des Stabes dagegen dreht sich beim Drehen des Stabes im Azimuth der Magnet im entgegengesetzten Simme vou dem durch die Theorie rerlangten, d. h. im gleichen Simne, wie der Stab. Der Grund dieser Abweichung ist folgender. Obige Schlüsse setzen solche Entfernung des Stabes voraus, dass dessen Wirkung durch ein dem Stabe paralleles Kräftepaar ersetzt werden könne. Soll dies auch bei grösserer Nähe des Stabes gelten, so muss dessen Drehung so stattfinden, dass die Entfernung seiner Pole ron den Polen des Magnetes, und die Richtung der Wirkung ersterer auf letztere für den einen Pol dieselbe bleibe, wie für den anderen. Damit dies zutrefte, muss der verlängerte Aufhängefaden des Magnetes durch die Mitte der Axen des Magnetes und des Stabes gehen, und des letzteren Drehung um die Terlängerung des Fadens geschehen. Schon bei der älteren [788] Art. del Stab aufzustellen, ist diese Bedingung insofern unvollständig erfüllt, als der Stab nicht $u$ die Mitte seiner Axe, sondern um einen seinem einen Pole nahen Punkt der Axe sich dreht. Doch wird hier der Fehler nicht gruss genug, um das gesetzmässige Terhalten zu rerdecken. Bei seitlicher Stellung des Stabes aber rerändert man bei dessen Urehung um Axe a $S$ (Fig. 2S) die Entferuung des einen Poles $(\boldsymbol{N})$ rom Magnete, während der andere $(S)$ nahe unverrückt bleibt. Geschähe die Drehung um die Mitte des Stabes, so würde sich der eine Pol sogar rom Magnet entfernen, während der andere ihm sich näherte. Die abstossende Wirkung des beispielsweise genäherten Poles des Stabes auf den ihm näheren Pol des Magnetes überwiegt aber die des stehenbleibenden, rollends des noch weiter fort bewegten Poles, daher der Iagnet in demselben Simne wie der Stab sich dreht.

Die Drehung in diesem Falle ist somit anderen Ursprunges. als die oben aus den Formeln abgeleitete, welche unter richtigen Bedingungen richtig affolgt. Da beide Drehumgen einander entgegengesetzt sind, so muss es eine mittlere Stellung des bis zur Entfernung $r_{2}$ genäherten Stabes geben, wo bei einer gewissen Drehung des Stabes im Azimuth keine Mblenkung stattfindet. Liesse man die Mitte des sich selber parallelen Stabes in aequatorialer Ebene einen Viertelkreis um die Mitte des Magnetes beschreiben, so müsste man diese mittlere Stellung irgendwo treffen zwischen der Stellung des Stabes senkrecht unter dem Magnete, wo der Nordpol des Magnetes, bei Drehung des Nordendes des 
Stabes beispielsweise nach Ost, sich westlich stellt, und der Stellung zur Seite des Magnetes, wo bei derselben Drehung des Stabes der Nordpol des Magnetes sich östlich stellt. Doch habe ich noch nicht versucht, jene mittlere Stellung des Stabes in Wirkhichkeit zu beobachten, wozu besondere Vorkehrungen erforderlich wären.

Bei den astatischen Nadelpaaren der Multiplicatoren ist es längst Regel, sie durch Abgleichung ihrer Homente so senkrecht wie möglich auf den Meridian zu stellen, und ihmen mit den Windungen in diese Lage zn folgen. ${ }^{1}$ So ist man sicher, die höchste Astasie zn haben, die das System in Anbetracht des unvollkomme- [789] nen Parallelismus der Nadehn zulässt. Offeuhar erreichte man auch an unserer jetzigen Einrichtmo die höchste Astasie, welche der jedesmalige Winkel of zulässt, wenn man bei aequatorialer Stellung des Nagnetes arbeitete.

Die Gleichgewichtsgleichung des Magnetes ist erfüllt, wenn er in der Diagonale des Parallelogrammes einsteht, dessen Seiten man erhält, indem man auf den Projectionen der Wirkungsebenen von Erde und Stab, rom Schneidepunkt dieser Projectionen ans, II und $S$ proportionale Stücke abmisst (s. Fig. 29). Wird der Magnet ans dieser Lage $\mathrm{nm}$ einen Winkel $\pm o$ abgelenkt, so zieht ihn darin zurück eine Kraft $\pm k \cdot \sin \varrho$, wo $k$ der Länge jener Diagonale proportional ist. Man hat

$$
k=\frac{H \sin \varphi}{\cos \left(\beta-\frac{\varphi}{2}\right)} .
$$

Sind die Pole des Stabes denen des Nagnetes gleich gerichtet, und durchläuft $S$ die Werthe son 0 bis $\infty$, so durchläuft $\beta$ die Werthe von $\beta=+\left(90^{\circ}-\frac{\varphi}{2}\right)$ durch 0 bis $\beta=-\left(90^{\circ}-\frac{\varphi}{2}\right)$. Die entsprechenden Werthe ron $k$ gehen ron $k=H$ bis $k=\infty$, da bei endlichem $H$ nur ein unendhiches $S$ den Magnet dem Stabe parallel stellen kann. Dazwischen hat $k$, wie man sogleich sieht, bei $\beta=+\frac{f}{2}$ ein Minimum. Der Magnet ist also am beweglichsten, wenn senkrecht zum Stabe. $k$ ist hier $=I I \sin \%$. mithin die Astasie um so rollkommener, je kleiner $q$. Für $\beta=0 ; \beta=-\frac{\varphi}{2}$ wird beziehlich $k=H .2 \sin \frac{\varphi}{2}$; $k=H \cdot \operatorname{tg} \varphi$ u. s. w.

Für $\beta=+\frac{q}{2}$ folgt aus (4) $S=H \cos \varphi$. Dieser Werth von $S$, und nicht, wie man meinen sollte, $S=I I$, giebt grösste Empfind-

1 Untersuchungen u. s. w. Bd. I. S. 169. - Vergl. oben S. 146, 147 . 
lichkeit. Die Verschiebung der kürzesten Diagunale nach Nord beruht darauf, dass der Magnet zum Einstehen in den Meridian, weil dann keine Seitenkraft rorhanden ist $(S=0)$, durch eine endliche Krraft $(I I)$ gebracht wird, während zum Einstehen in die Ebene des Stahes, weil dann die Seitenkraft $I I$ rorhanden ist, ein unendliches $S$ gehört.

[790] Alles dies gilt auch für astatische Nadelpaare, wenn man das Moment $\boldsymbol{M}$ der stärkeren Nadel, welches an Stelle von $H$ in (5) tritt, beständig nimmt. Ein astatisches Paar ist am beweglichsten, wemn die schwächere Nadel im Aequator steht.

In der Ausübung sind diese Uuterschiede bedeutungslos, da man bei astatischen Nadelpaaren wegen Kleinheit ron $\boldsymbol{q}$, bei astatischen Magneten anch noch wegen dessen Teränderlichkeit und Tnbestimmbarkeit, kein Mittel hat, $\beta$ gerade $=+\frac{\varphi}{2}$ zn machen.

Auch ohnedies wird aequatoriale Stellung des Magnetes ungleich grössere Empfindlichkeit gewähren, als axiale. Frfahrung muss zeigen, ob diese Empfindlichkeit nicht zu thener erkauft wäre durch verlängerte Beruhigungszeit und vergrösserte Variationsschwankungen, denen völlig - rorzubengen, wie zu fürchten ist (s. oben S. 378), sogar der Hexsex'sche Kunstgriff nicht rermag.

Um bei aequatorialer Stellung des Magnetes zu arbeiten, muss selbstrerständlich die Bussole so aufgestellt werden, dass die Axe ihrer Rollen axial steht. 


\section{Zu s a t z.}

[Hr. Prof. Victor vos Lang in Wien hatte die Güte, mich darauf aufmerksam zu machen, dass die Besorgniss wegen zu grosser Variationsschwankungen des aequatorial gestellten Magnetes grundlos sei. Differenzirt man $\alpha$ nach $\varphi$, so erhält man (Gleichung (3))

$$
d \alpha=\frac{\cos (\alpha+\varphi) \sin \alpha}{\sin \varphi} \cdot d \varphi \text {. }
$$

Für $\alpha=90^{\circ}$ wird $d \alpha=-d \varphi, d(\kappa+\varphi)=0$. So wenig also würde der streng aequatorial, d. h. senkrecht auf die zeitige Declinationsebene gestellte Magnet durch zu grosse Variationsschwankungen unbranchbar, dass er diesen Schwankungen vielmehr ganz entzogen ist.

Die Bemerkung hätte mir nicht entgehen sollen, da man sie Formel (3) schon ohne Entwickelung von $\frac{d \boldsymbol{d}}{d \varphi}$ entnehmen kann. $H=S \cos \varphi$ macht $\alpha=90^{\circ}$, welchen endlichen Werth auch $\varphi$ habe; $\alpha$ bleibt also unverändert $=90^{\circ}$, ob auch \& schwanke.

Bei weiterer Discussion ron $\frac{d \varkappa}{d \varphi}=f(\alpha)$ nach $\alpha$ findet man (mit Wiederholung des schon für $\alpha=90^{\circ}$ Gesagten):

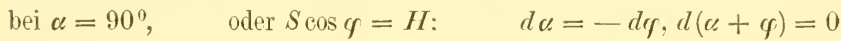

$$
\begin{aligned}
& \alpha=90^{\circ}-\frac{\varphi}{2}, \quad, \quad S=H: \quad d \alpha=-\frac{d \varphi}{2}, d(\alpha+\varphi)=\frac{d \varphi}{2} \\
& \alpha=90^{\circ}-\varphi,, \quad S=H \cos \varphi: d \alpha=0, \quad d(\alpha+\varphi)=d \varphi \\
& \alpha=0, \quad, \quad S=0: \quad d \mu=0, \quad d(\alpha+\varphi)=d \varphi .
\end{aligned}
$$

Also schon in der durch $\varphi$ gemessenen sehr kleinen Entfernung des Magnetes aus der aequatorialen Stellung - gerade in der Lage, welche grösste Empfindlichkeit bietet (s. oben S. 387) - macht der Hagnet die Schwankungen der Declinationsebene wieder vollständig mit, jedoch ohne dass sie durch Anwesenheit des Stabes vergrössert erscheinen.

Z wischen $\alpha=0^{\circ}$ und $=90^{\circ}-q$ findet ein Maximum der Function $f(\alpha)$ statt für $\cot 2 \alpha=\operatorname{tg} \varphi$ oder für $\alpha=45^{0}-\frac{\varphi}{2}$. Man hat 
$390 \mathrm{XV}$. Ueber aperiodische Bewegung gedämpfter Magnete. - Abh. IV. -

was $d(\mu+\varphi) z u$

$$
f(\kappa)_{\max }=\frac{1-\sin \varphi}{2 \sin \varphi},
$$

$$
\frac{\sin \varphi+1}{2 \sin \varphi} \cdot d \varphi
$$

macht. Damit $\boldsymbol{c}$ den Werth von $45^{\circ}-\frac{\Psi}{2}$ annehme, der in Bezug auf Variationsschwankungen somit als ungünstigster erscheint, muss

$$
\frac{H-S}{H+S}=\operatorname{tg} \frac{q}{2}
$$

sein, da nach Gleichung (4) damn $\beta=45^{\circ}, \operatorname{tg} \beta=1$ ist.

Ueber $\alpha=90^{\circ}$ hinaus wird $d(\alpha+\varphi)$ negatir, Stab und Erde haben gleichsam die Rollen vertauscht, indem ron $\alpha=90^{\circ}-\psi \mathrm{ab}$ die Erde den Magnet vom Stabe fort dem Aequator zu drängt. Bei $\alpha=135^{\circ}-\frac{\varphi}{2}$ findet ein negatires Maximum statt u. s. w.

Hr. vos Lang machte mich auch auf eine Anwendung der durch den Stab erzeugten Ablenkung aufmerksam, an die ich nicht gedacht hatte, nämlich um dem Magnet, behufs bequemerer Ablesung, eine beliebige, gewünschte Lage im Azimuth zu geben. Hr. vox LANG selber hat, was mir entgangen war, sich dieses Kunstgriffes längst in seinem 'Spiegelgalvanometer zur objectiven Darstellung' bedient. (Vergl. Exner in CarL's Repertorium für Experimental-Physik 11. s. w. München 1869. Bd. V. S. 8.)] 


\section{Register.}

Ablenkung, freivillige, astatischer Systeme, 132. 134. 146. - Deren Theorie nach Moser, 135. 138. - Nach Lloyd, 135. 138. 143. - Nach du Bois-Reymond, 139. 143. - Einerlei mit der Abweichung astasirter Magnete aus dem Meridian, 382. - Doppelsiunige Poggendorff's, 137.

Aequatoriale Stellung astatischer Nagnete, 379-389 (Abh. XV. §. 4).

Anaphorische Stromwirkung, 111. 120. 127. $128-130$.

Aperiodischer Zustand gedämpfter Magnete, 284-362 (Abh. XII. XIII. XIV. §. 1. 2, XV. §. 1).

Arbeitsraum, fenchter, 167. 168 (Abh. VIII. §. 7).

Astasiren, die drei Methoden des Astasirens, 306.

Astatische Nadelpaare, deren Theorie, 134-144 (Abh. VII). - Deren Herstellung, 146. 147. - Ursache der Schwankungen ihrer Gleichgewichtslage, 148. 149 .

Aron, Gleichgewichtslage astasirter Magnete, 382 .

Asbest, innerlich unpolarisirbar, 18. 21.

Arwoon'sehes Myographion von Harless und von Jendrássik, 272. 276.

Austrittsbausch, -ende, -hälfte, deren Polle beim äusseren secundären Widerstande, 87 .

Badeschuamm, innerlich polarisirbar, 20.
Barreswil und Rilliet, Wirkung des Chlorzinks anf Cellulose, 77.

Baumwolle, innerlich polarisirbar, 19. 20. Bäusche, balkenförmige, 7. - Sicherheits-, 7. - Keil-, 15. 89. - Art der Bereitung der Bäusche, 160. 161 (Abh. VIII. §. 4). Becquerel d. V.. Depolarisator, 76.

Becquered, Edmond, Leitungsfähigkeit des Kupfernitrats und Zinksulphats, 42 ; - verschiedener Elektrolyte, 77.

Bersz, W., Positive Polarisation, 6. 48. 59. - Fortsetzung der Untersuchungen über unpolarisirbare Elektroden, 75. Temporäre Magnetisirung harten und scheinbar bis zur Sättigung magnetisirten Stahles, 137. - Erklärung von Hipp's Erfahrung über das verschieden schnelle Ansteigen der Kraft von Elektromagneten bei Anwendung einer Kette und einer Sänle, die einen gleich starken Strom geben, 230. Messungen über den Verlauf der Induetionsströme, 235. 239. 250. 255.

Beins, Depolarisator zum Gebrauch bei thierisch-elektrischen Versuchen, 76.

BERJot's Amalgamirflïssigkeit. 159.

Bernstein, J., Versuch eine lineare Stromschwankung herzustellen, 207. Congruenzbedingungen der Anfangsund Endinduction, 256. - Verbesserung des Schreibehebels an Myographien, 275.

Beruhigungszeit aperiodischer Magnete, 308.

Bimsstein, innerlich polarisirbar, 17.18.Dessen secundärer Widerstand, 85. 95 . 
Biot und SAYart wenden bereits das Hauy'sche Verfahren an, um eine Nagnetnadel zu astasiren, 15\%.

Bluthuchen, innerlich unpolarisirbar, 18. 21. - Dessen secundärer Widerstand, 8.5. 86 .

Bosscha'scher Satz, dessen Anwendung in der Theorie des du Bois-Reymond'schen Compensationsverfahrens, 258.

C'hemische Reizung der Muskeln, Vorrichtung zu deren Beobachtung. 211 (Abh. VIII. §. 16).

Compensator, der runde, Vorrichtung zum Messen der elektromotorischen Kraft, 176-187 (Al). VIII. §. 11). - 257265 (Abh. X).

Congruenzbedingungen der Anfang- und Endinduction, 247-250.

Czermak, Glasspritzen als Zuleitungsgefässe, 164. - Myochronoskop, 223. - Elektriseher Froschsehenkeltanz, ebenda.

1) Avy, Humpiry, Widerlegung seiner Angabe, dass Färbung von Reagenzpapieren durch Ionen nur an Poldrähten stattfinde, 11.

Dämpfung durch das Multiplicatorgewinde, 150. - Aperiodischer Zustand gedämpfter Magnete, s. d. - Mechanische Dämpfung durch Oel, Wasser, Luft, 321. 366. 367 .

Doppelwippe, 267-269 (Abh. XI. §. 2). DRAPER, mechanische Dämpfung. 321.

Druch'ströme, beim Andrücken fenchter poröser Körper an Metalle. 27. 62.

$\mathbf{E}_{\text {CKhard, Einfluss, welchen auf die Grösse }}$ der durch eine Stromschwankung erzeugten Erregung die absolute Höhe der Ordinaten übt, zwischen denen die Schwankung stattfindet, 208. - Versuche am Zitterrochen, 215.

Eduund, die schliessungsinduetion übertrifft die Veffnungsinduction, 230. 313.
Eintrittsbausch, -ende, -hälfte, deren Rolle beim äusseren secundären Widerstande, si.

Eis, innerlich unpolarisirbar, 18.

Eiweiss, geronnenes Hühner-, innerlich polarisirbar, 18. - Dessen secundärer Widerstand, 82. 88. - Flüssigkeiten, mit welchen das Eiweiss seeundären Widerstand giebt oder nicht, 107.

Elektroden, gleichartige und unpolarisirbare, 42-79 (Abh. IV).

Elektrogalvanometer von Meissuer und Meyerstein, 156 .

Elehtrotransfusion am erregbaren Muskel, 126-130 (Abh. V. §. 13).

Erschütterungszuchungen am Schwaukungsrheochord, 205.

Exxer, Sigy., Leistung langer dünner und kurzer dicker Muskeln, 210.

F'allhammer, elektromaguetischer, Art ihn aufzustellen, 222.

Faradar, einseitige Hemmung der Multiplicatornadel, 45. - Erklärung des Einflusses des Verquickens auf den örtlichen Vorgang in den Säulen, $i t$.

Faserstoff; gerounen, innerlich polarisirbar, 18. 21. - Dessen secundärer Widerstand, $\rightarrow$ 5.

Federmyographion, 271-283 (Abh. XI. §. 4).

Federschlüssel, 267.

Fernwirkung der Hauptrolle des Sehlitteninductoriums, 233.

Fıск, АD., Pendelmyographion, 272. 276. 2s1. - Spiral-Pheotom, 281.

Flache Erregerpaare, 158.

Fliesspapier, innerlich polarisirloar, 19. 20.21.25. - Dessen secundärer Widerstand, 86. 57. 89. 95.

Froschpistole, 269. 271 (Abh. XI. §. 3). Froschunterbrecher, 215-227 (Abh. VIII. §. 19). - Anwendung zur Bestimmung der Muskelkraft und zur Wiederholung des Hermann'schen Versuches durch Rosenthal, 227.

Froschwecker zum Gebrauch bei Versucheu an elektromotorischen Fischen. 213--215 (Abh. IIIl. §. 15). 
Funke, O., chemisch reine Chlornatriumlösung efflorescirt nicht, 79.

Funke am Schlitteninductorium, Art ihn $\mathrm{zu}$ vermeiden, 232.

(Kalvani, elektrischer Froschschenkeltanz, 223.

Gauss, Vorschlag einer astatischen Doppelnadel mit Spiegelablesung, 157. 158. - Theoretische Alleitung des aperiodischen Zustandes gedämpfter Nagnete, 284. 306. 355. 368.

Gleichgewichtslagen der Magnete bei höherer Astasie, 379-390 (Abh. XV. §. 4 und Zusatz).

Glockenmagnete, ohne Astasirung aperiodisch, 353.

Giaduationsconstante eines Compensators, 261.

Grossunan, R., akustischer Tetanus, 170. Gyps, erhärterter, innerlich polarisirbar, 17.

Iförmige Anordnung balkenförmiger Bäusche, 13. 14 .

Haken zur unmittelbaren Reizung am Zuckungstelegraphen, 209.

HaLske, Unterbrecher (Veränderung des Wagner'schen Hammers), 169. Stellt fest (mit du Bois-Reymond) die Gestalt des Vorreiberschlüssels, 171; - des Compensators, 183. 263.

Hanf innerlich polarisirbar, 19. 20.

Harless, E., fenchter Rheostat, 188. Atwood'sches Myographion, 272.

Haux, erfindet das Verfahren eine Magnetnadel durch einen genäherten Magnetstab zu astasiren, 157.

Haux'scher Stab, beste Art ihn anzubringen, 363--366 (Abh. XIV. §. 3). 372-376 (Abh. XV. §. 2).

Heidenhain, meehanischer Tetanus, 169. 209.

Helmholtz, Polarisirbarkeit von Kupfer in Kupfersulphat, Silber in Cyansilberkaliumlösung, 44. - Setzt zuerst die objective Spiegelablesung mittels eines zuriickgeworfenen Lichtstrahles in's
Werk, 131. 132. 152. 153. - Seine Theorie der thierisch-elektrischen Ströme, 187. - Messung der Fortpflanzungsgeschwindigkeit der Reizung nach der Pouillet'schen Methode, 219. - Abänderung des Schlitteninductoriums, 231. - Zeitlicher Verlauf der Induction, 234.

Henry, Jos., stuft zuerst dureh Entfernung der Rollen von einander die Ströme eines Inductoriums ab, 168.Erklärung der verschiedenen Wirkung des Schliessungs - und Oeffnungsschlages, 229. - Versuch, sie gleichzumaehen, 230.

Hensen, V., Vorsehlag zur Verhütung der Variationsschwankungen, 378. - Gleichgewichtslage astasirter Magnete, 382.

Holz, innerlich polarisirbar, 18. 21. 26. 38. 39. - Secundärer Widerstand, 86. 95 .

Hydrophan, imnerlich polarisirbar, 17. 21. 26 .

Hydrothermoströme WILD's, 10.

Inductionsströme, voltaëlektrische, deren zeitlicher Verlauf, 22s-256 (Abh. IX).

$\mathbf{J}_{\ddot{A} G E R, \text { Nachweis der Ungleichartigkeiten }}$ metallischer (1)berflächen durch feuchtes Lakmuspapier, 74 .

Jendrássik, At w o o d'sches Myographion, 272.

Jürgensen, anaphorische Stromwirkung, 111. 120. 127, 128. 130.

Kálhstein, immerlich polarisirbar, 17.

Käse, Schweizer, innerlich unpolarisirbar, 18. 21.

Kataphorische Stromwirkung, 111. Am erregbaren Nuskel, s. Elektrotransfusion.

Kenp, Erfindet das Verquicken des Zinks in den Säulen, 74 .

Kinematische Kette zwischen der Erde und zwei künstlichen Magneten, 383.

Kinchноғғ, Stromnetz, 97. - Kirchhoff'sche Combination der drei Widerstände bei einer Nebenleitung, 244. 
KöLlikeR, conservirende Eigenschaft verdïnnter Chlornatriumlösung, 162. 163.

Kohle, innerlich polarisirbar, 22. 23. 26; nimmt keinen seeundären Widerstand an, 121.

Kreide, deren innere Polarisirbarkeit, 17. 18. 21. 27. - Deren secundärer Widerstand, 85. 95. .

Kronecker, Neue Behandlung der Theorie der aperiodischen Bewegung gedämpfter Magnete, 325. - Zusatz zu dieser Theorie, 351. 352.

Kühne, W., Ueber das Porret'sche Phänomen am Muskel, 126-130. (S. Elektrotransfusion und kataphorische Stromwirkung.) - Chemische Reizung der Iuskeln, 211.

Rupfer in Kupfersulphat auf Polarisation untersucht, 56. 68. 72. 73.

Kupfersulphatkrystalle, innerlich unpolarisirbar, 18.

\section{Ladungssäule aus Elektrolyteฑ, 9.}

Lamont, Bussole, 49. - Temporäre Magnetisirung, 306.

LANG, V. v., Spiegelgalvanometer mit regulirbarer Dämpfung, 366. 389. Variationsschwankungen astatischer Magnete, 389.

Langsames Wachsen der Stromstärke nach Umlegen der Wippe zeigt seeundären Widerstand an, 83. 84 .

Leim, erstarrter, innerlich unpolarisirbar, 18, - mit Messingspänen gefüllt, polarisirbar nach Art innerlich polarisirbarer Körper, 22. 23. - Dessen secundärer Widerstand, 86. 89.

Lenz, mechanische Dämpfung, 321.

Lloyd, Humphrey, Formel für die freiwillige Ablenkung astatischer Nadelpaare, 135. 138. 143.

Logarithmen, die Basis der natürlichen (e) unmittelbar abgelesen, 318 .

Logarithmisches Decrement der Magnetspiegel und -Ringe, 309. 310. 372.

Maasskette, bei Anwendung des Compensators, 178. 258.
Magnesia, gebrannte, innerlich unpolarisirbar, 18. 21.

Magnes, G., Brief an ihn über ein Verfahren, Spiegelablesungen objectiv $z u$ machen, 131. - Eisengehalt galvanoplastischen Kupfers, 148.

Makroskopisches und teleskopisches Verhalten aperiodischer Magnete, 355-362 (Abh. XIV. §. 2).

MAREY, myographisches Verfahren, 274. 281.

Martens, positive Polarisation, 6. 48.

Matтeucci, angebliche Unpolarisirbarkeit von destillirtem oder auch von verquicktem Zink in Zinksulphat- nder Chlorcalciumlösung, 43.

Meissner, mit Meyerstein, Elektrogalvanometer, 156. 363 .

Mellovi, unzureichende Erklärung der freiwilligen Ablenkung, 149.

Meyerstein, mit Meissner, Elektrogalvanometer, 156.363. - Mit Thiry, Sirenen-Myographion, 27 t.

Modellirthon, dessen innere Polarisation, 17. 26; - äusserer secundärer Widerstand, 85. 107. - Als Ersatzmittel der Eiweisshäntehen, 161. 163 (Abh. VIU. §. 5).

Монв, meehanische Dämpfung, 321.

Moser, Formel für die freiwillige $\mathrm{Ab}$ lenkung astatischer Nadelpaare, 135. 138.

Multiplicator für thierisch-elektrische Versuche, 145-152 (Abh. VIII. §. 1). - Titeratur über den Multiplicator, 152. - Vorzüge, die ihm vor Spiegelbussolen bleiben, 154. 155 .

Munk, H., Fortsetzung der Untersuchungen über secundären Widerstand, 126. Ansteigen des Erregungsmaximums, 225. - Zuleitungsvorrichtung für Ver. suche über Fortpflanzungsgeschwindig. keit der Erregung, 282.

Munk af Rosenschöld, Polarisation von Papierstreifen, 28.

Myograplien, Allgemeines über, 271.

Nebenschliessdraht beim Compensationsverfaliren, 176 . 
Nervmuskelpräparat, aus Gastroknemins mit Ischiadnerv bestehend, Art es am schnellsten zu gewinnen, 208.

Neumann, Fr., Polarisation und Uebergangswiderstand, 52. 69. 70. - Bewegliche Quecksilberverbindung, 177. 189. 199. - Mechanische Dämpfung, 366.

Neumayer, Variationen des Erdmagnetismus in Berlin, 376.

NoвiLI, Thonthermoströme, 10. 28. Astatisches Nadelpaar, 149. - Ueber die Hany'sche Methode der Astasirung, 157.

Olivenöl, Rousseau's Verfahren um dessen Verfälschung zu erkennen, 19.

Pará-Nuss, deren Albumen innerlich unpolarisirbar, 18.

Peltier, elektromotorische Gegenkraft an der Grenze verschiedener Metalle, 1. - Sein thermo-elektrisches Kreuz, 8. 14. - Aehnliche Vorrichtung zur Beobachtung der Polarisation an der Grenze von Elektrolyten, 8. 9. 14. Ladnngserscheinnngen an Muskeln, 28.

Pergament, vegetabilisches, Ersatzmittel der Blase der Eiweisshäutchen, 162.

Petrina, Graduationsmethode für Multiplicatoren, 186.

Pflanzengerebe, innerlich polarisirbar, 1s. - Dessen secundärer Widerstand, 86. 89. 118.

Pfltéger, Polarisation von Platin in Salpetersäure und von Kupfer in Kupfersulphatlösung, 55. - Eiweissröhren, 7s. 123. 124. - Durch Czermak's Glasspritzen und du BoisReymond's Zuleitungsröhren mit Thonspitzen ersetzt, 164. - Seine Erklärung des Umstandes, dass beim Anlegen zweier Metalle an Nerv und Muskel die Zuckung bei metallischer Berührung stärker ausfällt, als beim Berïhren der thierischen Theile mit einem der Metalle, 172. - Erster Gebrauch des Śchlüssels zum T'tanisiren bei seinen Versuchen am N. splanchnicus, 176. - Pheochord, 191. -
Totale Erregbarkeit der intrapolaren Streeke, 203. 204.

Platin in Schwefelsäure, Kochsalzlösung, Salpetersäure auf Polarisation untersucht, 54-56. - Platinschwamm nimmt keinen secundären Widerstand an, 121.

Poggendorff, seine Wippe, 33. 67. 73. Geschichte des Hauy'schen Verfahrens. zur Astasirung, 157. - Compensationsverfahren, verglichen mit dem von du Bois-Reymond, 180. 259. - Erfinder der Klemmschrauben, 171. 267.

Polarisation, äussere, an der Grenze ungleichartiger Elektroden, 1-12 (Abh. I). - Vergl. 16. - Combinationen welche negative äussere Pol. geben. 5 . welche positive geben, 6. - Deren absolute Stärke, 9. - Deren Theorie, 10.

Polarisation, innere, poröser mit Elektrolyten getränkter Halbleiter, 13-28 (Abh. II), - Körper welche sie zeigen, 17-19. - Deren absolute Stärke, 19. - Abhängigkeit von der Temperatur, 19. 20. - Theorie der inneren Polarisation, 20-27. - Abhängigkeit von den Dimensionen der innerlich polarisirbaren Körper, 29-41 (Abh. III).

Polarisation von Metallen in Elektrolyten, 54-73. - Positive, 6. 48. 57. 58. 59. 60.

Porret'sches Phänomen am Muskel, angebliches nach Kühne, 127.

Pouiluet'sche Methode der Messung kleiner Zeiträume, 322. 323.

Quecksilber, polarisirbar in verdünnter Schwefelsäure, 483 .

Quechillberschlïssel, 262. 266. 267 (Abh. XI. §. 1).

Quncke, G., kataphorische Stromwirkung 111.

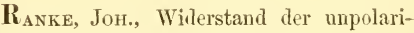
sirbaren Zuleitungsröhren mit Thonspitzen, 167; - des Rheochords, 194. Regnauld, Jules, angebliche Unpolarisirbarkeit von Elektroden aus reinem Zink in Zinksulphatlösung, 42. 43. - 
Thermoëlektrisehes Compensationsverfahren, 179. 185. 186.

Reizungsröhre, feuchte, 211. 213 (Abh. VIII. §. 17).

Rheochord zu elektrophysiologischen Versuchen, 1s7-196 (Al)h. VIII. §. 12). - Bei dessen Gebrauch in Reizversuchen zu beachtender Lmstand, 196198 (Abh. VIII. §. 13).

Rheostat von Siemens und Halske, 50. 190. - Feuchter Rheostat von E. Harless, 188.

Riıke, die Schliessungsinduction übertrifft die Oeffnungsinduction, 230. 313.

Pitter, J. W., Entdeeker der Polarisation, 1 .

Rohrzucker, hrystallisirter, innerlich unpolarisirbar, 18.

Rosenthal, I., Ersatz der Eiweisshäutchen, 162. - Torschlag zur Bestimmung des Einflusses, den die Steilheit der Curve, in der die Stromdichte ansteigt, auf die Erregung ïbt, 207. - Grössere Erregbarkeit des Nerven im Vergleich zum Muskel, 210. - Vorrichtung zur chemisehen Reizung der Muskeln, 211. - Trog mit mehreren Elektrodenjaaren zur Reizung (Rosenthal'scher Trog), 213. 26s. - Messung der Muskelkraft und Wiederholung des Herma nn'schen Versuehes am Froschunterbrecher, 227.

- Die Nebenströme in ihrer reizenden Wirkung der Schliessung beständiger Ströme vergleichbar, 251. - Verfahren um Anelektrotonus und Katelektrotonus zu demonstriren, 268 .

Rotationsmagnetismus Arago's, dessen höchste Stufe, 290.

Rousseat, Verfahren um Verfälschung des Olivenöls zu erkennen, 19.

Sand, innerlich unpolarisirbar, 18, Dessen secundärer Widerstand, 8. Sandstein, innerlich polarisirbar, 21. Sauerwald, Nene Eigenschaft astatiseher Nadelpaare, 137. - Rheochord, 191. Sayart s. Biot.
Schilling vor Canstadt, mechanisehe Dämpfung, 321.

Schlitten-Inductorium, 168.169.--Dessen Abänderung durch Helmholtz, 169. 229-233 (Abh. IX. §. 1).

Schlitten-Magnetelektromotors. Sehlitteninductorium.

Schlüssel, Vorreibersehlüssel, 171-17t (Abh. VIII. §. 9). - Dessen Gebrauch beim Tetanisiren dureh Inductions. ströme, 174-176 (Abh. VIII. §. 10).

Schulze, Fr., Wirkung des Chlorzinks auf Cellulose, 77.

Schüttelversuch mit polarisirten Elektroden, 109. 110.

Schwankungsiheochord, 198-20T (Abh. VIII. §. 14).

Schwefelblumen, innerlich unpolarisirbar, 15. - Deren secundärer Widerstand, 85.

Secundär-elehtromotorische Wirkungen, deren Begriff, 2.

Seide, innerlich unpolarisirbar, 18.

Seife, innerlich polarisirbar, 1s. 21. Deren secundärer Widerstand, 86. 89 .

Siemexs, W., Automatische Wippe, 33. 48. - Widerstand zwischen Eisen und Quecksilber, 205. - Aperiodische Magnete (Glockenmagnete) ohne Astasirung, 353-355 (Abh. XIV. §. 1).

Siemexs und Halske, Rheostat, 50, 190. 194. - Vertical-Galvanoskop, s0.

Silber in Silbernitrat auf Polarisation untersueht, 56.

Spiegelablesung, objective mittels eines zurückgeworfenen Lichtstrahles, 131133 (Abh. VI). 152. 153. - Von sir William Thomson beim atlantischen Kabel angewandt, 324.

Spiegelbussole, Wiedemann's, zu thierisch-elektrischen Tersuchen eingerichtet, 152-156 (Abh. VIII. §. 3). Vergleich ihrer Empfindlichkeit mit dem Nervenmultiplieator, 153. - Bequeme Gestalt der Seale, 156. -. Deren Dänıрfer, 307 .

Spielraum schwingungsloser Astasie, Bedingungen seiner Grösse, 370. 371. 
Stromuender zum Gebranch am Multiplicator, 150. 151.

$\boldsymbol{T}_{\text {anz }}$, elektrischer Frosehsehenkel-, 223. Teleskopisches und makroskopisches Verhalten aperiodischer Hagnete, 355-362 (Abh. XIV. §. 2).

Temperaturstiöme am menschlichen Körper und an Fliesspapierbäuschen, 20. 27. 28.

Temporäres Moment der Magnete, 137. 306. 369.384.

Tetanisiren, Vorrichtungen dazu, 168170 (Abh. VIII. §. ১). - Plan zu einer wissenschaftlich brauchbaren Vorrichtung znm elektrischen Tetanisiren, 255.

Thierische Gewebe, innerlich polarisirbar, 19. - Secundärer Widerstand, 87. 89. 95.118.

Thiry, Sirenen-Myographion, 271. 274.

Tномsох, Sir William, Bedienung des atlantischen Kabels mittels $\mathrm{du}$ Bois. Re ymon d's objectiver Spiegelablesung, 324. - Aperiodische Magnete mit Luftdämpfung, 366 .

Thon, gebrannter, innerlich polarisirbar, 17.

Thon, plastischer, s. Modellirthon.

Thonschiefer, innerlich polarisirbar, 20 .

Thonstiefelelehtroden, s. Zuleitungsröhren.

Thonthermoströme Nobili's, 10. 20. 28.

Trachyt, innerlich polarisirbar, 17 .

Trägheitsmoment des Vagnetes, dessen Piolle bei der aperiodischen Bewegung, 309. 353. 354 .

Trxdall, Magnetismus grüner Seide, 147 . - Diamagnetismus des Kupfers, 148.

Uebergangswiderstand, 69. 70. 73. 121. Unipolare Zuckingen, 233.

VAlentin, Kreisseheiben-Myographion, 271.

Tariationsschwankungen astasirter Magnete, 376-379 (Abh. XV. §. 3); 389.390 .
Volta, Erklärung der Polarisation, 1.

Torreiberschlü.ssel, s. Schlüsscl.

W EBER, W., Astasirung eines Magnetes durch einen verkehrt genäherten Stab, 157. 363. - Formel für den Ausschlag eines gedämpften, durch einen kurz dauernden Strom abgelenkten Magnetes, 303.

Wheatstone, dessen Stromnetz oder Brücke, 50, dient zum Abstimmen des Rheochords, 193. - Aperiorlischer Magnet vortheilhaft bei Widerstandsmessungen mittels der Wheatstone' schen Brïcke, 322 .

Widerstand, secundärer, 81-126 (Abh. V). - Fenchte poröse Körper, die ihn zeigen, 84. - Aensserer sec., 87. Innerer sec., 90. - Dieser bisher nur an Pflanzengewebe beobachtet, 95. Näher untersucht, 96. - Abhängigkeit des äusseren von Stromstärke und Quersehnitt, 101. - Flüssigkeiten die mit geronnenem Eiweiss äusseren secundären Widerstand geben, 107. - Aeusserer secundärer Widerstand mit metallischen Elektroden, 108. - Theorie des äusseren, 111-116. - Natur des inneren, 120. - Praktische Bedeutung in der Elektrophysiologie, 122.

Wiedemanx, seine Bussole von Sauerwald verfertigt, 49. s1. - Untersuchungen über die kataphorisehe Wirkung des Stromes, 111.

WiLd, Doppelwippe, 52. 268. - Hydrothumoströme, 10. - Nenmann's Methode znr Bestimmung der Polarisation und des Uebergangswiderstands, 52. 69. 70 .

Wippe, zur Beobachtung der Polarisation, 3. - W. Siemens' automatische, 48. 49. - Doppelwippe nach Wild, 52; - 267-269. - Poggen dorff'sche Wippe, 67. 73.

Wuxdt, Congrnenzbedingungen der Anfangs- und End-Induction, 233. 234. 247.

Würgung zwischen Salzlösungen durchströmter Eiweisscylinder, 104. 
Yink, rein und käuflich, unverquickt und verquickt in verschiedenen Flüssig. keiten auf Polarisation untersucht, 57-67. - In Zinksulphat- oder Chlorzinklösung gleichartig und unpolarisirbar, 60-64. 65. 66. $70-72$.

Zinksulphatkrystalle, innerlich unpolarisirbar, 18.

Zitterwelsschlag, Plan zur Messung seiner Dauer, 226.
Zuckungstelegraph, 207-210 (Abh. VIII. §. 15).

Zuleitungsdrähte bei thierisch-elektrischen Versuchen, deren Dicke, 174.

Zuleitungsgefässe, 157-160 (Abh. VIII. §. 3).

Zuleitungsröhren, unpolarisirbare mit Thonspitzen (Thonstiefelelektroden), 163-166 (Abh. VIII. §. 6). - Deren Gleichartigkeit, 166. 167. - Ihr Widerstand, 167. 

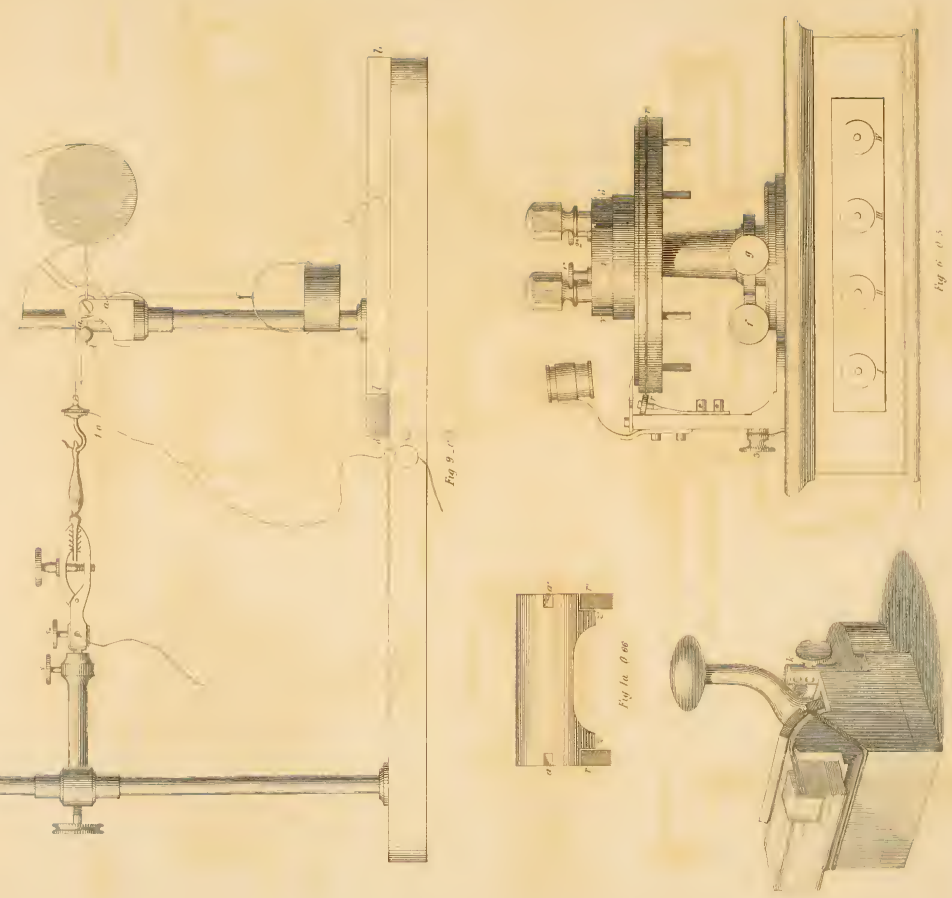



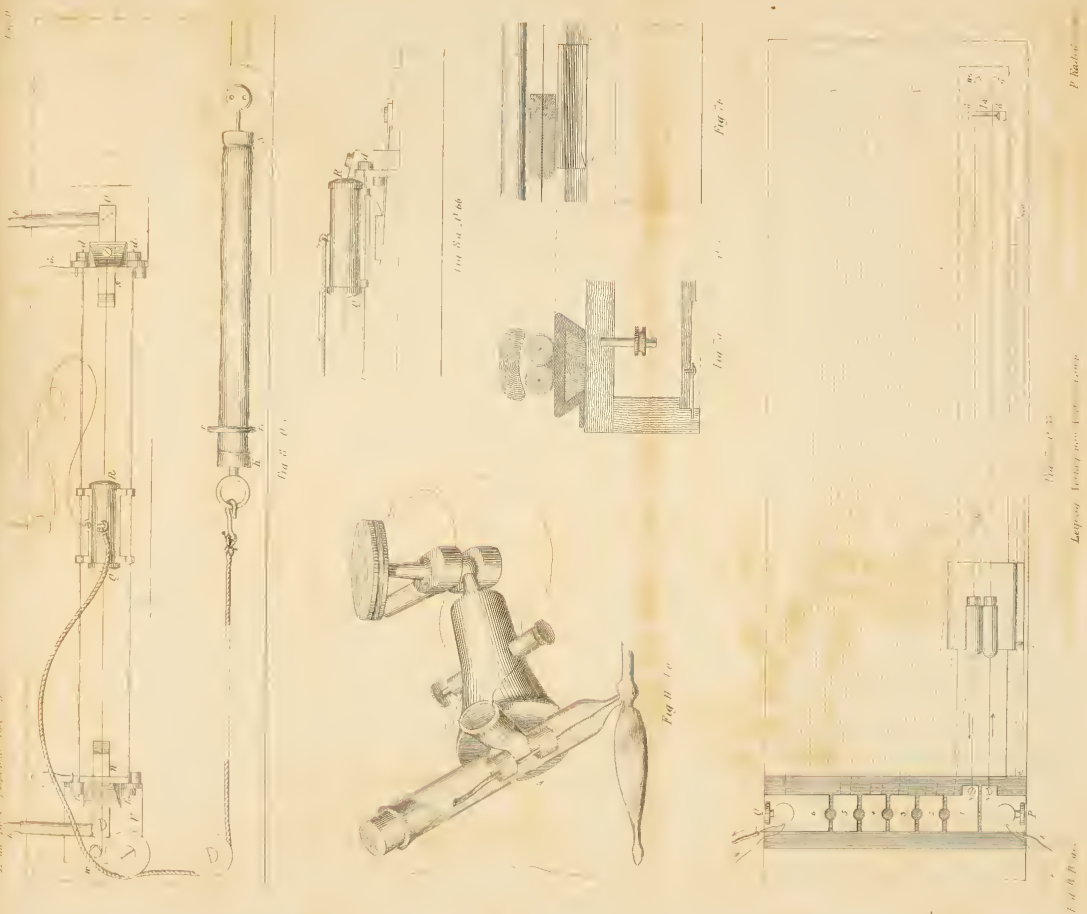





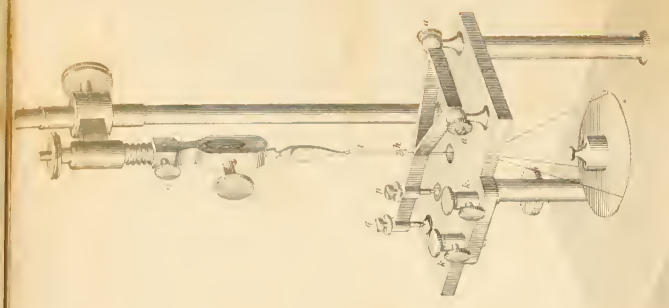







